RADIOACTIVE AND OTHER ENVIRONMENTAL THREATS TO THE UNITED STATES AND THE ARCTIC RESULTING FROM PAST SOVIET ACTIVITIES
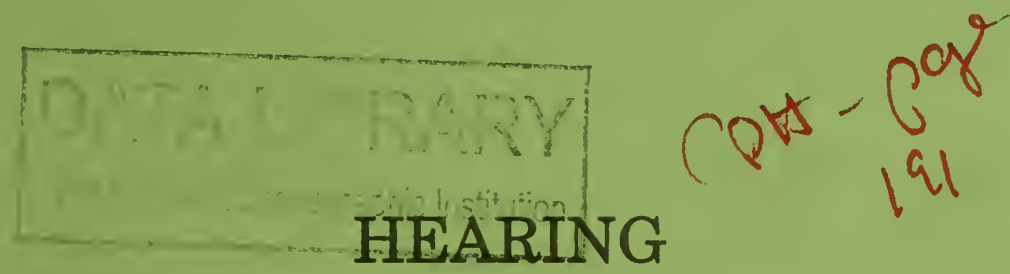

BEFORE THE

SELECT COMMITTEE ON INTELLIGENCE OF THE

UNITED STATES SENATE

ONE HUNDRED SECOND CONGRESS

SECOND SESSION

ON

RADIOACTIVE AND OTHER ENVIRONMENTAL THREATS TO THE UNITED STATES AND THE ARCTIC RESULTING FROM PAST SOVIET ACTIVITIES

SATURDAY, AUGUST 15, 1992

Printed for the use of the Select Committee on Intelligence

$$
\begin{aligned}
& \text { QH } \\
& 543.5 \\
& .43 \\
& 45 \\
& 1993
\end{aligned}
$$

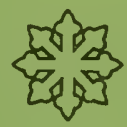




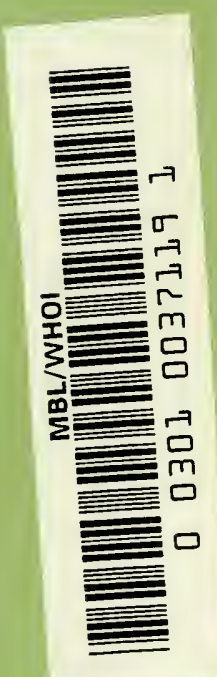




\section{RADIOACTIVE AND OTHER ENVI- RONMENTAL THREATS TO THE UNITED STATES AND THE ARCTIC RESULTING FROM PAST SOVIET ACTIVITIES}

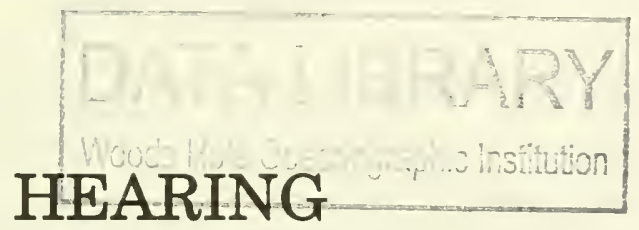

BEFORE THE

SELECT COMMITTEE ON INTELLIGENCE OF THE

\section{UNITED STATES SENATE}

ONE HUNDRED SECOND CONGRESS

SECOND SESSION

ON

RADIOACTIVE AND OTHER ENVIRONMENTAL THREATS TO THE UNITED STATES AND THE ARCTIC RESULTING FROM PAST SOVIET ACTIVITIES

\section{SATURDAY, AUGUST 15, 1992}

Printed for the use of the Select Committee on Intelligence

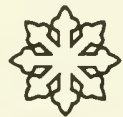




\section{SELECT COMMITTEE ON INTELLIGENCE}

[Established by S. Res. 400, 94th Cong., 2d Sess.]

DAVID L. BOREN, Oklahoma, Chairman

FRANK H. MURKOWSKI, Alaska, Vice Chairman

ERNEST F. HOLLINGS, South Carolina

BILL BRADLEY, New Jersey

ALAN CRANSTON, California

DENNIS DECONCINI, Arizona

HOWARD M. METZENBAUM, Ohio

JOHN GLENN, Ohio

J. ROBERT KERREY, Nebraska
JOHN W. WARNER, Virginia ALFONSE M. D'AMATO, New York JOHN C. DANFORTH, Missouri WARREN RUDMAN, New Hampshire SLADE GORTON, Washington JOHN H. CHAFEE, Rhode Island

GEORGE MITCHELL, Maine, Ex Officio ROBERT DOLE, Kansas, Ex Officio

George J. TEnet, Staff Director John H. Moseman, Minority Staff Director Kathleen P. McGhee, Chief Clerk

(II) 


\section{CONTENTS}

Hearing held in Fairbanks, Alaska:

August 15, 1992

\section{MORNING SESSION}

Testimony of U.S. Government Panel:

Bohlen, Hon. Curtis, Assistant Secretary for Oceans, International Environmental and Scientific Affairs

Gates, Hon. Robert M., Director of Central Intelligence

Guimond, Admiral Richard, A., Deputy Assistant Administrator for Solid Waste and Emergency Response, Environmental Protection Agency (EPA), and Assistant Surgeon General U.S. Public Health Service

Murkowski, Hon. Frank H., a U.S. Senator from the State of Alaska .........

O'Dowd, Hon. Donald D., Chairman, Arctic Research Commission

Ostenso, Dr. Ned A., Assistant Administrator Oceanic and Atmospheric Research National Oceanic and Atmospheric Administration

\section{AFTERNOON SESSION}

Testimony of Scientific Panel:

Aarkrog, Dr. Aasker, Chief, Ecology Section, Department of Environmental Science and Technology, Riso National Laboratory, Roskilde, Denmark

Alexander, Dr. Vera, Director, Institute of Marine Sciences, University of Alaska

Bolshov, Dr. Leonid, Director, Institute of Nuclear Safety, Russian Academy of Science

Hollister, Dr. Charles, Woods Hole Oceanographic Institute

Rogne, Dr. Odd, Executive Secretary, International Arctic Science Committee, Oslo, Norway

Shaw, Dr. Glen, Geophysical Institute, University of Alaska

White, Dr. Robert, Institute of Arctic Biology, University of Alaska, Fairbanks

Testimony of Health Panel:

Ebbeson, Dr. Sven, Institute of Marine Science, University of Alaska, Fairbanks, and Co-Director, Alaskan-Siberian Medical Research Program

Middaugh, Dr. John, State of Alaska Epidemologist

Tedford, Charles, Radiation Health Specialist, Department of Environmental Conservation, and Department of Health and Social Services, State of Alaska

Trufakin, Dr. Valerie, President, Siberian Branch, Russian Academy of Medical Science, and Co-Director, Alaskan-Siberian Medical Research Program

Testimony from non-governmental organizations:

Handler, Joshua, Research Coordinator, Greenpeace Nuclear Free Seas Program

Hajost, Scott A., Esq., International Counsel, Environmental Defense Fund

Johnson, Charlie, Inuit Circumpolar Conference

Pfirman, Dr. Stephanie L., Senior Scientist, Environmental Defense Fund

Testimony of Local and Arctic Resources:

Albert, Dr. Thomas F., Senior Scientist, Department of Wildlife Management, North Slope Borough 
Testimony of Local and Arctic Resources-Continued

Simeon, Calvin, Director of Natural Resources, Association of Village Council Presidents

Presentation of a Concept for Action:

Alexander, Dr. Vera, Director, Institute of Marine Science, University of Alaska, Fairbanks

Bolshov, Dr. Leonid, Director, Institute of Nuclear Safety, Russian Academy of Science

Gorsuch, Dr. Edward L., Dean, School of Public Affairs and Director, Institute for Economic and Social Research, University of Alaska, Anchorage

Proenza, Dr. Luis, Acting Vice President, Academic Affairs and Research, University of Alaska

Shipp, Dr. William, Manager, Reactor Technology Center, Pacific Northwest Laboratory, Battelle Memorial Institute

Written Statements submitted for the Record:

Statement of the Government of Canada

Statement of the Government of Iceland

Statement of the Department of Energy

Statement of the Government of Finland

Statement of the Arctic Marine Resource Commission

Statement of the International Union for Circumpolar Health ........................

Statement of the Alaska Health Project Reports:

The Finnish Assisted Joint Environmental Projects in Eastern Europe 1991-1992 submitted by the Ministry of the Environment of Finland, East Europe Project

An Overview of Radiation Safety Problems for the Population on the Territory of the Yakutskaya-Sakha S.S.R., translated by Congressional Research Service, Library of Congress

The State of Public Health in the Republic of Sakha (Yakutia), B.A. Yegorov, Minister

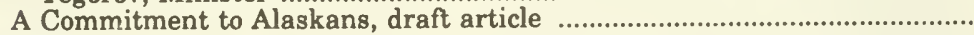
Appendix:

Report from the President of the Russian Federation, Moscow, 1993; Facts and Problems Related to Radioactive Waste Disposal in Seas Adjacent to the Territory of the Russian Federation (Materials for a Report by the Government Commission on Matters Related to Radioactive Waste Disposal at Sea, Created by Decree No. 613 of the Russian Federation President, October 24, 1992) 


\title{
RADIOACTIVE AND OTHER ENVIRONMENTAL THREATS TO THE UNITED STATES AND THE ARCTIC RESULTING FROM PAST SOVIET AC- TIVITIES
}

\section{SATURDAY, AUGUST 15, 1992}

\author{
U.S. SENATE, \\ SELECT CoMmitTeE ON INTELLIGENCE, \\ Fairbanks, $A K$.
}

The select committee met, pursuant to notice, at 10 o'clock a.m., in the Fine Arts Theater, University of Alaska Fairbanks, Fairbanks, AK, the Honorable Frank Murkowski, vice chairman of the committee, presiding.

Present: Senator Murkowski.

Also Present: John Moseman, minority staff director, and David Garman, select committee staff.

\section{ProceEdings}

Senator MURKowSKI. Good morning, ladies and gentlemen. Those of you who are in the back, you might want to come down and be seated.

Let me take this opportunity to welcome you to this field hearing of the Senate Select Committee on Intelligence. Let me introduce on my left John Moseman, Chief of Staff for the Minority, and David Garman on my right of the Senate Intelligence Committee Staff. Mary Johnson on the far right is acting as our Committee Reporter. We'll introduce Buff Bohlen in just a few minutes.

Let me give you some idea of what to expect. First of all, we have at last count some 25 ladies and gentlemen from government, the scientific community, and the indigenous community to testify today. As we get into the panel groups I will probably limit the witnesses to about six minutes each, but realistically allow them about 10.

I might add for the benefit of the groups that are testifying, I'm told this stage is self-leveling, so if you see startled faces occasionally from those up here I'm told it's not an earthquake but a sophisticated technology. I did want you to be aware of that.

I would also like to indicate that the Chairman of this Committee, Senator Boren, extends his regrets. He's from Oklahoma and as you know, there are few direct flights to Fairbanks, Alaska from Oklahoma, but nevertheless he asked to be remembered. I want to thank him for his efforts on behalf of this hearing today, recognizing the importance and significance of it. 
The fall of the Soviet regime has resulted in an outpouring of information about the practices and activities of the former Soviet Union. We've also see Congressional action on a Russian Aid Bill. The Senate Foreign Relations Committee, which I'm a member, adopted my amendment authorizing funds to map, monitor and contain environmental threats to the United States or the Arcticl SubArctic ecosystem. The accompanying Senate report makes it clear that the Senate Foreign Relations Committee intends that these activities be undertaken in collaboration with scientists from the former Soviet Union. The report also specified that the research plan should be developed in collaboration with the National Science Foundation, the Interagency Arctic Research Policy, and the Arctic Research Commission, and the State of Alaska.

The full Senate adopted the bill on July 2nd. Clearly, we have a Congressional dictate. And while it has not yet passed the House, I'm confident that it will.

Earlier this year the Senate Intelligence Committee began to receive reports from environmental and nuclear scientists in Russia detailing the reckless nuclear waste disposal practices, nuclear accidents and the use of nuclear detonations. We found that information disturbing to say the least. Also troubling is the fact that 15 Chernobyl style RBMK nuclear power reactors continue to operate in the former Soviet Union today. These reactors lack a containment structure and they're designed in such a way that nuclear reaction can actually increase when the reactor overheats. As scientists here at the University of Alaska have documented, polar air masses and prevailing weather patterns provide a pathway for radioactive contaminants from Eastern Europe and Western Russia, where many of these reactors are located. The threats presented by those potential radioactive risks are just a part of a larger Arctic pollution problem. Every day, industrial activities of the former Soviet Union continue to create pollutants. I think we should face up to the reality that in a country struggling for economic survival, environment protection isn't necessarily the highest priority. And that could be very troubling news for the Arctic in the future.

The Arctic is the principal food source for many Alaskans. Small amounts of heavy metals possible from industrial pollution or Arctic haze are already making their way as we know into the walrus and other marine mammals that feed many Arctic residents. Will radionuclides follow? We don't know. Do we have the monitoring mechanism in place to warn us should this occur? Can we address through bilateral and multilateral mechanisms the need to halt the spread and promote the cleanup of these pollutants? Who has the talent and capability to do this kind of work? These are all important questions which we hope to explore here today.

At today's hearing, which is the first ever field hearing of the Select Committee on Intelligence, we'll hear from a remarkable group of witnesses in an effort to explore these issues from several different perspectives. Because this is an international problem, we've asked the Assistant Secretary of State, Curtis Bohlen, to give us the State Department's perspective. As a senior member of the Interagency Arctic Research Policy Committee, Secretary Bohlen can also tell us what can and should be done to scientifically assess the threats facing the Arctic from these various pollutants. We also 
have the Director of Central Intelligence, Robert Gates, to provide us with an assessment of both the nuclear activities of the former Soviet Union and the role that the CIA can and should play in the environmental arena. Not only in this area, but in the realm of global change and other environmental concerns. The CIA of the post-cold war era is forging new ground in the area of environmental intelligence under the leadership of Mr. Gates. And we're pleased that he has chosen this occasion here in Alaska to outline some of these new initiatives.

Because many, including myself, have suggested that the scientific and environmental monitoring in the Artic should be undertaken in collaboration with Russian scientists, we have asked Dr. Donald O'Dowd, the former president of this University and Chairman of the Arctic Research Commission, to provide us with some thoughts about the opportunities and problems involved in scientific cooperation with our Russian neighbor. The Commission recently returned from a series of meetings with their counterparts in the Russian Academy of Sciences, so Dr. O'Dowd is uniquely qualified to address this question.

The nation's top official for oceanic and atmospheric research, Dr. Ned Ostenso, will outline the program that NOAA can bring to bear on these problems. One of the Environmental Protection Agency's top radiation and mixed waste experts, Admiral Richard Guimond, will provide the EPA's perspective on these problems. We'll also hear from a number of scientists and health experts, including some who have come from Russia, from Denmark, Norway and elsewhere, to provide information based on their experience, their research and their monitoring. We have representatives from the environmental community, one to specifically address issues involving the dumping of nuclear materials in the ocean, another to present information gathered about a broader range of pollutants and the mechanisms and that transport them around the Arctic. We've invited representatives of the North Slope Borough, the Inuit Circumpolar Conference and other representatives of the Native community to provide their thoughts. And at the end of the day we will hear from a panel representing an alliance between the University of Alaska and a national laboratory to set forth some concrete ideas about the course of action that should be undertaken to address some of these problems.

A number of other agencies, governments and organizations, including Russia, Finland, Iceland, the U.S. Department of Energy, the Arctic Marine Resource Commission, the International Union of Circumpolar Health, the American Society of Circumpolar Health, the Alaska Health Project, and many others have also submitted written testimony. I invite people in the audience to submit written testimony, if they're inclined to do so. The hearing record will be kept open for two weeks for the acceptance of additional public testimony.

[The documents referred to follow:] 


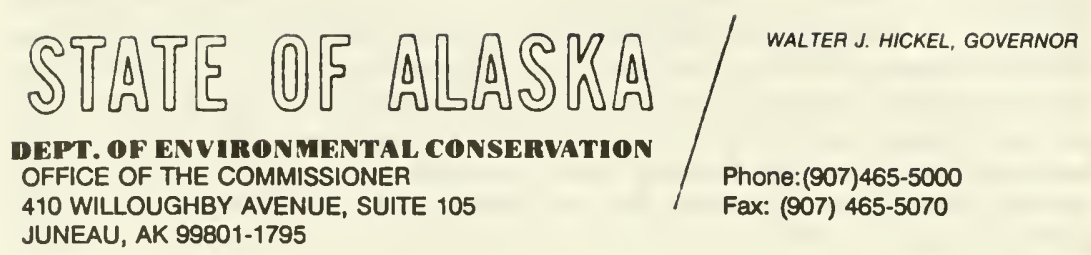

August 28, 1992

The Honorable Frank H. Murkowski, Co-chairman

Senate Select Committee on Intelligence

United States Senate

ATTENTION DAVID GARMAN

Rm. 211 Hart Senate Building

Washington, DC 20510

Dear Senator Murkowski:

Thank you for holding the Select Committee on Intelligence open hearing on radiation and environmental threats to the Arctic from the former Soviet Union on August 15. This was truly an extraordinary hearing and the State of Alaska appreciated the opportunity to testify.

With this letter, we wish to follow up on our suggestions for an action plan to further identify and respond to the threats discussed at the hearing. The Alaska Department of Environmental Conservation is one of several State agencies with responsibility for health and the environment; we work closely with the Alaska Department of Health and Social Services and with the Alaska Division of Emergency Services in the Department of Military and Veterans Affairs. The Alaska Department of Fish and Game also carries responsibilities in this arena. All of our Departments participate in the Northern Forum, an association of state, provincial and regional governors from Northern regions which is chaired by Governor Walter J. Hickel with a secretariat in Anchorage. As well, each of our agencies deal with counterpart federal agencies through a variety of cooperative agreements.

The key points of action we suggest in follow-up to what we've learned at the hearing, in coordinated federal and State action. are as follows:

1. The United States needs to establish a real-time radiation monitoring - system in Alaska and, through bilateral or multilateral agreements, Russian territory which neighbors Alaska. The State of Alaska is anxious to cooperate in this program. Our letter to the Environmental Protection Agency's (EPA) Rear Admiral Richard J. Guimond, describing this 
program in detail, is enclosed. We request, with this letter, Congressional funding of $\$ 285,000$ to install this monitoring effort.

2. The United States, Russia, regional governments in Russia, and the State of Alaska need to develop appropriate prevention and response plans for a nuclear incident, including a power-plant accident, submarine mishap. or rupture of improperly disposed nuclear waste. This plan needs to be tested with regular drills involving national and local governments.

A copy of Governor Hickel's April 20 letter to Ambassador Strauss requesting improved notification and monitoring is also enclosed.

3. The United States and other Arctic nations need to work with national and regional governments in Russia to fully identify, map and develop a mitigation plan for the nuclear and other major environmental threats in the Arctic. We understand the U.S. Arctic Research Commission has recently discussed this issue, with the objective of producing a hazards map for the eastern Arctic of Russia similar to the map produced by Norway, Poland, and Russia for the western Arctic. Besides finding the source of radionucleides in the Arctic, we must also work quickly to identify the source of mercury, cadmium, and PCBs which are increasingly found in the Arctic food chain. Mitigation can only begin when we know the source. The State of Alaska, through existing cooperative agreements with environmental agencies in Magadan, Kamchatka, and Vladivostok, can assist in this effort. The Northern Forum is also structured to assist in this effort. U.S. disarmament support programs, the Arctic Environmental Protection Strategy, and U.S. activity under the proposed aid package should help this work as well.

4. The United States and Alaska need to develop a coordinated action plan to use the Russian aid package to support environment, health, and key economic infrastructure in the Russian Far East that affects Alaska. Parts of the proposed aid package which support joint research, investment, and intergovernmental exchange should be used to support these goals.

By separate cover, you will receive a letter detailing the State's interest in this goal as the aid package goes to conference.

5. The United States should, wherever possible, support the Northern Forum as a means to strengthen local participation in international Arctic affairs and as a means to strengthen the role of regional governments in the Russian North. That support can include placement of U.S. State 
Department officials at the Secretariat in Anchorage es training in Arctic policy. Federal research for the Arctic Environmental Protection Strategy and other goals should be coordinated with efforts of the Northern Forum. The Northern Forum Secretariat could also serve as host secretariat for either the flora and fauna or the marine environmental protection programs of the Arctic Environmental Protection Strategy. We believe the Northem Forum, as it involves regional governments, is a better mechanism than the Arctic Council proposed by the Canadian government.

6. The United States needs to reverse the pattern of federal "neglect" of major health and environmental issues in Alaska by establishing an Arctic/Alaska region for the Environmental Protection Agency, and developing a better federal commitment to Alaska rural health and sanitation issues.

Immediate attention must be paid to the radiation and pollution legacy of the United States in the Arctic. Radioactive soils at Ft. Greeley from a disabled reactor, and in northwestem Alaska from the Project Chariot tests, should be packed and removed to safe storage at once. A sheet detailing some of what we know of these two sites is enclosed to this letter. As well, we are sending a draft copy of "A Commitment to Alaskans" detailing the huge problems rural Alaskans face in environmental health issues.

Senator, as a result of the Fairbanks hearing we believe U.S. and State policy makers are better informed than ever before on key environmental issues facing the Arctic. As Alaskans, we are concerned for the safety of our citizens. We are also concerned that the Soviet Union's "lackadaisical" practices with nuclear materials, as described by CIA Director Robert Gates, extend to other environmental practices throughout the former Soviet Union and continue today. Alaska competes with Russia in several basic resource industries - oil and gas, mining, timber, fishing-and, while we welcome the democratic and economic reforms which have made Russia a participant in the world market, we want to make sure Alaska and U.S. companies are not competitively disadvantaged because they incur the expenses necessary to protect the environment while Russia does not.

We were pleased to hear Assistant Secretary of State Curtis Bohlen's testimony commitment to push for a new U.S. Arctic policy, and to pay more attention to international Arctic issues. It is interesting to note that as the Antarctic Protection Treaty was signed to forestall energy and mineral development in the South Polar Region for $\mathbf{5 0}$ years, the end of the Cold War means that exchange, communication 
and joint development of the Arctic is only again possible after a hiatus of 50 years. We must use all the intelligence at our disposal to meet this opportunity safely, fairty, and immediately.

Thank you again for holding this hearing, and keeping the record open for this additional testimony.

Sincerely,

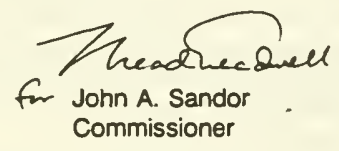

JEP/MT/bkt (h:\bettyt|commls\murkowskl.001)

\section{Enclosures}

cc: U.S. Senator Ted Stevens

U.S. Representative Donald E. Young

Curtis Bohlen, Assistant Secretary of State

U.S. Department of State

John Katz, Special Counsel

State/Federal Relations

Alaska Office of the Governor

Mead Treadwell, Deputy Commissioner/ADEC

Janice Adair, Assistant Commissioner/ADEC

James E. Powell, Deputy Director

Division of Environmental Quality/ADEC 


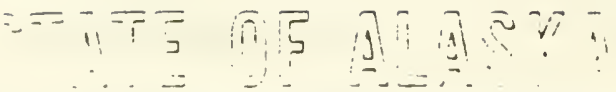

DEPT. OF ENVIRONMENTAL CONSERVATION OFFICE OF THE COMMISSIONER

410 WILLOUGHBY AVENUE, SUITE 105

JUNEAU, AK 99801-1795
WALTER J. HICKEL, GOVERNOR

Phone: (907) 465-5000

Fax: (907) $465-5070$

August 25, 1992

Rear Admiral Richard J: Guimond

Assistant Surgeon General

U.S. Public Health Service and

Deputy Assistant Administrator

Office of Solid Waste and

Emergency Response

U.S. Environmental Protection Agency

Washington, DC 20460

Dear Admiral Guimond:

Thank you for sending me a copy of your testimony at the recent U.S. Senate Intelligence Committee hearing in Fairbanks. The Department of Environmental Conservation (DEC) appreciates your commitment in addressing the issues surrounding radiation threats to Alaska, the Arctic environment, and the United States. I am sorry I and my deputy, Mead Treadwell, were unable to discuss this subject with you in greater detail.

The State of Alaska is committed to strengthening its partnerships with Russia's Arctic regions, the Northern Forum and others to define and deal with this vital issue. The joint efforts in upgrading radiation monitoring and response capability will be a good start. A five-phase program is proposed beginning with upgrading air radiation monitoring sampling equipment in the large population centers of Anchorage,

Fairbanks and Juneau. Mr. Jerry Leitch, the Environmental Protection Agency's (EPA) Region 10 Radiation Program Manager, has agreed to supply the ERAMS sampling equipment and support through the EPA lab in Montgomery, Alabama.

The second phase of the proposed radiation monitoring and response program is to install real time detectors, Portable Ionization Chambers (PICs) at the perimeter of the State. This system will provide an earlier warning system for Alaska and the nation. These monitors can be located in Barrow or Wainwright to cover the northern-most region; Nome, Unalakleet, St. Lawrence Island, Little Diomede, or Kotzebue to cover the central region; Bethel to cover the southern region; and one on the Aleutian Chain. 
The cost of establishing this system is estimated at $\$ 135,000$ for equipment, installation, and initial development of a reporting system to collect and coordinate the data generated by the system. We believe, through cooperation with the military, National Guard, Native health organizations, and others, we can operate the system with minimal costs.

The next three phases of the radiation monitoring and response plan consist of upgrading the Department's laboratory $(\$ 150,000)$, developing an emergency response capability, and establishing a monitoring system with the Russian Far East. We will be working to strengthen bilateral and multilateral agreements at the regional and national level to make this happen, and will work with the Northern Forum here, Paul Ringold at EPA and Ray Arnaudo at the State Department in that regard.

Please note the enclosed very positive editorial "Nuclear Concerns" in the 8/22/92 edition of the Anchorage Daily News. Would it be possible for your office to provide funding for Phase II and III in the current federal fiscal year? Obtaining this funding would enable us to get off to a good start.

Your support of these programs is appreciated. Also enclosed is a copy of the fivephase plan that is proposed for Alaska.

Sincerely,

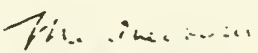

John A. Sandor

Commissioner

JEP/MT/JAS/cg (CO-comm) rad4)

Enclosures: Editorial "Nuclear Hearings"
Five-phase plan

cc: Paul Ringold

Environmental Protection Agency

Ray Arnaudo

U.S. State Department

The Honorable Frank H. Murkowski

United States Senate 
John Katz, Special Counsel

State/Federal Relations

Alaska Office of the Governor

Washington, DC

Dana Rasmussen, Regional Administrator

U.S. EPA-Region 10

Jerry Leitch, Acting Chief

Radiation and Indoor Air Section

Air and Radiation Branch

Air and Toxics Division/USEPA-Region 10

Al Ewing, Assistant Regional Administrator

Alaska Operations Office/USEPA-Region 10 
April 20, 1992

The Honorable Robert Strauss

United States Ambassador to Russia

Moscow (E)

Ulitsa Chaykovskogo 19/21/23

RUSSIA

Dear Bob,

The State of Alaska has recently learned of a radioactive release from the nuclear power plant at Bilibino, Russia, on July 10, 1991. This facility is closer to most communities in western Alaska than to the state capitol.

There is currently in place an international agreement that requires notification of these types of incidents to nearby or potentially-affected countries. The state is concerned about the lack of notification regarding this incident. I would like to know what caused this failure to carry out provisions of the agreement and what steps are being taken to ensure that the State of Alaska receives prompt notification of all future incidents.

This notification is critical for several reasons. First, and most importantly, the State of Alaska must be able to provide prompt information to protect our citizens from potential hazards. Second, the state must have immediate and direct information if we are to establish a meaningful monitoring system to evaluate possible impacts. Third, the state may be able to share resources with the Russian agencies and communities that may be directly affected by a radiological release.

Recent information indicates that there have been 270 unischeduled stoppages of nuclear reactors and five (5) releases from nuclear power plants in Russia since January 1, 1991. We also have a report that even as this nuclear power station 
The Honorable Robert Strauss

April 20, 1992

Page 2

in Bilibino considers a second stage, more than 170 top specialists have announced their intention to leave Chukotka, and there are currently no plans for their replacement. Your prompt assistance in helping to enlighten us on these matters will be appreciated.

With best regards.

Sincerely,

8/8 Walter J. Hickel

Walter J. Hickel

Governor

Enclosure

cc: U.S. Senator Frank H. Murkowski

U.S. Senator Ted Stevens

U.S. Representative Donald E. Young

William Reilly, Secretary of the Environmental Protection Agency

Administrator, Nuclear Regulatory Agency

Curtis Bohlen, U.S. Department of State

John A. Sandor, Commissioner, Department of Environmental Conservation Theodore A. Mala, Commissioner, Department of Health and Social Services Major General Hugh Cox, Commissioner, Department of Military and Veterans Affairs

WJH/JPH/DEC/In

DECLTR.SYM
1801

Radioactive Release

Bilibino, Russia 


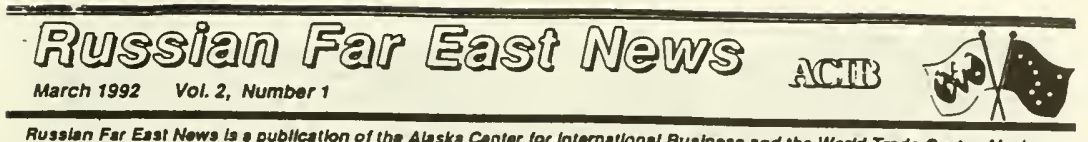

Rugsian Faf East Nows ls e publication of tho Alaska Center for International Business and ihe World Trade Center Aleake University of Ala aka Anchorage. Ruesian Far Esst News /s publlshed in associstion wh the Othes of Internatlonal Trads,

Alaska Dopartment of Commerce and Economic Development, and Inlormallon Technologles Lab of Viadivostok.

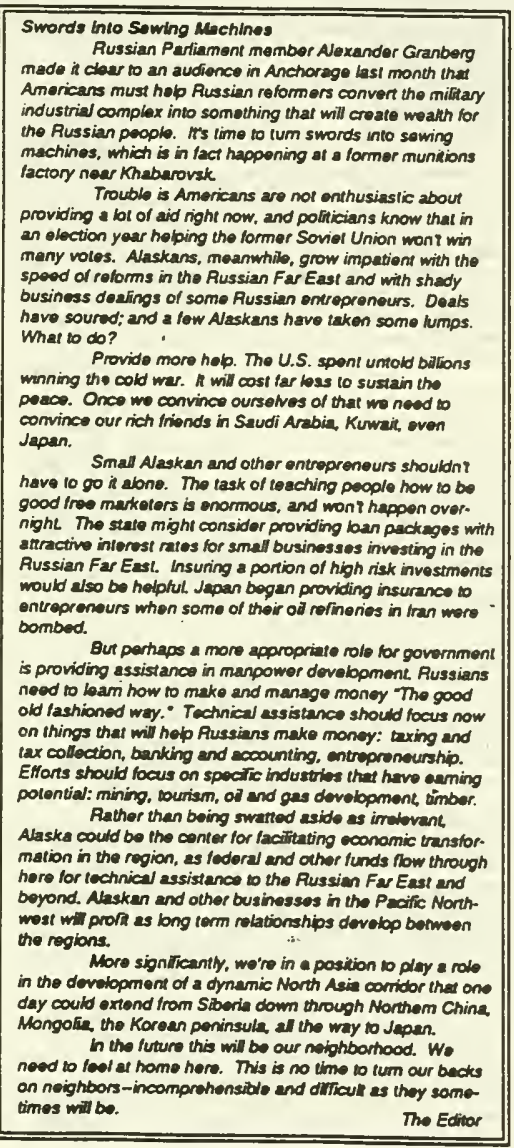

Independence for the Far East?

A bill recently adopied by the Association of Far Eastem Councils would give broad powers to the Far Eastem Eco. nomic Region (FEER) and lacilitate its independence. The bill proposes a \$pecial status for the FEER, which includes Pnmorsky and Khabarovsk regions, Sakhalin. Amursky. Magadan regions and Yakutia Sakha.

The Association of Far Eastem Councils wants to form a coordinating commitee with spectic authority and powers. makung the commitee in many respects a government for the Far East. This committee would like to receive a portion of Russian state taxes and revanues of local enterprises, and with them form a lund for development of the region. The comminee would like to buy the output of Far Eastem enter. prises (orecious metals exeluded) to lorm a special fund for exchange and export operations. Powers would also inctude tax prvileges, and the right to issue taritts, to determine prices lor main loodstulfs, raw materials and other products, and to determine lishing quotas in the cconomic zone. The bill also stpulates that the decisions of the Far Eastern Coordinating Comitee (FECC) would be mandatory tor the region.

A meeting will be held soon whth Boris Yeltsin concerning the FEER proposal, as well as the authorty of the region over use of its own natural resources. and a number of fax. customs. and other privileges. Granting these powers would be the lirst important step at creating a lree economic zone in the area. (I $1 / 24 / 91$ )

\begin{tabular}{|c|c|}
\hline WHATS INSIDE & \\
\hline Economic Summary & 2 \\
\hline Military & 2 \\
\hline Mining & 3 \\
\hline Opponunitios & 4 \\
\hline Trade ShowsilMissions & 4 \\
\hline Agriculture & 4 \\
\hline Fishing & 5 \\
\hline Commodity Exchanges & 6 \\
\hline Map of Administrative Regions of Far East & 7 \\
\hline Economic News & 8 \\
\hline Privatization & 9 \\
\hline Telecommunications & 10 \\
\hline $\mathrm{O}$ it and Gas Development & 10 \\
\hline Nuclear Power__ & 10 \\
\hline Foregn Relations/lnvestment & 11 \\
\hline Transportation_- & 11 \\
\hline Who's Who in the Pussian Far East_- & 12 \\
\hline Joint Ventures__ & 12 \\
\hline Housing & 13 \\
\hline Environment & 13 \\
\hline Miscollaneous & 14 \\
\hline Special Foature & 14 \\
\hline
\end{tabular}




\section{Nuclear Power - Chuikolka}

The leaders of the Chutkotka Autonomous Area have decided to linance the construction of the second stage of the Bilibino nuclear power station buik here in 1973. There is no record of damage to the air or water. There is a problem, however. More than 170 top specialists have announced their intention to loave Chukotka, and there are currently no olans for their replacement. (12/22/91)

\section{FOREIGN RELATIONS/INVESTMENT}

Externai Pelations Department in Primorye

An external relations department has opened in the Primorsky kral administration. hs head is the former deputy of chiel of ad ministration Vatery Lozovoy. The department has inree sections: foreign investments and foreng trade, international cooperation, and protocol service. (1/26/92)

\section{Development of Primorye}

The chief of Primorye's regional admininstration. V. Kusnetsov. recently refurned Irom a trip to organize economic ties between Primorye and British Columbua. Businessmen Irom British Columbia became interested in a plan proposed recently by Japanese specialisis for development ol the area. Otticials Irom Bntish Columbia will visit Vladivostok soon to discuss setting up a "link" between the two areas.

Kusnetsov is also meetung with officials Irom the European Bank of Reconstruction and Development (EBRD) on whether the bank will hatp set up market structures and sconomic

inlrastructure. The bank is accepting the lollownng responsibili ties: to help estumete the natural resource deposits in Primorye. to invest in future economic development ol Pnmorsky region directly of to assist with long-term loans. and to provide linancial and for unlrastructure. (11/17/91)

Japan To Open Consulate in Vladivostok A meeting was held recently in Vladivostok to discuss the opening of a Japanese Consulate in Vladrvostok. Mr. Suzuki Vatanabe, a vico-consul ol the consulate-general in Nahodka, stated that he would preler a location lor the consulate in downtown Vladivostok, since this summer a great number of tourists and businessmen will visit the ctry. (1/26/92)

\section{Taxation of Forelgn Investors in Primorye} A dratt decree issued by Russian President Bons Yehsin regarding Primory Tertitory contained a section on taxation that states that for loreign enterprises involved in mining, fishing. and tish-processing. the proft tax cannot exceed 20 percent. For the enterprises with loreign investments where the share of a foregn partner makes up more than 30 percent, the prolit tax cannot exceed 10 percent. (12/29/91)

\section{Registration Costs tor Forelgn Investments}

Chiaf ol the administration of Magadan region edopted a new ordar for the registration of enterpnses with loreign investments. Registration costs will be 3,000 rubles. Enterprises with investments up to 100 million nubles registered belore December 1, 1991 will be registered iren ol charge. (2/2/92)
Vladivostok as Major Aslan Trading Hub

Japan's major trading corporations expect the port of Vladivos. tok to become the major trading hub for cities in the Russian Far East. An oflicial of Mitsubishi Corp has indicated that Vladivostok "will become the center for most business opera. tions involving Japan and other Astan nations."

Russian authorties agreed to open the port enies of Vladivos. tok and Vostnochny to Japanese commerelal shipping. A group of Japanese trading companies called the Japar.

Russian Trade Association has agreed to provide development assistance lor the Port of Vanino.

But the Japanese are not the only ones getting involved. In June, a business delegation Irom Tacoma, Washington flew to Vladwostok and signed agreements establishing banking and port ties between Vladrostok and Tacoma. Under the banking agresment, Puget Sound Bank will pay for traning and edveation cosis for Vladivostok bankers who come to the Pactic Northwest to leam about U.S. banking methods.

Although Vladivostok lacks forexgn exchange banks and customs oflices, the massive harbor laclitios give great polential to the ctry's future as a trading hub. The Mitsubishi otlicial said Vladivostok is bound to become the most important outlet for Russian Far Eastem steel, lishery resources, oil, natural gas, and lorest products.

A mission of representatives of major Japanese commerica banks. trading corporations, and other private sector industries toured six crties of the Russian Far East recently. The purpose of the tour was to survey port and other intrastructure lacilities to find out Russian plans lor improving the ability to handle a substantial increase in port activity. Another mission will teach Russien authones how to turn Vladinostok into a commercially viable hub.

(Joumal of Commerce Intecnationat Edition. December 1991)

\section{TRANSPORTATION}

\section{Shipping Insurance in Far East}

Datrosso, a Far East Russian insurance joint stock company, is the first non-state comparny of its kind in the country. The company was registered in Vladivostok. and its founders include the Far Eastern. Prumorye, and Sakhalin shipping companies, Vostokyblkholodfbt fishing assocation, Kraporrabsoyuz, and cty executive committe ingostrakh.

Dalrosso has insured more than a thousand ships. It insures cargoes (both in hard currency and rubles), construction, as. sembly, adjustment and stant-up risks, ater-start-up guarantees, property interests of the pint ventures, state, cocperative, and public organizations, cars, fixed and current asssets, and other aspects of shpping. Dairosso is reportedly different from other Russian insurance companies in tis guar anteo - a policy whit the company ensures recoupment of losses.

Dalrosso has representatives in Vladivostok, Nakhodka, Khab. arovsk, Vanmo, Vostochnyı, Magadan, Patropavlovsk-

Kamchatski. Yakuts. Ulan-Ude, Novosibirsk, krutsk, and Moscow. An agreement has been reached with several Japanese companies lor Dalrosso to insure ther companies in Russe whils the Japanese inaure the Russian company in Japan. (12/29/91) 
of the referendum was not recession, but a Dew rationship with Russia. It does not wint to be govemed by the Russian con sciurion instead, it would like to sign a separate treaty with Rursia, which would give ara powers to the loal government.

In principle, there is no reason why Russia should not eive more powers to some of its terntories than wo others. The author of the new draft Russian constitudion has suggered making Tansan a "freety associ. atod sate" (someching Mikhail Gortacher once rugsested for the Baloic republic) $\mathrm{Mr}$ Yeloin stys that Taussan could have a sep ance sarus once it signs Russia's "federal treaty", which lays down the basic division of powers berween the country's centril and ocal povernments.

Tatasan, however, refuses co have anything to do with this traty. The federal enment fars that if it cedes special catr. traty saus to Tatursan, then other regions of Rusia will want the same After much am-wising, the government has per suaded is of the 20 autonomous republic

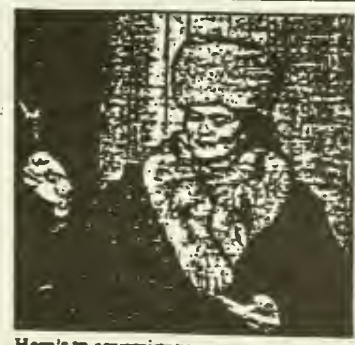

Here's to sovereienty $\quad . \quad: \cdots, \cdots, \ldots$

and regions io Russia to initial is treary. But the treary srill has to be ratified by the loea parliamens in those areas. If giving spocial satus to the Tatars encouraged the 18 othe areas to back out. that would quse an even bigger bust-up than simply allowing Tatarsar to take its leave.

\section{Nudear power Alarming}

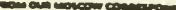

A 237 on the moming of March 24th $n$ 2 dioscrive noble pases and iodine $a$ aped inw the atmosphere from rencwor number three in the nuelear power phant at Somovy Bor, 100 kilometres ( 60 miles) wer of St Petesturr? It was a small acrident messring onty two on the seale of seven osed by the International Atomic Enery Asency (LeA) But it was a reminder that nueler disarer in the former Soviet Union is disurexingly likely.

The accident bappened when contamianted steam eaped from one of the $1.6 \%$ fuel channets in the recor's core either be cuse the channel rupoured, or, more likely, becuse a sed on the ehannel gave woy. Ever though the level of mdioactivity in the urbine hall rose to 60 micro-rity in the hour, three times its nomal level, according o the myor of Scanony Bor, there was never amy danger of a melt-down live that at Chemobyl. The recoor's afery syoms worked as derizned and quiddy quenched the nuelear reacion.

For all it harmlermess, the incident it herusus the afficioions bedevilling the nuclear industry. Lar January Swedish safery inspectoss visited Sconovy Bor and recommended a rif of improvemeno. Les than a month later the number of Ruerian safay inspectors was halved. be cause of lack of moner. Aceording to Vhadimir Suthoruchlio of the Xurchasov $\mathrm{Nu}$ cles Reserch Institute in Moseow, the fuel channed at Sosnovy Bor failed because of poor manuficrure or lesting.

A similar accidene could have ocourted almost anywher actoss the former Sovie Unuon. Poor manufecruring was to blame for $17 x$ of the 139 unscheduled stoppares at nuclear-power rectors in $19 \% 0$. Werem a

\section{9acidentts will happer -}

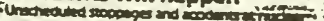

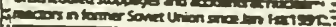
on

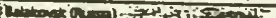

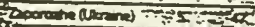

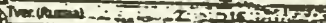

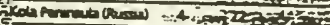

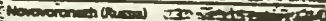

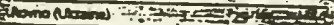

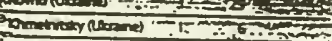

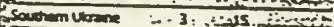

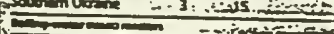

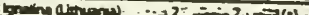

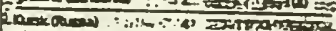

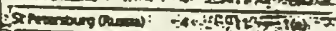

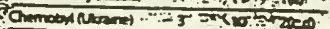

(1)

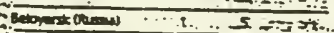

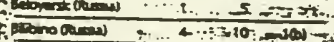

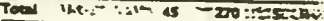

con Con

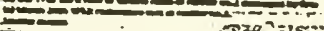

peres sty that al thouth nuclear techricians have plenty of sill, safery sandards are haphand likecr. sacy sandards ar officialdom, the mucler ins (alled Goatomnadroc) is in chas and strapped for esh. In a counuy where mak ing elecuricity has atwrys come before safery. the inspectorate has never been property isdependent of the enerty ministy.

-. If it were merdy a matter of trining and organiation, putting nuclear power right could proced apace The trouble is that So viea-built reacors are as flaved as the organisation that nuns them. Since the Chernobyl incident in 1986, loes of fifor has gone rowards correcing the fauls that led to the diester. Even so the reactors like that at Sosnoy Bor-alled reactors like that at

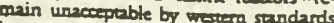
because of their fundamenvil derion. meant originally for making weapons erede pluto nium rather than electricity. Of the five nudear incidents that have nkea place since 1991 (set vble) all but one have ate sirce inside RMAX reache Moreove, none of them is sheathed in the buse concrete domes that contain radioscive material if there is an scoidene.

Ideally, these ractors (itke the oider Soviet built machines, the vver-230 prosurised water rectors, which were condermed in a repoet by the wen extier this yes would be thut down for carler this yes patched up. Wexem soverments hre been ureing the Rusians to do just that Ye the ex-Sovie Union needs nueler power.

- Since the Chernobyt dismer, 60 mudear-powe projects of various linds (both new reacos and exensions of old anes) have been abendoned, invoting the loss of toel of 160,000 metwats of enertin apciry. If all y ux and were closed, that would eliminate nenty balf of the remaining mueiear-power gener axing capacity and 65 of the former Sovie Union's elecuricity. In Armenis which is suffering an enero blockade by Atrbajian. the atomicenerot minister wates to reoper the mos dangerous of all Soviertuil plants a vrek-23o in an eartaquake zone fit wes closed in 1969) .......

- Recognising that it will take time to re place these reacros with saftr oner worer countres are tryins to do whas they can to

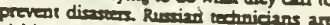
visiting the Wert, to witnes firthand the standirds of werem nuders operator internacional tean from Exrope and Canada will soon make a study of the $21 \mathrm{M} x \mathrm{r}$ accors that will be similas to the ura's soudy of the Wre-230 rectors. Each wre-230 m actor will coss $\$ 500 \mathrm{~m}$ to pur rithe Refirts rectors throughout the former conmunis countries could cost $\$ 73$ billion, on one eximate. Given the sele of the porblem, tens of millions of dollars milable to car rent worem effors are meage indeed. 


\section{Background Information on Formerly Used \\ Defense Sites Containing Radiation \\ in Alaska}

August 25, 1992

\section{PROJECT CHARIOT/CAPE THOMPSON}

Alaska Department of Environmental Conservation, Federal Facilities/Contaminated Sites section, received a report this week from Cook Inlet Vigil which contained several memos from 1962 and 1963. The memos describe and discuss the burial of approximately 43 pounds of radioactive isotopes, including fallout from nuclear testing in Nevada at Cape Thompson during Project Chariot. The isotopes were placed in 10 experimental plots and water applied in order to conduct a hydrological study by the United States Geological Survey agency for the Atomic Energy Commission. After the study the contaminated soil was buried under four feet of soil in the Snowbank Creek drainage in an area which appears to be approximately 3000 feet from the Chuckchi Sea. The area is used as a subsistence area for the villages of Point Hope and Kivalina.

The site is classified as a DERP-FUD (formally used defense site) and as such is the responsibility of the Army Corps of Engineers. The Corps has been contacted and they will contact $A D E C$ regarding their plans for removal. ADEC has informally expressed their desire for an emergency removal. Further research will center on the degree of risk posed by the isotopes and more specific information regarding the location of the burial. For more information contact Laura Noland (907) 451-2139.

\section{FORT GREELY}

'The repair to the building attached to the SM1-A nuclear reactor commenced the week of August 17. The contractor has begun the excavating process to remove part of the existing slab in preparation for pouring the new cantilevered retaining wall. According to John Davis, the radiation monitoring contractor, slightly elevated leveis of radioactivity were recorded in the excavated soil. This may incur storage and shipment of over 300 drums of radioactive waste to the Lower 48 . For more information contact Ron Short (907) 451-2156. 


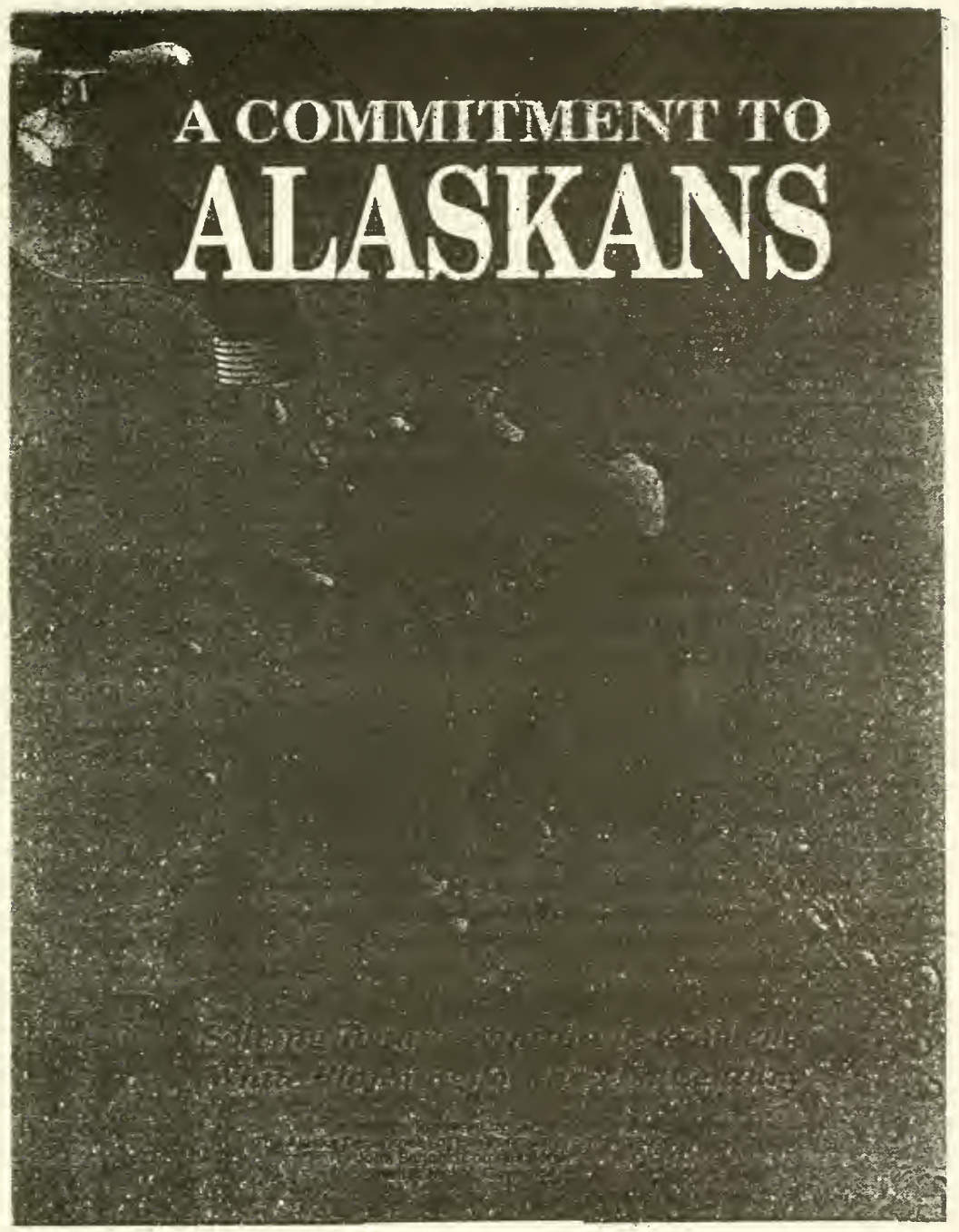


"A Commitment to Alaskans" is a working document meant to lay the foundation for a more refined plan in the future. As such, the Department would like to solicit public and agency input regarding information contained in this draft as well as any additional information or ideas which could be of assistance in this planning effort.

Additionally, an Interagency Task Force is being formed to act as a catalyst for advancing and refining the goals, strategies and objectives outlined on the following pages. If you are interested in participating in one of the Task Force's working groups, please let us know.

Please address all comments/ideas to:

John Sandor, Commissioner Alaska Department of Environmental Conservation 410 Willoughby Avenue

Juneau, AK 99801

Phone: 465-5050

Far: $\quad 465-5070$ 
As Alas sa looks to the future and a growing population, It is essential that we strive to provide sanitation services which protect the public health of our residents and provide a foundation for economic development opportunities.

It is the goal of this Administration that no Alasion be deprived of the quallty of life afforded by the provision of water, sewerage, and solld waste services. 


\section{OVERVIEW}

Without adequate water, sewerage, and solld waste facilities, the vitality of Alaska's communities is hampered, public health threatened, and opportunities for economic development severely restricted.

As the State looks towards the twenty-first century. it is critical that we commit to an efficient, well planned approach to providing these public services to all Alaska.

This document offers a strategy for formulating a systematic approach to addressing the water, sewerage, and solid waste needs of Alaska's communities. It presents recommendations for maximizing the efficiency of current sanitation systems and optimizing future capital project investments. As a long-term management proposal, goals are outlined and action strategies presented for review.

This is a working policy document meant to lay the foundation for a more refined implementation plan. 


\section{A BLUE PRINT FOR SOLVING ALASKA'S SANITATION NEEDS}

\section{FUNDAMENTAL GOAL:}

It is the goal of this administration that no Alaskan be deprived of the quality of life afforded by the provision of adequate water, sewerage, and solid waste services.

\section{STRATEGY:}

To achieve this goal, a five point management strategy is recommended.

- Develop a Comprehensive Interagency Approach to Problem Solving.

- Adhere to a Stable Six Year Funding Commitment.

- Six Year Capitalization of the Alaska Clean Water Fund.

- $\quad$ Promote a Solid State/Federal/Community Partnership.

- Enhance the State's "Insurance Policy" Programs (Training \& Technical Assistance).

\section{TIME FRAME:}

If the recommendations outlined in this plan are effectively implemented, water, sewerage, and solid waste services will be provided in every Alaskan community by the year 2010 . Intermediate steps may be required to achieve the final level of service. 
Due to the distinct demographic and economic conditions as well as the diverse sanitation needs of Alaska's urban and rural communities, two separate plans for implementing the State's overall sanitation management strategy are required.

The first plan, outlined on pages ** through **; is a strategy for addressing the sanitation needs of the State's urban communities. The second plan, which begins on page **, presents recommendations for solving the water, sewerage, and solld waste problems in rural areas. These plans are intended to stand alone and may, therefore, contain some redundancy.

Under each plan, management goals are presented followed by action strategies for goal advancement. 
GOALS AND STRATEGIES FOR SOLVING THE SANITATION NEEDS

\author{
OF
}

URBAN ALASKA 


\title{
The Sanitation Needs of Urban Communities are Dramatic.
}
The immediate and long term need for increasing the availability of funds for urban water, sewer, and solid waste management projects is dramatic. During the next twenty years, it is estimated that a minimum of $\$ 1$ billion will be needed to plan, design, construct, expand, upgrade, replace, and rehabilitate sanitation systems in the State's incorporated municipalities.

The majority of urban water, sewerage, and solid waste facilities in place today were constructed between 1973 and 1985 at a cost which exceeded $\$ 750$ million.

\section{AGING}

FACILITIES Since the average useful life of these facilities is 15.20 years, it is projected that there will be a major dernand for system replacement between 1992-2005. The exact extent of these replacement costs is not yet known, however, due to inflation and a variety of other economic factors, costs will exceed the first round invest. ment.
\end{abstract}

$\mid$

POPULATION GROWTH

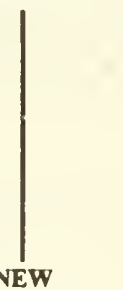

DRINKING WATER REQUIREMENTS

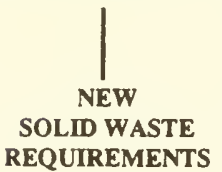

REQUIREMENTS

Alaska is the second fastest growing State in the nation and it's highest growth rates have traditionally been concentrated in incorporated communities. The population in many of these communities has already increased beyond the design capacity of their sanitation systems and system overload has become a serious problem. This increased burden on a treatment facility shorens its useful life and can result in inadequate treatment, recurring system malfunctions, or a complete system breakdown. New facilities need to be constructed or old facilities expanded to accommodate the growing population of these communities.

In addition to replacing aging systems and accommodating population growth, local govemments will soon be faced with meeting new federal drinking water and solid waste standards. Complying with these new standards will require a major invesument in extensive system upgrades for many communities.

The federal government has recently redefined safe drinking water requirements. The fiscal impact of the new standards is currently under review. It is known, however, that a major investment will be required to bring systems into compliance with new surface water filtration and lead/copper rules.

Due to the expense of upgrading landfills to meet new federal requirements, many cities will likely opt to close their landfills and build new ones. This will not be cheap. A recent study for the Juneau landfill, for example, estimated closure costs of approximately $\$ 10$ million. When constructing new facilities, communities will be required to meet federal design standards which will necessitate a substantial expenditure. 


\section{GOALS}

The following goals have been identified as cornerstones to addressing the sanitation needs of urban Alaska:

- Maximize limited State revenues through an equitable division of State and local financing alternatives.

- Promote a State/Community partnership approach to problem solving.

- Assist communities protect public health and attain/ maintain compliance with State and federal requirements.

- Develop a systematic approach to meeting community facility rehabilitation and replacement needs.

- Formulate an effective strategy for meeting population growth needs and ensuring adequate sanitation services are provided throughout urban Alaska.

Four Action Strategies are recommended as solid practical steps toward achieving these goals:

- Stabilize funding for sanitation infrastructure.

- Optimize the State's investment in sanitation facilities.

- Promote State/Community partnerships

Develop a planning database. 


\section{ACTION STRATEGY: Stabilize funding for sanitation infrastructure.}

A stable and predictable funding commitment for the construction of sanitation facilities is necessary to achieve the goal of adequate sanitation services in every Alaskan community.

As shown in the graph below, State funding of community sanitation facilities has been sporadic at best. When State revenues were high, it was relatively easy for local governments to obtain grants. However, as oil revenues declined so did the State's investment in these projects. The unpredictable nature of this "boom and bust" funding cycle has made planning for long term capital improvements virtually impossible for local governments. In fact, there have been instances where communities were successful in receiving State funding for the planning, design and the first construction phase of a project, but have not received financial assistance for the phases necessary to complete the project.

State Fundiag History of Sanitation Projects*

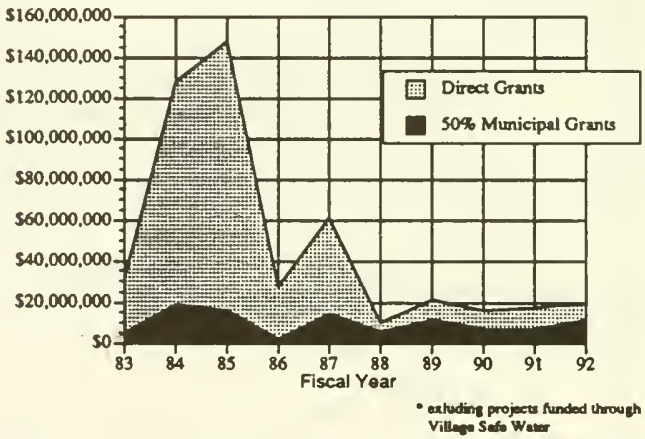

By committing to a stable Municipal Matching Grants budget, the State and local governments would be able to plan for and finance public sanitation projects in a more effective and efficient manner.

Likewise, by capitalizing the Alaska Clean Water Fund loan programs, the State would provide Alaska's urban communities with a predictable, perpetual and, evenrually, self-sustaining financial resource (as describe in objective 2 of the next Action Strategy. 


\section{Objective 2 Capitalize the State Construction Loan Program.}

For the next six years, the Department plans to request an appropriation to the State Construction Loan Program as part of its capital budget submission. Due to the large demand for financial assistance from this loan program (last year alone, community requests exceeded $\$ 95$ million), a minimum capitalization of $\$ 10$ million per year for six years is recommended. At this level, over $\$ 177.7$ million in sanitation projects could be financed over twenty years.

If revenues are available, a more aggressive six year capitalization commitment is recommended.

\section{AN ENDOWMENT FOR THE FUTURE.}

The graph below compares the value of new projects which could be financed through the State Construction Loan Program over a twenty year period under four capitalization scenarios, where \$10, \$15, \$20 and \$25 million are appropriated each year for six years.

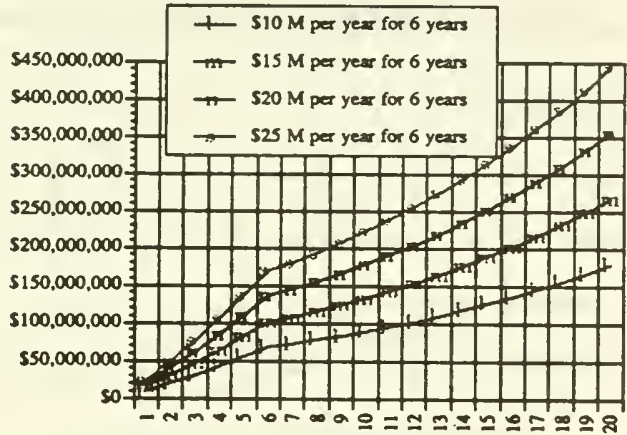

$544,159,125$

$5355,327,300$

$\$ 266,495,475$

$\$ 177,663,650$

Fiseal Year

Under Scenario 1, the Staic capitalizes the fund at the rate of $\$ 10$ million per year for six years. This commitment level would allow the fund to finance $\$ 177,663,650$ worth of projects over a twenty year period.

As the capitalization level increases under the remaining three scenarios, the number of projects that can be funded over a twenty years and the average return to the revolving fund increase proportionately. Under each scenario the State would realize more that a 225 percent return on its initial investment after 20 years. 


\section{$\overline{\text { Objective } 3}$ Promote an equitable solution to capital project} financing.

Addressing the water, sewerage, and solid waste needs of the State's urban communities is estimated to cost in excess of $\$ 1$ billion over the next 20 years. Unfortunately, local governments and the State have limited financial resources. So the question arises ... how will the planning, design and construction of these projects be financed?

The State can not do it alone. Revenues are declining and demands on budgets are already burdensome. Neither can communities afford to finance multi-million dollar projects. There are few revenue streams which local governments can dedicate to sanitation facility construction. Residential user fees are already steep in most communities and are earmarked for system operation, maintenance, and replacement costs.

The Department recommends an equitable division of financial responsibility between the State and local governments. The graph below compares the costs to communities and the State to construct $\$ 1$ billion in projects over the next twenty years under five financing mechanisms: State Direct Grants, State Construction Loans; Municipal Bonds; Municipal Grants combined with State Construction Loans; and a 50/50 Municipal Grant/community bond combination.

Comparison of cost 10 communities and the Stale to Construct 1 Billion in projects over the next 20 years under $\mathrm{S}$ financing alternatives.
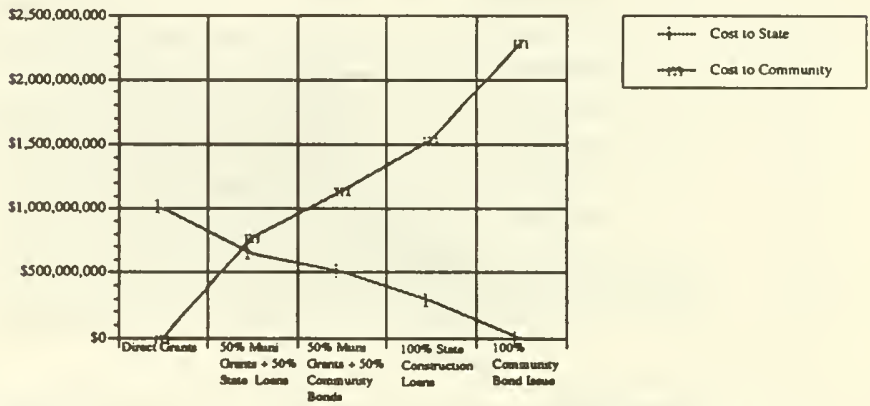

As shown above, the most equitable division of financial responsibility between the State and local governments would be provided by combining Municipal Grants and State Construction Loans. The granthoan ratio could be changed based upon a community's financial capabilities. This approach is used in many States throughout the U.S. where granuloan blends for water and sewer projects are based upon what is called an ability to pay index. 


\section{ACTION STRATEGY: Promote a State/community partnership.}

It is essential that community participation in a project go beyond signing a grant offer or passing a resolution. It is equally vital that the State's role transcends simply disbursing payments. Experience has shown that communities who actively work with the State and participate in the solution to their sanitation problems are more likely to adequately operate and maintain their facilities.

\section{$\overline{\text { Objective } 1}$ Local commitment to participate in funding.}

Requiring a local funding commitment not only ensures that projects are a community priority, it also increases community interest in operating and maintaining projects in which they have made a financial investment. Historically, the matching requirement of the Municipal Grants program has been the catalyst for this commitment in urban communities. Now, the Alaska Clean Water Fund loan programs are also available to assist all urban communities participate in project costs.

\section{$\overline{\text { Objective } 2}$ Cooperative planning.}

A successful project requires adequate and cooperative planning. Without planning, resources may not be available to complete construction; a community may get a project which is different from what they wanted; the facility constructed may not be feasible, practical, or the most cost effective alternative available; and the cost of operating and maintaining the system may be too expensive for the community. It is, therefore, vital that both local residents and individuals with experience and expertise are part of the planning team. Project cost estimates must be accurate or construction could be halted prior to completion. Public hearings should be held frequently during planning to ensure the community gets what it wants and has the information necessary to choose the most cost effective, feasible, and practical project alternative.

Cooperative Planning between communities and the Department is an integral part of successful projects. It is a requirement of Municipal Grants, Federal Wastewater Loans, and State Construction Loans.

\section{$\overline{\text { Objective } 3}$ Operation and maintenance.}

In addition to a commitment to properly operate and maintain their facilities, funding for sanitation projects should be conditioned upon a local commitment to (a) hire operators certified at a level commensurate with the technical complexity of the facility, and (b) require operator participation in refresher courses and skill advancement training.

The Deparment will provide assistance for addressing these requirements by (a) ensuring communities are aware of operation and maintenance costs associated with a project prior to construction, (b) assisting communities to calculate user fees sufficient to finance operation and maintenance costs, and (c) by offering training, technical assistance, and certification programs for system operators.

12. 
GOALS AND STRATEGIES FOR SOLVING THE SANITATION NEEDS

OF

RURAL ALASKA 


\section{Providing Adequate Sanitation Services is Crucial to the Vitality, Public Health, and Economic Growth of Rural Alaska.}

As Alaska looks to the future and a growing population, it is essential that we strive to provide services which protect the public health of our rural residents and lay a foundation for economic development opportunities.

Adequate water, sewerage, and solid waste services are comerstones to realizing these goals.

As the twenty-first century nears, citizens in over half of the State's rural communities do not have piped water or flush toilets. Over ninety percent of the sewerage facilities in rural Alaska have been assessed by the federal government as inadequate. State and federal agencies have estimated the costs of providing acceptable sanitation facilities in every rural community to be $\$ 1.2$ to $\$ 1.3$ billion. These are starling statistics and they highlight the magnitude of the problem.

Without adequate water and sewerage facilities, personal hygiene is difficult, if not impossible. The lack of facilities to properly dispose of human waste, combined with insufficient quantities of safe water often result in threats to public health. Village residents experience a number of waterbome and communicable diseases which could be avoided if means to support improved personal hygiene and safe drinking water were available.

The provision of acceptable sanitation services is often a prerequisite to economic development and growth. However, many villages lack these basic facilities. Numerous rural communities, for example, are unable to attract the seafood processing industry because their water and sewerage facilities do not meet standards required to support the industry. Likewise, the full potential of the tourism business may not be

realized in rural Alaska since even the most seasoned traveler would prefer to visit an area where safe drinking water and flush toilets are available and refuse is consolidated out of sight. Another example of an economic development opportunity which demands sanitation infrastructure is port development. To attract shoreline businesses, not only do our ports and harbors need adequate docks and breakwaters, but adequate water and sewer are also critical. Under MARPOL, coastal communities must also provide solid waste facilities in order to engage in marine commerce, yet adequate facilities are not available in many of our more promising rural ports.

One of the indicators often used to measure the quality of life in a community is the public service infrastructure provided to residents. Carrying a sloshing bucket of human waste to pitch in a pond or hauling water from a watering point would not be acceptable to the vast majority of Americans, yet many rural Alaskans contend with these hardships daily. Providing water, sewerage, and solid waste services to every community by the year 2010 will allow all Alaskans to experience the quality of life taken for granted throughout the rest of the nation and much of the world. 


\section{A CALL TO ACTION.}

After twenty years of trying to address the sanitation needs of rural Alaska, it is clear there are no quick fix solutions.

The problem is multifaceted. First, our current selection process for determining which projects will receive grant assistance is short-sighted. To often the State's annual sanitation funding plan is thrown together during the closing days of the legislative session based upon political criteria rather than need. A long term, stable funding approach has not been available.

Second, it has become clear that technology alone will not address the water, sewerage, and solid waste needs in rural Alaska. Competent operators, adequate user fees, proper accounting, and the support of a well managed community government are equally vital components to solving sanitation problems.

Third, demographic, economic, and climatic conditions make sanitation system construction and operation in rural Alaska among the most expensive and technically challenging in the world. Yet little research has been conducted to develop alternatives to expensive and complex piped systems capable of providing an equal level of service.

Finally, a long term strategic approach to solving rural sanitation needs has never been formulated. Rather, planning has been limited to a one year period and has been based solely upon the outcome of the State capital budget process. This process has proven ineffective.

As the first step toward addressing these and other related issues and instituting a more unified approach to solving the sanitation problems of rural Alaska, the Department recommends the formation of an Interagency Task Force. This group would act as the catalyst for advancing and refining the goals, strategies and objectives outlined on the following pages. 


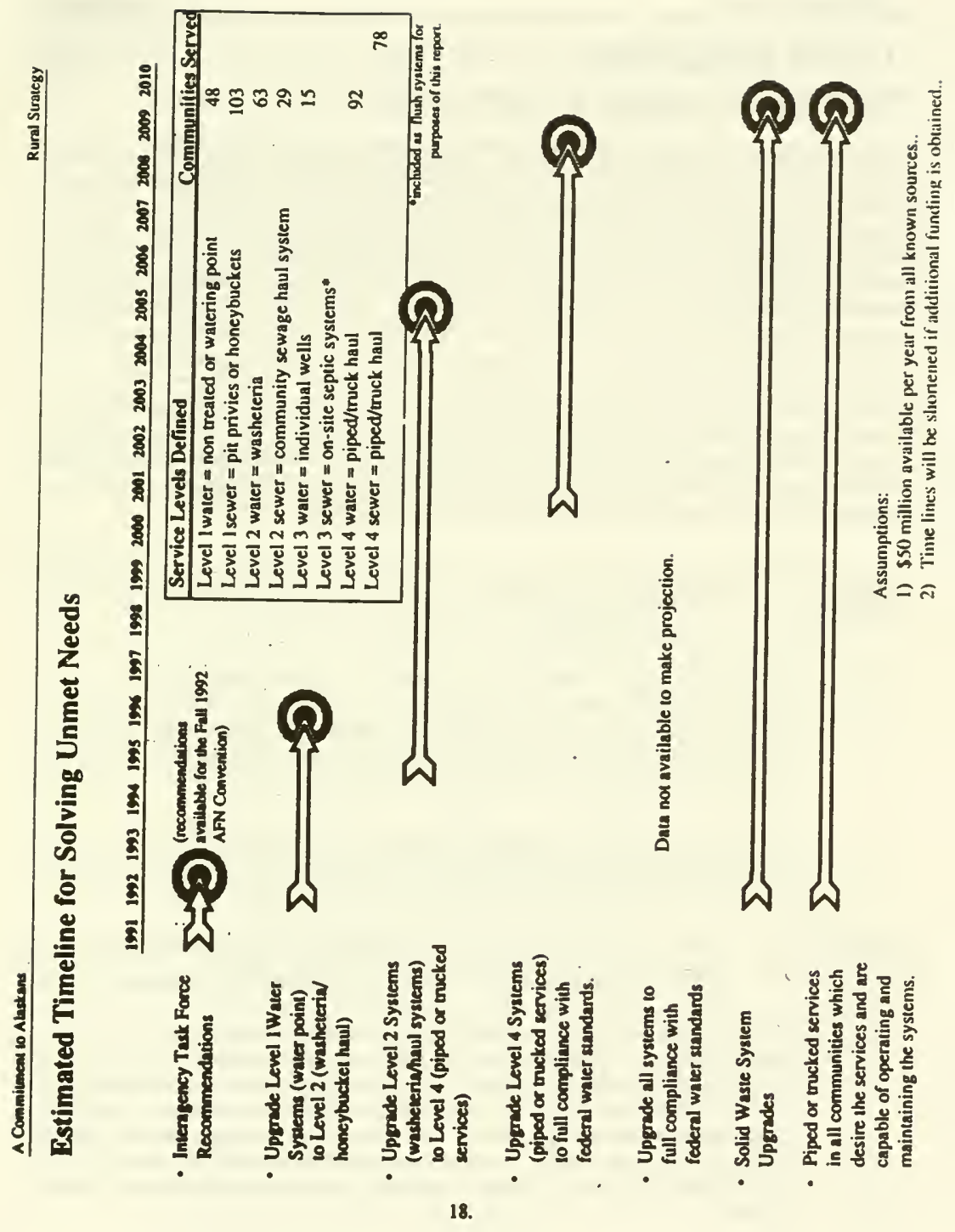




\section{ACTION STRATEGY: Form an Interagency Task Force.}

Due to the magnitude of sanitation needs in rural Alaska, a unified, multiagency approach to problem solving is necessary. An Interagency Task Force will be established to review, analyze, and recommend policies, standards, and solutions for formulating a federal/State/community twenty year rural sanitation strategy. The Task Force will consist of individuals, groups, and agencies representing a variety of interests and disciplines. Representation will include State and federal agencies, local officials, the Legislature, the University of Alaska, Health Corporations and rural leaders. Participation, input and recommendations from experts in the areas of engineering, housing, finance, business, health and education will provide the Task Force with the policy direction necessary to develop a comprehensive twenty year strategy for meeting the water, sewerage, and solid waste needs in rural Alaska.

Because of the complexity and number of issues at hand, the Task Force will work more efficiently if divided into several subgroups. Each subgroup will be assigned specific issues to analyze and will be responsible for reporting recommendations to the full Task Force for inclusion in the States rural sanitation strategy. During the first year of the strategy, the Department will concentrate on obtaining program direction from Task Force recommendations on the following:

\section{Objective 1 Establish uniform standards for federal and State housing}

The existing minimum water and sewerage service standards of State and federal housing programs will be reviewed by the Task Force. Current standards will be examined for compatibility with the State's overall goal of providing water, sewerage, and solid waste services to every Alaskan community. Where current standards are inadequate, specific parameters will be recommended as minimum health requirements.

If adopted, these parameters would be required in every new home constructed in Alaska by federal and State housing authorities. Additionally, methods for modifying plumbing in existing homes which do not meet the minimum code will be explored.

\section{$\overline{\text { Objective } 2}$ Develop a policy for subsidizing the operation and maintenance of village owned facilities.}

The Task Force will review the feasibility of providing a subsidy program for operation and maintenance of village sanitation facilities. Many villages do not have the population or economic base to adequately budget for operation, maintenance and replacement costs related to providing sanitation services. These costs will be reviewed and compared to the average household income in each rural region of the State to determine an equitable solution to O\&M budgeting. The cost of subsidized O\&M will then be compared to the cost and benefits achieved though expansion of the Remote Maintenance Worker Program. 


\section{$\overline{\text { Objective } 5}$ Develop and institute a sanitation education curriculum.}

Breaking the cycle of water borne disease in remote communities takes more than capital projects - a health education program is needed to augment ongoing construction activities. The Task Force will explore working with the Department of Education, the U.S. Public Health Service, and local school districts to develop and implement a complete "health education kit" including videos, posters, and text books. These materials would be made available to teachers in remote locations to educate children of the importance of personal hygiene, safe drinking water, proper sewage disposal, and adequate solid waste management.

It is suggested that health education become an integral part of all sanitation construction projects in rural Alaska. The whys and hows of properly using new facilities as well as information regarding communicable diseases (what they are, how they are spread, and how to prevent contacting them); the water cycle; the imporance of boiling non-treated drinking water, and the importance of separation distances between places where water is obtained and where sewage or solid waste is hauled would be among the topics explored.

\section{$\overline{\text { Objective } 6}$ Improve roads in communities where haul sys- tems are the selected alternative.}

Geographic, climatic, and economic conditions in many rural communities make piped utilities impractical or infeasible. In such cases, residents frequently select water and sewer haul systems as preferred project altematives. Haul systems require roads with bearing capacity adequate to handle large water and sewage transportation vehicles. Unfortunately, many of the communities who desire haul systems, either do not have roads or have roads which do not now have adequate bearing capacity.

The Task Force will explore coordinating funding and resources with the U.S Public Health Service, the Bureau of Indian Affairs and the Deparment of Transportation in order to construct new gravel roads or improve the bearing capacity of existing roads in communities where haul systems are the preferred alternative to piped systems.

\section{$\overline{\text { Objective } 7}$ Develop utilities for joint use by villages and schools.}

In many villages, two separate water and sewer systems are operated. One provides service to the community and the other to the school. As a result there are two treatment plants, two wastewater collection and disposal systems and dual plumbing, heating and electrical systems to support them.

-Based upon the recommendations of the Interagency Task Force, the Department proposes identifying those communities where dual systems exist; examining the requirements of each; and determining where joint utilities are cost effective and practical. It is further recommended that a joint utilities pilot study be conducted by REAA's prior to applying the "joint utilities" approach in several areas. 


\section{ACTION STRATEGY: Stabilize funding for rural water, sewer, and solid waste projects.}

It is virtually impossible for the State to enter the twenty-first century with hopes of providing every Alaskan community with adequate sanitation services without a stable funding commitment for the construction of necessary facilities.

As shown in the graph below, State and federal funding of rural sanitation facilities has been sporadic at best. When State revenues were high, it was relatively easy for local governments to obtain grants. However, as oil revenues declined so did the State's investment in water, sewerage, and solid waste projects. The unpredictable nature of this "boom and bust" funding cycle has made long term capital improvement planning virtually impossible for local governments. Likewise it does not allow for a systematic, long term Statewide approach to address community sanitation needs.

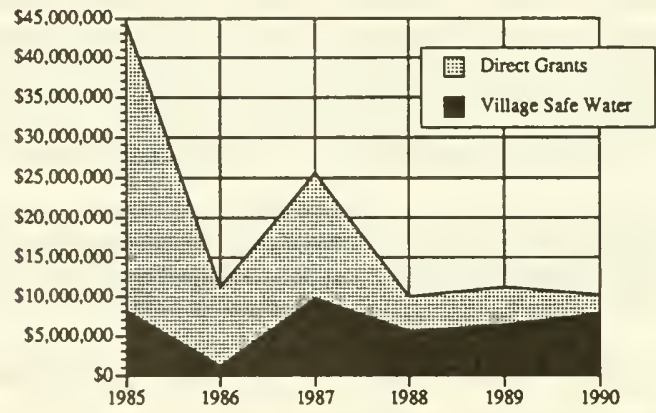

By committing to a stable Village Safe Water capital budget, the State, federal, and local governments will be better able to plan for and finance public sanitation projects. 


\section{ACTION STRATEGY: Assist communities increase operation and maintenance capabilities.}

The construction of rural sanitation facilities represents a multi-million dollar investment by the State in public health protection for village residents. Increased commitment to the operation and maintenance of these facilities is necessary if rural public health and the State's large investment in sanitation facilities are to be safeguarded. Weaknesses in planning, staffing, and budgeting lead to sanitation system failures as surely as equipment and mechanical breakdowns. Unless this trend is reversed, additional system failures are predicted and a tremendous financial burden will be placed on the State. The Department proposes the following multi-disciplinary approach to help deal with these problems.

\section{$\overline{\text { Objective } 1}$ Define operation \& maintenance capabilities and needs in each community.}

Using data obtained from Remote Maintenance Workers, Village Safe Water Engineers, Public Health Service Engineers, Native Health Corporations and community leaders, the Department will assess the operation and maintenance capabilities and needs in each rural community. The Operations Assistance program within the Department will use this information to target training efforts in communities lacking sufficient expertise for operating and maintaining their systems.

\section{Objective 2 Work with State agencies and authorities to develop and implement a utility management training program.}

The Department recommends working with the U.S. Environmental Protection Agency, and the Deparment of Community and Regional Affairs, and the Alaska Energy Authority to develop and institute a management training program to assist rural communities in implementing basic financial, accounting, bookkeeping and management systems necessary to properly manage public utilities. Through the program, local officials would learn to compare revenues to actual costs and adjust user fees accordingly; investigate altemative sources of system revenues; develop utility billing procedures and policies; and institute proper accounting and solid business management practices. 


\section{$\overline{\text { Objective } 4}$ Expand the Remote Maintenance Worker Program.}

Most of the State's rural communities lack a public works department, a full time professional water/sewer operator, and in many cases an electrician or plumber. Systems are frequently left in the hands of volunteers who, with limited resources and knowledge, face a wide array of mechanical, environmental, and public health related problems. In areas where climatic, economic, and demographic conditions make operation and maintenance of facilities arduous, technical expertise is of great imporance. However, the remote location of most villages makes it economically infeasible for outside services to be obtained when technical assistance is most needed. The Remote Maintenance Worker Program offers a partial solution to this problem.

Currently, the program consists of eight Remote Maintenance Workers (RMWs) who are mechanical experts as well as trainers. Each RMW is assigned a circuit of $10-15$ villages and resides in a hub community within their area. Through the efforts of these RMWs. the program employs a two-fold approach to protecting costly facilities and public health.

1. Technical Assistance. Due to the remoteness and climatic conditions found in most villages, even minor operational problems can result in malfunctions that can lead to catastrophic system failure. As technical experts, RMWs are available to villages 24 hours a day throughout the year for advice and emergency repairs.

2. Operator Training. As educators, RMWs provide operators with emergency and routine on-the-job training. Operators are trained at their own speed at a level commen surate with their individual requirements.

The solid commitment and ongoing cooperation of the legislature, the Department of Environmental Conservation, several Native Health Corporations, and rural villages throughout the State is positively reflected in the success of the RMW program.

Unfortunately, less than half of the State's rural communities are serviced by a Remote Maintenance Worker (refer to exhibit *)

The Interagency Task Force will evaluate expanding the RMW program so that within the next five years, all rural communities are served by a Remote Maintenance Worker. This will ensure the protection of rural public health and the State's capital investment in rural sanitation infrastructure. RMW assistance will only be provided until a community has obtained the competence to operate its system without State assistance. 


\section{ACTION STRATEGY:}

\section{New technology-research \& development projects.}

The Department proposes active investigation and promotion of innovative and alterative technology for the delivery of rural sanitation services. Demographic, economic, and climatic conditions make sanitation construction and operation in rural Alaska among the most expensive and technically challenging in the nation. A research and development program needs to be instituted to develop altematives to expensive and complex piped systems capable of providing an equal level of service.

Research and development activities should represent a community, State, federal, University and private sector cooperative effort both in funding and design. A multitiered approach to investigating and developing new sanitation technologies is suggested.

As the first step in this cooperative effort, the Department advocates sponsoring annual technology seminars where promoters of innovative and alternative sanitation technologies can present their concepts to the engineering community. This would encourage new ideas from manufacturers and designers and would introduce sanitation engineers to nontraditional technologies.

It is suggested that the Interagency Task Force include a research and development subcommitree to review new technologies including those presented during annual technology seminars to determine which merit further study .

As funding allows, those technologies recommended by the subcommittee as showing the most promise would undergo field testing which would consist of three phases. The first phase would include targeting a receptive village to host the demonstration project, a project inception briefing during a council meeting of the hosting community, and (if necessary) fabrication of prototype units. During phase two, prototypes would be installed in the homes of four to ten volunteer families. Phase 3 would consist of project evaluation. If the project is a success and well received by the village, expansion of the technology into the rest of the community would be recommended through the capital budget process.

This phased approach would allow communities to participate in and assess each step of a demonstration project before continuing on to the next phase. Further, it would allow communities to observe and evaluate technologies prior to deciding whether to adopt the new technology on a community-wide basis.

All studies, evaluations, and reports regarding the successes or failures of new sanitation technologies in village Alaska would be made available to interested parties. 
Written testimony for the hearing of the Senate Select Committee on Intelligence on Radioactive and other Environmental Threats to the Arctic resulting from past Soviet activities, Saturday, August 15, 1992, Fairbanks, Alaska, Thomas C. Royer

\section{An Action Plan for Arctic Pollution Studies}

Past pollution of the Arctic by the Former Soviet Union and the continuing contamination from the existing sites and practices in Russia pose potentially serious threats to the Arctic environments and its inhabitants as discussed in the oral testimony of 15 August 1992. The University of Alaska has expertise that can be brought to bear on this problem and the faculty of the University of Alaska have a direct interest in protecting the well-being of their families and neighbors; they are willing to respond with vigor to this problem.

The problem is an interdisciplinary and international one. It cannot be solved by one agency or country. It requires a very long duration commitment. It also requires the utilization of resources in what is considered by many as a remote region of the world, though not remote to those of us who live here. The use of existing organizations, cooperative agreements and facilities to address this problem would provide the most rapid and least expensive approach to this complex problem.

As mentioned in oral testimony of this hearing, the problem can be broken down into four tasks, 1) identification of sources of pollution, 2) monitoring for that pollution at a network of sites, 3 ) investigation of pathways for that pollution and 4) mitigation of the hazard. The potential sources include radionuclides, heavy metals, pesticides, hydrocarbons, and PCBs. How do we proceed?

We need both a long-term plan and immediate action. Immediate action should take advantage of existing programs in the Arctic nations. For example, air monitoring sites should be added to existing networks. Sampling opportunities in the Arctic marine environment are available in the upcoming months and they should be utilized. Within the next several weeks, at least two research vessels will be in the Chukchi Sea in both the Russian and US EEZ and could carry out some limited, initial sampling. These studies involve both University of Alaska Fairbanks and Russian scientists. Similar opportunities might exist in other areas such as wildlife ecology and public health that can be identified as helping with the problem. There currently exists a cooperative agreement on the Beringia Heritage Park that could be used to sample terrestrial systems on either side of the Bering Sea.

A long-term plan for Arctic Pollution Studies should be developed by an international group of science and engineering experts. This interdisciplinary group should develop a long-term action plan for the four tasks soon, beginning with an identification of existing data and information on Arctic pollution that expands on the information provided in these Senate Hearings. I propose that the University of Alaska host such a meeting and coordinate it with interested universities and other organizations including federal and state agencies. After a plan is established, requests for specific proposals can be made and the work begun.

A critical facet of this work will be the cooperation of Russian and other circumArctic scientists. While the faculty at the University of Alaska Fairbanks already have many collaborative agreements with Russian colleagues, it is important that ties between Arctic researchers be strengthened and ties established where they do not exist. The new International Arctic Science Committee (IASC) can play a major role here. A University of Alaska Fairbanks faculty member presently chairs the IASC Working Group on Global Change, which is concerned with environmental changes in the Arctic. Also, AMAP, the international Arctic Monitoring and Assessment Program is now devising a strategy for monitoring Arctic pollution, and University of Alaska Fairbanks faculty members are helping to write the US contribution to this strategy. Both of these activities will be brought into our proposed long-term planning. 
The University of Alaska is prepared to organize this planning meeting and to serve as a clearinghouse to coordinate an immediate response using existing expertise from universities and state, federal, and international agencies. UAF has ties with most of the federal funding agencies that might have interest in this problem; NSF, DOE, NASA, NOAA, Coast Guard, USFWS, EPA, NIH, CDC, Public Health and the Corps of Engineers.

\section{ARCTIC RESEARCH VESSEL}

It is recognized that the U.S. presently has a limited capability to sample the Arctic Ocean. U.S. Coast Guard icebreakers, Polar Star and Polar Sea, are available when not on other missions. Major expeditions have been carried out on these vessels but the sampling of frequently repeated stations is much more difficult. Russian ice breakers are another logical platform to use especially in the next few years. However, the long-term solution is for the U.S. to rely on its own Arctic research vessel.

The National Science Foundation has funded a conceptual design and is now funding a preliminary design of such a vessel with input from the scientists of the Arctic community. The final design is expected in 1993 with construction beginning in 1994. It should be available in 1996 and will be capable of addressing many of the Arctic pollution problems for the first quarter of the next century. This will be an important capability since it will ailow the U.S. research community to have control over its ability to sample in the Arctic. It will permit sampling on the Alaska and Siberian shelves unaided by escort for about six months of the year. Endorsement from the State Department and other federal agencies is appropriate to ensure that the design and construction of this vessel progresses in an orderly fashion.

Thomas C. Royer

Chancellor's Faculty Associate for Research

University of Alaska Fairbanks

Fairbanks, Alaska 99775 


\section{University of A Laska Fairbanks}

The Elmer E. Rasmuson Library

Fairbanks, Alaska 99775-1000

August 27, 1992

Honorable Frank Murkowski

United States Senate

709 Hart Building

Washington, DC 20510

Dear Senator Murkowsk1,

This is just a very brief follow-up on the hearings you held recently in Fairbanks with the select committee on Intelligence of the U.S. Senate rolating to nuclear pollution in the Arctic.

Whlle I know there is obviously a great deal of research to be accomplished identifying, profiling, and tracing the effects of nuclear pollution in the Arctic, particularly emanating from the former Soviet Union, I would like to stress two points.

The great volume of research done in the former Soviet Union is available at ths various scientific institutes, but not easily accessible because of language barriers. There should be, as part of this effort and others, an attempt to work with scientists and information scientists in the former soviet union to assess the breath, depth, and accuracy of much of the scientific research which is in the form of gray report literature now largely inaccessible to the West. Soviet information scientists are eager to work and collaborate with others, particularly U.S. librarians and information scientists, who may assist them in translating and making these many scisntific studies mors readily available to the world scientific community.

Also, as much of the scientific work procaeds, there is a need, often identified in the hearings you hald, to make sure that the peoples in the North know the results of the various scientific endeavors in a relatively timely fashion, and in a format readily understood by indigenous peoples and local populations who may not necessarily be scientifically sophisticated. Iibraries, both at the local lovel and in higher education, have a rolo to play in the dissemination of these research results. They should be integral to my offort to make the research results and prospective impacts available to the public. 
Honorable Frank Murkowaki

August 27, 1992

Page -2-

I found the hoarings extremely interesting and was very pleased that you took the opportunity to hold them in Fairbanks, particularly on the UAF campus.

sincerely yours,

Sawe ti. he Cacety

raul $\mathrm{H}$. Mccartiny

Director of Libraries 
Ụanadian Embaray

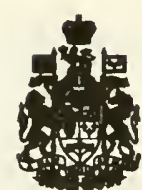

Autraseade an Tanada

501 Pennsylvania Avenue, N.W. Washington, D.C. 20001

August 13, 1992

The Honourable David L. Boren

Chairman

The Honourable Frank H. Murkowski

vice Chairman

Senate Select Committee on Intelligence

211 Senate Hart office Building

washington, D.C. 20510-6475

Dear Senator Boren and Senator Murkowski,

Further to Ambassador Burney's letter of July 14, I am pleased to provide a written statement for inclusion in the record of your August 15 hearing on radioactive and other environmental threats in the Arctic.

Please do not hesitate to contact me or my staff if we can provide additional information.

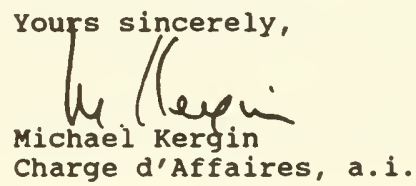

c.c. David Garman 


\title{
Radioactive and other Environmental Threats to the Onited states and the Arctic Resulting from past soviet Activities
}

\author{
Field Hearing conducted by the \\ select committee on Intelligence \\ united states senate \\ University of Alaska, Fairbanks \\ August 15,1992 \\ statement of the Government of canada \\ CIRCUMPOLAR ARCTIC ENVIRONMENTAL PROTECTION
}

over the past few years, Canada has shared in the growing appreciation of the importance of the Arctic ecosystem and its vulnerability to global sources of pollution. This subject is of great concern to the Government of Canada. We welcome this opportunity to share our views.

Threats to the integrity of the Arctic ecosystem arise from a number of sources, including anthropogenic radioactivity (1). Many are hemispheric in origin and can only be resolved through international cooperation. The eight Arctic countries -Canada, Denmark, Finland, Iceland, Norway, Russia, Sweden and the United states -- have recognised their responsibility as joint custodians of the Arctic environment and in 1989 embarked on the Finnish Initiative, a common strategy to address the threats.

\section{Contaminants in Northern Canadian Ecosystems}

Canada's initial involvement in the Finnish Initiative followed a period of focused attention on emerging problems relating to Arctic environmental pollution, beginning in 1985 with the establishment of an inter-agency Working Group on Contaminants in Northern Ecosystems and Native Diets. A baseline literature review commissioned by the Working Group underscored the need for a comprehensive assessment of wildlife contamination in northern Canada (2). In response, the Working Group undertook a co-operative program of studies based on an integrated ecosystem approach. The program of studies linked atmospheric, oceanographic and limnological transportation processes and pathways with biotic accumulation, human dietary patterns and possible health implications. Scientists and indigenous peoples worked together to design and conduct the project, the first comprehensive review of which took place at an international workshop in Ottawa in February, 1989 (3). 
The review, which has recently been published (4), considered four families of pollutants: heavy metals, organochlorines, acid precipitation, and radionuclides. The primary focus with regard to radionuclides was on long-lived fission products that have entered the Arctic terrestrial ecosystem, primarily through atmospheric fall-out from nuclear weapons testing between 1952 and 1980 and as a result of the chernobyl incident in 1986. Monitoring programs to assess the impact of radionuclides on Arctic biota and humans were carried out. Although the slow biological turnover rates in the Arctic have prolonged the natural dissipative processes, a steady decline in cesium-137 levels was observed. The results suggest that the consumption of caribou meat from Arctic Canada does not pose a significant cancer risk. This trend can be seen as evidence of the environment's ability to recover in response to corrective actions such as the atmospheric Nuclear Test Ban treaties.

The review also concluded that while acidic precipitation is not responsible for significant ecosystem stress in Arctic Canada, certain heavy metals (particularly cadmium, mercury and lead) and a variety of organochlorine compounds are found in surprisingly elevated concentrations in Arctic biota at the top of the food chain. In the case of organochlorines (e.g. PCBs, chlorinated dioxins, and DDT) and other persistent organics, the concentrations are the result of a combination of atmospheric pathway and chemical characteristics and the high affinity of these substances for fats. This has resulted in the significant biomagnification of the chemicals in many of the favoured dietary items of indigenous peoples (e.g. fish and marine mammals). The fact that some of the most ubiquitous substances in the canadian Arctic (e.g. the pesticide toxaphene) have never been used in Canada on a regular basis indicates that the Arctic pollution issue is global in nature and cannot be addressed by ourselves alone.

\section{The Finnish Initiative}

Recognition that environmental degradation of the Arctic requires a joint response underlies the Finnish Initiative. Delegates to the initial meeting in september, 1989, agreed that a series of reports on the state of the Arctic environment be prepared with respect to the following contaminants: Acids (drafted by Finland), Heavy Metals (U.S.S.R.), Noise (Denmark), oil (Norway), Organic Contaminants (Canada) and Radioactivity (Finland). It was determined as well that Norway and the U.S.S.R. would lead a review of national and international monitoring 
$-3-$

systems operating in the Arctic and develop proposals for future action in this field. Finally, it was agreed that canada and Sweden would begin work on the elaboration of an Arctic Sustainable Development strategy. Draft reports on these subjects were reviewed at the second meeting on the Finnish Initiative, in Yellowknife, in Canada's Northwest Territories, in April, 1990, and were subsequently published (5).

Several important developments occurred at the Yellowknife meeting. The first was the participation for the first time of Arctic non-governmental organisations -- the Inuit Circumpolar Conference, the (U.S.S.R.) Association of Small Peoples of the North, and the Nordic Saami Council -- as formal observers. Second, the structure of the Declaration on the Protection of the Arctic Environment and the companion Arctic Environmental protection strategy began to take shape (6). The Declaration and strategy were further developed at a preparatory meeting in Kiruna, Sweden, in January, 1991, and the Declaration was signed by all eight circumpolar countries in Rovaniemi, Finland, in June, 1991 (7).

The Afctic Environmental protection strategy

The Arctic Environmental protection strategy (AEPS) establishes objectives and defines a set of common principles to guide the Arctic countries in taking action to protect ecosystems and promote the sustainable utilisation of resources. The strategy contains a review of the problems posed by persistent contamination by organic substances, oil, heavy metals, noise, radioactivity and acidification, and a program of action to respond to environmental degradation resulting from these six issues. The proposed actions take advantage of existing international tools and mechanisms, where possible. For example, the eight Arctic countries agreed to utilise the Task Force led by Canada and Sweden under the United Nations Economic Commission for Europe (ECE) to develop proposals for international control of persistent organic compounds under the Convention on Long-Range Transboundary Air Pollution (LRTAP) by 1994.

The Strategy also outlines specific commitments related to Protection of the Arctic Marine Environment, Emergency Prevention, Preparedness and Response, Conservation of Arctic Flora and Fauna, and the establishment of an Arctic Monitoring and Assessment Program (AMAP). The latter is at present being developed by a circumpolar task force and its content is expected to be finalised at a meeting scheduled to take place in Toronto in December 1992 (8). 
The strategy is a living document. The eight Arctic countries have agreed to hold regular meetings to assess progress and to further develop the plan, and are to meet next at ministerial level in Greenland in September 1993. A practical instrument has thus been created through which the circumpolar nations can work together to address the type of issues of concern to the senate select committee.

\section{Canadian Initiatives}

The Government of Canada developed its own Green Plan in parallel with the development of the AEPS. Although this six-year, \$3 billion comprehensive national environmental plan includes components which relate to the Arctic only indirectly, it also includes a comprehensive plan of action exclusively devoted to the Arctic region -- the Arctic Environmental strategy (AES), unveiled in April, 1991 (9). The AES is a six-year, \$100 million program which sets out specific programs to address four key environmental challenges in the North: contaminants, water, the clean-up and disposal of waste, and the integration of economic and environmental considerations. The components of this plan of action were developed in partnership with local and national organisations of indigenous peoples, who are now also participating in its implementation. Through the Green Plan Arctic Environmental strategy, Canada is acting upon its share of the ministerial commitments made in the Rovaniemi Declaration.

\section{Bussia}

Any plan to protect the Arctic environment must include the effective participation of Russia, the territory of which includes a very large proportion of the land mass bordering the Arctic ocean and of the fresh water entering it. It is quite clear that the Government of the Russian Federation recognises its responsibilities in this area and is anxious to address them. However, trying to redress the legacy of the past poses enormous practical challenges.

Canada believes that the eight signatories of the Rovaniemi Declaration share a common resolve to be innovative in seeking ways to assist Russia. In most cases, assistance is taking place on a bilateral basis. In June of this year, prime Minister Mulroney and Russian President Yeltsin signed a new Canada-Russia Agreement on Cooperation in the Arctic and the North (10) which included a section addressing contaminants. The Agreement replaced earlier versions, which have already proven to 
be of great value in assessing the importance of pathways for the transport of persistent organics into the Arctic. Prime Minister Mulroney also announced that Canada will build an atmospheric monitoring station in the Russian Arctic to examine persistent organics, thereby complementing the actions planned under the AMAP and the Rovaniemi Declaration.

A second example of bilateral cooperation is the joint Norwegian-Russian investigation of former soviet nuclear dump sites in the Barents Sea, which will begin on August 15, 1992. A Canadian will participate in this activity, collecting samples for analysis in Canada, and Norway has been informed of our willingness to take part in future related studies. The full extent of nuclear disposal practises used by the former soviet Union in the Arctic is only now becoming known, and the potential environmental impact must be assessed. Theoretical considerations suggest that the degree to which radionuclides are dispersed following leakage from a marine dump site container will depend on the physico-chemical form in which the radionuclides are released. Many radionuclides such as plutonium-239 and 240 have a high affinity for particles and are therefore likely to be incorporated into sediments in a very localised area. However, some other radionuclides, such as cesium-137, strontium-90, technetium-99 and tritium would be mobilised much more easily and, therefore, ultimately would be widely dispersed throughout the Arctic ocean. The most widely studied test case at this time is probably that of the U.S. B-52 bomber armed with nuclear weapons which crashed through the sea ice near Thule, Greenland, in 1968. Although a major plutonium spill into the environment occurred, after 25 years little of this material appears to have migrated beyond fifty kilometres of the crash site (11).

An additional factor which must be considered in this regard is the ambient background of radioactivity already present in the Arctic Ocean. The level of radionuclides is similar to those in other oceans in the world, and the sources can be ranked in decreasing order of significance as follows: natural sources (e.g. polonium), atmospheric weapons testing, the sellafield nuclear fuel reprocessing plant in the United Kingdom and, finally, Chernobyl $(12,13)$. While the state of our knowledge should be further advanced by the $t$ ime the international scientific conference on Radioactivity in the Arctic and Antarctic convenes in Kirkenes, Norway, in August, 1993, there clearly remains much to be learned. 


\section{Conclusion}

Pollution of the Arctic, and in particular the bioaccumulation in indigenous peoples of organochlorine residues, is of great concern to Canada. We remain optimistic that these and other examples of environmental degradation in the Arctic can be reversed. The eight signatories of the Rovaniemi Declaration on the Protection of the Arctic Environment and the accompanying Arctic Environmental Protection strategy recognise that these problems cannot be addressed in isolation or by nations acting alone. Through the Strategy, the Arctic nations have achieved a workable institutional arrangement to bring about co-ordinated and comprehensive action. Although still young, this approach has already achieved significant advances through its own initiatives (e.g. the Arctic Monitoring and Assessment Programme) and through its influence on other activities (e.g. the ECE Task Force on Persistent organics). The strategy will continue to evolve under direction from the ministerial meetings, and Canada looks forward to achieving further progress at the 1993 session, in Greenland. 


\section{CITATIONB}

1. Shearer, R.G., D.T. Thomas and J.R. Reid (1991), "The Arctic -- Barometer of Global Change", The State of Canada's Environment (Ottawa: Government of Canada, 1991), pp. 15-1 to 15-28.

2. M.P. Wong (1985), Chemical Residues of Fish and Wildlife Harvested in Northern Canada (Environmental studies Report No. 46), (Ottawa: Indian and Northern Affairs Canada, 1985).

3. Indian and Northern Affairs Canada (1990), Contaminants in Northern Ecosystems and Native Diets: Summary of an Evaluation Meeting Held in Ottawa, February 28-March 2, 1989.

Expanded versions of the background papers presented at the workshops will be published in autumn 1992 in a special edition of science and the Total Environment.

4. Hamilton, E.I. and J. Nriagu (eds.)(1992), The science of the Total Environment 122, (Amsterdam: Elsevier Science Publishers, B.V., 1992), pp. 1-74.

5. The reports were subsequently published by the University of Lapland (1991): The State of the Arctic Environment: Reports (Arctic Centre Publication No. 2) (Rovaniemi, Finland: University of Lapland, 2991).

6. "Arctic Environmental Protection Strategy" (June 14, 1991), Rovaniemi, Finland,

7. "Declaration on the Protection of the Arctic Environment (June 14, 1991), Rovaniemi, Finland.

8. "Minutes of the First Meeting of the Arctic Monitoring and Assessment Programme Task Force (AMATF), Tromso, Norway, December 2-6, 1991", (Oslo: State Pollution Control Authority, 1992).

9. Indian and Northern Affairs Canada (1991), The Arctic Environmental Strategy: An Action Plan (Ottawa: Indian and Northern Affairs Canada, 1991).

10. "Canada Increases Assistance to Rusia and Other Countries of the Former Soviet Union", Release from the Office of the Prime Minister (June 19, 1992), Ottawa.

11. Aarkrog, A., S. Boelskifte, H. Dahlgaard, S. Duniec, E. Holm, and J.N. Smith (1987), "Studies of Transuranics in an Arctic Marine Environment", Journal of Radioanalytical and Nuclear Chemistry 115:1 (1987), pp. 39-50. 
$-8-$

12. Aarkrog, A., S. Boelskifte, H. Dahlgaard, S. Duniec, L. Hallstadius, E. Holm, and J.N. Smith (1987), "Technetium-99 and Cesium-134 as Long Distance Tracers in Arctic Waters", Estuarine, Coastal and Shelf Science 24 (1987), pp. 637-47.

13. Smith, J.N., K.M. Ellis, and E.P. Jones (1990), "Cesium-137 Transport into the Arctic Ocean Through Fram Strait", Journal of Geophysical Research 95:C2 (1990), pp. 1693-1701. 
MINISTRY OF THE ENVIRONMENT

FINLAND

August 11, 1992

United States Senate

Select Committee on Intelligence

Washington. D.C. 20510-6475

U.S.A.

Dear Sirs,

I wish to refer to your letter dated June 30, 1992 concerning an open hearing on radioactive and other environmental threats in the United States and the Arctic resulting from the past Soviet activities.

I would like to express my appreciation for the opportunity to testify in the hearing. It is my opinion that international co-operation and open and frank exchange of information are needed to overcome environmental threats resulting from past Soviet activities in the Arctic and elsewhere.

Indeed, the people of Finland have a serious interest in the topic of the hearing. That is why Finland has promoted international cooperation on environmental protection in the Arctic and in solving environmental problems in former socialist countries in Central and Eastern Europe. On the initiative of the Finnish Government, the eight Arctic countries are implementing a comprehensive strategy, adopted in Rovaniemi, Finland, 1991 for the protection of the Arctic environment. At the same time Finland is taking part financially in the environmental actions in the neighbouring regions, mainly in Russia and the Baltic countries. 
The Government of Finland has approved an Action Programme for Central and Eastem Europe, which concentrates in the areas close to the Finnish borders in Russian Federation and in the Baltic states. In this programme matters related to the improvement of the safety of the nuclear reactors of the former Soviet Union as well as environmental matters in general have a high priority.

Finland's bilateral grant contribution for these activities in 1990-92 amounts to approximately 45 million USS. At the moment some 30 million USS has been tied to joint environmenta! investments, pilot and technical assistance projects so that the total value of these projects already amounts to more than 120 million USS. Since it is not possible on this occasion to go into further details of our cooperation, please find attached a leaflet on our cooperation programs and an up-to-date list of joint ongoing projects within these programs.

In the energy sector the Finnish companies and institutions, with some government funding, are cooperating with Russian counterparts in improving safety in nuclear power plants in the Kola Peninsula and the Saint Petersburg region. During 1992 the Finnish Govemment has channelled FIM 6,5 million for this purpose. In Russian Carelia and the Saint Petersburg regions a major energy conservation pilot project including a masterplan and 10 industrial and power plants have recently been launched. This initiative is taking into account the alternative sources of energy to eventually make it possible to replace technically outdated conventional and nuclear power plants in the former Soviet Union. During 1992 - 1993 the Finnish Government will provide FIM 10 million to support these activities.

Through multilateral and bilateral cooperation Finland participates in solving environmental problems in the neighbouring countries. Our activity in this matter is based on the assessment that the environmental situation in the former socialist countries is alarming and the risks involved are a concem for the whole international community. In the case of Finland transboundary impacts and risks of pollution are of such magnitude that the environmental problems of our neighbouring countries must be taken fully into account in our nationa! environmental policies.

A lot of information has been collected and exchanged between us and our neighbours on environmental problems and their solutions. The pollution risks in Russia of the greatest concern to us are related to nuclear power and waste risks in the Kola peninsula and the Saint Petersburg regions, 
toxic and hazardous waste resulting from industries and dumping activities as well as major airborne and waterborne pollution from industrial activities and cities.

In the Circumpolar region environmental risks related to industrial and military activities are alarming. Our experience and knowledge in this region relate to huge copper and nickel smelters and their environmental impacts as well as nuclear power production.

The task concerning the improvement of nuclear safety and environment in the former Soviet Union is a huge one. Accordingly, intensified international cooperation and coordination is necessary. Finland welcomes the initiative made by the $\mathrm{G}-7$ in München regarding the improvement of nuclear safety. The Finnish Government is prepared to participate in and promote cooperation in this field in various international fora. Nuclear safety will be one of the main issues, for example, for the recently established regional forum, the Council of the Baltic Sea States.

All the work that we have been doing together with our Russian colleagues indicates that environmental problems of the former Soviet Unjon are alarming and the risks related to them should be of great concern to the international community. My government is ready to share all the information and experience that we have and to cooperate in the matter.

Yours sincerely,

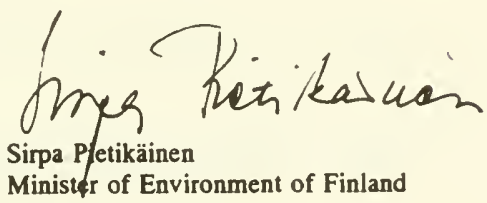

Annex: Information on Finnish bilateral environmental protection programs with Central and Eastem European countries 
THE FINISA ASSISTED JOINT ENIRONAIEMTAL PROJECTS IN BASTERH EUROPE 1991-1992

MINISTRY OF THE ENVIRONMENT OF FINLAND

East Europe project 
MINISTRY OF THE ENVIRONMENT

OF FINLAND

East Europe Project

5.8.1992

THE FINNISH ASSISTED JOINT ENVIRONMENTAL PROJECTS IN EASTERN EUROPE 1991-1992

\section{ESTONIA}

MECU

A full scale pllot desulphuriration plant for reducing sulphur and dust emissions of, the oll shale power plant in Narva (1991)

Eest1 Energia Tuotantoyhtymä, Estonla

A. Ahlström Ltd

Sludge dewatering equipment for the waste water

0,14 treatient plant of Tallinn (1991)

Tallinn Water Works, Estonia

DWT-Engineering Ltd

D1smantling of the Munckisaari wate water

treatment equipment and their dellvery to Tallinn (1991)

Tallinn Water Works, Estonla

Helsinki Water and Sewage Works

Planning, project management and training for the

0,32 improvement of waste water treatment of Tallinn (1991)

Tallinn Water Works, Estonia

Plancenter Ltd

Pilot renovation of the sewer systen of Tallinn, delivery of TV-inspection equipment and maintenance training (1991)

Tallinn Water Works, Estonia

Painehuuhtelu Ltd

Construction of a sewage treatment plant for a

hotel in Saarentaa (1991)

Kuresasr1 Town, Estonia

K. Jousmas KY

P1lot project for production of water chenicals

0,33

(1992)

The clty of Tallinn

Kemira Ltd

Waste water treatment in the town of Rohtla-Jarve.

0,07

1. phase: a Pllot Plant tudy (1992)

Polevkivikeemia, Estonia

Vesi-Hydro Ltd

Waste water treatment in 8 flah processing plant

0,14

in Vilnistu, Estonia (1992)

Esmar Ltd, Estonia

Protec Ltd, Processing techniques 


\section{RUSSIA}

Delivery of oil combatting and recovery equipment 1,36 to St. Petersburg, Russia (1991)

Pilarn-group, St. Petersburg

Lori Ltd

Sulphur dioxide and dust renoval in the Kosta-

muksha combine in Karelia, Russia (1992)

Kostamuksha combine

Tampella Power Ltd

3. POLAND

Wsste management project in Inowroclaw sodaplant

0.8 (1991)

Larox Ltd

Environmental profect in swiecie pulp and paper

1,6

plant (1991)

A. Ahlstrom Ltd

District heating system in Krakowa (1991)

0,44

Nokia Kaapel1 Ltd

Joint venture for manufacturing district heating

1,85

pipes in Warsaw (1991)

KWH-Tech Ltd, Ekono Ltd

Air pollution control renovation project in

0.5

Czeczott Mine (1991)

Outokumpu Engineering Ltd

oilcomatting equipent for Baltic sea coastal 0,05 area (1991)

Larsen-Marin Ltd

Delivery of sewage pumps for municipalities (1991) 0,36 Sarlin Ltd

Environmental renovation project of the $2 G-R u d n a$ industrial plant (1992)

Larox Ltd

Environmental renovation project of the ZG-

0,14

Boleslaw industrial plant (1992)

Larox Ltd 
MINISTRY OF THE ENVIRONMENT OF FINLAND

East Europe project

THE FINNISH FUNDED TECHNICAL ASSISTNNCE PROJECTS IN EASTERN EUROPE 1991-1992

Delivery of laboratory equipment to the Kola

The aater planning of water anagesent in the 0,03 Neva water ayste and the research and

improvement of the use and protection of waters.

in the areas close to the Pinnish-Ruesian border.

st. Peteraburg, Ruse1 (1991)

Kym1 Regional Water and Environment District

The regional deposition of sulphur, nitrogen, amonis and alkall netale in the province of Ky1, In southeastern border areas of Finland (1991)

Forest Research Institute

Evaluation of the enviromental impact and risk: by 8vetogorsk pulp and paper all1, 8t. Petersburg, Russia (1991)

Ristola Ltd.

Impect of two different mechandsan of forest darages (direct polson Impact and winter Impact) on the forest in the southeastern parts of Finland (1991)

Forest Research Institute

Preparation of cooperation prograne between 0,02

Eetonla and the province of Uuslase (1991) Administrative Board of Uusimaa

Preparation for the Jolnt research progran of 0,005 Lake Ladoga, Karelia, Rusala (1991)

The University of Joensuu/ Karelian Research Institute

Publication of an ekological bulletin a part of environmental cooperation between Eastern

0,01

Finland and the Republic of Karelis (1992)

Water and Environment District of Northern Karel1

Renovation of the main purpe in the sortaval Town Water Works, In Rarelia, Rusela (1992) Soll and Water Ltd. 
Support to the Environmental Data Center of the

0,05

Kola Peninsula, Murmansk Region, Russia (1992)

Water and Environment District of Lapland

The master planning of water management and

0,03

protection in the Neva water system (1992)

Kymi Regional Water and Environment District

Tertiary treatment of pulp and paper mill waste 0,01

waters, the Leningrad area, Russia (1992)

Kymi Regional Water and Environment District

The regional deposition of sulphur and nitrogen

0,04 in the province of $\mathrm{Kyml}$ and the Leningrad Region (1992)

Finnish Meteorological Institute

Ecological monitoring of Karelian forests (1992) Forest Research Institute

Study on Improving the production of $11 \mathrm{gnin}$ sulphonate in Rusian aulphite cellulose ills (1992) Lappeenranta university of technology

Measurements of the flue gas emissions of o1l 0,05 shale power plants in Estonla (1992)

Administrative Board of Uusimaa

Blomonitoring of deposition around thermal power 0,02 plants in Northeastern Eatonia (1992) Administrative Board of Uusimaa

Water quality claseification with sacroalgae as 0,01 bloindicators of the cities of Tallinn and Helsinki (1992)

Administrative Board of Uusimaa

Environmental cooperation with Saarenmaa, Estonia 0,01 (1992)

Administrative Board of Uusimaa

Survey of alrborne enisalons of the Kostamukaha area, Russia (1992)

Kainuu water and Environment District

Environmental impact assessment of Lake Ladoga,

Karel1a, Russia (1992)

University of Joensuu

Study on the impact of pulp and paper induatry

on water systems by means of examination of the

aedimentary formation of the Kondopoga bay.

Karel1a, Rusaia (1992)

Mikkeli Water and Environment District 
The activities of Water and Environment District

0,04 of Northern Karelia in the Lake Ladoga-project. Study on traditional biotopes of the Lake Ladoga in cooperation with the University of Helsinki, botanical museum.

Study on Lake Pyhajarvi, Karelia, Russia.

Study on environmental impact of forestry in Karella, Russia. (1992)

Water and Environment District of Northern Karelia

Studies on forestry in virgin forests in Karelia, 0,009 Russia (1992)

University of Joensuu

study on ecosystems of the area Oulanka-Paana-

0,002

jarvi in Karelia, Russia (1992)

University of Helsinki

University of oulu

Study on the toxic sediments of Lake Ladoga,

Karelia, Russia (1992)

Water and Environment District of Northern Karelia

\section{TRAINING}

Training program related to the laboratory project

0,02

of Kola Scientific Center (1991)

Water and Environment District of Lapland

Trainling program for the managers of Estonlan

0,05 power plants on environmental protection and technology (1991)

Technical Education Centre

Environmental technology and cooperation in

0,05

training in Southeast Finland and in

St. Petersburg Region (1991)

Administrative Board of Kymi

On-the-job training program for 11 Estonian trainees 0,03 in regional environmental administration in Finland (1991)

Survey of the needs for continuing education in

0,03 environmental protection in Karelia and st. Petersburg in Russia and in Estonia (1991) The University of Helsinki/ knowledge Services Ltd.

Support for the preparation of "Our Common

Environment Forum", to be held in St. Petersburg

27.7.-2.8.1992 (1991, 1992)

Finnish Association for Nature Conservation

A seminar dealing with the improvement of waste 0,02 water treatment in St. Petersburg (1991)

Kemira Ltd. 
Support for the training project "The Baltic Sea Environment", the Baltic state (1991)

The Turku Swedish University

A training course in measuring technlques of air

0,0005 quality for Estonian experts (1991)

Finnish A1r Pollution Prevention Society

Assietance for the preparation of the East-West

0,04

Distance Education Project

Post-graduate Energy and Environment Learning

Package in the North Western Parts of Russian

Federation (1991)

Unlscience Ltd.

Participation allowance of two Estonian experts

in a training course of environsental technology (1992)

The University of Turku

Cooperation in environmental technology and training in Southesetern Finland and the Lenlngrad Region ( 1992 ) Lappeenranta university of technology

A seninar dealing with water protection and treatment and a course of treatment technology In st. Petereburg, Russia (1992)

National Board of Waters and the Environment of Finland

Tralning couree for Russian leading water supply

adeinistrators and technical eanagers (1992) V1lmi Ltd.

Printing of an Estonian environnental biology

0,02

textbook for achools (1992)

Tuglas soclety

The seninar "The role of water works as part of the infrestructure and in inplementing water protection neasures" In Tallinn (1992)

Tampere University of technology

A seninar dealing with the state of the Gulf of Finland and Inprovemant of the waste water trestment in 8t. Petersburg Region (1992) University of Turku

A seninar for tescher of schools and vocational education institutions in the cities of Lappeenranta, Finland, and Vyborg, Ruseila, dealing with environmental education (1992)

The city of Lappeenranta 
A seminar dealing with principles and practices of the protection of the environment in Finland and in Russia (1992) University of Helsink1/Laht1 Research and Training Centre

On-the-job training program for Estonian and Russian 0, 05 trainees in regional environmental administration in Finland (1992)

3. THE REGIONAL ENVIRONMENTAL CENTER FOR CENTRAL AND EASTERN EUROPE, BUDAPEST, HUNGARY
The Finnish grant contribution for 1991
0,13
The Finnish grant contribution for 1992
0,11

4. SUPERVISION AND CONTROL OF EMISSIONS AND THE SंTATE OF THE ENVIRONMENT IN EASTERN EUROPE

Supply of a radiophone to the research vessel
"Mulkku" for 1ts activities in the Gulf of Finland
(1991) 0,01
National Board of Waters and the
Environment of Finland


Eatablimhent of the Environmental Data Center

0,02

In Estonia (1992)

National Board of Waters and the

Environment of Finland

Cooperation in monitoring alr quality in Estonia

0,001 (1992)

Helsink1 Metropolitan Area Council YTV

Equipment for the Leningrad Reglon forest research (1992)

Kotka Environmental Assoclation

Planning work for the waste water treatment plant in a chool in Estonla (1992)

Tampere Steiner School Association

study on nutrient and eutrophlcation dynanics in the Eastern Gulf of Finland (1992)

National Board of Waters and the

Environment of Finland

Delivery of equipment for the training progran of

Estonian trainees (1992)

Administrative Board of Vaasa

\section{PROJECT PLANNING AND PILOT PROJECTS}

The Environmental Review and Prlority Action

0,5

Programe for Karella and st. Petersburg in

Rusis and for Eatonla (1991)

Addendu to the Priority Action Programe (1992)

Plancenter Ltd.

Appralas of the pllot desulphurisation project

of Narva power plant (1991)

Energla-Ekono Ltd.

A pilot profect concerning the waste managenent

In PJatigorak, Rusaia (1991)

Jatekyyt1 Ltd./Ekomp Ltd.

A p1lot sewege treatment plant for a dalry in 0,02

Tarto, Estonia (1991)

Finnish Business Institute

A study on Increasing the efficlency of energy

use In the Industry of Eatonia (1992)

Imatran Volma Ltd.

Appraisal of the oulphur renoval project in

Montahegorsk, Kola Peninaula (1992)

Ekono Ltd.

study on blologlcal treatment of run-off waters

froe Estonian oll thale ash flelde (1992)

Tampere University of technology

0,01

0.05

0,04

0,04

0,006 
Feasibility study on the sludge treatment project

of Kehtna piggery in Estonia (1992)

Soil and water Ltd.

\section{NUCLEAR SAFETY}

Detailed planning of a jolnt project concerning

0,04 nuclear safety in $S t$. Petersburg nuclear power plant (1991)

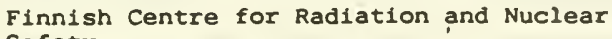

Appraisal and improvement of nuclear safety in

st. Petersburg nuclear power plant (1992)

Finnish Centre for Radiation and Nuclear Safety

7. TRUST FUNDS IN INTERNATIONAL FINANCING INSTITUTIONS FOR IMPLEMENTING THE BALTIC SEA ENVIRONMENTAL PROGRAMME (1992)

$\begin{array}{lr}\text { World Bank } & 0,18 \\ \text { IFC } & 0,09 \\ \text { EBRD } & 0,18 \\ \text { Nordic Investment Bank } & 0,36\end{array}$

8. OTHER STUDIES AND ACTIVITIES

A study on cooperation possibilities between the 0,005 Estonian Association for Environmental Protection and Finnish Association for Nature Conservation (1991)

Estonian Association for Environmental Protection

Estonian and Russian sumaries of the study

"Preconditions for creating the National Park of Eastern Gulf of Finland, Friendship II" (1991) Eest1 Looduskaitse Selts

Optialzation of air and water pollution control measures of Finland and the neighbouring areas (1991)

Ekono Ltd.

Atudy concerning environmental administration and policy in Soviet Union (1991) Exactia Ltd.

A computerized register for environmental projects 0,04 in neighbouring areas (1991, 1992) The Finnish Foreign Trade Association Plancenter Ltd. 
Appraisal of the Estonian air quality (1992)

0.01 Ekono Ltd.

Environmental pre-feasibility study of the

0,04 western coast of Estonia (1992)

Plancenter Ltd.

Environmental pre-feasibility study of the Tarto area and lake Peipus in Estonia (1992)

Plancenter Ltd.

A Finnish-Swedish-Estonian joint project for identifying radiation risks in Sillamaki, Estonia (1992)

Finnish Centre for Radiation and Nuclear Safety 


\section{East Europe Project: Co-operation for a better environment}

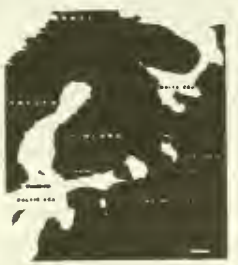

The East Europe Project, launched by the Finnish Ministry of the Environment in 1991 to protect the environment in neighbouring regions of Eastern Europe, is now fully under-way. The project has established itself as part of Finland's active, intermational environmenial policy.

Aiming at better air protection, protection of the Baltic Sea, and the development of hazardous waste management, using Finnish environmental know-how and technology.

The East Europe Project provides funds for joint projects which, when implemented, will bring significant cuts in airborne and waterborne pollution reaching Finland and the Baltic Sea. It will also improve hazardous waste management. Funds are granted to Finnish companies and corporations primarily promoting the use of Finnish environmental technology or testing new Finnish techniques or know-how.

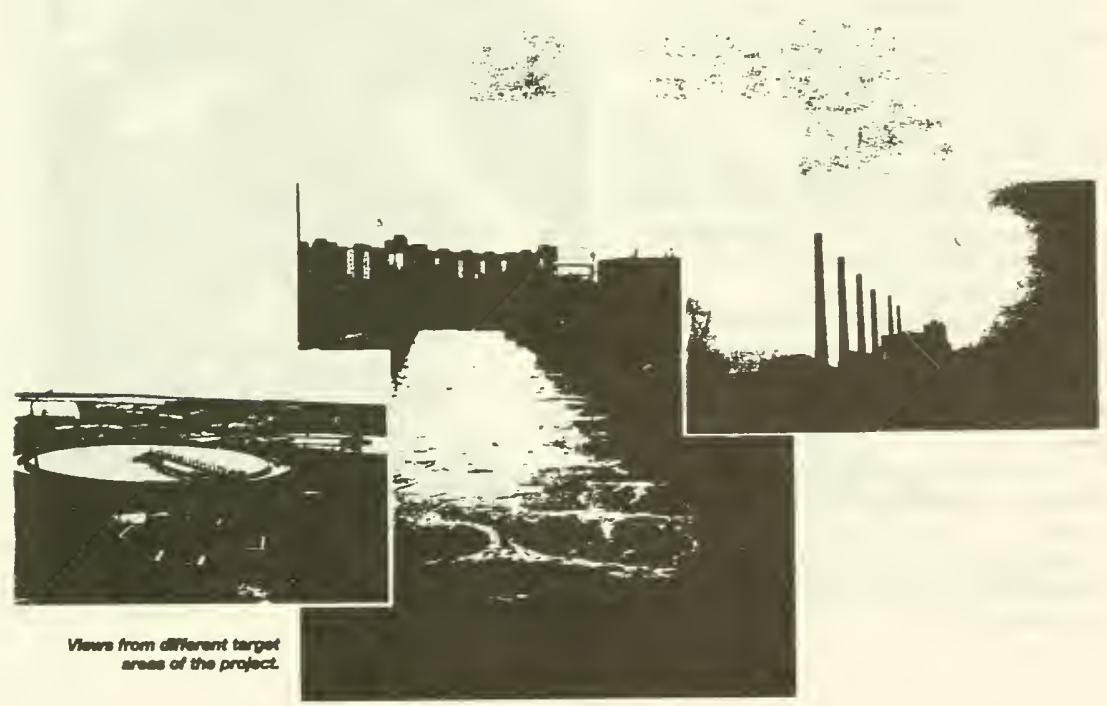




\section{Cepecities and conetruction years}

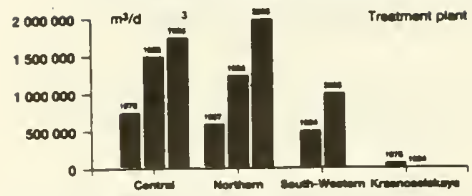

In St. Potersburg, waste water is trated of four plenter, whoee capecity is shown sbow.

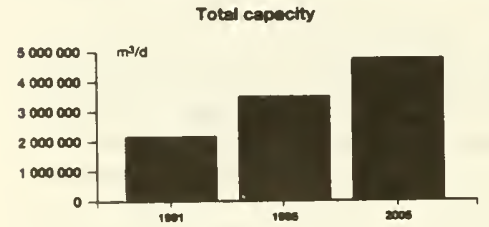

\section{First results already visible}

In 1991 five Finnish consulting firms together with local experts carried out a study of the main environmental problems in and around St. Petersburg in Karelia and in Estonia, also considering the measures needed to reduce them. The study found that there were some 60 significant problem areas. Sixteen projects were selected as priority targets. Eight of these are located in and around St. Petersburg, and four are in Karelia. In Estonia four priority projects were chosen.

Several Finnish companies involved un environmental technology are participating or planning to participate in these projects. Commercial contracts signed by early 1992 included the following projects:

- An expenmental desulphurization process for the oil-shale power plants in Narva, Estonia

- Improved waste water treatment in Tallinn, Estonia

- Supply of oil combatting equipment to St. Petersburg as part of the region's hazardous waste management programme - Phase One of the desulphurization project for the Kostamuksha muning plant in Karelia.

The total estumated budget for the 16 projects is around FIM 15 billion, with local currencies providing about FIM 9 billion. Financing in foreign currencies comes to around FIM 5 billion. The programme is expected to take about ten years.

As a result of the programme, sulphur deposition will decrease by $10-20 \%$ in some areas of eastern and southern Finland.

For the whole of the Gulf of Finland, the point load will decrease about $35 \%$ in the case of BODS, and about $45 \%$ for phosphorus.

\section{Project financing}

The programme will be carried out on the basis of commercial contracts between the companies and the plants concemed. The projects will primarily be funded locally, but they also include Western inputs, which may take the form of technical consulting, contracting, direct equipment deliveries, or training.

The joint projects will be implemented using local labour for the most par. The Finnish Government may provide budgeted supports for these environmental projects. usually to a maximum of $50 \%$ of the Finnish costs of the project. Another form of aid is to grant interest subsidies on loans. The Finnish Guarantee Board has been empowered to grant guarantees for loans concerning environmental projects. Aid meant for foreign companies or corporations will be paid to the Finnish partner.

Other Nordic financiers of environmental projects in Finland's eastern neighbours are the Nordic Investment Bank, the associated Nordic Environment Finance Corporation (NEFCO) and the Nordic Project Export Fund (NOPEF). In addition, inquiries about financing may also be addressed to Finnish Export Credit Ltd, and the Finnish Fund for Industrial Development Cooperation Ltd.

International financing for environmental projects in the Baltic region may also be obtained from the World Bank. the European Bank for Reconstruction and Development (EBRD), and the European Investment Bank.

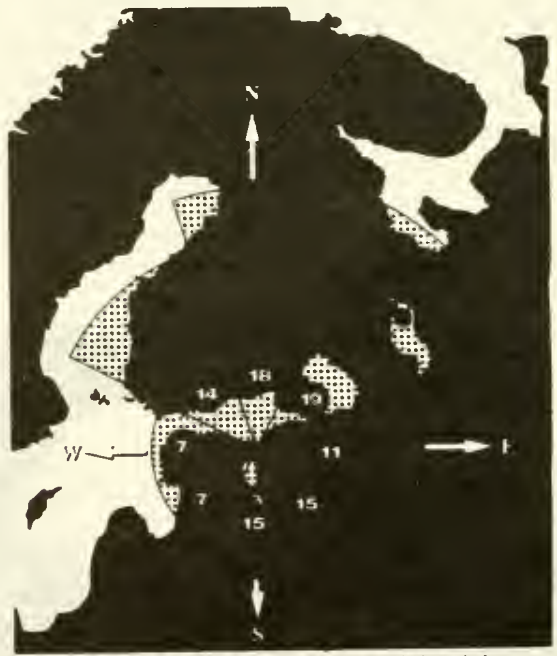

Arcenteges probabilities of difsetions taken by wind-cenied entedone 

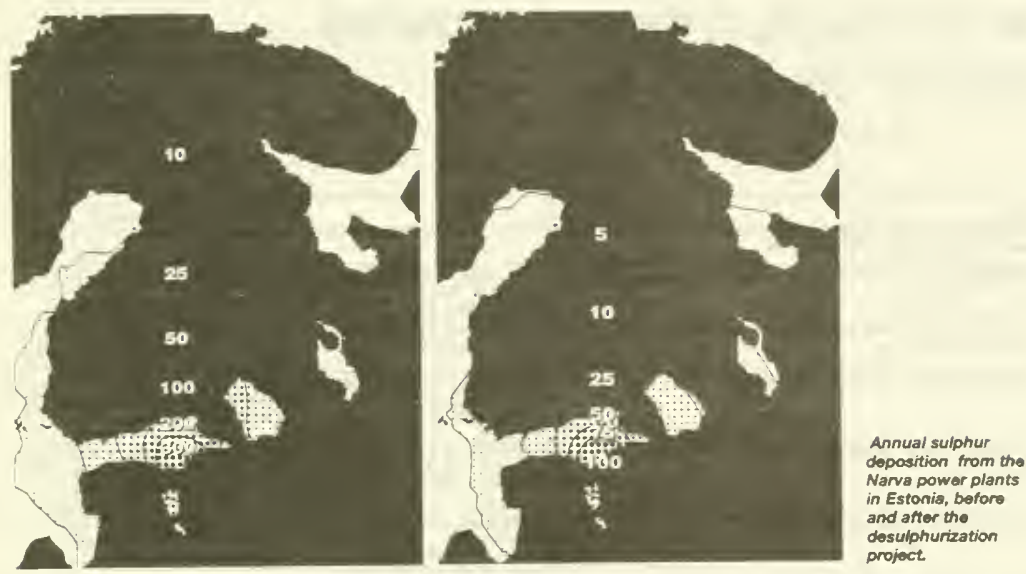

\section{The East Europe Project is part of Finland's active, international environmental policy.}

Finland has played an active part in negotiating bilateral and multilateral agreements on environmental protection and in promoting envuronmental projects. Since the early 1970s, Finland has taken part in activitues aimed at the protection of the Baltic Sea. The first multilateral convention for the protection of the marine environment of the Baltic Sea was signed in 1974; its implementation is administered by the Helsinki Commission (HELCOM).

Environmental protection in the Baltic Sea region is once again a central part of the programme for Eastern and Central Europe being drawn up by the Finnish Government, which establishes guidelines for future forms of co-operation. The East Europe Project is part of this programme.

The East Europe Project is also part of the environmental protection programme covering the whole Baltic Sea region, elaboration of which was decided on at the conference of prime ministers of the Baltic states, held in Ronneby, Sweden, in the autumn of 1990 . Beside the studies concerning St. Petersburg, Karelia and Estonia, similar studies will be made on other countries in the Baltic region. The joint environmental protection programme for all the states on the Baltc will be based on these studies.

Even in its preliminary phases, the East Europe Project has aroused great international interest. The role played by international financial insututions as funders of such projects is also growing.

\section{Effects of the programme on DOD load}

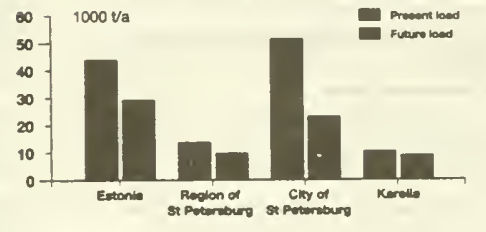

Effects of the programme on nitrogen load

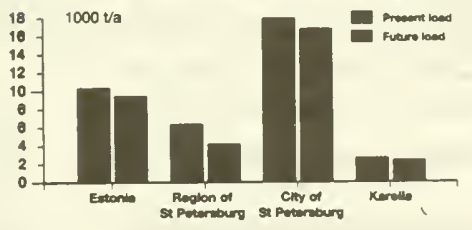

Effects of the programme on phosphorus loed

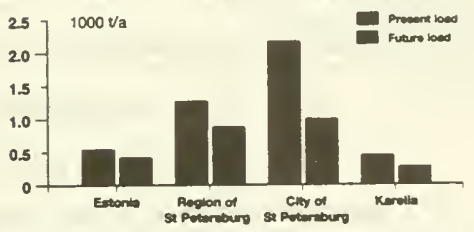

Estimated decreese in the load on the Gulf of Finland resulting from implamentation of the programmo 


\section{The 16 projects in the environmental protection programme}

\begin{tabular}{|c|c|c|}
\hline Praped & Am & Technoloew/ Proposed moesurs \\
\hline \multicolumn{3}{|l|}{ 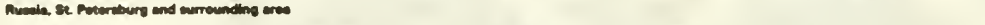 } \\
\hline 1 Phosohorus removal at the St. Petersburg wasto water treasment plent & $\begin{array}{l}\text { Reduction of load on the Gut of } \\
\text { Finland of BDD, 36\%. } \\
\text { Total N } 4 \% \text {. Total P 50\% }\end{array}$ & $\begin{array}{l}\text { Doochemical or brological } \\
\text { restmont }\end{array}$ \\
\hline $\begin{array}{l}2 \text { Construction of four disthet waste water treatment plants } \\
\text { in the } 5 \text { t. Petersburg woes }\end{array}$ & $\begin{array}{l}\text { Reduction of loed of } 80 D, 84 \% \\
\text { Total N 19\%. Total P } 66 \%\end{array}$ & $\begin{array}{l}\text { - Wro naw plants, - extonsion of } \\
\text { mo planes and the sowarage } \\
\text { spetern }\end{array}$ \\
\hline 3 Treetment of waste water containing heany metwis & $\begin{array}{l}\text { Reduction of heary metal content of } \\
\text { studge Cu } 75 \% \text {. Zn } \$ 7 \% \text {. } \\
\text { N1 } 50 \% \text {, Cot } 100 \% \text {. Po } 99 \% \text {. } \\
\text { C } 93 \%\end{array}$ & $\begin{array}{l}\text { - Lechnical improvernents in } \\
\text { preprocessing end processing at } \\
\text { it } 9 \text { gurtace finishing plents }\end{array}$ \\
\hline 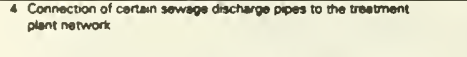 & $\begin{array}{l}\text { Reduction of loed on the } \\
\text { Gulf of Finland of. } 800,68 \% \text {. } \\
\text { Total N 35\%. Tow P } 82 \%\end{array}$ & 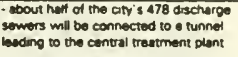 \\
\hline 5 Manegentent of hazardous waste in Se. Petersbure & 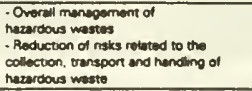 & 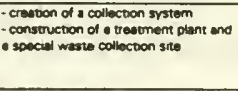 \\
\hline 6. Maregernent and utdizasoon of waste from pog and chicken forms & 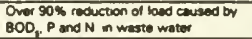 & - water tresenent \\
\hline $\begin{array}{l}\text { 7. Reduction of omvionmentes laed from the Svasstror prip and } \\
\text { peper mill and the Volhov themmium plemt }\end{array}$ & $\begin{array}{l}\text { Svesstror } 800,35 \% \\
\text { SO, } 55 \% \\
\text { Vohor } 800,40 \%, 50,60 \%\end{array}$ & $\begin{array}{l}\text { - process tectinotoor. - olectinc fitter } \\
\text { - weste water treatment plents }\end{array}$ \\
\hline 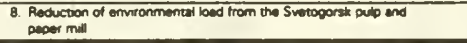 & $502: 60-75 \%$ & $\begin{array}{l}\text { - mprovements in processs tech- } \\
\text { nology. - external massures }\end{array}$ \\
\hline \multicolumn{3}{|l|}{ 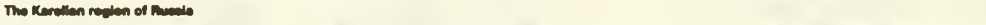 } \\
\hline $\begin{array}{l}9 \text { Reduction of enveronmentel baed from the Kosturnukathe } \\
\text { induatrul ares }\end{array}$ & $502.65 \%$ & - enternel desulphuritation \\
\hline $\begin{array}{l}\text { 10. Reduction of envwonmental problems } \\
\text { in the City of Pevrozavodst }\end{array}$ & $\begin{array}{l}\text { Reduction in loeding on Lake } \\
\text { Onepa: BOO, 34\%, Tores P } 81 \%\end{array}$ & 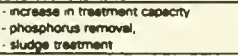 \\
\hline 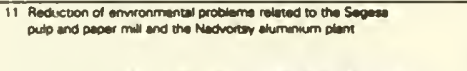 & 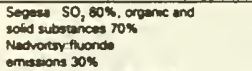 & $\begin{array}{l}\text { process technotiogy } \\
\text { - fiters } \\
\text { - pes soruobers }\end{array}$ \\
\hline 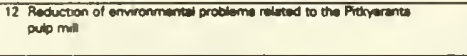 & 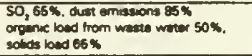 & $\begin{array}{l}\text { process tictinoloog } \\
\text { - fitters } \\
\text { - waste weter treatunent }\end{array}$ \\
\hline \multicolumn{3}{|l|}{ Eatonda } \\
\hline 13. Reductoon of envronmentel loed from the Nerve power plents & $50_{r} ; 0-90 \%$ & $\begin{array}{l}\text { - desubhurzation equipment } \\
\text { - replecememt of old boders }\end{array}$ \\
\hline 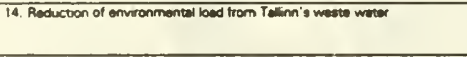 & $\begin{array}{l}\text { Reduction of loed on the Gulf of } \\
\text { Finlend from Talinn } \mathrm{BOO}_{3} 80 \% \text {. } \\
\text { Toted N 20\%. Totel P } 36 \%\end{array}$ & 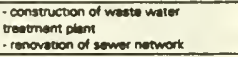 \\
\hline 15. Reduction of envionmental oroblems on the Lete Konde ercte & 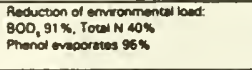 & 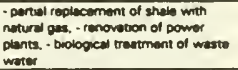 \\
\hline 16 Aeduction of envifonmental probleme releted to the Kelvia & SO, $65-70 \%$ & $\begin{array}{l}\text { - process technotogy } \\
\text { - electenc fhens }\end{array}$ \\
\hline 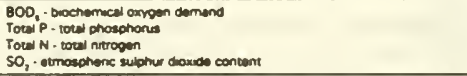 & \multicolumn{2}{|c|}{ 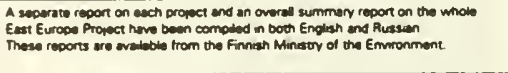 } \\
\hline
\end{tabular}

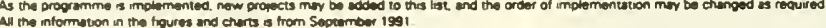

Additional information may be obcained from:

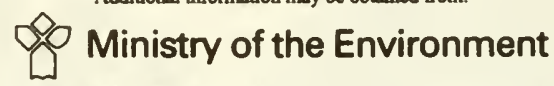

Ministry of the Environment, East Europe Project, P.O. Box 399, SF-00121 Helsinki, FINLAND

Tel. int. +358-0-19911, Fax int +358-0-1991 286, Telex 123717 ymin sf 


\section{EMBASSY OF ICELAND}

WASHINGTON, D.C.

August 10,1992

Ref. 21. B. 3

The Honorable

David L. Boren

Chairman

The Honorable

Frank H. Murkowski

vice Chairman

United States Senate

Seclect Committee on Intelligence

Dear Sirs,

Thanking you for your letters of June 30, 1992, to the Minister for the Environment of Iceland, the Honorabie Eidur Gudnason, and to myself concerning the forthcoming hearing of the Select Committee on Intelligence at the University of AlaskaFairbanks in Falrbanks, Alaska, I have the honor to forward to you a Statement by the Government of Iceland concerning Radioactive and other Environmental Threats to the United States and the Arctic resulting from past Soviet activities.

Upon your suggestion I have been in contact with MI. David Garman of the Staff of the select Committee on Intelilgence and I understand from him that my Government's statement will be entered into the records of the Committee's hearing next Saturday, August 15, in Falrbanks, Alaska.

I appreclate greatly your providing me with this opportunity to advance the attached statement of the Government of Iceland giving expression to its serious concerns about environmental threats to all circumpolar nations steming from ex-Soviet nuclear activites in the Arctic.

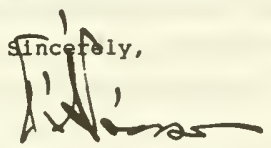

Tómas Á. Tómasson

\begin{tabular}{lllll}
\hline Postal Address: & Telephone: & Telelax: & Tolex: & Cable Address: \\
2022 Connecticut Ave., N.W. & (202) 265-6653 & (202) 265-6656 & $\begin{array}{l}\text { RCA 248596 } \\
\text { icexur }\end{array}$ & kembassy \\
Washington, D.C. 20008 & & &
\end{tabular}


Hearing of the Senate Select Committee on Intelligence of the U.S. Congress August 15, 1992 at the University of Alasks-Pairbanks

Radioactive and other Environmental Threats to the United States and the Arctic resulting from past Soviet activities .

Statement by the Govermment of Iceland

I.

The Government of Iceland is greatly concemed over the growing risk of serious contamination in the Arctic region. The threat is posed from various anthropogenic sources, not least from the alarming envirommental problems from past Soviet activities. Iceland's geographic position and the country's dependence on sustainable utlization of living marine resources, highlight the interests at stake.

Contamination in the Arctic region and pollution in distant areas can easily be transported by air and sea currents into the waters north of Iceland. A part of the Icelandic 200 mile exclusive economic zone borders the Arctic region and many of the living marine resources in Icelandic waters are dependent upon biomass productivity in the Arctic. Purthermore, ocean currents originating in the Arctic region have a significant impact on the development of marine life, through physical and chemical processes, in the waters around Iceland.

It is commonly accepted that the fragile ecosystem of the Arctic is very vulnerable to all linds of pollution or other environmental disturbances and should, because of its global significance, be subject to stringent envirommental protection (cf. the Rovaniemi Declaration).

II.

The rich marine life in the waters around Iceland provides a food source of global importance and is the mainstay of the Icelandic 
econorny. The fishery sector supplies over 70 per cent of Iceland's exported goods and generates more than 50 per cent of the total export revenue. Contamination of the waters would have far-reaching consequences. Pollution can endanger the fish stocks and, even more, marine mammals. Furthermore, the slightest indication of pollutant residues in marine products can have serious marketing repercussions, as was demonstrated by, for example, the effects of the Chemobyl disaster on the sale of certain foodstuffs, and the negative effects that radioactive discharges into the Irish Sea have had upon sales of fish from that area.

The waters around Iceland are highly vulnerable to transboundary pollution and risk of contamination from heavy sea traffic. Iceland is situated at the boundary between the warm waters of the Atlantic and the cold Arctic waters, i.e. on the ocean polar-subpolar front. The East Greenland Current brings water from the Arctic Ocean and the Gulf Stream water which has undergone admixture with waters off North America and Western Europe. These water masses affect both marine life and pollution levels around Iceland. The country is also located on the path of the extra-tropical depressions that move across the ocean from North America towards Europe, bringing air masses from both continents as well as from the adjacent ocean areas.

In view of the grave situation as regards marine pollution in the adjacent sea areas, such as the North Sea and some of the coastal waters in Northern Europe, the Icelandic Government decided in 1989 on a three-year program of extensive measuring and monitoring of heavy metals, organic compounds and radioactivity in Icelandic waters, inchuding sediments and biota. The purpose of the program is to provide baseline data for future marine research and monitoring and to evaluate the possible effect of transboundary pollution in Icelandic waters.

An interim report now being published indicates that marine pollution by radionucleides and heavy metals around Iceland is still insignificant. Notwithstanding, the measurements bave indicated that various pollutants are carried into Icelandic waters over a long distance by wind and ocean currents. For instance, while levels of radioactivity are low, the amount of cesium 137 in sea-water is substantially higher in the waters off the north coast than off the south coast, or $6 \mathrm{Bg} / \mathrm{m}^{3}$ 
compared to $3 \mathrm{Bg} / \mathrm{m}^{3}$. This difference is traced, among others, to seaborne radioactivity from nuclear industries and accidents in other far -off countries, e.g. the nuclear reprocessing plant at Sellafield in Cumbria on the west const of England.

III.

Although not yet fully made known in scope and detail, the collapse of the communist regime in Eastern Europe has resulted in disclosure of past dumping and discharges of radioactive and other toxic wastes into the sea, waterways or underground storage close to groundwater sources. All these activities pose a grave threat of marine pollution in the Arctic and could lead to serious consequences for the ecosystem and the indispensable food sources for humankind present in the northern seas.

It is, therefore, the firm view of the Government of Iceland, that further investigation of the scope and nature of pollution in the former Soviet Union should take place with urgency in the framework of international co-operation. The focus should be aimed at expedient steps to clesn up contaminated sites where feasible, and bringing others, where appropriate, under control to contain further spatial effects. Emphasis should also be placed on developing proposals for reducing and preventing further pollution and risks from installations still in operation that discharge heavy metals, persistent organic substances and radioactive materials. Particular emphasis should be placed on closing outdated and unsafe nuclear reactors in the light of experiences from Chernobyl, and this year at Sosnovy Bor and Ignalina.

An appropriate avenue for initiating such an international operation, in the view of the Icelandic Government, would be the recently established co-operation of Aretic countries on the Arctic environment. The Arctic Environmental Protection Strategy offers a ready political and technical framework for expedient actions. 
IV.

Pollution is by far the greatest threat to the Aretic region and its future sustainable development. The serious envirommental problems stemming from past Soviet activities is an acute example highlighting the urgency for more active international co-operation to control and monitor pollution on regional and global levels.

In particular the recently disclosed experience from past Soviet activities demonstrates the urgency for a globally implemented total ban on discharge of toxic substances, persistent organic substances, heavy metals and radioactive materials into the sea from land-based sources, as well as on emplacing such materials under the sea bed. Let us also bear in mind that in the context of possible global warming the marine environment provides one of the most important sinks for carbon dioxide. Increased marine pollution will undoubtedly reduce the assimilative capacity of the oceans. The Soviet experience illustrates also the immediate need for effective international regulations and supervision controlling sea-bome nuclear reactors and all ocean transport of radioactive or other hazardous substances and toxic wastes, whether for military or civilian purposes.

The Government of Iceland avails itself of this opportunity to confirm its commitment to the protection of the marine environment. It is the firm view of the Government that the highest priority must be attached to this task to safeguard our plant from ecological disaster. Therefore every effort possible should be pursued to curtail any consequences that past and present activities within the area of the former Soviet Union might have upon the environment of the Arctic region and the northern seas. 


\author{
STATEMENT OF \\ THE DEPARTMENT OF ENERGY \\ BEFORE THE \\ SENATE SELECT COMMITTEE ON INTELLIGENCE \\ UNITED STATES SENATE \\ AUGUST 15,1992
}

The Department of Energy (DOE) is pleased to provide its views on a developing issue: the discharge of radioactive and hazardous materials into the Arctic by the Former Soviet Union. The Department is aware of the importance of this matter to the citizens of Alaska and to the State and Local governments relative to the possible risks of radioactive and hazardous material contamination. One of the lessons of the Chernobyl accident is that radioactivity does not respect national boundaries. However, the dual degree of contamination and whether it has reached and contaminated Alaska is not known. Thus far most of these reports have been unconfirmed and unsubstant $i$ ated.

What concerns us today is possible radioactive and hazardous material contamination in the Arctic and Alaska which may have resulted from past Soviet practices. The contaminants of concern may include many of those with which DOE is examining, such as uranium and its decay products, heavy metals, organic contaminants, industrial solvents, and a wide range of pollutants from power plants and nuclear facilities. With respect to our domestic residue of the cold war years, DOE is dealing with all phases of cleanup, from assessing the nature and extent of contamination to developing remediation technologies design to improve current environmental restoration techniques. 
THE NATURE AND SOURCES OF RADIOACTIVE AND HAZARDOUS

CONTAMINATION IN THE ARCTIC

Potential arctic contaminants from the nuclear weapons complex of the former Soviet Union (FSU) include radionuclides and the following non-nuclear hazardous wastes: volatile organic and other organic compounds, inorganic compounds, heavy metals, and buried objects (tanks, barrels, and other containers).

The Department uses a number of characterization technologies, but the majority of the Department's programs and activities currently address contamination and pollution of $l$ and and groundwater rather than of deep-water areas.

There are four principal sources of discharges of radioactive and hazardous materials into the Arctic: Soviet nuclear weapons production plant discharges; atmospheric nuclear weapon testing; waste disposal; and ocean dumping.

Radioactive and hazardous materials that ultimately entered the Arctic were created in the late 1940s when the Soviet Union started up its first reprocessing plant at the Chelyabinsk nuclear weapons production complex about 1000 miles southwest of Moscow. Highly radioactive and hazardous waste solutions from the plant were discharged directly into the Techa River and ultimately entered the Kara Sea several hundred miles east of the island of Novaya Zemlya in northern Russia. Recent Russian statements estimate that 
close to three million curies of long-lived fission products were disposed of in this manner. However, these estimates have not been confirmed.

The Former Soviet Union began nuclear weapons testing at Novaya Zemlya in 1955 and continued through 1990, when a self-imposed testing moratorium was announced. The testing, particularly prior to the mid-1960s, ultimately resulted in the radioactive materials being carried into the stratosphere and distributed over the Northern Hemisphere, including Alaska.

There are many recent unconfirmed Russian and Western reports that Novaya Zemlya and its shallow bays have been used as a disposal site for unknown quantities of the radioactive wastes from Soviet military activities.

Andrey Zolotkov, a former deputy to the Supreme Soviet from Murmansk, announced last September that the Former Soviet Union had practiced ocean dumping of hazardous and highly radioactive wastes in the Barents and Kara Seas between 1964 and 1986. According to Zolotkov, 10,250 containers (each one cubic meter in volume) were dumped into the Arctic waters between 60 to 110 feet deep. 
DOE CAPABILITIES, TECHNOLOGIES AND EXISTING PROGRAMS FOR MONITORING, LOCATING, AND CHARACTERIZING CONTAMINATION

Before determining how to proceed, the nature and magnitude of the contamination must be identified, characterized, and quantified so that proper remediation procedures and technologies can be determined.

The U.S. has a variety of remote sensing and in-situ technologies capabilities $\therefore$ i.

- discovering and identifying specific sites that may need to be characterized and quantified in detail

- guiding detailed characterization and quantification efforts

- aiding in monitoring remediation work in real time if necessary

- supporting long-term monitoring of the sites whether or not remediation is performed.

There are many technologies currently available to assist with the location and characterization of Arctic contamination sites. Contaminants can be identified, located, characterized, monitored, and quantified by direct sensing, measurement, and analysis of the offending substance. They can also be characterized indirectly by observation of secondary effects on the 
environment. There are a variety of procedures that could be applied to each of the main categories of contaminants. For example, surface or subsurface contamination by radionuclides can be directly characterized using alpha, beta, and gamma spectroscopy techniques. Heavy metal contamination can be characterized indirectly through evaluating geological changes by thermal infrared and multi- or hyper-spectral technology. And contamination by volatile organic compounds can be characterized directly by active luminescence or in-situ infrared scanning of soil samples.

The technologies available vary with the contaminants they are designed to identify. The contaminants and procedures for identifying them are as follows.

Radionuclides. Alpha, beta, and gamma spectroscopy can be used for direct characterization of both surface and sub-surface contamination. Systems currently available include: air-borne; vehicle-mounted; transportable units; and in-situ monitors. There are also counting and spectrometry techniques for solid, liquid, and air samples to identify ultra low-level radioactive contaminants.

Hazardous Wastes (volatile and other orqanic compounds). A number of techniques are available for direct sample collection and characterization. These techniques include in-situ infrared (IR) scanning, thermal IR, passive luminescence, and active luminescence. 
Inorganic Compounds. Inorganic compounds can be detected through direct sample collection and characterization techniques. Both field and laboratory analytical techniques-such as in-situ active microwave (including ground penetrating radar), electromagnetic (frequency and time domain), thermal IR, and electromagnetic (high frequency)-are available.

Buried 0bjects. Currently available techniques for the detection of buried

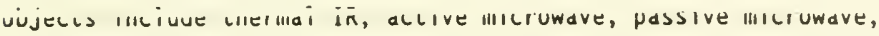
electromagnetic (Ferrous), sonar, active seismic, photographic, and multi/hyper spectral.

Heavy Metal Contamination. A number of techniques are available for direct sample collection and characterization. These techniques include photogrammetry, multi/hyper spectral, and active and passive microwave.

\section{THEORETICAL STRATEGIES FOR REMEDIATION}

If it is necessary to remediate a hazardous or radioactive waste site, the first step would probably be to retrieve intact waste containers. The Department is developing robotic retrieval techniques for use at its waste management site at the Idaho National Engineering Laboratory. Technologies developed and demonstrated there could be applicable to land disposed waste in the Former Soviet Union. These technologies may be modified to address retrieval from shallow bays. A commercially available mini-submarine is 
currently being used to retrieve waste containers from a water-filled quarry at Oak Ridge.

Retrieved containers would then need to be stabilized until they could be characterized for treatment. There are several commercially available methods-including standard overpacks, storage in air-supported buildings, and encapsulation in polymer tubes-that would provide short-term containment.

The Department has recentiy completed tests in which intact drums of hazardous and simulated radioactive waste were completely melted in à plasma-arc furnace. The resulting waste forms were a vitrified, non-leaching glass containing the fission products and a slagged metal. This technology could be rapidly developed for application to retrieved containers.

The second step would probably be to contain waste that has spilled from damaged containers but has not yet migrated far from the original waste area. Containment technologies available for contaminated soils include freezing in place, hydrologic barriers, grout barriers, in-situ vitrification and capping. These techniques have not been applied to shallow bays. The Russians have used caisson to back fill lakes used for disposal and have advanced grouting systems. 
REMEOIATION ANO THE NATIONAL LABORATORIES

DOE's national laboratories are conducting pertinent research in Arctic contamination, risk assessment, and remediation technology. These national laboratories have several geologists, glaciologists, hydrologists and other specialists who have direct experience in researching environmental conditions in the Arctic.

The naticnal iatj have been arialjzirig samples from nuclear tests for over 35 years. In addition, they have been analyzing environmental samples for over 30 years and have the analytical capability to detect extremely low concentrations of radioactive material. For alpha-and beta-emitting material, they are acknowledged to have the lowest detection limits in the world. In addition, researchers have studied the dispersion of fission products from nuclear tests in environments as varied as the Nevada Test Site and the South Pacific.

A world renowned expert in the study of the fate and transport of radioactive materials in the environment conducts research at a DOE laboratory. He has studied the Chernobyl nuclear accident and the spread of radioactive materials from the accident as well as the health risks associated with the release of those materials. DOE has also developed and used fate and transport models to study the mobility of contaminants in complex environments. 
HEALTH ASSESSMENTS

Besides demonstrating its capabilities for characterizing waste, remediating waste, and developing applicable technologies, the DOE has achieved much in its studies of the health effects of contamination. The DOE's most relevant project for this hearing is its investigation of the radiological health effects on the survivors of Hiroshima and Nagasaki, and on those exposed to high doses of radiation as a result of the Chernobyl accident in the Former Soviet Uniori.

Radiation Effects Research Foundation studies of Japanese Atomic Bomb Survivors have revealed much about the effects of both high-level and lowlevel exposure to radiation.

DOE's Joint Coordinating Committee for Civilian Nuclear Reactor Safety has set up working groups that will help determine the dose levels of the radionuclides that are associated with the health effects of Chernobyl. The primary working group will develop validated models for dose protection in future accidents and physical dosimetry for dose reconstruction with higher doses. Projects for the working groups include atmospheric dispersion modeling; evaluating radionuclides doses through the terrestrial and aquatic food chains; planning epidemiologic studies on thyroid effects and leukemia; conducting surveys of adult and child health; and analyzing clinical data on acute radiation syndrome patients. Overall, this project has helped DOE to determine the health and environmental effects of data for populations affected by the Chernobyl accident and to relate health effects to a level of 
exposure for use in setting and reviewing our own risk-based exposure standards.

\section{CONCLUSION}

This statement has not exhaustively examined the possibilities for characterizing and monitoring contamination in the Arctic. There are a variety of undersea characterization techniques that could be employed to locate and characterize the extent of deep-sea dumping in the Arctic. For example, remote submersibles could be used to monitor currents in the Arctic. This monitoring could then be used to conduct subsurface ocean-current analysis of thermal circulation and radioactive transport. In addition, ocean circulation models developed to study global warming could be employed to determine whether any measured contamination is moving from Novaya Zemlya through the Barents Sea and into Atlantic fishing regions. Much of the Department's work in environmental remediation and technology may contribute to the Nation's understanding of the contamination problems in the Arctic, and much can be applied to solving those problems. As noted in our testimony, the first step in the cleanup of radioactive or hazardous wastes is to characterize the nature and magnitude of the contaminant. Once this happens, many of these technologies no doubt could be employed expeditiousiy. In addition, not all of the research and applied technology at DOE will provide an adequate framework for addressing this contamination issue. For example, very little of DOE's experience in characterizing and treating contamination can be applied to the contamination of oceans. Although these environmental 
abuses are clearly the responsibility of the Russians to rectify, the DOE can hope that some of its projects to characterize, assess the magnitude of, and

clean up contamination will serve as an example of our Nation's potential for rendering assistance in these areas. 


\section{ARCTIC MARINE RESOURCE COMMISSION}

Statement to the

U. S. Sonate Select Committee on Intelligence

Fairbanks, Alaska

August 15, 1992

Thank you for this opportunity to address the U. S. Senate Select Committee on Intelligence on behalf of the Arctic Marine Resource Commission (AMRC). AMRC was established by several Alaskan native organizations to deal with common concerns about oil and gas development along the Alaskan Coast. Our primary concern is for the protection of marine resources upon which we depend on for our nutritional and cultural needs.

Our membership includes the Alaska Eskimo Whaling Commission, the Alaska and Inuvialuit Beluga Whale Committee, Alaska Eskimo Walrus Commission, Bcring Sea Fisherman's Association, Chukchi Sea Fisherman's Cooperative and the Northwest Arctic Native Association. Our members come from Alaskan villages as far south as Tyonek in the Cook Inlet Region to the northern arctic village of Kaktovik near the Canadian Boarder.

Since the revelation of nuclear dumping and toxic waste in the former Soviet Union, we have been waiting anxiously for more information.

We want to know if there are any harmful elements in marine mammals which we eat as part of our daily diet. Our diet is very important to our health. We have seen a jump in heart disease and diabetes in the indigenous population in Alaska with the addition of some western foods to our daily diet. Heart disease and diabetes were uncommon until the native population began eating more western foods. We are just learning how important it is for us to continue to include fish and other traditional foods in our diet to maintain our physical health.

We want and need to know about the pollution that has been recently been in the news from the former Soviet Union. We need baseline information and long range monitoring programs to see whether or not there are any harmful impacts on our marine resources such as fish, seal, walrus, bowhead and bcluga whales. 
Based on concerns expressed by native hunters, at least two member organizations of AMRC have sponsored studies to test for heavy metals in marine mammals. The Alaska Eskimo Whaling Comnission through the North Slope Borough studied levels of heavy metals in bowhead whale organs a few years ago. Their study showed a slight increase of cadmium levels in the kidney of bowhead whales over a period of three or four years. The Alaska and Inuvialuit Beluga Whale Committee has began a study to test for heavy metals on the Chukchi sea stock of beluga whales this year, the results of which should be available by next year.

We need to be kept informed about the ongoing investigations concerning nuclear and toxic waste dumping from industries in the Russian arctic regions.

We want to see the health of the Alaskan marine manumal resources maintained for our future generations. Our native cultures are based on traditional hunting and fishing practices and the availability of wildlife resources during their seasonal migrations near our villages. We have heard of extinction of wildlife resources because of mistakes mankind has made in other parts of the world. We want to avoid this kind of tragedy in the arctic.

We are urging you and other organizations to take action now to deal with the environmental disasters that have recently been made public by Russian and international news organizations. We are concerned not only for ourselves but for our relatives and neighbors who live in northern Russia and Canada. We share some of the same marine mammal resources upon which the Alaskan natives depend on for pur nutritional and cultural needs.

Thank you for this opportunty to address the U.S. Senate Select Committee on Intelligence about the concerns of AMRC regarding nuclear and toxic waste being reported from the former Soviet Union.

Marie Adams, AMRC Vice Chair

c/o North Slope Borough

P. O. Box 69

Barrow, Alaska 99723 


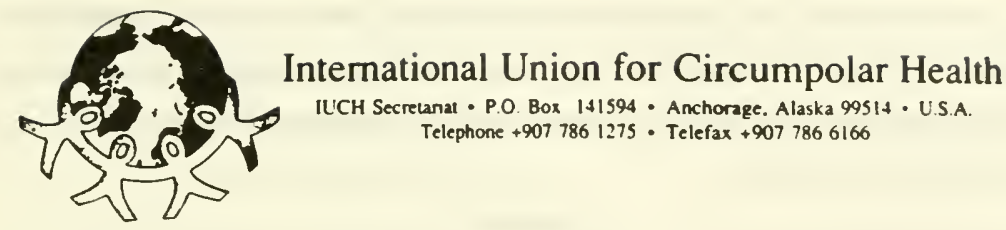

WRITTEN SUBMISSION AND TESTIMONY OF THE

INTERNATIONAL UNION FOR CIRCUMPOLAR HEALTH

to the

UNITED STATES

SENATE SELECT COMATTEE ON INTELLIGENCE

HEARING

$$
\begin{gathered}
\text { Fairbanks, Alaska } \\
\text { August 15, } 1992 \\
\text { by Dalee Sambo } \\
\text { Executive Director }
\end{gathered}
$$

Thank you for the opportunity to make this submission to the Senate Select Comittee on Intelligence. We are encouraged by the Committee's interest in Arctic and sub-Arctic envirommental matters and concerns, as well as the attention of the Central Intelligence Agency towards issues such as nuclear and industrial waste dumping in Arctic waters. The United States and the world community are beginning to realize the need for a comprehensive approach to the inter-related problems of environmental pollution and human health concerns. The International Union for Circumpolar Health (IUCH) has had a long-standing interest in this aspect of environmental conditions and we would like to share some of our work with you.

In regard to the topic of discussion at this hearing, we would like to describe the history, structure and work of the IUCH and address the services that the IUCH, as a long-standing international health organization, can provide to the various U.S. agencies and organs concerning themselves with Arctic matters.

Amencan Society for Ciscumpolar Health - Canadian Society for Circumpolar Health Nordic Council for Arctic Medical Research - Sibenan Branch. Russian Academy of Medical Sciences 
We would also like to describe our direct and indirect relationships with other international initiatives, and in particular, the International Arctic Science Committee and the Arctic Monitoring and Assessment Program of the socalled Finnish Initiative.

\section{HISTORT}

As early as the $1960^{\prime}$ s, medical scientists have been collaborating on Arctic medical research activities. Dr. Earl Albrecht, as Commissioner of Health for the Territory of Alaska from 1945 to 1956, envisioned an International Union for Circumpolar Health.

In $1967 \mathrm{Dr}$. Albrecht initiated the first circumpolar symposium, which took place in Fairbanks, Alaska. Participants came from the United States/Alaska, Canada, Norway, Denmark, Sweden, Greenland, Iceland, Finland and the (former) USSR. The 1967 participants decided to hold an International Congress on Circumpolar Health every three years.

Finally, in 1981 the IUCH was founded at the meeting of the 5th International Congress on Circumpolar Health in Copenhagen, Denmark. In May 1986 the first IUCH Constitution was drafted and adopted.

The IUCH is now an official, formal non-governmental organization. The subsequent activities of the IUCH and its "adhering bodles" have been able to provide an important and useful exchange of Arctic medical research and problems that has been beneficial to people worldwide. Because of the international nature of our work, we cooperate closely with other international organizations such as the World Health Organization, the Inuit Circumpolar Conference, the International Arctic Sclence Committee, and the International Council of Scientific Unions. 
The objectives of the IUCH are to:

* promote international cooperation in the study of circumpolar health:

* encourage and support research and exchange of scientific information in the circumpolar health sciences;

* promote public awareness of the current situation of circumpolar health;

* provide a means of communication with other relevant organizations.

One of the principal activities of the IUCH is the hosting of the triennial International Congress for Circumpolar Health. Such conferences provide a useful and Important forum for the exchange of Arctic medical research and health problems. Thus far eight Congresses have taken place in Fairbanks, Alaska (1967); Oulu, Finland (1970); Yellowknife, NWT, Canada (1974); Novosibirsk, USSR (1978); Copenhagen, Denmark (1981); Anchorage, Alaska (1984); Umea, Sweden (1987) and Whitehorse, Yukon Territory, Canada (1990).

The IX International Congress on Circumpolar Health (ICCH) will be held in Reykjavik, Iceland, fron June 20-25, 1993.

The IUCH is committed to ensuring the substantial involvenent of aboriginal peoples from all circumpolar nations in its work and circumpolar health issues generally. The Indigenous Progran of the IX ICCH in Reykjavik will be coordinated by the office of Dr. Ove Rosing Olsen (Inuit), Minister of Health and Environment, Greenland Howe Rule Government.

In addition to the triennial symposia, the IUCH has established a number of working groups on specific health problems of the circumpolar ragions, including matters relating to cancer, fanily health, tobacco and health, injuries, and AIDS. 
The IUCH also collects and disseminates information on circumpolar health and arctic medicine. The scientific journal ARCTIC MEDICAL RESEARCH is published, on a quarterly basis, in collaboration with the Nordic Council for Arctic Medical Research. The journal is indexed in Index Medicus and other biomedical databases. IUCH members receive a subscription to this official journal of the IUCH.

The J.A. Hildes medal which was established in 1986, by the IUCH, is awarded to outstanding international scholars in the area of circumpolar health and Arctic medicine. In 1990, at the Whitehorse Congress, the J.A. Hildes medal was awarded to Ms. Evelyn Cambe11 of Canada; Professor Henrik Forsius of Finland; Professor Frederick A. Milan of Alaska; and Professor Yuri Nikitin of Russia.

\section{MEMBERSHIP}

The "adhering bodies" of the IUCH include the:

American Society for Circumpolar Health (ASCH)

Canadian Society for Circumpolar Health ( $\mathrm{CSCH}$ )

Nordic Council for Arctic Medical Research (NCAMR)

Siberian Branch of the Russian Academy of Medical Sciences (AMS-SB)

Individual research workers, institutions, associations, or companies may adopt affiliated membership if they are not represented by the four adhering bodies. Current affiliated members include:

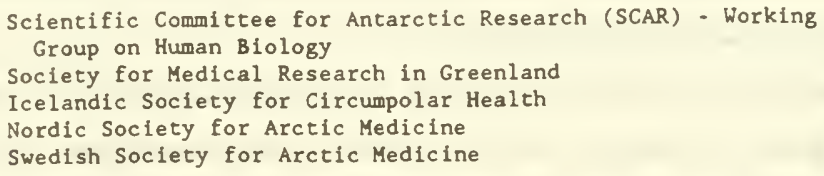

The IUCH Council consists of 11 members: two from each of the four adhering bodies, one from SCAR, and two delegates elected by the General Assembly, which meets in connection with the ICCH. 
Dr. J. P. Hart Hansen, President (NCAMR-Denmark)

Mr. Carl Hild, "ice President

(ASCH-United States)

Dr. Kue Young, Secretary/Treasurer

( $\mathrm{CSCH}$-Canada)

Dr. Ester Fjellheim (at large-Norway)

Dr. Gary Pekeles (at-large-Canada)

Dr. Jean Goodwill (CSCH-Canada)

Dr. Vlail Kaznacheev (AMS-SB-Russia)

Dr. John Middaugh (ASCH-United States)

Dr. Desmond Lugg (SCAR-Australia)

Dr. Yuri Nikitin (AMS-SB-Russia)

Dr. Hans Akerblom (NCAMR-Finland)

Dr. Hannu Vuori (Observer-WHO)

The IUCH Secretariat is located on the University of Alaska Anchorage campus. This office is to provide administrative and management functions for the overall organization, fundraising, and liaison with national and regional governments in the circumpolar zone, and assistance in Council meetings and the triennial International Congresses. The Executive Director of the Secretariat office is Dalee Sambo, Inuit of Alaska.

\section{HUMAN HEALTH AND ENVIRONMENT}

Many circumpolar human health problems can be directly attributed to environmental conditions and specifically the degradation or destruction of the environment, often by pollution sources far from circumpolar regions. In addition, the pollutants from the industrialized Arctic-rim countries are of 
major concern to the IUCH. As has been testifled to by CIA Director Robert Gates, the problem of nuclear and industrial waste ocean dumping by the former Soviet Union, will have grave human health effects. These environmental health problems will require monitoring and basic "risk assessment" and this is where the IUCH can best provide direct assistance.

The IUCH can assist governments, both regionally and at the communitylevel, as to the environmental health problems that may emerge and how to respond to such problems. The IUCH membership can assist by answering the questions that are raised by communities and also in providing information about the potential effects. As a circumpolar-wide health organization, we can also provide coordination of Arctic environmental health research.

We have made numerous contacts regarding our offer of services to a number of northern international fora. In particular, at the meeting of the International Arctic Science Committee (IASC), held last year in Oslo. Norway. IUCH President, Dr. Jens Peder Hart Hansen, was asked to investigate the need and opportunities for IASC to play a role in facilitating international cooperation for research in medical and health sciences in the Arctic. At the recent Council meeting of the IASC, April 1992, Dr. Hart Hansen introduced an IUCH proposal addressing liaison and cooperation, and the creation of a permanent IASC working group on medical and health sciences consisting of the IUCH Council and a temporary working group on monitoring of human health in the Arctic environment.

The IASC response to the proposal was formal agreement to liaise with the IUCH through the IUCH President. Furthermore, they agreed to that the IUCH Council would constitute a standing advisory body to IASC as to medical and health services in the Arctic. IASC will also draw on IUCH advice as to 
including these sciences into multi-disciplinary programs being initiated or supported by IASC.

The IASC is now well informed about the activities and potential of the IUCH and we are acknowledged as a body representing human health and medicine in the circumpolar regions. The Executive of the IASC has already called upon IUCH for specific advise on two health-related topics.

A very different example of "indirect" IUCH collaboration and cooperation on health matters is with the "Finnish Initiative". At the ministerial conference in Rovaniemi, Finland, June 1991, the eight Arctic countries adopted the Arctic Enviromental Protection Strategy and commitred themselves to establish an Arctic Monitoring and Assessment Program (AMAP) to monitor the levels of, and assess the effects of, anthropogenic pollutants in all compartments of the Arctic environment and to establish an Arctic Monitoring and Assessment Task Force (AMATF) to implement the program. An AMAP Secretariat has been established in Norway.

A working group is now finalizing a draft plan for the human health dimension of this work. Denmark/Greenland has been appointed the so-called lead country for the human health part of AMAP at a meeting in Tromso, Norway in December 1991. The IUCH President, Dr. Hart Hansen, is the Chair of this working group, thus, making the IUCH an indirect participant in this important work. In addition to human health matters, other concerns include atmosphere, marine enviromment, terrestrial environment, fresh water and rivers and remote sensing and modeling.

We have also offered our services, by way of an proposal, to the Northern Forum, a regional government initiative with a secretariat or main office in Anchorage, Alaska. At the Third Northern Regions Conference in September 1990 , 
ICCH President, Dr. Hart Hansen, chaired a session on circumpolar health. From this session emerged the recommendation that the IUCH encourage and establish new means of international collaborative research on circumpolar health problems and that further research in basic environmental and clinical sciences be adequately supported. At the founding meeting of the Northern Forum in November 1991, the IUCH proposal to provide support and assistance in all matters relating to northern health was adopted.

Finally, we also have formalized a collaborative-working relationship with the Inuit Circumpolar Conference (ICC). As many of you know, the ICC is an international indigenous non-governmental organization representing the Inuit of Alaska, Canada, Greenland and Russia. On July 24, 1992, the ICC General Assembly adopted a resolution agreeing to formally cooperate and collaborate with the IUCH in all areas of circumpolar health, and to further participate in the upcoming IX International Congress on Circumpolar Health, scheduled for June 1993 in Reykjavik, Iceland. We consider collaboration with northern indigenous organizations, such as the ICC, essential to truly improving the overall health conditions for northern peoples.

These are just some examples of the important contribution that the IUCH can make to the area of Arctic or circumpolar health and social conditions. We are eager to provide this assistance to the various agencies of the United States goverment and its political sub-divisions. Such collaboration and cooperation can be extremely beneficial to all northern peoples and governments.

If you would like more information or assistance, please call upon us. Thank you for the opportunity to submit this statement. 


\title{
American Society for Circumpolar Health
}

\author{
August 10, 1992
}

Senator Frank Murkowski

10112 th Avenue, Box 7

Fairbanks, AK 99701-6278

Honorable Senator Murkowski and

Members of the Senate Select Committee on Intelligence:

As President of the American Society for Circumpolar Health and Vice-President of the International Union for Circumpolar Health I commend you for holding this hearing on the risks of radioactive materials here in Alaska and the Arct1c. This is a timely hearing in that this past weekend's "Anchorage Daily News" contained an article stating that a fire in western Russia is burning an area contaminated after the chernobyl incident. It is known that the wind patterss in that region can bring the newly re-airborne radioactive material into the Arctic and potentially into northern Alaska.

Alaska has been a place for dealing with nuclear materials for many years.

* The first nuclear powered electrical generator plant in the world is not may miles from the site of your hearing and when it was shut down it raised many local concerns as to the pollution it may have, and may still be producing.

* The site of the first peaceful civilian use of atomic power was to be here in Alaska where a harbor was proposed to be blasted not far from the community of Point Hope.

* The Native populations of the north central part of the state became contaminated in the mid-1960s with radioactive cesium and strontium from the fallout of these materials after atmospheric testing around the world. The global wind patterns and magnetic drift of the particles caused them to precipitate and bioaccurulate in the Arctic food chain. Radioactive body burdens of up to 200 times the background levels were measured in the people of Anaktuvik Pass.

* The largest of the country's nuclear underground 'tests was performed at Amchitka Island in a very seismically active region of our state. There are still concerns over the hundreds of sea otters that were killed in the blast, as well as the potential hazard if a major earthquake opens the cavern that the blast created.

* A formal body of the indigenous people of the Arctic, the Inuit Circumpolar Conference, has requested repeatedly that the Arctic be a nuclear free zone.

* Most recently we have concerns coming from specific sources in Russia.

Carl Huld
President
Dand w. Templin
Anita Todd-Tiger

Treasurer
Jeanne R Roche

Secretary

P.O. Box 242822 - Anchorage, Alaska 99524 
Chernobyl impacts are still being assessed. "Science" July 24. 1992, page 481 discussed the possible impact on the mind not just from mental stress or "radiophobia," but actual damage to membrane phospholipids in brain cells. Our technology has out paced our understanding of the impacts that proceed with the advances that science provides. Now lack of government regulation and structure in Russia may increase the chance of an unintentional discharge of nuclear materials.

Internationally agencies of the United States have signed two agreements in the past few years to cooperate with the dissemination of information on circumpolar issues. The Finnish Initiative and the International Arctic Science Committee (IASC). At the April 27-29, 1992 meeting of IASC it was agreed that the "IUCH (International Union for Circumpolar Health) was the expert body on health issues in the Arctic," and "Council decided to liaise with IUCH through its President. IUCH's Council was asked to constitute a standing advisory body to IASC as to medical and health services in the Arctic. IASC would also draw on IUCH advice as to including these sciences into multi-disciplinary programmes being initiated or supported by IASC."

As Vice-President of IUCH and President of the American Society for Circumpolar Health, the adhering body of IUCH from the United States of America, I urge you to follow the international decision to involve our professional societies. I request that any and all materials that result from the investigation of the international transmigration of pollutants be reviewed for their medical and health implications. I request that local, regional, state, and Federal health officials be actively involved in the multi-disciplinary programs which should result from these hearings and the growing concerns of Arctic contamination. It is imperative to involve those to whom community health has been entrusted. Every citizen cannot understand the complexities and risk assessments that comprise these highly technical issues. The monitoring researchers must include the health scientists as well as the health care providers, all of whom can provide explanations as to the health impact of the changing environment to their own communities.

I thank you for your time and consideration of these issues. The American Society for Circumpolar health has for a quarter of a century worked to foster international cooperation in Arctic health science research. We must be involved at some level in any evaluation of nuclear monitoring in the circumpolar regions.

sincerely,

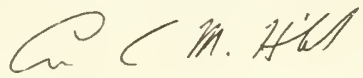

Carl M. Hild, M.S. Sci. Mgmt.

President ASCH

Vice-President IUCH 


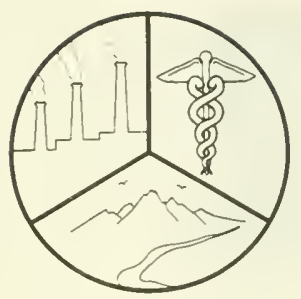

\title{
Alaska Health Project
}

Information and advocacy on occupational and environmental health. $1818 \mathrm{~W}$. Northern Lights Blvd., Sutte 103. Anchorage. Alaska 99517 (907) $276-2864$ in State 800-478-2864 Fax 907-279-3089 Modem 907-279-3128

\author{
August 10,1992
}

Senator Frank Murkowski

10112 th Avenue, Box 7

Fairbanks, AK 99701-6278

Honorable Senator Murkowski and

Members of the senate select Committee on Intelligence:

The Alaska Health Project (AHP) is a private, not-for-profit corporation. Our goal is to improve the health of Alaskans through top quality educational programs and environmental research efforts to prevent pollution. We work to keep those who must deal with hazardous materials or work in hazardous

situations safe from harm. As the Executive Director of this agency I sit on the State of Alaska's Emergency Response Comrission (SERC) representing a public interest group.

The Federal SARA Title III, Community Right To Know Law, requires that every citizen have the ability to learn what hazardous materials may be used, stored, or transported in their region. AHP sees this federal mandate applying to the pollutants which are carried from other countries into our state by global environmental forces.

We need to establish a regular system of documentation on what transboundry pollutants are coming into Alaska. We need to establish a mechanism to inform the public, public interest groups such as AHP, and state agencies of contamination that may impact the health of our residents.

We know Arctic Haze along the North slope is caused by coal fired electric generation and steel mills in eastern Europe. We know that radioactive fallout from the atmospheric testing of the $1960^{\prime}$ 's fell on Alaska and concentrated in the people of the northern interior due to their diet of caribou. We know that Chernobyl set the Arctic world on edge wondering where those materials would settle. Now we know that Russia is struggling to deal with its massive internal problems.

It seems likely that there is greater chance today that the people of Alaska will be exposed to incidental radioactive materials due to an unanticipated release than there has been over the past four decades that we would be the victims of a nuclear attack. It is no longer an issue of being exposed 
because one lives near a selected military target or strategic site, it is every man, woman, child, animal, and plant in every community, river, and region of the north.

If radioactive materials are released from the chernobyl area, during clean-up or as may be happening as this letter is written due to a forest fire that is burning contaminated regions, the fallout is very likely to sweep across the Arctic and precipitate on our North Slope. Meanwhile if nuclear reactors go off line, be they on land or in vessels, along the eastern coastal areas of Russia then the atmospheric and ocean contamination will sweep across the Bering strait and into western Alaska within a very short time.

The citizens of this state must be protected. The first Iine of defense is monitoring for the types of events I have just mentioned. That monitoring must be completed with an evaluation by health specialists and other scientists to make a risk assessment of the event. Then the public must be notified of that risk and informed on how best to behave in order to maintain their health. The Alaska Health Project is ready to make our services available in such a situation, however we must know in advance that we, and others of the health care community, are going to be integrally networked with any monitoring system that is proposed.

As the threat to the general population is no longer military in focus we believe that the community Right To know Law comes into effect. We believe that any monitoring scheme that is implemented be interfaced closely with the SERC and those Local Emergency Planning Committees who are planning the response to potential releases of hazardous materials. We also believe that there must be involvement of health scientists. Arctic health science research has already been provided guidelines on how to perform their work and provide information back to the impacted communities from the American Public Health Association. (Copies of that policy are enclosed)

I appreciate this opportunity to provide testimony to this committee. I am willing to work with any group that may be formed to address how best to keep the public informed on the results of the monitoring of radioactive materials in the Arctic and the risks to health which may result in any release.

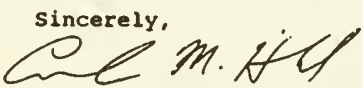

Carl M. Hild, M.S. Sci. Mgmt.

Executive Director and SERC Member

Enclosure: AHPA AHSRP

CC: SERC 


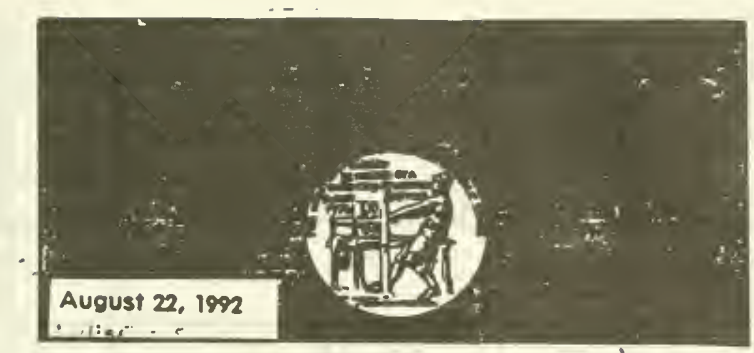
Nuclear concerns

\section{Senate Fairbanks hearings a start}

Central Intelligence Agency Director Robert Gates interrupted his family's Alaska vacation last Saturday and put on a suit and tie to testify about the CIA's knowledge of nuclear and heavy metals pollution in the former USSR.

Although Mr. Gates wasn't very forthcoming and offered littie new information, Sen. Frank Murkowski, R-Alaska, deserves credit for bringing him to Alaska.

Following Gates testimony at the Fairbanks hearing, several panels composed mainly of scientists, university and government officials took to the stage. There was a general consensus that nuclear and heavy metals pollution in the Russian Arctic is widespread, even catastrophic. But no one knows its extent and most say it first must be found and monitored, then cleaned up if necessary.

On a related note, said Dr. Stephanie Pfirman of the Environmental Defense Fund, the blanket of winter arctic baze is comparable to the size of Africa - and it's not just affecting the Arctic. It extends into Eurasia and even into the northern Midwest states. How has the U.S. contributed to arctic haze, and what will we do about it?

Summing up the day and volcing the thoughts of many colleagues, Dr. Vera Alexander of the University of Alaska Fairbonks succinctly sald we need an inter-disciplinary and multi-national approach to decades of Soviet-era pollution.

In light of this, U.S. scientists and government officials would do well by the American public - and Alaskans in particular - if they followed the Norwegians' lead. Briefly, the Norwegian government is working with Russia to map where Soviet-era nuclear dumping and testing took place at the Scandinavian end of the Russian Arctic Ocean.

Alaskans who heard about the Fairbanks event might well ask what it held for them. Part of the answer came from sketchy testimony that revealed polluted areas exist on the Alaska side of the former Soviet empire. Yet their extent and exact locations aren't widely known.

Like the Norwegians looking eastward, we must look westward across the narrow Bering Strait to find answers - and begin working with the nations and people of the Aretic on solutions. 


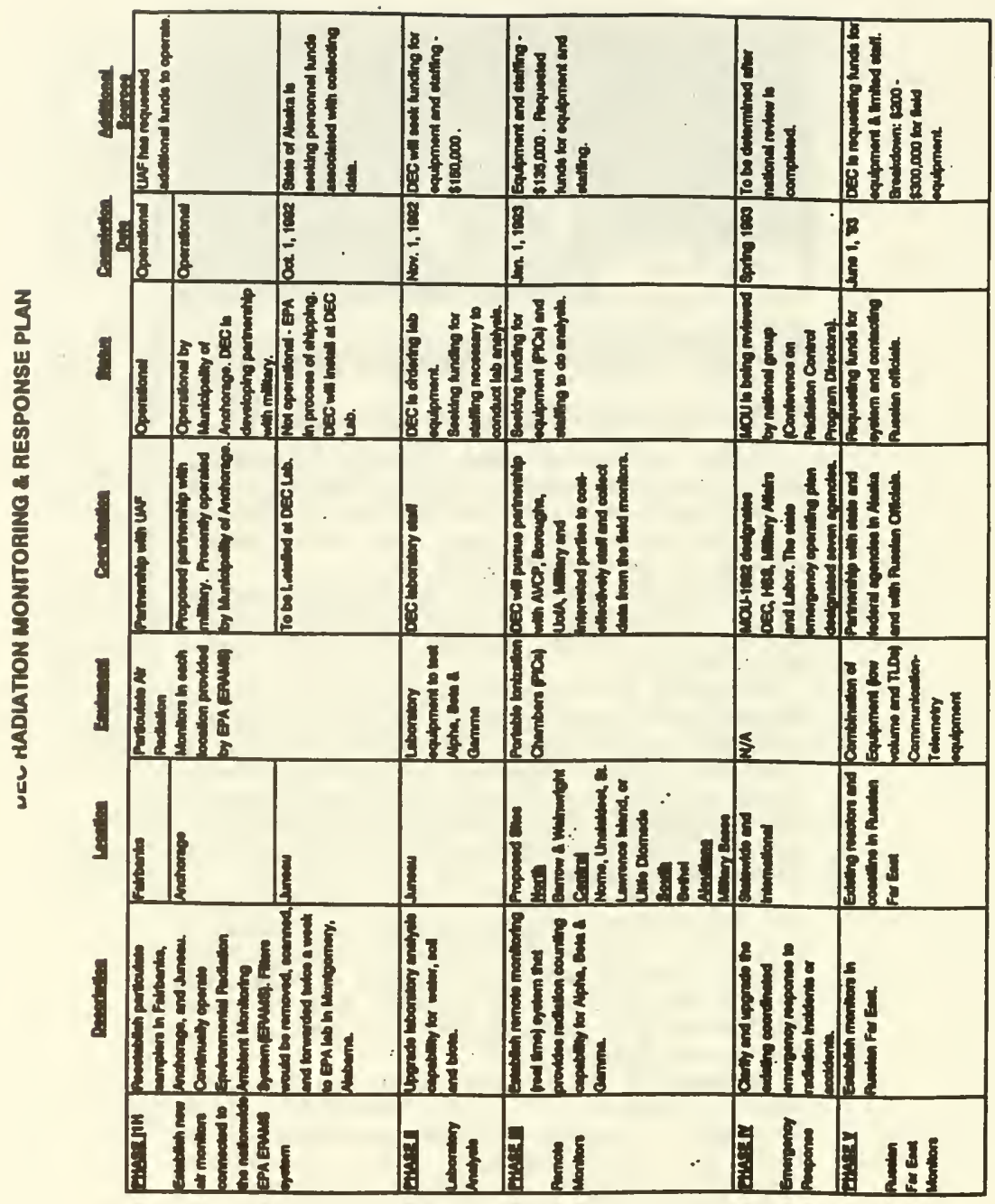


Senator MURKowSKI. Well, as you might imagine, these hearings are designed to hear from the witnesses, so I will conclude. We have a full day with many presentations. So without further delay, I'd like to introduce Secretary Bohlen and initiate the hearing.

Dr. Bohlen, please proceed with your statement.

[The prepared statement of Senator Murkowski follows:]

\section{STATEMENT OF U.S. SENATOR FRANK H. MURKOWSKI}

The fall of the Soviet regime has resulted in an outpouring of information about the practices and activities of the Former Soviet Union.

Earlier this year, the Senate Intelligence Committee began to receive reports from environmental and nuclear scientists in Russia detailing reckless nuclear waste disposal practices, nuclear accidents, and uses of nuclear detonations that I frankly found astonishing.

Also troubling is the fact that 15 Chernyobyl-style RBMK nuclear power reactors continue to operate in the Former Soviet Union. These reactors lack a containment structure, and they are designed in such a way that a nuclear reaction can actually increase when the reactor overheats. As scientists here at the University of Alaska and elsewhere have documented in their study of "Arctic Haze," the polar air mass and prevailing weather patterns provide a pathway for radioactive contaminants from eastern Europe and western Russia where many of these reactors are located.

The threats presented by these potential radioactive risks are just a part of a larger Arctic pollution problem. Everyday industrial activities of the Former Soviet Union continue to create pollutants. Let's face it, in a country struggling for its economic survival, environmental protection isn't necessarily the highest priority-and that could be troubling news for the Arctic.

The Arctic is the principal source of food for many Alaskans. Small amounts of heavy metals-possibly from industrial pollution or "Arctic haze" - are already making their way into walrus and other marine mammals that feed many arctic residents. Will radionuclides follow? Do we have the monitoring mechanisms in place to warn us should this occur? Can we address, through bilateral and multilateral mechanisms, the need to halt the spread and promote the cleanup of these pollutants? Who has the talent and capability to do this kind of work? These are all important questions we hope to explore today.

Today's hearing, which is the first ever field hearing of the Select Committee on Intelligence, will hear from a remarkable list of witnesses in effort to explore these issues from several different perspectives.

Because this is an international problem, we've asked the Assistant Secretary of State Curtis Bohlen, to give us the State Department's perspective. As a senior member of the Interagency Arctic Research Policy Committee, Secretary Bohlen can also tell us what can and should be done to scientifically assess the threats facing the Arctic from these various pollutants.

Director of Central Intelligence Robert Gates will provide us with an assessment of both the nuclear activities of the Former Soviet Union and the role that the CIA can and should play in the environmental area-not only in this area but in the realm of global change and other environmental concerns. The CIA of the post-cold war era is forging new ground in the area of environmental intelligence under the leadership of Robert Gates, and we are pleased that he has chosen this occasion here in Alaska to outline some of his new initiatives.

Because many, including myself, have suggested that scientific and environmental monitoring in the Arctic should be undertaken in collaboration with Russian scientists, we've asked Donald O'Dowd, the Chairman of the Arctic Research Commission and the former President of the University of Alaska, to provide us with some thoughts about the opportunities and problems involved in scientific cooperation with the Russians. The Commission recently returned from a series of meetings with their counterparts in the Russian Academy of Sciences, so Dr. O'Dowd is uniquely qualified to address this question.

The nation's top official for oceanic and atmospheric research, Dr. Ned Ostenso, will outline the programs that NOAA can bring to bear on this problem. One of the Environmental Protection Agency's top radiation and mixed waste experts, Admiral Richard Guimond, will provide the EPA's perspective on these problems.

We will also hear from a number of scientific and health experts-including some who have come from Russia, Denmark, Norway and elsewhere-to provide information based on their experience, research and monitoring. 
We have representatives from the environmental community-one to specifically address issues involving the dumping of nuclear materials in the ocean, and another to present information gathered about a broader range of pollutants and the mechanisms that transport them around the Arctic.

We have invited representatives of the North Slope Borough, the Inuit Circumpolar Conference, and other representatives of the Native community to provide their thoughts, and at the end of the day, we will hear from a panel representing an alliance between the University of Alaska and a National Laboratory to set forth some concrete ideas about the course of action that should be undertaken to address some of these problems.

A number of other agencies, governments and organizations, including Finland, Iceland, the U.S. Department of Energy, the Arctic Marine Resources Commission, the International Union for Circumpolar Health, the American Society for Circumpolar Health, the Alaska Health Project and many others, have also submitted written testimony. I invite anyone in the audience to feel free to do so as well. The hearing record will be kept open for two weeks for the acceptance of additional public testimony.

We have a very full day, with many presentations. So without further delay, I'd like to turn to Secretary Bohlen and get the hearing underway.

\section{STATEMENT OF CURTIS BOHLEN, ASSISTANT SECRETARY FOR OCEANS, INTERNATIONAL ENVIRONMENTAL AND SCI- ENTIFIC AFFAIRS, DEPARTMENT OF STATE}

Secretary BoHLEN. Thank you, Mr. Chairman. I am indebted to you for inviting me to testify today because I think this is a really critical issue that has been ignored too long. And this is a marvelous opportunity for us to hear from various experts the state of knowledge on this issue.

As far back as the 1940's the Soviet Union used the Barents and Kara Seas, in the vicinity of Novaya Zemlya, for dumping nuclear wastes. According to recent articles in the Russian press, reporting by environmental groups, and information from other sources, estimates suggest that as much as several billion curies of liquid and solid radioactive material may have been dumped, apparently with no concern for the environmental consequences. According to those same sources, somewhere between 10 to 15 nuclear submarine reactor cores as well as the mid section of the first nuclear icebreaker Lenin, with three reactors, now lie on the sea floor in the Barents and Kara Seas. Other reports suggest that the sea off the Kamchatka Peninsula has also been a dumping ground.

I think Mr. Gates will be able to give us much more detail on that afterwards.

The disposal of these radioactive materials and other toxic chemical and heavy metal wastes into the rivers which flow into the Arctic Ocean is of great concern to Russia's neighbors around the Arctic rim. The dumping and disposal activities may represent a serious environmental threat in the longer term. Unfortunately, all too little is known about the propensity of those radioactive and toxic wastes to spread throughout the Arctic.

I want to emphasize the seriousness with which we in the State Department and the whole U.S. government view these events. As I said, Mr. Chairman, your hearing today is timely and provides an opportunity to hear from both government and public witnesses about what is known about this Arctic dumping.

Ultimately it is Russia that must assume the responsibility for rectifying these environmental issues. But that does not mean that the United States can sit by and do nothing. We must and we are 
beginning to ascertain the nature of the problem and whether there is a likelihood of environmental danger to U.S. interests.

The first step is to seek from the former Soviet Union more information and support to determine precisely what dumping may have occurred. This we can do immediately. We strongly support the effort by the Secretary General of the International Maritime Organization to seek information from the Russian federation. And I think the International Atomic Energy Agency may also have an important role in this.

The next step is to undertake some sampling activities that may help define the problem. The International Arctic Research Policy Committee is presently developing a coordinated U.S. government response to this. I'm pleased to say that we are working with other U.S. agencies to place American scientists on ships transiting the Arctic Ocean for the purpose of taking samples. Finally, we may be able to use former Russian weapon scientists, ecologists and oceanographers in a broader scale effort to assess the problem and begin to outline what options there may be for Russia to correct the problem.

There are several things that are clear. There is a scarcity of available baseline data about the sediment and water chemistry, current circulation patterns, and the food web in the Arctic Ocean. We must find out what data has already been collected in the former Soviet Union and assess what new data collection is required.

Improving our understanding of these environmental situations will require international cooperation and participation. A high degree of cooperation and participation on the part of the Russian government will be essential.

Let me outline several courses we are pursuing currently in the Arctic. We are seeking to place a U.S. scientist on a joint RussianNorwegian research cruise, later next week. This vessel is planning on making measurements and taking samples at or near approximately 16 dump sites in the vicinity of Novaya Zemlya. On August 12 th the Russians advised our embassy that it was too late to join the cruise but we have suggested now that we talk about future cooperation on cruise missions, and so far indications are that their attitude is very positive.

We are also pursuing the possibility of a U.S. platform to conduct research. This past week I arranged to place a U.S. Geological Survey radionuclide chemist aboard the Coast Guard icebreaker Polar Star. Next month this vessel will be invoved in geophysical seismic research in the Chukchi Sea and northwest, toward Wragel Island, and it will be an excellent oppportunity to take water samples.

The next year we're investigating the use of the Polar Star as it is scheduled to make a transit of the Arctic Ocean through the North Pole in the company of the Canadian icebreaker Louis St. Laurent. And I should add that we've recently discussed with the Russians the possibility of them adding a ship of their own to this, so it would be a three-way international effort. The proposed track for these ships will begin at Barrow on or about August 20th next year and end at Tromso, Norway, in late September. The U.S. Coast Guard, U.S. Geological Survey, U.S. National Oceanographic and Atmospheric Administration, the Canadian Geological Survey, 
and the Canadian Department of the Environment are all involved in this effort.

A major gap in the proposed '92-93 sampling programs lies between the Kara and Chukchi Seas, particularly along Russia's Arctic coastline. Conduct of the research in this area, approximately parallel to the northern sea route, is probably most cost effective if carried out predominantly by Russian scientists aboard Russian ships, including their icebreakers. In this connection, the opportunity to use former weapons scientists in Russia is a good opportunity.

And that as I have alluded to earlier, we intend to explore the possibility of using Russian environmental scientists, their marine chemists, biologists, and geologists, to participate in retraining the former weapons scientists. Knowledgeable U.S. scientists may assist in this retraining. The retraining, if authorized, would be conducted in conjunction with the International Science and Technology Center announced by Secretary Baker that we are trying to establish in Russia.

These newly-trained scientists could, given their backgrounds, make additional contributions to the definition of the Arctic pollution problem and also sustain more complete and accurate monitoring work in that region in the future. Moreover, the Russia Aid Bill, which you are so responsible for, Mr. Chairman, that passed the Senate recently, would provide support for these and other important environmental objectives in the Arctic.

I'd like to say just a few words about the progress we've made in the last few years on international Arctic cooperation. This may prove to be of great use in assessing the number waste issue. Until recently we promoted our Arctic scientific and environmental interests internationally, through bilateral agreements or programs. Aside from the 1973 agreement on the conservation of polar bears, there was no Arctic-specific multilateral agreements or cooperative arrangements. In the late 1980's the Soviet Union began expressing interest in region-wide arctic cooperation for the first time, opening the door to prospects for such cooperation. As a result, the Arctic countries, Finland, Canada, Denmark on behalf of Greenland, Iceland, Norway, Sweden, Russia and the U.S., are now cooperating much more closely.

There are also two new Arctic initiatives which are relevant to the issue before us today. The first is the International Arctic Science Committee founded in August 1990. The IASC is a nongovernmental scientific organization established to encourage and facilitate international consultation and cooperation for scientific research concerned with the Arctic. It is comprised of representatives from the eight arctic countries plus six others which are other countries to have demonstrated substantial research in Arctic science. The IASC consists of a counsel, a regional board, working groups and a secretariat headquartered in Oslo, Norway. The U.S. representative to this group is the National Academy of Sciences. And I think the IASC must be requested to play a role in designing and planning the needed assessment of these nuclear waste discharges.

A second cooperative effort was initiated by Finland in 1989 and resulted in what we know now as the Arctic Environmental Protec- 
tion Strategy. It was signed at a ministerial level meeting in Rovaniemi, Finland in June of 1991.

The Arctic Environmental Protection Strategy is a plan for cooperation and coordination of Arctic countries' efforts to protect the environment. It is based on state of the environment reports prepared by individual lead countries and reviewed by all participants. These focus on six specific areas: oil, acids, persistent chlorinated organics, noise, and heavy metals, and radioactives. The strategy summarizes these reports and calls for specific actions.

Obviously the focus on radioactivity may prove useful as a tool in the situation with which we are concerned today. In particular, the strategy's Arctic Monitoring and Assessment Program, AMAP, may prove useful. Its goals are to coordinate existing and future monitoring efforts and to develop an Arctic data directory. Countries recognize that this first step of cooperation is essential to the future coordination of our response to pollution treats. Norway has volunteered to host the secretariat which is now located in Oslo. The Environmental Protection Agency and National Oceanographic Atmospheric Administration are the lead U.S. agencies for this program. It is important that they both devote the necessary resources and priorities to implement AMAP effectively. In particular, we would request AMAP to undertake a long-term monitoring program, a program to monitor these dumped nuclear materials.

$\mathrm{Mr}$. Chairman, there are also two other relevant bilateral agreements with Russia which bear on the problem of marine pollution. One is the 1972 U.S./USSR agreement on cooperation in the field of environmental protection which will be discussed by my colleague from EPA. The other concerns oil pollution. It is the agreement between the United States and the Soviet Union concerning cooperation in combating pollution in the Bring and Chukchi Seas, which was developed under the umbrella of the 1972 agreement and signed in May of 1989. The purpose of the agreement is to establish a mechanism to deal with the risk to the marine environment posed by potential oil development in the Bering Sea by both countries, and tanker traffic associated with such development and with the development of oil production in the Beaufort Sea. It's also designed to deal with pollution risks associated with the transport of other hazardous substances.

Pursuant to the agreement, both countries established a joint marine pollution contingency plan to facilitate a coordinated response to a pollution accident threatening one or both countries and to provide a communication net work and command structure for dealing with such incidents. The plan provides for prior agreement on procedures and responsibilities including customs and immigration clearances for personnel to enable response teams to move more quickly and effectively to contain or clean up a pollution incident. The plan also provides for regular coordination meetings and exercises. The plan is implemented and maintained by the U.S. Coast Guard and their Russian counterparts in the field of pollution response. While one might question what an oil pollution agreement has to do with nuclear waste dumping, the fact is that the agreement is a useful precedent. It demonstrates that the U.S. and Russia can reach agreement on an effective umbrella arrangement for dealing with environmental issues. 
Mr. Chairman, this describes some of the efforts that the department is addressing, using to address environmental threats in the Arctic. I think it's very clear that we don't know nearly as much as we need to about the effects of this dumping by the former Soviet Union, but I want to assure you that you have attracted our attention and we're going to go full throttle to see what we can do about this problem.

Thank you.

[The prepared statement of Secretary Bohlen follows:] 


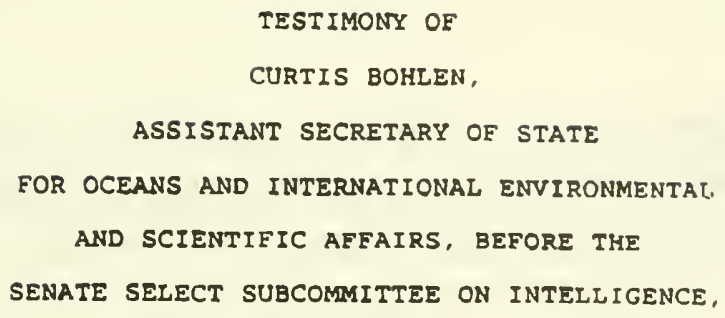

MR. CHAIRMAN :

I AM PLEASED TO APPEAR BEFORE THIS SUBCOMMITTEE TO DISCUSS INTERNATIONAL ISSUES RELATING TO RADIOACTIVE AND OTHER ENVIRONMENTAL THREATS TO THE UNITED STATES AND THE ARCTIC RESULTING FROM PAST SOVIET ACTIVITIES.

AS FAR BACK AS THE 1940 'S, THE SOVIET UNION USED THE BARENTS AND RARA SEAS, IN THE VICINITY OE NOVAYA ZEMLYA, FOR DUMPING NUCLEAR WASTES. ACCORDIMG TO RECENT ARTICLES IN THE RUSSIAN PRESS, REPORTING BY ENTIRONDESTTN GROUPS, AND INFORMATION FROM OTHER SOURCES. ESTIMATES SUGGEST THAT AS MUCH AS SEVERAL BILLION CURIES OF LIQUID AND SOLID RADIOACTIVE MATERIAL MAY MAVE BEEN DURPED. APPARENTLY WITH NO CONCERN FOR 
ITS ENVIRONMENTAL IMPACT. ACCORDING TO THE SAME REPORTS, SOMEWHERE BETWEEN 10-15 NUCLEAR SUBMARINE REACTOR CORES. AS WELL AS THE MID-SECTION OF THE FIRST NUCLEAR ICE-BREAKER, LENIN, WITH THREE REACTORS, NOW LIE ON THE SEA FLOOR IN THE BARENTS AND KARA SEAS. OTHER REPORTS SUGGEST THAT THE SEA OFF THE RAMCHATRA PENINSULA HAS ALSO BEEN A DUMPING GROUND.

THESE DUMPING AND DISPOSAL ACTIVITIES MAY REPRESENT A SERIOUS ENVIRONMENTAL THREAT IN THE LONGER TERM.

UNFORTUNATELY, ALL TOO LITILE IS KNOWN ABOUT THE PROPENSITY OF THOSE RADIOACTIVE AND TOXIC WASTES TO SPREAD THROUGHOUT THE ARCTIC.

I ALSO WANT TO EMPHASIZE THAT WE IN THE STATE DEPARTMENT, AND THROUGHOUT THE U.S. GOVERNMENT, TAKE THESE CONCERNS SERIOUSLY AND ARE SEERING TO ADDRESS THESE CONCERNS. YOUR HEARING TODAY IS A USEFUL OCCASION FOR BRINGING TOGETHER BOTH GOVERNMENT AND PUBLIC WITNESSES TO ASCERTAIN WHAT IS RNOWN ABOUT ARCTIC DUMPING IN GOVERNMENT CIRCLES AND IN ACADEMIA. 
MR. CHAIRMAN, ULTIMATELY IT IS RUSSIA THAT MUST ASSUME THE RESPONSIBILITY FOR RECTIFYING THESE ENVIRONMENTAL ISSUES. BUT THAT DOES NOT MEAN THAT THE UNITED STATES CAN SIT BY AND DO NOTHING. WE MUST, AND WE ARE. BEGINNING TO ASCERTAIN THE NATURE OF THE PROBLEM AND WHETHER THERE IS A LIKELIHOOD OF ENVIRONMENTAL DANGER TO U.S. INTERESTS.

THE EIRST STEP IS TO SEEK FROM THE FORMER SOVIET UNION MORE INEORMATION AND SUPPORT TO DETERMINE PRECISELY WHAT DUMPING MAY HAVE OCCURRED. WE WILL DO THIS IMMEDIATELY. THE NEXT STEP IS TO UNDERTARE SOME SAMPLING ACTIVITIES THAT MAY HELP TO DEFINE THE PROBLEM. I AM PLEASED TO SAY THAT WE ARE WORKING WITH OTHER U.S. AGENCIES TO PLACE AMERICAN SCIENTISTS ON SHIPS TRANSITING THE ARCTIC OCEAN FOR THE PURPOSE OF TAKING SAMPLES. FINALLY, WE MAY BE ABLE TO USE FORMER RUSSIAN WEAPONS SCIENTISTS IN A BROADER-SCALE EFTORT TO ASSESS THE PROBLEM AND BEGIN TO OUTLINE WHAT OPTIONS THERE MAY BE FOR RUSSIA TO CORRECT THE PROBLEM.

SEVERAL THINGS ARE CLEAR:

- there IS A sCARCITy OF baseline dATA about the SEDIMENT AND WATER CHEMISTRY, CURRENT CIRCULATION PATTERNS, AND THE FOOD WEB IN THE ARCTIC OCEAN. 
- IMPROVING OUR UNDERSTANDING OF THESE ENVIRONMENTAL SITUATIONS WILL REQUIRE INTERNATIONAL COOPERATION AND PARTICIPATION.

- A HIGH DEGREE OF COOPERATION AND PARTICIPATION ON THE PART OF THE RUSSIAN GOVERNMENT WILL BE REQUIRED.

LET ME OUTLINE TWO COURSES WE ARE PURSUING IN THE ARCTIC:

- WE HAVE BEEN LOOKING INTO THE PARTICIPATION BY A U.S. SCIENTIST (OR SCIENIISTS) ON A JOINT RUSSIAN-NORWEGIAN RESEARCH CRUISE IN LATE-AUGUST EARLY SEPTEMBER. THIS VESSEL IS PLANNING ON MAKING MEASUREMENTS AND TAKING SAMPLES AT OR NEAR APPROXIMATELY 16 DUMP SITES IN THE VICINITY OF NOVAYA ZEMIYA. ON AUGUST 12 THE RUSSIANS ADVISED OUR EMASSY THAT IT WAS TOO IATE TO JOIN THE CRUISE. THEY SUGGESTED THAT WE TALK ABOUT FUTURE COOPERATION ON CRUISE MISSIONS AND INDICATED THEIR ATTITUDE TO THIS WAS VERY POSITIVE.

-- WE ARE ALSO PURSUING THE POSSIBILITY OF A U.S. PLATEORM TO CONDUCT RESEARCH. WE HAVE ARRANGED TO PLACE A U.S. GEOLOGICAL SURVEY RADIO-NUCLIDE CHEMIST ABOARD THE COAST GUARD ICEBREAKER, POLAR STAR, ALSO IN THE LATE-AUGUST TO LATE-SEPTEMBER TIMEFRAME. THIS VESSEL WILL BE PRIMARILY INVOLVED IN GEOPHYSICAL 
SEISMIC RESEARCH AND ITS COURSE WILL BE CONSTRAINED BY THE ICE-PACK. WE EXPECT IT TO REACH AS FAR AS 600 NAUTICAL MILES NORTH-NORTHWEST OF ALASRA OVER THE CHUKCHI CAP.

IN THE 2993 TIMEFRAME, WE ARE INVESTIGATING THE USE OF THE POLAR STAR WHICH IS SCHEDULED TO MAKE A TRANSTT OF THE ARCTIC OCEAN, THROUGH THE NORTH POLE, IN THE COMPANY OF THE CANADIAN ICE-BREAKER, LOUIS ST. LAURENT. THE PROPOSED TRACK FOR THESE SHIPS WILI BEGIN AT BARROW, ALASKA, ON OR ABOUT AUGUST 20. 1993. AND END AT TROMSO, NORWAY, ABOUT SEPTEMBER 26, 1993. THE U.S. COAST GUARD, THE U.S. GEOLOGICAL SURVEY, THE U.S. NATIONAL OCEANIC AND ATMOSPHERIC ADMINISTRATION, THE CANADIAN GEOLOGICAL SURVEY AND THE CARADIAN DEPARTIENT OF THE ENVIRONMENT ARE INVOLVED IN THIS EFFORT.

A MAJOR GAP IN THE PROPOSED 1992-93 SAMPLING PROGRAMS LIES BETWEEN THE RARA AND CHUKCHI SEAS, PARTICULARLY ALONG RUSSIA'S ARCTIC COASTLINE. CONDUCT OF THE RESEARCH IN THIS AREA, APPROXIMATELY PARALLEL TO THE NORTHERN SEA ROUTE, IS PROBABLY MOST COST EFFECTIVE IE CARRIED OUT PREDOMINATELY BY RUSSIAN SCIENTISTS ABOARD RUSSIAN SHIPS, INCLUDING ICEBREAKERS. IN THIS CONRECTION, THE OPPORTUNITY TO USE FORMER WEAPONS SCIENTISTS PRESENTS ITSELF. 


$$
-6-
$$

ACCORDINGLY, AS I ALLUDED TO EARLIER, WE WILL PROPOSE THAT CONSIDERATION BE GIVEN TO THE IDEA OF USING RUSSIAN ENVIRONMENTAL SCIENTISTS--MARINE CHEMISTS, BIOLOGISTS AND GEOLOGISTS--TO PARTICIPATE IN RE-TRAINING THE FORMER WEAPONS SCIENTISTS. RNOWLEDGEABLE U.S. SCIENTISTS MAY ASSIST IN THIS RETRAINING. THE RE-TRAINING IF AUTHORIZED WOULD BE CONDUCTED IN CONJUNCTION WITH THE INTERNATIONAL SCIENCE-AND TECHNOLOGY CENTER ANNOUNCED BY SECRETARY BAKER.

THESE NEWLY-TRAINED SCIENTISTS COULD, GIVEN THEIR BACKGROUNDS, MARE ADDITIONAI CONTRIBUTIONS TO THE DEFINITION OF THE ARCTIC POLLUTION PROBLEM, AND ALSO SUSTAIN MORE COMPLETE AND ACCURATE MONITORING WORK IN THAT REOION IN THE FORESEEABLE FUTURE.

MR CHAIRMAN, I WOULD ALSO LIKE TO SAY A FEW WORDS ABOUT THE PROGRESS WE HAVE MADE IN THE LAST FEW YEARS IN INTERNATIONAL ARCTIC COOPERATION -- WHICH MAY PROVE TO BE OR GREAT USE IN ADDRESSING THE NUCLEAR WASTE ISSUE. UNTIL RBCENTLY, WE PROMOTED OUR ARCTIC SCIENTIFIC AND ENVIRONRENTAL INTERESTS INTERNATIONALLY THROUGH BILATERAL AGREEMENTS OR PROGRAMS. ASIDE FROM THE 1973 AGREEMENT ON THE CONSERVATION OF POLAR BEARS, THERE WERE NO ARCTIC-SPECIFIC MULTILATERAL AGREEMENTS OR 
COOPERATIVE ARRANGEMENTS. IN THE LATE 1980S, THE SOVIET UNION BEGAN EXPRESSING INTEREST IN REGION-WIDE ARCTIC COOPERATION FOR THE FIRST TIME, OPENING THE DOOR TO PROSPECTS FOR SUCH COORERATION. AS A RESULT, THE ARCTIC COUNTRIES - FINLAND, CANADA, DENMARK (GREENLAND), ICELAND, NORWAY, SWEDEN, RUSSIA, AND THE U.S. - ARE NOW COOPERATING MORE CLOSELY THAN EVER BEFORE.

THERE ARE ALSO TWO INTERNATIONAL FORA WHICH ARE RELEVANT TO THE ISSUE BEFORE US TODAY. THE FIRST IS THE INTERNATIONAL ARCTIC SCIENCE COMMITTEE (IASC), FOUNDED IN AUGUST 1990. IASC IS A NON-GOVERABENTAL SCIENTIFIC ORGANIZATION ESTABLISHED TO ENCOURAGE AND FACILITATE INTERNATIORAL CONSULTATION AND COOPERATION FOR SCIENTIFIC RESEARCH CONCERNED WITH THE ARCTIC. IT IS COMPRISED OF REPRESENTATIVES FROM EIGHT ARCTIC COUNTRIES WHICH ARE FOUTDING MEALERS, PLUS SIX OTHERS WHICH HAVE DEMONSTRATED SUBSTARTIAL RESEARCH IN ARCTIC SCIENCE - THE UNITED KIMGDOY, GERYANY, FRANCE, THE NETHERTANDS, POLAND, AND JAPAN. IASC CONSISTS OF A COUNCIL, A REGIONAL BOARD, WORRING GROUPS, AND A SECRETARIAT, HEADQUARTERED IN OSLO, NORWAY. 'THE U.S. REPRESENTATIVE TO IASC IS THE NATIONAL ACADEMY OF SCIENCES. 
A SECOND COOPERATIVE ARCTIC EFFORT WAS INITIATED BY FINLAND IN 1989, AND RESULTED IN THE ARCTIC ENVIRONMENT PROTECTION STRATEGY. IT WAS SIGNED AT A MINISTERIAL-LEVEL MEETING IN ROVANIEMI, FINLAND ON JUNE 14, 1991.

THE ARCTIC ENVIRONMENTAL PROTECTION STRATEGY IS A PLAN FOR COOPERATION AND COORDINATION OF ARCTIC COUNTRIES EFFORTS TO PROTECT THE ENVIRONMENT.

THE STRATEGY IS BASED ON STATE OF THE ENVIRONMENT REPORTS PREPARED BY INDIVIDUAL LEAD COUNTRIES AND REVIEWED BY ALL PARTICIPANTS. THESE FOCUS ON SIX SPECIFIC AREAS: OIL, ACIDS, PERSISTENT CHIORINATED ORGANICS, NOISE, AND HEAVY METALS, AND RADIOACTIVITY. THE STRATEGY SUMMARIZES THESE REPORTS AND CALLS FOR SPECIFIC ACTIONS.

OBVIOUSLY, THE FOCUS ON RADIOACTIVITY MAY PROVE USEFUL AS A TOOL IN THE SITUATION WITH WHICH WE ARE CONCERNED TODAY. IN PARTICULAR, THE STRATEGY'S ARCTIC MONITORING AND ASSESSMENT PROGRAM MAY PROVE USEEUL. ITS GOALS ARE TO COORDINATE EXISTING AND FUTURE MONITORING EFFORTS AND TO DEVELOP AN ARCTIC DATA DIRECTORY. COUNTRIES RECOGNIZE THAT THIS FIRST STEP OF COOPERATION IS ESSENTIAL TO THE FUTURE COORDINATION OF OUR RESPONSE TO POLLUTION THREATS. NORWAY HAS VOLUNTEERED TO HOST 
THE SECRETARIAT, WHICH IS NOW LOCATED IN OSLO. THE ENVIRONMENTAL PROTECTION AGENCY AND THE NATIONAL OCEANOGRAPHIC AND ATMOSPHERIC ADMINISTRATION ARE THE LEAD U.S. AGENCIES FOR THIS PROGRAM.

MR. CHAIRMAN, THERE ARE ALSO TWO OTHER RELEVANT BILATERAL AGREEMENTS WITH RUSSIA WHICH ALSO BEAR ON THE-PROBLEM OF MARINE POLLUTION. ONE IS THE 1972 US/USSR AGREEMENT ON COOPERATION IN THE FIELD OF ENVIRONRENTAL PROTECTION, WHICH WILL BE DISCUSSED BY MY COLLEAGUE FROM THE ENVIROMUENTAL PROTECTION AGENCY. THE OTHER CONCERNS OIL ROLLUTION. IT IS THE AGREEMENT BETWEEN THE UNITED STATES AND THE SOVIET UNION CONCERMING COOPERATION IN COMBATIING POLLUTION IN THE BERING AND CHURCHI SEAS, WHICH WAS DEVELOPED UNADER THE UMBRALA OF THE 1972 AGREBRENT, AND SIGNED MAY 11, 1989. THE PURPOSE OF THE AGREENENT IS TO ESTABLISH A MECHANISM TO DEAL WIIH THE RISKS TO THS MAINE EWVIRONAENT POSED BY POTENTIAT, OIL DEVLLOPNEMT IN THE BERING SEA BY BOTH COUNTRIES, AND TANGER TRAFFIC ASSOCIATED WITH SUCH DEVELOPMENT AND WITH THE DEVELOPHENT OF OIL PRODUCTION IN THE BEAUTORT SEA. IT IS ALSO DESIGHED TO DEAL WITH THE POLLUTION RISKS ASSOCIATED WITH THE TRAASPORT OE OTHER HAZARDOUS SUBSTANCES. 
PURSUANT TO THE AGREEMENT BOTH COUNTRIES ESTABLISHED A JOINT MARINE POLLUTION CONTINGENCY PLAN TO FACILITATE A COORDINATED RESPONSE TO A POLLUTION INCIDENT THREATENING ONE OR BOTH COUNTRIES, AND TO PROVIDE A COMMUNICATIONS NETWORK AND COMMAND STRUCTURE FOR DEALING WITH SUCH INCIDENTS. THE PLAN PROVIDES FOR PRIOR AGREEMENT ON PROCEDURES AND RESPONSIBILITIES, INCLUDING CUSTOMS AND IMMIGRATION CLEARANCES FOR PERSONNEL, TO ENABLE RESPONSE TEAMS TO MOVE MORE QUICKLY AND EFFECTIVELY TO CONTAIN OR CLEAN UP A POLLUTION INCIDENT. THE PLAN ALSO PROVIDES FOR REGULAR COORDINATION MEETINGS AND EXERCISES. THE PLAN IS IMPLEMENTED AND MAINTAINED BY THE U.S. COAST GUARD AND THEIR RUSSIAN COUNTERPARTS IN THE FIELD OF POLLUTION RESPONSE. WHILE ONE MIGHT QUESTION WHAT AN OIL POLLUTION AGREEMENT HAS TO DO WITH NUCLEAR WASTE DUMPING, THE FACT IS THAT THE AGREEMENT IS A USEEUT PRECEDENT. IT DEMONSTRATES THAT THE U.S. AND RUSSIA CAN REACH AGREEMENT ON AN EFFECTIVE UMBRELLA ARRANGEMIENT FOR DEALING WITH ENVIRONMENTAL ISSUES.

THIS DESCRIBES SOME OF THE EFFORTS OF THE DEPARTMENT TO ADDRESS ENVIRONMENTAL THREATS TO THE ARCTIC. I WOULD BE HAPPY TO ANSWER ANY QUESTIONS. 
Senator MURKowski. Thank you, Mr. Secretary.

Just a couple of questions. You, I believe, have been in Alaska for the last 10 days, have visited the Pribilofs, you were in Nome for the Arctic Research Commission Meeting, and you've been here at the University of Alaska for the Conference on Arctic Policy. Alaskans have always been a little sensitive to the emphasis of the State Department and the National Science Foundation on Antarctica, when we in Alaska see the Arctic from a perspective of people, resources, development and lots of questions but not very many answers. And I'm wondering, if, as a consequence of your trip, what kind of a message you might take back to convince some of your colleagues that much of the future wealth of North America lies in the Arctic. And we've got some questions that need scientific attention.

Secretary BoHLEN. Well, I would say first that it's become increasingly obvious in the last few years that the Antarctic is vitally important as a scientific laboratory to determine what is happening to the global environment, and of course the discovery of the ozone hole there was a prime example of this, and our ability to take ice corings from the glaciers. All of this is showing what we can learn from the Antarctic in terms of the vital processes that affect the globe. Having said that, I'm convinced after this trip that our nations-that the Arctic is far more important to our nation's vital interests. And not only are we very close to Russia and the contaminants that are being discussed today, but there are many other processes that we need to know much better, much more about in the Arctic, and above all, we have in the Arctic people that have lived here for generations. You don't find that in the Antarctic. And for these and many other reasons, I think we need to greatly increase our focus on the Arctic. I can't speak for the National Science Foundation but I can certainly speak for the State Department, that we are going to reorient our thinking in this direction.

Senator MURKOWSKI. Earlier this month I had an occasion to have a meeting with the Russian Ambassador to the United States, Ambassador Lukin. And yesterday I was given a copy of a letter, I might add it was in Russian, which purported to be an official policy statement of Russia relative to the subject matter of our hearing. And Mr. Garman tells me that it was translated last evening and that you might have had a chance to briefly scan it. We're going to enter that letter into the record. I'm not going to read it; it's rather lengthy. But I'd wonder if you'd care to comment on it at this time.

Secretary BOHLEN. Well, I was encouraged by it. I think the most-maybe I could read the most pertinent paragraph. Toward the end of the letter, the Ambassador, Ambassador Lukin, emphasizes that "Russia would be extremely interested in cooperation with the United States in the field of monitoring of environment in Arctic on bilateral basis, as well as in the framework of multilateral cooperation of Arctic states, in particular, on the program of Arctic monitoring and assessment." That's the AMAP program I mentioned earlier. That is certainly consistent with all the discussions we have had with the Russians. I think there is going to be a good deal of interest in the kind of cooperation that is needed. 
Senator MURKowSKI. My last question is relative to the tendency in Washington for the bureaucracies to kind of overwhelm each other. And I'm curious to know if you feel in your area of responsibility that we've got an adequate balance here, in the sense that the National Science Foundation, the Interagency Arctic Research Policy Committee in the Arctic Research Commission, the Environmental Protection Agency, NOAA and others all have a role in the Arctic. Somebody's got to orchestrate clearly the definitive priorities for Arctic research and, of course, that's part of your responsibility. And I wonder how those decisions are made. Is it the best prevailing argument on the merits, or the seniority within the structure, or the Agency that happens to have the funds? Oftentimes we get a little frustrated because we think we see an unmet priority but we can't seem to prevail in the structure that decides where the priorities lie.

Secretary BOHLEN. Well, we do have an excellent interagency committee that deals with Arctic issues. But that's only as effective as the policy leadership above them. And that's what I view as my task now is to make sure they get that inspirational direction to focus on these issues. And of course, it's a factor, as you well know, Mr. Chairman, of the budget. I would like to see NOAA take a much more active role than they are now in the Arctic, but that's a question of getting them the necessary funds. I think my visit to Nome a few days ago that you mentioned was to attend a meeting of the Arctic Research Commission. That was my first exposure to this commission, which was created I think by an act that you were involved in in 1984. I think that commission has a great potential for achieving better coordination among the various agencies. But my offhand observation is that they don't control the purse strings, and unless you control the purse strings, it's very difficult to make agencies move in the direction you want.

Senator MURKOWSKI. Well, Mr. Secretary, as one who's in the policy-making role in the State Department with regard to oceans and environment, we look to your for leadership. And there's an old saying in Alaska, when one sled dog said to the other, "the scenery never changes unless you're leading the pack." It's nice to know that you're leading the pack and that we can look to you as the individual to coordinate the priorities that come up through the process. And we very much appreciate your traveling to Alaska and spending so much time here and we look forward to the message that you're going to take back to Washington.

Secretary BOHLEN. I don't consider a visit to Alaska a hardship. A great pleasure indeed. Thank you, Mr. Chairman.

Senator MURKOWSKI. Thank you very much. I hope that you can be with us for a portion of the day and invite you to stay with us through this panel.

We're going to call the Director of the Central Intelligence Agency, Mr. Gates, at this time. And as he comes up I will make a few introductory remarks. Mr. Gates has been in his capacity as Director of the CIA for almost a year now. And we very much appreciate his being with us. We've got the seat warmed up for you and you can begin.

Speaking for the Chairman, Senator Boren and myself, and the Members of our bipartisan Committee, probably the only one in the 
United States Senate, that the opportunity to work with you and your colleagues has been very gratifying and we certainly commend you for your leadership and the fresh vision which you have brought to the agency and also to the policy makers in Washington, DC.

Mr. Gates, I very much appreciate the fact that you've taken time off from your family vacation to be up here with us today and to communicate some of the activities of your agency relative to intelligence on the environment. As we tailor our capabilities to a changing world, changing opportunities, it is clearly an obligation of the Intelligence Community to focus in on environmental concerns that constitute a potential threat. And with that, I'll look forward to your remarks. Please proceed.

[The prepared statement of Director Gates follows:] 
Testimony for the DCI at Onivarsity of Alaska Hearing

I am here today at the request of Senators Boren and

Murkowski and Senate select committee on Intelligence, to address two issues: possible environmental threats resulting from past Soviet nuclear activities; and the role of the Intelligence Community in addressing environmental problems.

Let me first discuss the role of the Intelligence Community with regard to environmental problems.

As you know, on November 15 th last year, the President signed the most far reaching directive to assess future intelligence priorities since CIA and the Intelligence Community were created in 1947 . The directive required some 20 policy agencies and departments to identify their intelligence needs to the year 2005. Their responses highlight the increased importance of environmental concerns as an intelligence issue. The National Security Council has integrated all the expressed priorities into one overall list and the Intelligence community is using this list as a guide for allocating resources.

Policymakers and members of Congress are asking CIA to increase its study of environmental issues because we have special skills, resources, and unique insights. For example: 
- At the request of Senator Murkowski, a team of analysts has been working to assess the potential environmental consequences of long-term nuclear testing and waste disposal practices of the former Soviet Union.

- Earlier this year I was asked by the President's Science Advisor, Dr. D. Allan Bromley, and Senator Albert Gore, to assist NASA in its effort to collect and analyze satellite data on the environment. The project--called the Earth Observation System--w111 help scientists to answer gom of today's nost pressing environeental questions such as "How do the oceans, forests, desert and atmosphere interact as an integrated system?" and "Is the earth's climate changing?" The CIA w111 provide guldance to NASA concerning the most-efflcient means for processing the large quantities of data that it is collecting for this project--because we have vast expertise in this area.

- At Dr. Bromley's suggestion, the Intelligence comunity recently assumed membership on the Committee on Earth and Environmental Research, which has become the primary coordinating body for national environmental programs. 
Membership on the Committee will provide the Intelligence Community a better understanding of the Committee's activities and requirements and will improve intelligence support to our environmental policymakers.

- Senators Gore and Murkowski have asked whether CIA data could be released to environmental scientists who are studying global change--and I have agreed to form a team of cleared scientists who will examine our data and determine what would be useful to environmental science.

- Under the Congressionally directed Dual Use Technology Initiative, technology developed under the auspices of the Intelligence Community will be transferred to the private sector where appropriate--technology especially useful in answering questions in areas like the environment, law enforcement, and medicine. Twelve projects--costing $\$ 30$ million--have been selected. Roughly half of the funds are for environmental projects. Intelligence is applying its special capabilities to nontraditional areas--such as the environment and related foreign nuclear safety issues. For several years the CIA has brought a value-added to the work done on these problems--in our analysis, 
our use of unique collection assets, and in our ability to collect and assimilate vast quantities of information.

For example, CIA analysts assessed the scope of the unprecedented environmental damage which occurred when Iragi forces sabotaged Kuwaiti oil fields last year.- Agency specialists used erhanced commercial weather satellite imagery to track daily oil slick movements in the gulf and they used unique collection systems and comercially-available Landsat imagery to verify the number, location, and status of the burning oil wells in Kuwalt. The data used by CENrcom in the bombing that stopped the flow of oil into the Gulf was provided by intelligence. The CIA worked with private experts to develop and build a computer model capable of projecting concentrations of key pollutants-primarily sulfur dioxide and particulates--and their impact on human health and crops.

Since the late 1980s, the Intelligence Community has been contributing to us government efforts to work with other countries to protect the global environment from a host of threats:

- Ozone depletion, which poses risks of increased skin cancer, blindness, declining agricultural yields, and 
Isheries losses, will only be stopped by a worldwide effort--laid out in the Montreal Protocol--to stop using chlorofluorocarbons (CFCs). The Intelligence community has been following this problem for several years and is starting work on a program to determine whether we can monitor emissions of CFCs.

- Tropical deforestation is a phenomenon that jeopardizes the world's climate, causes local problems such as llooding and mudslides, and leads to the extinction of plant and. animal species needed for biomedical research. CIA analysts have done work on these iseues, using satellite imagery and other tools, to support US policymakers in their multi-year efforts to secure an international treaty on forest protection.

- Possible cllmate change, and measures adopted by governments to reduce greenhouse gas emissions in an effort to avert 1t, have potentially far-reaching consequences. As US negotiators worked at length to forge the international agreement on this important issue that opened for signature two months ago in Rio, CIA analysts provided them, over the course of a three-year 
period, with a comprehensive series of reports on this multi-faceted problem.

other similar issues that are the subject of ongoing analytic work include: ocean dumping of hazardous substances; water scarcity and degradation; the environmental conseguences of narcotics cultivation; the impact of earthquakes and other natural disasters; food shortages and agricultural resource decline; and the pressures faced by developing and industrialized countries alike as they grapple with the costs of environmental protection. While some of these projects have been started within the past several years, many go back a long way. Our work on agriculture, for example, has been ongoirg for decades.

A related subject for intelligence is monitoring the nuclear power programs in countries of concern. This is not a new issue for intelligence. And this brings me to the second and primary part of my presentation--possible enviromental threats arising from past Soviet nuclear activities. CIA has kept an eye on the Soviet nuclear power program since the startup of their first small prototype power reactor in 1954. In the years that followed, we compiled an extensive collection of technical literature on the program and on the reactors themselves. CIA integrates this data with information acquired from our 
satellites to assess the national security, economic, and asfety implications of the program.

Since the Chernobyl disaster in 1986, CIA experts have worked closely with other US government agencies to prepare detailed studies of Soviet-designed power reactors. We are now working with these agencies to determine the most effective way to improve the safety of these reactors. At the same time, we continue to collect information on reactor problems such as the recent accident at the Chernobyl-type reactor located near st. Petersburg, Russia.

CIA has monitored Soviet handling of nuclear waste since 1948, when the reactor that produced the plutonium for the first Soviet nuclear weapon began operation. We now look at environmental contamination due to a variety of nuclear activities--most of which supported nuclear weapons production-and questions about the safety of storad but radloactive 11quid and solid waste. This includes reprocessing of fuel from civilian and naval reactors, and naval nuclear activities.

The former Soviet Union's attitude toward safety in handing radioactive waste materials was lackadaisical from the very beginning of its nuclear program. Radioactive wastes resulting 
from the extraction of plutonium for the USSR's first nuclear weapons at Chelyabinsk-65 were discharged directly into the Techa -iver, resulting in severe contamination of the watershed for thousands of kilometers downstream. Subsequent practices were hardly better--highly radioactive waste was dumped into Lake Karachay at the plant beginning in 1951. Today, despite ongoing cleanup efforts, 120 million curies of radioactive materials are in the lake, and as little as one hour's exposure to the radiation at the shoreline could be fatal. Radioactive contamination in the groundwater has spread 2 to 3 kilometers erom the lake. Additionally, an explosion in a waste tank at the aite in 1957 contaminated ovar 23,000 square kilometers, and much of the land remains unusable today.

The situation in chalyabinsk--though perhaps the most aevere--is hardly unique. Similar plants in romsk -7 and Krasnoyarsk-26 also contaminated the local environment. Open pools of water at Tomsk raportadly contain elevated levels of plutonium and other radioisotopes, resulting, in considerable wildife contamination, including elk, hare, duck, and lish, which are consumed by the local populace. Reactors at the Krasnoyarsk plutonium production plant use water directly from 
the Yenisey River for cooling, and have contaminated the river with cesium, strontium, and other radioisotopes for hundreds of kilometers downstream. One of these reactors remains operational today.

Even though these facilities are not in the Arctic, their impact has been observed in the region. All watersheds from these sites flow to the Arctic Ocean, and waste from the polluted Techa River reportedly was discovered in the Arctic as early as 1951. Moreover, the waste handling practices at these altes were all too typical of soviet attitudes toward nuclear afety and the environment.

The greatest single source of radioactive contamination of the Arctic environment has been from nuclear weapons testing, especially atmospheric testing at the Novaya zemlya test site in the Arctic from 2955 to 1962 . About half of the USSR's approximately 200 atmospheric tests were conducted at Novaya zemlya. Virtually all of their highest yield explosions were conducted there, with a total yield of over 300 megatons. Among these was the world's largest explosion in 1961--approximately 55 megatons, over 3,000 times the yield of the Hiroshima explosion. In addition to sometimes severe local contamination from fallout, 
Soviet atmospheric testing also was the greatest contributor to radioactive contamination of Alaska and northern Canada.

The severity of the contamination decreased dramatically after the 1963 Iimited Test Ban Treaty--especially in Alaska and Canada--but Soviet underground nuclear weapons testing and peaceful nuclear explosions continued. Russian statements indicate over 130 peaceful nuclear explosions for mining, seismic sounding, or creation of underground storage cavities were conducted throughout the Soviet Union. A few of these explosions were part of a program to develop the capability to excavate canals using nuclear explosions. These crater-producing explosions produced widespread contamination. In an August 1987 test, for example, the concrete plug placed to contain the explosion was blown out of the tunnel, and radioactive material spewed into the atmosphere. Some of the other explosions may have contaminated the local groundwater, and a few may have leaked radioactive materials. Except for tests at Novaya Zemlya, which sometimes spread contamination into the broader Arctic environment, these leaks probably produce only limited local contamination. 
Soviet nuclear reactor accidents also have contributed to contamination of the Arctic. Numerous studies have documented the disproportionately heavy fallout in northern Norway, Sweden, and Finland from the Chernobyl' accident in April 1986. Fifteen of the unsafe Chernobyl'-type nuclear reactors remain in operation in the former Soviet Union, and together with other types of old, unsafe soviet-designed reactors, comprise over half of the power reactors now operating in the CIS and Eastern Europe. In the Arctic, four small reactors using aimilar technology to theे Chernobyl' reactors are at the remote settlement of Bilibino in the Russian Far East, and a power plant on the Kola peninsula has four aging pressurized-water reactors. The demise of the USSR and its East European client governments has left all of the raactors largely bereft of material support and regulatory guidance. The situation is made worse by the region's severe conomic problems, which are undermining efforts to maintain and improve safe operations.

In addition to power reactors, hundreds of reactors are aboard CIS submarines and naval vessels, the majority of which are based in or near Arctic waters. A September 1985 explosion during refuelling of a Soviet nuclear submarine near vladivostok 
illustrates the potential for serious accidents in these reactors. The explosion scattered radioactive material onshore and into the bay, which reportedly was only haphazardly and incompletely cleaned up. In addition, comments by former soviet navy personnel and two well-publicized sinkings of soviet submarines since 1986 illustrate the danger fire and accidents pose to CIS submarine reactors. The large number and advancing age of these reactors will increase safety risks, particularly as the CIS begins to dismantle many of the vessels.

Deliberate dumping of radioactive waste materials into Arctic waters, or improper land-based storage is another source of radiological pollution. The USSR dumped substantial quantities of radioactive waste in Arctic waters, including tha three damaged original nuclear reactors of the icebreaker Lenin, and reportedly reactors from several submarines--including some with nuclear fuel aboard. Radioactive wastes, mostly from naval reactors, also are buried on Arctic shores. Only Soviet records, if any, or detailed scientiflc surveys can determine the amount, type, and potential hazards from the materlal which has been dumped. I expect that we will learn more about these and other concerns in light of the new scientific cooperation, such as the 
foint Rusalan-Norwegian expedition to survey nuclear waste disposal sites in the Kara Sea planned for this month, and information-sharing made possible by the collapse of communism. The newly tree republics of the former soviet Union and Eastern Europe face enormous environmental challenges. The deteriorating industrial infrastructure presents a high risk of disasters. The chemical and energy sectorg-where much of the equipment is old and in need of replacement--appear to face the highest risk, but serlous breakdowns could occur in railroads, civil aviation, and nuclear power plants. In some cases, accidente have already occurred. For example, an 011 well in Uzbeklatan drilled with inadequate equipment ruptured in March, contaminating farmland and threatening to pollute vital river. only through intensive round-the-clock efforts, aided by os experts who in turn were supported by intelligence reports, were workars able to cap the well and protect the river.

Environental destruction caused by Soviet troops in Eastern Europe is adding substantially to the alraady heavy cleanup burdens new governments face as the result of four decades of environmental neglect by the region's former communist rulers. 
The destruction being revealed by the pullout of soviet forces clearly will take many years and billions of dollars to repair. Corroded petroleum, oil, lubricants, pipelines and storage tanks as well as poor fuel-handling practices make contamination of soil and groundwater the most ubiquitous pollution problem at former Soviet facilities. Lax safety standards combined with poor storage and accounting practices at ammuition depots have led to soil and water contamination with a variety of heavy metal, acids, and other toxic--and often explosive--wastes. Solvents, paints; coatings, and plating materials have been poorly stored and carelessly dumped. Troop maneuvers involving heavy tracked vehicles and live-firing exercises have destroyed terrain, worsened erosion and water pollution, and contaminated the soil with lead and other substances. Unexploded ordnance presents a safety hazard in and around training areas. East European governments are assessing the dimensions of the pollution problem they have inherited from the soviet military, but it probably will be many years before these areas can be cleaned up and returned to productive use.

Another Region struggling with the residue of soviet actions is Central Asia's Aral Sea basin. Over the past 30 years, Soviet 
efforts to expand Central Asian cotton production--which required diverting large quantities of water from the rivers that feed the Aral--has reduced the sea by over 40 percent of its volume and 60 percent of its surface area. The leaking and dumping of pesticides into water supplies, the absence of water pricing policies, and fierce competition for water--particularly among the Uzbeks and Turkmen--have significantly worsened Central Asia's critical water situation. Existing political, economic, and ethnic tensions in the region are being further strained by Aral "refugeas" joving to cities in search of guaranteed medical care, eccure employment, a stable source of drinking vater, and essential foodstuffs. Central Asian leaders--faced with serious economic and political difficulties--have discused cooperation on environmental issues, but have yet to formulate, much less Implament, a concrete plan to halt the Aral's desiccation. Even under the best possible circumstances, with effective regional cooperation and massive foreign assistance, it will take at least. Ilve to tens years of consistent effort before any progress in halting the Aral's destruction can be realized. Without such cooperation, the Aral basin is likely to become an environmental dead zone. 
Although the CIS is faced with a daunting legacy of

environmental problems, it is making progress in some areas. For example, for several years they have been converting highly radioactive civilian and military waste to glass--in order to 1mmobilize it and make it more manageable. In other areas, key data on existing and potential environmental problems does not exist because soviet authorities feared collecting the data might compromise secret activities.

The CIS countries will be unable to meet the costs of clean up--estimated at'billions of dollars. Russia took the lead in launching an environmental protection plan based on economic incentives in 1991, but lack of revenues as industrial output declines has resulted in a negative balance that is getting worse. Although CIS environmental ministers have agreed to cooperate on some environmental issues--such as joining with the EC on funds to help with costs incurred from Chernobyl'--each country has turned to the west for aid, including technology and expertise, and will continue to do so. But they have yat to prioritize needs, or to resolve such issues as ownarship of land and industrial assets and liability for damages. 
For its part, the CIA is helping US agencies working with the cIS to identify the most pressing problems so that our government leaders can ensure that us assistance is used effectively.

The issues that I've talked about today are all considered "nontraditional" intelligence issues. They do not constitute the bulk of CIA's work, but they are important areas of interest to the President and other leaders in our government. In an era of decilining budqets, it.will be a special challenge for the Intelligence community to enhance its capabilities in some of these newer areas, while continuing to monitor more traditional concerns such as proliferation, terrorism, regional disputes, the former Soviet Union and some aspects of international economic artairs. 


\section{STATEMENT OF ROBERT N. GATES, DIRECTOR OF CENTRAL INTELLIGENCE}

Director Gates. Thank you, Mr. Chairman. I'm here today at the request of Senators Boren and Murkowski and the Senate Select Committee on Intelligence to address two issues: possible environmental threats resulting from past Soviet nuclear activities, and the role of the Intelligence Community in addressing environmental problems.

Let me first briefly discuss the role of the Intelligence Community with regard to environmental problems.

As the Senate and House Intelligence Committees know, on November 15th last year the President signed the most far-reaching directive to assess future intelligence priorities since CIA and the Intelligence Community were created in 1947. The directive required some 20 policy agencies and departments to identify their intelligence needs to the year 2005. Their responses highlighted the increased importance of environmental concerns as an intelligence issue. The National Security Council has integrated all of the expressed priorities into one overall document and the Intelligence Community is using this document as a guide for reallocating its resources.

Policy makers and members of Congress are asking CIA and the Intelligence Community to increase their study of environmental issues because we have special skills, resources and unique insights. For example, at the request of Senator Murkowski, a team of analysts has been working to assess the potential environmental consequences of long-term nuclear testing and waste disposal practices of the former Soviet Union. Earlier this year I was asked by the President's Science Advisor, Dr. Allan Bromley, and Senator Albert Gore to assist the National Aeronautic and Space Administration in its effort to collect and analyze satellite data on the environment. The project, called the Earth Observation System, will help scientists answer some of today's most pressing questions on the environment, such as how do the oceans, forests, deserts and atmosphere interact as an integrated system, and is the earth's climate changing? CIA will provide guidance to NASA concerning the most efficient means for processing the large quantities of data that it is collecting for this project, because we have a great deal of expertise in this area.

At Dr. Bromley's suggestion, the Intelligence Community recently assumed membership on the Committee on Earth and Environmental Research, which has become the primary coordinating body for national environmental problems and programs. Membership on the Committee will provide the Intelligence Community a better understanding of the Committee's activities and requirements and will improve intelligence support to our environmental policy makers.

Senators Gore and Murkowski also have asked whether CIA data could be released to environmental scientist who are studying global change; and I have agreed to form a team of cleared scientists who will examine our data and determine what would be useful to environmental science.

Under the Congressionally-directed Dual Use Technology Initiative, technologies developed under the auspices of the Intelligence 
Community will be transferred to the private sector where appropriate; technology especially useful in answering questions in areas like the environment, law enforcement and medicine. Twelve projects costing $\$ 30$ million have been selected and roughly half of the money is for environmental projects.

Intelligence is also applying its special capabilities to other nontraditional areas, such as the environment and related foreign nuclear safety issues. For several years the CIA has brought a valueadded to the work done on these problems, in our analysis, our unique collection assets, and in our ability to collect and assimilate vast quantities of information.

For example, CIA analysts assessed the scope of the unprecedented environmental damage which occurred when Iraqi forces sabotaged Kuwaiti oil fields last year. Agency specialists used enhanced commercial weather satellite imagery to track daily oil slick movements in the Gulf and they used unique collection systems and commercially available Landsat imagery to verify the number, location and status of the burning oil wells in Kuwait. The data used by the Central Command in the bombing that stopped the flow of the oil into the Gulf was provided by U.S. Intelligence. CIA worked with private experts to develop and build a computer model capable of projecting concentrations of key pollutants, primarily sulfur dioxide and particulates, and their impact on human health and crops.

Since the late 1980's the Intelligence Community has been contributing to U.S. government efforts to work with other countries to protect the global environment from a host of threats:

Ozone depletion, which poses risks of increased skin cancer, blindness, declining agricultural yields, and fisheries losses, will only be stopped by a worldwide effort, as laid out in the Montreal Protocol, to stop using chlorofluorocarbons, CFC's. The Intelligence Community has been following this problem for several years and is starting work on a program to determine whether we can monitor emissions of CFC's.

Tropical deforestation is a phenomenon that jeopardizes the world's climate, causes local problems such as flooding and mud slides, and leads to the extinction of plant and animal species. CIA analysts have done work on these issues, using satellite imagery and other tools to support U.S. policy makers in their multi-year effort to secure an international treaty on forest protection.

Possible climate change, and measures adopted by governments to reduce greenhouse gas emissions in an effort to avert it, have potentially far-reaching consequences. As U.S. negotiators worked at length to forge an international agreement on this important issue that opened for signature two months ago in Rio, CIA analysts provided them, over the course of a three-year period, with a comprehensive series of reports on this multi-faceted problem.

Other similar issues that are the subject of ongoing analytic work include ocean dumping of hazardous substances; water scarcity and degradation; the environmental consequences of narcotics cultivation; the impact of earthquakes and other natural disasters; food shortages, and agricultural resources decline; and the pressures faced by developing and industrialized countries alike as they grapple with the costs of environmental protection. While some of 
these projects have been started within the past several years, many go back a long time. Our work on agriculture, for example, has been going on for decades.

A related subject for intelligence is monitoring the nuclear power programs in countries of concern. This is not a new issue for us. And it brings me to the second and primary part of my presentation: possible environmental threats arising from past Soviet nuclear activities. CIA has kept an eye on the Soviet nuclear power program since the start-up of their first small prototype power reactor in 1954. In the years that followed, we compiled an extensive collection of technical literature on the program and on the reactors themselves. CIA integrates this data with information acquired from our satellites to assess national security, economic, and safety implications of the program.

Since the Chernobyl disaster in 1986, CIA experts have worked closely with other U.S. government agencies to prepare detailed studies of Soviet-designed power reactors. We are now working with these agencies to determine the most effective way to improve the safety of these reactors. At the same time, we continue to collect information on reactor problems such as the recent accident at the Chernobyl-type reactor located near St. Petersburg, in Russia.

CIA has monitored Soviet handling of nuclear waste since 1948, when the reactor that produced the plutonium for the first Soviet nuclear weapon began operation. We now look at environmental contamination due to a variety of nuclear activities, most of which supported nuclear weapons acquisition and production, and questions about the safety of stored but radioactive liquid and solid waste. This includes the reprocessing of fuel from civilian and naval reactors and naval nuclear activities.

The former Soviet Union's attitude toward safety in handling of radioactive waste materials was, to say the least, lackadaisical from the very beginning of its nuclear program. Radioactive wastes resulting from the extraction of plutonium for the USSR's first nuclear weapons at Chelyabinsk-65 were discharged directly into the Techa River, resulting in severe contamination of the watershed for thousands of kilometers downstream. Subsequent practices were hardly better; highly radioactive waste was dumped into Lake Karachay at the plant beginning in 1951. Today, despite ongoing cleanup efforts, 120 million curies of radioactive materials are in the lake, and as little as one hour's exposure to the radiation at the shoreline could be fatal. Radioactive contamination in the groundwater has spread two to three kilometers from the lake. Additionally, an explosion in a waste tank at the site in 1957 contaminated over 23,000 square kilometers, and much of the land remains unusable today.

The situation in Chelyabinsk, although perhaps the most severe, is hardly unique. Similar plants in Tomsk-7 and Krasnoyarsk-26 also contaminated the local environment. Open pools of water at Tomsk reportedly contain elevated levels of plutonium and other radioisotopes, resulting in considerable wildlife contamination, including elk, duck, fish and hare, which are consumed by the local population. Reactors at the Krasnoyarsk plutonium production plant use water directly from the Yenisey River for cooling, and have contaminated the river with cesium, strontium, and other 
radioisotopes for hundreds of kilometers downstream. One of these reactors remains operational today.

Even though these facilities are not in the Arctic, their impact has been observed in the region. All watersheds from these sites flow to the Arctic Ocean, and waste from the polluted Techa River reportedly was discovered in the Arctic as early as 1951. Moreover, the waste handling practices at these sites were all too typical of Soviet attitudes toward nuclear safety and the environment.

The greatest single source of radioactive contamination of the Arctic environment has been from nuclear weapons testing, especially atmospheric testing at the Novaya Zemlya test site in the Arctic from 1955 to 1962 . About half of the USSR's approximately 200 atmospheric tests were conducted at Novaya Zemlya. Virtually all of their highest yield explosions were conducted there, with a total yield of over 300 megatons. Among these was the world's largest nuclear explosion in 1961, approximately 55 megatons, over 3,000 times the yield of the Hiroshima explosion. In addition to sometimes severe local contamination from fallout, Soviet atmospheric testing also was the greatest contributor to radioactive contamination of Alaska and northern Canada.

The severity of the contamination decreased dramatically after the 1963 Limited Test Ban Treaty, especially in Alaska and Canada, but Soviet underground nuclear weapons testing and peaceful nuclear explosions continued. Russian statements indicate over 130 peaceful nuclear explosions for mining, seismic sounding, or creation of underground storage cavities, were conducted throughout the Soviet Union. A few of these explosions were a part of the program to develop the capability to excavate canals using nuclear explosions. These crater-producing explosions produced widespread contamination. In an August 1987 test, for example, the concrete plug placed to contain the explosion was blown out of the tunnel, and radioactive material spewed into the atmosphere. Some of the other explosions may have contaminated the local groundwater and a few may have leaked radioactive materials. Except for tests at Novaya Zemlya, which sometimes spread contamination into the broader Arctic environment, these leaks probably produced only limited local contamination.

Soviet nuclear reactor accidents also have contributed to contamination of the Arctic. Numerous studies have documented the disproportionately heavy fallout in northern Norway, Sweden and Finland from the Chernobyl accident in April 1986. Fifteen of the Chernobyl-type nuclear reactors remain in operation in the former Soviet Union, and together with other types of old, unsafe Sovietdesigned reactors, comprise over half of the power reactors now operating in the Commonwealth of Independent States and Eastern Europe. In the Arctic, four small reactors using similar technology to the Chernobyl reactors are at the remote settlement of Bilibino in the Russian Far East, and a power plant on the Kola peninsula has four aging pressurized water reactors. The demise of the USSR and its East European client governments has left all of the reactors largely bereft of material support and regulatory guidance. The situation is made worse by the region's severe economic problems, which are undermining efforts to maintain and improve safe operations. 
In addition to power reactors, hundreds of reactors are aboard CIS submarines and naval vessels, the majority of which are based in or near Arctic waters. A September 1985 explosion during refueling of a Soviet nuclear submarine near Vladivostok illustrates the potential for serious accidents in these reactors. The explosion scattered radioactive material on shore and into the bay, which reportedly was only haphazardly and incompletely cleaned up. In addition, comments by former Soviet navy personnel and two wellpublicized sinkings of Soviet submarines since 1986 illustrate the danger fire and accidents pose to CIS submarine reactors. The large number and advancing age of these reactors will increase safety risks, particularly as the CIS begins to dismantle many of the vessels.

Deliberate dumping of radioactive waste materials into Arctic waters or improper land-based storage is another source of radiological pollution. The USSR dumped substantial quantities of radioactive waste in Arctic waters, including the three damaged original nuclear reactors of the icebreaker Lenin, and reportedly reactors from several submarines, including some with nuclear fuel aboard. Radioactive wastes, mostly from naval reactors, also are buried on Arctic shores. Only Soviet records, if any, or detailed scientific surveys can determine the amount, type and potential hazards from the material which has been dumped. I expect we will learn more about these and other concerns in light of new scientific cooperation, such as the joint Russian-Norwegian expedition to survey nuclear waste disposal sites in the Kara Sea planned for this month, and information-sharing made possible by the collapse of Communism.

The newly free republics of the former Soviet Union and Eastern Europe face enormous environmental challenges. The deteriorating industrial infrastructure presents a high risk of disasters. The chemical and energy sectors, where much of the equipment is old and in need of replacement, appear to face the highest risk, but serious breakdowns could occur in railroads, civil aviation, and nuclear power plants. In some cases, accidents have already occurred. For example, an oil well in Uzbekistan drilled with inadequate equipment ruptured in March, contaminating farmland and threatening to pollute a vital river. Only through intensive round-theclock efforts, aided by U.S. experts who are in turn supported by U.S. intelligence information, were workers able to cap the well and protect the river.

Environmental destruction caused by Soviet troops in Eastern Europe is adding substantially to the already heavy cleanup burdens new governments face as the result of four decades of environmental neglect by the region's former communist rulers. The destruction being revealed by the pullout of Soviet forces clearly will take many years and billions of dollars to repair. Corroded petroleum, oil and lubricants pipelines and storage tanks, as well as poor fuel-handling practices make contamination of soil and groundwater the most ubiquitous pollution problem at former Soviet facilities. Lax safety standards combined with poor storage and accounting practices at ammunition depots have led to soil and water contamination with a variety of heavy metals, acids and other toxic-and often explosive-materials. Solvents, paints, coat- 
ings, and plating materials have been poorly stored and carelessly dumped. Troop maneuvers involving heavy tracked vehicles and live firing exercises have destroyed terrain, worsened erosion and water pollution, and contaminated the soil with lead and other substances. Unexploded ordnance presents a safety hazard in and around training areas. East European governments are assessing the dimensions of the pollution problem they have inherited from the Soviet military, but it probably will be many years before these areas can be cleaned up and returned to productive use.

Another region struggling with the residue of Soviet actions is Central Asia's Aral Sea basin. Over the past 30 years, Soviet efforts to expand Central Asian cotton production, which required diverting large quantities of the water from rivers that feed the Aral, has reduced the sea by over 40 percent of its volume and 60 percent of its surface area. The leaking and dumping of pesticides into water supplies, the absence of a water pricing policy, and fierce competition for water, particularly among the Uzbeks and Turkmen, have significantly worsened Central Asia's critical water situation. Existing economic, political and ethnic tensions in the region are being further strained by Aral refugees moving to cities in search of guaranteed medical care, secure employment, a stable source of drinking water, and essential food stuffs. Central Asian leaders faced with serious economic and political difficulties have discussed cooperation on environmental issues but have yet to formulate, much less implement, a concrete plan to halt the Aral's desiccation. Even under the best possible circumstances, with effective regional cooperation and massive foreign assistance, it would take at least five to 10 years of consistent effort before any progress in halting the Aral's destruction can be realized. Without such cooperation, the Aral basin is likely to become an environmental dead zone.

Although the CIS is faced with a daunting legacy of environmental problems, it is making progress in some areas. For example, for several years they have been converting highly radioactive civilian and military waste to glass in order to immobilize it and make it more manageable. In other areas, key data on existing and potential environmental problems does not exist because Soviet authorities feared collecting the data might compromise secret activities.

The CIS countries will be unable to meet the costs of cleanup, estimated at billions of dollars. Russia took the lead in launching an environmental protection plan based on economic incentives in 1991 , but the lack of revenues as industrial output declines has resulted in a negative balance that is getting worse. Although CIS environmental ministers have agreed to cooperate on some environmental issues, such as joining with the European community on funds to help with costs incurred from Chernobyl, each country has turned to the West for aid, including technology and expertise, and will continue to do so. But they have yet to prioritize needs, or to resolve such issues as ownership of land and industrial assets and liability for damages.

For its part, CIA and the Intelligence Community are helping U.S. agencies working with the CIS to identify the most pressing 
problems so that our government leaders can ensure that U.S. assistance is used effectively.

The issues that I've talked about today are all considered nontraditional intelligence issues. They don't constitute the bulk of our work, as Senator Murkowski indicated, but they are important areas of interest to the President, the Congress, and others in our government. In an era of declining budgets, it will be a special challenge for us in the Intelligence Community to enhance our capabilities in some of these newer areas while continuing to monitor more traditional concerns such as proliferation, terrorism, regional disputes, the former Soviet Union, and aspects of international economic affairs.

Thank you, Mr. Chairman.

Senator MURKOWSKI. Thank you very much, Mr. Gates.

I think you've certainly laid out the situation as it exists, and certainly highlighted the exposure. I wonder if you can provide us with any explanation relative to the prevailing lackadaisical attitude that has been evidenced in the Soviet's disposal of high level nuclear waste, recognizing that they have a knowledge of their exposure if nuclear wastes are improperly disposed of. Can you enlighten us at all on why there was not more consideration given to the proper disposal of this waste?

Director GATES. Well, it's hard to say, but I would speculate that the primary reason, particularly during the period of the worst pollution, in the 1940's and 1950's, had to do with the urgency of the tasks of producing nuclear weapons and the single-mindedness with which that was undertaken by the Soviet government at the time, without regard for the costs, either financial or environmental or the impact on human life, in terms of exposure of individuals to radioactive contamination and so forth. Over the years, there was some gradual improvement in Soviet handling of radioactive wastes, but it was throughout decidedly inferior to the handling of that waste elsewhere in the world. For example, the Soviets moved from dumping radioactive waste, high levels of radioactive waste, into rivers; they moved from that to dumping them in lakes, and then into storage containers; and now this new measure that I described of turning it into glass to immobilize it. So there have been some improvements over the years, but fundamentally these measures have been decidedly inferior to those in the West and have clearly been inadequate.

Senator MURKOWSKI. I wonder if you have any information relative to the health effects on the residents of the areas. It's a vast area. I gather there is not much documentation. But I can recall a meeting I had in Washington with a gentleman by the name of Nikolai Vorontsov who was the former environmental minister of the Soviet Union. He made some starting revelations about the health effects on residents, but much of that information has not been able to be substantiated because of lack of any centralized documentation.

Director GATES. We don't have any independent assessment of the impact on the population. There have been some studies, we understand, done by Soviet authorities in the past, but it's our belief that these studies are probably deeply flawed because of the unreliability of the data gathering and the way in which the stud- 
ies were carried out and also a political agenda associated with the studies. I think that the kind of studies that are needed of this sort may now become possible with the collapse of Communism and with greater levels of interest on the part of the new Russian authorities.

Senator MURKowSKI. Cooperation obviously between Russia and the United States on the environment depends on stability of government, and there's always a continued concern about President Yeltsin's, I won't say state of health, but the state of the political situation over there. The economic situation in Russia is obviously a factor in that stability. I wonder if you could give us any assessment on the current status of that stability. Might we look forward with pretty good odds to a continuation of the current government, or is there still a relatively high level of risk that the bad guys in the wings are ready to come out and reinstitute the regime that we had previously seen prevalent in Russia?

Director GATES. Well, I think that there's no possibility of a restoration of the previous regime or of Communism. As you suggest, Russia, in particular, is undergoing severe economic hardship. It clearly has political implications. President Yeltsin has a fine line to walk between going forward with political and economic reform and at the same time trying to provide or to assure that people are fed and that people continue to have jobs. So far he remains clearly the most popular and, I would say, the most skilled politician in Russia. His poll numbers have been declining over the months as these economic hardships have increased and as the measures, the economic reform measures, have begun to bite. But I think it's reasonable to say that we see no imminent threat to his continuation in office, and I think he still has tremendous public support. I think reform continues to have substantial support. But there are undoubtedly going to be some zigzags in this course as these people try to do something that's virtually unprecedented in history, and that is try to change their political and economic systems from a 1,000 year legacy of autocracy, Communism and state-directed economic activity to a Western-style democracy, and market economy. It's never been done before, certainly not on this scale, so I think it would be unfair to Mr. Yeltsin to underestimate the challenge that faces him. I think he's done a pretty remarkable job so far.

Senator MURKOWSKI. I'm wondering, in our relationship with the Russians relative to monitoring activities associated with the environment, is it on the basis of a quid pro quo where they want something from us in order for you to get a cooperative effort on a joint evaluation of a particular environmental priority? In other words, if we are going to go in and evaluate sites of nuclear activity, do they want some of our information as well, or are they pretty much in a cooperative mode where they understand that they need our help.

Director GATES. We have. not had any exchanges with the Russians, among the intelligence services, on information relating to nuclear waste or the kinds of environmental problems that I discussed in my statement. There is, in our government, a federal coordinating council on science, engineering and technology, and there is a subgroup of that that deals with environmental issues, and it is in that forum that discussions with the Russians would 
go forward I think, in terms of exchanges of data on the kinds of issues we'd been discussing, that would be more under the auspices of other agencies of the government than the Intelligence Community.

Senator MURKOWSKI. You mentioned in your statement the thought of clearing scientists for classified information. I wonder if you can elaborate a little further, because I know it would be of interest to many who are going to testify today, relative to their participation with the Central Intelligence Agency. What specifically might you have in mind that you can tell us?

Director GATES. The basic purpose in the endeavor that is underway now is to ascertain whether in the now 30-some-year-old archive of satellite-collected information, particularly imagery satellites, there is information in that data bank, stretching back over that period of time, that would allow environmental scientists to document change in the global environment. And the first step in what we're trying to do, and there's a coordinating committee made up of Congressional staff, the Intelligence Community, and the scientific community, is to identify scientists in some 10 different disciplines who would receive security clearances and be given access to this data in order that they might ascertain whether or not there is value in it for the scientific community. And if they conclude that there is, then the next step will be for us to figure out how we might be able to make that data available for exploitation. We also probably will draw on their help and offer our help, particularly in this NASA project, with respect to the information-handling architecture for the vast quantities of data that are going to be collected by the earth observation system. We probably have more experience than anyone in the world in terms of processing and integrating this kind and quantity of data, and I think we can perhaps have something to offer in that arena as well. So the purpose of it is simply, in effect, to allow the formation of a search party to explore this data and see if there's something there that can be of value.

Senator MURKowSKI. Senator Boren and I collaborated on this question and we thought it appropriate to have it in the record, and as you know, our Intelligence Community voted on the 1993 Intelligence budget, which the Senate will debate when we return in September. And there's going to be some who want to take some deep cuts, as much as an additional two billion. I'm curious to know for the record if this amendment is adopted, how it will affect the ability of the Intelligence Community to continue its emerging role in global environmental issues.

Director GATES. Well, there are probably some things that we can do to be helpful that represent little additional cost to us. But I think that there is an interest, both in the Administration and in the Congress, in having us expand this effort and undertake some more ambitious activities. While the environment is an important issue from a national standpoint and a very high priority from a national standpoint, in the prioritization of intelligence issues given to us by the President and the government, and the Congress I might add, clearly it is not as important as a number of other issues that are the more traditional province of our activities. So clearly, deep cuts, while they might not stop the kind of 
activity that I've just described that we're prepared to go, to undertake, they would clearly circumscribe our devoting other additional assets to it.

Senator MURKOWSKI. I want to take this opportunity to thank you for inviting Dr. Wilford Weeks of the Geophysical Institute here at the University of Alaska to be a member of your panel of scientists, and I think this confirms our belief that Alaskan scientists have achieved a level of experience in Arctic science that is recognized throughout the world. I want to thank you very much, Mr. Gates, for being with us today. I also want to recognize your Congressional affairs liaison who is with us, Stan Moskowitz, another Irishman. I don't know where Stan is but he's out there somewhere. And I know you got up very, very early this morning to fly up to Fairbanks and be with us, and we're going to have one more panel and break for lunch. We'll have additional questions and you can expect questions as well from other members of the committee when I get back and brief them, and I want to again thank you. I think that your testimony has provided a level of credibility with regard to information that has been gathered by our Intelligence Community on what has happened in the former Soviet Union. And it's now a question of our government and our scientists to address, in cooperation with the Russian scientific community, a procedure for evaluation monitoring and then an action oriented program to initiate what should be done. And I think it's important to keep in mind that what we're attempting to do is to make decisions based on sound science rather than emotion, because as highlighted by $\mathrm{Mr}$. Bohlen and $\mathrm{Mr}$. Gates, one could move to some rather dramatic conclusions with this information on its surface as opposed to the facts that we need to generate. And that's something that occasionally in Washington we lack. Oftentimes, an individual who makes the most compelling speech, who advances the most emotional argument, or who has the best lobby often prevails. On the other hand, I think it's fair to say that sometimes there's a reluctance in the scientific community to step forward and lay their reputation on the line with recommendations. But I think we are appealing for that, we need that, and the presentation by the panel this morning, I think, sets the tenor for the balance of the witnesses relative to the obligation we have before us. And without the facts and the information, we will not be able to generate action. So I want to thank you, gentlemen. You may be excused.

I would call the Honorable Donald O'Dowd, Chairman of the Arctic Research Commission. With Dr. O'Dowd no stranger to these premises, please proceed, Dr. O'Dowd.

[The prepared statement of Dr. O'Dowd follows:] 
Testimony for the Hearing Before the

U.S. Senate Select Committee on Intelligence

August 15, 1992, Fairbanks, AK

Dr. Donald D. O'Dowd, Chairperson

Arctic Research Commission

THE CHALLENGE AND THE OPPORTUNITY

The United States is an Arctic nation, yet most American people do not think of Arctic Alaska as a part of the United States in the same way that they think of the distinctive geographical regions of other states.

People, however, live in the U.S. Arctic -- and have lived there longer than anywhere else on the continent. Moreover, the economic dependence of the United States on Arctic mineral and living resources is increasing. Twenty-six percent of U.S. domestic oil production is currently extracted from the Alaskan North Slope,

representing $11 \%$ of the total national petroleum usage. The Bering Sea offers one of the richest fisheries in the world; nearly $28 \%$ of the total U.S. commercial catch and $10 \%$ of the world's supply of fishery products are obtained there. A zinc/lead mine that has the potential of becoming the world's largest began operations in northwest Alaska in 1990. U.S. coal reserves north of the Arctic Circle may exceed the total reserves of the entire lower $\mathbf{4 8}$ states. Deposits of strategic minerals in the U.S. Arctic are abundant, but their extraction is not yet economical.

In the new Russian Republic over half of the land area is arctic and subarctic and much of this landscape is underlain by various forms of frozen ground. Economic development of the Russian North has been their government's objective for many years, and huge quantities of oil, gas, minerals and timber have been extracted from the north. The current extraordinary political changes occurring in Russia have made two facts clear to the West. First the long-term economic and 
military activities especially in northern Russia have generated very large amounts of environmental pollution -- both industrial wastes and radioactive materials -- with apparently unprecedented negative effects on people and ecosystems. Second, the continuing decline of military confrontation and concurrent rise of democratic governance provide new opportunities for collaboration, particularly in science, on issues of common concern. One of the more urgent issues demanding attention is the potential movement of Russian pollutants to other countries as well as their impacts on common resources in the world oceans.

The Arctic has a vulnerable environment that is extremely sensitive to perturbations. The delicate balance between its physical, chemical and ecological components, governed by the very low rate of biogenesis and chemical turnover, makes the Arctic an "early warning system" for global change, where the signatures of climate change are expected to occur first.

The Arctic is an active component of the global geosphere-biosphere system. Atmosphere-ocean coupling in the Arctic is an important feedback mechanism in the thermodynamic machine that controls the climate of our planet and atmospheric processes in the Arctic play a crucial role in shaping the weather and climate of the entire northern hemisphere. The Arctic Ocean is an essential component of the circulation of the world's oceans and a regulator of the global climate. A dominant world water mass, the bottom water in the Atlantic, is formed mainly from Arctic ocean water; thermohaline circulation involving sea ice determines the temperature, oxygen, carbon and nutrient content of this deep reservoir. Highty localized physical, chemical and biological processes in the Arctic Ocean's upper layers play a crucial role in the removal of carbon dioxide and other biogenic and man-made materials from the atmosphere.

In addition, the Arctic is a natural storage reservoir for atmospheric and water pollution. Industrial aerosols from lower latitudes in eastern Europe and the Soviet 
Union appear in the form of "arctic haze" over large regions of the Arctic. The Arctic Ocean receives as much as $10 \%$ of all of the world's riverine discharge in spite of representing only $1.2 \%$ of the total ocean water mass. Since this ocean has limited outflows into the other world oceans, it is much more vulnerable to industrial, urban and agricultural pollutants discharged into rivers flowing into it than any other ocean.

\section{POTENTIAL FOR INTERNATIONAL RESEARCH COLLABORATION ON ARCTIC ENVIRONMENTAL POLLUTION}

International cooperation is an integral component of many scientific endeavors in the Arctic, linked to, and often inseparable from, the normal process of research planning and execution. The Commission, charged with advising the President and Congress on arctic research policy and priorities, promotes those international aspects of science that are beneficial to United States arctic research.

Scientific cooperation among the circumpolar nations, as well as among other countries with scientific activities in northern latitudes, is accelerating. The U.S. and Russia have had since 1972 a bilateral agreement in the field of environmental protection which was renewed this year. Cooperative activity in the Arctic, however, has been limited. Quite generally, the increasing number of international bilateral and multilateral agreements for arctic research in recent years signals the rising importance and breadth of both governmental and nongovernmental international collaboration in the Arctic.

In August 1990, the International Arctic Science Committee (LASC), which the Arctic Research Commission has advocated since 1986, was formally constituted as a non-governmental body to facilitate collaboration in arctic science. In June 1991, a ministerial meeting among the eight arctic nations, initiated by Finland, was held to complete intergovernmental accords for protection of the arctic environment. Included was a concept for an Arctic Monitoring and Assessment Program (AMAP) 
I first visited the former Soviet Union in 1987 when I served as President of the University of Alaska to explore cooperative opportunities in science. In July 1992 and as Chairman of the U. S. Arctic Research Commission, I met with the Arctic Research Commission, Russian Academy of Sciences and traveled to parts of the Russian Arctic. These experiences, I believe, are relevant to your discussions as there have been many changes in Russian science over the past five years.

My primary observations are:

1) In 1987, leaders of Russian science that I met in Moscow and Siberia expressed a desire to establish greater contacts with western scientists, particularly in the U.S. and especially to learn U.S. scientific methodologies and to gain access to U.S. technologies such as computers. The means of doing so was bilateral agreements premised on the host country pays all in-country expenses of the visiting scientist.

2) In 1990 I traveled to the Soviet Union to sign a series of agreements including a plan to establish a joint international science center in Magadan supported by the Far East Branch of the Soviet Acaderny of Sciences and the University of Alaska.

I note that 14 bilateral agreements between the University of Alaska and various research institutes across Russia have been been signed (see list). The degree of activity in each is primarily a function of U.S. funding because in today's economic realities Russia cannot pay costs of U.S. scientists in Russia. Although openness had engendered even more willingness to propose joint research projects in 1990, access to many areas of the Russian Arctic remained under tight control.

3) In July 1992, the Arctic Research Commission went to Northeastern Russia, met with various officials and scientists and visited a number of sites of scientific and 
technical interest. Our objectives were to: i) acquire information about the operation of the Commission's Russian counterparts, the Arctic Scientific Council of the Russian Academy of Sciences, ii) develop more extensive contacts with the Russian Academy of Sciences and the regional academies and their institutions of mutual interest and potential cooperation, and iii) observe relevant field conditions that affect scientific research in the Russian Northeast.

In summary, we learned that:

a. Organization of science in the Russian Academy of Sciences as well as the government ministries is undergoing redirection and new appointments. The trend is toward more regional and local representation of people and issues, more applied emphasis, and more effort to coordinate among institutes and between central and local units.

b) Priorities in Russian northern science appear remarkably similar to U.S. arctic priorities. Perhaps this is not surprising considering decades of exchanges and international conferences in the scientific community. To elaborate the areas of priority research and current international cooperation, Table 2 lists eight scientific areas and cooperating U.S. organizations for the Far Eastern Branch of the Russian Academy of Sciences.

c) To illustrate the capacity of the Russian science enterprise, Figure 1 presents the 30 research institutes of the Far East and assigned staff $(7,935)$ in 1988.

Although numerous observers have noted that Russian research institutes have large numbers of technicians and are greatty overstaffed; none-the-less, the numbers of technical personnel engaged in arctic science is impressive.

Because of a favorable dollar to ruble exchange rate and because salaries of Russian scientists are notoriously low, science done in Russia is a great buy if it addresses relevant problems and meets western standards. 
d) In May 1991, the Presidium of the Russian Academy of Sciences established an Arctic Center in Moscow to help set science priorities and help coordinate research. Also established in Magadan was the International Center "ARKTIKA" with U.S. and Russian Co-Directors. ARKTIKA will facilitate joint research by providing logistic arrangements within the Russian Far East. It demonstrated this capability for our recent trip by arranging meeting space, meals, hotels and transportation by bus, fixed wing plane and helicopter. We traveled about 2700 miles in the Russian Arctic.

e) The issue of the scientific quality of past Russian data and the currency of some areas of Russian science continues to be of concern among western scientists. On the first point, my recent observations are that Russian scientists are vigorously exercising their independence of political control. They are eager to establish the independence, integrity and rigor of their work. On the issue of quality control, we can help ourselves and Russian science by insisting that scientific proposals as well as resulting scientific articles for publication be rigorously reviewed by objective international expert peers.

\section{$\underline{\text { In Conclusion }}$}

There is no doubt based on my observations and experience that Russian scientists very much want to collaborate in research even on sensitive issues such as radioactive dumping and environmental damage. They have capabilities and experiences to contribute, but almost no funds to support cooperative efforts. It is in U.S. interests to collaborate for at least two fundamental reasons: 1) we need to know if the Arctic is threatened by pollutants before toxicants reach our shores, and 2) assisting Russian science is a sound contribution to a stable Russia and to world peace. In my opinion it is also morally and scientifically the right thing to do. It is also desirable to collaborate on a multi-national level among circumpolar nations. 


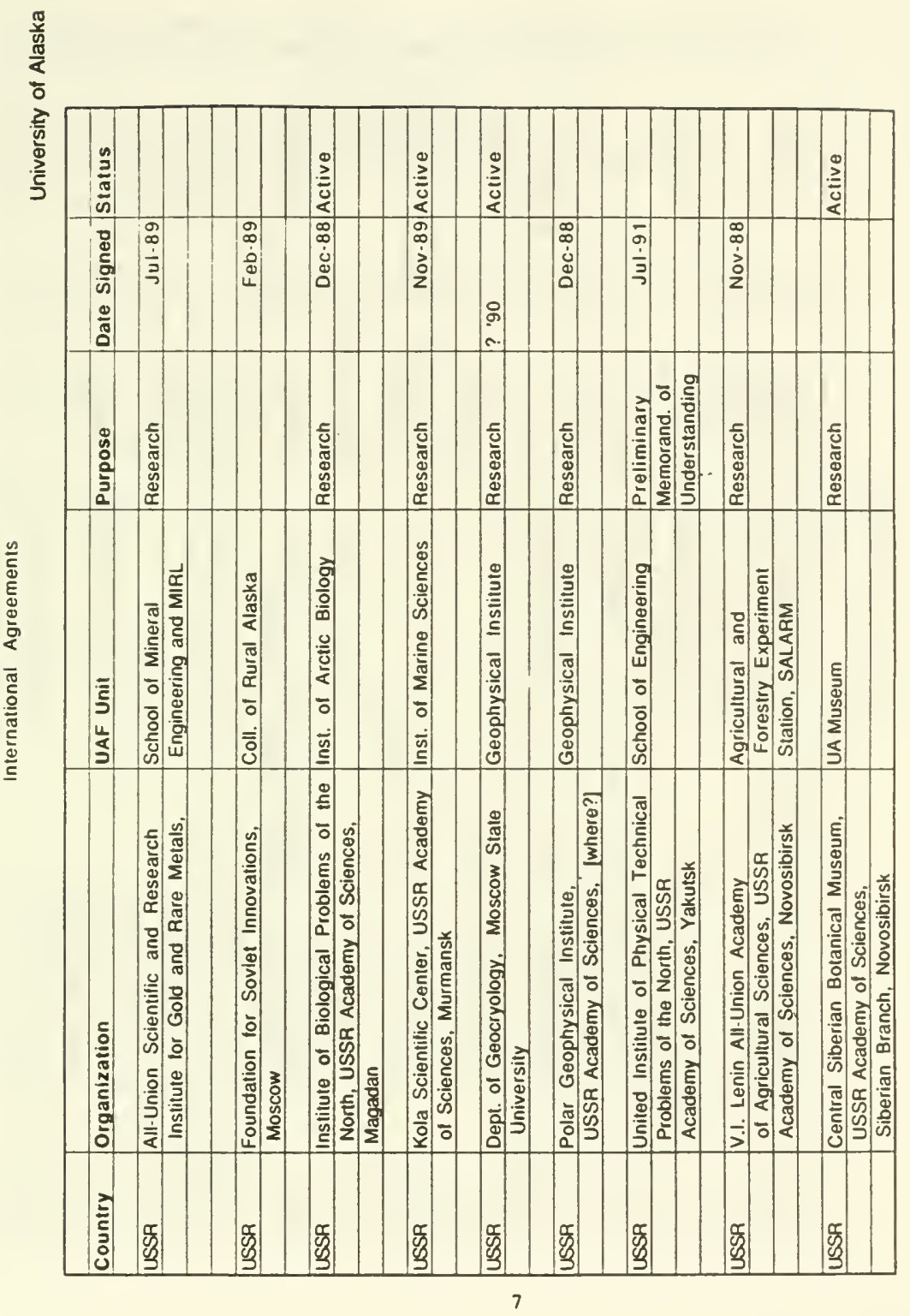




\section{6}

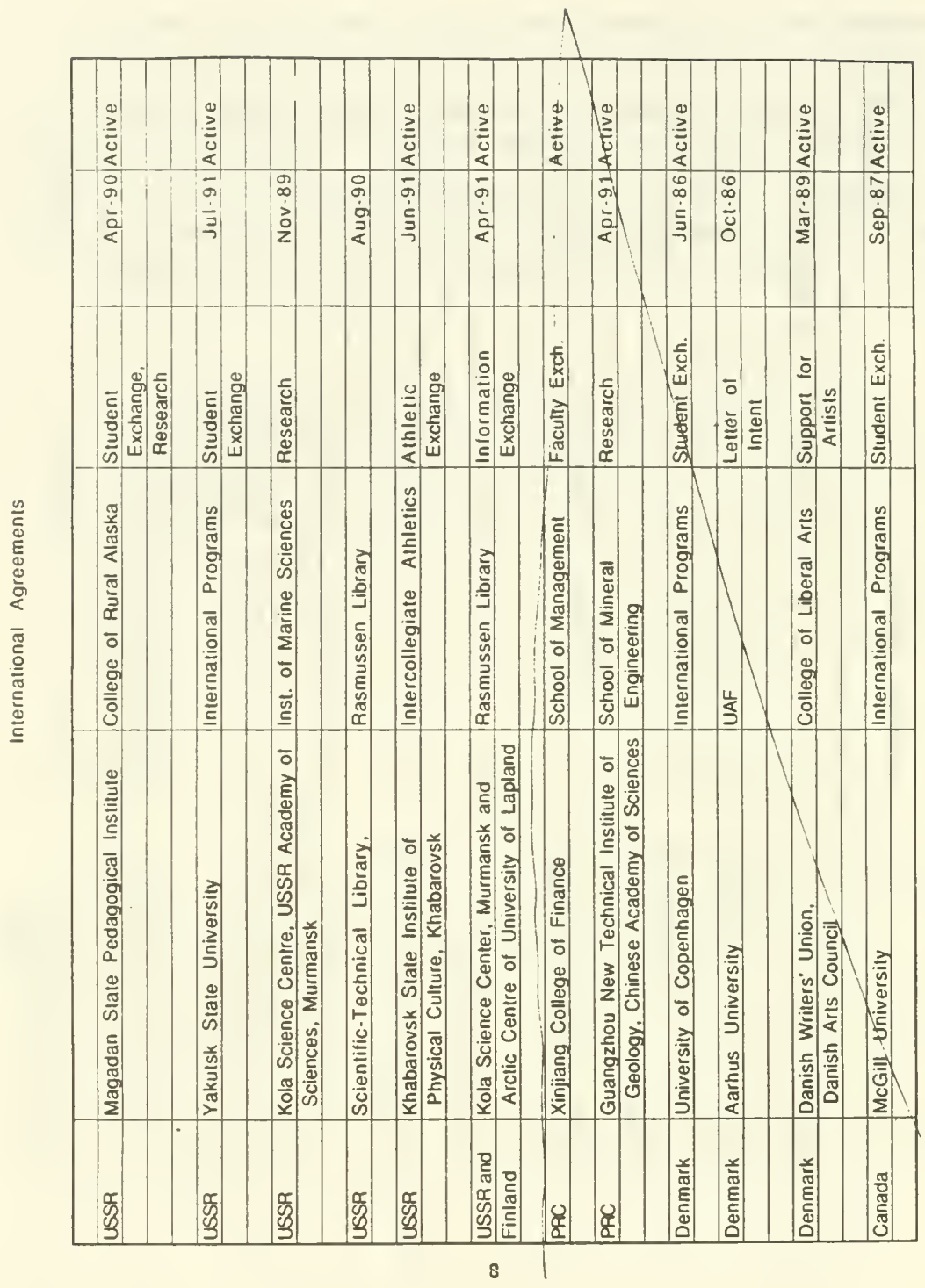


Organization of the Far Eastern Branch of the Academy of Sciences, USSR*

National Academy
of Sciences

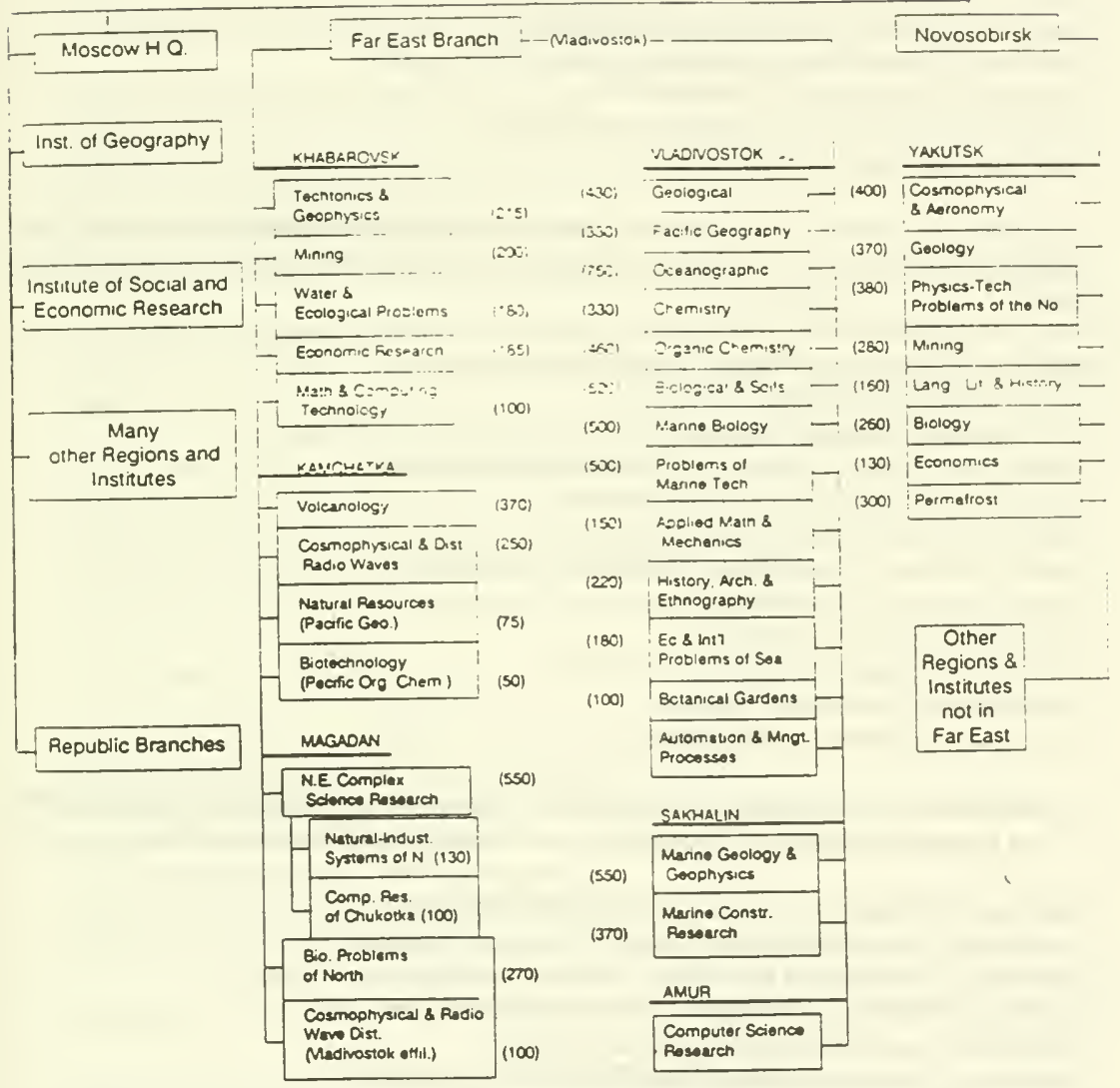

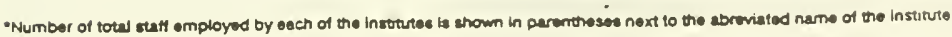


PRIORITY DIRECTIONS OF JOINT RESEARCH CONDUCTED BY THE INSTITUTIONS OF FEB RAS AND UNIVERSITIES, INSTITUTES AND LABORATORIES OF THE UNITED STATES

1. Oceanographic research in the Arctic seas of the Russian Far East and the northern area of the Pacific Ocean to determine climatic global changes, seasonal, synoptic and minor variants of weather.

Pacific Oceanologic Institute (Vladivostok)

Institute of Marine Technologies (Vladivostok)

Institute of Automatics and Remote Control (Vladivostok)

University of Washington (Seattle)

Scripps Institution of Oceanography (San Diego)

University of California (San Diego)

2. Studies of biochemical ecosystems to determine the evolution of the flora, fauna and mainland habitats in the northeastern Russian Arctic and Arctic seas in the Russian Far East.

Institute of Biological Problems of the North (Magadan)

Research Center "Chukotka" (Anadyr)

Institute of Ecology and Resource Use (Petropavlovsk Kamchatskii)

Institute of Water and Ecological Problems (Vladivostok)

Institute of Biology and Soils (Vladivostok)

Institute of Marine Biology (Vladivostok)

Pacific Institute of Bioorganic Chemistry (Vladivostok)

Pacific Institute of Geography (Vladivostok)

University of Alaska (Anchorage)

University of Alaska (Fairbanks)

University of Washington (Seattle)

University of California (San Diego)

3. Research on the anthropogenic contaminative impact on land, ocean and the atmosphere in the Russian northeastern Arctic and the Arctic seas in the Russian Far East

Institute of Biological Problems of the North (Magadan)

Northeastern Interdisciplinary Research Institute (Magadan)

Institute of Ecology and Resources Use (Petropavlovsk Kamchatskii)

Institute of Water and Ecological Problems (Khabarovsk)

Institute of Applied Mathematics (Vladivostok)

Institute of Automatics and Remote Control (Vladivostok)

Institute of Biology and Soils (Vladivostok)

Institute of Marine Biology (Vladivostok) 
Pacific Institute of Bioorganic Chemistry (Vladivostok)

Chemistry Institute (Vladivostok)

Pacific Oceanologic Institute (Vladivostok)

Far Eastern Geological Institute (Vladivostok)

University of Alaska (Anchorage)

Lniversity of Alaska (Fairbanks)

University of Washington (Seattle)

University of California (San Diego)

4. The ecology of humans living in Arctic environments

Institute of Biological Problems of the North (Magadan)

International Scientific Research Center "Arktika" (Magadan)

Pacific Institute of Geography (Vladivostok)

University of Alaska (Anchorage)

University of Washington (Seattle)

University of Hawaii (Honolulu)

5. Research on the flora and fauna on the mainland and in the Arctic seas of the Russian Far East to obtain physiologically active substances (for solving the problems of human ecology)

Pacific Institute of Bioorganic Chemistry (Vladivostok)

Institute of Biological Problems of the North (Magadan)

Pacific Institute of Geography (Vladivostok)

International Scientific Research Center "Arktika" (Magadan)

Research Center "Chukotka" (Anadyr)

6. Developing new technology for Arctic concitions

Institute of Problems of Marine Technologies (Vladivostok)

Institute of Automatics and Remote Control (Vladivostok)

Institute of Chemistry (Vladivostok)

Pacific Institute of Bioorganic Chemistry (Vladivostok)

Pacific Oceanologic Institute (Vladivostok)

Institute of Volcanology (Petropavlovsk Kamchatskii)

North-Eastern Interdisciplinary Research Institute (Magadan)

7. Studies on the relations of environment, human and economic potentiality in the Arctic

North-Eastern Interdisciplinary Research Institute (Magadan)

Institute of Biological Problems of the North (Magadan)

Pacific Institute of Geography (Vladivostok) 


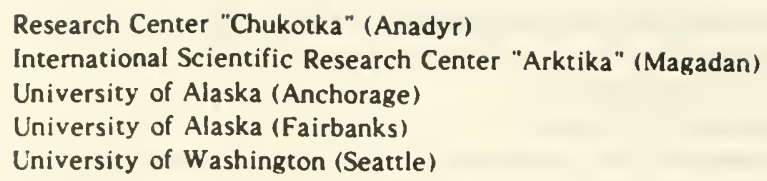

8. Research on the heritage. living conditions, and development trends of Native populations in the Russian Far East

Institute of Biological Problims of the North (Magadan)

Research Center "Chukotka Anadyr)

Institute of Ecology and Nature Resource Use (Petropavlovsk Kamchatskii)

Institute of Water and Ecological Problems (Khabarovsk)

Institute of Biology and Soils (Vladivostok)

Institute of Marine Biology (Vladivostok)

Pacific Institute of Bioorganic Chemistry (Vladivostok)

Pacific Institute of Geography (Vladivostok)

University of Alaska (Anchorage)

University of Alaska (Fairbanks)

University of Washington (Seattle)

University of California (San Diego) 


\section{STATEMENT OF DR. DONALD O'DOWD, CHAIRMAN, ARCTIC RESEARCH COMMISSION}

Dr. O'DowD. Mr. Chairman, thank you for inviting the U.S. Arctic Research Commission to comment on radioactive and other environmental threats emanating in Russia and threats to the wellbeing of the U.S. Arctic, its peoples, their culture, its economy and ecosystem.

Let me say a word about the Arctic Research Commission. It was created by the Arctic Research and Policy Act of 1984, consists of seven members appointed by the President, and it is charged to formulate Arctic science and engineering research policy for federal agencies that do and fund Arctic research. It also recommends and monitors coordination of federal Arctic science and serves as an advocate for and promotes Arctic science.

Mr. Chairman, relevant to this hearing, as you mentioned earlier, the Arctic Research Commission visited Magadan in early July to meet with Russian counterparts. At that meeting we met with representatives of the Arctic Research Commission of the Russian Academy of Sciences and also with the Commission on Arctic and Antarctic Affairs of the Russian federation. These are referred to as the Committee from the Academy and the State Committee concerned with Arctic affairs. Also present were representatives of the Far East branch of the Russian Academy of Sciences and representatives from numerous institutes from the Far East branch.

The objectives of this trip were to determine how the Russian commissions operate, what are their jurisdictions, how our two systems are alike and different, what we might do in cooperation with the Russian Academy, who are the players, not only by name but to have an opportunity to meet the people, and finally, exploration of the field conditions for research in the Russian Far East. We did this at the invitation of the Russian Academy, which goes back about two years.

During the meetings we raised the issue of radioactive, heavy metal, chemical and related pollution on the Russian north. We inquired about its extent, severity, danger and how it's spread by air, ocean and land transport. The acknowledgement that we received was that the problem is severe, it was pretty apparent that he people with whom we are talking did not know how severe, and probably no one knows. My guess is that although in this country we have a reasonably good idea of our pollution problems, we continue to learn more about them as our abilities to measure these things grow better-in Russia I suspect no one has anything but the vaguest idea of how great the problem might be. During the course of our meeting, someone raised the question about six million deaths that might be attributable to radiation exposure over the nuclear era in Russia. This is a number that had been used by a Russian minister visiting in Washington some time ago. I thought the response might be a response of, "that's three orders of magnitude too great." The response was, "well, that seems a little high." And in talking with people informally, two or three million did not seem to be a shocking number to the scientists that we talked to. It's a shocking number to us, but in that context it was not. 
A few observations. Visual inspection of the Russian Arctic coast reveals endless debris; barrels in great piles, mining equipment abandoned on the beaches, old vehicles, bulldozers; just an incredible array of materials abandoned, the contents of which probably no one knows nor has looked at for a long time. In speaking with Russians who work along the Arctic coast, they say this is a condition that is endemic in the Russian Arctic, just great piles of unidentified but probably undesirable materials along the beaches and along the immediate shoreline.

In visiting with Russian medical personnel, I was talking recently with some people who are circuit riders. They visit villages to carry out medical services in relatively small communities on a periodic basis. Their comment was that particularly in sections of the Arctic north, in the villages, there are many instances of people with illnesses that stem from radiation exposure. Particularly these individuals were reporting on the diamond mining region where nuclear explosions were used apparently to fracture strata down one kilometer, to a kilometer and a half below the ground, and the local people evidently become exposed to high levels of radiation in the course of their work or in working in the immediate area.

All this is compounded by the extreme secrecy which has characterized the handling of such information in the past. The medical personnel report, for example, that they never discussed what they observed in the way of radiation impact with any other people, because this was information, the dissemination of which could land you in prison. And so the medical people said they did not even talk of these findings with other doctors. However, they are in their records. They were required to keep careful records of what they observed and the types of treatment and problems that they were dealing with, and if those records could be secured, translated, analyzed, we probably could learn a great deal about problems that are of relevance to the Arctic.

I was interested that one of the Russian officials during our meeting when we talked about pollution said that until last year such information as the impact of auto emissions on air quality in cities was instantly classified as secret information, not available to anyone. I read recently of another facet of this issue. A Russian scientist commenting on the Russian nuclear energy program, pointed out that all accidents and mishaps were secret so that if operators in one plant made an error of some sort, the operators in other plants could not be informed of it because of the classified nature of the information, and so they were in danger of making the same mistake over and over again. This strictly classified information could not be shared even within the nuclear industry itself.

A few recommendations. The central government agencies are eager to be principal players in any joint efforts to evaluate, monitor, mitigate or clean up pollution in the Arctic. In the course of our discussion, the Ministry of Ecology and Natural Resources in Moscow was identified as a key Russian agency that should be central to any activity that would occur. It was interesting to us that in response to that suggestion the representatives of the regional branches of the Academy of Sciences said in a very nice way, they don't think we should work with those people, because they never get anything done. And in any case, the probably would take 
your money and disappear. If you would work with us they said, we would be able to make a lot more progress. They noted: we have the data, we have the expertise, we have the motivation because the problems are in our regions and affecting our people. From what I observed, the branches of the Academy and the institutes have acquired a degree of autonomy that was unthinkable even three or four years ago. Interestingly enough, some of this discussion between central representatives and the branches occurred while a local television station was recording the activities. The regional units are not at all shy about expressing their autonomy and their willingness to work separately from central government, if that can be arranged. I would urge that this be considered.

I should note also that he Academy of Sciences, the Academy of Medical Sciences, and the Academy of Agriculture are different agencies, and they tend not to communicate very much with one another, and all of them have capabilities that are relevant to our concerns with the impact of pollution in the Russian Arctic. I believe it would be desirable to work with at least these three agencies in seeking information and initiating changes that we might desire.

Also, there is a sharp division between military science and civilian science in Russia. Recently Dr. Roederer has written on his experiences in Russia, and he makes this distinction. There is very little communication between these two bodies of scientists in Russia, and working with one does not engage the other. As we approach the Russian Scientific establishment, we need to be alert to its different units and regions and dimensions and take advantage of the unique capabilities of each rather than dealing only with the central government agency.

In conclusion, pollution of the Russian Arctic by radioactive materials, heavy metals, industrial wastes, et cetera, appears to be a large and perhaps a catastrophic problem. It threatens the people, culture, the economy and the ecosystem of the U.S. Arctic along with the entire Arctic. It has consequences ultimately for the vast population in the mid latitudes, and in time we hope that they will be aware of the fact that in this regard we are very much connected.

Working with Russian scientists, we must ascertain the scope of the problem, measure it, monitor it, develop control regimes and in time help clean up and correct the disaster that has already happened.

Also, by working with a broad spectrum of Russian scientists we can support their faltering science community, and I think it's been widely agreed within the American science community that it's very desirable to do so. We can mitigate a major problem that is already in place and we can do so at very limited cost, given the current Russian economic conditions, if we deploy our resources wisely.

So a need and an opportunity coincide to which the U.S. should respond in its own interest at this time. Thank you.

Senator MURKOWSKI. Thank you very much, Dr. O'Dowd.

Our next panelist is Dr. Ned Ostenso, Assistant Administrator for Oceanic and Atmospheric Research, National Oceanic and At- 
mospheric Research Administration, otherwise known as NOAA. Please proceed, Dr. Ostenso.

[The prepared statement of Dr. Ostenso follows:] 


\section{STATEMENT}

OF

NED $A$. OBTENSO

ABSIBTANT ADMINIETRATOR

OFFICE OF OCEANIC AND ATMOSPHERIC REBEARCH

NATIONAL OCENNIC AND ATMOBPHERIC ADMINIBTRATION

O.8. DEPARTMENT OF COMMERCE

$$
\text { BEFORE THE }
$$

\section{BELECT COMMITTEE ON INTELLIOENCE ONITED GTATEB BENATE}

\section{FAIRBANKB, ATASRA}

AUOUST 25, 1992

Mr. Chairman and Members of the Committee:

Your invitation to testify at this open hearing raises a concern that the reported contamination of the Arctic by the Former soviet Union by radionuclides and other toxic substances could pose a serious risk to the Arctic environment and 1ts ecosystoms. We in the National oceanic and Atmospheric Adminlstration (NOAA) share this concern.

\section{INTRODUCTION}

In recent months I have been represented at and kept informed of alscussions of this matter by the staff of Interagency Arotic Research Pollcy committee (IARPC). These discusslons have addressed the potentlal contamination by the Former soviet Union of the Arctic by radionuclides and other toxic substances such as persistent organic compounds and heavy metals. It is evident, however, that the major concern has been focused on radionucl 1de contamination. For instance, it has been reported by the media 
that the amount of anthropoganic radioactivity in the former Soviet Union 18 greater than a billion curles. Some of these roports claim that ouch contamination levels are resulting in shorter 11 fo-spans for many of the Former Soviet Union cltizens. Reports also note that the duration of human 11 fo in several parts of the Former Soviet Union doas not exceed 30 years.

\section{Although the claims of these contamination lavels and theits spatlal extent need to be verifled, as well as the contamination} measurement methodology and other laboratory technlques used, the numbers that have been reported for radioactivity and other contaminant levels provida cause for concern from the standpoint of ecological and human hoalth. Furthermore, such concern ia trans-boundary in nature because such contaminants do not respect political or national boundarles. Howevar, in putting such concerne into perspective, it is important not to overreact and waste resourcer; it 1s imperative that an assessment of the problom be pursued in a phased manner that is interdisciplinary in nature and coordinated with the other Arctlc-rim countries. such an accesament chould include the definition of:

- Existing pertinent information;

- Sources of Former Soviet Union radlonuclides and othe: toxins directly introduced to the Russian Arctic or transported to the Arctic via ocean, river, and atmoepherlc transport and through preclpitation: 
* Fates of radionuclides in the Russian Arctic, determined through modelling and observational measurements in the water column, sediments and biota:

* Effects of the contaminants as determined at the organism, community, ecosystem and Iishery, and human levels:

* Definition of policy implications;

* Recommendations for action, remedial measures, and other studies:

* Logistical requirements;

- Equipment requirements; and

* Resource requirements

NOAA 18 working with the Interagency Arctic Research Policy Committee (IARPC) to assess the degree of this potential problem and to take approprlate action with other IARPC agencles. As you have mentioned, NOAA also has other ongolng programs that are pertinent to this topic.

\section{REIATED NOAA PROCKAYS}

NOAA is a national focal point for information related to understanding our environment. Because of the Arctic's unique role in the balance of the earth and its vast resources, NOAA puts a high level of Importance on developing a better understanding of the Arctic. Consequently, all of NOAA's 1 ine organizations are very involved in Arctic research. A few of the key activities that NOAA is involved in that would have a bearing on the potential contamination of the Arctic aro: 
Tissue Archival project (AMMTAP), sponsored by the Minerale Management Service (MMS) of the Department of the Interior, is now belng managed by NOAA's National Marine Mammal Tissue Bank and stranding Archive Network Program. Based on an agreement with MMS, tissues will continue to be collected and w11l subsequently be stored at the Department of Commerce's National Instltute of standards and Technology (NIST), where all samples are banked. Samples from as many as 20 bowhead whales taken during the 1992 subsistence hunts at Barrow, Alaska, will be collected as part of the AMMTAP. The sampling will be conducted with the help of the North slope Borough Department of Wlldilfe Management. With the aseistance of the NMFs's Weatern Alaska Field office in Anchorage, samples might also be collected this year from beluga whales (as many as 5 animals) taken In native subsistence hunts or from strandings in cook Inlet. In the caee of both the bowheads and the belugas, additlonal samples will be collected for contaminant analysis by the MMFs Northwest Fisheries center.

NOAA'B National status and Trends (NSGT) Program for Marine Environmental Quality includes projects that periodically monitor the levele of about 70 different toxic contaminants, both heavy metals and persistent organic contaminants, at sites around the coasts of the United states. Nine of these sites are along the 
U.8. Arctio cosst $(6$ in the Bering Sea, I in the chukchl sea, and 2 in the Beaufort sea). Contaminant levels are measured in both biota and sediments from 3 stations at each site.

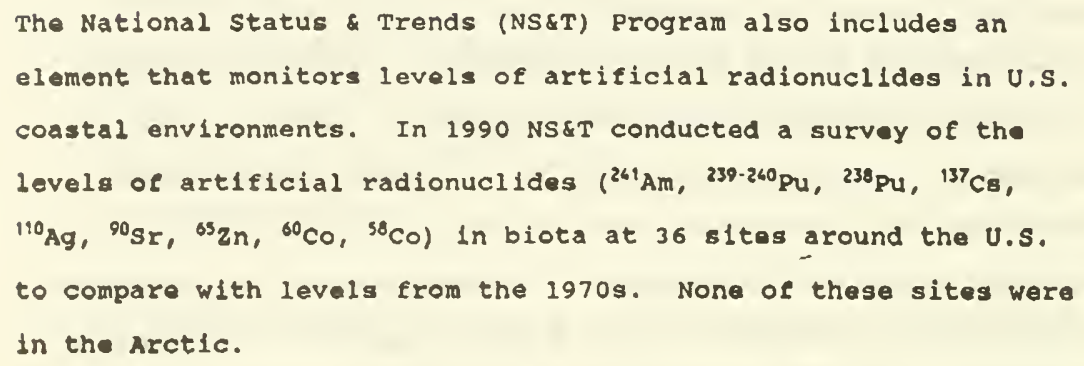

\section{OTHEB CONSTDERATIONS}

NOAA has also been involved with the Department of state on the deliberatione that led to the Arctic Environmental proteotion strategY (AEPS), and with the assoclated Arctic Monitoring and Agsessment Program (AMAP) where NOAA is CO-Chair with the Environmental Protection Agency for the United States' Involvement. I belleve that an appropriate assessment by the United states of the contamination of the Arctic by the Former Soviet Union is quite litting with the United states' responeibilities under AKAP and the associated AEPS. 


\section{CONCLUDING_REMARKS}

To conclude my brief remarks to the comnlttee, speaking for NOAA I support the approach of an appropriate coordinated interagency assessment of the potential contamination of the Arctic by the Former Soviet Union, and I am anxious to work with you in this regard. NOAA is well positioned, both scientifically and programmatically, to contribute significantly to such an assessment. I do believe that NOAA can best fulfill its responsibliities in this respect, however, by continuing to work with the Interagency Arctic Research policy comittee in their deliberations to define an appropriate strategy to respond to the reported contamination of the Aretic by radionuclides and other toxic substances.

Mr. Chairman, this completes my prepared atatement. I will be glad to answer any guestions. 
STATEMENT OF DR. NED A. OSTENSO, ASSISTANT ADMINISTRATOR, OFFICE OF OCEANIC AND ATMOSPHERIC RESEARCH, NATIONAL OCEANIC AND ATMOSPHERIC ADMINISTRATION, U.S. DEPARTMENT OF COMMERCE

Dr. Ostenso. Thank you, Mr. Chairman. Your invitation to testify at this open hearing raises a concern that the reported contamination of the Arctic by the former Soviet Union by radionuclides and other toxic substances could pose a serious risk to the Arctic environment and its ecosystems.

In recent months I have been represented and kept informed of discussions on this matter by the staff of Interagency Arctic Research Policy Committee, or IARPC, for which I am the Department of Commerce representative. These discussions have been addressing the potential contamination by the FSU of the Arctic by radionuclides and other toxic substances. It is evident, however, that the major concern has focused on the radionuclide problem. Although the claims of these contamination levels and their spatial extent have not verified nor has measurement technologies and other laboratory techniques used, the numbers that have been reported for radioactivity and other contaminant levels provide cause for concern from the standpoint of ecological and human health. Furthermore, such concern is transboundary in nature because such contaminants do not respect political and national boundaries. However, in putting such concerns into perspective, it is important not to overreact and to waste resources. It is imperative that an assessment of the problem be pursued in a phased manner that is interdisciplinary in nature and coordinated with other Arctic ring countries. Such an assessment should include a definition of the existing pertinent information; sources of former Soviet Union radionuclides and other toxins directly introduced into the Russian Arctic or transported to the Arctic via rivers, air transport, through precipitation; fates of radionuclides in the Russian Arctic, determined through modeling and observational measurements in the water column, sediments and biota. We must know the effects of the contaminants as determined at the organism, community, ecosystem and fishery, and human levels. We must have a definition of policy implications. We must develop recommendations for action, remedial measures and other studies. We must contemplate logistic requirements, equipment requirements, and finally resource requirements.

NOAA is working with IARPC to assess the degree of this potential problem and to take appropriate action with other agencies. As you have alluded to, NOAA has a number of programs in the Arctic, and I will list just a few of the ones that are salient.

We have a marine mammal tissue archive, a national status and trends program, a climate monitoring and diagnostic laboratory station at Barrow. We operate two polar satellites. We conduct Arctic Ocean circulation studies. We do Arctic air transport studies. Our geophysical fluid dynamics laboratory modeling efforts are relevant to the Arctic. We with the Navy run a Joint Ice Center. And finally, we run the National and International Environmental Data Centers.

All of these programs have some scientific bearing on assessing the potential of environmental risk due to contamination of the 
Arctic. I will provide some detail on the first two programs because they were specifically mentioned in your letter of invitation.

The marine mammal tissue archive is part of the National Marine Mammal Tissue Bank and Stranding Network Program managed by NOAA's National Marine Fisheries Service. It is designed to conduct on a regular basis the collection and storage of selected marine mammal tissue based on available funds, the national goal is to conduct a standard suite of analysis on 10 to 20 marine mammals in each region from which tissue is taken. The normal suite of analysis will include organics, inorganics, toxins, necropsy, and histopathology. The Alaska Marine Mammal Tissue Archival Project sponsored by our sister agency, the Minerals Management Agency of the Department of the Interior, is now also being managed by NOAA's National Marine Mammal Tissue Bank on a cooperative basis. Based on this agreement, tissues will continue to be collected and will be stored together at a national repository at our Institute of Standards and Technology. Samples from as many as 10 bowhead whales taken during 1992 subsistence hunts at Barrow, Alaska will be collected as part of this program. The sampling will be conducted with the help of the North Slope Borough Department of Wildlife Management. With the help of NMFS's Western Alaska field offices in Anchorage, samples might also be collected this year from beluga whales, as many as five animals, taken in native subsistence hunts or from standings in Cook Inlet. In the case of both the bowheads and the belugas, additional samples will be collected for contaminant analysis by our Northwest Fisheries Center.

NOAA's National Standards and Trends Program for Marine Environmental Quality includes projects that periodically monitor the level of about 70 different toxic contaminants, both heavy metals and persistent organic contaminants, at sites around the coasts of the United States. Nine of these sites are located along the U.S. Arctic coast, six in the Bering Sea, one in the Chukchi Sea, and two in the Beaufort Sea. Contaminant levels are measured in both biota and the sediments and from three stations at each site.

The National Status and Trends Program also includes an element that monitors levels of artificial radioactivities, radionuclides in the U.S. coastal environments. In 1990 we conducted surveys of the levels of americonium, plutonium, cesium, silver, strontium, zinc and cobalt in biota at about 36 sites around the U.S. to compare with levels from 1970. Unfortunately, none of these sites were in the Arctic environment.

NOAA has also been involved with the Department of State on deliberations that led to the Arctic Environmental Protection Strategy, which Secretary Bohlen referred to, and with its associated Arctic Monitoring and Assessment Program, AMAP, where NOAA is co-chair with the Environmental Protection Agency for the United States' involvement. I believe that an assessment by the United States of the contamination of the Arctic by the FSU is quite fitting with the United States' responsibilities under AMAP and associated AEPS.

To conclude my brief remarks to the Committee, and speaking for NOAA, I support the approach of a coordinated interagency assessment of the potential contamination of the Arctic by the former 
Soviet Union, and I'm anxious to work with you in this regard. I do believe that NOAA can best fulfill its responsibility in this respect by continuing to work with the Interagency Arctic Research Policy Committee in their deliberations to define an appropriate strategy to respond to the reported contamination of the Arctic by radionuclides and other toxic substances.

Mr. Chairman, this completes my prepared statement. I'll be glad to answer any questions in the future.

Senator MURKowsKI. Thank you very much, Dr. Ostenso.

We're going to hold the questions until the last statement has been made.

Let me introduce Admiral Richard Guimond, Deputy Assistant Administrator for Solid Waste and Emergency Response, Environmental Protection Agency, and Assistant Surgeon General of the U.S. Public Health Service. I believe your uniform is one of an Admiral in the Public Health Service, is that correct?

Admiral GUIMOND. That's correct.

Senator MURKOWSKI. So you certainly wear many, many hats. Please proceed, Admiral.

Admiral GUIMOND. Thank you very much, Mr. Chairman. In the interest of time, I'll summarize my remarks and perhaps you can include my entire statement for the record.

Senator MURKOWSKI. It will be entered into the record as if read. [The prepared statement of Admiral Guimond follows:] 


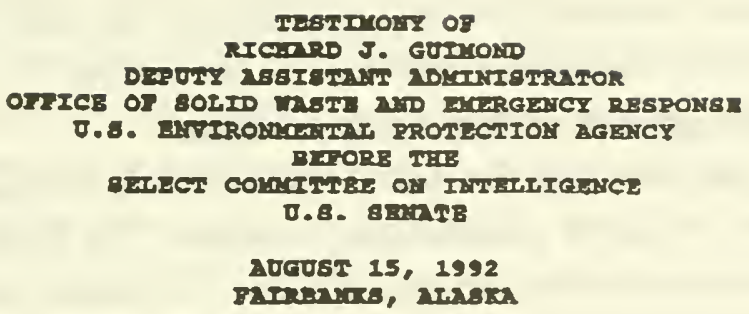

\section{Introduction}

Good morning, Mr. Chaiman and distinguished members of the Committee. I am Rear Admiral Rlchard J. Guimond, Deputy Assistant Administrator of EPA's Office of Solid Waste and Emergency Response. I an an Assistant Surgeon General in the United states Public Eealth service. I am also the former Director of ER's office of Radation Programs. ConsequentIy, I am familiar with both radiation and hazardous substance issues. Thank you for the opportunity to discuss EPA's efforte to address the radioactive and other threats to the drctic resulting from past soviet activities. In your lettor of invitation, you requested that I address the potential environmental and human health impacte on both Alaske and the Arctic of the past nuclear and the ongoing industrial activities of the former soviet onfon. You also requested that I pay particular attention to the effecto of radiomelides, heavy metals, peraistent organic pollutants and air pollution on this fraglle enviroment. I am pleased to be able to addrese these iscues today.

My testimony this morning will focus on three issues: what EPA know about pollution in the Arctic, what we have done in the 
past on marine radioactivity pollution issues, and what the Agency thirks is necessary to be done in the future.

Curcent EPA knowledge of Afctic contamination

While EPA considers the issue of radioactive contamination of the Arctic to be of considerable importance, BPA does not currently have extensive information about the extent and type of radioactive contamination found in the Arctic. In addition, EPA does not have extensive information about other types of contamination that may be damaging to the Arctic Because of the lack of comprehensive data, it is diffeult to say with much precision the extent of the risk to human health and the environment caused by such contamination. I would like to take this opportunity to describe to you the relevant types of information that BPA does have at this point.

EPA has been involved in monitoring studies at formar ocean disposal sites in the Atlantic and Pacific. Yonitoring surveys were conducted from surface vessels, as well as manned and unmaned submersibles. He also evaluated monitoring data from a former international dump site administered by the Nuclear Fnergy Agency/Organization for Economle Cooperation and Development.

This facility accepted nuclear and other wastes from several European countries.

EPA has undertaken several initiatives, often in cooperation with NOAA, in studying past radioactive waste disposal activities. One important task was to locate and identify waste containment packages on the sea lloor. In addition, EPA 
participated in making detailed measurements of the concentrations of both naturally-occurring and man-made radionuclides in the disposal areas, examining and evaluating the performance of the waste packaging in the marine environment, and evaluating the state of the environment to determine if there was a threat to human health through various marine transport pathways.

The studies found that the transport and uptake of radionuclides in the lood chain was dependent on the radiolsotope. Some radioisotopes are not as easily available for bloaccumulation/bioconcentration by plants and animais in the food chain. For exauple, many radionuclides (such as plutonimin) adsorb to the coean sediment. Such radiolsotopes are much less available to marine organicms, except for those bentbic (bottomdwelling) organisme that ingest this sediment. In contrast, strontium-90 is highly mobile, and would therefore be more available to pelagic (non botton dwelling) organisms such as plankton and salmon.

Even for those radionuclides that are more easily taken up by organtam in the rood chain, hovever, the dilution factor in the ocean can reduce the risk of uptake. This would make low concentrations of soluble radionnclides, such as strontium-90, less of a threat to the food chain.

Another item to consider when evaluating the potential threat to human health and the environment is the half life of the radioisotopes found there. Kany isotopes released into the 
marine environment have very short half-lives of anywhere from a few minutes to a few years. These isotopes, when released into the ocean, will both disperse and radiodecay rather rapidly. Some of the radionuclides that may have been released in the Arctic could be fairly long-lived: for example, plutonium-238 has a half-life of approximately 86 years, plutonium-239 has a half-life of 24,400 years, and plutonium-240 has a half-life of 6,850 years. Strontium-90 and cesium-137 have hall-1ives of 28 and 30 years respectively.

Examination of the environmental impact resulting from the 1986 Chernobyl accident illustrates the effect of such radiodecay. In 1989, EPA entered into a cooperative agreement ${ }^{1}$ with the Institute of Biology of the Southern Seas (IBSS) in Sevastopol, oxraine, to study the transport, partitioning, and efrects of Chernobyl's principal fallout radionuclides on the Black See. In June 1990, at the invitation of IBSS, a jolnt monitoring survey was conducted in the northern Black sea aboard the oceanographic survey ship protessor vodyanitsky. The radionuclides tracked by this effort were cesium-134, cesium-137, rutherium-106, cerium-144, and strontium-90. During the years since Chernobyl, all of the radionuclide concentrations have been decreasing through dilation and radiodecay until only the longlived cesium-137 is at concentrations that are still eas1ly measurable. 
In addition to these considerations in evaluating the extent caused by radioactive contamination in the Arctic, any analysis of the potential impact of such radiation on human populations such as the Inuit would require consideration of the dose of radiation likely to be received by both an "average" and a "maximum exposed individual." In all likelihood, the Inuit could represent the "maximum exposed individual." In addition, the population of individuals Itkely to be affected, by living near the coast or consuming Arctic marine seafood, is an important consideration in evaluating the risk posed by the contamination.

As you can see, while IAPA does have some data about behavior of radionuclides released into the marine environment, we know little about the speciflc contamination in the Arctic. However, we do know the kinds of information that need to be collected to assess the risks from Arctic pollution. Wrach more information needs to be gathered in order to fully geuge the risk posed to human beings and the enviroment by the activities of the former Soviet Union.

cyreent and propord BPA activities relatinc to Arctic contamination

EPA is conducting several additional activities designed to further our understanding of Mrctic contamination. EPA does not have sufficient data about the concentrations of radionclides arising from various activities of the former Soviet Unton. Potential sources include disposed reactor vessels and waste drums, aerial transport of resuspended radlonuclides, and 
radioactivity antering from Russian rivers that empty into the Arctic.

More data needs to be gathered to determine the concentrations and characteristics of the radionuclides present in the Arctic. In addition, the behavior of the various isotopes in Arctic waters and sediments needs to be evaluated to include such parameters as sediment erosion velocities, water/sediment partitioning coefficients $\left(K_{d}\right)$, benthic bioturbation, prevalling currents and ocean circulation patterns in, for example, the Barents and Rara seas.

Also of particular importance are potential biological transfer pathways to man -- including any "short circuit" mechanisms similar to the 11chan-to-caribou transfar of radionuclides on land.

A concurted and rystomatic monitoring program, coupled with appropriate transport models, could provide many of the answers regarding the impact from the inventory of radionuclides in the Arctic enviroment. Russian marino soientists are currently coordinating with Norwegian marine scientiste to conduct a survey; using a Rnsetan oceanographic vessel, of the Barenta and Kara seas in August/September 1992. IPA is currently trying to place a scientlst on board this vessel, or at a minimum, to obtain sediment samples for radiochemical and geochemical analysis at EPA laboratorles. This effort could provide information to help determine the levels of radloactivity that may have resulted from disposal of reactor vessels from the 
icebreaker Lnin, radioactive waste drum disposals, and from radioactivity released to these seas from pollution in northwardflowing Russian rivers.

As noted above, EPA is already working cooperatively with the former Soviet Union's Ministry of Ecology on a research initiative. The objective of this particular study is to continue examining the movement and partitioning of radionuclides resulting from the Chernobyl accident as they are carried from the Danube and Dnepr river grtem into the Northern Black Sea. The focus of the research is on the distribution and concentration of radionuclides in water, sediment and biota. The study is being condacted in cooperation with the Institute of Blology of the southern seas (IBSs), Sevastopol, ofraine. A second joint survey is currantly underway in the Black sea.

On MaY 13, 1992, EPd regresentatives met with the pxecutive secretary of the U.S.-Raesia Blletaral Agreament, Rumian Ministry of Ecology, to discuse future cooperative studies and the etatur of rork ander the study described above. The participants in these discussions agreed that XPA could expand its cooperative studies pertaining to the protection of marine ecosystens with appropriate Russian partnors. It is expected that any of these activities would be performod within existing resources. Areas for mitual cooperation could include:

Establisbmant of a joint "intercalibration" program for measurement of enviromental samples from sites in Rusele contaminated by disposal of nuclear wete and by accldental release of redioactive materials. 
- Otilization of a Geographic Information System for site characterization.

- Evaluation of models for predictive assessment and forecasting of effects from transport of radioactive contaminants and other pollutants.

- Demonstration, testing and evaluation of remedial technologies pertaining to the clean-up of sites contaminated with radioactivity.

- Initiation of bioeffects studies focusing on environmental impacts from radioactive contamination.

EPA currently participates in a program conducted by the National Oceanic and Atmospheric Administration-(NOAA), the primary objective of which is to determine the status and longterm trends of toxic contaminants in bottom-feeding fish, shellfish, and sodiments at coastal and estuarine locations throughout the United states. The program, entitled the National status and Trends Program, has two components, Benthic surveillance and sussel watch.

The National status and Irends Program primarily addresses synthetic chlorinated compounds, polychlorinated biphenyls (PCBs), polynuclear aromatic hydrocarbons (PAHs), and toxic trace elements. In 1986, the office of Radiation Programs of EPA initiated an informal working agraement with NOAA to antablish monitoring station and obtain samples for radlonuclide analysis. Samples were collected from the former ocean disposal sites in the Atlantic and Paciflc. The results for radionuclide analybes of sediment and biota samples were within the expected fallout ranges from past auclear weapons testing. However, no further 
monitoring for radionuclides has occurred since 1988. This program could be extended to include Alaskan sampling stations. With respect to air contamination, EPA has an Environmental Radiation Ambient Monitoring System (ERAMS), which was used to track the movement of Chernobyl aerial particulate radioactivity and can also be used to detect any significant atmospheric particulate radioactivity arising from Arctic contamination. We currently have ERAKS stations operating in Juneau and Anchorage, and are in the process of establishing a station-at Fairbanks. conclusion

EPA is concerned about these releases in the Russian Arctic ocean as it has been about releases that may have occurred in J.S. coastal waters in the past and from the Chernobyl accident. Although it is clear that this environmental situation is the responsibility of the Russians to rectify, EPA intends to support future cooperative studies to better understand this issue.

Inis completes my prepared testimony, and I will be happy to respond to any questions from members of the committee. 
STATEMENT OF ADM. RICHARD GUIMOND, DEPUTY ASSISTANT ADMINISTRATOR, OFFICE OF SOLID WASTE AND EMERGENCY RESPONSE, U.S. ENVIRONMENTAL PROTECTION AGENCY

Admiral Guimond. I appreciate the opportunity to discuss EPA's efforts to address radioactive and other threats to the Arctic resulting from past Soviet activities. In your letter of invitation, you requested that I address the potential environmental and human health aspects of both Alaska and the Arctic of the past nuclear and the ongoing industrial activities of the former Soviet Union. I am pleased to be able to address these issues today.

My testimony this morning will focus on three issues: What EPA knows about pollution in the Arctic, what we have done in the past on marine radioactivity pollution issues, and what EPA thinks is necessary to be done in the future.

I'll begin with current knowledge about Arctic contamination. While EPA considers the issue of radioactive contamination of the Arctic to be of considerable importance, at present we do not have extensive information about the extent and type of radioactive contamination found in the Arctic. In addition, we do not have extensive information about other types of contamination that may be damaging to the Arctic. Because of the lack of such comprehensive data, it is difficult to say with much precision the extent of risk to human health and the environment caused by such contamination. However, I would like to describe the relevant types of information that we currently have.

EPA has been involved in monitoring studies at former ocean disposal sites in the Atlantic and the Pacific. Monitoring surveys were conducted from surface vessels as well as from manned and unmanned submersibles. We have also evaluated monitoring data from a former European international dump site. This particular facility accepted nuclear and other wastes from several European countries.

EPA has undertaken several initiatives, often in cooperation with NOAA, in studying past radioactive waste disposal activities. One important task was to locate and identify waste contaminant packages on the sea floor. In addition, EPA has participated in making detailed measurements of the concentrations of both naturally-occurring and manmade radionuclides in the disposal areas, examining and evaluating performance of the waste packaging in the marine environment, and evaluating the state of the environment to determine if there was a threat to human health through various marine transport pathways.

The studies found that the transport and uptake of radioactive contaminants in the food chain was dependent on the specific radionuclides. Some radionuclides are not as easily available for bioaccumulation or bioconcentration by plants and animals in the food chain. For example, many radionuclides such as plutonium adsorb to the ocean sediment. Such radionuclides are much less available to marine organisms, except for those benthic organisms that ingest this sediment. In contrast, strontium-90 is highly mobile, and would therefore be more available to organisms that do not dwell on the bottom, such as plankton and salmon. 
Even for those radionuclides that are more easily taken up by organisms in the food chain, however, the dilution factor in the ocean can substantially reduce the risk of uptake. In some cases, this could reduce the impact of the food chain of such soluble radionuclides like strontium.

Another item to consider when evaluating the potential threat to human health and the environment is the half life of the radionuclides involved. Many radionuclides released into the marine environment have very short half lives, of anywhere from a few minutes to a few years. These radionuclides, when released into the ocean, will both disperse and decay rather rapidly. On the other hand, some of the radionuclides that may have been released in the Arctic could be fairly long-lived. For example, strontium-90 and cesium-137 have half-lives of 28 and 30 years respectively. And many other radionuclides have even longer half-lives, some of them getting into thousands and thousands of years.

Examination of the environmental impact resulting from the 1986 Chernobyl accident illustrates the effect of such radiodecay. In 1889, EPA entered into a cooperative agreement with the Institute of Biology of the Southern Seas in the Ukraine, to study the transport, partitioning, and effects of Chernobyl's principal fallout radionuclides on the Black Sea. In June 1990, a joint monitoring survey was conducted in the northern Black Sea. The radionuclides tracked by this effort were cesium-134, cesium-137, ruthenium-106, cerium-144, and strontium-90. During the six years since Chernobyl, all of the radionuclide concentrations have been decreasing through dilution or radiodecay until only long-lived cesium-137 is at concentrations that are still easily measurable in the Black Sea.

In addition to these considerations in evaluating the extent caused by radioactive contamination in the Arctic, an analysis of potential impact of such radiation on human populations such as the Inuit would require consideration of the dose of radiation likely to be received by both an average and a maximally exposed individual. The maximally-exposed individuals are those that you might expect to have particularly high exposure because of their proximity to the sources and their dietary preferences. In addition, the population of individuals likely to be affected, by living near the coast or consuming Arctic marine seafood, is an important consideration in evaluating the risk posed by the contamination. In all likelihood, the Inuit might very well represent the maximum exposed individuals.

As you can see, while EPA does have some data about the behavior of radionuclides released generally into the marine environment, we know little about the specific contamination in the Arctic. However, we do know the kinds of information that need to be collected in order to assess the risks from Arctic pollution. Much more information needs to be gathered in order to fully gauge the risk posed to human beings and the environment by the activities of the former Soviet Union.

Potential sources of radiation from the former Soviet Union include disposed reactor vessels, waste drums, aerial transport of radionuclides, and radioactivity entering from Russian rivers that 
empty into the Arctic, as we've heard from a number of the other witnesses.

More data needs to be gathered to determine the concentrations and characteristics of the radionuclides present in the Arctic. In addition, the behavior of various radionuclides in Arctic waters and sediments needs to be evaluated to include such parameters as sediment erosion velocities, water/sediment partitioning coefficients, benthic bioturbation, prevailing currents and ocean circulation patters, for example, in the Barents and Kara Seas.

Also of particular importance are potential biological transfer pathways to man, including any short circuit mechanisms similar to the lichen-to-caribou transfer of radionuclides on land.

A concerted and systematic monitoring program, coupled with appropriate transport models, could provide many of the answers regarding the impact from the inventory of radionuclides in the Arctic environment. Russian marine scientists are currently coordinating with Norwegian marine scientists to conduct a survey of the Barents and Kara Seas, using a Russian oceanograph vessel. EPA is currently trying to obtain sediment samples from this mission for radiochemical and geochemical analysis at our laboratories. This effort could provide information to help determine the levels of radioactivity that may have resulted from disposal of reactor vessels from the icebreaker Linin, or from radioactive waste disposal drums, or from radioactivity released to the seas from pollution of the northward-flowing Russian rivers.

We are currently undertaking a second joint survey of the Black Sea to expand our knowledge of the distribution and concentration of radionuclides in the marine environment. On May 13th of this year, EPA representatives met with the Executive Secretary of the U.S.-Russia Bilateral Agreement and Russian Ministry of Ecology to discuss further and future cooperative studies and the status of work already under way. The participants in the discussions agreed that EPA could expand its cooperative studies pertaining to the protection of marine ecosystems with its appropriate Russian partners. It is expected that a number of activities could be undertaken within the existing resources. Some of those that are currently being considered include establishment of a joint intercalibration program; utilization of geographic information systems for site characterization; evaluation of models for predictive assessment and forecasting; demonstration, testing and evaluation of remedial technologies for cleanup; and initiation of bioeffect studies focusing on environmental impacts from radioactive contamination.

EPA currently participates in an additional program conducted by NOAA, which its primary objective is to determine the longterm trends of toxic contaminations and bottom feeding fish, shellfish, and sediments. In 1986 EPA initiated an informal working agreement with NOAA to establish monitoring stations and obtain samples for radionuclide analysis. Samples have been collected from the former ocean disposal sites in the Atlantic and Pacific. Results for radionuclide analysis of sediment and biota samples that were obtained from this found that they were within the range of expected fallout from past nuclear weapons testing. No other fur- 
ther monitoring was done. This program could be expanded and extended in the future to include Alaskan sampling stations.

I talked a little bit, and I think so far most people have focused on what could be done with respect to past contamination. I think we can't rule out, however, because of some of the deterioration as we've heard of some of the nuclear facilities over there, that you might have some future events that would require us taking some protective action. As a consequence of that, I think it's worthwhile considering various prudent types of activities that could provide early warning as well as information associated with any further future contamination.

With respect to air contamination, EPA has a network called the Environmental Radiation Ambient Monitoring System, which is used to track the movement of Chernobyl aerial particulate radioactivity and could be used to detect any significant atmospheric particulate radioactivity that might arise from Arctic contamination in the future. We currently have ERAM stations operating in Juneau and Anchorage, and we've just established a station at Fairbanks, which I believe was set up within the past few days.

I'd like to talk a little about coordination with other nations and interested groups. As we've noted, the Interagency Arctic Research Policy Committee is a very significant activity to try to focus on this. We have recognized the significance of the Arctic environmental protection strategy which was signed last year. EPA participated in the development of the strategy and we intend to further activities in developing that particular strategy, such as our activities along with NOAA in looking at an environmental monitoring work group.

In conclusion, EPA is concerned about the releases in the Russian Arctic Ocean as it was about the releases that may have occurred in U.S. coastal waters in the past and from the Chernobyl accident. Although it's clear that the environmental situation is the responsibility of the Russians to rectify, EPA intends to support future cooperative studies to better understand this issue.

This completes my testimony and I'd be glad to respond to any questions you may have, Mr. Chairman.

Senator MURKowskI. Thank you very much, Dr. Guimond. Let me ask Dr. O'Dowd the first question. You've just returned from a visit to Russia. And from indications the Russians have for a long time been studying the Arctic. As you know, Dr. Komisar, and Ray Vecci, Chairman of the Alaska Airlines, and Marjorie Johnson, the Chairperson of the Alaska State Chamber of Commerce, and Chuck Becker of the Department of Commerce, and myself were in Vladivostok over the Easter recess. We were stuck by the number of people involved in research, I think the indication was some 14,000 in the Far East Branch of the Russian Academy of Sciences, with a total of some 25,000 involved in Arctic science in Russia. I wonder if you could give us an opinion of how good their science is? Some of their facilities appear to be somewhat antiquated, but nevertheless the proof is obviously not in the facilities but the quality of their science. I'm told that to some degree much of the science is not involved in teaching but in pure, basic scientific research. Do you have any thoughts on that, Doctor O'Dowd? 
Dr. O'DowD. Whereas we integrate instruction and the training of new scientists into our ongoing science establishment, the Russians have developed a different system, separating almost completely their instructional program from their scientific investigations. The numbers of people involved in Russian science are very large, and now the Russian establishment is recognizing that it probably is far larger than it needs to be, in the sense that there are more scientists, more technicians and more staff than most comparable Western science entities use to carry out their business-probably by at least twice-so that you get very large numbers of people doing the kind of scientific activity that we do on a much reduced diet. One advantage that we find in working with Russians is that they do have the capability of collecting extensive data, because they have the hands and heads to put to work on data collection in a way that we simply don't have available to us. My observation is that Russian science is very uneven. There are points of brilliance

Senator MURKOWSKI. You make a good politician. That's a good answer.

Dr. O'DowD. There are points of brilliance and there are points of great weakness. I recall once being introduced to a person and later the scientist with whom I was traveling said, "you don't need to pay much attention to him, he is the son of academician so and so." In working with Russian scientists, it's possible very quickly to identify good laboratories for they will make the discriminations for you. They do not want to be embarrassed in working with Western scientists and they are quite willing to tell you frankly where to turn and where not to turn. The University of Alaska has agreements with institutes scattered throughout the Far East, and probably knows more about Russia Far East science than any other institution in the United States or elsewhere in the Western world. Scientists from this part of the nation are working with people throughout Siberia and the Far East, where we probably know less about the contamination problems than we do in the northern part of Western Russia, were more work has been done and where the Norwegians in particular have been gathering data very intensively. So, I think there is a strong science establishment but it's not large, and one has to be very selective, I know the State Department is sending a delegation to Siberia and the Far East late this fall to try to identify those scientists with whom we might work most fruitfully.

Senator MURKOWSKI. Let me ask you another question relative to logistics. You recently, with your commission, journeyed to one of the more interesting places that occasionally we in politics get involved in, namely Wrangel. And having lived on the Island of Wrangell, Alaska, spelled with two L's, I am quite familiar with many of the constituent letters that come in as to an explanation of our alleged "giveaway" of the other Wrangel Island spelled with one L. I understand and your group went up there in a helicopter, a Russian helicopter, which itself is an adventure-an hour, hour and a half over open water, with no survival gear. And the question is logistics. How much of their logistic capability can be utilized in a monitoring scenario? And I wonder if you could elaborate 
on their logistical performance? We know their icebreaking capability probably is second to none.

Dr. O'DowD. Senator, Russian science, at least in the part of the world where I've been most active, has had access to a level of logistical support that U.S. scientists are not accustomed to, in the way of air transportation, helicopter transportation, and surface transport. The academies have been able to command a great deal of equipment, personnel, and energy to carry out their work. I think the scientific equipment with which they work, in most cases, is pretty primitive, but the transportation equipment and the staging areas that they have to work from are really pretty good. I think that we could count on a good deal of help at very modest cost from Russians in pursuing work with them in measuring such things as the transport of hazardous materials. I think Mead Treadwell mentioned the other day, that he had a quote of $\$ 135$ an hour for helicopter support in Russia as against something like $\$ 2500$ an hour for equivalent support in the U.S. So, funds will go a long way, and I think we could do a great deal of study, and gather a lot of valuable information quickly, using the support structure that they have available.

Senator MURKOWSKI. Well, obviously their pricing is a little different than ours. I recall research ships in Vladivostok that could be available for next to nothing they were so anxious to get somebody to charter them, put some fuel in them and get under way.

Let me move to Dr. Ostenso. I noted that NOAA did no radionuclide monitoring in the Arctic but there were some 36 other areas on the U.S. coast where monitoring did occur. Is it a matter of money, because clearly I think this monitoring is needed in areas off the Arctic coast of North America.

Dr. OSTENSO. Yes. Our program reflected out priorities based on available resources.

Senator MURKOwSKI. Have you got any degree of comfort for us relative to what your priorities are going to be in your next budget presentation?

Dr. OSTENSO. God, OMB and the Appropriation Committees willing, we will be able to step up to the challenge.

Senator MURKOWSKI. Do you intend to recommend specifically sites in the Arctic?

Dr. Ostenso. Yes, I do.

Senator MURKOWSKI. Thank you. Let me move to Admiral Guimond. NOAA and EPA, of course, are the lead agencies for implementing the AMAP program. And I'm curious to know what you're planning with regard to your agency's budget for next year. Are you going to implement an AMAP request in the budget?

Admiral GUIMOND. We've put a request together in the program, as with the other agencies, and depending upon how the appropriations committees fare with the agency will determine where we go.

Senator MURKOWSKI. There's another area that doesn't affect nuclear waste, but the tremendous dumping at sea in the north $\mathrm{Pa}$ cific associated with the factory fish processors. As opposed to shore-based plants that utilize virtually the entire biomass, the factory processors throw an awful lot over the side. And we're curious whether EPA has a responsibility in this area and whether they're meeting that responsibility. 
Admiral GuImond. Yes. I understand that there's a concern in that area. I'm going to have a defer a little bit. I have asked some folks in our Region 10 office in our water programs that are dealing with that what they can do to look into what control we can have in that. And I believe that we are currently trying to determine what laws we can bring to bear to provide some additional controls. But I don't think it's as clear-cut as we would like it to be.

Senator MURKOWSKI. Well, I'd appreciated it if you'd re-remind them, because we've sent a couple letters and they're still giving it some consideration as to what their role may or may not be. So, we'll certainly hold the record open for a couple of weeks.

Admiral GUIMOND. Will do.

Senator MURKOWSKI. And if you could gently urge them to take a look at that we'd appreciate it. One other question. We're in the process of setting up some radioactive monitoring in Alaska but we want to do it wisely. And I'm wondering if you could share what the priorities might be, the point of view of EPA, between airborne capability, monitoring against another event like a Chernobyl, or marine mammal tissue evaluation, or other types that we haven't mentioned?

Admiral GuImoND. As I said earlier, I think there's two areas that you're trying to focus attention on and be prepared for. One is trying to assess what have been the impacts of the past, and that's why a number of the things that we've talked about that we in EPA and the AMAP program would deal with would hopefully give you better indication of how much damage has occurred. The next area, we'll be trying to be protective in having the early warnings for the future. One is the monitoring stations that are currently in place and one that was just put in Fairbanks a few days ago will give you an indication of if any future events occur what kind of deposition might be occurring in this area. However, that's not truly early warning. That will let you know after something has come and you'll get it, you know, a few days later, but you'd like to have something a little earlier than that. So I think I would recommend that you would also have what I would call real time monitors that we would place closer to the coastal areas, closer to where they would be impacted by any airborne materials coming first over and would give you an instant type of indication so that, if necessary, people could be notified to take whatever protective action might be appropriate.

Senator MURKOWSKI. All right. Well, I appreciate that. We're going to conclude this morning's portion. And let me make a couple of announcements. We'd like to invite everyone to sign in, because if you sign it, you're going to receive a published copy of the transcript and the hearing record. It's going to take, I'm told, about eight weeks to complete that, so be patient. If you don't get it in eight weeks, why it's fair enough to call collect.

[Whereupon, at 12:15 o'clock p.m., the Committee was recessed.]

AFTERNOON SESSION

Senator MURKowSKI. We call the hearing back to order. And we'll thank our court reporter again. I would ask that you find a comfortable seat. 
First of all, we're going to depart a little bit. Two of our guests on the scientific panel have chosen to go later on in the day, and that's our friend from Russia, Leonid Bolshov, and Dr. Vera Alexander of the Institute of Marine Sciences of the University of Alaska.

I would introduce this panel now, Dr. Aaskar Aarkog, head of the Ecology Section, Department of Environmental Sciences and Technology, at Risó National Laboratory in Denmark. Dr. Charles Hollister of the Woods Hole Oceanographic Institution. Dr. Robert White, Institute of Arctic Biology, University of Alaska. Dr. Odd Rogne, International Arctic Science Committee, Oslo, Norway. And Dr. Glenn Shaw, Geophysical Institute, University of Alaska. Is there an order, gentlemen, or shall we start with the introductions?

Mr. GARMAN. Hollister's first.

Senator MURKOWSKI. Hollister's first. All right. We're ready for you. Please proceed.

\section{STATEMENT OF DR. CHARLES HOLLISTER, WOODS HOLE OCEANOGRAPHIC INSTITUTE}

Dr. Hollister. Thank you, Senator. I have to admit that it's a very brave person that's going to bring together the kinds of individuals that we have here; the environmental community and all the government sectors and private sectors that are involved in this debate, and I just want to congratulate the Senator on the foresight.

Thirty years ago last night I finished the first assent of the southeast side of Mount McKinley, first and only time anybody's been dumb enough to go up that side of that big mountain. And that was just 30 years ago. And now I'm back in a completely different uniform.

Why am I here? Well, Woods Hall Oceanographic Institution has done a lot of things in the ocean, around the world, including using robots to go down the grand staircase of the Titanic to look inside the ballroom, take a look at the remaining art work, and 'they've got us on the front cover of Time Magazine, but that's not what we do for a living. What we do is use these robots and our experts and scientists to figure out what's going on in the ocean and how to make it useful for you all.

The other thing we've been doing vis-a-vis the problem we're talking about today is that we've been studying the waters coming out of the Arctic for nearly 30 years while we look at the radioactive material that has been coming down the pipes of the reprocessing plants of Wind Scale, nuclear reprocessing plant on the shores of Great Britain, and recently renamed Sellafield, it's the same place, however. And we have noticed that most of the radioactive material going into the Arctic and coming out of the Arctic originates from those reprocessing plants.

However, we have seen interesting little spikes of cobalt-60 coming down the East Greenland current that was hard to explain using the outfall scenario. But we shrugged it off, thinking it had to be from fallout. We noticed a little blip of cesium about 4,000 feet below the North Pole and some of this information comes from our colleagues from Denmark, so I'm putting it sort of in a bouillabaisse here for you very quickly, which we couldn't explain very 
easily either. So, we knew somewhere in the Arctic up current there was a nuclear reactor doing something. So, it was not a huge surprise when we learned that there were radioactive materials, that there are radioactive materials, and indeed reactors in the Arctic, and that explains some of our funny little oddities in our measurements over the last couple of decades.

Well, where does this stuff go? When does it get released? What does it do when it gets to wherever it gets to? And who cares? These questions have been of interest to us and to myself for a long time. My expertise is in the physics of sediment transport. Much of the material coming from these radioactive, these reactors, will be bound up in the particles, the particles will move with the water, so it's important to know which way the water goes, obviously.

There is a great deal of knowledge about how rapidly the sediments on the bottom scavenge or cleanse the water as they pass through and they pick up the radioactive materials, and much of it ends up in the mud, except for the more soluble forms of cesium and strontium which have a longer pathway, if you will.

We spend a lot of our professional life at Woods Hall trying to figure out how material moves around and the water moves around, and we think the issue at hand here is the material in the Barents Sea on its way to Alaska or, if not, where is it going. I don't think it takes a great leap of faith to realize that we need to know probably, first, and this would be my first step, and that is to find out where the reactors are that contain the fuel rods. That's probably the most dangerous part of the equation right now, that is the fuel rods or the high level material inside the reactors. How it's been reported that there are of the order $10,12,15$ reactors sitting in various places around Novaya Zemlya and perhaps other places in that neck of the woods, and that a fairly small number are supposed to have fuel rods in them.

So to me, just as a first order scientific question, is how soon will water pass into the reactor through the fuel rods and out into the ocean. Now I don't myself have any expertise in how the Russians have made their reactors, but it would seem a logical thing to find out, to ask them or perhaps some of our own Navy sources know more about it than-well, I think we may have some information that would be very useful; let's put it that way. And the question is, where are the reactors weak, where's the water going to come in, and how long will it take before the water enters the reactor and starts corroding and eroding the fuel rods themselves. That to me would be the first thing to do rather than any sort of emotional, by God, we've got to go pick them up, clean them up. I've spent a lot of my career worrying about the Thresher and the Scorpion. In fact, I have the reports on what we've learned about the radioactive release from our own two nuclear submarines that went down accidently and came down and made a heck of a mess. And most of the submarine imploded; the two sides of a submarine coming together and going past each other out the other side is not a pretty sight. But the reactor vessels themselves don't seem to be in that bad of shape, and we've been measuring the sample; we've been measuring the mud and the animals growing on, in, near and under the reactors that are on the bottom that we own, and we find 
very small amounts, a little cobalt, a little bit of cesium, out two or 300 yards away, none of it anywhere near lethal amounts. And I suspect that that's going to be the case for these other reactors for perhaps a very long time.

Keep in mind also that the circulation of the Arctic is important. And from what I can tell from my colleagues, both here and in Woods Hole, the circulation is such that material that may get out of the Kara, White, Barents Sea that probably a very unlikely pathway would be up onto the shelf off of Alaska. More likely it would end up going back down eventually out and through the East Greenland current. But there are experts right next to me here who could prove me right or wrong.

So the question really is, okay, what do we do? And I would think we ought to look at what we've learned from our own reactors on the bottom. We ought to look at where the reactors are that are dangerous, and that we should probably monitor those very closely and periodically with the robots rather than submarines, which in that depth of the water and that neck of the woods is probably overkill. We have instruments that can go down and measure trace metals. And I would simply think that you'd find out which reactors are fueled and monitor those and keep track of what's going on. But I don't think there's any cause for any great serious alarm or concern.

But just to be sure, we're going to go over and talk, and I'm sure that a lot of you realize that the scientific community is a fairly small group of dedicated people. They speak a million different languages and they all have faxes now, which is really kind of interesting. And we have great communication with our colleagues. And to that extent, I've been asked to lead a U.S. delegation of scientists, of people who are expert at robots, and reactor shielding experts, to go over to St. Petersburg next month and start talking to the people who build the Russian nuclear submarines about the possibility of, with robots, monitoring the MIKE class Kosmolets submarine that went down off Norway, and set up some sort of a protocol for doing it logically, methodically, scientifically so that we can start to learn how to work with our Russian colleagues. And I must say that I'm looking forward to my first trip to St. Petersburg and to Moscow and I'm really looking forward to talking to some of my colleagues over there in order to sort of join hands in a joint research effort to figure out, is this a big problem, a little problem or a non-problem.

Thank you, Senator. That concludes my oral testimony.

Senator MURKOWSKI. Thank you very much, Dr. Hollister, for your presentation and staying within the time limits as well.

I would next move to Dr. Asker Aarkrog, Head of the Ecological Section, Department of Environment and Technology, at the Riso National Laboratory in Denmark. We welcome you to the committee and look forward to your testimony, Doctor.

Dr. AARKROG. Thank you very much, Senator. Thank you for asking me to come here to this very interesting hearing. I had actually planned to give my presentation using overheads. So if I may do so. 
Senator Murkowski. Surely. We're even set up, I'm told, so that's great.

[The prepared statement of Dr. Aarkrog follows:] 
Hearing on Radioactive and other Environmental Threats to the Arctic resulting from past Soviet activities. Alaska-Fairbanks Aug. 15, 1992
Asker Aarkrog, D.Sc.

Ris National Laboratory

DK-4000 Roskilde

Denmark

\title{
ENVIRONMENTAL RADIOACTIVITY IN
}

\author{
THE ARCTIC
}

\section{Definition of the Arctic}

In the present context the Arctic regions comprises all areas north of the arctic circle. The major part of the area is the Arctic Ocean and the inland ice of Greenland, but it also includes the northern parts of the European, Asian and American continents.

\section{Characteristics of the Arctic regions}

The low temperature and large amplitude photocycle (dark winters and nightless summers) are the primary factors which influence the arctic ecosystems. Although the atmospheric deposition in Arctic regions tends to be low the impact of pollution on the ecosystems may be significant. This is due to the often long residencetimes of pollutants and to the high sensitivity of arctic ecosystems because the organisms in these systems already are under severe stress due to the unfavourable living conditions. The foodchains are usually formed by a few species which means they have large natural fluctuations. They are thus more weakly balanced than we know it from temperate and tropical ecosystems.

\section{Sources and inventories of radioactive contamination}

The concern for the Arctic in connection with radioactive contamination came up in the early sixties when multimegatons nuclear weapons were tested at the USSR Novaya 
Zemlya test site. Global fallout from testing of nuclear weapons in the atmosphere in the fifties and sixties are still the main source to radioactive contamination of Nordic regions although it in certain areas in Scandinavia is overruled by the contamination from the Chernobyl accident in 1986. (UNSCEAR, 1982 and 1988).

The amount of local fallout from the Novaya Zemlya test site is not reported. It seems however, that the Arctic Ocean (Fig. 1) contains about 4 times more ${ }^{137} \mathrm{Cs}$, ${ }^{90} \mathrm{Sr}$ and ${ }^{239}$. ${ }^{240} \mathrm{Pu}$ than we would expect from global fallout (LAEA, 1988). Hence it is tempting to assume a contribution from local fallout. However it has also been suggested that the Siberian river systems, which in the forties and early fifties were used for disposal of high level radwaste from the USSR nuclear weapons programme (Cochran et al, 1990) may be a source of input of radioactivity to the Arctic Ocean.

Discharges of especially ${ }^{137} \mathrm{Cs}$ from the BNFL reprocessing plant Sellafield in the UK in the seventies and early eighties contributed significantly to the North Atlantic inventories (Fig. 2).

The Arctic regions have been contaminated locally from various sources e.g. with $1 \mathrm{TBq}$ ${ }^{239,240} \mathrm{Pu}$ at Thule (Aarkrog 1984b) from the B-52 crash in 1968, with shortlived fission products (e.g. ${ }^{95} \mathrm{Zr}$ ) in northern Canada from the loss of the Soviet Cosmos 954 satellite in 1978 (Tracy et al, 1984) and with ${ }^{131}$ I from loss of nuclear submarines e.g. the Komsomolets submarine in the Norwegian Sea in 1989. (Fig. 3). Among these local sources only the Thule contamination has so far been of longterm radioecological interest.

Zolotkov (1992) has recently reported that radwaste throughout the years has been dumped along the east coast of Novaya Zemlya. The waste has also included nuclear shipreactors, some still containing their nuclear fuel elements.

\section{Special radionuclides in the Arctic}

The long environmental halflife of radionuclides deposited on moss and lichen in Arctic regions has made it possible to reveal the presence of some radionuclides normally not 
seen globally in environmental samples e.g. ${ }^{207} \mathrm{Bi}$ and ${ }^{60} \mathrm{Co}$ (Aarkrog et al, 1984a).

Technetium-99 is another example of a radionuclide especially observed in Nordic regions, in particular in the marine environment, where it is concentrated in brown algaes (Aarkrog et al 1987a).

\section{Terrestrial Ecosystems in Nordic regions}

In 1961 a group of Scandinavian scientists with Kurt Lidén, Jorma Miettinen and Dietrich Merten (LAEA) as keypersons initiated the so-called RIS-symposia (Paakola, 1990). RIS stands for Radioactivity In Scandinavia. These meetings were especially concerned with the critical pathways of radiocaesium in the Nordic regions, in particular with the foodchain:

$$
\text { lichen - reindeer - man. }
$$

Reindeer-breeders thus became a group of special concern in connection with radioactive fallout in Nordic regions. Beside of Northern Scandinavia, reindeers are found in Alaska, Northern Siberia, Greenland and Iceland.

The high surface to weight ratio of lichen and the long effective halflife of ${ }^{137} \mathrm{Cs}$ in the lichen carpet is the main reason for the high radioecological sensitivity of lichen to radioactive fallout. Reindeer eat lichen during winter, which results in high levels in meat during this part of the year. (Mattsson, 1972; Hanson, 1973; Miettinen, 1966) Similar seasonal variations are seen in the reindeer breeders. The highest levels reported in man are from Northern Siberia in 1964 where bodyburdens of $0.13 \mathrm{MBq}{ }^{137} \mathrm{Cs}$ were observed. Similar levels were measured in the Murmansk region in the winter 1966-1967. After Chernobyl high levels in reindeer meat ( $\left(50 \mathrm{kBq} \mathrm{kg}^{-1}\right)$ were observed at various localities in Norway and Sweden (Gunnerød et al 1989; Erikson 1990). But although the contamination at such locations were about an order of magnitude higher than in the sixties, the problems were not of a circumpolar nature as after the global fallout period.

Johanson et al (1990), Bakken et al (1990) and other radioecologists observed after the 
Chernobyl accident that mushrooms were an important source of radiocaesium to grazing ruminants and some game animals. A strong seasonal variation of ${ }^{137} \mathrm{Cs}$ in roe deer was e.g. demonstrated in Sweden. This variation was mainly due to consumption of mushrooms in the autumn. Thus the availability of mushrooms becomes important for the observed radiocaesium levels in certain game animals and grazing ruminants (e.g. goat and reindeer). A steady decrease of ${ }^{137} \mathrm{Cs}$ is thus not always observed in such animals.

Herbage - sheep - man is another critical pathway for radionuclides in Arctic regions. (Hove et al, 1990) The effective halflife of ${ }^{137} \mathrm{Cs}$ in this foodchain is quite long.

\section{Freshwater Ecosystems in Arctic regions}

Drinking water in the arctic and subarctic is usually derived from surface water including melting of snow and ice. Hence we do not see the same efficient removal of radionuclides from the water as is the case for groundwater derived drinking water. Especially in Greenland where permafrost is common the drinking water levels tend to be relatively high. Furthermore the ${ }^{90} \mathrm{Sr}$ concentration seem closer related to the accumulated fallout than to the fallout rate (Hansen et al, 1990).

Already in the sixties it was observed that lakes with a low conductivity (oligotrophic lakes) contained fish with a relatively high ${ }^{137} \mathrm{Cs}$ content (Carlsson, 1976, Häsänen et al, 1966). It was also observed that the excretion of ${ }^{137} \mathrm{Cs}$ decreased with decreasing temperature (Kolehmainen et al, 1966). After the Chernobyl accident the combination of high fallout and low conductivity resulted in fish levels in the middle part of Sweden greater than $1.5 \mathrm{kBq}^{137} \mathrm{Cs} \mathrm{kg}^{-1}$ fish. (Håkanson, 1991).

\section{Marine Ecesystems in Nordic Regions}

Fig. 4 shows the current system in the Arctic. Dotted lines represent warm currents and full lines are the cold ones. The discharges from nuclear reprocessing in Western Europe have been used to measure dilution factors and transport times in this current system (Aarkrog et al 1987). A waterborne pollutant in the North Sea is found about five years 
later in the East Greenland Current and two-three years later it has reached Thule in NW-Greenland. It is amazing that pollutants can travel that far and still be detected.

The studies of global fallout ${ }^{90} \mathrm{Sr}$ and ${ }^{137} \mathrm{Cs}$ in arctic waters (Aarkrog 1989) have shown that the effective mean residence time of these radionuclides in the surface water of the Arctic Ocean is about 15 years. However, this may be an overestimate if the Arctic Ocean is supplied with significant amounts of run-off from land e.g. from the Siberian rivers. The vertical mixing in the Arctic waters is more rapid than we see it at lower latitudes in the world ocean. This implies a shorter residence time of pollutants in arctic surface water than what is seen in temperate and tropical waters.

At Thule in NW Greenland an arctic marine ecosystem has been studied with regard to transfer of plutonium since the B-52 accident in 1968. (Aarkrog et al 1984b It appears that the effective halflife of $\mathrm{Pu}$ in biota is significantly less than the radiological halflife of 24000 years. It is further more evident that there is a discrimination against Pu when we move to higher trophic levels in the foodchain.

\section{Conclusion and Summary}

Although the radioecological sensitivity of food products from Arctic regions tend to be higher than we know it from temperate regions, the very low productivity of Nordic regions imply usually low collective doses from these regions. However, high individual doses from radioactive contamination may be seen in the Arctic as we have observed it for e.g. reindeer breeders.

Radiocaesium is concentrated from lower to higher trophic levels. The marine animals contain orders of magnitude lower ${ }^{137} \mathrm{Cs}$ levels than terrestrial animals in Nordic regions and the transfer of ${ }^{137} \mathrm{Cs}$ is one to two orders of magnitude greater than that of ${ }^{90} \mathrm{Sr}$ to meat of animals. (Fig. 5) 


\section{Euture radioecological studies in the Arctic}

More information is particular needed on the radioactive contamination of the Arctic from previous nuclear activities in the former USSR and the following questions may be asked:

1. How much radioactivity was deposited locally and regionally in the Arctic from the Atmospheric test series during the fifties and early sixties at Novaya Zemlya?

2. What has the runoff of radioactive substances with the Siberian rivers from nuclear activities in the former USSR been? In particular how much activity has been transported by the $\mathrm{Ob}$ river system to the Arctic bassin?

3. What are the radioecological impact of the radwaste dumped at Novaya Zemlya? Will in particular the disposed nuclear ship reactors influence the levels of marine radioactivity in the Artic?

4. What is the inventories of ${ }^{90} \mathrm{Sr},{ }^{137} \mathrm{Cs}$ and plutonium in the Arctic Ocean? Are the levels higher than expected or have the measurements carried out so far been too few for a reliable estimate?

5. Are the Arctic Bassin and the Siberian rivers potential sources of contamination of important fishing areas in the North Atlantic region and what would then be radioecological impact?

The ecological halflives of ${ }^{90} \mathrm{Sr},{ }^{137} \mathrm{Cs}$ and transuranic elements should be determined in marine as well as terrestrial ecosystems in the Arctic in order to evaluate the radioecological consequences of radioactive contamination in this part of the biosphere. 


\section{R E F E R N C E S}

Aarkrog, A.

(1979)

Aarkrog, A., Dahlgaard, H., Holm, E. \& Hallstadius L.

(1984a)

Aarkrog, A., Dahlgaard, H., Nilsson

Karen \& Holm, Elis

(1984b)

Aarkrog, A, Boelskifte, S., Duniec, S., Hallstadius,

Holm, E. \& Smith (1987a)

Aarkrog, A. (1989)
Environmental Studies on Radioecological Sensitivity and Variability with Special Emphasis on the Fallout Nuclides ${ }^{90} \mathrm{Sr}$ and ${ }^{137} \mathrm{Cs}$.

Risø-R-437. (1979) pp. 548

Evidence for Bismuth-207 in Global Fallout. Journal of Environmental Radioactivity 1, 107-117 (1984)
Further Studies of Plutonium and Americium at Thule, Greenland.

Health Physics 46, 29-44 (1984)
Technetium-99 and Caesium-134 as long Distance Tracers in Arctic Waters. Estuarine, Coastal and Shelf Science (1987) 24, 637-647.
Chernobyl-related Monitoring and Comparison with Fallout Data. Proc. Seminar on Project "MARINA" Bruges 14-16 June 1989, p 229-249. 
Bakken, Lars R. \& Rolf A. Olsen

(1990)

Carlsson, Sten

(1976)

Cochran, T.B. \& Norris, R.S.

(1990)

Eriksson, Olof (1990)

Gunnerød, T.B., Blakan, I., Ugedal, O., \& Skogland, K. (1989)

Hanson, Wayne C. (1973)

Hansen, Heinz J.M. \& Aarkrog, A.

(1990)
Accumulation of Radiocaesium in Fruit Bodies of Fungi. In: Transfer of Radionuclides in Natural and SemiNatural Environments.

Elsevier Applied Science (1990) p 664-668.

Caesium-137 in a Dysoligotrophic Lake. A Radioecological Field Study.

Ph.D. Thesis. Lund University, Sweden 1976. pp. 108.

Soviet nuclear warhead production. Natural Resources Defence Council, Washington, DC..20005, NWD 90-3, 1990.

Cs-137 in Forage Plants vital to Reindeer (Rangifer Tarandus Tarandus 1.) in Northern Sweden. In: Transfer of Radionuclides in Natural and Semi-natural Environ. ments.

Elsevier Applied Science (1990) pp. 194-201.

Freshwater and Alpine Ecosystem Response to Chernobyl Fallout in Norway. In: Environmental Contamination following a Major Nuclear Accident. LAEA-SM-306/41 (1989) p. 59-67.

Fallout Strontium-90 and Caesium-137 in Northern Alaskan Ecosystems During 1959-1970.

Ph.D. Thesis. Colorado State University. May 1973. pp 242.

A Different Surface Geology in Denmark, The Faroe Islands and Greenland Influences the Radiological Contamination of Drinking Water. 
Wat.Res.24, 1137-1141 (1990)

Hove, $K$ \& Strand, P. (1990)

Häsänen, E.,

Kolehmainen, S. \& Miettinen, J.K. (1966)

Håkanson, Lars

IAEA

Johanson, Karl J., Bergström, R., von

Bothmer, S. \& Karlen, G. (1990)

Kolehmainen, S., Häsänen, E. \& Miettinen, J.K. (1966)
Predictions for the duration of Chernobyl radiocaesium problem in non-cultivated areas based upon reassessment of the behaviour of fallout from nuclear weapons tests. Proc. FAO/LAEA/UNEP/WHO. Int. symp. on environmental contamination following a major nuclear accident. (LAEA-SM-306/40) Vol 1, 215-223.

Biological Half-time of ${ }^{137} \mathrm{Cs}$ in three Species of Fresh-water. Fish: Perch Roach and Rainbow Trout. In Radioecological Concentration Processes. Stockholm 1966. p. 921-923.

Ecometric and dynamic modelling exemplified by caesium in lakes after Chernobyl.

Springer Verlag pp. 162. (1991)

Inventories of selected radionuclides in the Ocean. IAEA-TECDOC -481 (1988) pp 181

Radiocaesium in Wildlife of a Forest Ecosystem in Central Sweden. In: Transfers of Radionuclides in Natural and Semi-natural Environments. Elsevier Applied Science (1990), 183-193.

${ }^{137} \mathrm{Cs}$ in Fish, Plankton and Plants in Finnish Lakes During 1964-65 in Radioecological Concentration Processes.

Stockholm $1^{\urcorner} 66$ p. 913-919. 
Mattsson, Sören

(1972)

Miettinen, J.K.

(1966)

Paakola, Olli

(1990)

Rey, Louis (Editor)

Tracy, B.L., Prantl,

F.A. and Quinn, J.M.

\section{UNSCEAR}

UNSCEAR

Zolotkov, A.A.

(1992)
Radionuclides in Lichen, Reindeer and Man.

Ph.D. Thesis. Lund University, Sweden 1972 pp. 103.

Concentration of ${ }^{137} \mathrm{Cs}$ and ${ }^{55} \mathrm{Fe}$ through food chains in Arctic and Subarctic Regions. In Radioecological Concentration Processes.

Stockholm 1966 p. 267-274.

Radioactivity in the Arctic region - a Status Report (30 Jan. 1990) Protection of the Arctic Environment. pp 18.

The Arctic Ocean. Comité Arctique International (1982) pp. 433.

Health impact of radioactive debris from the satellite Cosmos 954.

Health Physics 47, 225-233 (1984)

Ionizing Radiation: Sources and Biological Effects. (1982) United Nations pp 773.

Sources, Effects and Risks of Ionizing Radiation (1988) United Nations pp 647.

Nuclear power industry as a Source of the marin pollution of the Arctic Basin. (in Russian) ACOPS Conference on Assessment of Land-Based Sources of Marine Pollution in the Seas Adjacent to the C.I.S. Sevastopol 5-10 April 1992, p. 33-34 Vol. II. 
NORTH ATLANTIC GLOBAL FALLOUT CONCENTRATIONS

IN 1989

SURFACEWATER CONTAMINATED BY GLOBAL FALLOUT ONLY:

$2.9 \mathrm{~Bq}^{137} \mathrm{Csm}^{-3} \quad 1.8 \mathrm{~Bq}^{90} \mathrm{Srm}^{-3} \quad-10 \mathrm{mBq}^{239,240} \mathrm{Pum}^{-3}$

ARCTIC OCEAN SURFACEWATER (GLOBAL FALLOUT ONLY)

4.6 Bq ${ }^{137} \mathrm{Csm}^{-3} \quad 3.7 \mathrm{~Bq}^{90} \mathrm{Srm}^{-3} \quad 12.5 \mathrm{mBq}^{239,260} \mathrm{Pum}^{-3}$

BALTIC SEA

$14 \mathrm{~Bq}^{137} \mathrm{Csm}^{-3} \quad 17 \mathrm{~Bq}^{90} \mathrm{Srm}^{-3}$

Fig. 1.

(From Aarkrog, 1989) 
INVENTORIES IN THE NORTH ATLANTIC (1989)

${ }^{137} \mathrm{Cs}$

Global fallout $\quad$-150PBq

Reprocessing - 30PBq

Chernobyl - 20PBq

${ }^{90} \mathrm{Sr}$

Global fallout $\quad$-100PBq

Reprocessing - 5PBq

$239.240 \mathrm{Pu}_{\mathbf{U}}$

Global fallout $\quad$ - 3PBq

Fig. 2

(from Aarkrog, 1989) 


\section{7}

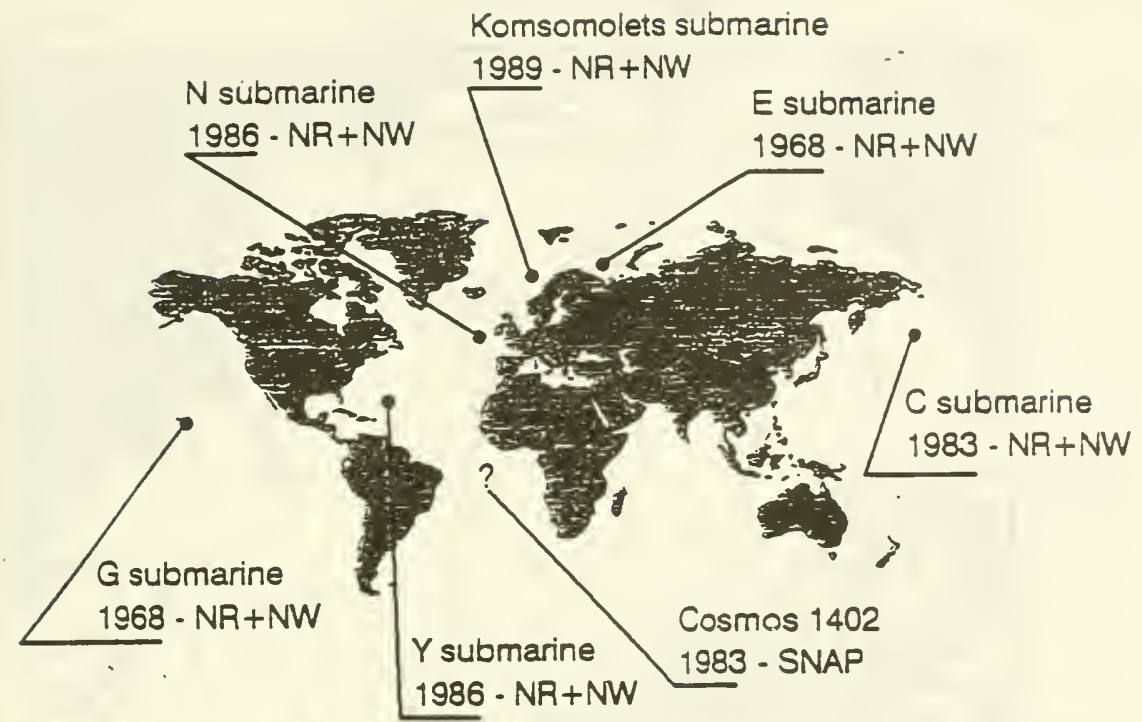

Lost Soviet nuclear devices.

Keys to figure: NR: nuclear reactcr, NW: nuclear weapon.

Eig. 3

(unpublished. IAEA infornation, 1991) 


\section{8}

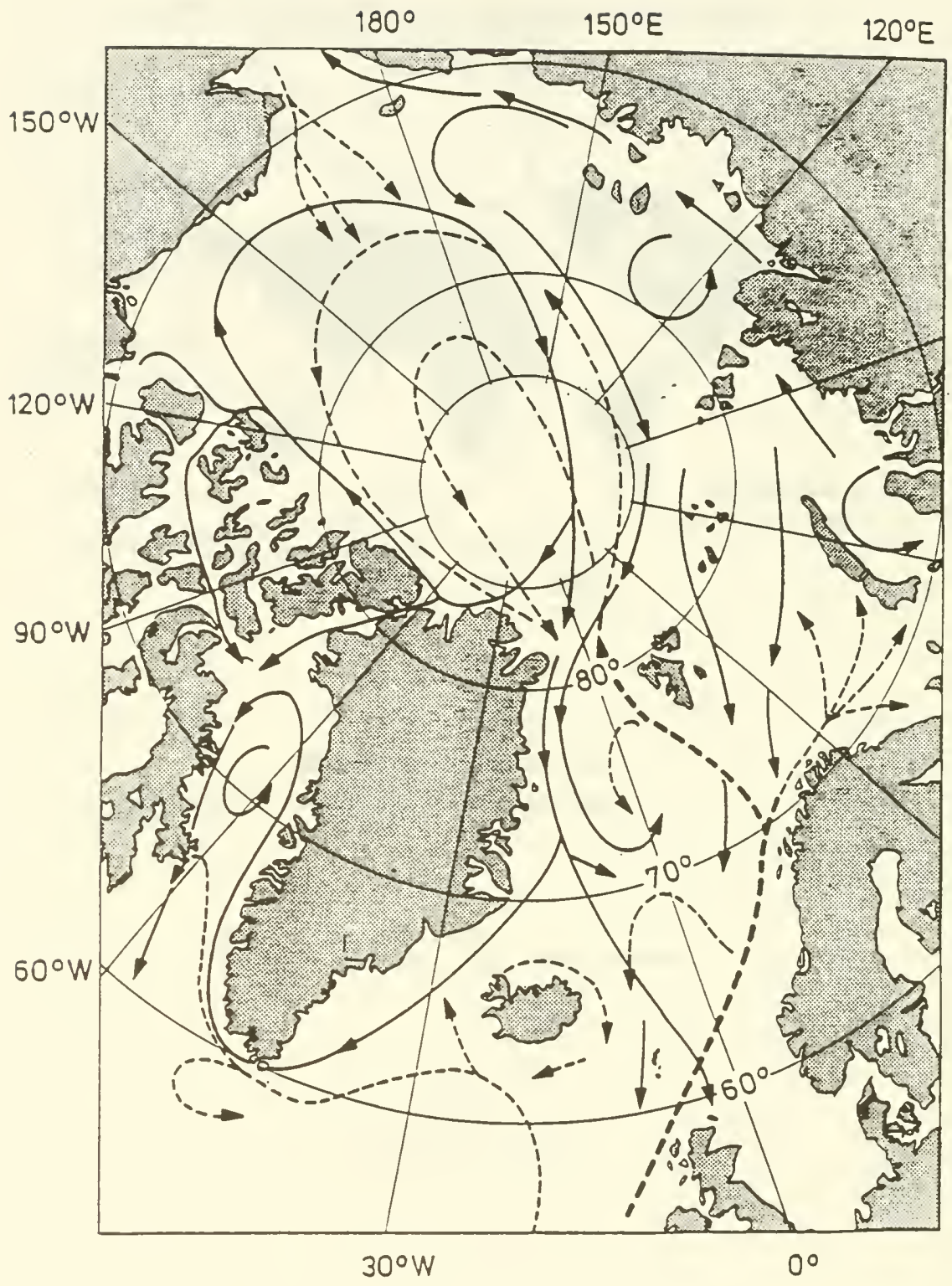

Fia. 4 


\section{RADIOECOLOGICAL}

\section{SENSITIVITY OF}

\section{Cs-137 and ${ }^{90} \mathrm{Sr}$ IN GREENLAND ANIMALS}

$$
\text { Bq } \mathrm{kg}^{-1} \text { y } \mathrm{pr} \mathrm{kBq} \mathrm{\textrm {m } ^ { - 2 }}
$$

Cs-137

${ }^{90} \mathrm{Sr}$

Marine fish

10

3

Seals

Whale

Seabirds

Mutton

Reindeer

Muskox
5

0.3

15

1

5

150

5

1500

15

Fig. 5

(from Aarkrog, 1979) 
STATEMENT OF DR. AASKAR AARKROG, CHIEF, ECOLOGY SECTION, DEPARTMENT OF ENVIRONMENTAL SCIENCES AND TECHNOLOGY, RISO NATIONAL LABORATORY, DENMARK

Dr. AARKROG. The Chernobyl accident. That is the major known source. But beside these major known sources there is a number of possible major sources to radioactive contamination of the Arctic. And here I will mention, first of all, local fallout from the Novaya Zemlya test sites for nuclear weapons. We don't know how much that is. Runoff with Siberian rivers from nuclear activities in the former Soviet Union, we have heard about it, and dumping of, for example, ship reactors at Novaya Zemlya. These have all been mentioned, these things.

If we for a moment look at the former Soviet empire and we can see here the Novaya Zemlya and we can see here what I called the major rivers running into the Arctic Ocean. That's the Ob River system, the Yenisey River system, and the Lena River system. And all these river systems are connected to some nuclear facilities. The $\mathrm{Ob}$ River system is connected to the Urals, we have heard about, and there is also a connection to Semipalatinsk where they have had nuclear explosions, and there is furthermore through the Tomsk River a connection to the reprocessing of plutonium production plant at Tomsk. And in case of the Yenisey River, it is the Krasnoyarsk reactor establishment where they produce plutonium. And finally, the Lena River has contaminated area around Yakutsk where a large number of peaceful underground explosions has been going on.

Furthermore, I have very recently heard that in '58 there was a rocket failure in this area here. And this rocket may have contained radioactive material. So this is all sources to the radioactive contamination of the Arctic Ocean.

If we turn to the $\mathrm{Ob}$ River system, which I consider the most important, then we have three major contamination events in the Urals which may influence the contamination of this river system.

First of all, we had the discharge to the Techa River from ' 49 to '51. We learned about it from Mr. Gates this morning. We had the Kyshtym accident in '57 and we have had a wind dispersion of activity from Lake Karachay which contained these enormous amounts of radioactive contamination.

We have been studying these contaminations in this area because in 1990 we were invited by the Russians to visit a number of places in Russia. I was at that time president for the International Union of Radioecologists and that was in that capacity we were invited to go around to these sites. And the interesting thing was that we were allowed to collect samples at the sites and bring the samples with us home. That means that for the first time we had the opportunity in the West to have our own measurements of these local contaminations. And it was at that occasion we found this last mentioned contamination because the two ones were partly known but the last one was completely unknown at that time. And we have published a paper on that in Journal of Environmental Radioactivity, which I will give here to the hearing.

If we should try to summarize what I think is important to do in the future, I might go back to my place now. 
During the '50's and early '60's at Novaya Zemlya we do not have an exact answer on that, I think it is important to know because I think there has been some more local fallout than we have thought until now.

And the second question, what has the runoff of radioactive substances with the Siberian rivers I mentioned before from nuclear activities in the former USSR been? In particular, how much activity has been transported by the Ob River system to the Arctic basin. And I can mention that there are connections we have with the Russians in the Urals has now started, this cooperation has now started a project on the Ob River, a very preliminary project. In these days scientists from this institute are at the outlet of the $\mathrm{Ob}$ River to the Arctic basin and taking some preliminary samples in order to get an idea of what is in the sediments.

And the third question, what are the radioecological impact of the waste dumped at Novaya Zemlya. Will in particular the disposed nuclear ship reactors influence the levels of the marine radioactivity in the Arctic? I do not consider this so important myself as the runoff from the rivers.

And the fourth question, what is the inventories of strontium and cesium and plutonium in the Arctic Ocean? Are the levels higher than expected to have the measurements carried out so far-

UNIDENTIFIED SPEAKER. Excuse me, we can't hear.

Senator MURKOWSKI. Thank you. I'm sorry. If you can't hear, we'll certainly-

Dr. AARKROG. What are the inventories of strontium-90 and cesium-37 and plutonium in the Arctic Ocean? Are the levels higher than expected to have the measurements carried out so far been too few for reliable estimates? The reason for this question is that estimates made on the inventories in the Arctic Ocean is actually coming out with higher levels than we would expect from the known input to the Arctic Ocean.

And then the last question, are the Arctic basin and the Siberian rivers potential sources of contamination of important fishing areas in the north Atlantic region and what would then be the radiological impact. Personally I am not sure it would be very high. Thank you.

Senator MURKowSKI. Thank you very much, Dr. Aarkrog.

Our next panelist will be Dr. Robert White, the Institute of Arctic Biology, University of Alaska. And if you have trouble hearing in the back, let us know. Please proceed, Dr. White.

[The prepared statement of Dr. White follows:] 


\title{
PRESENTATION TO THE SENATE SELECT COMMITEE ON INTELLIGENCE
}

\section{SATURDAY, AUGUST 15, 1992 \\ RADTONUCUIDES AND BOLLUTANTS NVARCTIC TERRESTRIAL SYSTEMS}

\author{
Robent G. White \\ Instimure of Anctic Biology \\ University of Alasion Fairbantos \\ Fairbank, AK 99775 \\ (907) 474-7648
}

My name is ROBERT GORDON WHITE and I am the Acting (Interim) Director of the Instimte of Arctic Biology at the University of Alasta Fairbanks. By training I am 2 nutritional-biochenist in the animal services and more recently a nurritional ecologist working with caribou, muskoxen and moose. I have beon working with Dr. Dan HOLLEMAN, who is a radio-ecologist, for over 20 years on the movement of mdioactive cesinm in the licheo-caribou-wolf food chain. We have used this knowlodge as a tool to study the ecology of caribon and wolves, for development of models of cesinm transport and to make assessments on human exposure through consunption of caribou. We have assisted in the training of scientists working on the effect of Chemobyl in Norway. Measwement of radio-nuclide levels in reindeer and caribou can be used to monitor a large land area so these are integrated measures over time and space.

I would like to focus my presentation on the ternestrial, or land, component of tho cosystem with addod reference to how radio-nuclides, and other pollutants, may move from other sources such as rivers, streams, the marine system and the atonosphere to the land-based systems.

\section{RADIOACTIVE AND OTHER ENVIRONMENTAL THREATS TO THE ARCTIC} RESULTING FROM PAST SOVIET ACTIVITIES:

The first priority should be a recomnaissance inventory and assessment of the nature and exteat of pollutants in the Russian North that conld nlfimately impact Alaska or aretic systems in general. This would involve collabaration with Russisns in mapping spocific 
locations of pollumes (inciuding radio-usclides, heary metals, toucic bydrocarbons, and other potendal conaminantas); determining the type and magnitode of those present; and the conditions under which they exist as a basis for astessing their potential to move into marive, amospheric or terrestrial systems. Withour this information, no well-directed researect and monitoring program in Alasice or the marine envionment can be adequatraly designed

\section{UAF-Ecology}

\section{PATEWAYS}

There are four important pathways for movement of redio-molides to the terestrial system:

No. 1. The lichen - caribon - man or wolf (bear and scavengex) system In this system atmospheric fallout of pollntans are sequested by lichens, which are prefercatially consumed by caribna and reindeer in winter and caribon and reindecr are enten by people and other predatrox. At each trophic lovel concentration of pollotant in the tismes increases dramatically. Hromans are then at risik becanse they on food ther can be enriched in the polluont.

Biological procestes sch as this not only omcentonte pollotents, but also rodistribure them from hot-spota throngh the moryment of animals and direct the pollutent to nexprystems.

Thus, animals will be the major carier of pollutants between the main ecosystems, diver/stream-tecreatrial and marino-tercorrial

No. 2. Transport to teucstral syctoms from rivers/streans and the marive systeen The second system concerns the lifely roles of shore-birds and mignary water-fowl in transport of pollumants from marine besches, and tidal basins whene they aggregros and feod and from river and stream erturies, where ers are hid and young grow and mamre, to local and remote sires where the birds mag release pollusents through defecation and death, or they may be raken by honeers and predatore. Sea-binds that feed at sea ca a nmmber of trophic levels in the marine system frequently next 00 cliffs that accumplate large amount of bird 
droppings. Pollutams in the droppings may eater the land system turough secpage and decomporidion, and then as uptake by plants. Feeding activities of other animals move pollutants in feces into other components of the land-based system. Another route for the move to terrestrial system is amimals, anall and large, that feed on inter-tidal plants and small organisms. These amimals move pollotants from the inter-tidal to tho local land-based system

No. 3 Atmospheric pollutants. Atmospheric bom pollutants fall out over wide areas through movement of air masses, but also may be concentratod to form "hor-spots" dne to local precipitation - as occured following the Cheroobyl disaster.

No. 4 Land-based transport systerns. Once in the terrestrial system, the effect of pollutants depeads on the way plants take-up, sequester (store) and turn-over the chemical component, and the extrent that they are food resources for amimals. Lichens and many mashrooms preferentially tike-up and store some pollutants (e.g. radioactive cesinm) - thes they reanita a source of contanination for long peciods of time. Other vegetation may tum. over pollunats quictdy and therefore are a source of pollotion only briefly - for erample compare monstrooms and beeries as long-term and short-term direct sources of dietary contamination for northern peoples.

In summary, biological processes influence PATHWATS by:

ACCELERATING movements between system components CONCENTRATING pollutants successively in trophic levels

DISTRIBUTING pollutants bally and world-wide by vitwe of amimal movements

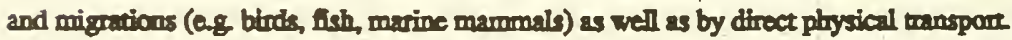
INCREASED RADIOACIIVITY IN THE ARCTIC

The Arctic bion is impartant to local inhabitants for dietry sustenance, and as a source of cash income and clothing. Subsistence hunting and fishing is ar the very coure of the social systems of Native Alastons. Thes, in many areas people mayibe almost complosely depeodent on fish, birds, and marine and terestrial mammils for meat and plant 


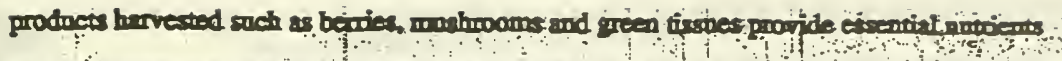

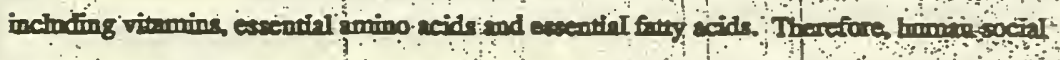

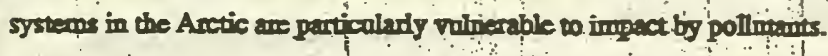

This inpect may bo hî̉ her in the Apctic than fin more teriperute systems as

i) Elemental kinetics in biologicil systems in the Autic may be dower than in low latibudes which may result in ingher concentrations in pimaing, production and in higher trophic levels.

17 Redio-nnclides may, be maintrined in biological cheolation for maiy year long

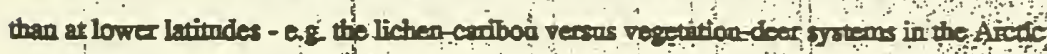
and lower 48 respectively.

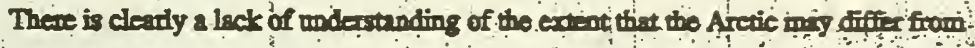

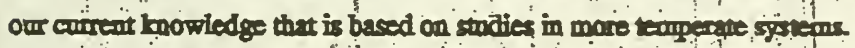
MONITORING

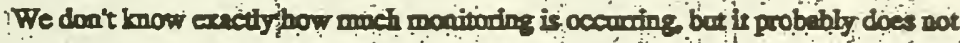
addnets the inmedive concen Namely, are there dignifont Rnstim derivedmotio-minctides

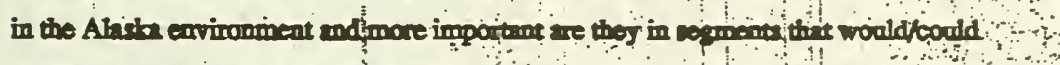

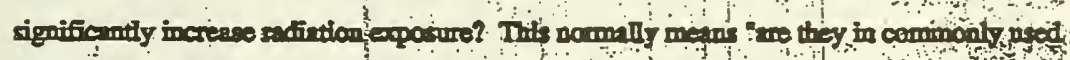

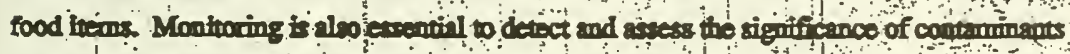
thes mif reach Alsten in the fuime.

UAF is in a good ponition to do thic type of moxinaping a well as to offer "whole body

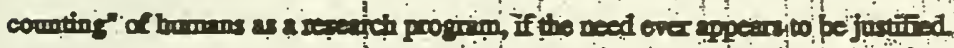
IS MORE SCIENTIFIC RESEARCH NEEDTOD?

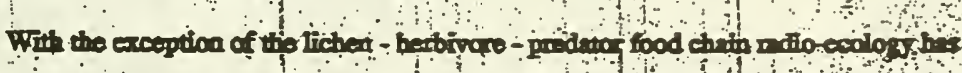

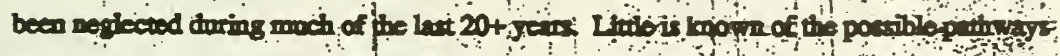

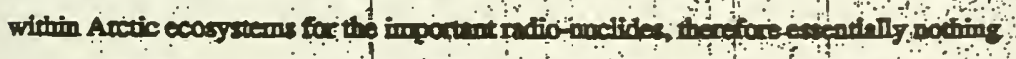

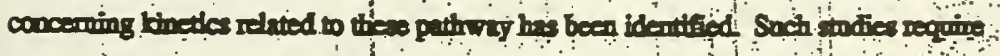

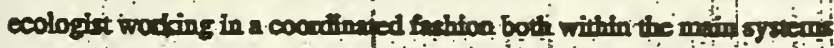


(land/4and

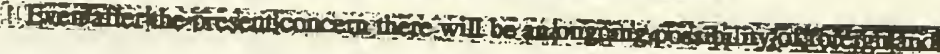

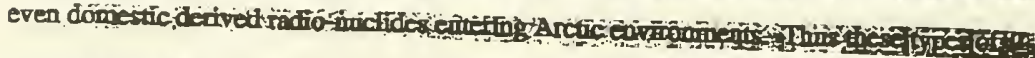
studiesainécrücial " "

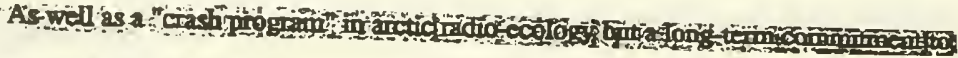
a long trimproblem is noeded:s:

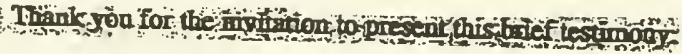

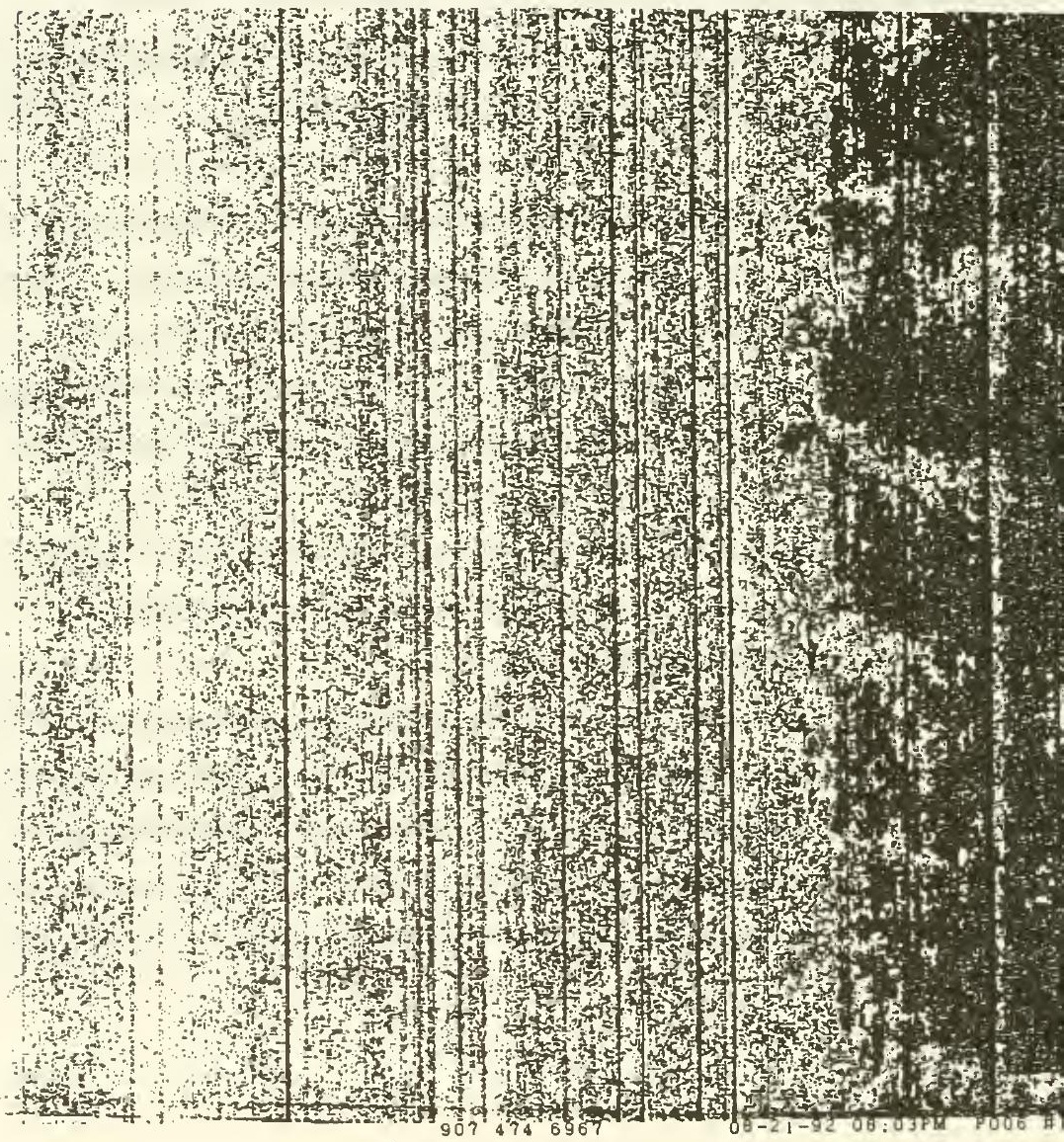




\section{STATEMENT OF DR. ROBERT WHITE, INSTITUTE OF ARCTIC BIOLOGY, UNIVERSITY OF ALASKA}

Dr. WHITE. Thank you for the invitation to talk today, Senator Murkowski. I've been working in the area of radioecology with a close colleague and several other people for more than 20 years, monitoring radioactive cesium in the lichen-caribou-wolf food chains in a number of systems in Alaska. And so it's with this perspective and the perspective of the land component that I'd like to talk about a little bit.

We've used the knowledge that we've gained from these studies to study the ecology of caribou and wolves. We've also developed models of cesium transport which we've used to make assessments on human exposure through consumption of caribou. We also assisted in the training of scientists who have been more recently working on some aspects of the Chernobyl disaster as it impacted Norway and other countries.

Our studies also tell us that the monitoring of radioactivity in reindeer and caribou could certainly be used as a method to scan large areas of the land mass for possible contaminated hot spots, and whereas particularly a large number of ground samples would need to be counted in order to do the same integrated measure.

However, what I'd really like to mention today, besides this insight I have, is that first of all we have to know the amounts and where the contamination is, for without that information no welldirected research and monitoring program in Alaska or the marine environment can adequately be designed. From a University of Alaska perspective, what I see is that we're rich in ecologists and rich in the understanding of some components of the ecosystems that I think that can be brought to bear on the study.

Now there are four main pathways that I feel important for the transport of radionuclides and perhaps other pollutants to the terrestrial system. An example is the lichen-caribou, man or wolf, bear or scavenger system that has been intensively studied and gives us a few important quantitative measures of the rates of transport and turnover in such a system. In the system atmospheric fallout of pollutants are sequestered by lichens. The lichens are preferentially consumed by caribou and reindeer, in winter, and the caribou and reindeer are eaten by people and other predators. At each trophic level, contamination or pollutants in the tissues increases very dramatically, something like two to ten-fold, depending on the pollutant, as you move up the trophic system. Humans then are at risk because they eat food that can be enriched in the pollutant.

I would maintain that biological processes such as this not only concentrate pollutants but also distribute them from hot spots to other areas through the movement of animals and particularly migratory species, and they direct pollutants therefore to new systems, as animals maybe a major carrier of pollutants between the main ecosystems, between river, stream and terrestrial systems, and between the marine and terrestrial systems. In this respect, likely rolls of shore birds and migratory water fowl in transport of pollutants from marine beaches, tidal basins where they aggregate and feed, and from river and stream estuaries where eggs are laid and young grow to maturity, then migrate to close-by areas, local 
areas, and to remote sites where the birds may release the pollutants through defecation, death, or they may be taken by hunters and other predators and redistributed. Sea birds that feed on the sea on a number of trophic levels in the marine system frequently nest on cliffs that accumulate large amounts of bird droppings. Pollutants in the bird droppings may enter the land system through seepage and decomposition and then they're taken up by plants. Feeding activities of other animals move the pollutants in feces and into other components of the land-based system.

Another route for the movement of two terrestrial system in animals are the small and large animals that feed on inter-tidal plants and small organisms. These animals move pollutants from the inter-tidal area to the local land-based systems.

With respect to atmospheric pollutants, atmospheric-borne pollutants fall out over wide areas through movements of air masses, but they also may be concentrated to form hot spots due to local precipitation such as occurred following the Chernobyl disaster. Once in the terrestrial system, the effect of pollutants depend on the way they're taken up and stored by plants and the rate of turnover of the chemical component, and the extent that they are then used as a food resource for animals. Lichens and many mushrooms preferentially take up and store some specific pollutants, and in this case an example is radioactive cesium. Thus they remain a source of contamination for long periods of time. In Alaska, the level of pollution in lichens and mushrooms is virtually identical, and which is a new finding and rather exciting biologically. Other vegetation may turn over pollutants quickly and therefore they are a very quick source of pollution; they are only seen briefly. Compare, for instance, mushrooms being harvested by people and berries being harvested by people. Mushrooms, a long-term level, and berries being there, being polluted for a rather short period of time.

In summary, biological processes influence pathways by accelerating movement, by concentrating pollutants and redistributing the pollutants locally and worldwide by migratory movements. In the Arctic, subsistence hunting and fishing is at the very core of the social systems of Native Alaskans; thus in many areas people may be almost completely dependent upon fish, birds and marine and terrestrial mammals for meat and plant products harvested, and also other plant products harvested such as berries, mushrooms and green tissues provide essential nutrients including vitamins, essential amino acids and essential fatty acids. Therefore, human social systems in the Arctic are particularly vulnerable to impact by pollutants.

We're limited in our knowledge of predicting what all of these impacts are going to be because the elemental kinetics in biological systems in the Arctic are not well known. We predict that they would be slower than in lower latitudes and therefore higher concentrations may be found in various levels of the trophic systems. Radionuclides may be maintained in biological circulation longer in the Arctic than elsewhere as well.

With respect to your questions on what kind of monitoring is going on and should be done, we don't know exactly how much monitoring is occurring, but it probably does not address the immediate concern for the Arctic. 
Is more scientific research needed? Well, with the exception of the lichen herbivore predator food chain radioecology studies in the Arctic, and we know something about them, there's been very little radioecology studies conducted in the Arctic for the last 20 years. Little is known of the possible pathways within the Arctic ecosystem for the important radionuclides; therefore, essentially nothing concerning kinetics related to these pathways have been identified.

We see these kinds of studies important to us and we see a role for the University systems and academia in these kinds of studies. Thank you very much.

Senator MURKOWSKI. Thank you very much, doctor.

Dr. Odd Rogne, International Arctic Science Committee, Oslo, Norway.

[The prepared statement of Dr. Rogne follows:] 
15 A ugust, 1992

506/92/OR/341 (final revision)

\section{RADIOACTIVE AND OTHER ENVIRONMENTAL THREATS TO THE UNITED STATES AND THE ARCTIC RESULTING FROM PAST SOVIET ACTIVITIES.}

\section{Summary of a testimony given by Odd Rogne, the Executive Secretary of IASC, The International Arctic Science Committee, at an open hearing organized by the United States Senate, Select Committee on Intelligence in Fairbanks, Alaska on 15 August, 1992.}

Let me first congratulate the US Senate, Select Committee on Intelligence on taking a serious interest in the arctic environment, and on calling this very timely hearing. In the invitation to this hearing I was asked to submit new information on the subject. As it is hard to tell what you already know, I have prepared an introduction in which I briefly will introduce some major events that - in my mind call for some action. In addition I have prepared an appendix that is a short summary of information in various reports and other sources available to me. 1 am pleased to note that $\mathrm{Mr}$. Gates mentioned half of my items and only two not being in my list.

\section{New Information - Causes for Concern.}

Some 30 nuclear dumpings or accidents are noted when reviewing a series of reports and sources, see details in the Appendix. Verifying this list is impossible till the Russian files are made open, or documented in other ways. Another aspect is that the list is growing each month, and even this long list may only represent the tip of the iceberg.

However, there is sufficient alleged information that causes a strong concern and calls for immediate attention.

Let me give you a few examples representing different categories of problems:

- 12 submarine and 3 icebreaker reactors were dumped in the waters off Novaya Zemlya. Some 17,000 containers of liquid and solid nuclear waste dumped in the same coastal waters.

Bilateral Norwegian-Russian meetings indicate that this information is close to the truth, and is the task of a bilateral field investigation that started a few days ago. Norwegian authorities have also indicated that they may contribute to a clean-up action of this nuclear waste.

- The Mayak Plants: probably the worst contaminated nuclear area in the world, and it drains into the Arctic. It is estimatea to be "l00 times worse than Chernobyl". Major accidents have occurred at Kystym and Karachy with "death clouds" affecting 10,000 and 430,000 people respectively.

An illustration of the situation is that you get a deadly radioactive dose in just one hour if you are on the shore of Lake Karachy without any protection. 
In addition to being a potential threat to the arctic environment, the real challenge of the Mayak Plant is to organize an enormous clean up action that calls for a major international effort. Hnw to do that is a political question.

- About 80 nuclear submarines of the Northern Fleet should be disposed of during this decade, i.e. about 150 nuclear reactors, and presently representing a hazard to the arctic envionmrnt. Russia lacks proper nuclear storage and other resources to do it safely.

This problem represents a major challenge both as to costs and safety, and there are few countries that can contribute to the solution.

- Nuclear testing to start at Novaya Zemlya in October this year.

This decision is depending on US stopping their nuclear testing. I have noted that US Senate recently has voted positively on this issue, and I really hope that this will be the final outcome. The fragile arctic environment has been exposed to sufficient radio nuclides already.

- Industrial emissions.

Another type of threat to the arctic environment is industrial emissions both within the Arctic and transported to the Arctic by air masses or in other ways. This is an ongoing process and alarming values of heavy metals, PCB and other pesticides have been measured.

Some emissions in the arctic part of Russia:

$-716,000$ tons of various toxic emissions in the Kola area

- 2.6 million tons at Norilsk

Although this contamination has the worst effects within the regions mentioned such as growing industrial deserts, severe health damage etc., toxic clouds are drifting to most of the Arctic. An illustration again: A report claims that in Norilsk children have to stay indoors 90 days a year because of this pollution.

- I refer you to Appendix I for further details and other examples.

\section{Monitoring Programs.}

2.1 Ongoing Monitoring.

There is a modest network of sampling stations in the Arctic as to radio nuclides transported by air, supplemented by airborne programs.

My main concern is that there is no regular monitoring of the arctic marine environment, although some sampling has occurred in the Arctic Ocean and adjacent seas but more on an ad hoc basis.

For details see: Report on Radioactivity in the Arctic Region, prepared by O. Paakkola, in The State of the Arctic Environment Reports, Rovaniemi 1991. 
2.2 AMAP - The Arctic Monitoring and Assessment Progamme.

This is a govemmental cooperative programme between the arctic nations under the Arctic Environmental Protection Strategy (the Finnish Initiative).

Planning has started and plans for a comprehensive monitoring program for the arctic environment are expected to be ready at the end of this year.

Most of the activity will comprise a coordination of ongoing monitoring, although there are gaps that have to be filled. Monitoring of radio nuclides will be included but details are not yet known. An active participation by the US in AMAP is undoubtedly one important step to be taken.

3. Future Needs.

The furst steps to be taken do not require any new basic science initiatives. However, experts and scientists would have to be involved in such actions as for instance:

- Documentation of information on nuclear waste dumping etc. representing serious threats to the arctic environment, and assessment of risks.

As mentioned earlier the bilateral Norwegian-Russian investigations will be made available in the form of a preliminary report to the meeting in November this year of the London Commission. Norwegian environmental authorities will also share this information bilaterally with interested countries.

- Adequate monitoring, establishing a network of monitoring stations for the marine environment is needed. No further comments should be needed.

- Accumulation of radio nuclides, heavy metals etc. in marine and terrestrial ecosystems: Some investigations and studies of effects have been carried out, but they are far from sufficient to give a complete picture of all the Arctic.

- Another type of initiative that should be mentioned is the proposal to NACC (North Atlantic Cooperative Council, a joint NATO and earlier Warsaw Pact members' forum) for a study on safe scrapping of nuclear submarines and handling of nuclear waste. The intention is that the study should constitute the basis for working out intemational guidelines, which do not exist. A wholehearted participation by USA in this effor would be most valuable.

\section{The Role of IASC.}

IASC - The Intemational Arctic Science Committee - is a non-govemmental scientific organization established to encourage and facilitate intemational consultation and cooperation in arctic research. The strength of IASC is that it embraces all fields of arctic science, covers all the Arctic and promotes a circumarctic approach. All arctic countries are members as well as six other countries having a major research activity in the Arctic. IASC is well suited to take interdisciplinary science initiatives. 
IASC has several programs underway of importance to the arctic environment, one of which is the International Arctic Global Change Programme.

As for the alleged nuclear threat to the arctic environment, there seems to be a need for a clarification as to what will be done bilaterally, what will be covered by special programs such as AMAP and other specialized organizations (IOC, SCOR).

The IASC Executive will discuss this question in early November and monitor the development till then. If there is a need for an international science based initiative that best can be met by IASC, we are most willing to do so.

\section{Conveying of Regrets.}

I have been asked by two other persons being invited to this hearing to convey their regrets for being unable to attend:

- Academician Igor S. Gramberg of St. Petersburg, Russia said that he strongly supported your effort, and that he would offer one of his institute's ships for an environmental cruise to the high Arctic. An invitation for international participation will be distributed through IASC.

- Mr. Lars-Otto Reiersen, the Executive Secretary of AMAP, mentioned that US interest both in radio nuclides and other pollutants that can seriously harm the arctic environment is most welcomed. 
Appendix I

\section{Radioactive Pollution of the Barents and Kara Seas.}

The information contained in this list has not been verified by me. It is a simple list of information collected without any effort to sort or organize it in any way. If a report or other source includes information that can add to the reliability, a short remark is added.

The intention is not to give a full overview or scrutinize the subject as such. It is made for my own use at a public hearing. However, it is beyond doubt in my mind that some of these wastes and potential accidents represent a danger to the health of the people living close to the sites and to the environment both close to the sites and where a major radionuclide pollution can be transported by sea currents and otherwise. As such it is an environmental problem of concem to several arctic states.

Russian environmental authorities seem to have taken this problem seriously, and of course it is an environmental threat primarily of concem to Russian people and environments. However, the magnitude of the problem and resources needed to solve it call for bilateral and intemational cooperation both in science, technology, monitoring and financial support.

\section{The Barents Sea - Biological Resources and Human Impact.}

A map published in 1991 by Norsk Polarinstitutt in cooperation with a Russian and a Polish institute. The nuclear problem is put in a broader context on this map, which gives only general information. Russian scientists had rather detailed information in 1990 and were strongly concerned, but verifying it to a degree necessary for a responsible research institute was impossible at that time. The published and non-published inform ation was handed over to the environmental authorities in Norway and has led to Norwegian-Russian cooperation ( see below ).

Environmental non-govemmental organizations became engaged in this field and have produced a lot of information, often in cooperation with Russian environmentalists and with specific information from Russian officials in addition.

\section{The Expert Group to Investigare Asserted Dumping of Nuclear Wastes in the Barents and Kara Seis.}

Norwegian environmental authorities brought up this question bilaterally with Russian authorities based on information from 1) and other sources, and they agreed to start joint investigations in connection with the assertions conceming dumping, or in other words : both Norwegian and Russian authorities had sufficient information to be really concemed. It was also agreed that Norway should prepare a proposal for a joint programme of investigations.

An expert group was tasked to make this proposal. Their report contains a summary of available information ( 1991 ) and a proposal for a joint programme. The activities suggested were:

- Meetings and visits in order to obtain information and facts about the handling, storage and discharge/ dumping of radioactive material in northem areas.

- Mapping of radioactive pollution by means of field work in northem marine areas, in order to determine whether some of this pollution originates from dumped nuclear wastes. 
- Possible localization of dumped nuclear wastes, and investigations to determine if leakage is taking place from the dumped material to the marine environment.

- Undertaking an impact analysis to determine the effects on human beings and the environment of pollution from different sources.

- Informing the public about the results of the investigations.

The repon gives further details and can be useful studying.

The programme will be carried out in 1992 and 1993.

Later reports from bilateral meetings give details on field investigations, methods to be used etc. Field work to stan 14 August 1992.

\section{Asserted Information on Nuclear Wastes.}

Please note that some of the listed information overlaps. This is due to the fact that the list is based on various reports and sources.

- 12 submarine nucleas reactors and three icebreaker reactors have been dumped in the waters off Novaya Zemlya

- One whole submarine - the K-27 - powered by a liquid-metal cooled reactor, was dumped in the Stepovov Gulf after an accident in May 1968. Its two fueled nucleas reactors were dumped in the same location off the southem island in 1982.

- Eight reactors, three of which still contain their nuclear fuel, were dumped with sections of four accident-damaged nuclear submarines in waters just off the $\mathrm{K}-27$. The submarine sections from the K-11, K-3 Leninski Komsomol, K-19 Hiroshima, and one unknown - were repontedly dumped during the years 1964-65.

- Three damaged reactors from the icebreaker "Lenin" are dumped at sea close to Novaya Zemlya.

- Over 17.000 containers of liquid and solid radioactive waste were dumped.

- Novaya Zemlya (Russian Arctic island) is now the only nuclear test site in Russia, and has proven to be one of the largest nuclear dumping grounds ( Alexander Yemelanenkov, Russian chaiman of the anti-testing association "Towards Novaya Zemiya", and also by Andrei Zolockov a nuclear engineer aboard the "Imandra", a nuclear refueling ship for icebreakers in Murmansk).

- Novaya Zemlya Trench : 1450 contsiners. Barge with a damaged reactor (activity: $170.000 \mathrm{Ci}$ ) Barge with liquid radioactive wastes.

- Neypokoyev Gulf ( Novaya Zemlya ): Solid radioactive wastes ( activity : $3.400 \mathrm{Ci}$ ).

- Sivolky Gulf ( Novaya Zemlya ) : 4750 containers. The barge "Bauman". The central section of the icebreaker "Lenin" and screen assembly and three damaged reactors.

- Oga Gulf ( Novaya Zemlya) : 850 containers.

- Stepovov Gulf ( Novaya Zemlya ) : 1850 containers and a damaged nuclear submarine with two fueled nuclear reactors. The submasine is reportedly the K-27 which had a liquid metal accident on 24 May 1968, the reactors were dumped in 1982.

- Abrosimov Gulf ( Novaya Zemlya ) : 550 containers. Sections of four accident-damaged nuclear submarines with a total of eight reactors, three of which still contain nuclear fuel. Sections of submanines K-11, K-19 Hiroshima, K-3 Leninski Komsomol, and another unknown, that were dumped in 1964-65. The K-19 had a severe accident in the North Allantic in 1961.

- Blagopoluchiye Gulf (Novaya Zemlya): 650 concsiners. 
- Techenniya Gulf ( Novaya Zemlya ) : Accident-damaged nuclear reactor without their nuclear fuel (Activity: $1.850 \mathrm{Ci}$ ). Open sea ( two different sites ): 400 and 250 containers respectively.

- Unnamed location on southern end of Novaya Zemlya : presumed location of regional radioactive waste storage.

- Sites of Nuclear Explosions on Novaya Zemlya :

- Sykhoy Nos Cape : The area where the biggest atmospheric nuclear explosions took place.

- Matochin Char: This is where the last test took place.

- Black Inlet : Area of the first underwater, above water, and under-seabed nuclear tests on Novaya Zemlya. Area where the vessel "Kit" was located and presumed location of the sunken submarine "Komsomolets"

- South-west sector of Novaya Zemlya : The presumed area for the development of a longrange program of nuclear testing. (See : map of Novaya Zemlya by Greenpeace)

- Dumping of lowgrade liquid nuclear waste continues in the Barents Sea (July 1992 ). Less dangerous, but should have been dumped in deaper waters (3-500 Ci )

- Dumping of solid wastes continued till 1990. In that year 219 cubic metres solid nuclear wastes were dumped, and 6000 cubic metres liquid wastes ( V. Perovsky, Director of the lnstitute of Energy Technology, St. Petersburg )

- Russia needs storing fascilities for 75.000 cubic metres of nuclear wastes, including many of the 270 reactors on board nuclear vessels ( Perovsky)

- Every year 1100 cubic metres of solid nuclear waste is being produced in the Kola area, and about 6.500 cubic metres of liquid wastes. Only 5-6\% is high grade. The nuclear plant Poljamy Zori is the biggest producer of wastes, followed by the naval yards in Poljamy and Severodvinsk (Perovsky)

- Producers of nuclear wastes on the Kola Peninsula ( Perovsky ):

-4 operative reactors in power plants

-7 nuclear icebreakers

- 5 nuclear support vessels

- "Lenin", the first nuclear icebreaker, no longer operative,and the reactors are still on board representing medium active nuclear waste

.170 nuclear submarines, of which 80 are modem

-2 nuclear cruisers

- Large quantities of accumulated nuclear wastes are stored on board vessels harboured in Murmansk. There is no permanent storage for nuclear wastes.

- Nuclear submarine "Komsomolets" caught fire and sank April 7, 1989, 193 kilometers southwest of Bear Island (Norwegian Arctic ), 42 of its 69 crewmen were killed in the accident. Measurements in 1991 showed barely measureable traces of radioactive cesium from its reactors. Norwegians will take regular samples in the area

- The Soviet Union dumped radioactive waste in the Kara Sea during summer 1991 ( A. Mikhailov,top nuclear safety official, Murmansk )

- Russia must scrap 10 nuclear submarines by 1996, but lack resources to do it (Vice Admiral O.Yerofayev, commander of the Northem Feet)

- About 50 nuclear submarines should be decommissioned between now and the end of the decade (Russian manager of the submarine building yard at Sverodvinsk, the largest in the world)

- US Navy operates 120 nuclear submarines and 15 nuclear surface ships

- CIS Navy - the Northem Fleet- continues dumping of liquid nuclear waste at sea (June 1992). The vessel "Amor" is being used ( A. Kiss, Chaiman of the Murmansk Environmental Committee) 
- Some 80 submarines are awaiting disposal, and another 80 nuclear submarines are likely to be retired in the next few years. meaning some 300 submarine nuclear reactors will have to be disposed of (Greenpeace)

- CIS admirals seeks US support to destroy 79 nuclear submarines. Most of the submarines are anchored at sea - a situation that could lead to corrosion and pipe breaks in the system that cool the ships'nuclear reactors ( Admiral Mahonin, in WSJ 3/27/92)

- Since 1957 about 120 atomic bombs are detonated on Novaya Zemlya., 86 bombs in the atmosphere, 3 under water in the Barents Sea, 5 in the air over the Barents Sea and the rest underground on Novaya Zemlya. Detonations of nuclear bombs will be resumed in October 1992 if USA continues their nuclear testing in the Nevada Desert. Novaya Zemlya is now the only nuclear testing ground in CIS after the closure of Semipalatinsk, which was closed due to strong protests from local residents (Bellona information)

- USSR has detonated 115 "civilian" nuclear bombs in connection with geological activities. In 1972 and in 1984 two bombs were detonated in a mine in Kola to increase the production of ore (Bellona)

- USSR exploded approximately 130 "peaceful" nuclear detonations to build dams, mines, and underground storage of toxic wastes (A. Yablokov. Environmental Advisor to Yeltsin )

- Nuclear bombs have been used to destroy toxic wastes on Novaya Zemlya,and is now being advertised by a Russian company as an efficient way of disposing of extremely toxic wastes ( Bellona)

- The power plant at Poljamy Zory with its 4 reactors is one of the most dangerous plants in the world. During 1987-91 they had 8 minor accidents and one of them leaked an unknown quantity of nuclear pollution ( Bellona)

- Nuclear wastes from hospitals and industry is being stored at the Ura lake wrapped in plastic and put into concrete containers of bad quality (Bellona / enviromentalist Lena Vasiljeva. Murmansk)

- Murmansk Shipping Company have 6 nuclear icebreakers and one container ship based in Murmansk. Nuclear wastes are being stored on 5 vessels for $1-3$ years before the wastes are sent to Tsjelabinsk in Siberia. Security routines are severely criticized. (Bellona)

- The Mayak plants are the military and industrial nuclear works in Siberia some 50 miles north of Tsjeliabinsk, and the nucleus of Soviet nuclear production since 1948. " Mayak represents a problem 100 times that of the Tsjemobyl " ( A. Penyagin. chairman of the committe for nuclear ecology of the Supreme Soviet ). Nuclear wastes were dumped into the river Techa which is nnning north and flows into arctic waters. In Metlymo, a small town down the river, the population was not informed and used the containated water till the whole town was evacuated in 1958. Then the small lake Karachay was used for dumping of neuclear wastes. This lake is the most contaminated place on earth, one hour at the shores of it represents a deadly dose of nuclear radiation. Two major accidents in the area : that of Kysthym in 1957 releasing nuclear material of 2.1 mill. curie and forming a radioaktive cloud drifting some $300 \mathrm{~km}$ to the northeast. About 10.000 people were evacuated ( 100 few and too late), all vegetation killed within an area of 5 square kilometers. compared to Tsjemobyl more than 100 times of cecium 137 and 500 times more of strontium 90 were released. The other accident occured in 1967 as a radioactive dust drift from the lake Karachy, area affected similiar to that of Kysthym and about 430000 people were affected. About 5 mill. curie were released (Bellona) 


\section{Information on other industrial emissions.}

Emissions from other industrial activities may represent a bigger threat to the arctic environment as a whole than that listed under nuclear wastes, although the latter is a matter of serious concem. Information on industrial emissions form the former Soviet Arctic is still not very spesific,but the following may represent a start and is sufficient for a serious concem :

- Annually 716.000 tons of toxic emissions are released into the air on the Kola Peninsula leading to deforestation spreading by one kilometer each year. Vegetation in neighbouring states are already affected and will be increasingly so.

- Emissions by area ( all on the Kola peninsula only ):

- Nikel : 280.000 tons of SO2, nickel, heavy metals and dust.liquid wastes into a lake that is leaking into arctic waters,

- Apatity/Kirovsk: 62.000 tons of SO2, wastes stored on land

- Murmansk : 65.000 tons of SO2 and dust, several leakages to the sea

- Monchegorsk : 240.000 tons of $\mathrm{SO} 2$, heavy metals discharged into a lake

- Olenogorsk : 20.000 tons of SO2, 11 mill. tons of waste to be disposed of every year

- Kovdor : 16.000 tons of SO2, 1 mill. tons of other wastes

- Kandalaksja : 26.000 tons of SO2, obsolete technology

- Norilsk. east to the river Jenisej in Siberia, is a major mining and industrial city and a heavy polluter of the Arctic:

-2.4 mill. tons of SO2 released every year and the toxic clouds are drifting to most of the Arctic

- About 250.000 tons of metals are released every year

- 90 days a year the air is so toxic that the children has to be kept indoors, severe health damages are reported

- trees and vegetaion killed by SO2 and heavy metal in an enomous area that is increasing annually

( mostly from Bellona information )

\section{The Arctic Environment - Selected References.}

In addition to the rather spesific information given above, you may wish to get an overview of the arctic environment in general. The following publications may serve that purpose :

- The State of the Arctic Environment Reports

Rovaniemi 1991, 405 p.

This volume presents six spesific state of the environment reports:

- Acidification in the Arctic Countries

- Heavy Metals

- Underwater Noise

- Oil Pollution

- Organochlorines

- Radioactivity in the Arctic Region

This is probably the most authoritative and comprehensive overview of the state of the arctic environment.

- Jaworowski, Zbigniew

Pollution of the Norwegian Arctic: A Review

Oslo $1989.93 \mathrm{p}$.

Although some attention is given to the Norwegian Arctic. the author reports on all the Arctic. 
STATEMENT OF DR. ODD ROGNE, EXECUTIVE SECRETARY, INTERNATIONAL ARCTIC SCIENCE COMMITTEE, OSLO, NORWAY

Dr. Rogne. Thank you, Senator. Do you hear me? Good. Let me first congratulate the U.S. Senate Select Committee on Intelligence.

Senator MURKowSKI. I think you better speak a little closer into the microphone.

Dr. RoGNE. All right. It's better now? Okay. Let me first congratulate the U.S. Senate Select Committee on Intelligence in taking a serious interest in the Arctic environment, and on calling this very timely hearing. In the invitation I was asked to submit new information on the subject. As it is hard to tell what you already knew, I have prepared an introduction and I have prepared an appendix. And in the appendix you will find a summary of all information I have had from various reports and sources. And after hearing this hearing this morning, I'm also pleased to note that Mr. Gates mentioned half of my attempts and only two not being in there.

First, new information and some causes for concern. You will find in the appendix that about 30 nuclear dumpings and accidents are noted when I've reviewed a series of reports and sources. Verifying this is impossible till we get the Russian files opened. And I think that is extremely important. From the Norwegian side, we have done what we possibly can do, but a mouse cannot scare an elephant. So we had to go on field trips to find out reality.

However, the material we have at hand is sufficient alleged information that causes a strong concern and calls for immediate attention.

Let me give you a few examples representing different categories of problems. You have mentioned earlier that 12 submarines and three icebreaker reactors which were dumped in the waters off Novaya Zemlya. Also some 17,000 containers of liquid and solid nuclear waste dumped in the same coastal waters.

Bilateral Russian-Norwegian meetings indicate that this information is close to the truth, and is now the task of bilateral field investigation and bilateral cooperation, and you have also heard mention shortly that there's a cruise started two days ago. I would not be so worried about these as also the Norwegian authorities have indicated that I will be willing to contribute a cleanup action.

My second example is the Mayak plants, probably the worst contaminated nuclear area in the world. And the area drains into the Arctic. In some reports you will see that this problem is 100 times worse then Chernobyl. Of course, that is a rough estimate. However, as reported just a few minutes ago, some major accidents have occurred at Kyshtym and at Karachev with death clouds affecting 10,000 people and 430,000 people respectively. An illustration of a situation at the Lake at Karachev is that you can be at the shore for about one hour till you get a deadly dose.

In addition to being a potential to the Arctic environment, the real challenge is to organize an enormous cleanup action, and it calls for international effort. How to do it is a political question in the scientific world. So, it's your turn, not mine. 
Let me take another example. About 80 nuclear submarines of the Northern Fleet should be disposed of during this decade, and that is about 150 nuclear reactors. And presently representing a hazard to the Arctic environment. Russia lacks proper nuclear storage and the resources to do it safely. This problem represents a major challenge both as to costs and to safety, and there are few countries that can contribute to the solution.

The next item, which might be a good one, but worse at the start, nuclear testing to start at Novaya Zemlya in October this year. This decision is depending on U.S. stopping their nuclear testing. And I've noted that the U.S. Senate recently has voted positively on this issue, and I really hope that that also will be the final outcome. The fragile Arctic environment has been exposed to sufficient radionuclides already.

I also want to take just one item outside this radionuclear feat, namely industrial emissions. This is a different type of threat but it is a known threat. It is a thing going on all the time, both by industrial emissions within the Arctic and those being transported to the Arctic. And in some places there have come forward some alarming levels of heavy metals, PCB and other pesticides.

If I should give just some figures for emissions in the Arctic part of Russia, there is in the Kola area about 716,000 tons of various toxic emissions every year. In the Norilsk area 2.6 million tons of the same stuff. Of course, this contamination has the worst effects within the region locally, with also growing industrial deserts, in the Kola area about one kilometer each year, causing severe health damages, toxic clouds are however drifting all over the Arctic.

Just to give an illustration, in Norilsk they report claims that the children in the town have to stay in house 90 days a year because of the local contamination.

The second question pu: As to ongoing monitoring $v_{b-}$ 's, there is a model network of sampling stations in the Arctic as to radionuclides transported by air, and of course supplemented by airborne programs. My major concern, however, is the marine environment. there is no regular monitoring program going on on a circum-Arctic basis, although some samplings have occurred in the Arctic Ocean and adjacent seas on more or less an ad hoc basis.

You will also have in the written statement a reference to a review of this question, given in The State of the Arctic Environment Reports, Paris and Rovaniemi.

The next one I would like to mention is AMAP, as mentioned earlier. I will not repeat what has already been said. Planning on this program has started, and radionuclides will be included. But the plans will be finished at the end of this year, so it's too early to give further details. However, I would strongly encourage the United States not to stand in the doorway as to AMAP but come in and join the others with full participation. You should be a lead country, not a slightly interested country.

I also was asked about future needs. And of course, this question had been answered by several at the table already. Documentation of information; we'll not go into that except for mentioning these bilateral Norwegian-Russia field investigations. I've had a possibility to read all the reports and seen all the planning documents. 
And I think others could benefit from what already have been done and also share other experiences. The results from the NorwegianRussian investigations will be made available in the preliminary report to the meeting in November this year in the London Commission. Norwegian environmental authorities will also share this information bilaterally with interested countries.

Then follows, of course, the need for adequate monitoring, talking about AMAP, and no further comment is needed.

As to accumulation of radionuclides in heavy metals in marine and terrestrial ecosystems, reports have been given already here. And we could conclude that the studies of effects have been carried out but are very few and not at all sufficient to give a complete picture of all the Arctic.

I would, however, like to mention quite another type of initiative. You should know that there is a proposal to NACC, the North Atlantic Cooperative Council, a joint NATO and earlier Warsaw Pact members' forum, for a study on safe scrapping of nuclear submarines and handling of nuclear waste. The intention is that the study should constitute the basis for working out international guidelines, as to scrapping nuclear submarines, such guidelines do not exist. A wholehearted participation by U.S.A. in this effort would be most valuable. And I'll refer you back to what was said about Russian submarines need to be scrapped.

I should also add a few words about the role of IASC, the organization I presently represent. The International Arctic Science Committee is a non-governmental scientific organization established to encourage and facilitate international consultation and cooperation in the Arctic. The strength of IASC is that it embraces all fields of Arctic science, covers all the Arctic and promotes a circum-Arctic approach. All Arctic countries are members as well as six other countries having a major research activity in the Arctic. IASC will be well suited to take interdisciplinary scientific initiatives. IASC has several programs underway of importance to the Arctic environment, one of which is the International Arctic Global Change Program.

As for alleged nuclear threat to the Arctic environment, there seems to be a need for a clarification as to what will be done bilaterally, what will be covered by special programs such as AMAP, and other specialized organizations like IOC or SCAR.

The IASC Executive will discuss this question in early November and monitor the development till then. If there is a need for an international science-based initiate that best can be met by IASC, they are most willing to do so.

I have also been asked to convey some regrets. Academician Igor S. Gramberg of St. Petersburg, Russia told me that he strongly supported your effort, and he would offer one of this institute's ships for an environmental cruise to the high Arctic. An invitation for international participation will be distributed through IASC.

Also, the Executive Secretary of AMAP sends his best regards, and mentioned that a strong U.S. interest both in radionuclides and other pollutants that can seriously harm the Arctic environmental are very welcome. Thank you.

Senator MURKowSKI. Thank you very much, Dr. Rogne. 


\section{2}

Our next member of the panel is Dr. Glenn Shaw, the Geophysical Institute of the University of Alaska. Please, Dr. Shaw, proceed.

[The prepared statment of Dr. Shaw follows:] 


\title{
Transport of Radioactive Material to Alaska
}

\author{
Glenn E. Shaw \\ Professor of Physics \\ Geophysical Institute \\ University of Alaska
}

Testimony to U. S. Senate Select Committee on Intelligence

\begin{abstract}
There is clear evidence that in winter the Arctic fills up with air pollution from industrialized areas of surrounding continents. The cause is lack of solar rediation, which contributes to the high stability of the air. Records from ice cores indicate a marked increase in the pollution levels in this century, particularly since the mid 1950 's. Since Eurasian industrial pollutants contribute the largest fraction of Arctic Haze, there is a definite probability that radiosctive releases in Eurasia could spread across the Arctic Basin. Implementation of a large and sophisticated international networt of early waming stations, along with excellent science research programs involving leadership from universities around the circumpolar north is vitul. First priority needs to be addressed to health concems of people living in the Arctic Basin.
\end{abstract}

\section{INTRODUCTION}

In this testimony I would like to point out that the Arctic is like a stagnant pond. In the winter, the whole of the arctic atmosphere, an aimass roughly the size of the continent of Africa, becomes mascively polluted The situation is much like that in the Los Angeles Basin: air pollution builds up because of the lack of an outlet. This is a potentially threatening situation if contaminants are released into the air.

In my opinion, given the high probability of releases of radioisotopes into the atmosphere from the former Soviet Union, it is critical to implement an early warning network of stations scross the Arctic. Such a networt wonld provide waming for episodic relenses of rudionctive material and, of course, would have to be an intemational project, involving nations of the circumpolar region.

\section{SOME COMMENTS ADOUT ARCTIC haze POLLUTION}

Scientists in Canada, the United Stutes and Scandinavia in the last few years have been invertigating the chemical, climatic and health effects of srprisingly strong industrial air pollutants suspended throoghout the aretic atmosphere. This so-called Arctic Haze phenomenon was discovered independently in Alacta and Norway twenty years ago.

Though arctic is pollution has been under intensive scientific invertigntion (there have been several books published on the mbject and more than 700 scientific articles), there still are major unanswered questions that relate to contamination of wide areas of the Arctic by possible radioective relenses into the eunosphere.

Of particular concem is the lare uncertainty about the pathways and fate of pollution products released or injected into the aretic atmosphere. We know that material released into the arctic atmosphere has a long life and therefore travels for great distunces. What isn't known, is the extent and location of the geographical regions where the material falls out of the atmosphere and enters the ecological system. This is suspected to be in sources near seas entering the Aretic, where sources of moisture form clouds which remove the material. There is the possibility, therefore, of 
impact to fisheries. Since answers to such questions are so critical when we speak of possible radioactive contamination, a strategy must be developed to involve excellent multidisciplinary scientific research, in addition to mere monitoring. The problem must involve the major scientific apparanus of states.

\section{A cCidental Releases of Radioactive material from the former Soviet UNION}

As this hearing unfolds, a large and varied number of examples of accidental contamination of the arctic environment will be brought to light. I will use the story of Chemobyl to illustrate that it is by no means an academic issue to speak of a rapid and unexpected contamination of the Arctic. As it happened, the weather patterns were anomalous during late April and early May when the plume spread out The radioactive cloud traveled along the north Pacific, thus sparing the Arctic from receiving what otherwise might have been a catastrophic event.

When the 1000-megawatt nuclear power plant at Chernobyl village, 80 miles North of Kiev in the Ukraine, lost coolant to the reactor's core in April, 1986, the fission continued within the nuclear fuel rods; without water to cool them off, heat built up rapidly. As the temperature rose, the remaining water turned to steam and gases which exploded, shattering the building, igniting the graphite and blowing out the core. The radioactive material injected into the atmosphere split into two paths, one passing over and affecting Scandinavia, the other traveling across southem Siberia and the north Pacific.

Strong storm systems near the Aleutian Islands helped scrub the radioactivity out of the atmosphere, resulting in only modest amounts of debris falling out on western North America, including Alaska. Figure 1 shows the rise, then decline of radioactive material measured by the University of Alasta after the Chernobyl explosion.

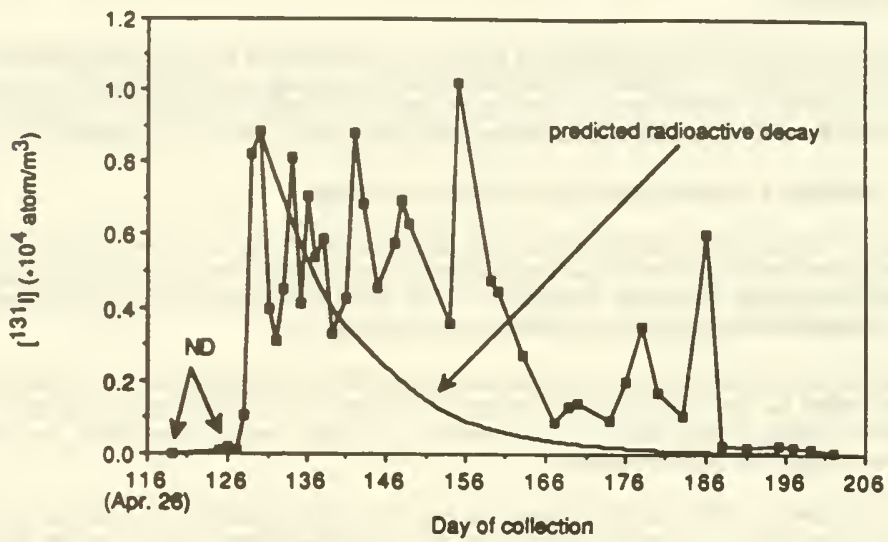

Figure 1. Time profiles of the ladine 131 concentrations at Fairbanks. 
a fortunate sttuation for alaska durng the Chernozyl Embrgency

Arctic Haxe builds up to maximum strength in winter. The affected zone lies mainly within the boundaries of the meteorological features of the Aretic Front, shown in Figure 2.

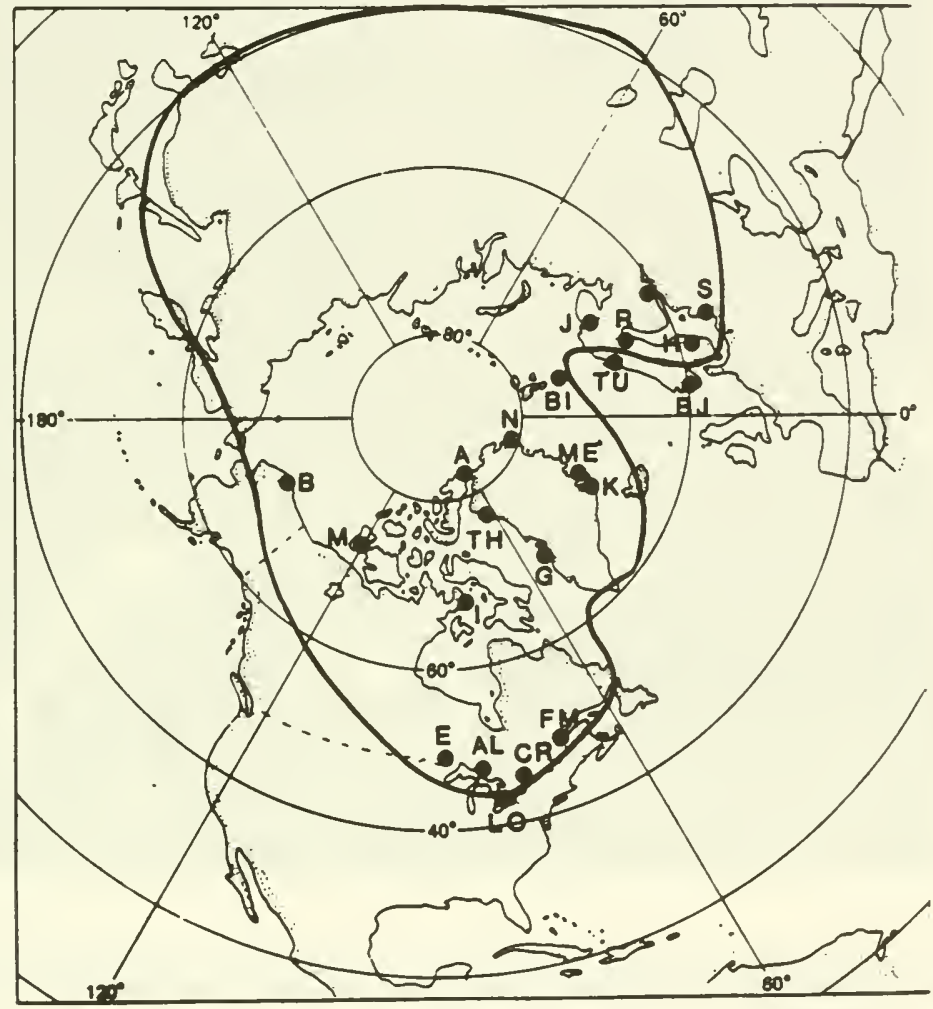

Figure 2. The Arctic Front boundary in winter. The region within the frons is strongly polluted in winter from incustrial sources in Eurasia. 
The extensive pollution building up throughout the arctic atmosphere is caused by the lowered rates of atmospheric cleansing. In a way, the arctic atmosphere is like a stagnant pond of water, possessing very little turbulence. There are also lowered rates of removal by precipitation and clouds, both of which are sparse in the Arctic. This science concept is illustrated in the cartoon in Figure 3.

ARCTIC HAZE

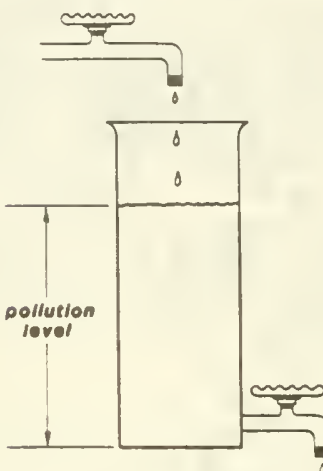

output tap

nearly closed off
NORMAL MID LATITUDE

AIR POLLUTION

large input

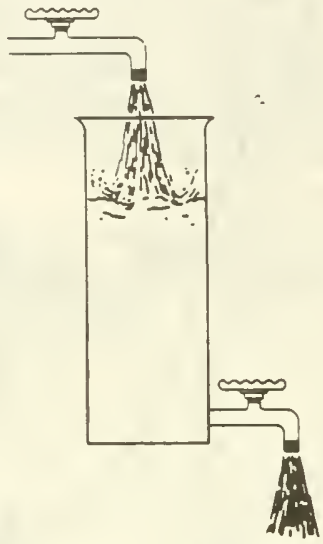

tap opened wide

Figure 3. Ilburation of how pollution builds up in the Arctic because the "ourput tap" is nearly closed off.

Research programs conducted by our university and other organizations over the last twenty years have identified chemical fingerprints of specific pollution sources in the former Soviet Union. For example, fumes from the large copper-nickel mining and smelting complex at Norilsk on the Taymhr Peninsula (the satellite photo in the figure) have been detected at Barrow. 


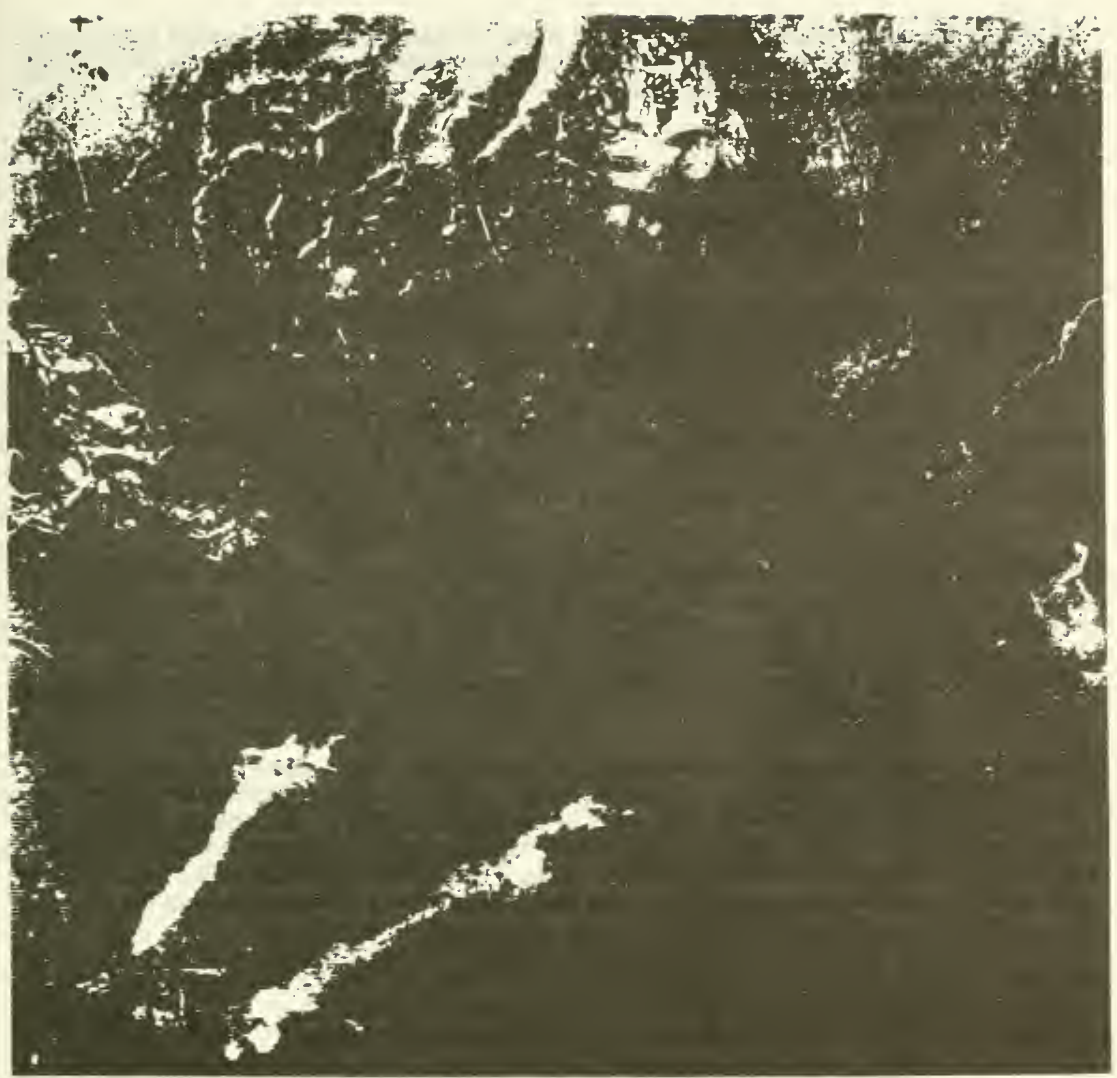

Figure 4. Satellite photo showing plumes from the smelting complex at Norilsk in Siberia. 
Specific pathways for pollutunts traveling in the Arctic to Alaska have been identified and classified into patterns. The most commonly occurring transport route for air pollutants from Russia to Alasto are simite to thoce shown in Figure 5.

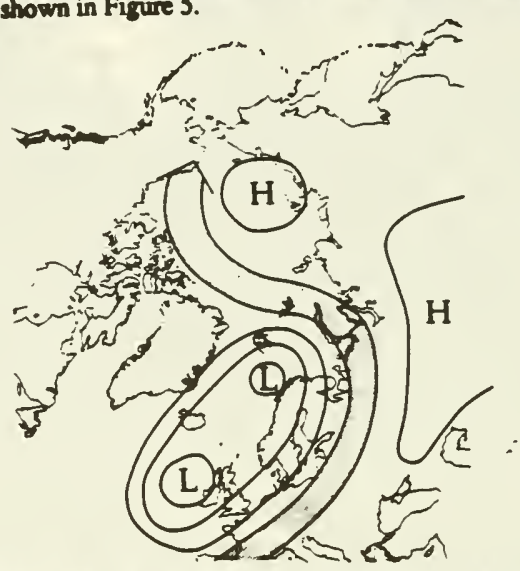

Figure S. A spical trousport route for polluted air troveling from Eurasio to Alasta during spring months.

Since the weather patterms were anomalous in April, 1986, rather small quantities of fallout cocurred in the Arctic Basin. It is quite common to have "injection pathways" of pollutants traveling from the centril and westem regions of the USSR into the Arctic during this time of year when Arctic Haxe is a its maximum. We have been measuring the Aretic Haze at Poker Flat Research Range nee Pairtents for many years. Note in the figure, showing data from the University of Alaka's mearuing system, that the concentrution is maximum in April-May.

rater The

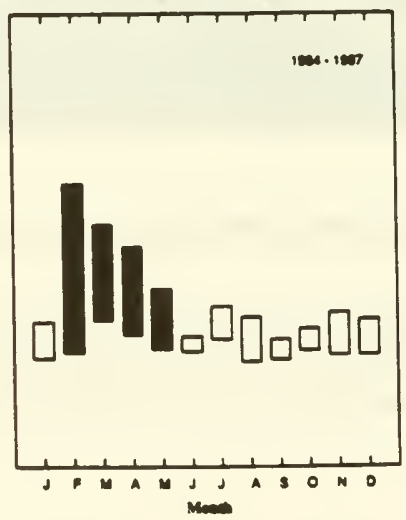

Figure 6. The Seasonal variation in pollution-derived seleniwn in air sampled near Fairbanks. Nodice the madimum concentration occurs in the spring months. 
Even though the atmospheric transport pathways from the Soviet Union to the Arctic Basin are commonly open in spring, the weather patterns in late April and early May, 1986, carried the material from the accident away from the Arctic... indeed, a very fortunate circumstance for Alasiea!

\section{RECOMMENDATION FOR FORMING A STRATEgic PLAN}

I should like to compliment the Select Committee for conducting an open forum os this subject. This bearing is a good first step!

There must, first of all, be recognition that the understanding, modeling, monitoring and conversion of toxic materials passing through the environment is an extraordinarily complex issue, involving virtually every branch of buman knowledge. The job to be done is complex and must not be trivialized.

Odd Rogne's testimony today spelled out excellent major tasks of science, including documentation, monitoring, study and tracking of accumulation in marine and terrestrial ecosystems and modeling of transport. I urge the adoption of such wide-range thinking into the planning process.

Pollution of the arctic atmosphere is a transcontinental problem. By its aature it must involve affected states, especially those circling the Aretic. The governmental cooperative program called Arctic Monitoring and Assessment Programme (AMAP, the Finnish Initiative) is a starting place to belp coordinate some activities. There are other organizations with Arctic-wide viewpoints, such as the IASC and the North Atlantic Cooperative Council. The US State Department, in conjunction with its counterpart in the former Soviet Union, under the bilateral agreement might well begin activity to design a strategic plan.

The peoples of the arctic regions are under possible threat from future accidental releases of radionuclides and, possibly, from continued releases of beavy metal and organic compounds from the former Soviet Union. I would hope that groups like the circumpolar council insist that quality science and health programs be implemented on this issue.

Above all, it needs to be recognized that the Aretic is a very different environment than most people are familiar with. Residence times of materials, in marine and terrestrial ecosystems and in the atmospbere, are generally mucb longer due to the lack of moisture passing through the system. Paradigms borrowed from experiences of radiasctive waste treatment at mid-latitude sites are inappropriate for the anctic conditions. Atmospheric dispersion models, developed to accommodate air pollution abetement in mid leciudes are irrelevant for the polar conditions.

We need to demlop a strategic air dispersion model treating the need to accommodate data eatering in nearly real tine in order to develop emergency responses to episodic releases of radioactive material. We need to develop an extensive early warning system to protect buman bealth in the event of an emergency.

There is the need to extend the measuring network to toxic materials, such as pesticides and heavy metal pollutants. Such compounds already are beginning to affect the Arctic Basin. The major infliction pathways involve northward-flowing currents of air flowing over central Eurasis.

The stagnant pond analogy for the aretic atmosphere must be borne in mind. The arctic pollution is the largest documented polluted area on the planet. It may even have climste significance. 
In searching for a model in which societies have adopted to solve complex systems problems of the environment, like the present one, I turn to the example set by the National Center for Atmospheric Research, which is managed by a consortium of Universities under the University Corporation for Atmospheric Research. It has in recent years diversified its operation to include international affiliates. Funding for the enterprise has entered through a variety of sources, but mainly from the National Science Foundation. Research involving complex systems, including the climate change issue, by NCAR is continually reviewed, boch internally and externally. Pertaps in searching for a strategic model to handle the contamination of the Arctic, we might implement something like an international UCAR. 


\section{STATEMENT OF DR. GLENN SHAW, GEOPHYSICAL INSTITUTE, UNIVERSITY OF ALASKA}

Dr. SHAw. Thank you, Senator Murkowski. It's indeed a pleasure. The last time I was on this stage I was playing as a beginning violin player with the youth symphony and this is much easier, I can assure you.

My testimony is primarily directed today at two topics: the first one is, as everyone might guess, the topic of Arctic haze, which is the propensity of the Arctic regions, the Polar regions in general, to build up pollution. And the second thing that I want to talk about is some recommendations for general strategy regarding the topics that we're discussing at the hearing today.

Within the numerous mobile beltways on the planet, even perhaps including the liquid core of the earth, the floating planets, the most mobile medium by far, of course, is the atmosphere. And so in the event of a release of material that enters overtly or covertly perhaps by accident into the atmosphere, of course it's well known that the atmosphere has the characteristics that it transports material from one point on the planet to another point on the planet.

Now, for the most part, although this is recognized, it is not taken into account because materials in the atmosphere generally remain in the atmosphere for a fairly short time. So, for example, if you're living in the city and there is pollution in that city, it generally doesn't reach the next city over. It falls out of the air by the time transport occurs. In the Arctic what our research that was started 20 years ago and has been subsequently enhanced by many other groups has shown is that the output tap is closed, if you will, for the Arctic basin in general. That means that the Arctic atmosphere can be conceptualized as a bathtub with the output tap closed. The situation is somewhat similar to that occurring in the Los Angeles basin, except in this case it's a basin roughly the size of the continent of Africa. Anyone who has lived in Fairbanks has experienced the phenomenon of ice fog. If you're so fortunate as to not have to spend your winters in Fairbanks, you can go into the supermarket and observe that the cold air in freezers is dense and remains in the freezers, just sloshes around, even in Phoenix Arizona on a hot day. This is roughly what happens in the Arctic.

I have three view graphs that tend to conceptualize this general paradigm of the Arctic being a stagnant pond. They aren't showing too well, but I think you can see that the first view graph is making the point that there's two ways to fill up a beaker with fluid. One, of course, is to pour lots of fluid in, that's the normal pollution situation that we tend to think of here in the mid latitudes. But the other way that's just as effective is the stagnant pond analogy, the Los Angeles basin analogy, if you will, where a small amount of material into such an air mass will build up into rather large pollution values.

The Arctic atmosphere in general, as far as that goes, the Antarctic polar atmospheres on planets have this general property that the output plug is not working. As a result of this, many of the models, much of the knowledge, a great deal of the chemistry that has been compiled so far by agencies and by scientists regarding the transfer and fate of air pollutants, does not apply to the Arctic. And so one of our tasks is to invent new knowledge. 
Now if you'd be so kind as to show the next view graph, please. The next view graph, I'm sorry it doesn't show a little better. The yellow glowing region is that region of the Arctic within the meteorological feature called the Arctic front. This feature becomes severely polluted during the winter and late spring. And although the view graph doesn't show too well, you can see that this system extends over the Eurasian continent, in the middle of it, and it extends down over Canada and North America. This meteorological continent, if you will, is the size of Africa and becomes filled with rather strong, surprisingly strong, air pollution, air pollution that rivals that found in many large cities.

Now you can imagine perhaps if even a relatively minor atmospheric injection of radioactive debris were to be released in central Eurasia, for example, for that matter in northeast Canada, that this entire air mass could become polluted, affecting the peoples that are living in this air mass.

And I have one final view graph, please. This view graph is showing a pathway. About the only thing that can really be seen clearly is the yellow glowing arrow. This pathway passes around great meteorological fluid flows in the atmospheric system and is the most common form of pathway that extends from the, let us for tactful state, say Eurasia to the North American Arctic. Our monitoring efforts-I think we can have the lights back to normal, please. Our monitoring efforts at the University of Alaska and other people's as well have shown that the pollution episodes that I've must spoken of are truly global in extent; they occur every year; they're of more than academic interest; they're of more than academic interest, particularly because when dangerous compounds are injected into this affected air mass, they can affect very large areas.

In concluding my remarks, I would like to point out several things in making some recommendations. First, I would like to remind that this is not a problem in meteorology or oceanography or sociology or economics. It's a problem in all of these. This phenomenon is the legacy of the cold war. It's a legacy that we have to pass on to our children and perhaps it's the saddest legacy of all. My intuition is that the cleanup costs, both in health and monetary terms, to set the situation right, will be in the hundreds of billions of dollars eventually, if I had to make a guess. I would urge you, Senator and the Committee, I would urge that we don't parochialize the process and we don't fibulize it. That we don't imagine that there's one country or one agency, one university, one institute that can handle this problem. I would urge you to start adopting broad thinking. I think we need leadership from the scientific community, and in thinking how one might establish leadership like that, I'm wondering if perhaps we might consider implementing something like an overseeing agency of universities surrounding the polar regions. Something in the nature of the University Corporation for Atmospheric Research. Well, you could have the best part of corporate flexibility and the best part of intellectual insight brought to bear on this subject so that we can do it expeditiously and so that we can do it with as little cost and pain as possible. 
I have made some specific recommendations of things that shov' be done, like attention should be logicalıy given not only to radiu active isotopes but also to organic pesticides, heavy metals, which we know are affecting even Fairbanks in the spring from the former Soviet Union. And that we establish new modeling efforts on supercomputers that have so far not hardly even been thought about by any existent agency or university. We have a great task in front of us. I compliment you, Senators, for putting this hearing forward, and thank you very much for your attention.

Senator MURKOwSKI. Thank you very much, Dr. Shaw. I very much appreciate the input from the panel. It would be helpful if any references that you had in your presentations could be submitted. I think there was one on the Thresher accident that we would welcome. Any other references would be helpful because we will compile them in the record. I think the presentation by the scientific panel, everyone would agree, is certainly thought provoking and relates to the tasks ahead. And thank you, gentlemen, for your professional evaluation, and we look forward to your continued commitment to address a response with sound science. We wish you a good day and hope that you can be with us for the balance of the day.

I would excuse the panel and call our next panel. Our health panel is next. The first witness will be Dr. Sven Ebbeson, Institute of Marine Science, the University of Alaska in Fairbanks, and Alaskan-Siberian Medical Research Program. He will be followed by Academician Trufakin, Vice President of the Russian Academy of Medical Science, and Chairman, Siberian Branch, Russian Academy of Medical Science. Please be sensitive to my pronunciations here. Dr. John Middaugh, State of Alaska Epidemiologist. Charles Tedford, Radiation Health Specialist, Department of Health and Human Services, State of Alaska. We look forward to your presentations. And again, since we have a substantial number of witnesses left, I am going to suggest that if you run over 10 minutes to please wind up your remarks in fairness to the others. So, with that, I see that you're all seated and Sven has got a glass of water and ready to go. Fair enough? Dr. Sven Ebbeson, Institute of Marine Science, University of Alaska. Please proceed. lows:]

[The prepared statement of Dr. Ebbeson and Dr. Trufakin fol- 


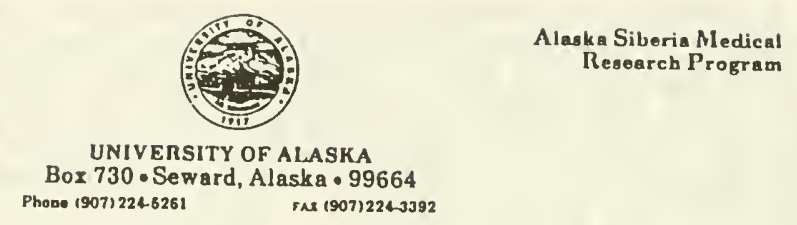

27 August 1992

Senator Frank Murkowski

United States Senate

709 Hart Building

Washington, D.C. 20510

Dear Senator Murkowski:

You are to be commended for opening the Pandora's box of radionuclide contamination in Russia and its effect on human health there and here. Once having opened the box, we all hope you can do something about the health issue.

The University of Alaska, through its Alaska Siberia Medical Research Program, is the logical organization to research the extent of contamination of the human population for the following reasons:

1) We have been working on the epidemiological aspects in siberia for four years.

2) We are currently assessing genetic damage to people at risk of contamination in the Altai region.

3) The Russian Academy of Medical Science and the Ministry of Health wants to work with the University on this topic (see attached testimony).

4) We have the expertise to pursue the necessary work in Russia and here.

Please find attached a written version of our testimony with an addendum of new information provided by the Academy and the Ministry of Health. Some of this is still in Russian. We hope that you can have it translated. Copies should be provided to CIA etc. as some of the detailed information may be new to the intelligence agencies.

Funding obtained by you for this important work would go a long way toward establishing the University of Alaska as a major player in circumpolar health. We thank you for thinking of the 


\section{5}

health issue and for allowing us to participate in this pivotal work.

sincerely yours,

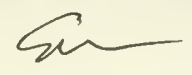

Sven O.E. Ebbesson, Ph.D., D.Sc.

Director
cc: J. Komisar
L. Proenza
D. Behrend
L. MacLachlan 


\author{
Testimony \\ before the \\ Select Committee on Intelligence \\ United States Senate \\ 15 August 1992
}

Dr. Sven O.E. Ebbesson, Director, Alaska Siberia Medical Research Program, University of Alaska

Dr. Valery Trufakin, President, Siberian Branch Russian Academy of Medical Science Novosibirsk

Title

"Circumpolar health concerns related to radioactive pollutants a plan for action"

Dr. Ebbesson:

Mr. chairman, thank you for the invitation to testify. I am Dr. Sven Ebbesson, co-director, with Academician Valery Trufakin, of the Alaska Siberia Medical Research Program.

The presence of radioactive pollutants in polar regions may have greater impact on quality of life than in temperate areas. It is believed that the fragile arctic is less able to buffer the effects of biohazards, including radioactive wastes. The persistence of unaltered toxic substances in the environment allows opportunity for their incorporation into the food chain and ultimately into man, where they host the greatest risk to human health. The assessment of that risk should be given the highest priority.

The polar region is small in area compared with the temperate zone, and less populated, but includes many political sovereignties. Effective strategles to cope with hazardous waste discharge and human health surveillance requires cooperation of all countries sharing the region.

Concerns about alleged extensive pollution of radioactive substances in siberia has led Dr. Trufakin and me to look into the matter as it relates to human health. We have obtained some preliminary information through a number of sources, especially the Minister of Health in Yakutia, Dr. Boris Yigorov. Within siberia there are numerous regions with levels of radiation dangerous to man and within these regions increases in certain cancers and malformation of newborn have been observed during the last twenty years. For example in one contaminated region deaths 
from cancer in children have increased eighteen times in the last twenty years.

As an example of the new available data, it is known that certain rivers such as the Enisiy River contain such radioactive pollutants as plutonium, titanium and cesium-137 below a certain reactor, and that fish in this river contain such radionuclides as phosphorus-32, zinc 65, cesium-137 and, closest to the plant, sodium-24. Such contaminated $f$ ish have been found along the entire 1000 mile length of the river. Contaminated fish are consumed by the local population.

As to such pollution entering the food chain in the Arctic Ocean and the Bering sea, we have no data, nor are we in a position to predict such pollution at this time. We have obtained some specific data about location and quantities of some radioactive sources in a few regions of siberia and data on the apparent correlation with increased health problems. Those details are part of this report to the committee. We must stress 1) that we cannot say if we are dealing with cause and effect and 2) that the data must be regarded as preliminary findings only.

There is no doubt that the health officials in siberia are concerned about what appears to them as a serious health problem. Much additional data have to be collected before the extent of the hazard can be determined and what populations are at risk.

The University of Alaska already directs an active health research program in cooperation with the Russian Academy of Medical science. A successful relationship has been enjoyed by the Alaska-siberian Medical Research Program (ASMRP) since 1988, when it was initiated by Drs. Donald o'Dowd and Ted Mala. The major foci of the program have been investigation of lifestyle and nutritional factors and their impact on diabetes and heart disease of native populations, seasonal depression, alcoholism and cold adaptation. Epidemiological and cancer studies are also underway. The current program enlists expertise from elsewhere in the U.S.A.

In view of the success of the ASMRP, the University of Alaska and the Russian Academy of Medical Science, as partners, are in a unique position to direct further human health investigation in the region, and in particular, assess the health effect of additional radiation burden. The capability to conduct baseline clinical assessments and periodic medical surveillance of populations at risk, as well as assessment of food sources already exist within the ASMRP, but we would hope that other agencies would also become partners in the task.

Considering the similar potential threats of pollutants to both the siberian and Alaskan populations, it is clear that a collaborative program will be most effective and should be built on the foundation of the already existing Alaska Siberia Medical Research Program. The program should include 1) defining the 
potential hazards to the human populations, 2) clarifying which populations are at $r i s k, 3)$ the generation of epidemiological baselines using common methodologies, 4) the generation of preventive strategies and 5) the development of long term surveillance of the human populations.

Both the Academy of Medical Science and the Ministry of Health have asked for our help in health research related to radioactive pollution, as they do not have the resources to do the subject justice. We in Alaska are eager to help, provided we have the necessary resources. My counterpart in siberia is Academician Valery Trufakin, President of the siberian branch of the Russian Academy of Medical Science and Vice President of the National Academy. He has under his wing some 30 institutes, similar to our NIH, spread out from the Urals to the Bering Sea. He will provide a short synopsis of the situation as he sees it. After that we will gladly answer any questions you may have. Thank you Mr. Chairman. 
Dr. Trufakin:

I thank you for the invitation to visit Alaska and talk at the hearings. The preliminary material on the radiation hazard and health conditions of people in siberia is with Professor sven Ebbesson, the co-director of the Alaska-siberia Medical science program. They are ready for review by members of your committee.

I would like to comment on a few facts in this short communication. In assessing the radiation situation in siberia, it should be noted that it falls within acceptable norms. Nevertheless, research shows that radiation contamination of the atmosphere, water, soil, plants and animals in individual cases and at certain times was substantial. The reasons for this are probably as follows:

1. Natural sources of radiation: natural background gamma radiation due to outcropping on the surface of ancient crystalline rock, outcropping on the surface of radioactive ore, from radon and natural construction materials.

2. Global fallout of radiation due to testing on Novaya zemlya, at semipalatinsk, in china and from the accident at Chernobyl.

3. Radiation contamination from technological sources due to the utilization of isotopes in medicine, prospecting for uranium, extraction of tin and gold, and underground peaceful nuclear blasts (from 1974 through 1987 there were about 12 such blasts).

4. Radiation hazards from technology: automatic power plants and light houses powered by isotopes, industry in the cities of Novosibirsk, Krasnoyarsk and Tomsk.

We have conducted analysis in various regions of siberia of the illness and mortality statistics on the population. Illness and death from cancers, toxicoses, child mortality and tumor illness are important indices of growing ecological contamination in the territory, for example:

Chukotka. of the major causes of death, cancer ranks second (increased from 10.38 in 1970 to 26.98 in 1988). Child mortality and oncological illnesses were two times higher among the native populations. Cancer of the respiratory system increased especially quickly.

Tomsk. Illness from cancer since 1976 has increased by 2.5 times. Research from space indicated that high rates of occurrence of oncological illnesses correspond with areas of greatest contamination by industry.

Magadan. The amount of air pollution over the last ten years has grown by 2.5 times; during the same period illnesses 
due to tumors increased by 42.48 , mortality from cancer by 78 .

Altai. Over the last 40 years, illnesses due to tumors have increased by 5 times, while oncological illnesses of the respiratory organs increased by 50 times. Mortality due to tumors increased by 7 times, while death of children increased by 18 times.

Therefore, although analysis of the illness and mortality statistics indicate an unfavorable ecological situation, we cannot conclude that radiation is the leading cause for the increases in tumors. There are other possible causes: water and air pollution, changes in diet, spread of viruses or bacteria in the environment, etc.

Combined, multidisciplinary research of all aspects of the problem is required, including the effects of the radiation situation in siberia on health of the population. It would be best of all to do the research within the context of the Alaskasiberian Scientific Medical Program, which already exists.

With the collapse of the soviet Union, a rapid development of industry and mineral resources is occurring. This must be done with consideration of the up-to-date achievements of science, new technologies and the gradual restoration of the natural environment in the north. The unfavorable ecological situation in the north will remain for a long time, it may be irreversible and quickly spread to northern countries. Urgent ecological, sanitary-hygenic and demographic mapping of the siberian regions is required, including renewed monitoring.

Studies need to be initiated of the ranges of $f i s h$ and animals in siberia, along with the utilization of the $f$ ish and animals from ecologically unfavorable regions in the diets of the populations, a practice which could lead to illnesses. The placement of newly developing industries must be made with due consideration of the ecological conditions, including radiation in the soil, water, and plants. Of special concern is the interment of the waste from nuclear industry.

Work in Russia is moving in the above directions. However, to accelerate and expand the work, so that the spread of ecologically unfavorable conditions does not continue, the efforts and resources of all northern nations need to be combined. 
A REVIEW OF THE PROBLEM OF RADIATION HAZARDS TO THE POPULATION IN THE TERRITORY OF YAKUTSK-CAKHA SSR

It 18 necessary to clearly and unequivocally state that the mafor dosage received by men from technological sources of radiation come from medicine. The dosage from a single fluorographic examination in a year constitutes $2 / 3$ of the annual radiation load received by a person. The problem on the surface is a general systematic unavoldable irradiation of the whole population over the last ten years, although it is comparable to the normal radiation hazard and tens of previous generations have lived under low natural background radiation levels.

I. Natural radiation sources.

I. I. Natural background gama radiation

Most of the territory of the republic is characterized by low (up to $20 \mathrm{uR} / \mathrm{h}$ ) values of natural background gamma radlation. But in certain regions where rock strata of ancient crystalline structure and errupted acidic rock outcrop to the surface, natural gamma radiation equal to $30-60 \mathrm{uR} / \mathrm{h}$ reach values of $80-$ 100 and more UP/h over fairly broad areas, comprising a total of a thousand square kilometers of southern Yakut, olenekskiy, Yst'Yanskiy region and eastern Yakutia.

In 1991 a mapping of the natural background radiation on a cale of 1:2500000 was begun. The work cost 70 thousand rubles, the necessary'can be completed in 1992 for 20 thousand rubles.

1.2. Outcropping to the surface of radloactive ore.

During exploration for uranium sources, more than 15 thousand radiometrically anamolies were found, of which more than 10 thousand are on the surface, including several hundred anamolies and ores with intensities of from 200-500 up to 1500 $\mathrm{uR} / \mathrm{h}$. In general, these are localized phenomenon, but they cover areas of kilometers and extend to tens of kilometers in tectonic zones and strata of sedimentary rock. The radiation is associated not only with uranium and thorium, but can also be associated with rare earths, rare metals, apatites and other types of minerals. In any case, one must consider not only the radioactivity, but surface outcroppings of uranium - easily dispiaced and highly toxic. It is necessary to emphasize although we have avallable information on the location and characteristics of these situations, the ecological ramifications have not been studied (in particular, fish are absent from the river, animals avoid the regions, a river in which the upper waters run through uranium ore might be the oyun-Kyuel').

1.3. Radon

According to the assessment of the scientific committer on the effect of atomic radiation $O O N$, radon along with its daughter products of radioactive decay is responsible for about $3 / 4$ of the annual individual effective radiation dosage, recelved by the population from terrestrial radiation sources. In the republic, measurement of radon concentrations in dwellings has not been done before.

The results of measurements done in the zarechnyy Aldanskiy 
village region in 1991 in living and social-service buildings revealed values exceeding the allowable levels by an order of magnitude or more. This is essentially the only information in the region to date.

The problem is the result of a lack of counting equipment (highly sensitive instruments are planned for in 1992 at a cost of 8-10 thousand rubles, 5-10 instruments are necessary).

1.4 Building materials.

The wide usage by the construction industry in southern Yakutsk of granite material has undoubtedly already lead to the presence in living and industrial bullding of high radioactivity levels. And although in recent years many buliding-materials businesses, at least in central yakut, conduct radiation contamination assessments on both the raw materials and finished products, the problem demands resolution and the establishment of opeciallzed laboratories in the republic.

2. Global radiation fallout.

At the end of the $1950 \mathrm{~s}$ and the start of the $1960 \mathrm{~s}$, radioactive anamolies were fixed over the entire territory of yakut by geophysicists during radiometric prospecting. Especially high values, exceeding $1000 \mathrm{uR} / \mathrm{h}$, were found in the northern region along the coast. This was due to a wide region of contamination. In subsequent years up till now, organizations in the republic have not especially addressed this question. And although the majority of the radioactivity is from short-lived radionuclides, the degree of contamination of the northern tundra by strontium-90 and cesium-137 has not yet been studied.

3. Contamination of the territory by radionuclides of technological origin.

3.1. Acquisition of radioactive materials.

At the end of the $1940 \mathrm{~s}$ and start of the $1950 \mathrm{~s}$, the development and exploitation of the radioactive element monocite and uranium ore occurred in southern Yakut (Basil'yevka) and in the Momskiy region (Sugunskily, Dal'stroya region).

The businesses were liquidated, primarily because they were unnecessary and secondarily because the ore was too poor. Nevertheless, in these regions active disturbance of the source occurred. In Vasil'yevka there are now outcrops of radioactively enriched commercial material. The sugunskiy industrial region was surveyed in 1991, since the possibility of leaching of the tailings to the foot of the slopes on the Ulakhan-Chistay Platue presented a hazard to the population.

3.2. Geological commercial working of uranium

Due to the geo-industrial processing of uranium during the past 25 years in southern Yakut, the problem of radioactive tallings has arisen, accompanying heavy mining operations. The organizations which did this mining have been liquidated, their settlements were given over to other concerns. And if the problem of 1 iquidation of radioactive waste has been technically and practically addressed, the problem of tallings requires a serious approach.

3.3 Acquisition of gold and tin.

During the extraction of gold and tin from ores, extractions of materials enriched in heavy metals, including radioactive 
materials, result. The slag concentrate can in some cases reach radioactivities of 2000-3000 uR/h, in extracting gold without amalgamation, the nonmagnetic fraction reaches 7000-10000 uR/h.

In Kulare from the first years of exploitation, the radioactive rare-earth mineral kularite went into the slag.

3.4. Underground peaceful nuclear explosions.

From 1974 through 1987 twelve nuclear explosions were conducted: 9 in the Mirninskiy region and one each in the Bulunsk, v-vilyuysk and Kobyaysk regions. Two were accompanied by an epulsion of radionuclides: a near-surface blast for building a talling reservoir 2-5 km from Udachnyy village and an accident during a seismic stratigrafic study $39 \mathrm{~km}$ from Aykhal village. In both cases recultivation work is necessary, in the latter case it is necessary to follow the trail of the radioactive cloud.

In the remaining blast areas, it is necessary to conduct detalled radiometric observations with the goal of providing a control on the radioactive situation over time. Monitoring must be organized.

It is necessary to conduct medical-genetic research on populations in regions of nuclear blasts are conducted.

4. Radioactively dangerous technologies and the sources of ionizing radiation.

As of 01-07-1991, there were 198 enterprises at 405 sites using 3083 sources of lonizing radiation, including 2503 lsotope sources. This presents a broad spectrum of problems for the government oversight and clean up agencies. Among the various sources are Gidromet atomic batteries, used to power meteorological station and light houses. These units have a charge up to $100000 \mathrm{Cl}$, and were scattered along the coast of the ocean, in river deltas, on islands and they number in the many tens.

In the future we face the "Malaya energetika" of Minatomenerroproma, with its self regulating unmanned atomic thermo-electric station (NC ATES "Elena"). Now, at the technological development stage, qualified independent expertise is needed, since the very technological task is deposited on the assumption that under normal operation introduction of radioactive products into the cooling water, the ground water and the air must conform to the requirements of NRB $76 / 87$.

5. Introduction of radionuclides with food products.

Considering the scale and numerous channels in which produce enters the republic and the wide participation of private commerclal structures, the problem of controling the radioactivity of food products is difficult. The problem can be solved by distributing simple indicators of irradiation and dosometers among the public.

There are yet an additional series of problems, for example, the unsanctioned introduction of contaminated material, which raises the question of equipping the proper government agencies (transport, police, costumes) in the republic with modern detection equipment.

A Serious problem in the near future involves the burial of 
radioactive waste from industries in the republic, which was carried out until now in the khabarovsk region.

Head of the Inspection of Radloactive Security, Yakutsk Region

Gosortechnadzor RSFSR

A. S. Tsyganov

PRELIMINARY DATA ON RADIOACTIVE POLLUTION NOVOSIBIRSK KRASNOYARSK

In the Altaysk region, due to its geographic location in southwestern siberia very close to china and Kazakhstan, radioactive pollution in the area is of substantial concern. The following sources contribute to the radioactive pollution of the environment: a series of large nuclear explosions conducted on the semipalatinsk test site and in china, the accident at the Chirnobyl atomic power plant, testing of atomic weapons on Novaya zemlya, products from the burning of organic fuels in bollers and TETs (thermo-electric stations?), raising of ash dust and also source of radioactivity of natural origin.

Radioactive contamination of the soil on the territory of Altaysk results mainly from the accumulation over many years of atmospheric fallout from long-lived strontium-90 and cesium-137, thrown into the atmosphere during the testing of nuclear weapons. In addition, mineral enrichment gradually introduced directly into the soll is another substantial source of radioactive contamination. Contamination of the surface water results from the runoff of strontium-90 from atmospheric fallout onto the surface of the soll.

In the Novasibirsk region radiometric analysis of atmospheric-fallout samples (monthly data from the center for Observation of Pollution of the Natural Environment) has shown that the density of the fallout during 1990-1991 did not exceed the established control value of $110 \mathrm{Bk} / \mathrm{m} 2$ of total beta-active radiation during a day and averaged $0.7 \mathrm{BK} / \mathrm{m}-2$ in the Novasibirsk region. In areas where radioactive contamination is continuously recorded, average values in the density of fallout are as follows: Bolotnoe and Karasuk, $0.8 \pm 0.5 \mathrm{Bk} / \mathrm{m}-2$ each, Barabinsk $1.0 \pm 0.4 \mathrm{Bk} / \mathrm{m} 2$, Novos $1 \mathrm{blrsk} 1.5 \pm 0.7 \overline{\mathrm{Bk}} / \mathrm{m}-2$ and Ogurtsogo $1.4 \pm 0.7$ $B k / m-2$. The maximum radioactive fallout was the following: Barabinsk $6.3 \mathrm{Bk} / \mathrm{m}-2$, Novosibirsk $10.0 \mathrm{Bk} / \mathrm{m}-2$, Ogurtsogo 18.5 $\mathrm{Bk} / \mathrm{m}-2$.

Radioactivity in the atmospheric layer next to the ground resulted from fallout from the stratosphere of the production of the radioactive decay from materials produced by nuclear testing done during previous years. Most of the radioactive contamination is caused by the presence of such materials as cesium-137 and in a series of cases, contamination of soll by 
thifgium-232 has been observed.

The magnitude of the dosage from the soll averages 20-50 $\mathrm{uR} / \mathrm{h}$, however, in some cases maximal dosages are possible (in the sanatory-restricted zone of a tailings reservoir at po Khimkontsentrat in Novasibirsk values up to $275 \mathrm{uR} / \mathrm{h}$ occur, due to the commercial activity of this business).

The available official data on the contamination of air, water and soil of the Novasibirsk region do not provide a complete picture of the condition of the environment in this rogion (and ite varioue territoriee); neverthelese, they fully indicate zones of possible anthropo-technical stress resulting in possible health problems in the population.

In the Tomsk area substantial increases in the radiation background. 42 noted in the mouth of the chernil'shchikov tributary where it flows into the $O b$ and entering from Tomsk area 7: water $100 \mathrm{~m}$ from the bank had $30 \mathrm{uR} / \mathrm{h}$, general background was 30-35 uR/h. One must take into account that at the point of measurement the water from the chernil'shchikov was already considerably diluted with ob water. Considering the fact, that water from the $O b$ and its tributaries is considerably lower ( $1 \pm 4$ $u R / h)$, one can attribute the above values to combination of the industrial production in Toms -7 and the background levels in the atmosphere and rivers of the surround region.

In the Krasnoyarsk region in 1989-1991 research was done by the Krasnoyarsk Scientific center, So RAN, to assess the radioecological conditions in the Enisiy River. Aero-gamma-surveys and complex investigations were done $1000 \mathrm{~km}$ below the sewage outflow of the Gornokhimicheskiy plant using a specially equipped vessel. Over a distance of $1000 \mathrm{~km}$ more than 600 water samples, bottom grabs, soil, fish and plant samples were collected. The investigations revealed all radioactive pollution components, including plutomium, tritium and also cesium-137 and phsophorus32 (the major dosage-forming radionuclides).

It was noted that in the onow where sewage water from the plant mixes, maximum concentrations are attained by sodium-24, magnanese $-56,2.6 \times 10-7 \mathrm{Ki} / 1$ and $2.3 \times 10-7 \mathrm{ki} / 1$ respectively, which exceeds the maximum allowable concentration (MAC) according to NRB $-76 / 82$ by 10 and 2 times respectively. In Atamanovo Village, the first inhabited region below the sewage fallout, due to decay and dilution, the concentration of the individual nuclides was below the MAC, however, the total radloactivity was close to the allowable norm.

The concentration of the long-lived radianuclides (cobalt60, cesium-137, europium-152, 154) in a day of flow at the Balchugovskiy channsl for an average water helght was about $1 \mathrm{~K} i$. The total amount of radionuclides of technical origin below islands where studies were done is about $17 \mathrm{Ki}$. The distribution of radionuclides in profiles of bottom sediments is vary uneven at varlous points in the river.

Much attention was devoted to studies of the radioactive contamination of $\mathrm{fish}$. More than 40 samples were analyzed from various species of endemic and anadromous fishes. The main nuclides accumulating in the tissues of $f$ ish were phosphorous-32, zinc-65, cesium-137 and closest to the outflow sodium-24, and it 
was noted that contaminated fish swim a considerable distance from the outflow, both upstream and downstream. Techno-genic radiation was observed in fish from the Kransoyarsk region. Maximum concentrations of phosphorous-32 (5.0x10-7 Ki/kg), the major dosage-generating nuclide, were observed in the carcasses of grayling collected near Pavlovshina village, $60 \mathrm{~km}$ below the outfali. The analysis shows that in almost ali the portions of the river along the $1000 \mathrm{~km}$ distance there was a collection of contaminated fish and that their use as food by local inhabitants results in measurable dosages.

The density of the contaminated flood land in terms of total nuclides changes as one gets further from the source from 160 to $0.2 \mathrm{uk} 1 / \mathrm{m} 2$. According to the data of the Institute of Biological Problems of the North, DVO RAMN, on Chukotka the general gamma background of natural radioactivity is about $15-30 \mathrm{uR} / \mathrm{h}$ (which does not exceed the allowable levels and differs little from that of other regions).

To the north of the Kransoyarsk region, gamma background is 25-30 uR/h. In the Magadan region gamma background is $15-30$ uR/hi cesium-137 and strontium-90 (eg. products of nuclear fallout after blasts) do not contribute substantially to the formation of background radiation in the north.

The radioactivity of muscle in deer is $0.1-2.7 / 10-9$ curies per $\mathrm{kg}$, which amount to 0.03 per $\mathrm{kg}$ (or $3 \mathrm{t}$ ) and is an allowable amount in these products.

In Mirnyy (Vilyui River basin), the gamma background does not exceed the allowable level.

According to the Leningrad Institute of Radiation Hygiene, natural background radiation in the north is a little higher than is generally characteristic of the north. Reindeer moss absorbs radioactive nuclides, therefore the radiation background in deer and man is a little higher. It is known that health conditions are most affected by radionuclide compounda, not gamma background.

Socio-demographic studies are underway to follow the connections between pollution by radionuclidea, chemical agente and also physical make up of the radiation factors in the Altaysk region. It was shown that beginning in 1950 (time of the first nuclear tests) for 40 years, the continuous increase in the ecological contamination has created a complicated demographic situation.

During the period from 1950 to 1990 the population grew from 2396.2 thousand to 2828.3 thousand individuals. The total increase was 432.1 thousand persons or 18.08 . Such an increase in population over a 40 year period cannot be considered great.

Some indices of slckness and death in the population are also indices of the growth of environmental contamination in the region.

In the region from 1950 through 1990 there was an unfavorable tendency in the dynamics of the health indices in the population with respect to malignancies. The growth in cases is close to linear (first time cases increased by 4.6 times). The most unfavorable changes in the indices of first-time iliness occurred for malignant tumors of the lungs (increased by more 
than 50 times), skin cancer (increased by 3.4 times), and malignant breast tumors (by 4.6 times).

cinfl Alalignant tumors were also on the increase in the digeetive tract. However, in recent yeare they have stabilized and even decreased.

There was also an increase in the occurrence of blood cancer (first time occurrences were up by 1.2 times, total cases up by 2.4 times). However, periods of increase (1974-1975 and 1989$1990)$ and decrease $(1979-1980)$ were noted.

other forms of cancer were observed only occasionally or the occurrence of first cases was stable (cancer of the urogenital organs) or it was decreasing (uterus cancer) against a background of Increasing llineasea.

Among the various nosological indices, the most unfavorable involved iron deficlent anemia in children up to 14 years of age (Increases of first occurrence by 4.7 times), neonatal 11 inesses (up by 2.3 times), including hemolytic disease (up 2.3 times) and birth abnormalities (up 1.8 times). There is also an unfavorable trend in the frequencles of toxicoses in the second half of pregnancies.

There has been a substantial increase in the mortality statistics in the region from malignancies: in the whole population it is 6.9 times, in males 9.1 , in females 5.2 times.

In the middle of the 1960 s the mortality of men from malignancies exceeded that of women, the values of tho elevated mortalities are steadily increasing (1.1 in $1970,1.5$ in 1990). The increase in mortality from oncological illnesses is characteristic of all age groups of the population. Mortality indices in the working age classes of the population increased by 3.8 times, in the retired age classee by 6 times and in the children by 18.3 times.

The leading cause of death in the population of the region with respect to all malignancies is those of organs of the digestive system. The mortality from the above cause gradually increased from 17.7 in 1950 to 64.9 in 1990 . Mortality of men from digestive tract malignancies was greater than in women. The main portion of individuals dying of digestive tract malignancies was in the retired age group.

Malignant cancers of the lungs is the second highest cause of death of the population among the cancer patients, and thelr portion is gradualiy increasing. During the period from 1950 to 1990 , the mortality index increased (from 1.65 to 56.02 or 34 times). The mortality rate in men was higher than in women by 3.3-7.2 times.

There has been a gradual increase in the mortality of women due to breast cancer (from 2.47 to 14.28 ). The greatest increase occurred from 1959 to 1970 , later the rate decreased slightly.

Malignancles of the sex organs was an important cause of deaths due to cancer in women of the region (up to 258). During 1950 through 1965 there was a sharp increase in mortality of women due to the above illness (by 3.4 times). However, in the last 20 years death of working age women due to this cause declined substantially (from $38.3 \%$ to 10.7\%). In the last 20 years there was a 2.4 fold increase in death of men due to cancer 
of the sex organs (from 3.3 to 7.98 of deaths).

Mortality due to cancer of the blood increased in the region from 1959 through 1990 (from $4.87 \%$ to $8.68 \%$ ). Increases in mortality of men and women from blood cancer was similar (1.2-1.7 times).

Mortality of the population due to 11lness of the endocrine system also showed a gradual tendency to increase with maximum values in 1981-1985, followed by a decline. Mortality in women from this cause was 1.5-2 times that of men.

Analysis of the epidemiology data (malignancies, thyroid illnesses, 111 ness in new borns) and mortality statistics (from malignancies, mortality of youth, still births and birth abnormalities) indicate the very high probability that radioactive contamination of the region was factor. The research material indicate that the effects on the health of residents was direct and indirect (combination of direct influences from environmental contamination and effects through the mother, directly impacted by the radiation). Although the harmful signs are being eliminated from the population (decreased birth rate, age of death), there are possible long term effects of radiation on future generations.

In depth research on the influence of radiation on the public health is necessary using data on the radiation load (contamination levels) in the territory and social-hygenic methods of cohort analysis, which would permit a more accurate determination of the degree of influence of radioactive contamination of the natural environment on the public health.

In Novosibirsk high levels of cancer are observed in the Maslyaninsk, Kochenevsk, Kolyvansk, Chistoozern and Kargatsk regions, and also in Novosibirsk city itself (more than 250 cases per 100 thousand inhabitants).

Mortality from lung cancer is highest (above 40.0 per 100 thousand inhabitants) in chistoocern, Ubinsk, Bagansk, Kochenevsk, yst'-Tarsk, Ordynsk, Moshkovsk, Toguchinsk, Kolyvansk, Suzunsk, Maslyaninsk, Bolotninsk and zdvinsk regions, and also in Berdsk city. Low level (less than 30 per 100 thousand) were noted in Barabinsk, Vengerovsk, Dovolensk, Kochovsk, Severn, Tatarsk and Chanovsk regions. The Moshkovsk region fill out in the very bad group for health problems and statistics confirmed the high significance of mortality from stomach cancer in the mortality statistic from cancer. A similar situation is present in the Kolyvansk region. Upon examination of the statistics, Tatarsk was moved from the "high average" category to the "bad" category, Ust'Tarksk and Bagansk from the "low average" to "Bad" and severn region from "good" to "low average".

A more accurate picture of the relationship between environmental factors and cancer in the population of a region is produced by a complex analysis of the four indicators (mortality and illness from all classes of malignant pathologies, and also mortality from lung and stomach cancer). In this case, Chistoozern, Kochenevsk, Moshkovsk, Kolyvansk and Maslyaninsk regions fill in the bad category. As the above analysis showed, in the first two regions lung pathologies were primarily 
increasing, the latter two regions stomach-intestinal pathologies. In Maslyaninsk region a variety of cancers predominate.

As earlier analysis indicated, the unfavorable radiation situation in Novosibirsk city and the Moshkovsk region was due to contamination of tha soll and air due to radioactivity and chemical substances form the khimkontsentrat company; this includes the arrangement of unsanctioned dumping of waste by this and other companies in the city in Moshkovsk and the Novosibirsk region. The problem in Maslyaninsk region is the largest in the whole area $(200-210 \mathrm{~kg}$ per individual per year and $70-80 \mathrm{~kg}$ per hector of contamination of agricultural land by mineral fertilizers and poisonous chemicals).

In the Tomsk region there has been an increase in oncological 11 inesses related to environmental contamination. For example, in 1976 ilinesses from malignant tumors was 107.9 per 100 thousand individuals, in 1986 the figure was already 277.4 per 100 thousand, a 2.5 fold increase. Research was done by several agencies (HII, Tts SO RAMN and VTs TIASYRa) using photographs from space of Tomsk city: one of the photographs showed (are left blank on page) in infrared radiation in the range of $0.8-0.9$ micrometers on 19-June-1988, when laid on a map of Tomsk of analogous scale, showed a correspondence of the dark spots with the location of the industries in the city.

In Magadan the complex index expressing the amount of atmospheric contamination varied from 7.7 in 1980 to 19.3 in 1988 , eg. an increase of more than two times. It was shown that the effects of air pollution on human health in combination with extreme ecological factors lead to the formation of specific pathological conditions, increases in pnemoniabronchitis and allergies (bronchial asthma). This is indicated by the illness and death statistics in Magadan from cancer. During the last ten years, 11 iness from cancers of all kinds rose by $42.4 \%$, respiratory cancer by $65 \%$. Death from all cancers in the Magadan region rose by $73 \%$ in the last 10 years, while death from respiratory cancer almost doubled.

There were sharp increases in mortality in residence of the Magadan region from illness related to radiation contamination. During the last ten years oncological illnesses related to radiation increased by more than two fold. Note that mortality among Magadan residence from digestive tract cancer decreased during this period by $15 \%$.

Total and standardized mortality indices in the Magadan population from the above causes increased, with the exception of the rural population (men), where the standardized index stabilized at the 1979 level. In urban men, mortality in 1986 as compared to 1970 rose by $31.6 \%$, but in rural men it decreased by $6 \%$ during this period, which is due to migration from rural regions, especially by men.

In women the mortality from cancer in urban areas increased by $19.48 ;$ in rural areas by 23.48 .

In addition to migration factors, changes in the mortality statistics due to cancer is related to environmental pollution, mainly air pollution. This is indicated by the mortality 
statistic of the population from cancer of the respiratory system and other localizations, which indicate that the rise in mortality from resplratory cancer is substantially higher than from that of other areas of the body.

A certain significance was also played by aging of the population, especially for rural women of 60 years and older, for whom increases in the standardized mortality indices in 1986 rose by 12.5 times with respect to those of 1970 , while in rural men of the same age group and the same period, the mortality decreased by 38 .

In comparison with other territories and the Far East in general, the total coefficient of mortality in the Magadan region is lower. Therefore, the current trends in mortality of the Magadan population due to malignant tumors is occurring over a background of ever increasing levels of environment contamination (air) and changing demographics (changes in the migration and age structure of the population, especially rural).

complex oclo-ecological research on the natural and anthropogenic environmental factors on the health of the Magadan population indicate that anthropogenic and technical factors Influence the living conditione and health indices, in partlcular due to air quality. The effect of ecological factors is connected with climate factors and also with the quality of the drinking water. The effects of these factors on the health indices occur either massively or sporadically as several therapeutic and infectious diseases.

The study of the total epidemiology in adults and subadults in Magadan indicate the unfavorable direction of these phenomenon. Since the total number of illnesses increased by 2.2 times from 1979 to 1989 , the first occurrence of diseases increased during that time by more than five fold. An especially bad situation with respect to disease has developed among chlldren. The total number of 11 inesses increased from 1979 to 1989 by 10 times.

Among adults and subadults there were also increases in the rates of 11 iness from diabetes (by 2 times), cardiovascular disease (by more than 3 times) and others.

The Far East region has a complex ecology, including the radiation situation and medical-demographlc processes. Monsoon climatic features (the monsoon climate exists only in primorye, In the other regions there is a hard continental climate or polar climate) under condition of anthropogenic contamination put great pressure on the adaptive mechanisms in the native and immigrant population and therefore, there is frequent iliness. Resplratory iliness amounts to 429.0 per 1000 (translator note: they may mean 1000 thousand here, possibly a misprint) residents, nervous system - 101, digestive tract 89, infectious diseases 59.7, of which 2.8 are tuberculosis (the corresponding numbers for the Russian Federation are 401, 104, 88, 52 and 2).

High levels of trauma and poisoning increase the levels on oncological illness. Total mortality of the population of Dal'niy vostok is 7.8 per 1000 (107 in the whole Russian Federation). 


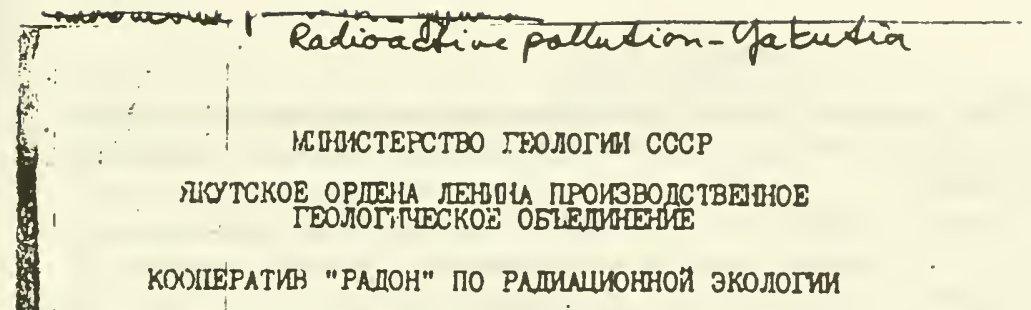

\section{$\begin{array}{llllllllllll} & T & Y & B & T\end{array}$}

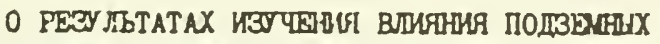

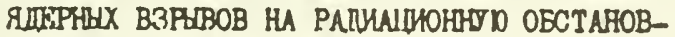

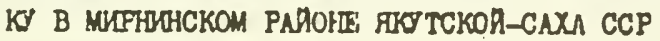

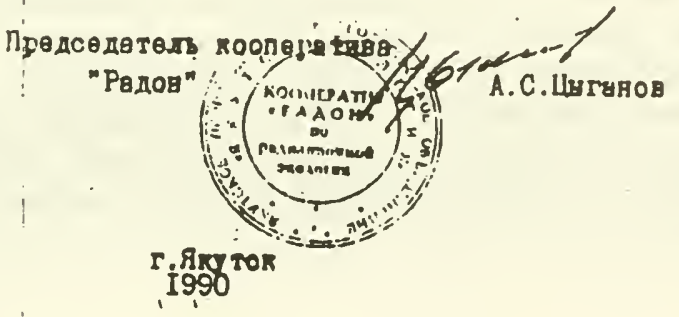




\section{2. โЕЗУЛЬTATI PALOT}

торме излохения төкотв настсяшего ғөздела пуопиктоввна стрен

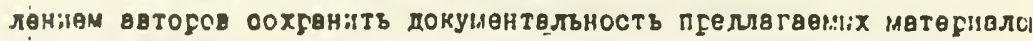
"' реаультатов.

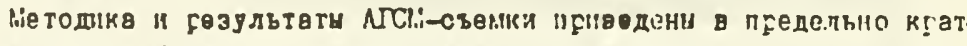

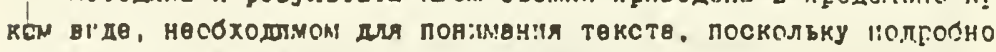

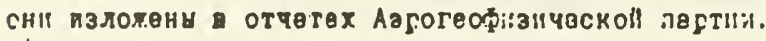

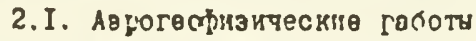

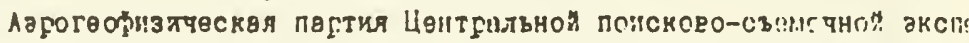

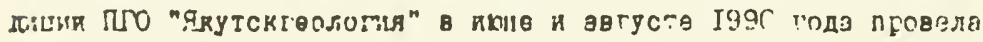

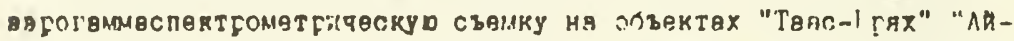

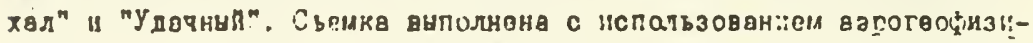

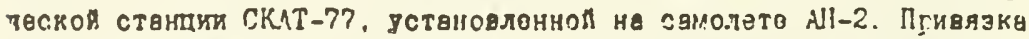

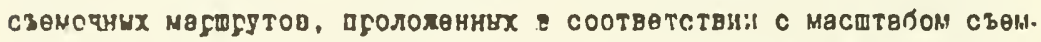
ки - I:25000 вегез $250 \mathrm{~m}$ и I:ICCCC чегез ICC $\mathrm{M}$. осушествлялась

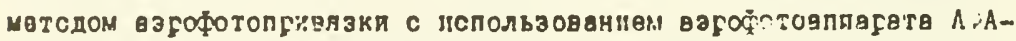
-17. Весотв полөтс вндегхиввлась в пределах 5C-75 метгов на.и

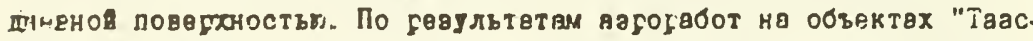

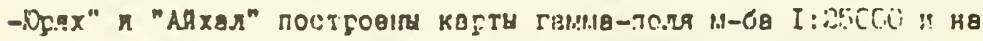

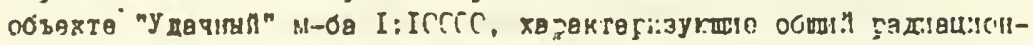

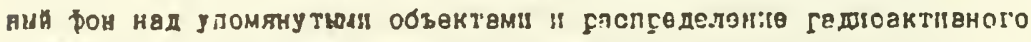
порявленгя по плодаль.

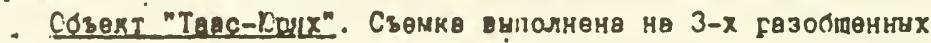
участках Hs $I, 2$ и 3 (Pic.2).

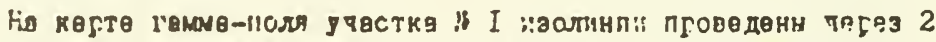

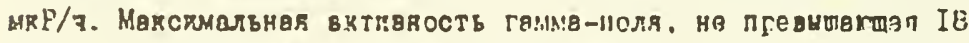

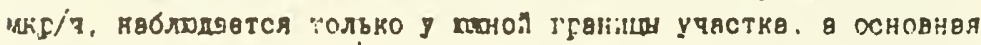

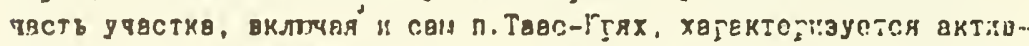

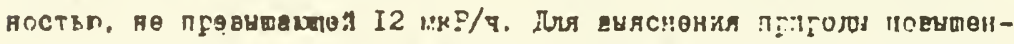

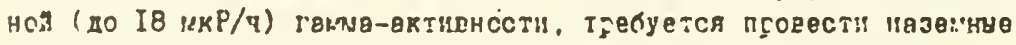

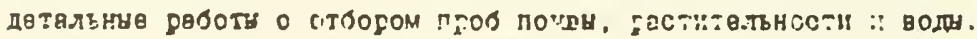

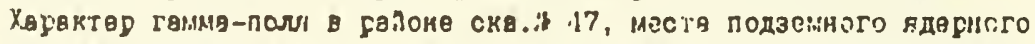

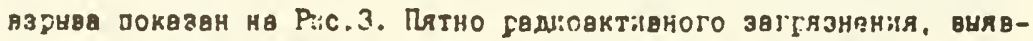

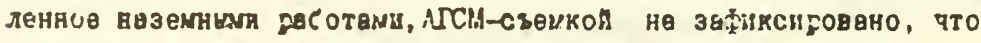

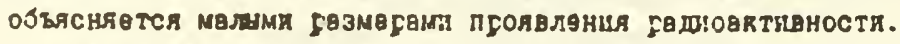

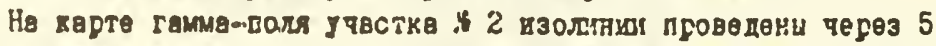

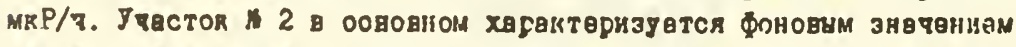

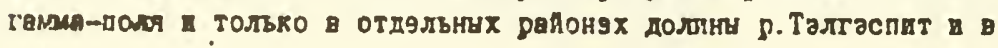




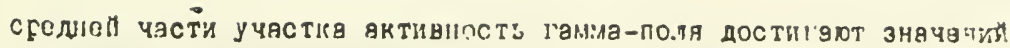

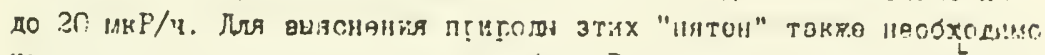

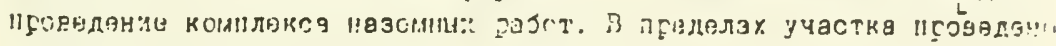

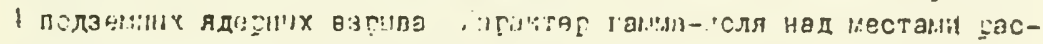

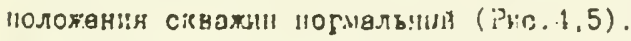

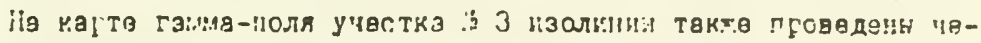

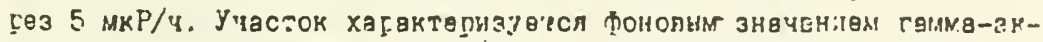

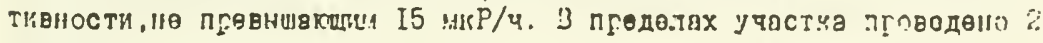

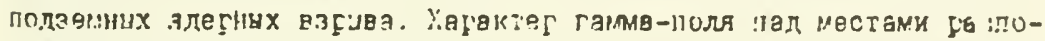

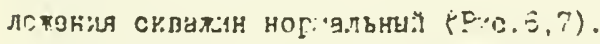

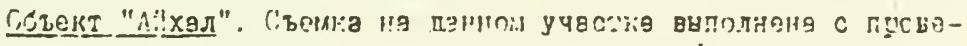

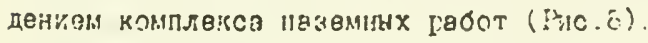

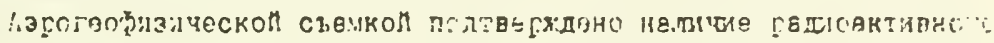

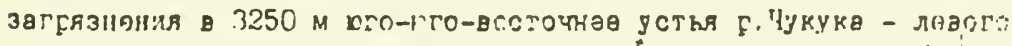

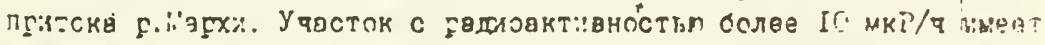

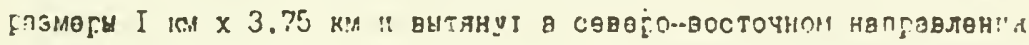

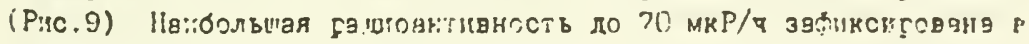

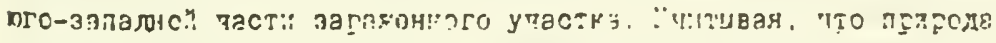

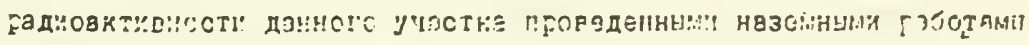

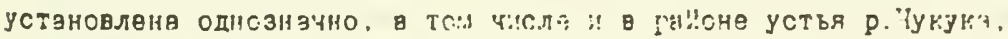

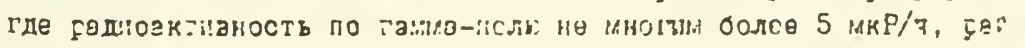

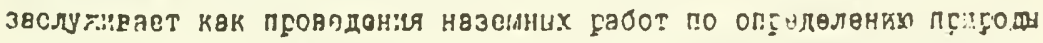

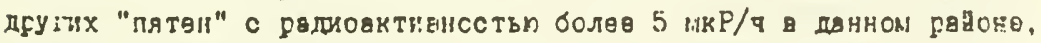
так и ғвсшисения площвдл псд аәсобяботу с цөльр виявления подобннх "пятен" в псилегакшіх ра Аонах.

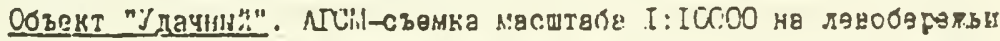

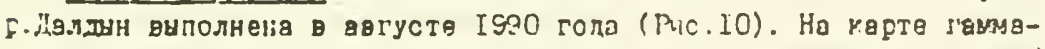

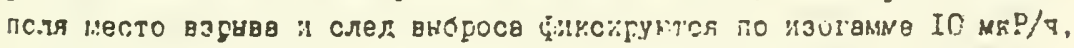

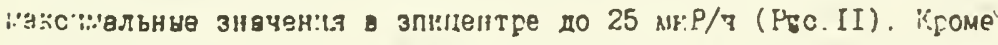

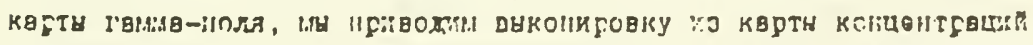

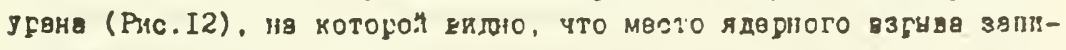
свлось в в усвнсвон квнале.

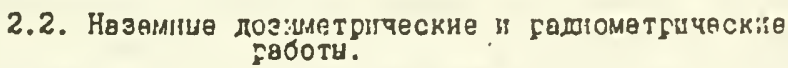

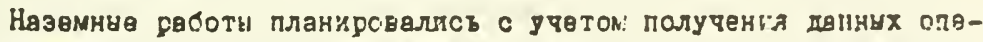

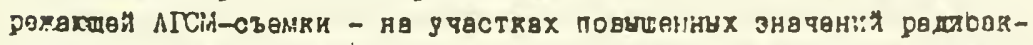

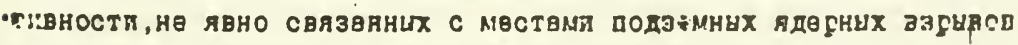

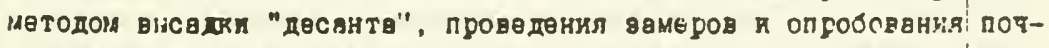

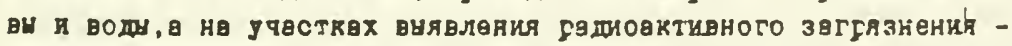

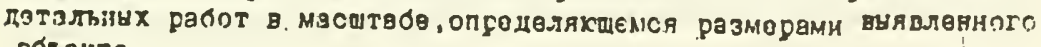
объекта. 


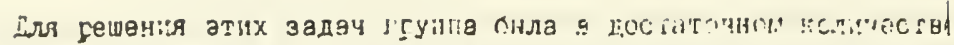

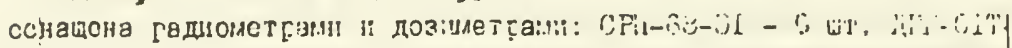

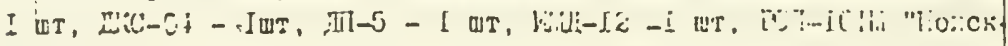

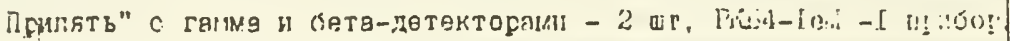

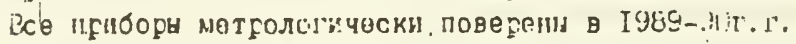

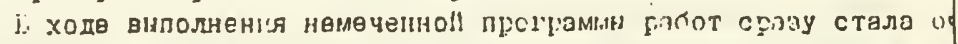

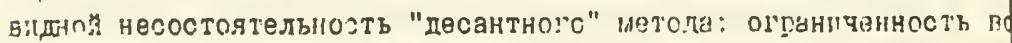

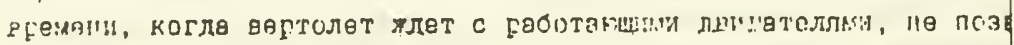

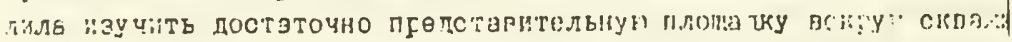

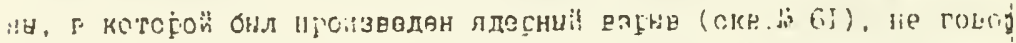

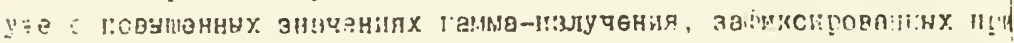

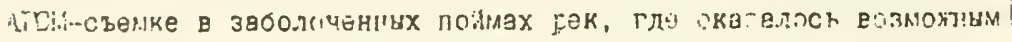

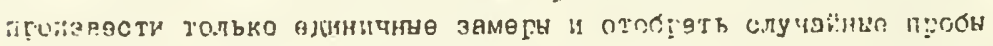

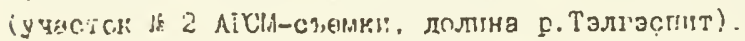

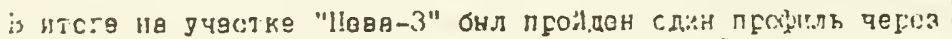

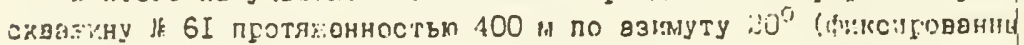

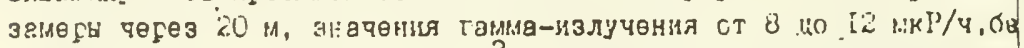

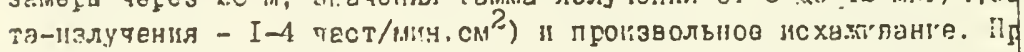

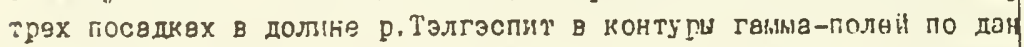

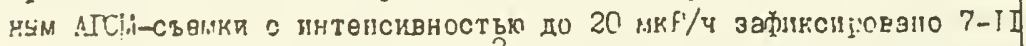

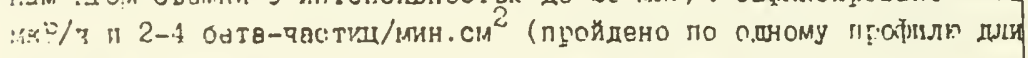
Hลน IC $(\mathrm{N}-\mathrm{I} 2 \mathrm{O} \mathrm{M})$.

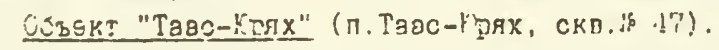

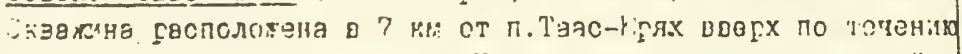

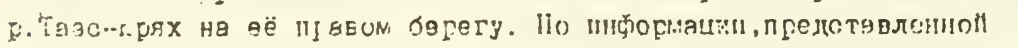

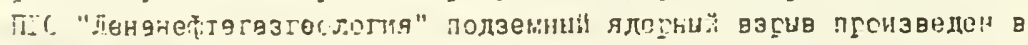

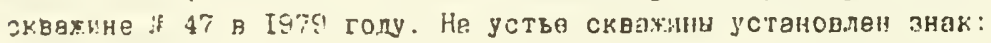

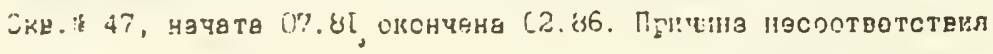
не ясна.

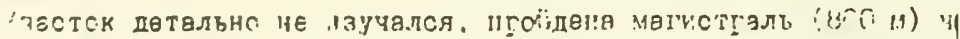
f.e =

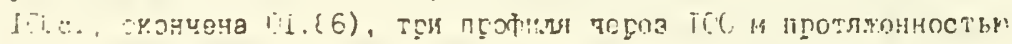

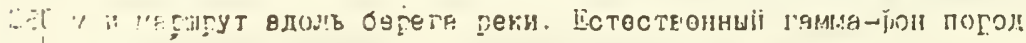

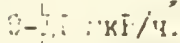

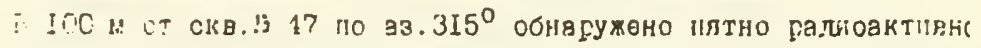

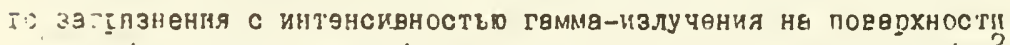

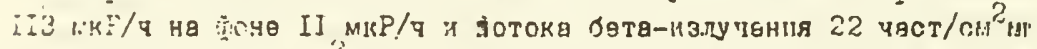

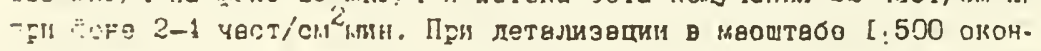

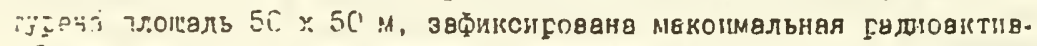
:

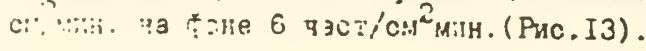




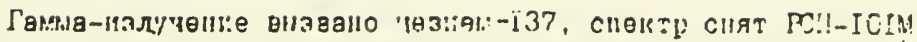
(โก:เc. I1).

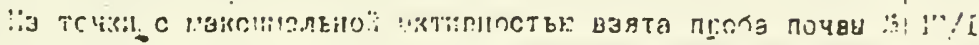

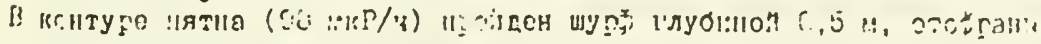

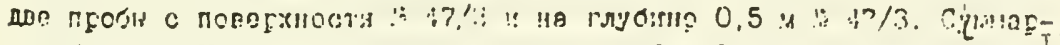

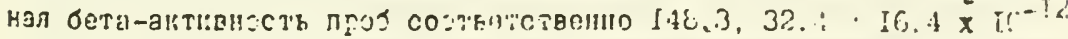

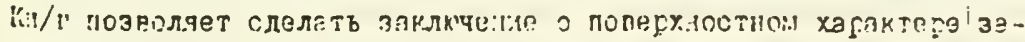
гглзиенія .

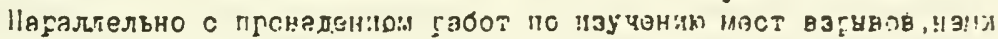

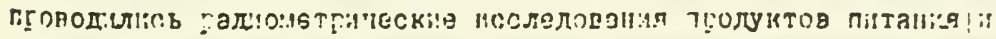

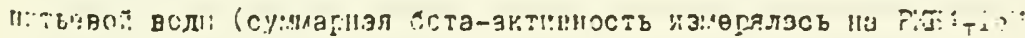

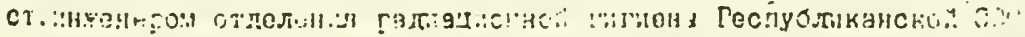

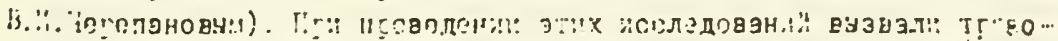

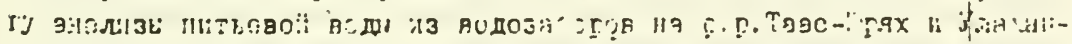

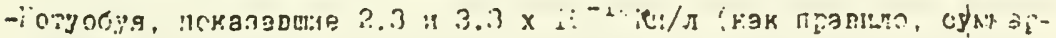

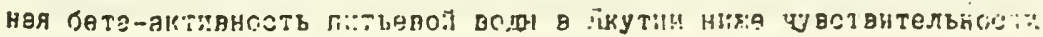
Pis:i-Ir...).

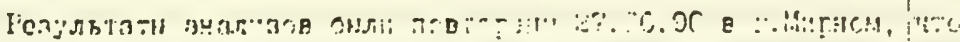

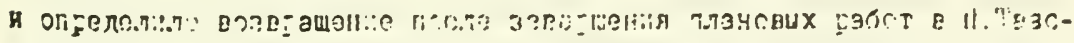

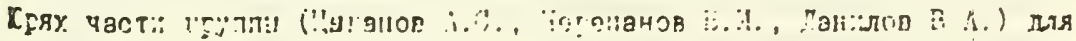

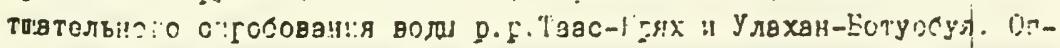

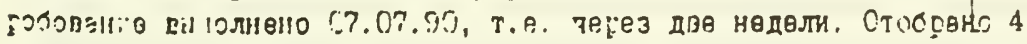

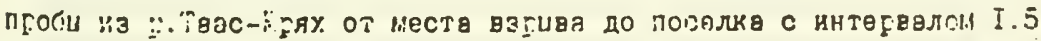

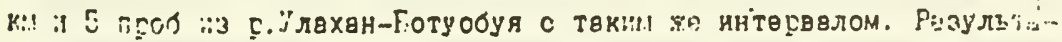

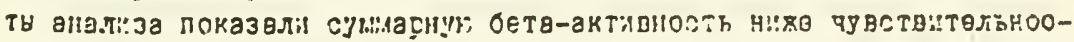

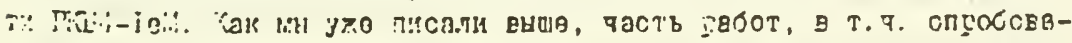

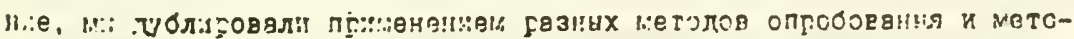

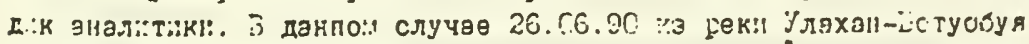

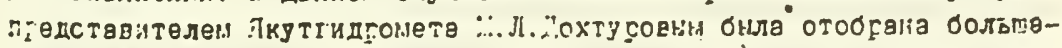

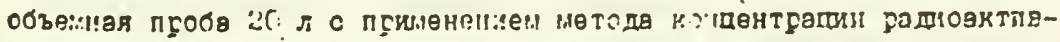

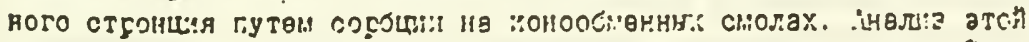

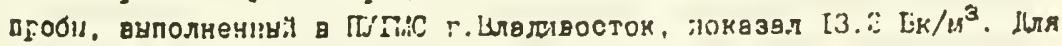

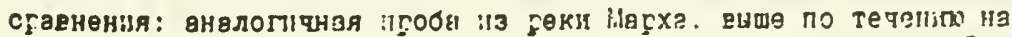

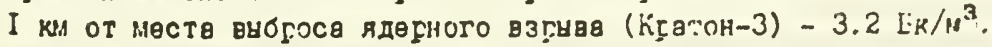

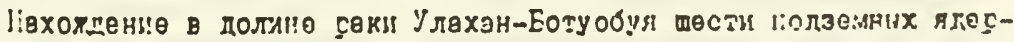
ннХ взбнвов, сасположөнних внше неств отборе пғоб и близяое сосел-

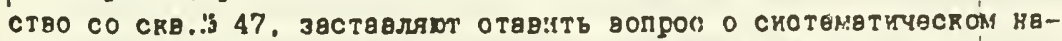

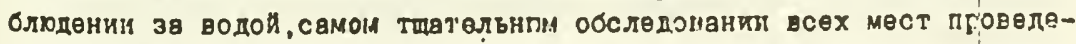

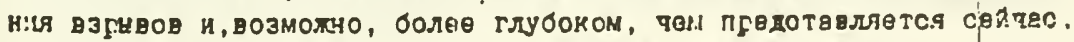

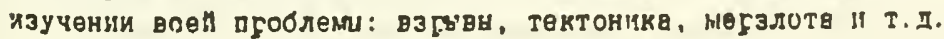




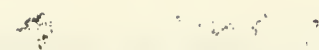

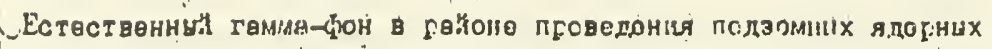

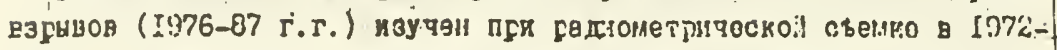
76 г.г., өыполненноП БотуобинкоЯ өкспөдицея (Отчөт с гөологи-

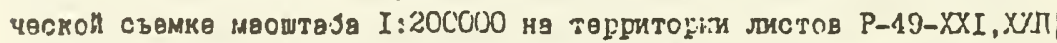

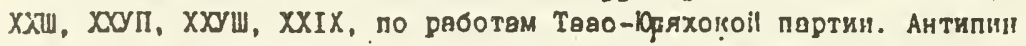

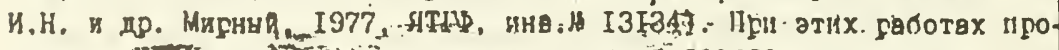

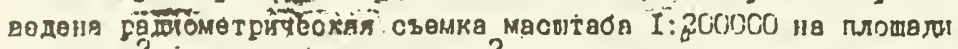

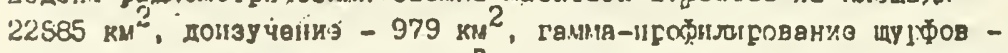
4475.E пог.м. хвнав - 636.8 $\mathrm{M}^{3}$, гамнв-каротвж - 66I, I п.м. прослушивание керів ЛтБ-25 - 1010,6 пот.м. Радиовктивность пород: чөтвертичние отлохөния (оуглинки, пөоки, глини, гялочиики) - 1-10

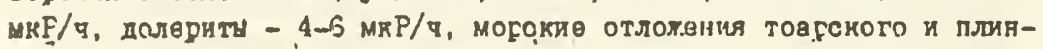
сбахското яцусов - 1-8 мкР/ч, туфы - 8-10 мкР/ч, сГавнитөлън вн-

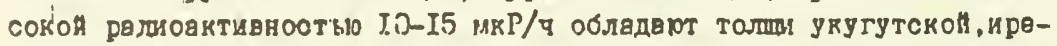
ляхокоИ, плгинокой верхолөнскоһ овит, в такжо отлохөния срөднего пөлөсзоя в ордовига. В раноне продедөния взрнов өстөственни ганме-фон горних порох не превншвет I4 икP/ч.

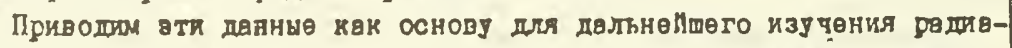

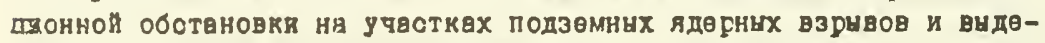
गения на этом фоне питен радновтивного загсязнения.

QСъект "У дачны". В плане работ но стоял по причне птсутотвия своденй у Коогдияегіонного советв по РБ о проведенном здесь ядег-

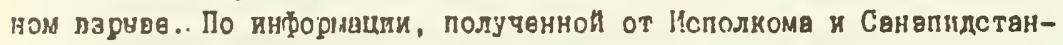

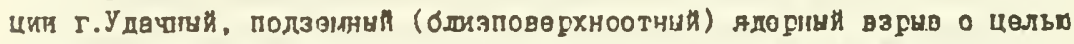
соэдвния плотину водохрвнилищв пропзведөн в $2.5 \mathrm{kм} \mathrm{к} \mathrm{оөвөро-воо-}$

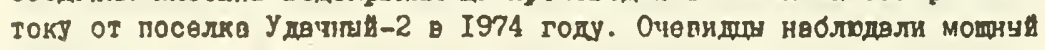
2yóno.

Нв местө взрнва уедиовктиность $50-65$ мкР/ч, на повепхнооти . и ID $200 \mathrm{MKP} / \mathrm{q}$ э эвкопуше нв гдубине $0,4 \mathrm{M}$.

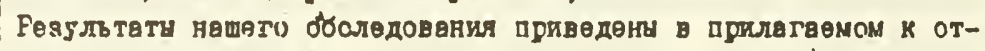
чету вате (Прилоление 115 ).

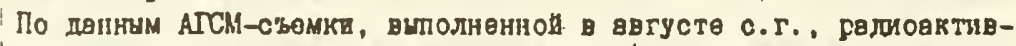

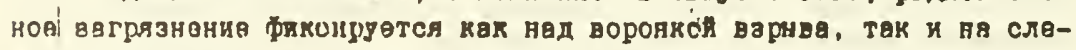
де облакв (Рто.II).

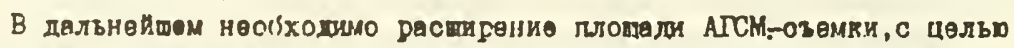

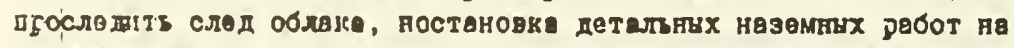

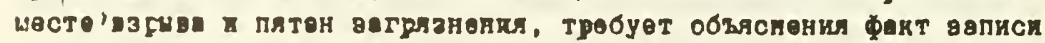

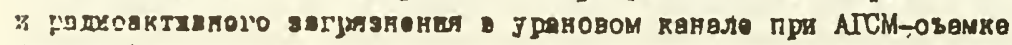
(Pic. I2). 


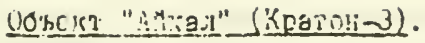

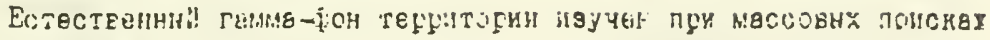

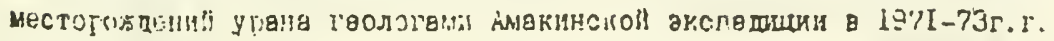

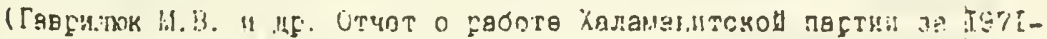

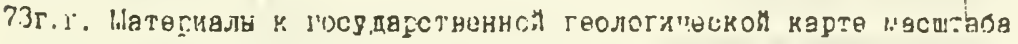

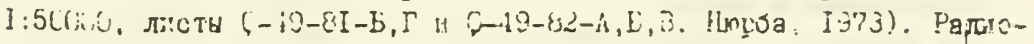

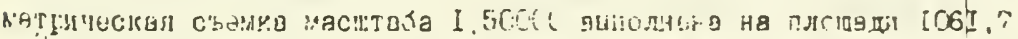

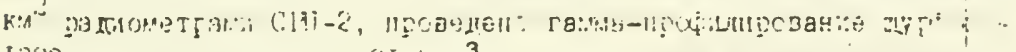

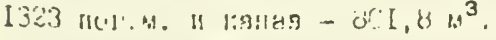

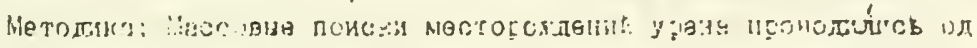

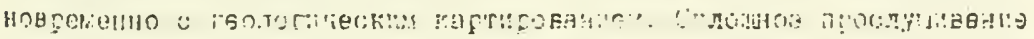

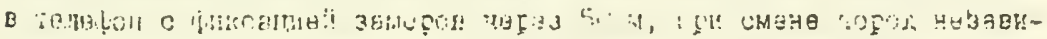

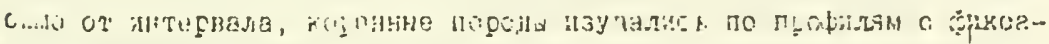

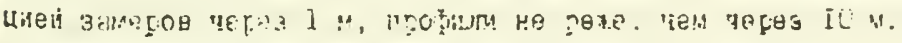

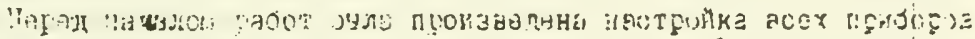

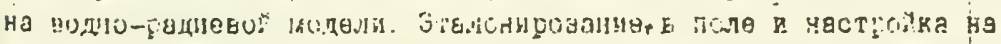

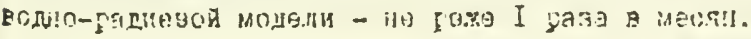

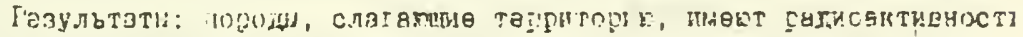

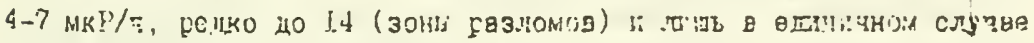

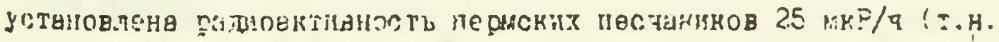
9.16).

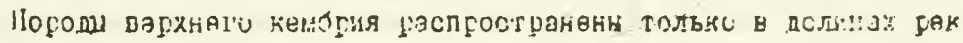
Мврхи и Кучууіу

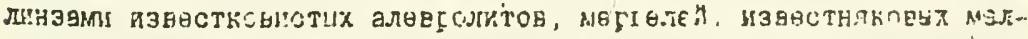

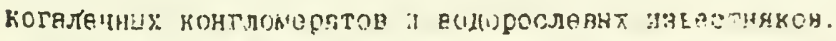

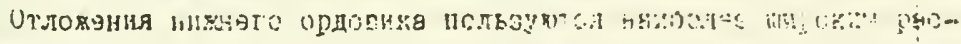

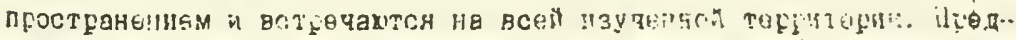

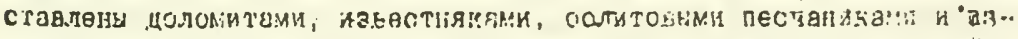

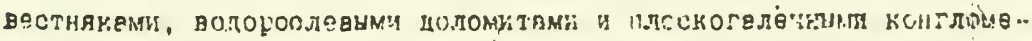
farain.

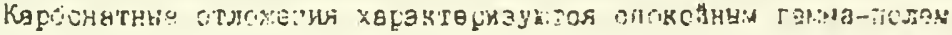

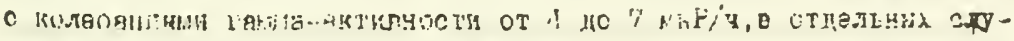

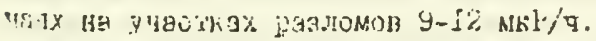

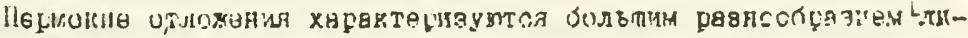

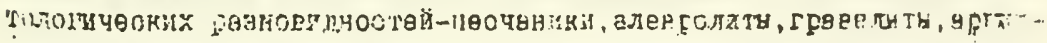

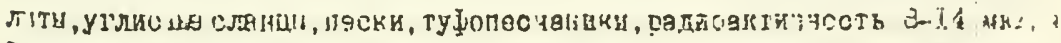

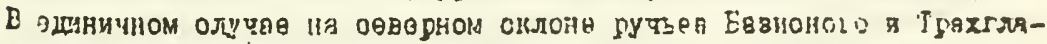
DOTо в гөсчанцRах до $25 \mathrm{mRP} / 9$.

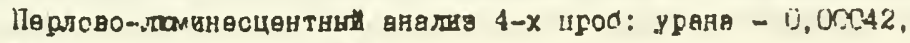
$0,00125,0,0001,0,00005 \%$.

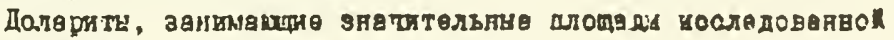
тесриторив, от 4 до $5 \mathrm{mx} \mathrm{P} / \mathrm{q}$. 


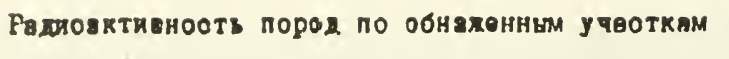

MK $P / q$

Ko. -

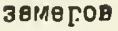

I. Кзеөстняки и доломиту

1-7 I:8

2. Donepity

$455 I 2$

3. Пегжскив отдогентя

$8-11$

75

4. Четвестін 中не отлохспін

G-8

5. Зони безтомов нағбонатноी толье

$9-12 \quad 76$

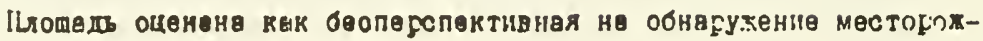

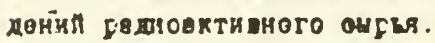

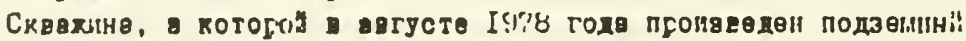

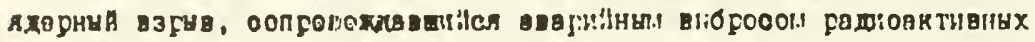

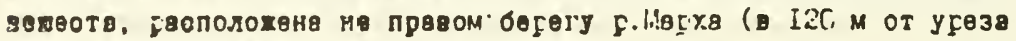

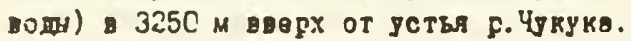

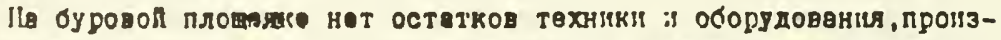

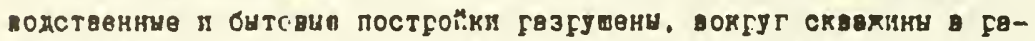

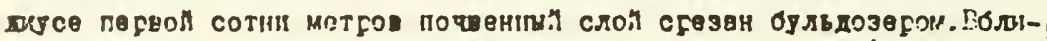

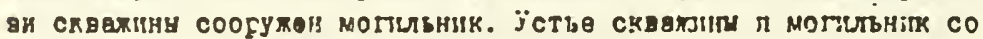

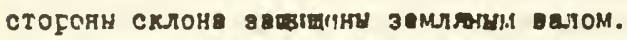

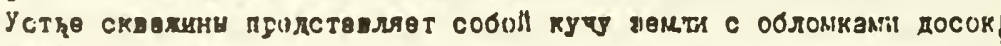

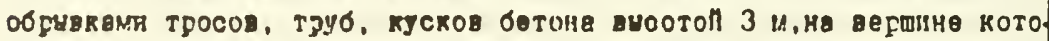

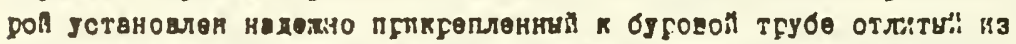

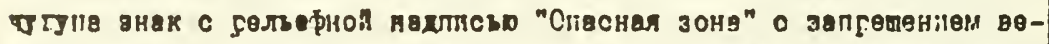

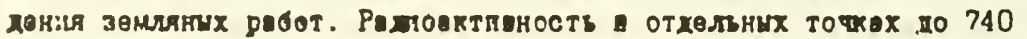
แa $P / \mathbf{q}$.

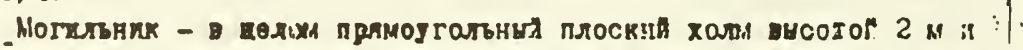

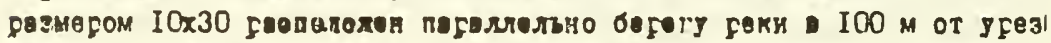

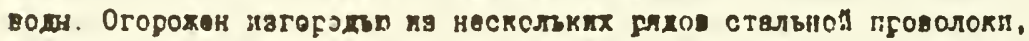

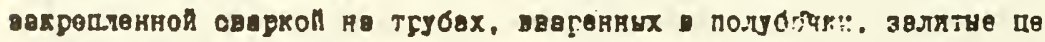

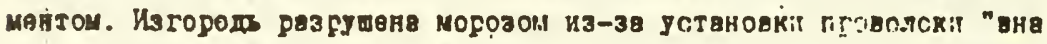

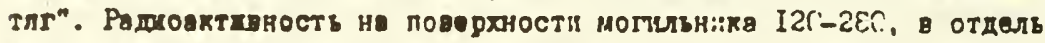
พux тоपкex $20700 \mathrm{MRP} / \mathrm{q}$.

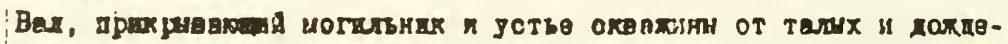

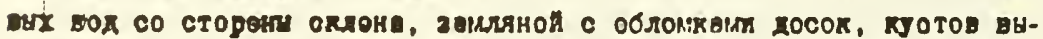

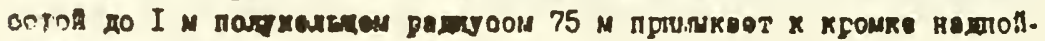
кевнọl торpaci.

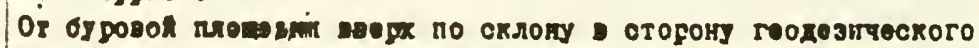

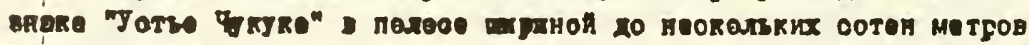

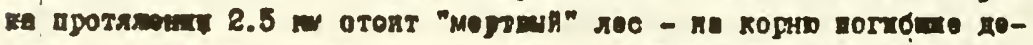

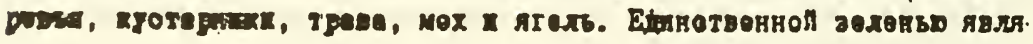




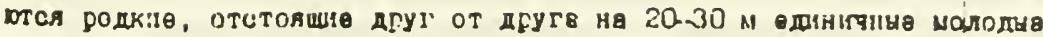

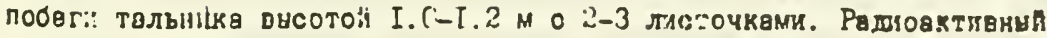

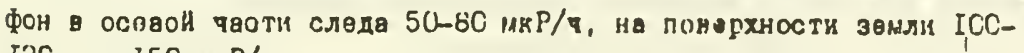
I2O, до $15 \mathrm{C}$ мкP/प.

Лоз:метгическив изнөцения.

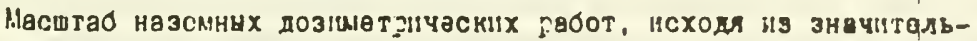

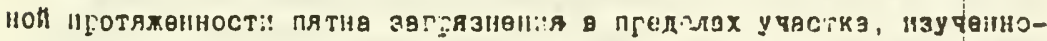

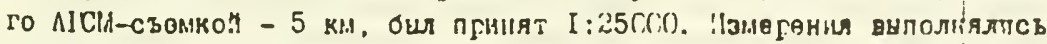

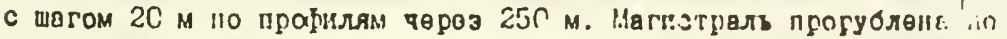

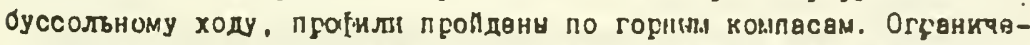

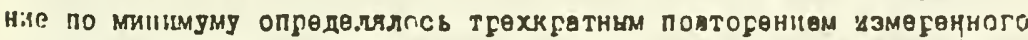
уғовня 9-IO мкР/ч. Еотөстваннић ф̆он горних пород, слагавинх изуча̇емур тесриторив 8 мкP/ч.

Всего пғолдено Iź профилен протяхенностьв от 500 до I7C0/N,pa-

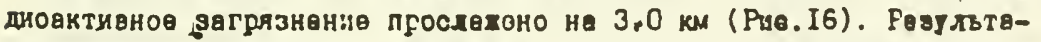

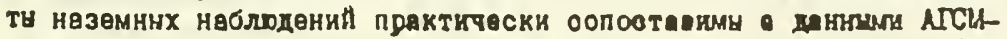
оземки.

Природв гаммв-излучения по полевмм набльдениям објатовяев̈ нвличием цөзия-I37 (Р)о.І7, А-Е).

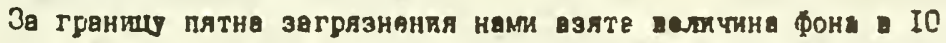

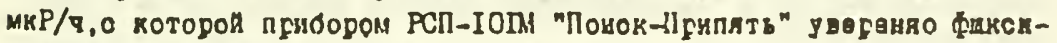

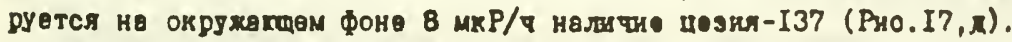

Плотность потокв бетв-төотнц в хонтуре плтна эегранания достл-

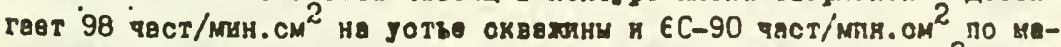

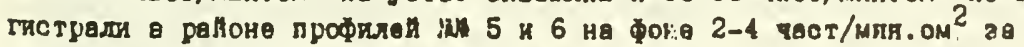

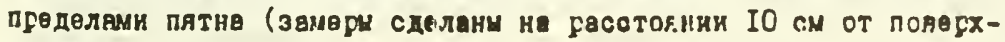
ности).

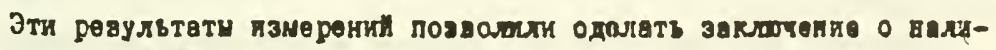
чня отронтия -90 .

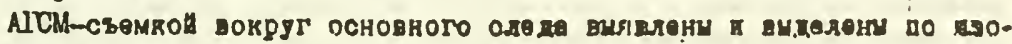

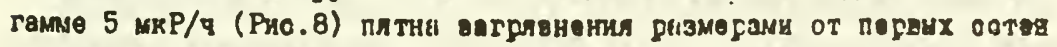

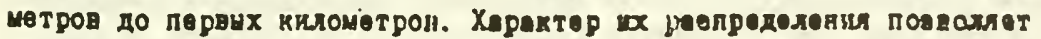

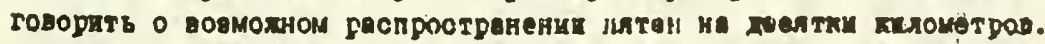

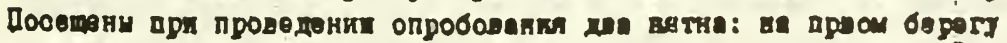

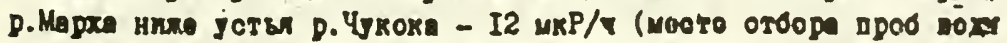

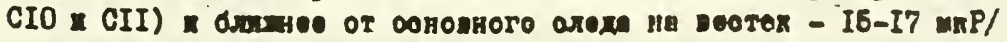
(неоте отборе проб у -

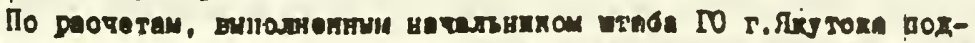

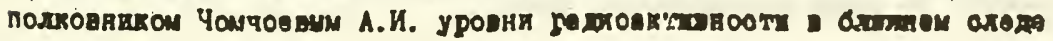




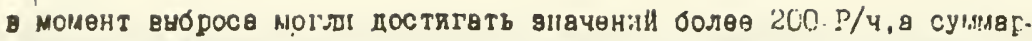

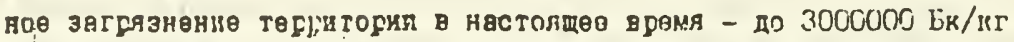
(гесчети спелвки до полученіл результатов өнализов).

Результвтн опспбоввния.

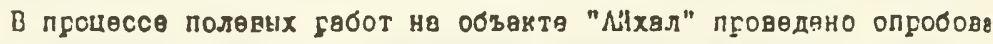

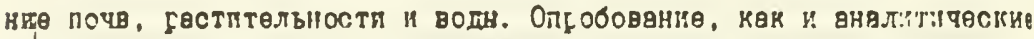

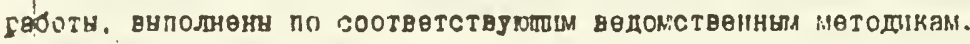

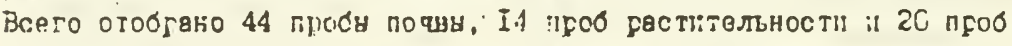

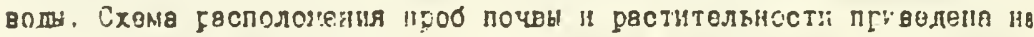
l'uc. 18, волы - на Pho.19:

- По гезультатөм либсбаторичх исслодоявни взднв прямея зввиси-

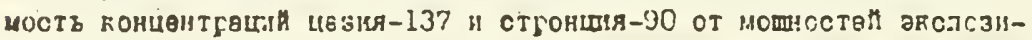

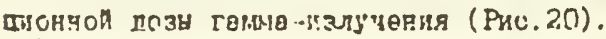

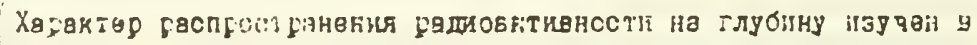

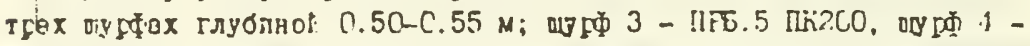

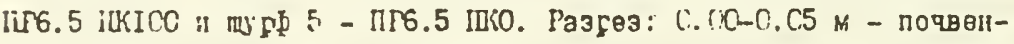

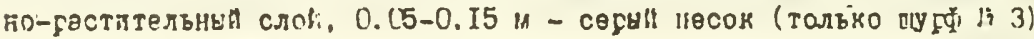

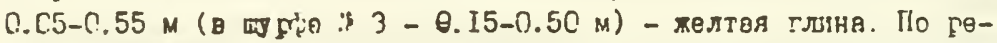

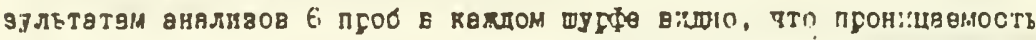

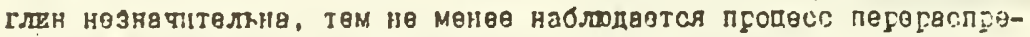

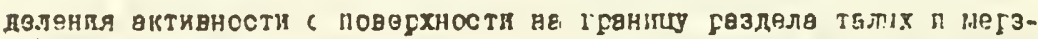
лих пород (Рис.2I).

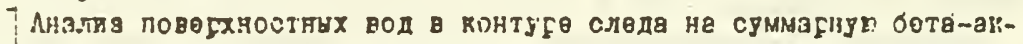

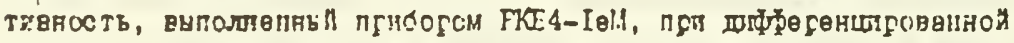

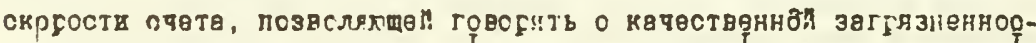
ти води (прпбв CII2 - $24.6 c^{-1}$. CII3 $-26.4 c^{-1}$, CII1 $-29.9 c^{-1}$,

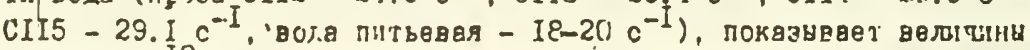
Biexe IxIO-IOL/

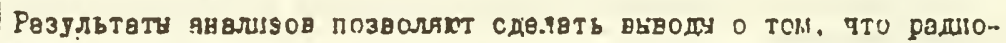

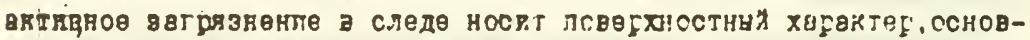

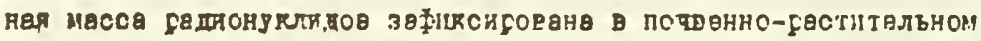

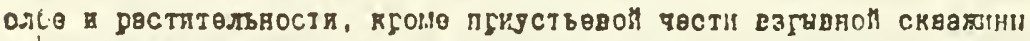

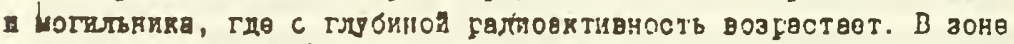

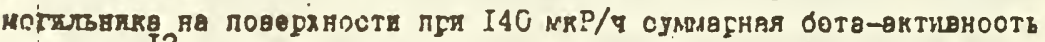

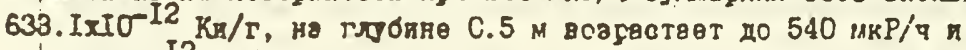
$1193.6 \times 1 \sigma^{-12} \mathrm{Kr} / \mathrm{r}$.

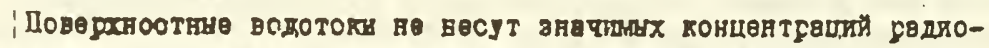

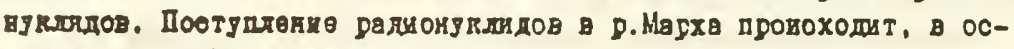

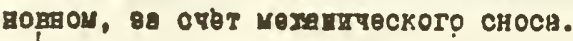




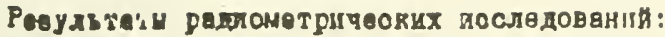

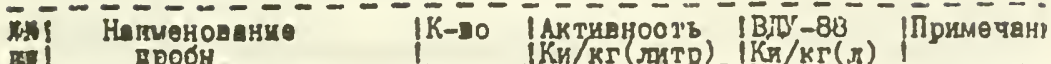

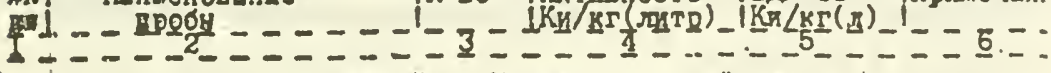

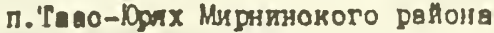

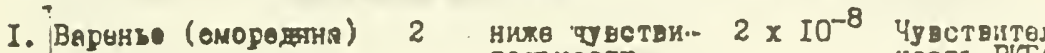
тельнотя. НОСТВ PLIA прибоба

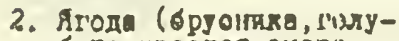

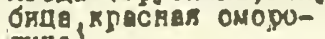
Arita)

3. Pros jcopora, xapucis,

4. MรOO (Голядена)

5. Мsco (сминтка)

6. Малоко (घежніо0)

7. Dox (B.5. Botgoogs:)

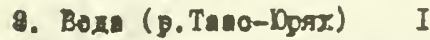

9. Boze roghtomer (ERD. 61)

IO. Bovi guтзева (P. E.

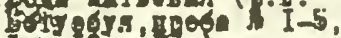

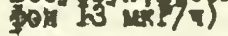

$3-n-$

4 - " -

$3-n-$

$2 \quad-"$

$7 \quad-"-$

$3,3 \times 10^{-10}$

$2,3 \times 10^{-10}$

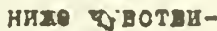
TеЛЬHOCTR прнбөре

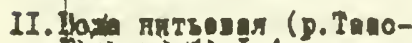

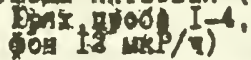

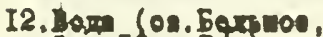
(OF IO waP/T)

I3. Iosm (on, Xept-Kexs, Con a mply

I4. Tos RT (OFr. 6I, $12 \operatorname{paxp}>$ i)

10. T.p 然H 25 UxP ₹

16. Ipy H7 2 (q⿴囗十) 17.

17. Isnt $3(8 \% 4)$, $\$ 0 \mathrm{~m} 100 \mathrm{mP} / \mathrm{s})^{4,}$ I

I8. Ipyax I (ops.47, Don 98 LEP/A)

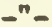

$5 \quad-n$

\section{4} I

I

I

I

I

-

I gañ pona

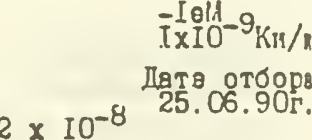

$5 \times 10^{-8}-"$

$8 \times 10^{-8}-$

$5 \times 10^{-8}=$

I $\times 10^{-8}-1-$

$5 \times 10^{-10}=$

$-"=$

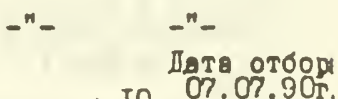

$5 \times 10^{-10} 07.07 .30 \%$

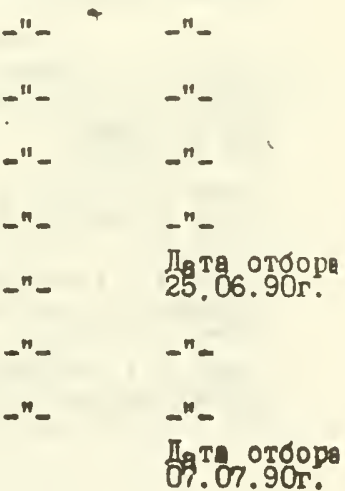


6.

8. Грунт 2 ( 67 MirR/4)

0. Гpy II 3 (ckg.47 Ha поверхности Фон $239 \mathrm{MKP} / \mathrm{q}$ ) i.

$$
\text { : }
$$

Bода грунтовая

(ксатег взснвв оноло Ј пачного)

I Huz "97. की

Водв питьевая (p.УлаХан-Ечснттลх, : $\mathrm{KM}$ от меств

В 30 pas вนมอ Фона

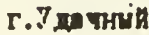

- Грунт и

- TрYHT li 2 (pro-38naxMKP ОКЛ , ФОК I2

' нуле ууотеительоотЕ

- Tryht 3 (ha moroOOCTOK, ФоH 6C MRP/s)

I

- Гryht n 1 tcesero-octoqHail склоR 20 От รรебнл, ФОН IIO uKP/a)

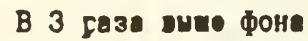

- Ifgiti da 5 (ha conepoboctor a $7 C \mathrm{M}$ of rpeo-

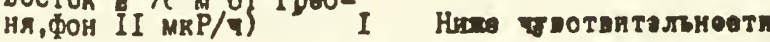
Pera Hepra, $60 \mathrm{~km}$ or J Iavioro

- Геунт I I ( MECOR he I kM hHE cyXoro py qOH IC $\operatorname{MKS} / 7$ )

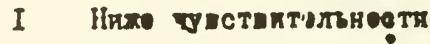

Jarn orgapa

- Г⿸ynt n 2 : $30 \mathrm{~m}$ от

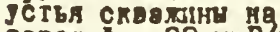
วenex, ФОH $20 \mathrm{MKP} / \mathrm{Y})$

- Tejar 3 (coaeghan

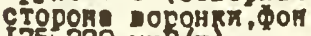
$175-220$ ux $3 / 7$ )

I B 2,5 gезе sure pore

01.07.90r.

- Гรуht 4 (oro-bocточная сторонв 由оронкх, фон I30-150 мкP/7) 


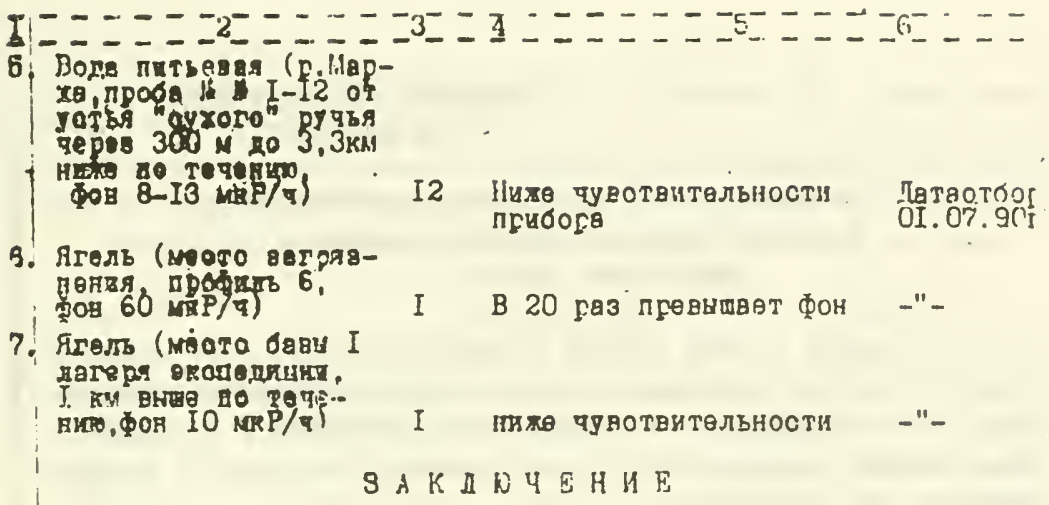

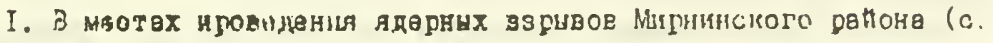

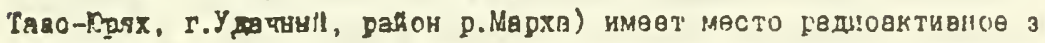

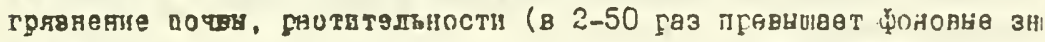
чөнтя).

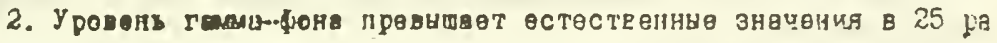
a bus6a.

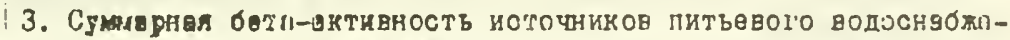

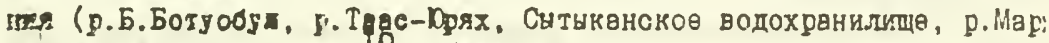

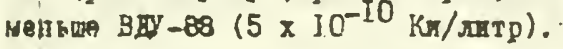

П Р ЕДЛО ХЕНИЯ

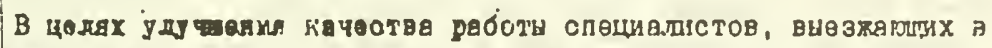

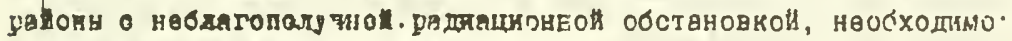

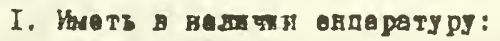

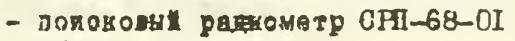

- njóop RCR-IOU⿻

- Lовmesp MP-OIT

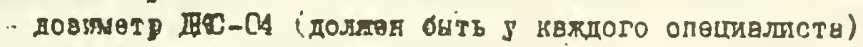

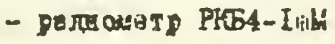

- parinowo.2 Fr-OII

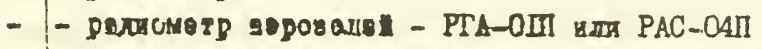

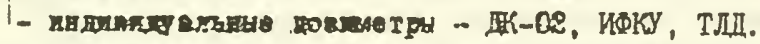

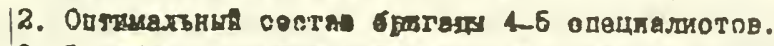

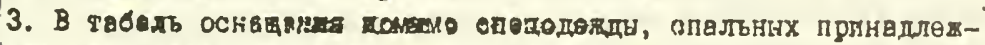

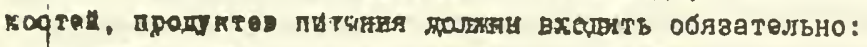

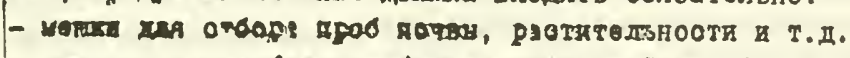

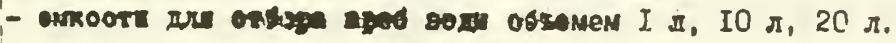




\section{Ивотптут бrovorzh Янц CO NH CCCP}

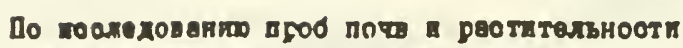

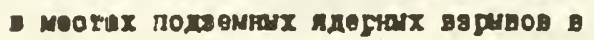
Mhpirsoxom patroue

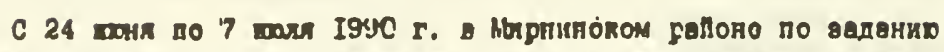

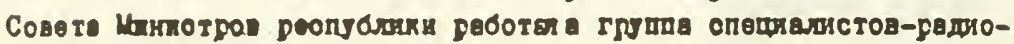

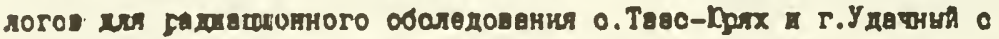

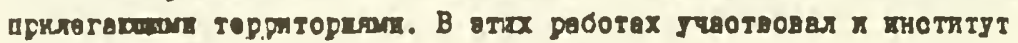
бвомогس भHय CO .UH CCCP.

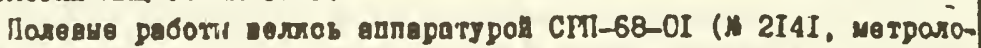

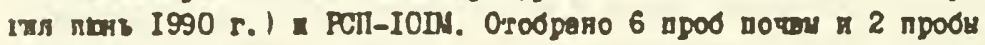
реотщтенност:.

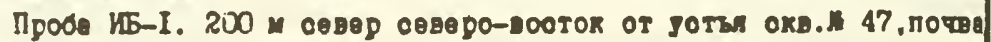
ФOR $110 \mathrm{mRP} / \mathrm{s}$.

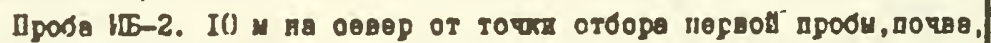
фон 25-30 $\mathrm{mRP} / \mathrm{q}$.

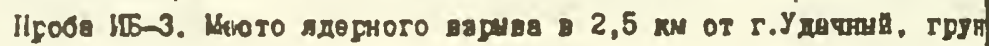
Фон I20 NRP/4.

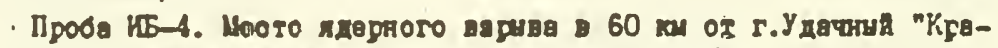
тон-3" јетье сканmas, грунт, ФОН $750-800 \mathrm{mRP} / \mathrm{q}$.

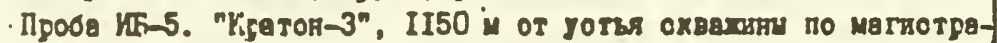

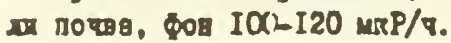

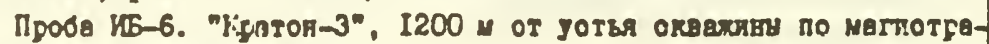

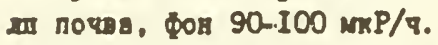

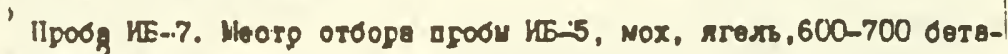

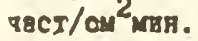

Пробя ИБ-8. Меото отбора пробн КБ-6, мох, ягель, 300-350 бетв.

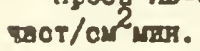

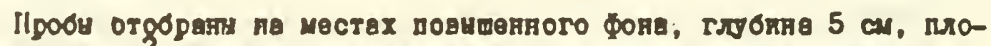

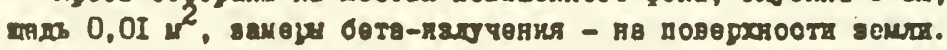

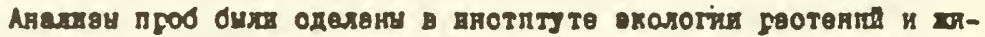

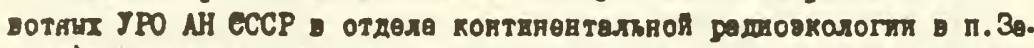

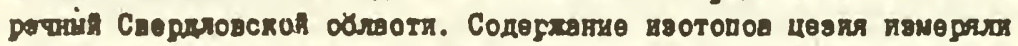

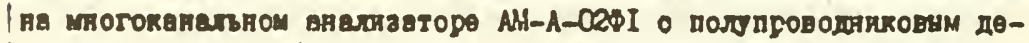

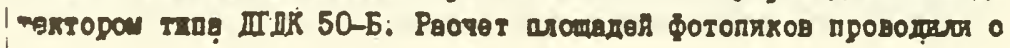




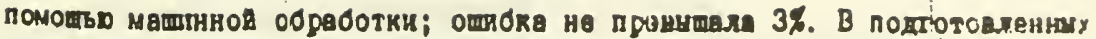

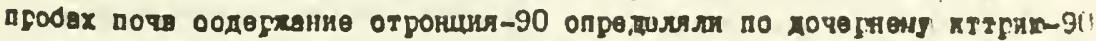

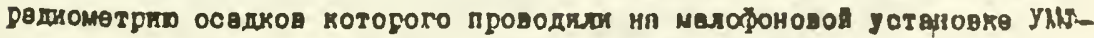

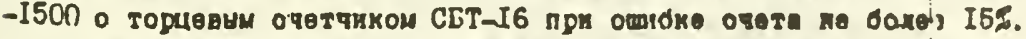

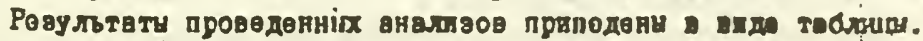

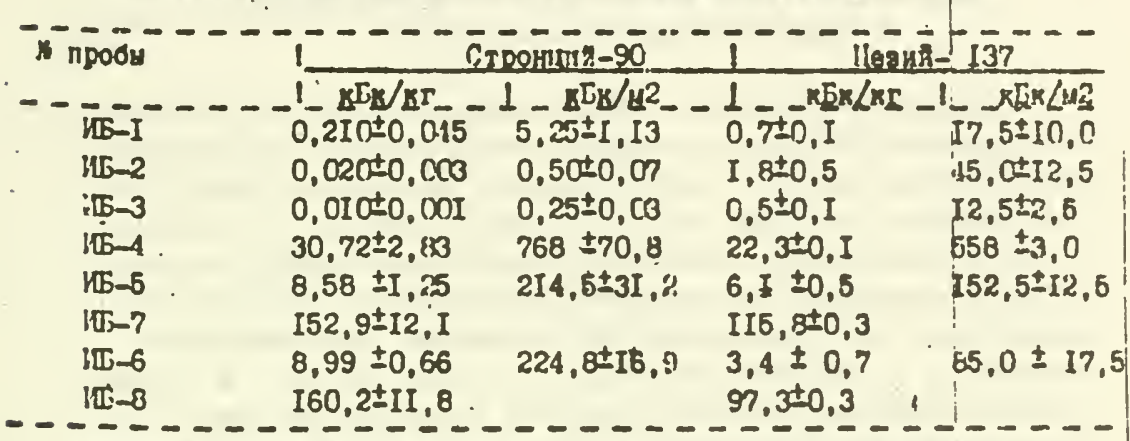

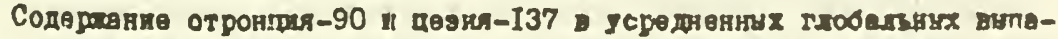

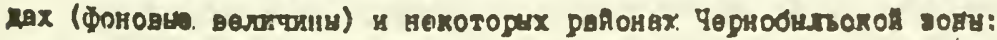

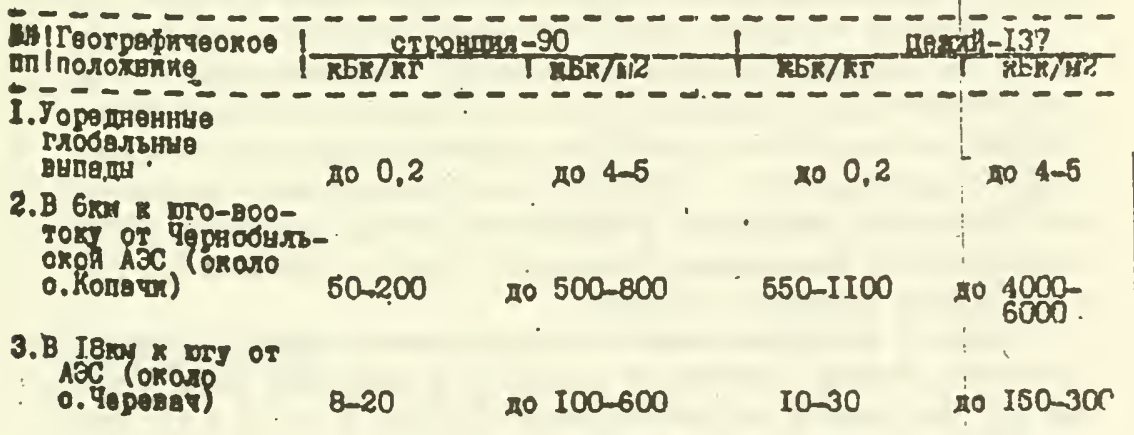

М.в.0, แнттитутв

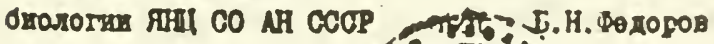

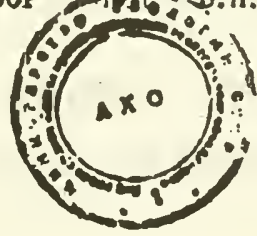


Лвборвтобия отдетв рвдивщонно

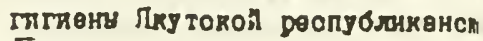
$\overline{\operatorname{CxC}}$

$P: B .3$ y $\pi$ b T A T L

санометспчвзкого внвльзв проб почв, отоб ғанних

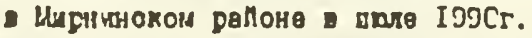

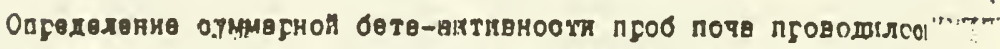

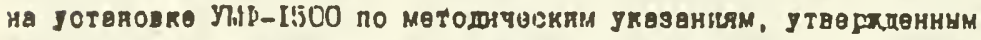

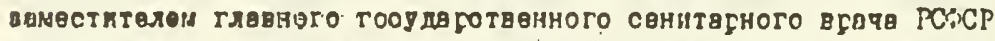

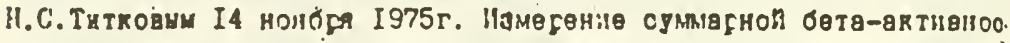

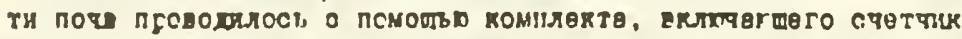

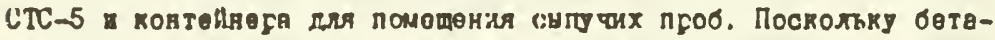

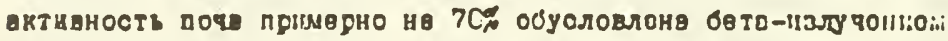

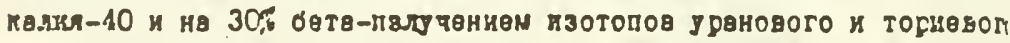

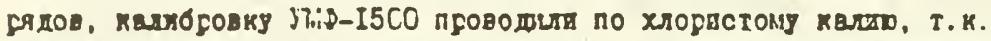

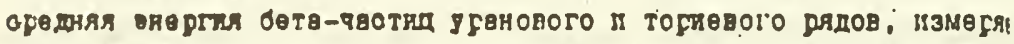

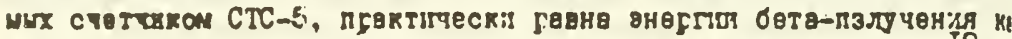

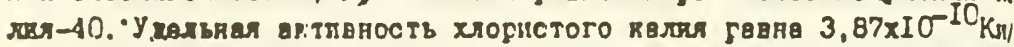

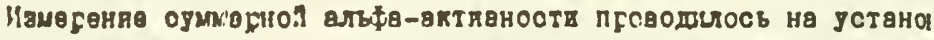

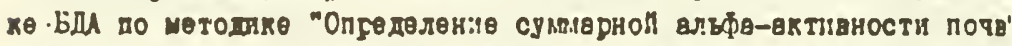

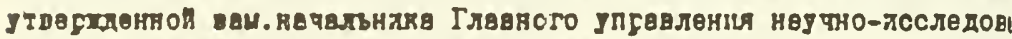

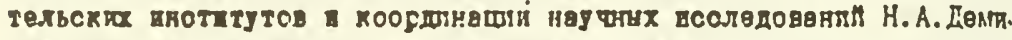

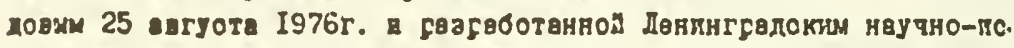

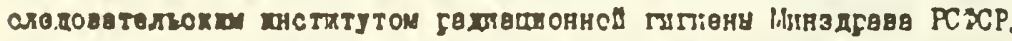

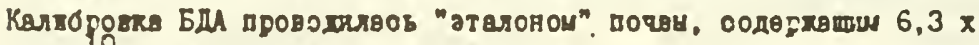
$x$ I0-10 коде тогия на, I 5 потв.

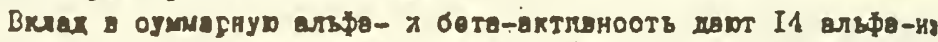

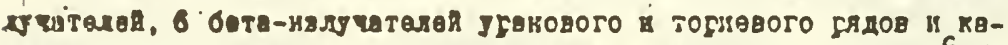

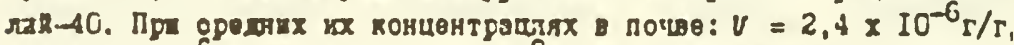
$T h=8 \times 10^{-6} \mathrm{r} / \mathrm{r} \times \mathrm{K}-40=2 \times 10^{-2} \mathrm{r} / \mathrm{r}$ оумедерная влье и бетвakrxoucor notri posky:

$Z_{\alpha}=8_{n \alpha}(V)+6 \mu(T h)=6.4 \times I \sigma^{-12}+5.3 \times I . \sigma^{12} \mathrm{Kr} / \mathrm{s}=I I, ?$ $\Sigma \mu=3 n \rho(V)+3 n \rho(T h)+n \rho\left(K^{40}\right)=\left(2,4 \times 10^{-12}+x I \sigma^{-12} \mathrm{KF} / \mathrm{i}\right.$ $\left.+2,6 \times 10^{-12}+16.2 \times 10^{-12}\right) \mathrm{kH} / \mathrm{s}=21.2 \times 1 \mathrm{C}^{-12} \mathrm{ku} / \mathrm{s}$

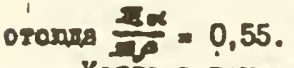

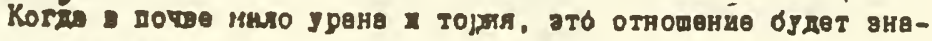

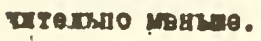

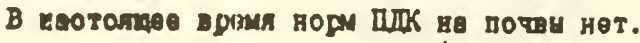


Суммарная бетв- n вльра-активность потв

II

an! Мөoтo отбога проб

I. Марнаноке- район

p. Ampza

2. -"-
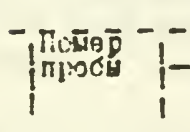

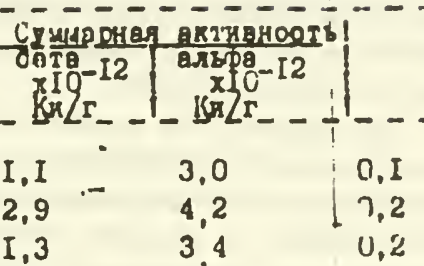

3. $-"$

$$
\text { i. }
$$

5. $-n$

b. $-"-$

?.

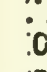

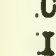
5

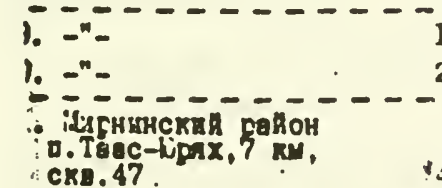

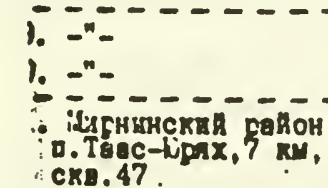

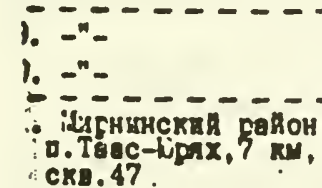

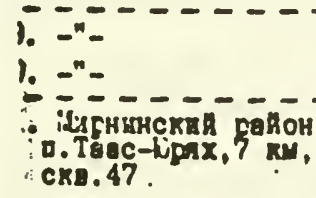
2. $=$

$\overline{-a}=$

3. ing

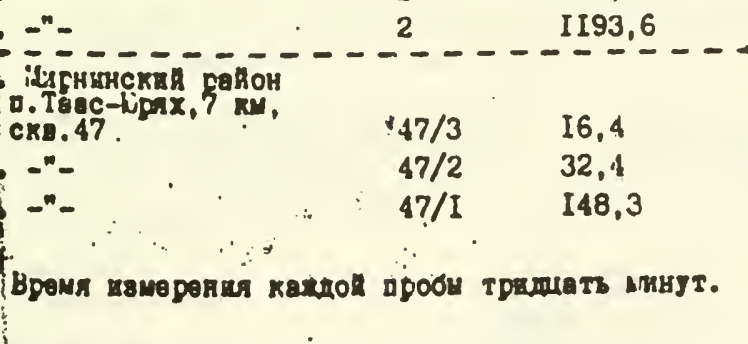

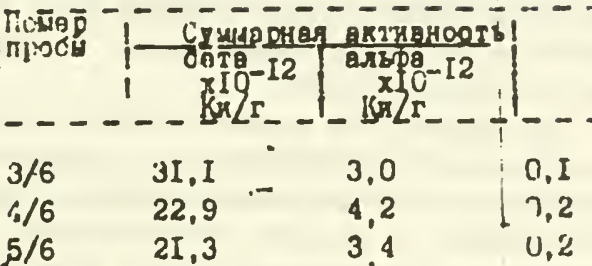
(n)

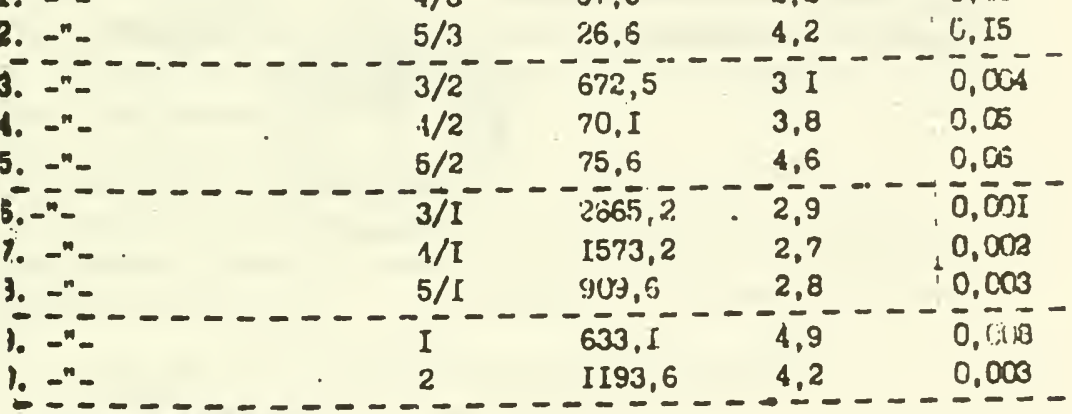


Срөдая суммадная Јетв- и өлфф-активнооть пахотнчх почв ЯACCP ооотевляет соответотвенно $20-25 \times \mathrm{IC}^{-12} \mathrm{Ku} / \mathrm{s}$ и $7-10 \times$ IC

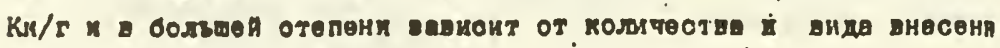
мкнерельних удоб бенти.

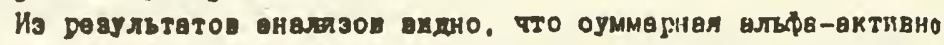

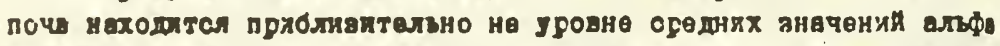

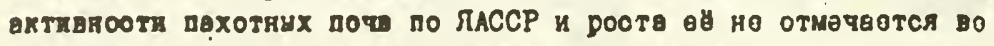

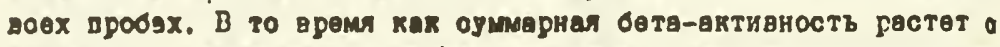

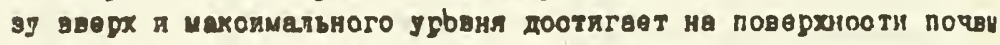

Это овихетельстаует о том, тто имеет меото загрязненио пот бөтв-пветчвтегямก.

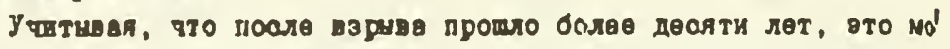
гут бчть строяция-90 и цеван-I37, перно, патуреопвдв которнх охоло 30 seт.

Врач-лаборант ратамлотачеого

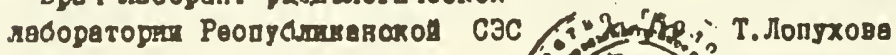

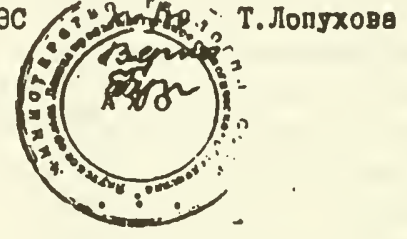


Яют тькая Республяганская

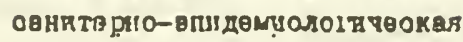
отэнนия

З А К Л Ч Ч Н К Е

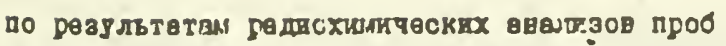

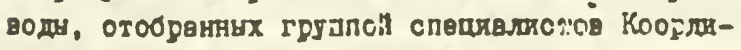

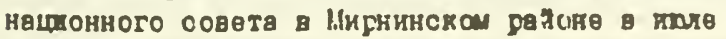
I990r.

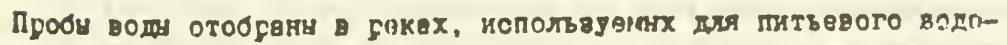

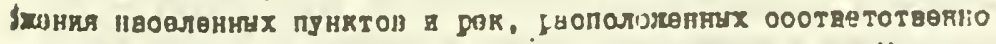

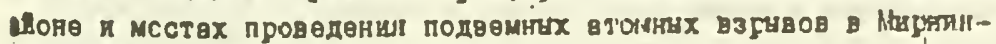
- раноне.

Цељь лаборөтопного ясслодования - попи'ьтьоя јствновкть воз-

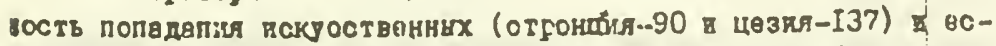

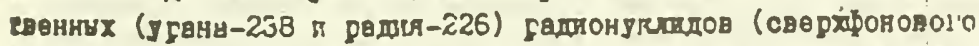

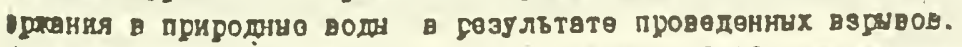

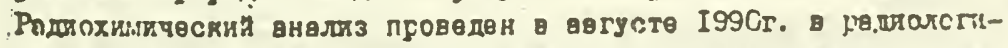

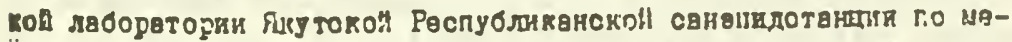

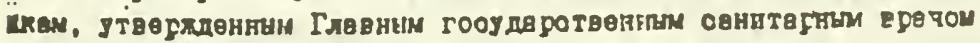
P П.. H. Lуғгвсовим 03 I2.79r.

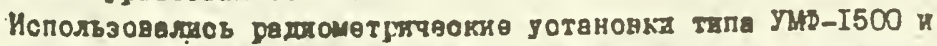

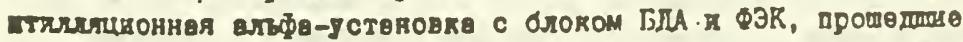

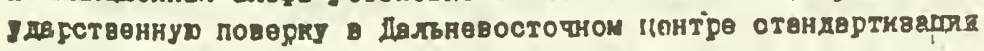

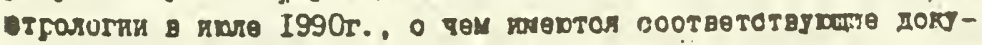
กบ.

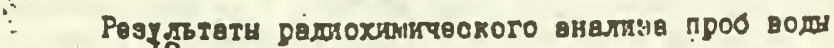

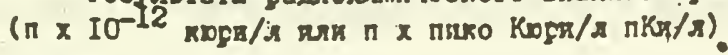

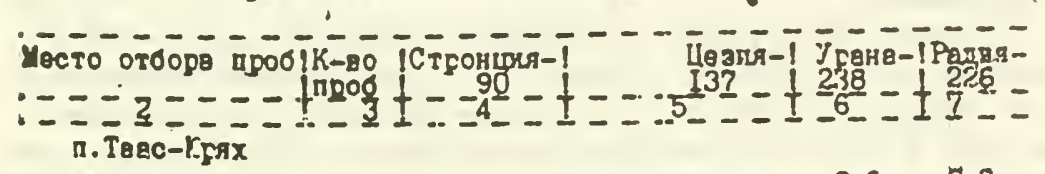
p. Т8в0-Desx
I. 6
ILехе миираяетьо
$\begin{array}{ll}0,6 & 0,2 \\ 0,3 & 0,3\end{array}$
ร. Элвхан-Еотуокуя I
I. 5

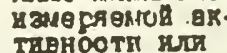
ก.У пачนด
f. Маста (Јстье рутья

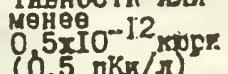

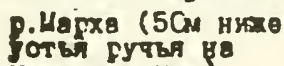
шесте вз (580)
$I \quad$ I.5
$0,3 \nmid 0,2$
2,5
$\therefore$
$0,3 \quad 0,2$

$\therefore$ 


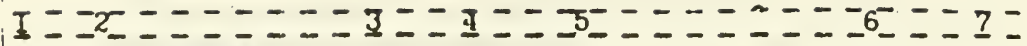

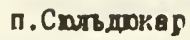

$$
\begin{aligned}
& \begin{array}{llllll}
\text { 5. p. Shroth I I I.5 } & 0.3 & 0.2
\end{array} \\
& \begin{array}{lllll}
\text { n.Cвет rast } & \text { I } & 3,0 & 0,2 & 0,2
\end{array}
\end{aligned}
$$

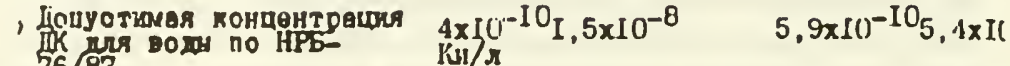

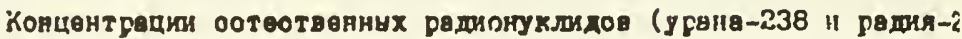
в иослеловенних пғобех вон гек Мирнпнокого санона нехолягся нв убовнө оредних знвчения многолетних (с I983) леборвтогнвх нвблюд

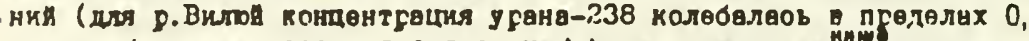

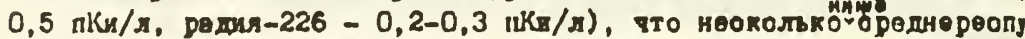

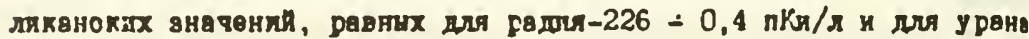
$2.38-0,5 \mathrm{nKH} / \mathrm{d}$.

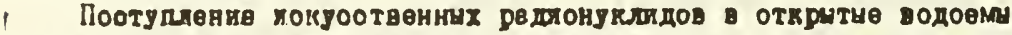

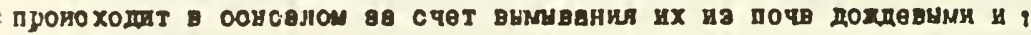
, MNK Dorawn.

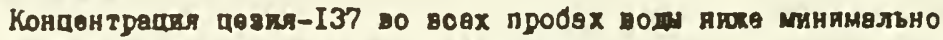
намеряемо ектнаности й менеө $0,5 \mathrm{nKu} / \mathrm{d}$.

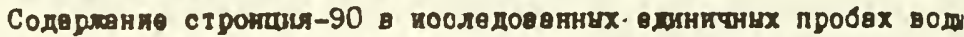

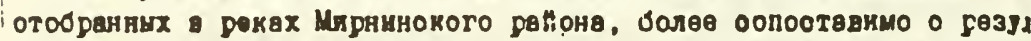

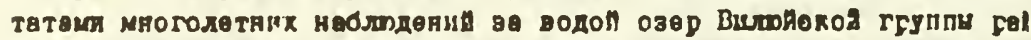

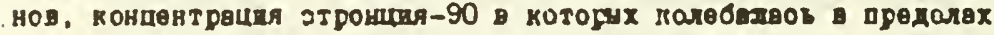

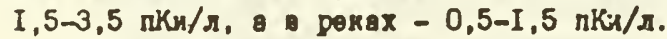

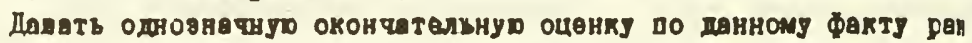

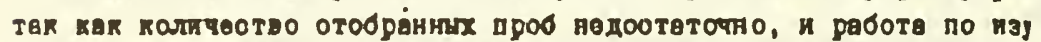

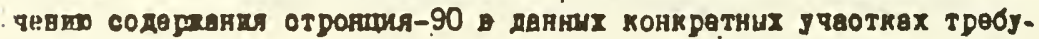
อт пуохолсоная.

А велом ковцөнтрация өотөотвевних (уранв-238, рөдяя-226) в

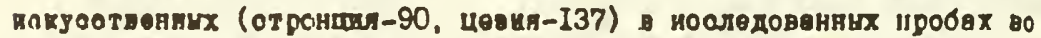

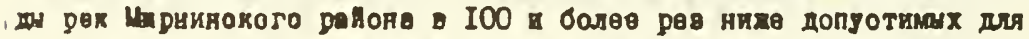

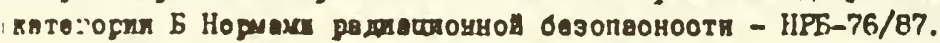

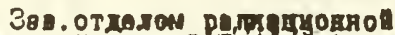

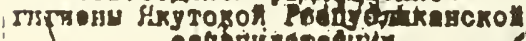

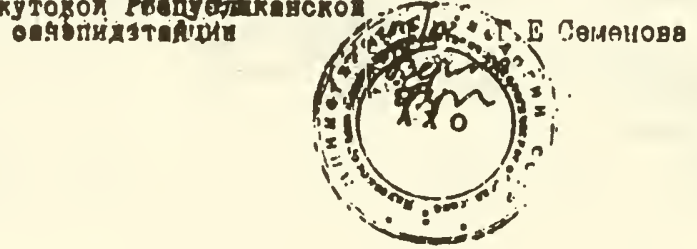




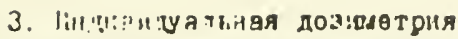

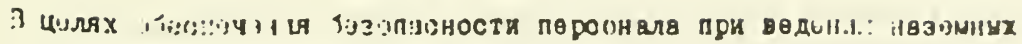

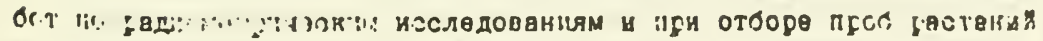

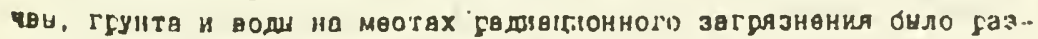

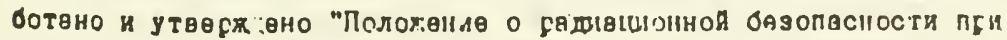

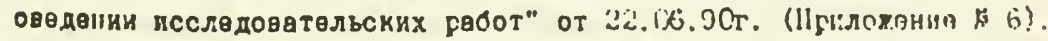

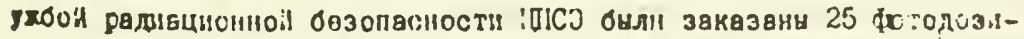

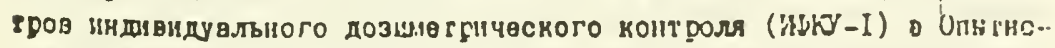

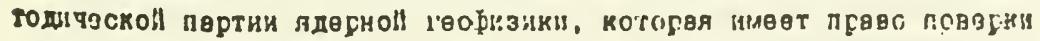
тодозіметров от Лвльневосточного центре итвндастизвции и иот соло-

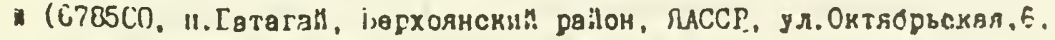

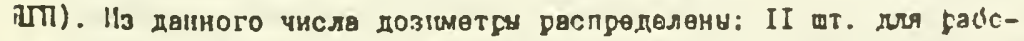

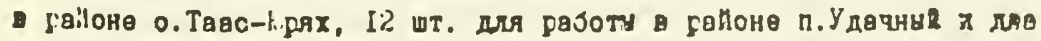

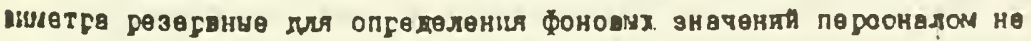

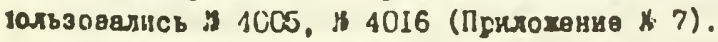

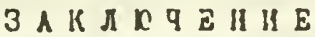

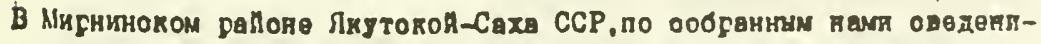

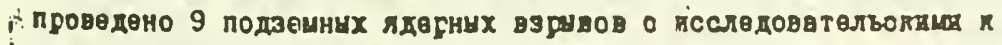

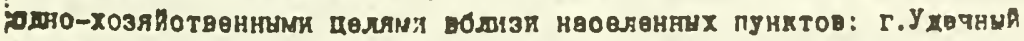

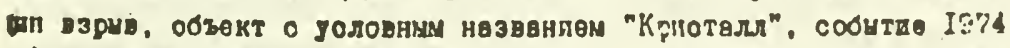

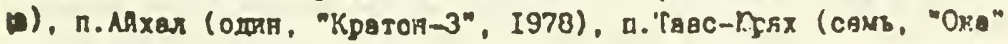

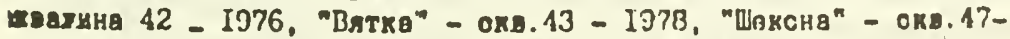

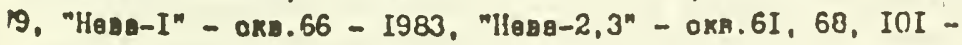
B).

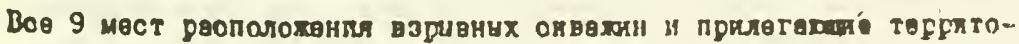

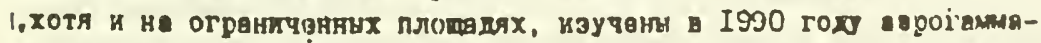

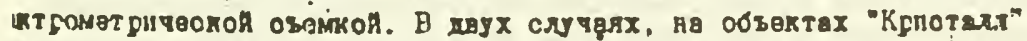

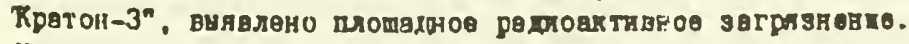

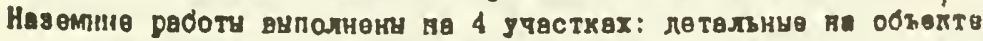

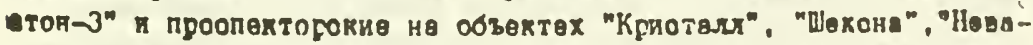

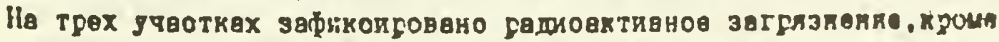

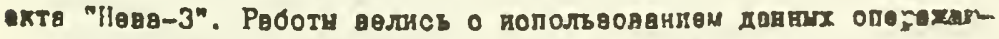

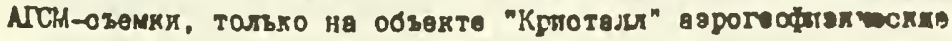
ors проведены позхе.

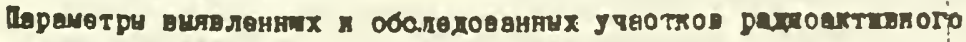
рээнөнкя :

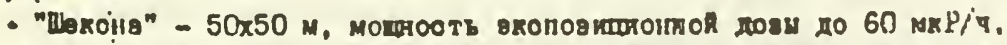

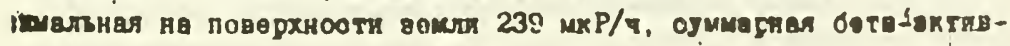


нооть потв C.j( (.162) Lк/кг (злесь ІІ далев по тексту - -өзуль-

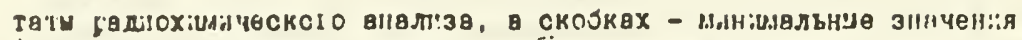

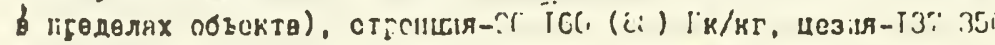

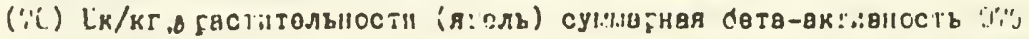

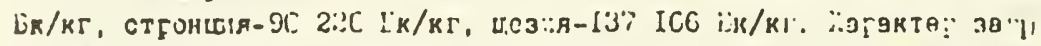

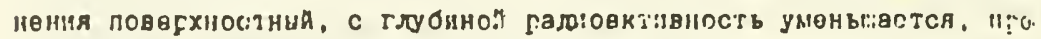

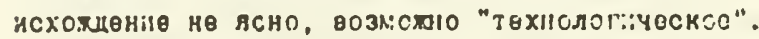

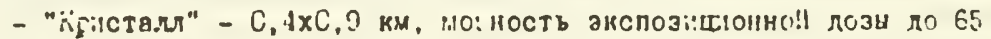

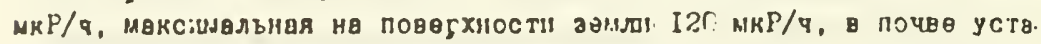

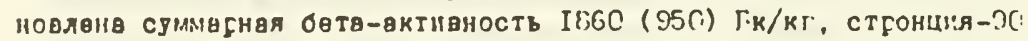

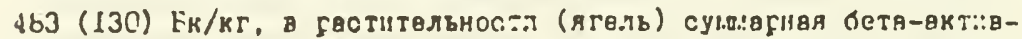

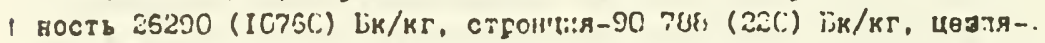

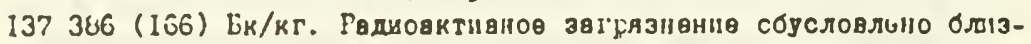

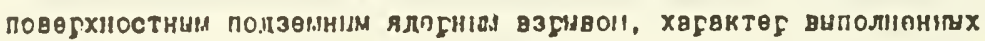

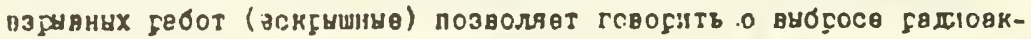
тионости, пбедусиотбенноІl пғоектон.

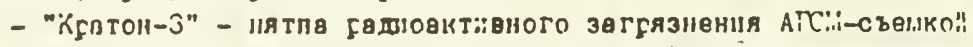

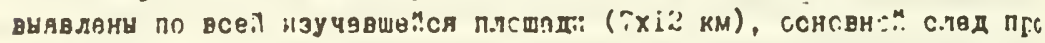

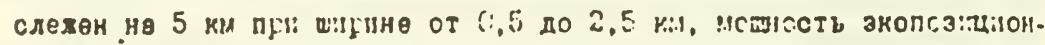

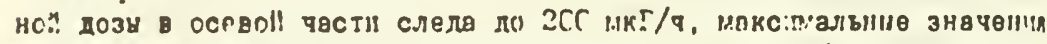

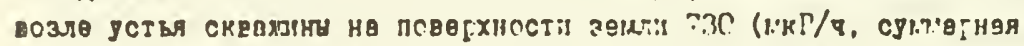

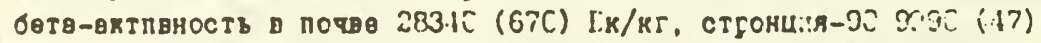

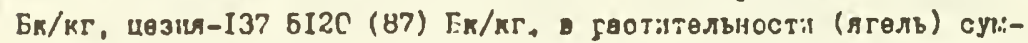

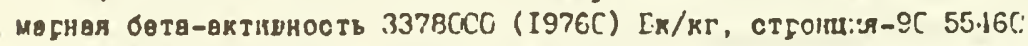

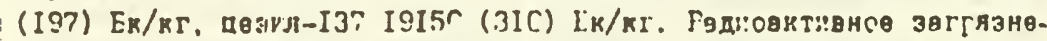

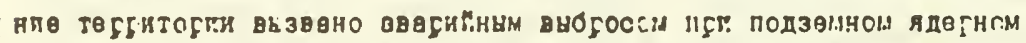

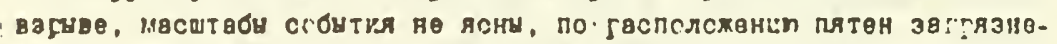

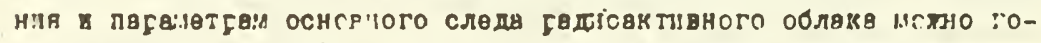

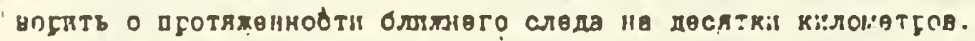

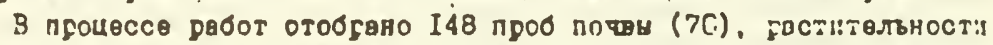

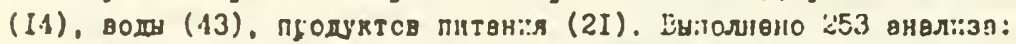

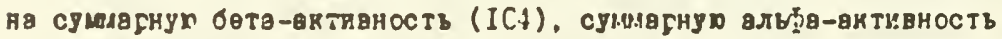

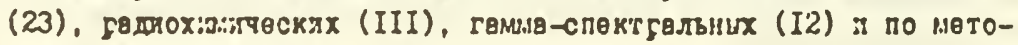

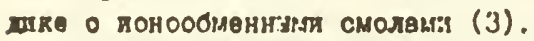

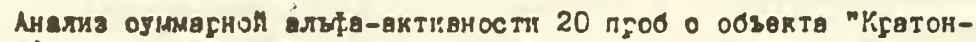
3" и 3 проб с объөктв "Lексна" покөзал гезультату нв уровне сбед-

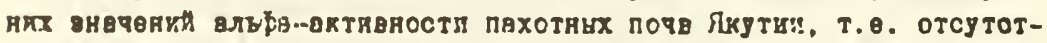

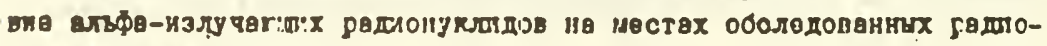

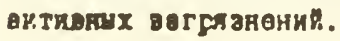




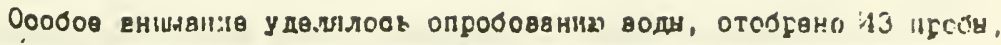

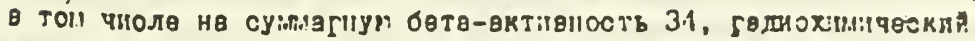

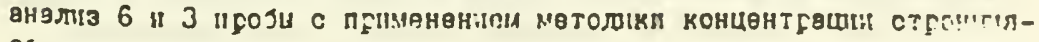

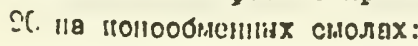

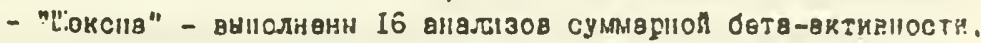

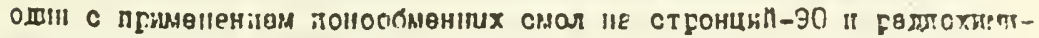

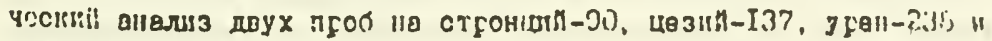

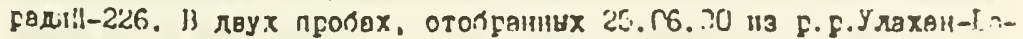
туобуя и Тавс-

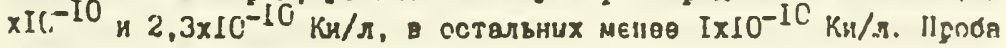

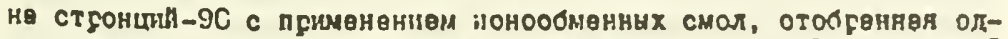

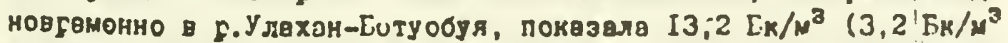

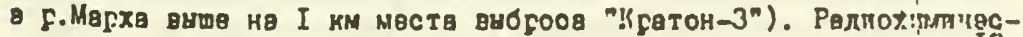

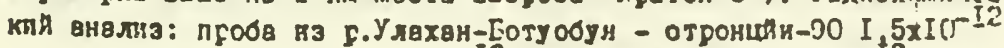

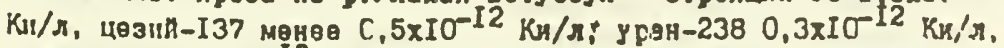

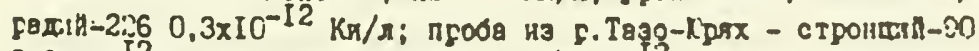

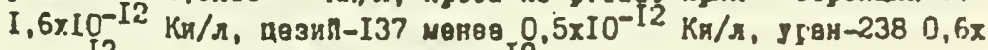

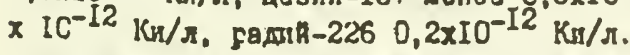

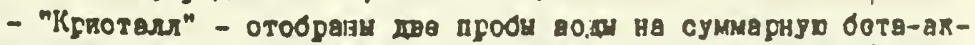
тивноств, одна в ксетере взрная, вторея в р.Улахан-Еиснттах.

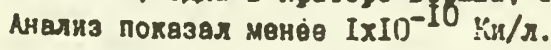

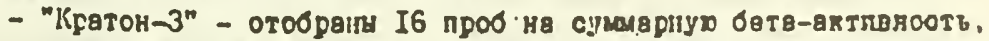

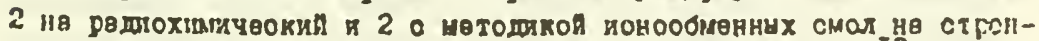

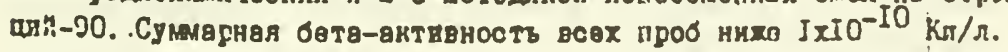

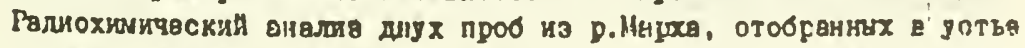

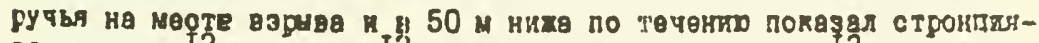

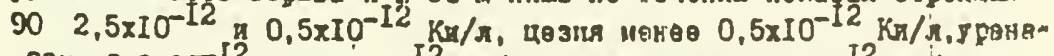

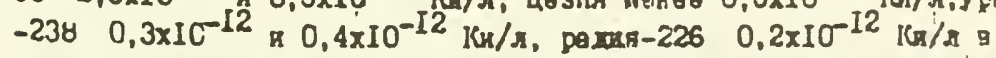

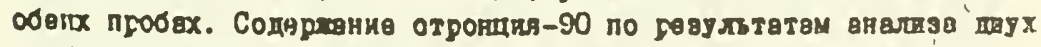

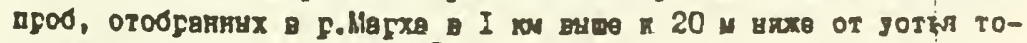
ro $x$ gy $7 \mathrm{~h} 3,2$ \% $8,5 \mathrm{br} / \mathrm{m}^{8}$.

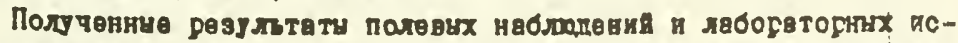

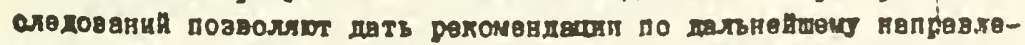

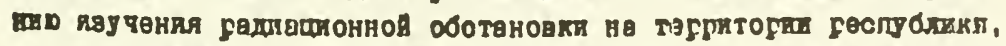

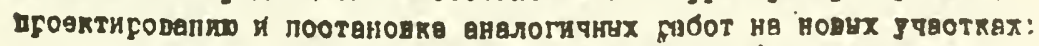

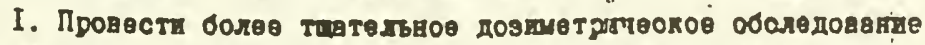

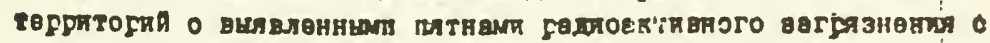

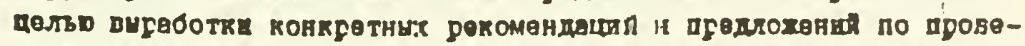

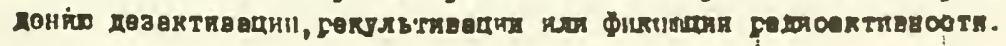




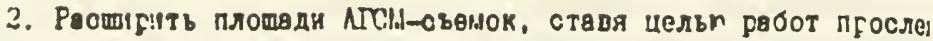

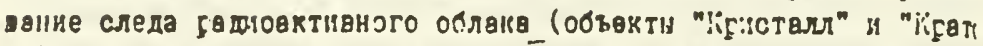

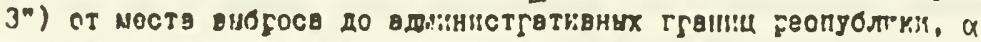

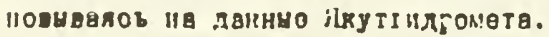

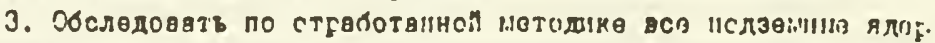

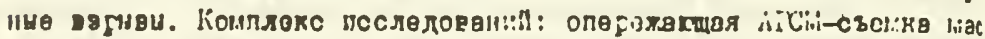

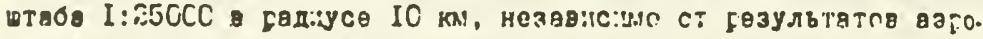

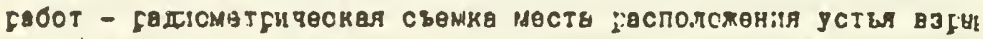

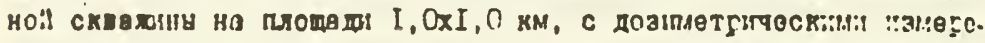

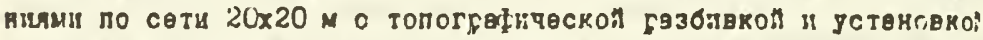

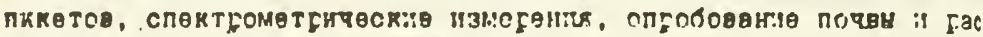
тительности тө:богенно негушенного и не нағушонного ленлшіф

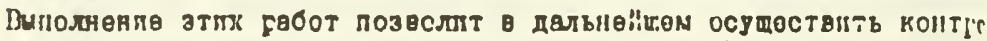

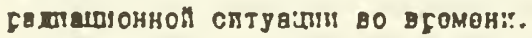

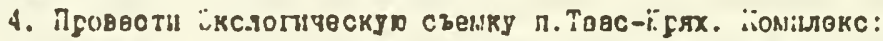

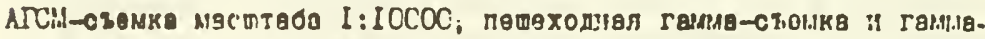

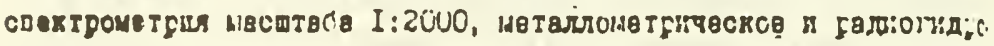

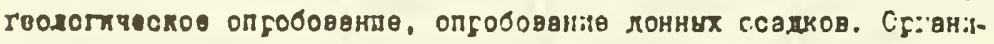

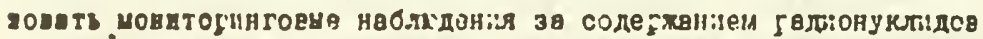

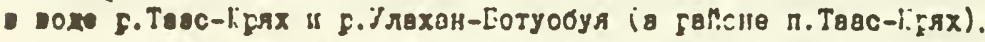

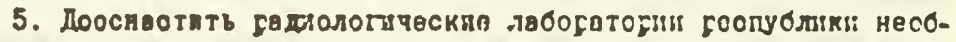

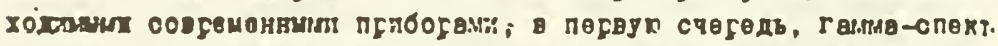

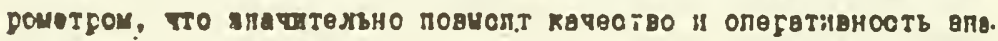

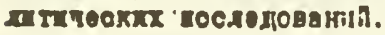




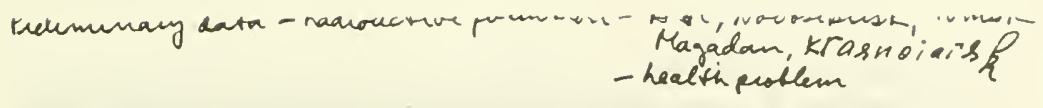

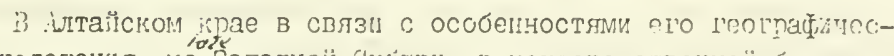

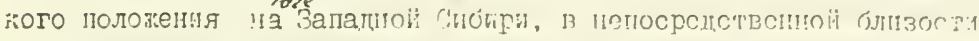
凡 Китаю и :Һазахстану, суцественное зиачение имеет ратиоаттыное затрязнение территори. П числе осивных источников раниоантивното гагрязнения природной средн на территории края вителятт

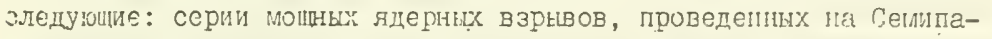
.ағичском полигоне и в Китае, авария на Чернобыльской АЭС, испытания лдерных зарядов на Нової земле, продукты сжигания органического топлива в котельншх и тЭц, пыление отвалов золы, а тагже \%стници радиоактвного загиязненил естественного происховдения.

Радиоактивне загрязение почвы на территории Алтайского крдя оределгется в оснонном ьноголетними накоплениями на почве вапатений из атностеры долгокивуших стронция-э0 и целзия-І37, забјсшенных в атіосыеру при испыганиях ядерного оруяия. Ііроме того, занетним источником радиоактивюго загрязнения почвы являются внос:лье непосредственно в почву минеральные удобрения. Загрязнение поверхностных вод обусловлено смнвом атмосферными осадками

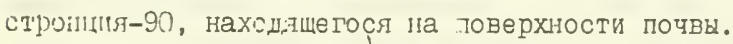

5 Новосиоирской области јадиометрический анализ проб атмосд̈ерних выпашений ( по ежемесятнм данншм Џентра наблюдений за затү:язиением природі. среды) показал, что плотности осадков в

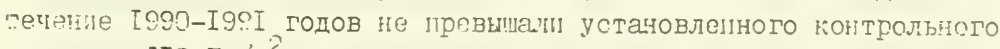
आачения IIO $\mathrm{bK} / \mathrm{m}^{2}$ в течение суток по суммарной бета-активности 4 составили в срепнем по Новогибирской ооласти $0,7 \mathrm{Ek} / \mathrm{m}^{2}$. В местах постоянной регистрации радиағионного загрязения средние величин плотности осадков инеют следующее значение: гг. Еолотыое 15 Карасук по $0,8 \pm 0,5 \mathrm{5k} / \mathrm{m}^{2}, \Gamma$.Барабинск - I, $0 \pm 0,4 \mathrm{5 \pi} / \mathrm{m}^{2}$, г. Новосибирск $-1,5 \pm 0,7 \mathrm{\textrm {k }} / \mathrm{m}^{2}$ и п.Огурцово - I,4 $\pm 0,7 \mathrm{\textrm {k }} / \mathrm{m}^{2}$. :.аксинальные щатения выпапения рапиоактивнх осапков в Еара-

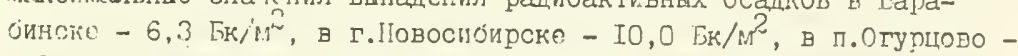
- I $\xi_{,} \therefore$ Fr: .

Ра;иоактивность приземного слоя атмосқ্еры обусловлена онла

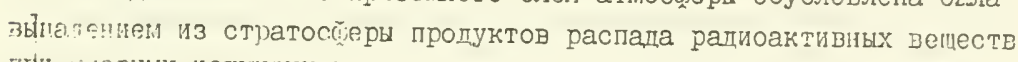

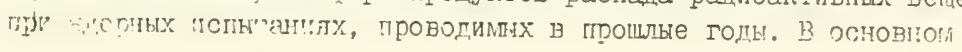
једі:

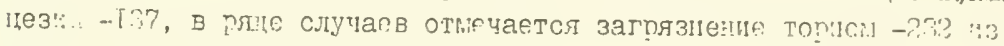
no $111 \%$. 


\section{6}

:fоицссть доза от почвы составляет в среднем 20-50 мкр/час, оннаго возможно в ряде случаев максималыое значение дозы (в сани'арџ:о-защитной зоне хвостохрапилниа По "Химконцентрат" (г.Новосибирск) -.. .цо $275 \mathrm{mk} /$ час, что осусловлено производствєчио: деятельностыо этого предприятия).

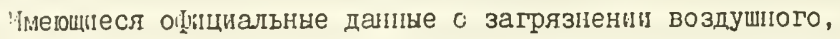
водитого бассейа и почьн Џовосисирской области не дапт полно-

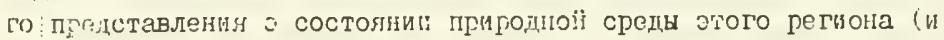
orде.I ных его терэиторй), тем не менее они виолне иогут свицетельствовать о зонах возионого антропотехнического напрякегия, следствием которого могут быть потери в здоровье населевия.

В Томской области значительное превыление радиационното иона наблюдается в устье протоки Чернильщитовой - месте выхода в р.по́ воды, поступающеi с территории Томска-7: вода в IOG м чт берега - 30 мке/час, обий йон - 30-35 мкР/час. Следует учесть, что li точке зачега зи-рязненная вода поступает уже в значительнсі степени разбанленная водоиі протоки р.06н - Чернильмновоц.

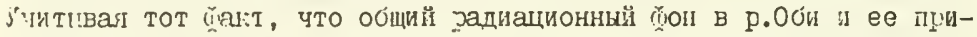
токеу. намного пиле ( I +4 мкP/час.) указалных значений, мокно говсјить о связи промншленного производства в г.Томске-7 с таким уровнен сона атностеры и ренн в прилегаюих районах.

В Краснояғском грае в I989-I99I гг. Іірасноярским научным цечтиюм СО PAH Сити проведени исслецования по оценке радиоэно-

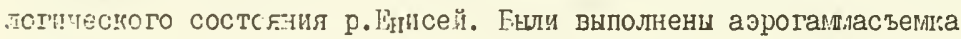

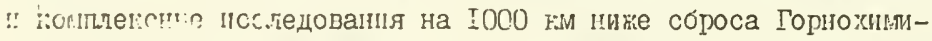

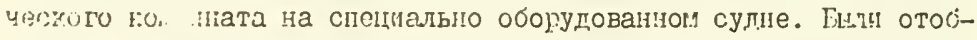

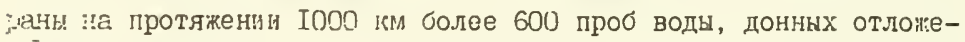
Іат, почвн, рыбн и пастительности. Ісслепования охватшали песь

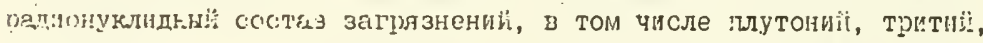

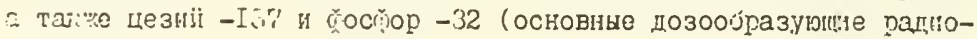

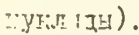

Гыло отмечено, что в зоне смещения сбрссиых вод комбнната Ііансольей концентрации тостигают иэтрй -24 и марганец -56 ,

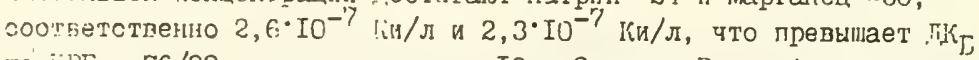
по I:T - 76/82 ссответственно в ІО и 2 раза. В пос.Атаманово переом населенно пункте после сброса, за счет процессов распага 
и разбавления концентрация отцельныу нуклидов в воде была ниже LK: однако суммарная активность в уоде близка к предөлу допустимой нормы.

Содержание долгоживущих рационуилидов (кобальт -60 , цезий -137, европий -I5:,I54) в днє Еалчуговской протоки для средних услозий водности составляет около I Ки. Полный запас техюгенных нуклидов в ухвостьях исследуегых островов оценивается примерго е I7. Ки. Fаспределение радионуклидов по профилю дониого грунта краіне неравномерно на различных участках реки.

Большое внимание при проведении исследований уделялось "зучению радиоактивного загря:знения рыбы. Всего было проапализировано более 40 проб тринапцати различных видов туводной и прохопних ц̆юрм рыбы. Ос!юnными нуклидами, накапливаемыми в тканях рєбы бнли фосфор -32 , цинк -65 , цезий $-I 37$ : в ближней зоне натриі1 -24 , было отмечено, что загрязненная рыба отлавливается иа зіачительном удалєнии от месті сброса активнссти, как ниже по течению, так и выше. Техногенные рапионуклиды обнаружены в рыбе, вщовленной в районе г.Краснолрска. Максимальная кошентрация

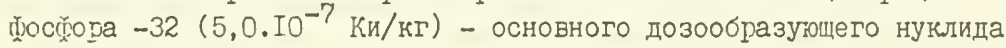
“ила отиечена в тушке хариуса; отловленного в районе пос.Павловшина (60 км ниже с:броса). Выголненный анализ показывает, что практичеси на всеи исследуемом участке реки лротяненносты I000 км

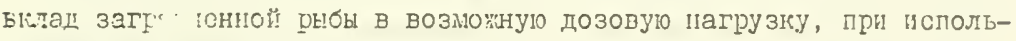
зовании её в рацине питания местныии кителями, является опре-

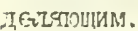

Плотность вагрязнения поһнд по сумме техногеных нуклицов изменялась по меге удаления от источника от I60 до $0,2 \mathrm{mk}$ пй $/ \mathrm{M}^{2}$.

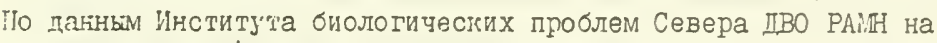
туритье общй $\gamma$-.уон естественной радиоактивности составляет, I:-30 микро /час (что не превышает допустимыј уровень и мало отआичеется от других территориі.

На севере Кгасноярского края \-фон составляет 25-30 микроR/че i3 i:ıгшланской објасти $\gamma$-фон I5-30 микроR/час, при этом цезий -I37 и стронций -90 ( $\because . е$. продукты ядерного распада после взрывов) пе внослт прантически своего вклапа в формирование радианионного خ̆она на Севере.

Радиоактивность мыш оленины определена в $0, I-2,7 / 10^{-9}$ кюри 


\section{8}

на кг, что составлнет 0,03 на кг (или $3 \%$ ), и лвляется допустимым для этих процуктов.

Б г.іирный (бассейн р.Вилюй) $\gamma$-ұ̆он не превышает допустимых цй̆р.

По данным Ленинградского института радиагионной гигиены естественный радноактивньй фон на Севере повышен, что характерно нообпе для Севера. Ягель накапливает, сорбирует радиоактивные вейес'гва, поэтому и.б. повышение рациационного циона в организме оленей и человека. Ик естно, что, в состоянии здоровья большую роль играют радионуклидные соединения, а не $\gamma$-(јон).

Социолого-демографические исследования, где прослеживается свізз загрязнения среды радионуклидами, химическими агентами, а та飞ке физических составляюих радиационното фактора, в настоящее धрепя ऑроводятся в Алтайском крае. Выявлено, что, начиная с I950 г. (гремени первых ядерных испытаний) за 40 лөт, пе без влияния возpocıе нй набтерцтории экологической нагрузки, в грае сбормировалась слоинея демограф̆ическая обстаповка.

:а период с 1950 по І990 гг. его население с 2396,2 тнс.чел.

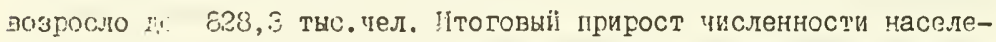
гия составил + 43z, І тыс.чел. или на I8,0\%. Такая величина приюоста́ паселения за 40-летниі период не может быть призана дюсэатотісй.

Пеготорне показаяели зацолеваммости и смертиости паселсния Ђвля:тся своего рода инцикаторами роста на территории зкологиче-

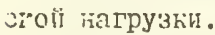

13 крае с 1950 по I990 ГI. отмечались неблагоприлтне тенден-

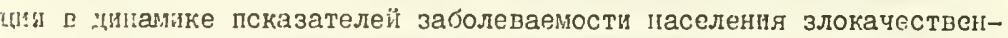
имй Іовообразованияли. Лля .их характерна поступателыная тепценция роста, близкая к линеиной (увеличение показателей первичой забогевяемости составило 4,6 паза). Наиболее неблагоприятние изi.енепя показателей первичной заболеваености наблюдались для злокачественных новообразований органов дихания (рост более чем в 60 раз), злокачестзенних повоюбразований кочи (в 3,4 раза), зло-

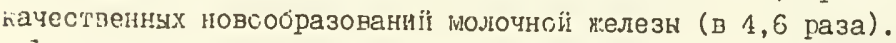

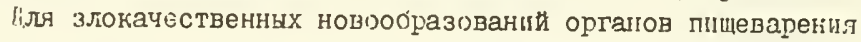
такі.е было харагтерно увеличение показателей заболеваемости. Oпиако; в последнес песятилетие отмечалась их стабилизация и цаке 
снияение.

Рост показатөлей заболенаемости бшл хврактерен и для злюкачественных нэвообразований крови (первичнои заболеваемости в I,2 раза, болезленности в 2,4 раза). Однако, в их изменениях отмечались периода по:ъема (I974-I975 и I989-I990 гг.) и спада (I979-I980 гт.).

у друтих злокачественных новообразований, расслзатриваемых отдельно, отмечаласт, лико стасилизация первичной заболеваемости (злокачественные новообразования мочеполовых органов), либо ее энияение (злокачественные новообразования шейки матли) на бјоне роста џоказателеи болезненности.

Среди других индикаторншх нозологий наиболее неблагоприятные изменения были характерни для заболеваемости детей края (до I4 лет) телезодефицитпй анемией (рост первичной заболеваемости составил 4, ' саза), заболеваености новорожденныу (рост показателей в 2,3 раза), в том числе гемолитической болезнью (є 2,5 раза), вроденцыи аномалиями (в I,8 раза). Неб́лагоприятна тенденция частоти токсикозов второй половини бөременности.

З краө произсшіо значитөльное увеличение показателей смертност:"от злоначест.яенных новоюбразований: всего каселенил-в 6,9 ; муичин-в $9, I$, женшінн-в 5,2 раза.

C' середины 60-х годов смертность мужчин от злокачественных новсобразований превьшает таковую у женшин, величина этого превышенія постоянно уьеличивается (в I970 г.-в I, I; в I990 г.-в I,5 үаза). Возрастание уровня смеотности от онкологических заболеванй характерна гля всех основных эозрастных групп населения. іскезатель смертности діл населения трудоспособного возраста увеличился в 3,8 рага, пенсиониого-в 6 раз, детского населения-в I8, 3 ․․aza.

Зедупей пғичикой смертисти населения кдая в структуре всех элокачественных новообразовани ивлялись злокачествениые новсобразования срганов пищеварения. Смертность от данной притини пмела поступатәльную теңденци роста-показатөля с I7,7\%... в І950 Г. до $64,9 \% .$. в I990 Г. Смертность можчин от данно причинь ธнла внше, чем у женщия. Основная даля лиц, умерших от злокачественных новообразовакий органов пищеварения приходилась на пенсионБіए возраст. 
Злокачественне новообразования органов дыхания являртся туторой по значимости .ричиной смерти населения г:рая среди злокачесгенных новообэазований, их доля постоянно возрастает. За период с I950 по I990 годы показатели смертности увеличились (с โ, 65\%... до ЕЕ,02\%,... или в 34 ра.за). Уровень смертности мужчин был выше, чөл у женщин в 3,3-7,2 раза.

Постоянно ұосла смертность женщин и от злокачественных нонообразований мслочной железы (соответственно, с $2,4 \%$... In $[4,2 \%$...). Іаибсльший прирост показателей произошел с I059 по 1970 год, в дальнсйшем темпы прироста несколько снижаются.

Значимое место в структуре смертности женшин края от злокачесг'зенных овообразований занимают злокачественные новообразования половых органов (до 25\%). В пәрюод с I950 по I965 гг. произотшло резкое повишение смертности женшин от данной причины (в 3,4 рәза). Однагі, п последнее пвапиатилетие смертность жениин трудоппособного эозраста от этой причины значительно снизилась (с $33,3 \%$... до I(),7\%...). За последние 20 лет в 2,4 раза повысилась слертность и мужского населения от злокачественных новообразонаниі половых органов (с 3,3 до 7,9\%...).

उровень сирлтности от Елокачественных новообразований трови z крале с I959 пю I990 годы уєеличился (с 4,87\%... до 8,68\%...). Показатели смертиости вужчин от данной причинн превышают аналогичнще у венщин (в $[, 2-I, 7$ раза).

Скертность населения о' солезней эцдокинной системы также имела посто:ниую тенденцию к росту с максималыныи значенияли в 198I-I985 гг,, с последующим незначителынм сіиикением. Слертность

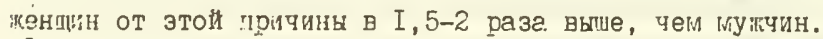

Анализ инцикаторной заболеваємости (злокачественними новообईазозачиями, тирэотоксикозом, заболеваемости новорояденных) и слериости населения (от злокачественных новообразованй, младенэескея смертность, мертворождаеность, от вропденных аномалий) с P.'сокон стененьо веролтностй показнвает, что имел и продолжает иметь место радиагионный фактор загрязнения территории крал. Џітериалы исследования свидетельствуют, что воздействие было

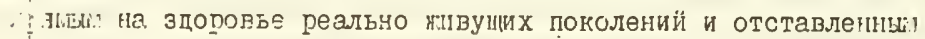
(сочетанное пряуое влияние загрязнения природной среды н возце:ствия через материиское поколениө, пряяо попавшее поп влияние 
рвдидионного фактора, на послелующие поколения). Н хотя вредние признаки элиминируется из популяиии ( снижекие ромдаемости, рост смертности), возможны еш( отдаленные последствия рапиационного ф̆ат:тора, которше могут проявляться во мнгоих последуюших поколєн!ях.

Необходимо углубленное изучение влияния радиационной загрязнености на здоровье населения с использованием данннх об уровчях ратнационой нагрузки на территории края и социальногигияническіго метода когортного анализа, позволяющего достаточin точно определить степень в.лияния радиоактивного загрязнения гриподной среды на здоровье населения.

В Новосибигскол осласти высокий уровень заболеваемости паселэния злокачєственными нозообразованиями отмечается в Маслянинсксм, Коченёвском, Колшвансток, Чистоозерном и Каргатском

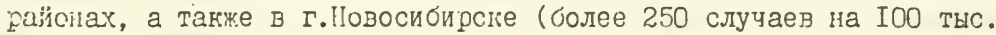
населения).

Смертность ст рака легких намболее высока (свыше 40,0 на I00 төс.населения) в Чистоозерном, Убинском, Баганском, Коченевском Усть-Тареком, Орденском, Иошювском, Тогучинском, Колыванском, Сузунском, lаслянинском, Болотнинском и Здвинском районах, а также в Г. Бердске. Низкий уровень (менее 30,0 на IOO тыс.населения) огмечен в Барабинском, Венгеговском, Цоволенском, Кочиовском, Сезерном, Татарсксм и Чановском районах. При этом Мошковский райor попал в группу с "очень плохим" уровнем здоровья и подтвердил сольшус значимость смертности от рака желудка в бормировании показателя смертности от новообразований. Такое же положение имеет и Кольванский райсн. Негативные переходы (в более худшую группу здоровья) при рассмотрении данных показателей имеют также Татарскй (из "выше сүєцнего" в "плохую"), Усть-Тагский и Баганский (из "нике среднего" в "плохую") и Северный районы (из "хорошей" в "ните среднего").

Наиболөе точное представление о связи бакторов среды с разватием новообразишаний у населенил районов дает комплексная оценка всех 4-х пока:ателей (смертность и заболеваемость по всему глассу элокячестиенной патолюгии, а также смертность от рака легцих и желудка). В этом случае в труппу с "плохим" уровнем здоповюя гопали Тистоозернші, Коченевский, Аошковский, Колыванскиі: и 


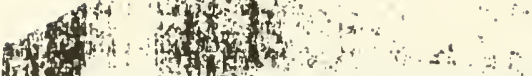

Mаслднински раһ̆оны. Причем, как показал предндущй анализ; в

рлорвых 2-ц районах приоритөтным являөтся развитиө легочной пато-

1. логда, в:2-х посльдуюши - желудочно-кишечного тракта. В Масля-

i. ниском раноне прюобладают разние виды злокачественных новообра-

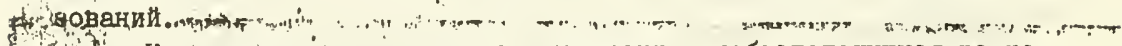

. Кақ, показали последние исслөдования, нөблагополучная радиационна́ обстановта в г.Новосибирске, Мошковском районах могла :

бать связаң̆а, с за:тязнөниё почвы и воздуха радиактивными и хими -

уескими веществами предприятия "Химгонцентрат"; в том числе в .

1, фвяаи. с устроиствін несанкционированных свалои отходов этого и

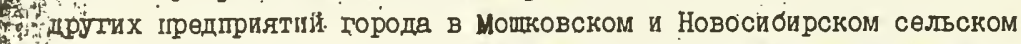

5. ранонах. В Маслянынском раноне имеет место также наибольшее в

области (200-2I0 кг на I жителя в год и 70-80 кг на I га пашн

затрязнение посевых плоцадөй минеральными удосрениями и ядохимикатамю.

В г.Томске отмечается рост онкологических заболеваний, что . связано с загрязнөнием окружающей срөды. Так, в I976 г. заболеваөмость злокаче́ственными опухолями составила I07,9 на I00 тыс. человек, а в І9̣86 г. у за выше. Резуль́тагы исследованиц нИИ онкологи тц СО РАМН и ВЦ ТИАСУРа по дешифорованию космических снимков Г.Томска: один из एу снимнов, в инфракрасном излучении в диапазо1. не 0,8 - 0,9 микрометров I9 июня I988 года, наложенный на карту'

H.'. Томска аналогичного масштаба, показывает совпадение темных пятен 7. с-предприятиями города.

t. В г.Магадан.э комплексннй показатель, характеризующи й степень загрязнения атмосферного воздуха колебался в пределах с 7,7 е 1980 г. до I9,3 з I988 г., т.ө. увеличился более чем вдвое.

установлено, что .эоздействие на организм человека загрязнени й ᄂатмосферного воздуха в комбинации с экстрөмальностью экологичөсния факторов природной среды приводит к формированию специфичес-

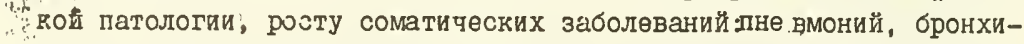
тоэ, аллергозов (бронхиальная астма). 00 жтом же свидетельствует с статистика заболеваөмости и смертности жителей Иагадана от рака. - Так, за последнее десятилетие заболеваемость от рака всех локали7 запий возросла на $42,4 \%$, а от рака органов дыхания на $65 \%$. Смержересть среди жителей Магадана от рака всех локализаций за последнөө मөсятилетие возрасла на $73 \%$, а от рака органов дихания почти

Brifos.

asil 


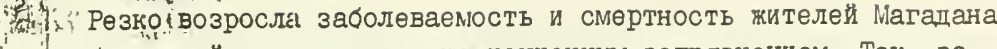
ст заболөваний, связанных с радиационным загрязнением. Так, за последнеө дөсятиләтие онкологичөская заболеваемость, связанная с ратиационным, фактором, возросле болеө чем вдвоө. Следует отметить, что за әтот жө период показатели смертности среди кителей Магадана от рака оргазов пищеварения снизились на I5\%.

:

общие и стандартизованнке пожазатели смөрпности населөния Маганской области от этой причины возросли, за исключением сөльского населения(мущин) где велитина показателя стандартизован- ного стабилизировалась на уронне I979 года. У городских мужчйн, 4 смертность в-I986 $\Gamma$. по сравнению с I970 г. возросла на $31 ; 6 \%$,

1 а у'сельски: мужчин она за этот период снизијась на $6 \%$, что

связано с увеличением отрицатєльной миграции из сельской местности, 1) осббенно мужчин.

у уенщин смертиость от новообразований в Городской мөстности 5. возросла на I9,4, в сельской -. на $23,4 \%$.

Кроме миграционных факторов изменения показателей смертности от новообразований связаны с загрязнением природной среды, главным образом атмосберного воздуха. об этом свидетельствует статистика смертности населения от рака органов дыхания и других локєлизаций, нотсрая показывает, что төмпь роста смертности от сака органов дыхания значительно выше аналогичных при пругих локачи зациях:

1. 4. Определөннсе значение имөли демографические факторы постарения насөления, осљбөнно для сельских женщин в возрасте 60 лет и старше, у которых величина стандартизованного показателя смертности в I986 году в сравнении с I970 годом увеличилась в I2,5 paза, тогда кащ у сөльских мужчпн зтой же возрастной группы за этот жө лериод она снизилась на $3 \%$.

$\therefore$ По сравненик с другими территориями й Дальним Востоком в целом общие коэфйциенты смертности в Магапанской области ниже.

- Таним образом, ссвременные төңденции сиөртности населения Магаданской осласяи от элокачественных новообразований формируются на Фооне' все возрастскщего уровня загрязнений окружагщей природной CDолы (атмосфјөрного воздуха) и демографиических процессов (и зменения миграции и псловозрастной структуры населения, особенно сель-1 crioto). thil 
Комплексныє социально-экологические исслөдования по оценке влиянйя факторов приро:пнй и антропогенно-измеңенной средь ка здоровье населения в условиях Магадана показали, что әнтропогенно-техногенные факторы воздействуют на санитарные условия жизни и гоказатели здоровья, главным образом за счет атілосйерного воздуха. Воздействие эгологических факторов природной среды связанс о климатическими бакторами, а так же с качест'вом иитьевой.всдьі. Воздействие зтих цакторов на показатели здоровья пюроян山отсл ваиде массовой или спорадической заболеваемости некоторьми төрапєвтическими и инфекционными болезнями .

Изучение динамики общей заболеваемости среди взрослых и подростков Магадана эвидетельствует о неблагоприятной тенденции и напращленности зтого явления. Так общее число заболеваний в I989 г. Iо сравпению с Іэ79 г. увеличилось в 2,2 раза, в том числе количество впервые вынвленных болөзней увеличилось более чем в 5 раз. сообо неблатоприялтая ситуация по заболеваемости сформировалась среди детеи. Общєе количество заболеваний увеличилось в I989 г. по еравнению с Iś79 Г. почти в Іо раз.

Среди взрослых и подростков отмечаются высокие темпы роста показателей по таким заболеваниям каґ сахарный диабет (в 2 раза), сөрдечно-сосуцистые заболевания (более чем в 3 раза) и др.

Регнон Дальнего Востока характеризуется сложнщи экологическоні, в том числе гациационной обстановкой, и мецико-демограп̆ическими процессани. особенности мусоннэго климата 'в условиях антропооенной нагрузщ вызывают больгую !апрякенность адаптационння неханизмов у коренного и пришлого населендя и, как следствие, высокую заболеваемость. Еолезни органов дыхания составляот 429.0 "!a' ТО00 населения, нервной системы - IOI.0, органов пищеварения' - 89.0, ино̆екционная патологя - 59.7, из них - 2,8 составлянт ॐольнне туберкулезом (по Российской Федерацин соответственио 40I, 0 ; I04,0; 88,0; 52,0;2,0).

Высок уровечь травм и отравлений, растет онкологическал заболеваемость. Осщая смертность населения на цальнем Востоке сбстапляет 7,8 на IOOO (по Российской Федерации IO,7).

Впервые вытдлены соматические заболенания у 20,5\% обследоsанінх; из них заболевания ЛОР-органов встретились у $33,6 \%$; заболевания глаз -- у 66,3\%; неврологическис нарушения - у 5I, З\%;

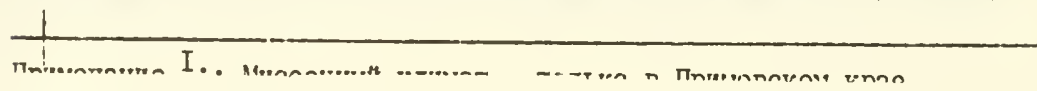


I8\% расочих признана непригодньми х работе во вредных условиях "труда и им рекоменғовано трудоустройтво, вщелены "группи диска" по развитио продзаболеваний, ву ждаюиеся в набллдении и проведе-

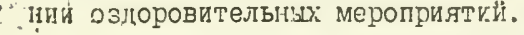

$\because$ Предьиитепьные исследования гозволили выявить нарушения в клеточном звене іммунологической геактивности не только у заболевших, но и в группе лиц, считаюии себя практически здоровции, но подвержеж:ты влиянию изучаемых зкологических бакторов. З этой групне сохранен йагоци царный резерв, но снинена, сагоцитарпія активность нейрройилов крови, увәличена доля лиц, имеюих критические отклонения в содегиании Т-лимбоцитов, что позволило отнести их к групше риска развития иммунологической недостаточE.ocTis.

у лиц прибывших из других регионов страны (Сибирь, Урал, Европейский регион), внше уровень гуморальных показателені; таких гак естественные антитела, лизоцим сыворотки крови, сыворотоэние вимуноглобулины классов А, M, С. Полученные результаты свидетельствуют о более напряженном боункционировании на ДВ системн иммучитета у мигрантэв, что сопровоядается изменониями показателеї состояния биологических мембран клеток по характеристикам ПоЛ и : "Aӧ. У мигрантов, прибывших из "холодных" климато-географических 1. рөгионов, выше уговень МІА и ниже активность глутатионредуктазы. Cпустя 5 меслцев пребывания в новшх условиях обитания в обеих группа - узтанавливаєтся одинаковый уровень ІША в эритроцитах, общих, сво8. ботных " связаннух Н-групп, восстановленного глутатиона и глутатионредуктазы. Установлени как рбиие закономерности адаптации уеловека' нөзавпсимо от направления перемещения, так и выявлены специјчески изменєния процөссов адаптации и реапаптации, заклоча1 юинеся в измененгях межполушарной нейродинамики и обеспечивающи новые способы восприятия и переработки инбормации (в сторону их улучшения); показано, что процесс адаптации при перелете на Запап приобретает сіолее длительный харақтер, но более ускоренный в период реадаптаци; лоихическая адаптированность к работе в море на 2-3 года скорөе наступает у лиц, постоянно или длительно проחивающих в район:L: Приморья, вне зависимости от индивидуально-типологических особенностей. У моряксв, приезжающхх из различных ра́̆іннов страны, наибольшему риску заболеваний подвергается диха$\cdots$ 
телыая сис ома и психологическая сф̆ера. Набподаемые нарушения

- социальнон психологической адаптации в период мөпду рейсами

4ориводят"к өлкоголизации моряков, с преобладаниөм социельно-дө- .

7у төрминированньх, эубмиссивных и псевдокультурных мотивацин, а

1. теңже мотиваций поиска новых стимулов.

П При проспективном изучөнии популяци пршшлах и коренных . атөлөй Чукотки установлөно: в среднем чөрез 5 лет после пөрвич;ното скрининга среди пришлого населения (мужчины 30-59 лет) с - јвеличением пребывания на Севере и с возрастом возрастајет частота АГ, причем за счет доли лиг с тякельми формами АГ. Прирост !"снежих" случаев $A \Gamma^{\prime}$ достоверно внше, чем в редких широтах:

I. $3 \%$ - на чукотке и 6\% - в Москве.

Распространенность пограничнои артериальной гипертонии (ПАГ)

среди пришого населения, прошедшего повторное обследование, составила.24,A\%, что более чеи в 2 раза превышәет таковую в среднем по СНГ. Среди лиц с ПЦГ преобладағт лица с диастоличөским варнантом ПАГ, что прогностически неблагоприятно в плане риска осложнений сердөчно-сосудистых заболеваний (ССЗ) (инсультов и инфарктов).

Проведенноє углубленное обследование коренных жителей

" पукотки показало, что среди. тех, кому при первичном осмотре быт: цоставлен диагнсз стөнокардии на основании стандартного опросника ВО'З,' лишь у половины диагноз подтвержден. А у тех, кому повторно поуттердили диагноз стенокардии, только в I/3 случаев выявлена истинно ишемическая болезнь сөрдца, у остальних-некоронарогенние заболевания.

В результате проспективного наблодения на Чукотке вњявлено, что болеө 50\% приезжих мужчи страцает гипертонической болезнью, с увеличением северного стама частота АГ достоверно возрастает. Среди коренного населения прирост свөжих случаев АГ значительно выне, чем в средних широтах. Распространенность ревмативма среди коренных жителен статистически выше, чем в других регионах странघ́ (4,6\% среди мпжчин, 5\% среди женцин). Деф̆ормирующим артрозом страпает 38\% мужин и 23\% менщин. Знауитөльное место в патологии у |коренннх житөльниц Севера занимают анемии - I0,4\% и пелезодетицитнне состолтия - 35; $5 \%$.

Показано, что при отсутствии у коренньб жителей Чукотки таких распространенных среди пишлого и европейского населения 
is:

фаkторов риска как АГ, атерогөнный спектр липидов в крови и т.д., стенокардия напрякенуя у них встречается одинаково часто жак и

$\because$ в Новосибирской популяшии, а рубцовые измөнения миокарда на эКТ в I,5 раза чаще, :ясока частота гиертрофин миокарда.

Установлено, что фактором риска в данном случае является избнток в рационе дитания коренни жителей Чукотки Пник омега-3, иоторнө оказывают токсидеский эффект на миокард.

Oпределены сэстав и соотношениеінію̆ различных семейств в ли-

- падах мөмбран эритроцитов крови у тундровых и прибрежных жияөлей Чукотки, шмевщих различный пищевой рацион. 


\section{radiation problems yakutia}

Обзор проблем папиаци онн ої бөзопасности насөленй на тердитории Якутской-Саха ССР

НөобходмМ чөтко и однозначно прөдотөвлять, что основной вклад в дозу, пблучаөмур сөловөкаи от төхногөнньх псточников раднации, внослг мөдицнна. Доля только одчоразового Џиюорограчнеского обслөпования в год составляөт $2 / 3$ годовой лучөвой

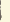

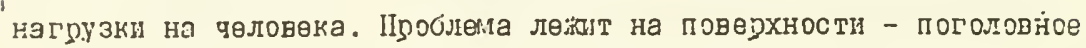

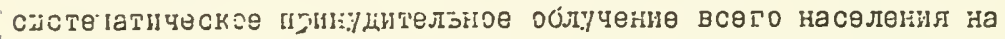

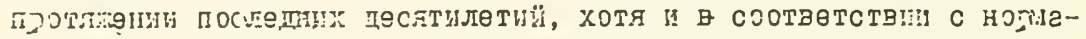

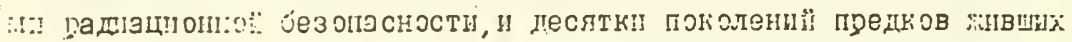

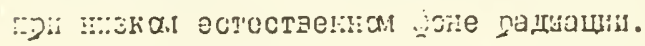

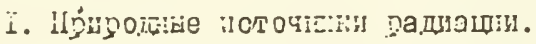

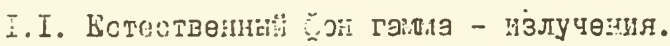

Ос:ювная тедритория วеспублик хэрактөризуется низкияи

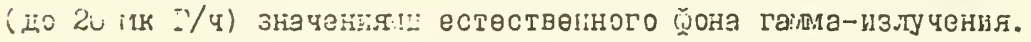

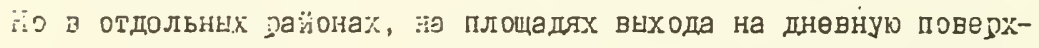

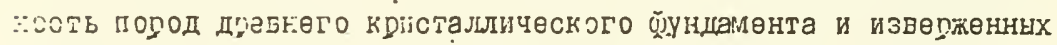

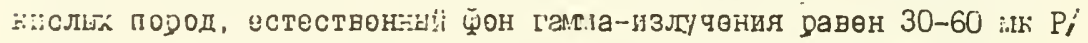

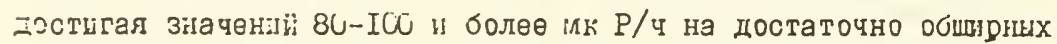

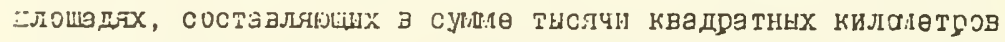

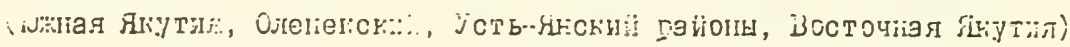

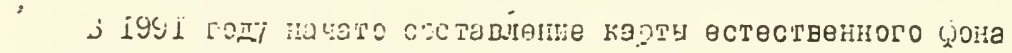

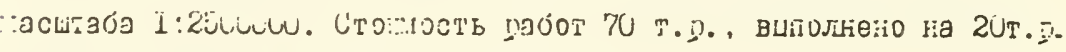

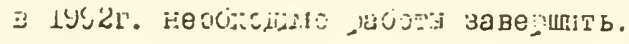

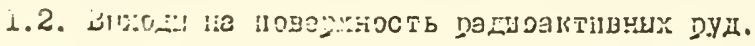

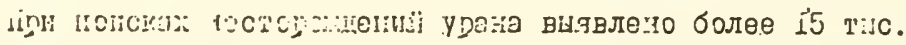
- эног 


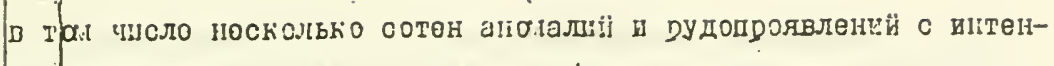

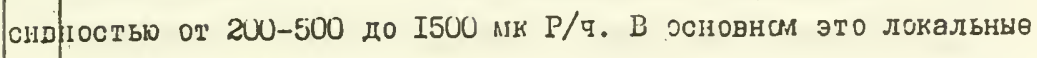

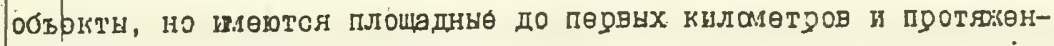
iне па цөслтки кијслетров в төктоннчөских зонах и пластах осадоч:ік пород. Рашнактивность связана нө тольно с рудами собствөн10 урана и тоуня,но зачастую сопровождаөт уөдкозөмөльную, рөдкаметальную, анатитовую и другия типы минералшзащи. В любам случае слөдуєт учитнвать нө только радиоаттвность, но и выхопн на Поовөрхность урана - лөгто мигрнгущиего й внсоко токсичного: Hөобходамо подчөркнуть, что, хотя мь расдолагаөм информащөй о

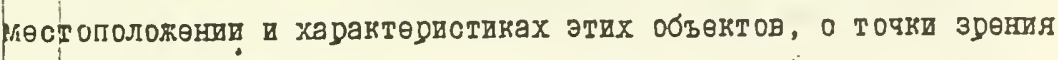

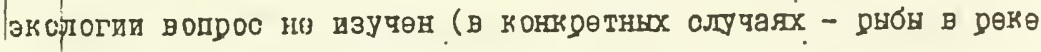
нөт|, звөрь стараөгся обойтв стороной, рөка, в вөрховьях когорой урановоө рудопрояплениө, можөт называться Ойун-Кюөль).

\section{I.3. Радон.}

- Согласно оцөшкө Научного коитета по действњ аталної радыа-

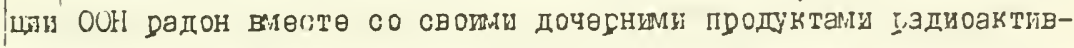

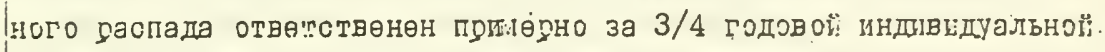

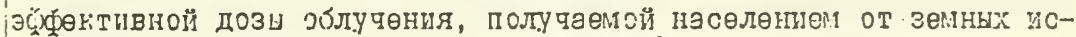

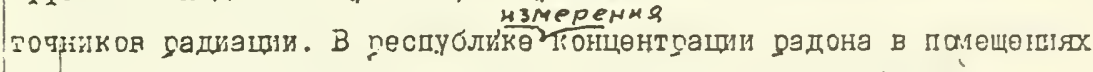

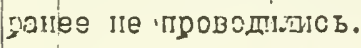

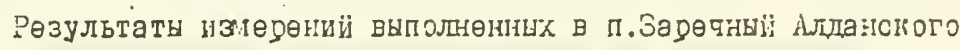

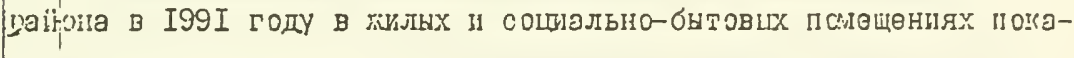

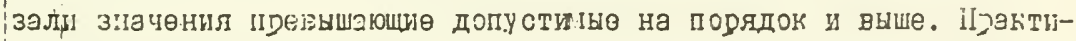

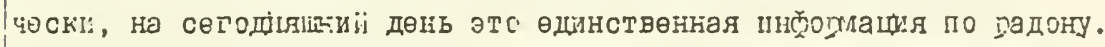
Цроблө:1а зак.точаөтся в отсутстви отөчөстөөннсі! аппауатуци (вцпуск чувствительних приборов планпруөтся в I9у2 году, стог-

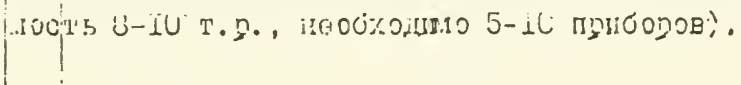


I.4. С́трсительнне материалш.

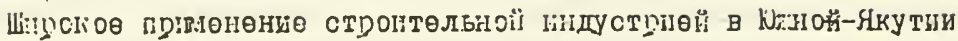

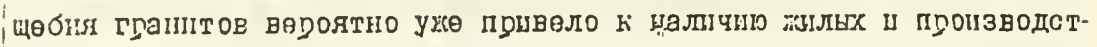

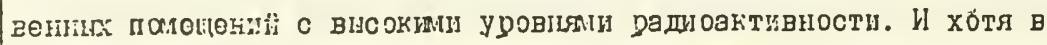

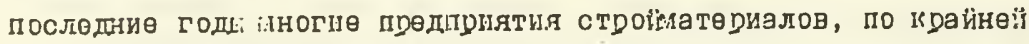
i. оценку как сылья, так и готовой продукпии, проблөма трөбует каудинального решеншя - созданпя в рөспубликө спецшалшзированной лаборат ории.

2. Глобальннө вндады радуоактвности.

В конце 50-х начелө 60-х годов на воөй төрритории Якутии

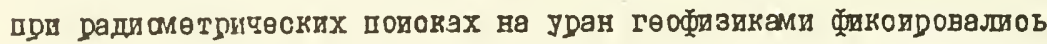

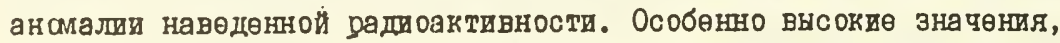

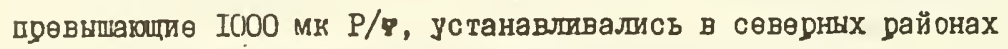

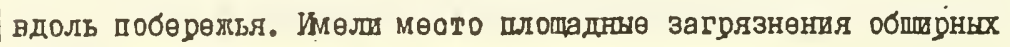
төрриторий. В послөду бише годы й до наотоящөго врөмөни спөшаль-

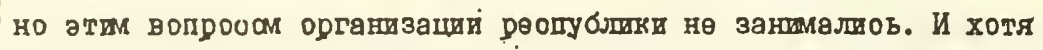

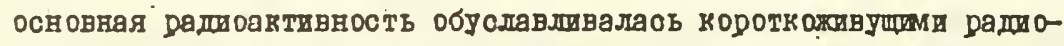
मуклшдами, отөпень загрязненнооти оөвернвх паотбй стронцшем - 90 у цезтем - IЗ7 в наотояпев время не изучөна.

3. Төхногеннов загрязнөниө төррит ории ради онуклшдами.

3.І. Добчча раддоктивних минөралов.

В конще 40-х начале 50-х годов проводелись развөдочнье в

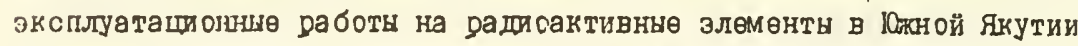
(Васильөвка) монацита из поссвпей и в Момскам районе (Сугунский 
развөд. Файон Даљьстроя) урановьх р.д.

Предприятил были ликвидирована: пөувоө за нөнадобностью, второө из-за бөдности руд. Төм нө мөнөө на зтих объөктах провөцөно активноө виенатөльство в нөдра: на Ваоильөвкө и сөйчас ціөюся отвали гешиоактивного обогащөнного прокнвкой матөциала, Сугунскиї пазвөдрайон обслөдован в I99I гоцу, поскольку вызывала т.евогу насөленуғ воэнокноть сноса отвалов гопных внпаботок к. подиония склснов на. плато Улахан - Чнстац̈.

3.2. Гөолот-о-разв̈өдочння работы на уран.

В рөзультатө провөдения в төчөнне 25 лөт гөологопазвөдочнех работ в Һкной Якутии пөрөд нами встала пробліма радиоактивных (рудных) отвалов, сопфоводдаюиих тякелне горннө выработки. Организагия посеоднвшая эти работн ликвидыфована, еө посөлки перөданы други вөдамствам. II өоли вопросы ликвидащи радиоактвного загрязнөния в посөлках төхничөски и практичөски сөйчас рөшаются, то пробілөма отвалов трөбует оөрьөзного подхода. РөальнЕм экспөртам п шорөктантам прөдставляөтся ВНИПИрамтөхнологин Мнаталэнергопфала, остаөтся опредөлить кто заказчшк.

\section{3. Добача золота п олова.}

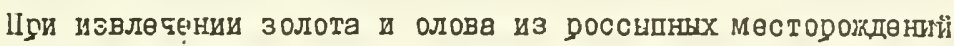
происхопит извлечөние и обогащенше тякөльх минералов, в там числе h уадиоктивных. Оловяншй концөнтрат достигаөт в отдельных с.пучаях уадиозктнвности до 2000-3000 мк P/ч, (контөйнвр), прн извлечөпии золота без анальгэмзцни - помагнитиая йракция цинха $7000-10000 \mathrm{mKP/y}$ (полуббочка).

Нэ Куларө с пөџвьх лөт эксплуатаци рапиоактивний рөдкоземөл

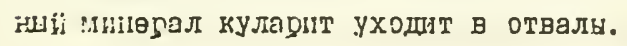




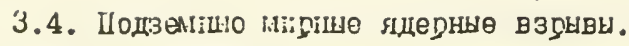

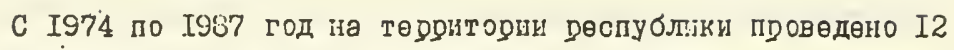

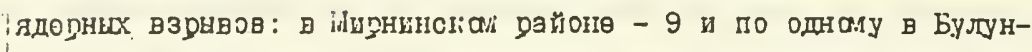
ска., В-Вилюйскал н Кобяйскаи районах. Два из них сопрововдалио внбросаки радионуклидов: олнзкоповедхностның с цөлью строитөль-

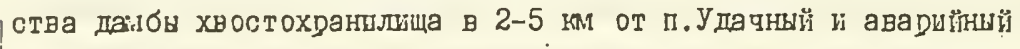
при глубннном сөйслџческам зондировании в 39 км от п.Айхал. В сбоих случаях нөобходмм рөкультивационные работы, в последнем нөобходум ость прослөдать слөд дальоактинного облака.

На остальных объөкта̀х взрывов пров̊өсти дөтальные радиомет-

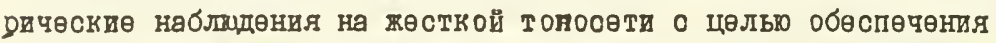

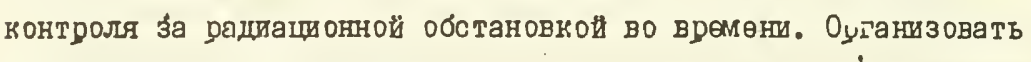
мбнуторинг Овне наблодения.

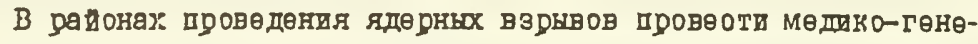
тичөсков обсльдованве насөлөншя.

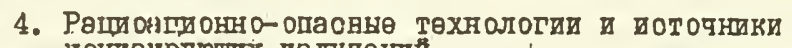

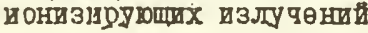

По состолнио на ОI.07. I99Iг. I98 предпршятий на 405 объек. тах шспользуюг 3083 поточғика ионшзируюшх излучөний, в там числе 2503 пзотопнах. Здесь ширский опөктр проблем Госгортөхнадзора и Госоаннадзора. Срәду всөГо разнообразия истоцников внделяются РИТЭГи ("атомнне батарев") Гидрамөта, обөспечиваюци работу авт сматичөских мөтөостанцй и маяков. Эти приборы имеют зарялку до І00000 Ки, разбросанн по побөрөжью окөана, в дөльта рөк, на островах, их количество иочисляөтся многими десятками.

Впереди перөд нами "Малея әнөргетика" Минатамәнергопрама

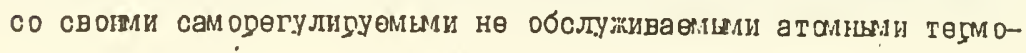




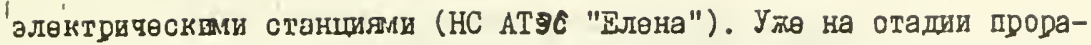
ботки төунического задания нунна квалчфицированная нөзависияая экоппутиза, поскотьку самим технтческим заданиея оговаривается,

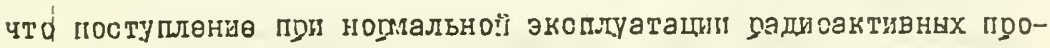
гууктов в охлаждағицу воду, грунтовне води й в воздушдую среду цол̈:ны соотвөтствонать трөбования НРБ 76/87.

5. Шоступлөние радионуклидов с продуктани питандя.

У पптывая масштвбы и многоканальность поступлөнпя в республану продовольствия, шерокого учаотия частных коммерчөских струкT7D, обостряется проблема контриля за радиоактивностью продуктов

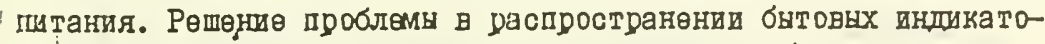

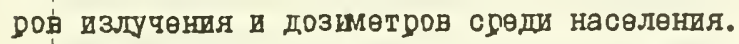

- Существует єще ряд проблем как, напрбмер, нөсанкцонированнеточников 4 ноя поступлөнщекагоязнөнньх Матөрџалов, что ставит вопрос оснащения соврөменной аппаратурой соотватствуших слуяб рөспублли: тувіспортной милЕІци, тамовну.

Сөрьөзной пуюблөмой в блшжайшем будуцем представляөтся рөшөние вопроса захоронения радиоактивньх отходов преддриятий рестублики, ноторие провзводвлось до настояшего времөни в Г.Хабаровскө.

Начальник ІЕспекции радиащи онно оһ безопасност⿻ ЯкутсKого ОКруга Госгортехнапзора РСФCP

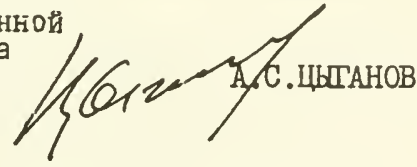



к исх. N $10 / 17-08$ От 31.07 .92 Якитскои инспекиии Госатоннадзора России

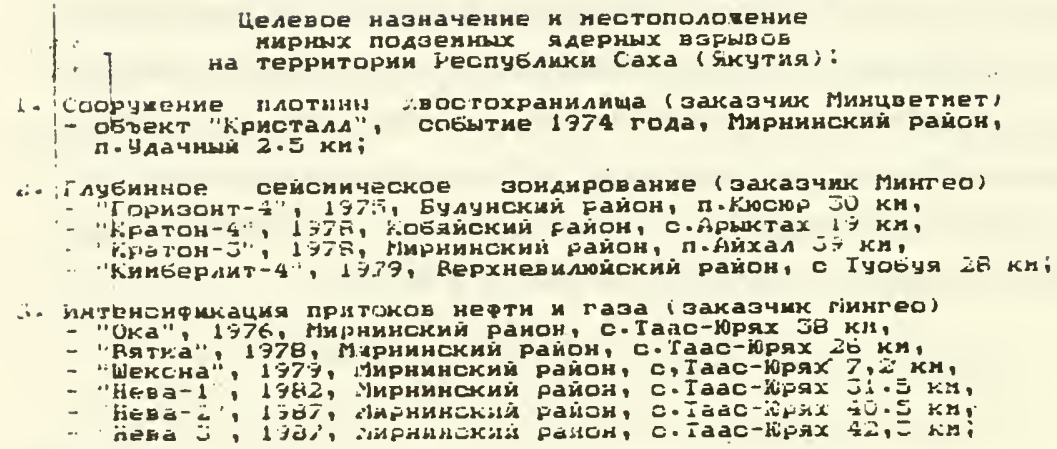

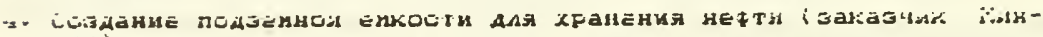

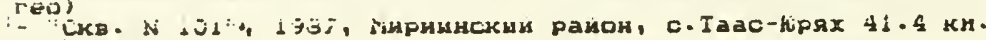

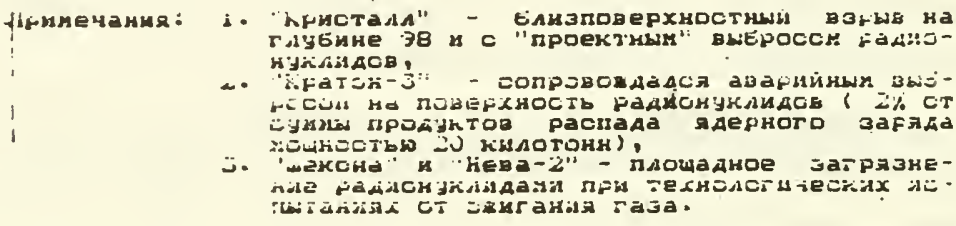




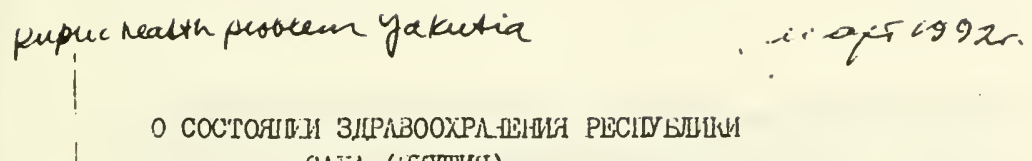

CATA (

$$
\text { Министр Б.А.ЕГоров }
$$

Эістренальность той или иной зони зависит от многіх с̆агторов природиой срецы и прежце всего от илиматичесиц

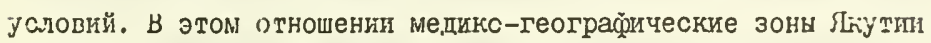
лглілптсл типичным цримером природной экСтремельной зоны. Lуровость климата ґкутии определяется в основном необнчайно "мичельно й иесткой зимой с очень низтими температурами, горотиим холодньм летом, резкими нарущениями оошчной фотоцериодичности, резгини перепацами атмосферного давления, температуры, сильькми й частняи ветрами, магнитными возмуще-

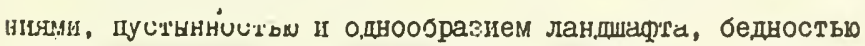

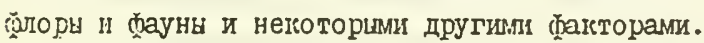

Совершенно естественно, पпо әкспреналызость метикогеограп̆ческих зон љкути может бнть обусловлена не толысо IJus I: этону следует цибавить и возмодное неблагопринтное

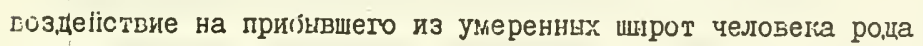
соцтальних талторон, тальг, кан террлторнальная отцаленность от пेрлвнчных ропных нест, от семьи и близиих, от центров прояніленности и клльтры, сложность транспортных сообцений, особенности питания, тру.а и отпнха и т.д.

унзн в суров'х условиях Ягутии сопроводдается увеличе-

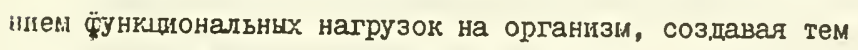
сацы: большо риск нарушения или утраты здоровья. Критерия здорлвья населения отражают стешень его соцааљьн-оиологичеоной адаптированности к комплексу климато- 


\section{6}

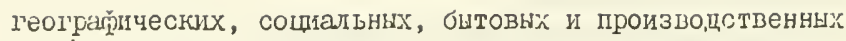

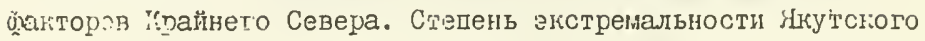
рюгіона страны спределяется јазмерами той биосоцнальної платы, которая потребуется дпя достщения ацаптированности популяџҢ В этой зоне.

В настояцее время впалне очевидно, что отратегия и тақтика здравоохранения и соответствуюего развития мешиінскої науни, полкны в полном объеме учитывать своеобразие :

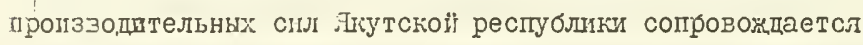

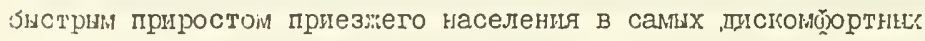

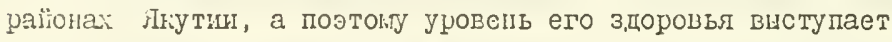

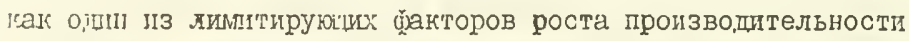
труіна.

¿алная роль з сохранении, загреплени и полноценнои щспользованиц трудоспосооншх понтангентов принаплежит нестным органам здравоохранения и северной меднцине.

Ґрюим принејом в этом отношении иопет служить тегучесть

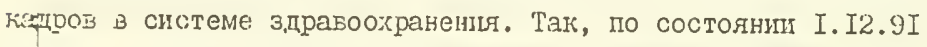
голе, Е систему прахтического зцравоохраненил Якутии прибнло 55k врача, II56 срешних мешицнских персоналов, а выбнло 754 врача и 1762 человена из әреднего медперсонала.

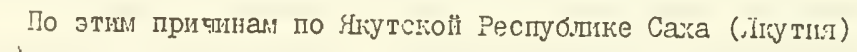
об:! численносте врачей цостигает 3394 врача и II467 срецнего мецперсснала, т.е. пропент укомплектованности кантами системы здравоохраненш составляет соответственно r.

Следует отметить, что за последние десятилетия в стране создалась очень критическая ситуация в попготовке кацров, и особеніл в области зцравоохранения. Это 
отранается й пля нашей респулшки. Иб этом свидетельствурт

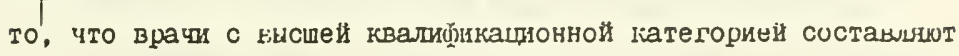
личь $৬, \jmath \%$ от ооияго количества врачеИ, работаюих лечеоношррфилактических учрежцениях ренцишики, врачи первой кваличинационной категчиии - $10,0 \%$, второй категории $-5,8 \%$. Iругин словами 78,9\% врачей оистеми зиравоохранения He нмеют квалчикац:оные категорџи;

В свлзи с әтщя мы планируем разработать програмлу подтотови персонала здравоохранения и преподавателей с целью поддеркания на должном уровне и повншения его ювали-

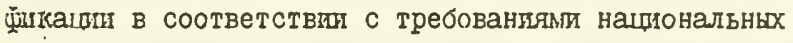
стратегий достижения з.цоровьл, пля всех. В этов плане Яһутская респуслика просит $В 03$ огазать помоць в поцготовке руковопғших катров здрашо охранения.

В настояцее время в северных областях странн лечебная работа ведется без долиного учета северной спетпфии и условиях слаботехнического оснацения маломоцньх лечебно-

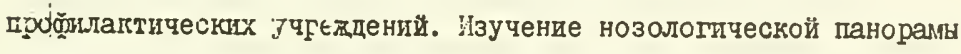

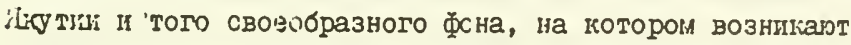
забјоледания, покизввают, что пля гигантского экстремального природного регнона Акттии характерны не только разные формы гриопатология, июјекщи и паразптозн, болезни сердечнососудистой, леготной, ппчеварнтельной и нервной спстем, но в паталотичеслг процессн, связанные с биохипчестии фақторами. Шыроко распространены в Якутии гинофтороз, гупонозизы и қележсдефиитные состояния, вся полнота илинических проявлени которнх в настолщее время еие мало изутена, не могут бчть сведены только к кариесу, эндемпческому зобу и так назнваемым полнрньм анемпям. 
He меньшее значение шмеют различные форомы патологи,

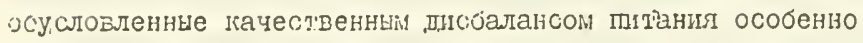
.детского населенгт (ионо- й полигиповптамннозн, гипопро"елнози, нецооцеіне значения газличных липцдов, преоллацанце

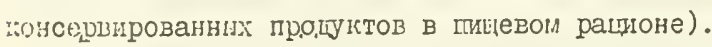

особое иесто в нозолодичесіой понараме ікути занимет праевая патологи -- јилюйский энцейаломиелит, ран пиево,ца и губернулез, иі:енциеская болезнь сердца и гипертоническая јолезнь. В јцути суцествует ецинтвенний в мире природный очаг нецзвестной этиологии Вилюйский энцеф̆аломпелит, который лре.цставльет сосон тяжелую воспалительно-иегенеративную юлєзи иервной системн, встречающейся во многих сельскохо-

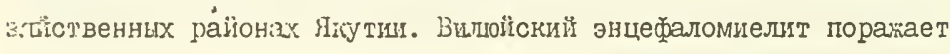
юиличтелын только представителей северных народов путтов, әвенков.

IІо мненио миюІих ученшх ВЭ вероятно относится и медленним неироинс̆екция. Поцобние болезни, имеюите большое виенвее сходство с ВЭ, бнли шіроко распространени на

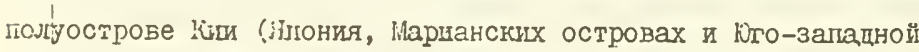

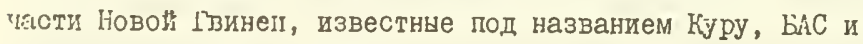
їертинсонизма с деменшіей.

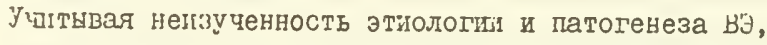
отсутствия средстз спещйидеского лечения, пробилактић и метоцое лабораторной диагностики, пробуетсл проведение углубленных на кагественно но:зом уровнейундаментальных псспедований по вияснению прироцы вЭ.

рестублика Сема (Якутия) просит экспертной комитетон 23)' помсчь современным оборудованием для исследования 


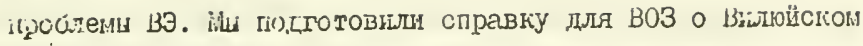
энцес̆атомиелите.

Каспроотраненность инфекпонних заболеваний в лкутии

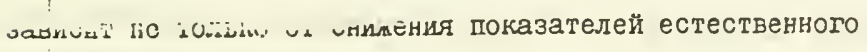
пимунитета, но и :з оольшей мере обусловлена спецальным (ралторами інсјниј:ст:ворительное состояние водоснабженил и ізчества питьевой зоды. даже водопроводная воца по балтернальным критерия за послецние 5 лет была нестанцартна от-I2,8 до I9,6\%. в населенншх пунгтан, не иеюши, где вспользуется воца из открытьх водоемов, во.ца по бакнонтролю не соответствовала стандарту ст $52,4 \%$, до $40,4 \%$.

На рис. I поназа уровень забслеваемости кипечной ннфекпей, врусн.м гепатитом ит туберкулезом. Эти даннне оэице'тельствуют о неблагополучной эпцениолопическй

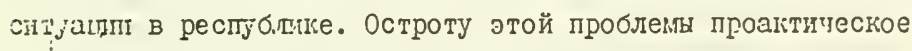
зправоохранение мкжет сникать провецением комплекса

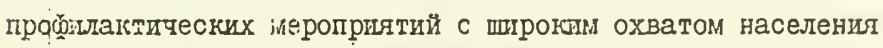

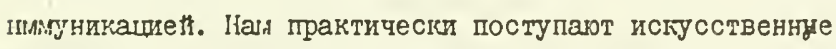
средства пля повинения показателей иммунного гомеостаза северлн. 
Более $60 \%$ каселенил Якутии страдарт воспалительными зебодева-

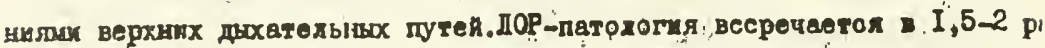

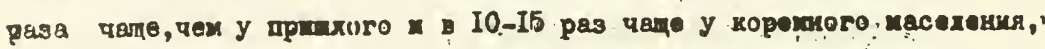

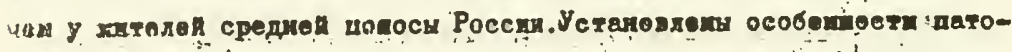

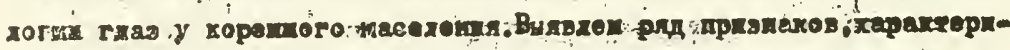

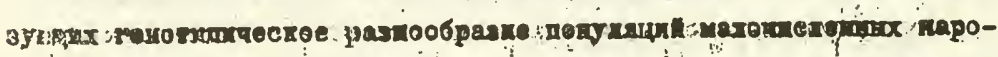
तु.

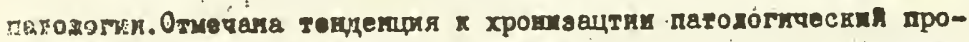

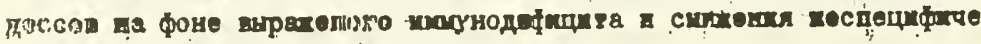
cRopl masxotuarmoct opriarusza.

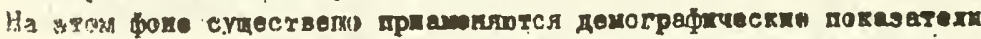

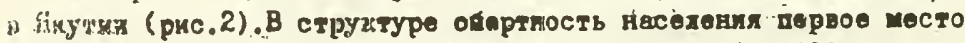
зансами болезни органов: ситемы кровообращения (в 1980r.'65,5 и в 1990г.-23I,3 на 100.000 нседеня). Следует отметить чт

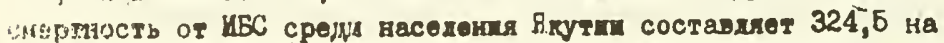
- 190.000 масөления, че.е. занимает $3 \rightarrow$ место по СНГ после Латвии $(520,2)$ и Зстонии $(492,8)$. Второе место в структуре обцеј смерниости занимазт несчастные случак, травмы (I980-25I,7 и в I990-I66,3 на I00.000 населения), третье место -злонаечственное новоогразование (в I980.-IOI,8 и в I990r.-I2I,9 на I00000 нас.) четвертие м есто-болеэни органов дьхвния в $1980-98,5$ и в I990r. -4 I, 2 на I00.000 нас., пятое место-болезни органов пющеваpeния (I900-3I,3 и в I990r-26,4 на I00.000 нас.). 0 состоянии здоровья детей в респубинке Саха (Якутия) отратает поқазатели смєзгноти среди детско населения (рис.2).Высокая детская

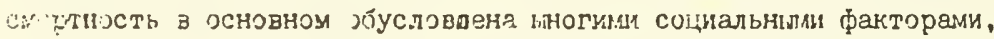
иะ гонорл о чисто недидинских пробтенах здравоохранения.

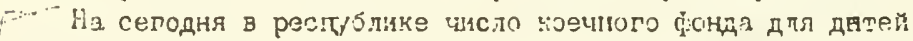

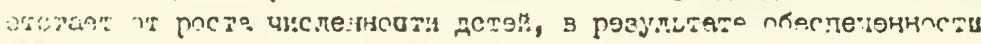

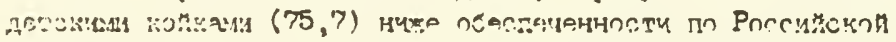

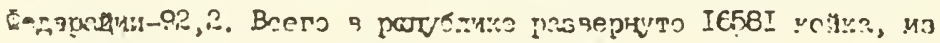

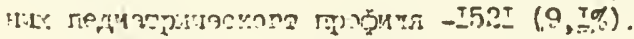

- В структуре причин мдаденчөской смертности I место занимают аасолевания перинатального периода (49\%), причем отмечается стойная теңнең; ия к рэсту смертности от данньх причин. На 2 месте -вровденные аномалии и уродства - 23,6\%. Каждый 2-й ребенок zмe whin в возрасте до I года в Iө9I году умер от заболевании перинет दального периода, каждый 4-й от врожденных аномалий и 
уродсть развития. НЕ Ј-м месте - врожденнь:е Јолезни органов дыхени - ㄱ,-70, мертность от зазолевыня органов дыхания имеет

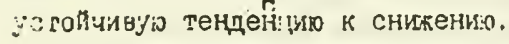

Рзст и высокий уровень перинатальног) пррняениғ (калдый 2-и ребеноя), в основком, обусловлен неблагополучным состоянием

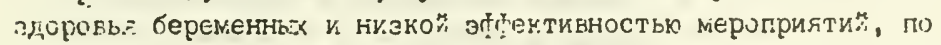

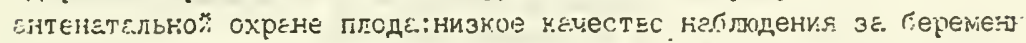

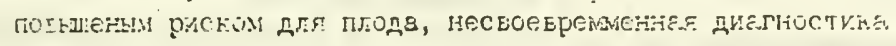

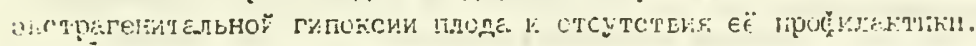

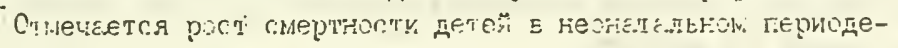
т.,

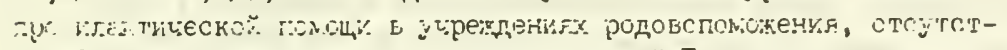

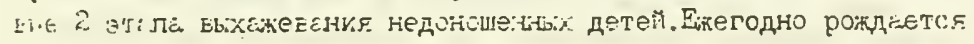

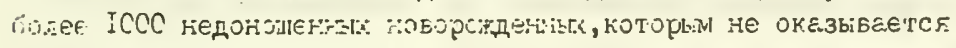

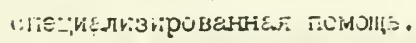

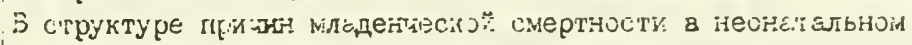

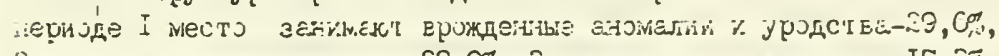

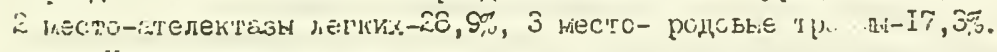

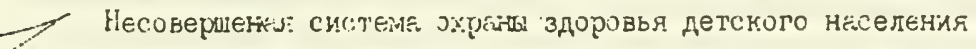
реслублики в основном связана с низким уровнеи развития катериел: өлько-технической бвзы эдравоохраненя в сельской местиости. Тєк материально-техтуческа база, центральных ребонных в оль-

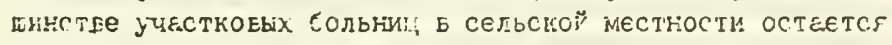
пранн неудовлетворительнои, из 862 объектов здравоохранения

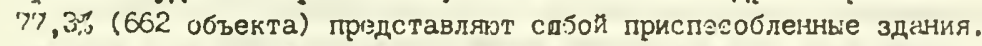

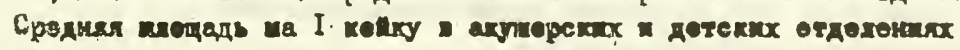

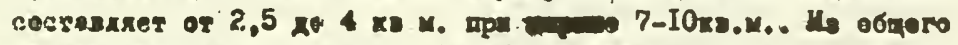

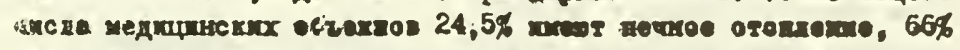

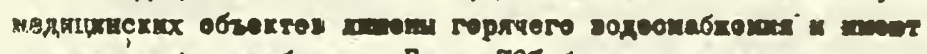

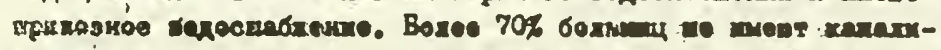

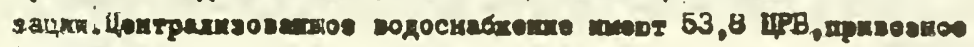
166. 4 P.

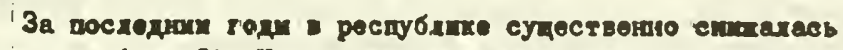
ратдархость (рис. 2). Что хасаегсл продопитехьнсеги хизни севкрян, то она прямо связана с не тохьхо с медико-биодотичоскон

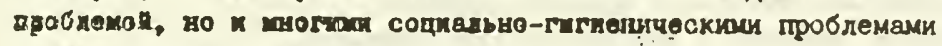
охқана адоровья север в.

Покезвтели прод, одительности северян отрахены в рис.3.

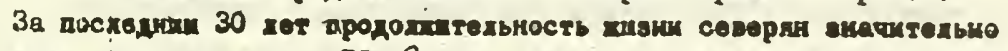

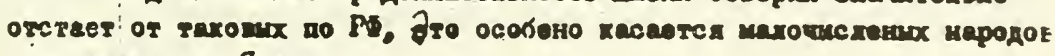

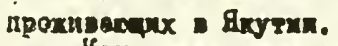

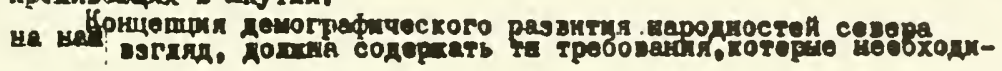


иก выплиить дя осушествления перехода к иитенсивному типу воспроизводства населения:

1. Повияние среднеЯ продохиитедьности визии ггародностей Севора.

2. Стабилизация вжсохой рохгеамости.

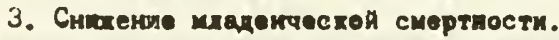

4. Сюгение смертиости : трудоспособном в

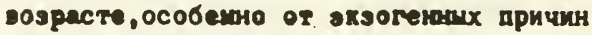
- nomirar nospacre.

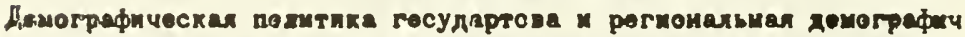
ческви похттхка ран̆нах прохивания народностей Севора долхиа поночь решкть оті дроблем.

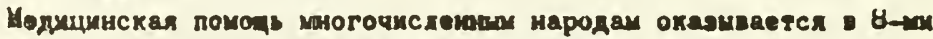

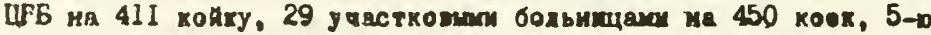

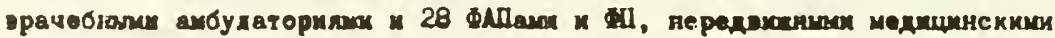
oтpr.s nux.

Иs обдего чнсла участковых больниц около $60 \%$ построенншх в период $30-30$ годи, имерт в настояпе время иянос от $40 \%$ до $100 \%$, все эти медучреддени находлтс.4 в приспособдених помеиениях.

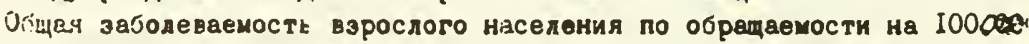
часеления $3 а$ I99Ігод составляет 7І4,7. По структуре заболеваемости внсок удельна простудна заболевания, болезния хенских органов29,0 , ослогпений беремекности и родов-18,9, бохезни педудочно-киечнн

1) тракта,забодевакия почек и кариоз зубов. Показатедь мдаденческой смертности 1990 году, составих $45,0 \%$.

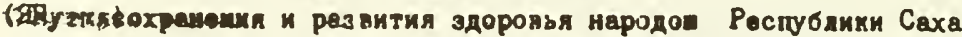
(Якутия) завистт от ресения многих кврдинальннх проблом:

- генетические троблеме здоровья,

- охрана sдоровья матери и ребенка,

- уәеличение продсдитедьности хмзии и сниение смертности,

- oxpyzanarar cpexe и aдoposbe.

- одалтация и урбенизация: өспекти әтническии и психобиологиyeckre,

- биологхческме и социальне рмтия и эдоровье народов Якутии,

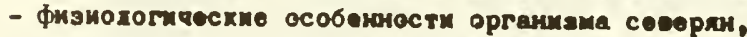

- предбодезнь и перокиеал профихахтика,

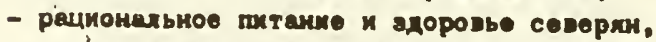

- народная мелицина и пробгем охранд адоровья,

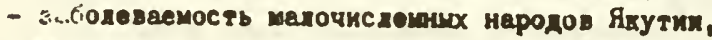

- особенности и течение обцерастространненних и специфнческих 
зебелепвикй у сөверяі,

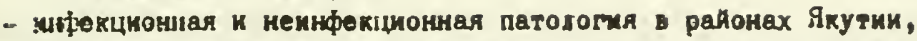

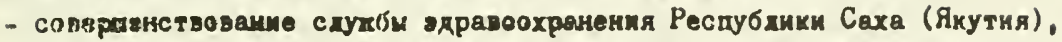

." ортвкнзеция специялизпрованно иодицинской помоци республкке,

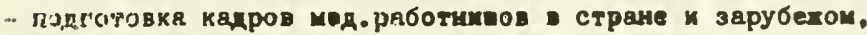

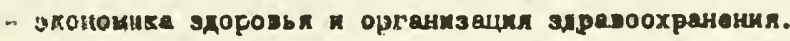

Дал редвния өзих пробхем здрапоохранекия ием кеобходимо дөльней-

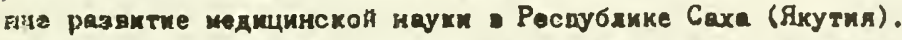

ॐедицинскяя наука в респубхике представкена федеративно-ведомствени

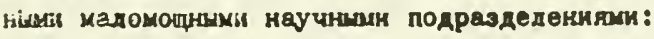

.. Якутским филивгок туберкулеза Мз $\mathbf{P \Phi}$.

- ЦLасіораторкей морфофункцмонашьнх исследований Института медпроблем Се

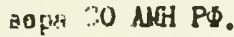

.. Сектором медицинской экохогии ЯНЦ СО РАН.

- Hэлицинским сектором Ииститута проблем мөдочисденных народог Севера SHLL Vo ratt.

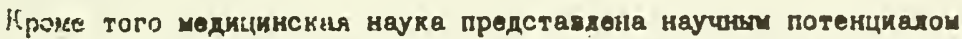

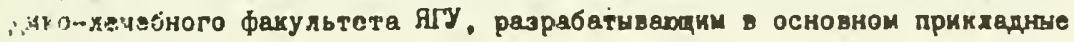
няугиче нодросн.

Но иэ-зв маломощности материвљьно-техническоЯ базы, и связвнного

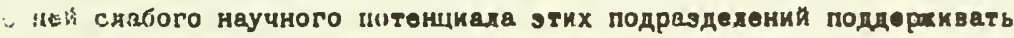

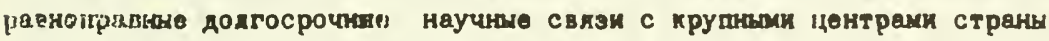
" әА рубетом эти подраздодения не состояни. И ото явкхось причиноИ того, что территории рестублкки девно уге сдугит без какой-либо 1:дпин ляя рестубахвнского эдрввоохранения сырьевой научной бвоой

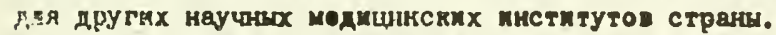

Это зестаимхо руховодство респубаки принять решенке Преаидента

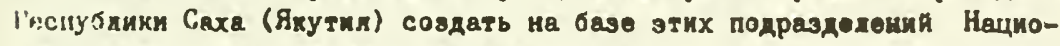
І:А ьныИ инстнгут эдеровьл народов Якутии.

8 качестве основни научиш направдоний с учетом приоритетности 1я респубаккансото әдравоохранения рабочая комиссия по организа-

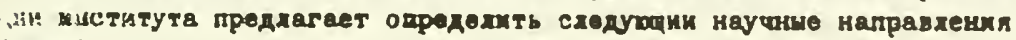
(pre.3):

I. Э'кодогхческие дробдемы медицико.

2. Экодогическеи пвтодогия вуберкухема.

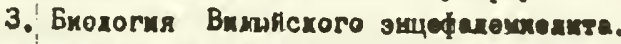

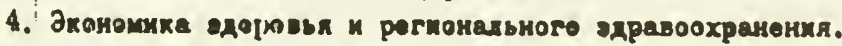

5. Народнеа медицина вародоз Вхугик. 
STATEMENT OF DR. SVEN EBBESON, INSTITUTE OF MARINE SCIENCE, UNIVERSITY OF ALASKA FAIRBANKS, AND CODIRECTOR, ALASKAN-SIBERIAN MEDICAL RESEARCH PROGRAM

Dr. EBBESON. I'm the Co-Director of the Alaska-Siberia Medical Research Program. And my counterpart in Russia is my neighbor here, Academician Trufakin. And he will comment

Senator MURKowski. You are going to have to speak right into the microphones. I don't want anybody in the back row to be sleeping back there.

Dr. EBBERSON. Concerns about alleged extensive pollution of radioactive substances in Siberia has led Dr. Trufakin and me to look into the matter as it relates to human health. We have obtained some preliminary information through a number of sources, especially the Minister of Health in Yakutia, Dr. Boris Yegerov. Within Siberia are numerous regions with levels of radiation dangerous to man and that within these regions increases in certain cancers and malformation of newborn have been observed during the last 20 years. For example, in one contaminated region, deaths from cancer in children have increased 18 times in the last 10 years. As an example of some of the available data that we are presenting to the Committee, we have learned that certain rivers such as Yenisey River contain such radioactive pollutants as plutonium, tritium, cesium-137 below a certain reactor plant, and that fish in this river contain such radionuclides as phosphorous-32, zinc-65, cesium-137, and closest to the plant, just below the plant, sodium-24. Such contaminated fish have been found along the entire length of the 1,000 mile river. Contaminated fish are consumed by the local population, apparently because they don't know it's contaminated.

As to such pollution entering the food chain in the Arctic Ocean and the Bering Sea, we have no data nor are we in the position to predict such pollution at this time. We have obtained some specific data about location of some radioactive sources and quantities in a few regions of Siberia and data on the apparent correlation with increased health problems. These details are part of the report to this Committee. We must stress one, that we cannot say if we're dealing with a cause and effect, and two, that the data must be regarded as preliminary only. We have very little information in relation to the enormity of the problem.

There is no doubt that the health officials in Siberia are concerned about what appears to them as a serious health problem. Much additional data have to be collected before the extent of the hazard can be determined and what populations are at risk.

The University of Alaska already directs an active health research program in cooperation with the Russian Academy of Medical Science. A successful relationship has been enjoyed by the Alaska-Siberia Medical Research Program since 1988, when it was initiated by Dr. O'Dowd and Dr. Ted Mala. The major foci of the program have been the investigation of lifestyle and nutritional factors and their impact on diabetes and heart disease in native populations in Siberia and Alaska; seasonal depression, alcohol, cold adaptation. We have also some epidemiological and cancer studies underway. The current program enlists expertise from elsewhere in the United States. 
In view of the success of this program, the University of Alaska and the Russian Academy of Medical Science, as partners, are in a unique position to direct further human health investigation in the region and, in particular, assess the health effects of additional radiation burden. The capability to conduct baseline clinical assessments and periodic medical surveillance of populations at risk as well as assessment of food sources already exist within the program, where we would hope that other agencies would also become partners in our task.

Considering the similar potential threats of pollutants to both the Siberian and Alaskan populations, it is clear that a collaborative program would be most effective and should be built on the foundation of the already existing Alaska-Siberian Medical Research Program. The program should include one, defining the potential hazards to the human population; two, clarifying which populations are at risk; three, the generation of epidemiological baselines, using common methodologies; four, the generation strategies; and five, the development of long-term surveillance of the human populations.

Both the Academy of Medical Science and the Ministry of Health in Yakutia have asked for our help in health-related research as they do not have the resources to do this subject justice at this time. We in Alaska are eager to help, provided we have the necessary resources.

My counterpart to the left here is Valery Trufakin, President of the Siberian Branch of the Russian Academy of Medical Science and Vice President of the National Academy. He has under his wing some 30 research institutes similar to our NIH spread out from the Urals to the Bering Sea. And he will provide a short synopsis of the situation as he sees it. After that we'll be glad to answer any questions you may have.

Thank you, Mr. Chairman.

Senator MURKOWSKI. Thank you very much, Dr. Ebbeson. I might add that you concluded your remarks in seven minutes. So I think the quality speaks for itself.

Our next panelist is Academician Valery Trufakin, Vice President of the Russian Academy of Medical Science and Chairman of the Siberian Branch of the Russian Academy of Medical Science. We welcome you as our Russian guest and look forward to your input on the panel. Please proceed.

STATEMENT OF DR. VALERY TRUFAKIN, PRESIDENT, RUSSIAN ACADEMY OF MEDICAL SCIENCE, SIBERIAN BRANCH, AND CODIRECTOR, ALASKAN-SIBERIAN MEDICAL RESEARCH PROGRAM

Dr. TRUFAKIN (through interpreter). First of all, I would like to thank Senator Murkowski for the invitation to come here and for the opportunity to make a short presentation during this important hearing. The Director of the Alaska-Siberian Scientific Medical Program has got all necessary data about the present-day situation of the radiation in Russia, and other members of the committee will have an opportunity to study them.

In my short presentation I would like to comment upon some facts. Evaluating the radioactive situation in Siberia, I should say 
that it is quite normal and it is in their standards but alongside the data that was-but at the same time the results of their scientific research show that the radioactive pollution of air, water and soil, fish and animals in some places in Siberia was quite significant.

There are several reasons for that radioactive pollution. Thus, for example, the first reason is the nature of gamma radiation due to the open deposits of ancient crystals and radioactive minerals and usage of radon and other natural construction materials. The second reason is a global radioactive pollution because of the nuclear weapons on Novaya Zemlya and in Semipalatinsk, in China, and after the nuclear explosion in Chernobyl nuclear power station.

The third reason is technical radioactive pollution as a result of radioisotopes used in medicine, extraction of the radioactive materials, geological exploration in Noralt (ph), gold and tin extraction, underground nuclear explosions in Yakutsk Republic, and during the period of 1974 to 198712 underground nuclear explosions were made on the territorial republic. The fourth and the last reason is dangerous radioactive technology, like automatic meteorological stations working on the basis of isotopes and some industrial enterprises in Novosibirsk, Krasnoyarsk, Tomsk.

The analysis indicating the rates of people's death was made in some regions of Siberia. The people's deaths of cancer, thyroid toxicosis, infant death are important indicators of the increasing ecological pollution on the territory. I would like to give you several examples.

Chukotka. Cancer takes the second place among the reasons of the people's death on the territory of this region. In 197010.3 percent of death were caused by cancer, and in 1988 the percentage increased and it was 26.9 percent. Infant death, because of the cancer, is two times higher among the native population. Especially high is the level of death because of lung cancer.

The City of Tomsk. The level of cancer was increased by 2.5 times from 1976. And scientific research made in space showed that the highest level of oncological disease occur in their industrial regions with the highest level of pollution.

In Magadan the level of their air pollution increased by 2.5 times and their oncological diseases increased for the last 10 years by 42.4 percent and death caused by the cancer increased by 73 percent.

The Region of Altay. For the last 40 years the level of the oncological diseases increased by five times and the level of their lung cancer increased by 50 times. The people's death increased by seven times and the infant death, because of the cancer, increased by 18 times.

Thus although the analysis of the reasons of all diseases shows the bad ecological situation, we can speak about the leading role of the radiation as the main cause of the oncological diseases.

There are some other reasons, like significant pollution of air and water, the change in the food, bacterial situation. That's why I think it is very important to make a joint detailed scientific research of the whole complex of the problems, including the influence of the radioactive situation in Siberia on the health of its population. And it is better to do within the frames of the existing 
Alaska-Siberian Scientific Medical Program. It is important to do because due to the breakdown of the former Soviet Union, the ecological situation is changing now, and intensive development of the industry and exploration of the Siberian deposits is taking place right now. But it should be done with new technologies and new scientific achievements, taking into consideration slow process of nature's regeneration. And this bad ecological situation is the north of my country could be spread over other northern countries.

It is necessary to make ecological, demographic and other maps of the regions and it is necessary to have monitors for this program, for the fulfillment of this program. It is necessary to study the animals and fish in the regions that have high level of pollution because usually the food products are made of fish and animals. Now more and more joint ventures are being established in my country and they deal with the geological exploration of the natural deposits, so that's why it is necessary to know the situation in soil, water. And it is very important to solve the problem of barring of the radioactive tailings and to know about its influence on the soil.

I would like to add that this work has been started three years ago but we need your help. And I think these problems are so important that they could be solved only by the joint efforts, by the efforts of all countries. And thank you for your attention.

Senator MURKOwSKI. Thank you very much, Dr. Trufakin, and we thank your interpreter, and I'm sure that your comments fell on very receptive ears. Your figures were certainly startling and I think told a story relative to the impact on the health of the areas affected. And it's of grave concern. Thank you.

[The materials provided by Dr. Trufakin follows:] 


\section{УЧАСТНИКАМ КОНФБРВННИИ}

"PAДИОАКТИВНАЯ И ЭКОЛОГИЧЕСКАЯ УТРОЗА СНА И АРКТИКЕ ОТ IPOUЛОИ ДЕКТЕЛЬНОСТИ СССР В ЭТОМ РЕГИОНБ"

Разделая обеспокоенность Соедшненках Штатов Америки по позоIу сложнон әколотигеской обстановки в ряде раяонов Арктики и понимая акту альнооть дан:ой проблөмы, считал бн делөсообра знвм пропнформировать учаотников конберенции о нашө огенге соотаяния и прдчши радповтувного загрнзнандя арктичеоких морей, а такзе

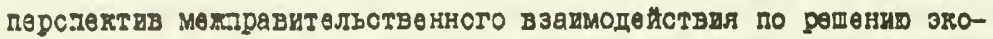
логучестах ароблем региона.

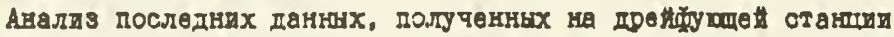

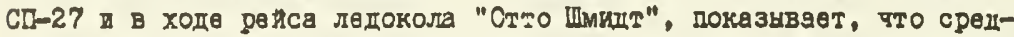
ния конгентрации цезия-IЗ7 в водах арктичөското бөссенне состав-

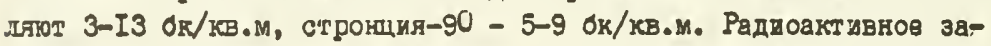
грязненде арктически морен обусловлено в первур очередь глобальными радиовстдвными вндадениями и переносом о морокими төчениямд

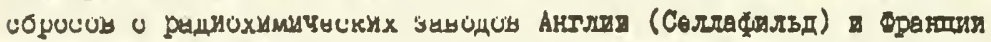
(Ля АГ). Максамальене Уровни загрязнөндя цездем-IЗ7 вод, лосту-

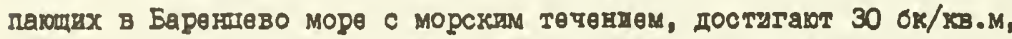

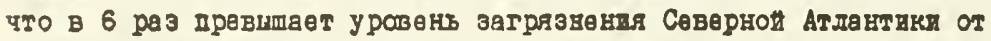

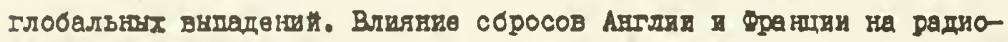
активно загрязнене арктитесклх морен додтвердпетсл сходотвом состава радонуклидов в морско воде в соросах.

По режльтатам работ россинско-норвежокон гругия экспертов по проблемам Јапиовктивного загрязнения Баренпеве и Карокого морей, созданнон в овязи с имериииися публикациямп о захораненшл х радиоактивных отходов бивштм СССР в этих морях, норвежскамп спецдалшстамд представлены авалогучвые панные о влаяния сбросов Англит

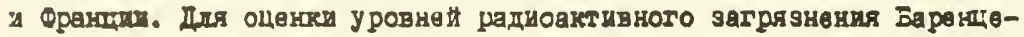
ва д Карокого морей, в гом тислв в результатө предполагавмого затороневия радиоактиних отходов бивши СССР, подғотовленя совмөстная росолисто-норвөхская экспедпция. В работе атон әкспедиция пландруєтен јчвстия прөдставдтөля МАГАТЭ. 
Предварительны материаль әкспедица плакуруется представить на дрөдотоямөм засөданди лондонско й коквөнцид до дөмпнвгу.

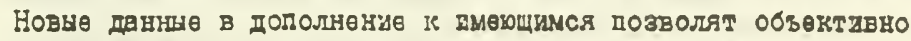

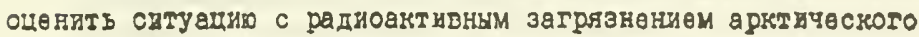

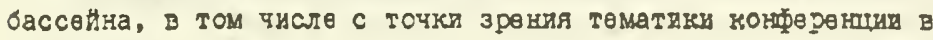
ゆetp poeraxce.

В целях оненки химического загрязнения пограничны рановов России Ћ СПА создана ДВусторонняя паучнал программа БЕРЕАК, จ памках котороћ раз в 3-4 года проводлтся совместные комплексияе гидрагогичөсквя, Гидрохимичөские и гидробиогогуческве исследования в Уукотском д Беринговом морях. Данњые әтих экспөдини, а

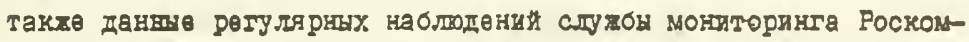
гидрометя догазывают, что эти моря относятся $\leftrightarrow$ фоновим раионам

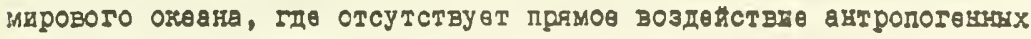
дсточнднов загрязнения. Однако возросшая в послепние годы хо

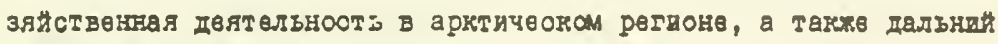

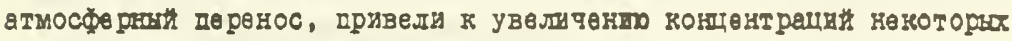

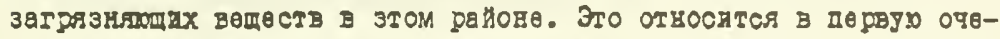
редь х далиароматнческим углеводородам, в частности, - беня(а)-

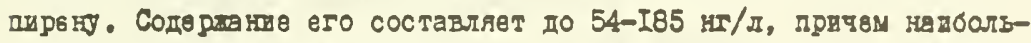

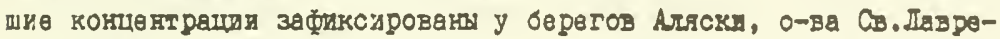
нуя (СلА) в в Бөринтовом праливе. Это вецество обнарушиваөтся таклв в донных отлотөниях й лтанктонных организмах.

Јстажовлеко такке, पто концентрадии тялелых металлов нахо-

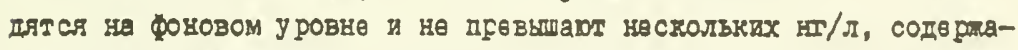

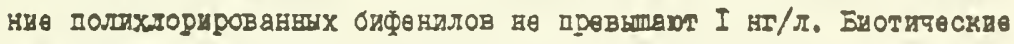
комповөкту पунотского у Берингота мореи в раноне Аласки находятся

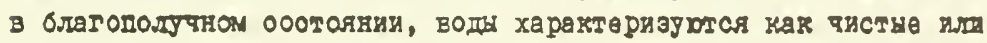

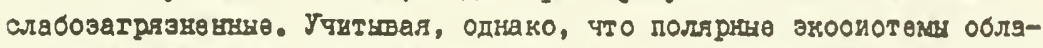

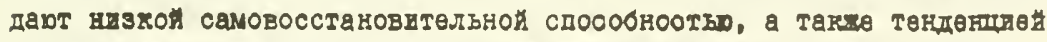

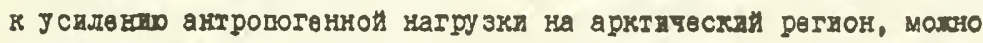

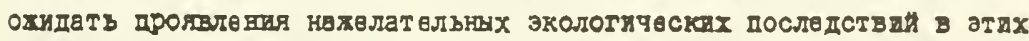
моркх. 
В этон овязя РОСой бела би кранив заннтересована в сотруд-

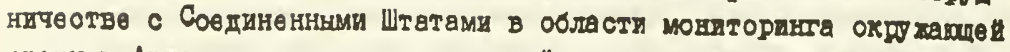
срегі в Арктике как на двусторонней основе, так и в рамках уного сторовнего сотрудничества пруарктических государств, в чаогноств, по "Программе арктичөского монит орднга и оценек" (АмаI).

По нешей оценхе, данная конференция мо гля бн явитьоя первнм шагом в налалавании широкого практ ического дву стороннего согрд нияества в этон актувльной сфере.

Пальзуясь случяем, хочу полелагь участндкам конферендии успеш-

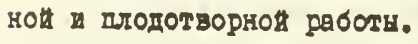
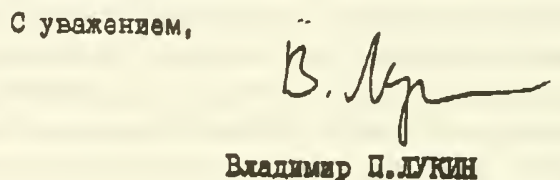

Ilocar Pooone B Cill 


\section{Iradestim puoberns yakutia}

Обзор проблөм падиационной бөзопасности насөления иа теруитории Якутской-Саха СCP

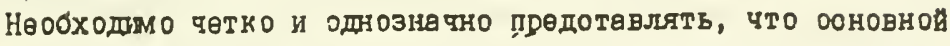
вклад в дозу, пблучаөмур чөловекаи от төхногөнньх всточников Фэдиаши, вносит мөдицна. Доля талько одноразового đ్поорограभџеского облядэвания в год составляөт $2 / 3$ годовой лучөвой 1 нэгрузки на чөловөка. ІІроблена лезыт на повөухности - поголовноо

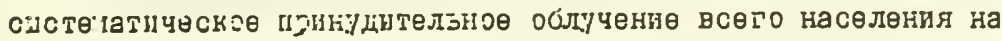

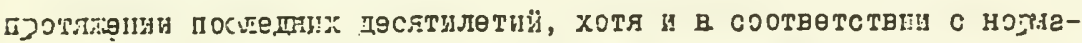

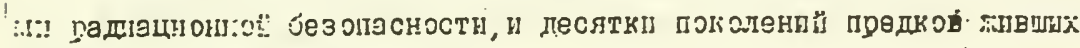

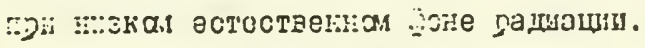

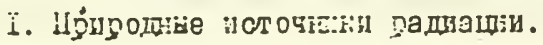

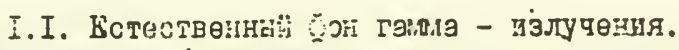

Ос:२яная төдргтория วөспубликі хәуактөризуется низкими

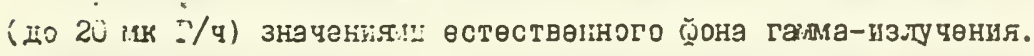
гі в отдольних районах, нэ площадях внхода на днөвную поверх-

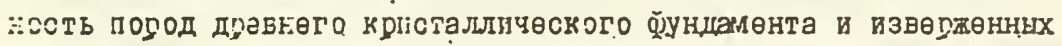

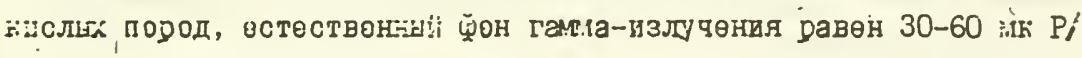

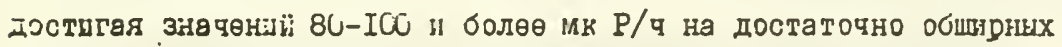

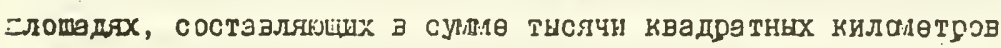

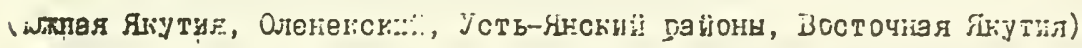

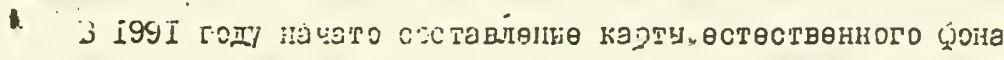

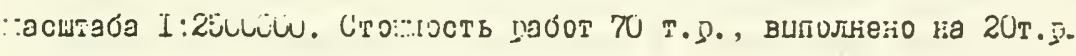

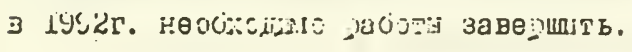

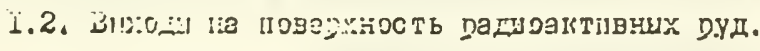

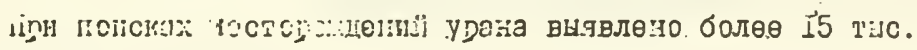

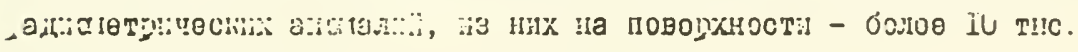


a

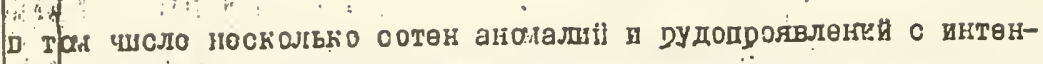
сиронотыо от 200-500 до I500 мК Р/प. В .оновнсм это локальные

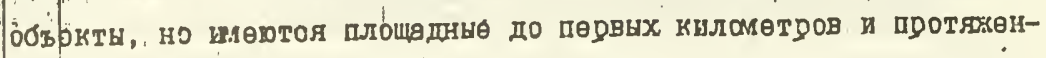
iне на цеоятки килалетров в төктонических зонах и пластах осадочнық подод. Рашоактивность связана нө только о рудами собствөнно урана и тория,но зачастуо сопровождаөт рөдкозөмельнуо,

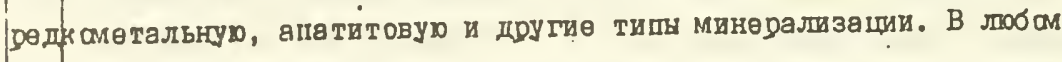
олучае слөдует учштнвать нө только радиоактшенооть, но и выходы на Һовөрхнооть урана - легто мигригуриего в внооко токовиного: $\therefore$ Нөобходамо подчөргнуть, что, хотя мн раополагвем информашни о

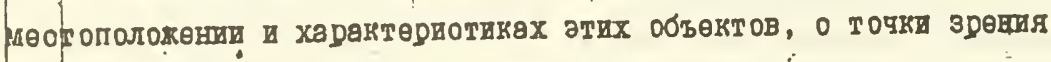

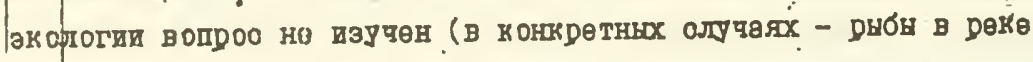
нөт., зверь стараөгоя обойтв стороной, рөка, в вөрховьях когорои урановое рудопроявлөния, мохөт називатьоя Ойун-Крөль).

I.3. Радон.

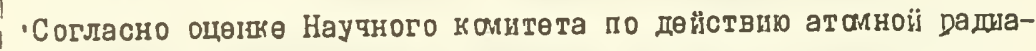

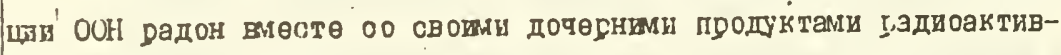
ного уаопада отвөтствөнен пукіерно за $3 / 4$ годовой инднвидуальной.

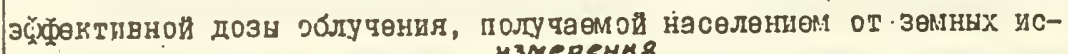

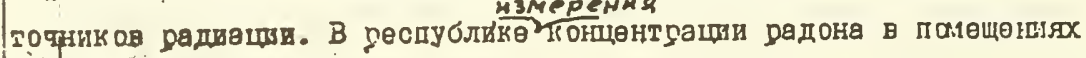

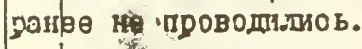

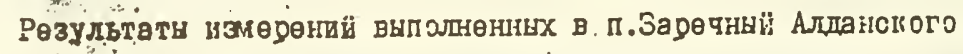

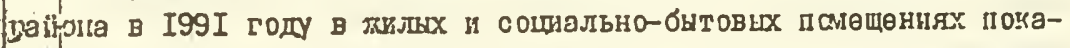

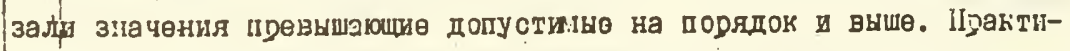

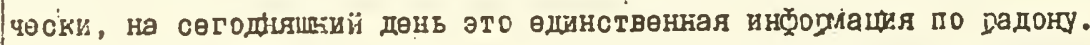

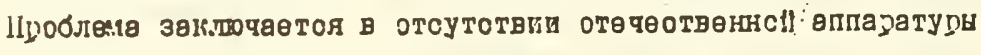
(вцпуск чувствитөльних приборов планшруется в I9g2 году, стов-

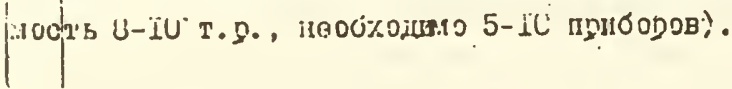


I.4. Стусытельнн ілатериалы.

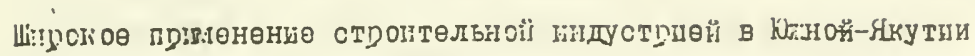

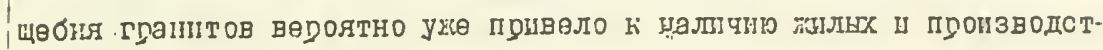

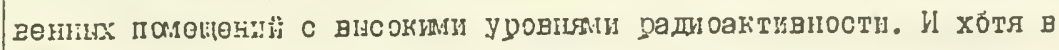

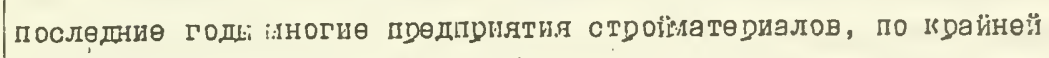

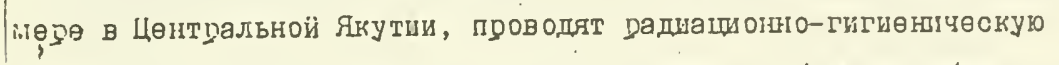
оценку нак сыця, так у готовой продукпи, проблөма трөбует кардинального рөшенуя - созданшя в рөспубликө спецалшзированной лаборатории.

2. Глобальные выпады радиоактвности.

В конге 50-х наче.те 60-х годов на воөй төрритории Якутии при радтометричөских повсках на уран гөофтзиками фикоровалшоь

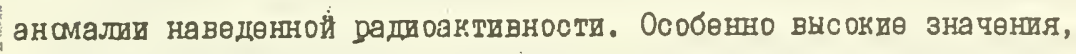
прөвншация IOOO мк P/q, устанавливались в сөвөрных районах вдоль побөрөлья. Имөле мөсто плопадные загрязнөния обшшеных

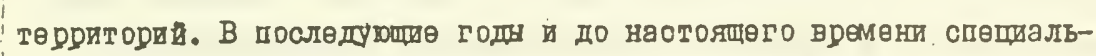

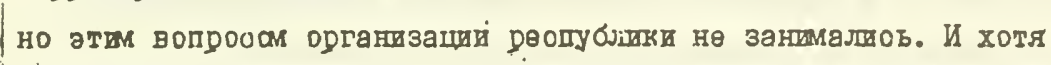

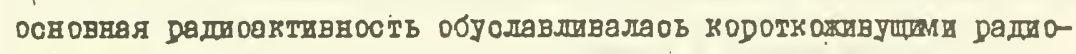
нуклтдами, отөпөнь загрязнөннооту .овөрннх пвотбищ стронциям - 90 в цөзием - ІЗ7 в наотоящеө время не изучөна.

3. Төхногенное загрязнөния төрдитории радионуклддами.

3.I. Добнга радпоктивных минөралов.

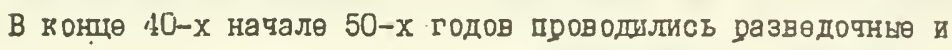
эксплуатационне работн на радноактивнне элемөнты в Южной Якутии (Васильөвка) монацшта из россыпей и в Момском районө (Сугунский 
развөд. DaНон Дальотроя) урановьх руд.

Предпритня бшли ликвидырована: первое за нөнадобноотьо, второө из-за бөдногти руд. Төм нө менөө на этих объөктах провөдөно активное виештельство в недра:. не Ваонльөвне и сөйчас пюются отвали уа.џооктнвного обогащөнного проинвкой матөцияла, Сугұнскиї развөдрайон обслөдован в I99I году, поскольку внзывала туевогу населения воэмоность сноса отвалов горных внцафоток к:подгоняя склснов на плато Улахан - Чнотай.

3.2. Гөолого-разведочнне работы на упан.

В рөзультөтө провөдения в төчөнве 25 лөт гөологоразвөдоч-

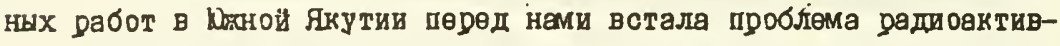

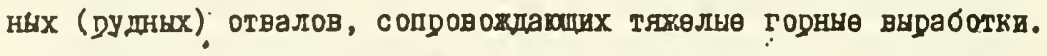
Организация прсводывшая ати рөботы ликвидарована, өө посөлки пөрөданы другым вөдамствам. И еоли вопросы лшквидаши радиоактивного загрязнөния в поовлках төхнияскй и практичөоки сөйqас рөпахтя, то проблөма отвалов трөбуөт оөрьөзного подхода. Рөальньм әксдөртам проектантам прөдстөвляөтоя ВКИПиромтөхнологив Мнаталзнеропрана, остаөтся опредөлнть кто заказчик.

3.3. Добача золота в олова.

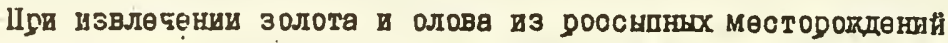
происходит изөлечөние п обогэщенте тявөльх минералов, в там числе i рады офктнинх. Словяннй концөнтрат достигаөт в отдөльных случаях уаділоктивнооти до 2000-3000 мк P/T, (контөйнөу), прш

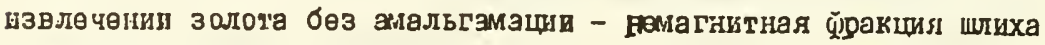
'7000-ICO00 мкP/u (полубочка).

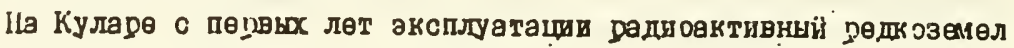
жшl :нерал куларит уходнт в отввлн. 


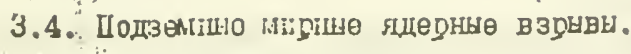

C I974 по I987 год на төрикторни рөспубліки провөдено I2

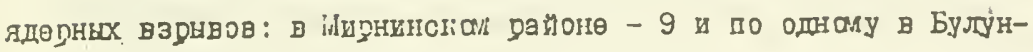
ска., В-Вилюйскаи и Кобяйскам районах. Два из них сопроводдалис внбросами рапионуклпдов: Олизкоповепхностны с цөлью строитель-

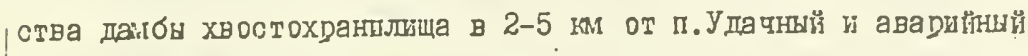
при глубиннам сөйсалческам зондированди в $39 \mathrm{kм}$ от п.Айхал. В обоих случаях нөобходғмы рөкультинационнне рабогы, в послөднем нөобходемоть прослөдть слөд уалшовктвного облака.

Не оотальннх объөктах взрнвов пров̈өств дөта̇льные радиомөт

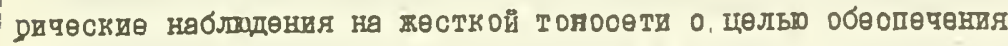
контроля за радшацшонной обстановкой во времөну. Оуганизовать мбншторшнговне наблодения.

В ранонах провөдения ядерньх взрывов провөотв Медтко-Гөнөтичөское обслөдованнө насөлөнтя.

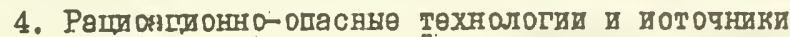

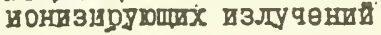

По состоянио на 0I.07.I99Ir. I98 предприятий на 405 объек-

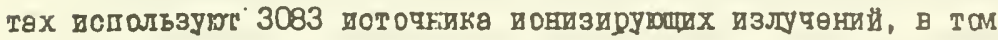
чшоле 2503 взотопных. Здесь шпроки опекту проблем Гоогортехнадворе в Госоаннадзора. Среди всего разнообразия истоцников выделяотоя РИТЭГи ("атамнне батареп") Гидрамөте, обөопөчивагии работу өвтоматичөских мөтөостанци в маяков. Эту приборы гмеют зарядку до I00000 Ки, разбросаны по побөрежью окөана, в дөльта рөк, не островех; их количөство иочисляөтся иногияи дөсятками. Впөдеди пөред неми "Мелая әнергетика" Мннетомәнергопрама

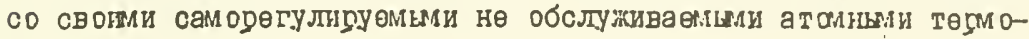


hition

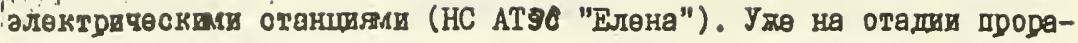
ботки төхничөокого задания нужая квалкцйцированная нөзввиомая 1

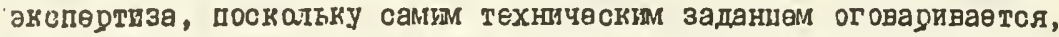

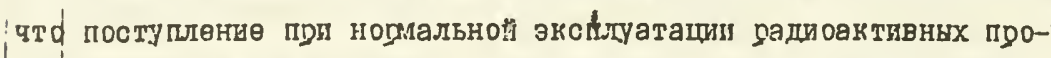
гуктов в охлаждаюиц вопу, гпунтовне води в в воздушгую среду доланы соотвөтствовать требованням НРБ 76/87.

5. Поотуплөние радионуклидов с продуктами питаншя.

Учптнвая мөоштвбы м многоканальность достудлөндя в рөотублвцу продовольствия, шорого учаотия частних комерчөских отруктур, обостряөтоя проблема контроля за радшоактвностьо продуктов питания. Рөшенше проблемн в раопространөнив бнтовшх пишикато-

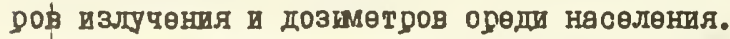

- Сущөствуөт єщө ряд проблем как, напримөр, нөсанкциондрован-

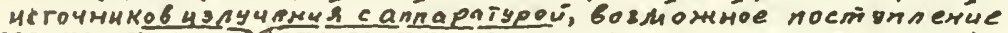

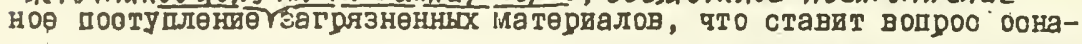

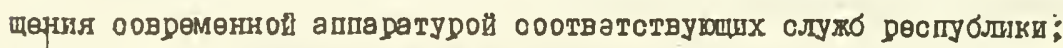
туанспортной милиции, тамовни.

Сөрьөзной проблекой в блшжайшөм будушем прөдставляөтсяุ рө-

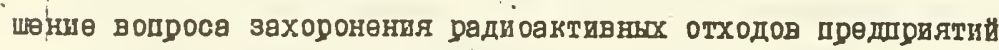
уеспублкв, котороө провзводилось до настоятөГо времөни в Г.Хабa'pobose.

Начвлыния Инсдекции раднаши онн ой бөзодаоности Якутского округа Госгортөхнадэ ора РСФСР

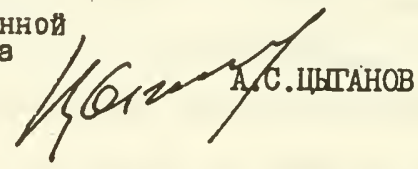




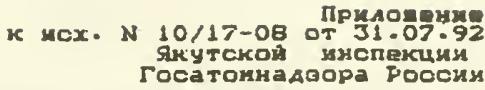

Lелевое назначение и нестополовение

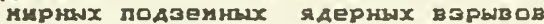

на территории Теспублики Caxa (Sxстия) :

1.

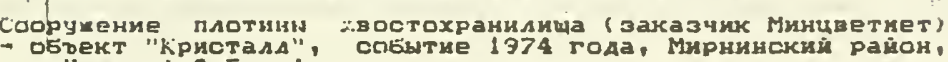
П. УАачниї 2.5 Кв;

¿.- ГАубинмое сейсмическое зондирование (заказчик Мнятео)

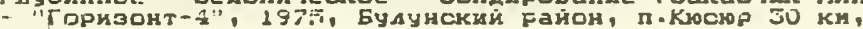

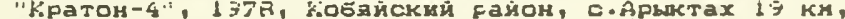

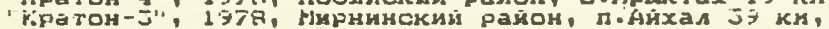

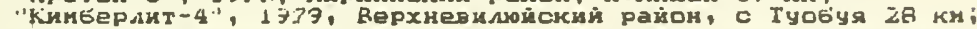

$\therefore$ Һінтенснфикачия притоков нефти ги газа (заказчик гіинтео)

- "Ока", 1976, ннрнннский раион, 0.Таас-10рах ј8 ки.

- "Вятуа", 1778, Мернинский район, с.Таас-10рах $26 \mathrm{kn}$,

- "Шексна", 1979, Мирнинскнй ракон, 0, Таас-10рях 7,2 кн.

- "Нева-1": 1

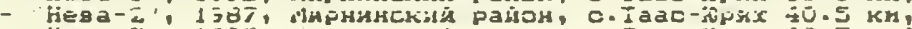

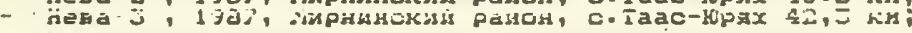

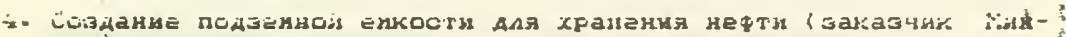
reat

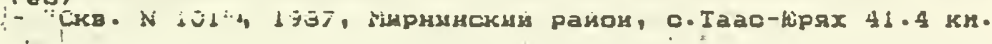

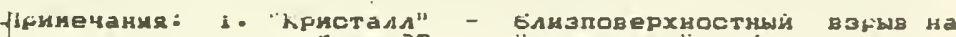

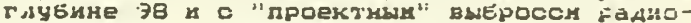
HYFisiALCB,

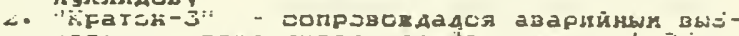

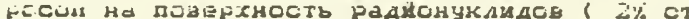

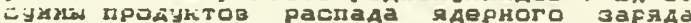

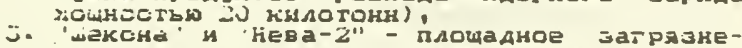

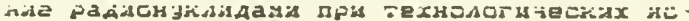

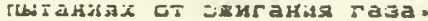


Congressional Research Service - The Library of Congress • Washington, D.C. 20540-7000

\section{Translation -- Russian}

\section{AN OVERVIEW OF RADLATION SAFETY PROBLEMS FOR THE POPULATION ON THE TERRITORY OF THE YAKUTSKAYA-SAKHA S.S.R.}

[sic -- formerly the Yakutskaya Autonomous Soviet Socialist Republic, now known as Yakutia or, in the native indigenous language, as the Republic of Sakha]

It should be stated clearly and unequivocally that modern medicine is the primary source for the dosage of radiation which human beings receive as a result of technology. The share from only a single fluorographic examination a year amounts to $2 / 3$ of the yearly radiation load on bumans. Superficially, the problem consists in the general, systematic induced irradiation of the entire population over the course of recent decades, although in accordance with radiation safety standards, and dozens of generations of ancestors who lived with a low natural radiation background.

\section{Natural Sources of Radiation}

\subsection{Natural Gamma-Radiation Background}

The main territory of the Republic is characterized by low values (up to 20 microroentgens/hour) of natural gamma-radiation background. However, in specific regions, in areas cropping out onto the day surface of rock from the old crystalline foundation and igneous acid rock, the natural gamma-radiation background is equal to 30-60 microroentgens/hour, reaching values of $80-100$ microroentgens/hour or more in rather extensive areas, comprising a total of thousands of square kilometers (Southern Yakutia, the Olenekskiy Rayon [rayon = administrative subdivision], Ust'-Yanskiy Rayon, and Eastern Yakutia).

In 1991, compilation of a map of the natural background was begun, on a scale of $1: 2,500,000$. The cost of the work is 70,000 rubles, 20,000 rubles' worth has been executed, and in 1992, the work must be completed.

\subsection{Outcrops onto the Surface of Radioactive Ores}

In prospecting for uranium deposits, more than 15,000 radiometric anomalies were detected, and of these, more than 10,000 on the surface, including several hundred anomalies and ore manifestations with an intensity of 200-500 to 1,500 microroentgens/hour. Basically, these are local sites, but there are surface sites as far as the first few kilometers and extended sites for dozens of kilometers in tectonic zones and strata of sedimentary rock. The 
CRS-2

radioactivity is linked not only with ores of uranium and thorium proper, but it frequently accompanies rare-earth, rare-metal, apatite and other types of mineralization. In any case, not only should radiosctivity be taken into account, but also the outcrops onto the surface of slightly allochthonous and highly toxic uranium. It is necessary to emphasize that although we have information about the location and characteristics of these sites, from the viewpoint of ecology, the issue has not been studied (in specific cases - there are no fish in the river, animals try to go around the side, and the river, in the headwaters of which the uranium ore manifestation is found, can be called Oink-Well).

\subsection{Radon}

According to an analysis by the United Nations Scientific Committee on the Effect of Atomic Radiation, radon, together with its daughter products of radiosctive decay, is responsible for approximately $3 / 4$ of the annual individual effective dose of radiation exposure received by the population from earth sources of radiation. In the Republic, measurements of radon concentrations in buildings had previously not been conducted.

The results of measurements performed at the Zarechnyy Settlement of the Aldanskiy Rayon in 1991 in residential buildings and social centers showed values exceeding the tolerable limits by a factor or more. This is virtually the only information on radon so far.

The problem consists in the lack of a national organization (the manufacture of sensors is planned in 1992, at a cost of 8,000-10,000 rubles, and 5-10 devices are necessary).

\subsection{Building Materials}

The wide-spread use of granite gravel by the construction industry in Southern Yakutia probably already led to the presence of high levels of radiosctivity in residential and industrial buildings. Even though many building-materials firms, at least in Central Yakutia, have been conducting in recent years a radiation-hygienic analysis of raw materials as well as finished products, the problem requires a radical solution: setting up a specialized laboratory in the Republic.

\section{Global Radioactivity Fallout}

At the end of the $1950 \mathrm{~s}$ and the beginning of the $1960 \mathrm{~s}$, throughout all the territory of Yakutia, during radiometric prospecting for uranium by geophysicists, anomalies of induced radioactivity were recorded. Especially high values exceeding 1,000 microroentgens/hour were distinguished in the northern regions along the coast. Surface contamination had occurred over vast territories. In subsequent years and up to the present time, organizations in the Republic have not specially studied this issue. Even though the basic radiosctivity was caused by short-lived radionuclides, the degree of contamination of the northern pasturelands by strontium-90 and cesium-137 is not currently under study. 
3. Contamination of the Territory with Radionuclides, Which is Caused by Technology

\subsection{Mining of Radioactive Minerals}

At the end of the 1940s and the beginning of the 1950s, prospecting for radioactive elements and recovery operations were carried out in Southern Yakutia (Vasil'yevka) for monazite from placers and in the Momskiy Rayon (Sugunskiy Prospecting Region of Dal'stroya) for uranium ores.

Enterprises were liquidated: the first enterprise for lack of use, the second enterprise because of the leanness of the ores. Nevertheless, at these sites, the bowels of the earth were actively interfered with: at Vasil'yevka today, there are spoil banks of radioactive material concentrated with an ore washer. The Sugunskiy Prospecting Region was examined in 1991, since the possibility for the spoil banks from the mining operations to drift down to the foothills at the Ulakhan-Chistay Plateau provoked alarm among the public.

\subsection{Prospecting for Uranium}

As a result of carrying on prospecting in Southern Yakutia for 25 years, we were confronted with the problem of the radioactive (ore) spoil banks which accompany heavy mining operations. The organization which had conducted these operations was liquidated, and its settlements were banded over to other departments. If issues regarding the elimination of radioactive contamination in the settlements are going to be resolved technically and practically at the present time, then the problem of the spoil banks requires a serious approach. The All-Union Scientific Research and Planning Institute for Industrial Technologies under Minatomenergoprom [Ministry of the Nuclear Power Industry] claims to be a real expert and designer, yet it remains to determine who is the customer.

\subsection{Mining of Gold and Tin}

During the extraction of gold and tin from placer deposits, heavy minerals, including radioactive minerals, are recovered and concentrated. In specific cases, tin concentrate reaches radioactivity of as much as 2,000-3,000 microroentgens/hour (container), and during the extraction of gold without amalgamation - the non-magnetic fraction of heavy concentrate has 7,000-10,000 microroentgens/hour (half-drum).

At Kular, since mining first began, the radioactive rare-earth mineral kularite [= monazite] has been running off into spoil banks.

\subsection{Underground Peaceful Nuclear Explosions}

From 1974 through 1987 on the territory of the Republic, 12 nuclear explosions were conducted: nine in the Mirninskiy Rayon, and one each in the Bulunskiy Rayon, Verkhnevilyuyskiy Rayon and Kobyayskiy Rayon. Two of these were accompanied by releases of radionuclides: a shallow, sub-surface blast for the purpose of building an embankment for a tailings storage pit at $2.5 \mathrm{~km}$ from the Udacbnyy Settlement and an accidental detonation during a deep seismic sounding at $39 \mathrm{~km}$ from the Aykhal Settlement. In both cases, recultivation work is necessary, and in the latter case, there is a need to follow the trace of the radioactive cloud. 
At the other explosion sites, it is necessary to conduct detailed radiometric observations on the rigid topographical network in order to provide monitoring of the radiation situation over time. Monitoring observations need to be organized.

In regions where nuclear explosions were conducted, it is necessary to perform medical and genetic examinations on the population.

\section{Hazardous Radiation Technologies and Sources of Ionizing Radiation}

According to the situation as of 01 July 1991, 198 enterprises at 405 sites have used 3,083 sources of ionizing radiation, including 2,503 isotopic. This poses here a broad spectrum of problems for Gosgortekhnadzor [State Committee on the Supervision of Industrial Work Safety and Mines, RSFSR Council of Ministers] and Gossannadzor [State Sanitary Inspection]. Among the entire range of the various sources, RITEGs [expansion not given, possibly radioisotopic thermoelectric generators] ("nuclear batteries") from Gidromet [Hydrometeorological Directorate] have been distinguished; these ensure the operation of automated weather stations and lighthouses. These devices have a charge of as much as 100,000 curies; they are scattered along the ocean coastline, in river deltas and on islands; and the number of these devices amounts to several dozen.

We have yet to confront the "Small Power Industry" of the Ministry of the Nuclear Power Industry, with its nuclear thermoelectric power plants which are self-regulating and are not serviced (NS [expansion not given, possibly pumping stations] of the nuclear thermoelectric power plant Elena). Even at the stage of working out the technical program, a well-qualified independent expert appraisal is necessary, insofar as it is stipulated by the technical program itself that during normal operation, the entering of radioactive products into the cooling water, the ground water and the atmosphere must meet the requirements of Radiation Safety Standards 76/87.

\section{Entry of Radionuclides into Foodstuffs}

Taking into account the extensiveness and the many channels for foodstuffs to enter into the Republic and the broad participation of private commercial structures, the problem of monitoring radioactivity in food products is aggravated. The issue of distributing household radiation indicators and dosimeters to the public needs to be resolved.

There still are many problems such as, for example, the unsanctioned entry of radiation sources with equipment and the possible entry of contaminated materials, which raises the question of fitting out the appropriate services in the Republic (transport police and customs) with modern equipment.

In the near future, resolving the issue of burying radioactive waste from enterprises in the Republic will be a serious problem; this burial has taken place up to the present time in the city of Khabarovsk. 


\section{CRS-5}

Director of Inspection of Radiation Safety for the Yakutsk District of the Gosgortekhnadzor RSFSR [State Committee on the Supervision of Industrial Work Safety and Mines, RSFSR Council of Ministers]

[signed]

A.S. Tsyganov 
Appendix to Outgoing Document No. 10/17-08 dated 31 July 1982 from the Yakutsk Inspection of the Gosatomnadzor [State Nuclear Supervision] of Russis

\section{SPECIFIC PURPOSE AND LOCATION OF PEACEFUL UNDERGROUND NUCLEAR EXPLOSIONS ON THE TERRITORY OF THE REPUBLIC OF SAKHA (YAKUTLA)}

1. Construction of an embankment for a tailings atorage pit (customer: Miniatry of NonFerrous Metallurgy)

- Kristall site, 1974 event, Mirninskiy Rayon, Udachnyy Settlement 2.5 km

2. Deep seismic sounding (customer: Ministry of Geology)

- Gorizont-4, 1975, Bulunskiy Rayon, Kyusyur Settlement 30 km

- Kraton-4, 1978, Kobyayskiy Rayon, Aryktakh Village 19 km

- Kraton-3, 1978, Mirninskiy Rayon, Aykhal Settlement 39 km

-- Kimberlit-4, 1979, Verkhnevilyuyskiy Rayon, Tuobuya Village 28 km

3. Increasing the Supplies of Petroleum and Gas (cuatomer: Ministry of Geology)

- Oka, 1976, Mirninskiy Rayon, Tas-Yuryakh Village 38 km

-- Vyatka, 1978, Mirninskiy Rayon, Tas-Yuryakh Village 26 km

- Sheksna, 1979, Mirninskiy Rayon, Tas-Yuryakh Village 7.2 km

- Neva-1, 1982, Mirninskiy Rayon, Tas-Yuryakh Village 31.5 km

- Neva-2, 1987, Mirninskiy Rayon, Tas-Yuryakh Village 40.5 km

- Neva-3, 1987, Mirninskiy Rayon, Tas-Yuryakh Village $42.5 \mathrm{~km}$

4. Creation of an Underground Tank for Storing Petroleum (customer: Ministry of Geology) -- Hole No. 101, 1987, Mirninskiy Rayon, Tas-Yuryakh Village 41.4 km

Remarks:

1. Kristall -- shallow, sub-surface exploaion at a depth of 98 and with a "planned" release of radionuclides.

2. Kratok-3 - was accompanied by an accidental release of radionuclides onto the surface ( $2 \%$ of the total of the decay products from the nuclear charge with a yield of 20 kilotons).

3. Sheksna and Neva-2 - area contamination by radionuclides during technological teats from combustion of gas.

Translated by: Kathleen Sweeney CRS Language Services 14 January 1993 


\section{Preliminary data - radioactive contamination \\ [illegible], Novosibirsk, Tomsk, Magadan, Krasnoyarsk \\ Medical Problems from Exposure to Radiation}

In the Altay kray radioactive contamination is a great concern, due to its geographical location in the south of Western Siberia in the immediate vicinity of China and Kazakhstan. Among the main sources of radioactive contamination of the environment in this Region, the following have been identified: a series of powerful nuclear explosions conducted on the Semipalatinsk test site and in China, the accident at the Chernobyl nuclear power plant, nuclear tests on Novaya Zemlya, combustion products of organic fuel in boilers, heat and power plants, dusting from ash dumps, and also sources of radioactive contamination of natural origin.

Radioactive contamination of soil in the territory of the Altay kray is determined mainly by the accumulation in the soil over many years of fallout from long-lived strontium- 90 and cesium- 137 that had been emitted into the atmosphere during nuclear weapons tests. In addition, mineral fertilizers applied directly into the soil are a significant source of its radioactive contamination. Contamination of surface waters is caused by the wash-off of strontium-90 from the soil surface by atmospheric precipitation.

In Novosibirsk oblast, radiometric sampling of atmospheric fallout (according to the monthly data from the Center for Monitoring Environmental Contamination) indicated that during 1990-1991 the fallout density did not exceed the established control value of $110 \mathrm{~Bq} / \mathrm{m}^{2}$ per day in terms of total beta-activity, and on average was $0.7 \mathrm{~Bq} / \mathrm{m}^{2}$ throughout Novosibirsk oblast. At the permanent sites for recording radioactive contamination, the mean values of fallout density are as follows: $0.8 \pm 0.5 \mathrm{~Bq} / \mathrm{m}^{2}$ in the cities of Bolotnoye and Karasuk, $1.0 \pm 0.4 \mathrm{~Bq} / \mathrm{m}^{2}$ in the city of Barabinsk, $1.5 \pm 0.7 \mathrm{~Bq} / \mathrm{m}^{2}$ in the city of Novosibirsk, and $1.4 \pm 0.7 \mathrm{~Bq} / \mathrm{m}^{2}$ in the town of Ogurtsovo. The maximum radioactive fallout was $6.3 \mathrm{~Bq} / \mathrm{m}^{2}$ in Barabinsk, $10.0 \mathrm{~Bq} / \mathrm{m}^{2}$ in Novosibirsk, and 18.5 $\mathrm{Bq} / \mathrm{m}^{2}$ in Ogurtsovo.

The radioactivity of the surface atmospheric layer was caused by fallout from the stratosphere of products of the decay of radioactive substances during nuclear tests conducted in previous years. Basically the radioactive contamination is determined by the presence of substances such as cesium-137; in a number of cases contamination by thorium-232 from the soil was noted.

The soil dose rate is, on average, $20-50 \mu \mathrm{r} / \mathrm{hr}$, yet in some cases the maximum dose goes up to $275 \mu \mathrm{r} / \mathrm{hr}$ (in the exclusion zone of the tailing dump of the Production Association Khimkontsentrat in the city of Novosibirsk, which results from the production activities of this enterprise). 
The available official data on the contamination of air, water and soil in Novosibirsk oblast do not provide the full picture of the environmental situation in this region (and its constituent areas), yet they can effectively indicate zones of possible anthropotechnical stress, which can result in damage to the health of the population.

In Tomsk oblast, a substantial increase in the background radiation is found at the mouth of the Chernilshchikova Channel where water coming from the Tomsk-7 area flows into the River Ob: $100 \mathrm{~m}$ from the bank, water registers $30 \mu \mathrm{r} / \mathrm{hr}$, and the general background is $30-35 \mu \mathrm{r} / \mathrm{hr}$. It must be taken into account that contaminated water at the measuring point has been already diluted substantially with water from the

Chernilshchikova Channel of the River Ob. The fact that the general background radiation in the River $\mathrm{Ob}$ and its tributaries is significantly lower $(1-4 \mu \mathrm{r} / \mathrm{hr})$ than the above values suggests that industrial production in the city of Tomsk-7 is related to these levels of the atmospheric background and river background in adjacent areas.

In the Krasnoyarsk kray, in 1989-1991 the Krasnoyarsk Scientific Center of the Siberian Branch of the Russian Academy of Sciences conducted investigations of the radioecological conditions of the Yenisey River. An airborne gamma-ray survey and comprehensive investigations were performed $1,000 \mathrm{~km}$ downstream of the discharge from the Mining Chemical Integrated Works, using a specially equipped vessel. Over 600 samples of water, bottom sediments, soil, fish and vegetation were taken along a section $1,000 \mathrm{~km}$ long. The investigations covered the entire radionuclide composition of contaminants, including plutonium, tritium, and also cesium-137 and phosphorus-32 (the main dose-forming radionuclides).

It was found that in the zone of displacement of discharged water from the integrated works, sodium- 24 and manganese- 56 reached the highest concentration, $2.6 \cdot 10^{-7} \mathrm{Ci} / 1$ and $2.3 \cdot 10^{-7} \mathrm{Ci} / 1$ respectively, exceeding the $76 / 82$ radiation safety standards by 10 and 2 times, respectively. In the town of Atamanovo, the first settlement downstream from the discharge site, the concentration of certain nuclides in water was below permissible concentrations due to decay and dilution, but the total activity in water was close to the upper limit of the permissible value.

The content of long-lived radionuclides (cobalt-60, cesium-137, europium-152, 154) on the bottom of the Balchugovsky Channel, for the average water content, was about $1 \mathrm{Ci}$. The entire reserve of technogenic nuclides in the tailings of the islands that were studied is estimated at approximately $17 \mathrm{Ci}$. The distribution of radionuclides through the bed varies greatly along the length of the river.

During the investigation, much attention was given to the study of radioactive contamination of fish. Altogether over 40 specimens of thirteen nonmigratory and migratory species of fish were analyzed. The main nuclides accumulating in fish tissue were phosphorus-32, zinc-65, cesium-137, and, close to the source of activity, sodium-24. Contaminated fish were caught at a great distance from the site of discharge, both 
downstream and upstream. Technogenic radionuclides were found in fish caught close to the city of Krasnoyarsk. The maximum concentration of phosphorus-32 $\left(5.0 \cdot 10^{-7} \mathrm{Ci} / \mathrm{kg}\right)$, which is the principal nuclide produce, was found in a grayling caught in the area of the town of Pavlovshin ( $60 \mathrm{~km}$ downstream from the discharge). The analysis that was performed indicates that practically throughout the entire $1,000 \mathrm{~km}$-long sector of the river under study, contaminated fish consumed by the local population is the major component of the possible dose load.

The density of contamination of the flood plain in terms of total technogenic nuclides varied with the distance from the source, from 160 to $0.2 \mu \mathrm{Ci} / \mathrm{m}^{2}$. According to the data from the Institute of Biological Problems of the North of the Far Eastern Branch of the Russian Academy of Medical Sciences, in Chukotka the general $\gamma$ background of natural radioactivity is $15-30 \mu \mathrm{r} / \mathrm{hr}$ (which does not exceed permissible levels and is somewhat different from other areas).

In the north of the Krasnoyarsk kray the $\gamma$-background is $25-30 \mu \mathrm{r} / \mathrm{hr}$. In the Magadan oblast, the $\gamma$-background is $15-30 \mu \mathrm{r} / \mathrm{hr}$, with cesium-137 and strontium-90 (i.e. products of nuclear decay after explosions) making practically no contribution to the radioactive background in the North.

The radioactivity of venison muscles was determined as $0.1-2.7 / 10^{-9} \mathrm{Ci} / \mathrm{kg}$ which is 0.03 per $\mathbf{k g}$ (or $3 \%$ ) and is permissible for these products.

In the city of Mirny (basin of the Vilyuy River) the $\gamma$-background does not exceed permissible levels.

According to data from the Leningrad Institute of Radiation Hygiene, the natural radioactive background in the North is high, which is typical of the North in general. Reindeer moss accumulates and absorbs radioactive substances, which may result in a higher radioactive background in deer and in human bodies. It is known that radionuclides play a greater role in the state of health than the $\gamma$-bacigground.

Sociological and demographic studies tracking the connection between contamination of the environment with radionuclides, chemical agents, and also the physical components of the radiation factor, are currently underway in the Altay kray. It was revealed that in 40 years, starting in 1950 (the time of the first nuclear tests), a complex demographic situation has developed in the kray, partly due to an increase in environmental stress.

During the period from 1950 through 1990, its population increased from $2,396,200$ to $2,828,300$. The total population increase was 432,100 or $18.0 \%$. This amount of population growth over 40 years cannot be accepted as sufficient. 
Certain indices of population morbidity and mortality are indicators of some sort of increase in the ecological stress throughout the area.

From 1950 through 1990, unfavorable trends were revealed in this region in the dynamics of cancer morbidity. They were characterized by a progressive growth trend, close to a linear one (the increase in primary morbidity indices was 4.6 times). The most unfavorable changes in primary morbidity indices were observed for malignant respiratory tumors (an increase by more than 50 times), malignant skin tumors (by 3.4 times), malignant breast tumors (by 4.6 times).

The incidence of malignant digestive organ tumors also increased, but during the recent decade, the trend has stabilized and even shown a decrease.

An increase in the morbidity indices was also observed for hematologic neoplasms (primary morbidity rose by 1.2 times, susceptilility to disease by 2.4 times). Yet their dynamics showed periods of increase (1974-1975 and 1989-1990) and decrease (19791980).

Other malignant tumors, examined separately, manifested either stabilization of primary morbidity (malignant tumors of the urogenital organs), or decrease (malignant tumors of the cervix), while susceptibility to the disease increased.

Among other indicative nosologies, the most unfavorable changes were characteristic of the morbidity of children in the region (up to 14 years of age) with anemia due to iron deficiency (an increase in primary morbidity was 4.7 times), neonatal morbidity (indices increased by 2.3 times), including the hemolytic disease (by 2.5 times), and congenital anomalies (by 1.8 times). There has been an unfavorable trend in the frequency of toxemias of the second half of pregnancy.

The mortality from malignant tumors has increased markedly in the region: by 6.9 times for the entire population, by 9.1 times for men, and by 5.2 times for women.

Since the mid-1960's, male mortality from malignant tumors has been higher than that of women, and the gap has been widening (from 1.1 times in 1970 to 1.5 times in 1990). An increase in the level of mortality from oncological diseases is characteristic of all major age groups of the population. The mortality index for the working-age population increased by 3.8 times; for retirees by 6 times; and for children by 18.3 times.

Of all malignant tumors, those of the digestive organs have been the leading cause of mortality in the region. Mortality from this cause progressively increased from $17.7 \%$ in 1950 to $64.9 \%$ in 1990 . Men displayed higher mortality from this cause than women. Most individuals who died from malignant tumors of the digestive organs were in the retirement age group. 
Malignant tumors of the respiratory organs are the second most important cause of death from malignant tumors among the region's population, and their percentage has been constantly increasing. During the period from 1950 to 1990 , mortality indices increased (from $1.65 \%$ to $56.02 \%$ or by 34 times). The mortality level among men was increased by 3.3 to 7.2 times higher than among women.

Women's mortality has been increasing constantly also from malignant tumors of the breast (from $2.4 \%$ to $14.2 \%$ ). The highest increase occurred from 1959 to 1970 after which the rate of increase was somewhat slower.

Malignant tumors of the urogenital tract have a significant place in the structure of mortality of women in the kray from malignant tumors (up to $25 \%$ ). The period from 1950 to 1965 showed a sharp increase (by 3.4 times) in women's mortality from this cause. In the last 20 years, however, mortality of working age women from this cause has decreased substantially (from $38.3 \%$ to $16.7 \%$ ). In the past 20 years, mortality of the male population from malignant tumors of the urogenital tract also increased by 2.4 times (from 3.3 to $7.9 \%$ ).

The mortality level from hematologic neoplasms in the kray increased between 1969 to 1990 (from $4.87 \%$ to $8.68 \%$ ). The mortality of men from this cause is higher than that women (by 1.2-1.7 times).

The incidence of mortality from the diseases of the endocrine system also showed a constant growth trend, which peaked in 1981-1985 and was followed by a slight decrease. The mortality of women due to this cause is $1.5-2$ times higher than that of men.

Analysis of indicative morbidity (malignant tumors, thyrotoxicosis, neonatal morbidity) and mortality (from malignant tumors, infant mortality, stillbirth, and congenital anomalies) shows with a high degree of probability that the radiation factor had and continues to have a place in the contamination of this region. The investigation shows a direct effect on the health of living generations as well as a delayed effect (a combination of the direct effect of environmental contamination and the effect on subsequent generations through the maternal generation, which was directly exposed to the radiation. Although detrimental characteristics are eliminated from the population (decreased birth rate, increased mortality), remote consequences of the radiation factor may still be manifested in many subsequent generations.

An in-depth study of the effects of radiation contamination on the health status of the population is needed, using the data on the radiation load in the kray and sociohygienic cohort analysis, which would permit a sufficiently accurate determination of the effect of radioactive contamination of the environment on the health of the population. 
In Novosibirsk oblast, a high level of morbidity with malignant tumors is found in the Maslyanino, Kochenevo, Kolyvan, Chistoozemoye, and Kargat rayons, and also in the city of Novosibirsk (over 250 cases per 100,000 people).

Mortality from lung cancer is the highest (over 40.0 per 100,000 people) in the Chistoozernoye, Ubinskoye, Bagan, Kochenevo, Ust-Tarka, Ordynskoye, Moshkovo, Toguchin, Kolyvan, Suzun, Maslyanino, Bolotnoye, and Zdvinsk rayons, and also in the city of Berdsk. A low level (less than 30.0 per 100,000 people) was found in the Barabinsk, Vengerovo, Dovolnoye, Kochki, Severnoye, Tatarsk, and Chany rayons. In this regard, the Moshkovo Rayon was classified in the group with "very poor" health, and confirmed that cancer of the stomach accounts for much of the mortality from tumors. The Kolyvan Rayon is in the same situation. Negative transitions (to a worse health group) were also made by the Tatarsk (from "medium" to "poor"), Ust-Tarka and Bagan (from "below medium" to "poor"), and Severnoye (from "good" to "below medium") rayons.

Comprehensive evaluation of all four indicators (mortality and morbidity in the entire class of malignant pathology, and also mortality from lung and stomach cancer) provides the most accurate concept of the connection between environmental factors and the development of tumors. In this case, the Chistoozernoye, Kochenevo, Moshkovo, Kolyvan and Maslyanino rayons come under the "poor" state of bealth rubric. In addition, according to the previous analysis, pulmonary pathology is the leading factor in the two former rayons, and that of the gastrointestinal tract in the latter two. Various kinds of malignant tumors are prevalent in the Mastyanino rayon.

According to recent studies, the unfavorable radiation situation in the city of Novosibirsk and the Moshkovo rayon could be traced to soil and air contamination with radioactive and chemical substances from the Khimkontsentrat enterprise, in particular to illegal dumping sites for waste from this and other enterprises in the Moshkovo and Novosibirsk rural areas. In the Maslyanino rayon, the contamination of farmland by mineral fertilizers and pesticides is the highest in the oblast $(200-210 \mathrm{~kg}$ per person per year and $70-80 \mathrm{~kg}$ per hectare of land under cultivation).

In the city of Tomsk, an increase in the incidence of oncological diseases related to environmental pollution was found. Thus in 1976, the incidence of malignant tumors was 107.9 per 100,000 people, while in 1986 it jumped to 277.4 per 100,000 people, i.e. by 2.5 times. The Research Institute of Oncology of the Siberian Branch of the Russian Academy of Medical Sciences, and the Computer Center of TLASUR analyzed satellite photographs of the city of Tomsk and found that an IR photograph dated June 19, 1988 in the 0.8-0.9 micron range superposed on the city map of the same scale indicated that the dark spots matched industrial enterprises of the city.

In the city of Magadan, the comprehensive index that characterized the degree of atmospheric pollution rose from 7.7 in 1980 to 19.3 in 1988, i.e. it more than doubled. It 
was found that the effect on the human organism of air pollution, combined with extreme natural ecological factors, causes specific pathologies and an increase in the incidence of somatic diseases: pneumonias, bronchitis, allergies (bronchial asthma). This is also supported by the cancer morbidity and mortality statistics in Magadan. Thus during the last decade, the overall cancer morbidity increased by $42.4 \%$, and cancer of the respiratory organs by $65 \%$. Over the same period, mortality among the inhabitants of Magadan from cancer of all localizations has increased by $73 \%$, and that from cancer of the respiratory organs almost doubled.

The morbidity and mortality of the Magadan population from diseases related to radioactive contamination have increased sharply. Thus during the last decade, oncological morbidity related to the radiation factor has more than doubled. It should be mentioned that during the same period mortality from cancer of the digestive organs dropped by $15 \%$ in Magadan.

Due to that cause, general and standardized mortality of the Magadan oblast population increased, except for the rural population (males) where the standardized index stabilized at the 1979 level. Among urban males, mortality from 1970 to 1986 increased by $31.6 \%$, and among rural males it decreased during the same period by $6 \%$, which is linked to the increase in outmigration from rural areas, particularly by men.

Among urban females, mortality from.malignant tumors has increased by $19.4 \%$, and among rural females by $23.4 \%$.

Besides the migration factors, changes in mortality from malignant tumors are related to environmental pollution, mainly atmospheric pollution. This is supported by mortality statistics for cancer of the respiratory organs and other sites, which indicate that the rate of increase in mortality from cancer of the respiratory organs is significantly higher than that for other sites.

A certain contribution was made by demographic factors of the population's aging, particularly for females in rural areas, age 60 and older, for whom the established mortality rate increased 12.5 times from 1970 to 1986, while for rural males of the same age group it dropped by $3 \%$.

In comparison with other areas and the Far East as a whole, the general mortality index is lower in the Magadan oblast. Thus, constantly increasing environmental pollution (atmospheric air) and demographic processes (changes in migration patterns and the age and sex distribution of the population, particularly in rural areas), contribute to present-day trends in mortality from malignant tumors in the Magadan oblast.

Comprehensive socio-ecological studies evaluating the effect of the natural and anthropogenically modified environment on the health of the population in Magadan indicated that anthropogenic and technogenic factors do affect the hygienic and health 
indicators, mainly due to the condition of air in the atmosphere. The environmental effects are related to climatic factors as well as to the quality of drinking water. The effect of these factors on health indicators are manifested in the form of mass or sporadic morbidity with certain therapeutic and infectious diseases.

Study of the dynamics of general morbidity among adults and teenagers in Magadan indicates an unfavorable trend. Thus, the total morbidity increased by 2.2 times from 1979 to 1989, while the number of new cases increased by more than 5 times. A particularly unfavorable morbidity pattern emerged among children. From 1979 to 1989 , the total morbidity increased by almost 10 times.

Adults and teenagers show a high rate of increase in the incidence of diabetes mellitus (by 2 times), and cardiovascular diseases (by more than 3 times), etc.

The Far East is characterized by a complex ecological situation, including a radiation element, and complex medico-demographic processes. A monsoon climate combined with the conditions of an anthropogenic load causes substantial stress to the adaptation mechanisms of both indigenous and immigrant populations, resulting in high morbidity. The incidence of respiratory diseases is 429.0 per 1,000 people; diseases of the nervous system, 101.0; diseases of the digestive organs, 89.0; infectious pathology, 59.7; including $\mathbf{2 . 8}$ tuberculosis cases (for the Russian Federation the corresponding figures are 401.0; 104.0; 88.0; 52.0; and 20. .

There is a high level of traumas and poisonings; oncological morbidity is on the rise. Total mortality in the Far East is 7.8 per 1,000 (in the Russian Federation it is 10.7).

Somatic diseases were found for the first time in $20.5 \%$ of examined patients, including otorhinolaryngological diseases, $33.6 \%$; eye diseases, $66.3 \%$; neurological disorders, $51.3 \% ; 18 \%$ of workers were found unfit for work under hazardous working conditions and a change in occupation was recommended; occupational "risk groups" who needed observation and rehabilitation were identified.

Preliminary investigations made it possible to reveal disruptions in the cellular link of immunological reactivity not only in the sick, but also in individuals who consider themselves to be practically healthy, although affected by the ecological factors under study. This group retains the phagocytic reserve, but the phagocytic activity of neutrophils is reduced, and the proportion of individuals with critical deviations in the Tlymphocyte count increased, which made it possible to include them in the risk group for the development of immunodeficiency.

Individuals who arrived from other regions of this country (Siberia, the Urals, the European region) have a higher level of humoral indices such as natural antibodies, blood serum lysozyme, or serum immunoglobulins of classes A,M,C. The results indicate 
a greater strain on the functioning of the migrants' immune systems in the Far East, accompanied by changes in the state of biological cell membranes in terms of the POL and AOS characteristics. Migrants who arrived from "cold" climatic geographical regions have a higher level of MDA and lower glutathionereductase activity. After five months in a new environment, both groups develop the same level of MDA in erythrocytes, common, free and bound $\mathrm{H}$-groups, reduced glutathione and glutathionereductase. The general mechanism of human adaptation was found regardless of the direction of migration. Also found were specific changes in adaptation and re-adaptation processes, which consist of changes in interhemispheric neurodynamics and ensure new (and improved) methods of perceiving and processing information. It was shown that the process of adaptation upon arriving to the West is more prolorged, but it is more accelerated in the re-adaptation period; psychiatric adaptation to sea voyages lasting two or three years takes less time to develop in individuals who are permanent or long-term residents in the maritime area, regardless of their individual and typological peculiarities. The respiratory system and the mental health are at the greatest risk in seamen coning from different parts of this country. The disruption of the social and the psychological adaptation observed between voyages results in alcoholism in seamen with a prevalence of socially determined, submissive and pseudocultural motivations, and also motivations to search for new stimulations.

Prospective investigation of migrant and indigenous populations of Chukotka revealed that an average of 5 years after the primary screening, the incidence of hypertension increases in the migrant population (males aged 30-59 years) with the length of stay in the North and with age, with serious forms of hypertension accounting for most of the increase. An increase in the number of new cases of hypertension is reliably higher than in lower latitudes: $13 \%$ in Chukotka and $6 \%$ in Moscow.

The incidence of borderline hypertension among the migrant population after the second screening was $24.4 \%$, twice as high as the CIS [Commonwealth of Independent States] average. Among the patients with borderline hypertension, individuals with the diastolic variant of borderline hypertension predominate, which is prognostically unfavorable in terms of the risk of complications of cardiovascular diseases (strokes and infarctions).

An in-depth examination of indigenous inhabitants of Chukotka indicated that among those who during the primary examination were diagnosed with angina on the basis of the standard WHO questionnaire, the diagnosis was confirmed in only half of the cases. In those diagnosed with angina for the second time, a true ischemic cardiac disease was found only in one third of the cases, and the others had noncoronary diseases.

As a result of prospective studies in Chukotka it was found that more than $50 \%$ of migrant males have hypertension, and the incidence of hypertension increases reliably the longer they stay in the North. Among the indigenous population, an increase in new 
cases of hypertension is significantly higher than in middle latitudes. The incidence of rheumatism among indigenous persons is statistically higher than in other regions of the country (4.6\% in males and $5 \%$ in females). Deforming arthritis was found in $38 \%$ of the males and $23 \%$ of the females. A considerable proportion of indigenous females suffered from anemia (10.4\%) and iron deficiency (35.5\%).

It was shown that in the absence of such risk factors as hypertension, atherogenic lipid profiles, etc., which are so common among migrant and European populations, angina stress can be found in indigenous Chukotkans with the same frequency as in the Novosibirsk population, cicatricial changes in the myocardium as revealed by EKG are 1.5 times more frequent, and the frequency of myocardial hypertrophies is high.

It was found that in this case the risk factor is an excess of polyunsaturated fatty acids $\Omega-3$, in the diet of the Chukotka indigenous inhabitants, which have a toxic effect on the myocardium.

The composition and the ratio of polyunsaturated fatty acids of different families in the lipids of erythrocyte membranes were determined in tundra and littoral inhabitants of Chukotka with different dietary habits. 


\section{THE STATE OF PUBLIC HEALTH IN THE REPUBLIC OF SAKHA} (YAKUTLA)

\section{B.A. Yegorov Minister}

The extreme condition of an area depends on many environmental factors, above all on climatic conditions. In this respect, the medico-geographical zones of Yakutia are a typical example of a naturally extreme zone. The severity of Yakutia's climate is determined mainly by an unusually long and harsh winter with very low temperatures, a short and cold summer, sharp disruptions of ordinary photoperiodicity, sharp differentials of atmospheric pressure and temperature, strong and frequent winds, magnetic disturbances, an arid and monotonous landscape, scarce flora and fauna, and certain other factors.

It is perfectly natural that the extreme condition of medico-geographical areas in Yakutia can be caused not only by climatic, but also biochemical and biotic factors. Add to this the possible adverse effects of a number of social factors on an individual arriving from moderate latitudes, such as a territorial remoteness from home, family, and loved ones, from centers of industry and culture, transportation problems, specific aspects of diet, work and rest, etc.

Life under Yakutia's severe conditions is accompanied by an increase in functional stresses on the body, creating a serious risk of the disruption or loss of health.

The criteria of public health reflect the extent of social and biological adaptation to a whole set of climatological, geographic, social, domestic and production factors of the Far North. The extent of the extreme condition of the Yakut region of the country is determined by the magnitude of the biosocial cost associated with achieving the degree of adaptation of the population in this zone.

At the present time, it seems quite obvious that the strategy and tactics of public health and the corresponding development of medical science must take into account the entire gamut of specific climatic and geographical features of Yakutia. The development of production in the Yakut Republic is accompanied by a rapid increase in migrant population in the harshest areas of Yakutia, and therefore the level of health in Yakutia appears to be factor limiting the growth of labor productivity.

Local public health bodies and Northern folk medicine play an important role in retaining, consolidating, and fully utilizing the labor force.

The turnover of specialists in the public health system is a striking example of this situation. Thus, as of December 1, 1991552 physicians and 1,156 paramedical personnel 
were added to the practical public health system of Yakutia, but 754 physicians and 1762 paramedical personnel departed the system.

This explains why the Yakut Republic of Sakha (Yakutia) has 3,894 doctors and 11,467 paramedical personnel i.e. $70.9 \%$ and $84.5 \%$, respectively, of the authorized positions in its public health system.

It must be noted that during the last few decades the country as a whole has arrived at a very critical situation in the training of specialists, especially in the area of public health. This is also true for our republic. Evidence of this is provided by the fact that physicians in the highest skill category make up only $5.3 \%$ of the total number of physicians working in therapeutic and preventive care institutions of the republic, physicians of skill category I make up $10.0 \%$, and those in skill category II make up $5.8 \%$. In other words, $\mathbf{7 8 . 9 \%}$ of physicians in the public health system do not qualify for any skill categories.

In this regard we are planning to develop a program for training public health personnel and instructors for the purpose of maintaining the appropriate level of skills and upgrading them in accordance with the requirements of the national strategy of providing health care for everybody. Thus, the Yakut Republic requests the WHO to provide assistance in training management personnel in the public health system.

At present, therapeutic work in northern regions of this country is conducted without adequate regard for the specific northern conditions through poorly equipped and poorly staffed therapeutic and preventive care institutions. Investigation of the nosological pattern of Yakutia and the specific background against which diseases occur, indicates that the gigantic, extreme, natural region of Yakutia is characterized not only by various forms of cryopathology, infections and parasitoses, diseases of the cardiovascular, pulmonary, digestive and nervous systems, but also by pathological processes connected with biochemical factors. Conditions of hypofluorosis, hypoiodism and iron deficiency are very common in Yakutia. While the entire picture of their clinical manifestations has yet to be investigated, they cannot be merely reduced to caries, endemic goiter and the so-called polar anemias.

No less important are various forms of pathology caused by an imbalance of the quality in the diet, especially among children (mono- and polyhypovitaminoses, hypoproteinoses, underestimation of the importance of various lipids, and the prevalence of canned food in the diet).

A special place in the nosological picture of Yakutia is occupied by the regional pathology: Vilyuy encephalomyelitis, cancer of the esophagus, tuberculosis, ischemic cardiac disease, and hypertension. Yakutia has the world's only natural focus of Vilyuy encephalomyelitis of unknown etiology. It is a very serious inflammatory degenerative disease of the nervous system found in many agricultural areas of Yakutia. Vilyuy 
encephalomyelitis affects only individuals representative of the northern peoples, Yakuts and Evenki.

Many scientists believe that Vilyuy encephalomyelitis probably belongs to the class of slow neuroinfections. Such diseases, which appear to have many features in common with Vilyuy encephalomyelitis (VE), used to be very common on the Kii Peninsula (Japan), in the Mariana Islands and in the southwestern part of New Guinea; they were known as kuru, BAS and Parkinsonism with dementia.

Considering the lack of study of the etiology and pathogenesis of VE and the absence of means of specific treatment, prevention and laboratory diagnostics, an attempt is being made to conduct in-depth basic research on a qualitatively new level to determine the nature of VE.

The Republic of Sakha (Yakutia) requ sts the expert committee of the WHO for assistance with modern equipment for research on the VE problem. We have prepared a reference document on Vilyuy encephalomyelitis for the WHO.

The incidence of infectious diseases in Yakutia is caused not only by a decrease in natural immunity, but to a greater extent by special factors (unsatisfactory conditions of the water supply and poor quality of drinking water). Over the past five years, even tap water was substandard with bacterial criteria from $12.8 \%$ to $19.6 \%$. In settlements with no running water, where water from open bodies of water is used, from $52.4 \%$ to $40.4 \%$ of the water was substandard according to bacterial tests.

Figure 1 shows the level of morbidity from intestinal infection, viral hepatitis and tuberculosis. These data indicate an unfavorable epidemiological situation in the republic. Proactive public health care can alleviate the severity of this problem by carrying out a comprehensive program of preventive measures, including widespread immunization of the population. We are receiving synthetic agents for increasing the indices of immune homeostasis of the northerners.

More than $60 \%$ of Yakutia's population suffer from inflammatory diseases of the upper respiratory tract. Otorhinolaryngological pathology is found 1.5-2 times more frequently in the migrant population and 10-15 times more frequently in the indigenous population than in the population of central Russia. The specific characteristics of eye pathology in the indigenous population were established. A number of symptoms were revealed that characterize a genotypic variety of small ethnic groups and have pathogenetic importance for the development of chronic pathology. There is a tendency for diseases to become chronic against the background of explicit immunodeficiency and toward a decrease in the nonspecific resistance of the whole organism.

The demographic indices for Yakutia are presented against this background (Figure 2). In the hierarchy of causes of mortality, first place belongs to diseases of 
organs of the blood circulatory system (in 1980, 268.5; in 1990, 231.3 per 100,000 people). It should be mentioned that mortality from ischemic cardiac disease is 324.5 per 100,000 people, which places Yakutia third in the CIS after Latvia (520.2) and Estonia (492.8). Accidents and traumas take second place in the general hierarchy of mortality (in 1980, 251.7 ; in $1990,166.3$ per 100,000 people), malignant tumors are in third place (in 1980, 101.8 ; in 1990, 121.9 per 100,000 people), respiratory diseases are in fourth place (in $1980,98.5$; in 1990, 41.2 per 100,000 people), and in fifth place are diseases of the digestive organs (in 1980, 31.3; in 1990, 26.4 per 100,000 people). The state of children's health in the Republic of Sakha (Yakutia) is indicated by the indices of mortality among children (Figure 2). The high mortality rate of children is caused mainly by many social factors, not to mention purely medical problems of public health.

Currently in this republic, the number of hospital beds for children lags behind the increase in their population. As a result, the availability of children's hospital beds (75.7) is less than that in the Russian Federati in (92.2). Altogether the republic has 16,581 beds, including 1,521 allocated for pediatric patients $(9.1 \%)$.

In the hierarchy of causes of infant mortality, diseases of the perinatal period are in first place (49\%), and mortality from these causes increases consistently. In second place are congenital anomalies and deformities $-23.6 \%$. One in two children who passed on during the first year of life in 1991 died from diseases of the perinatal period, one in four died from congenital anomalies and developmental malformations.

Congenital respiratory diseases are in third place (10.0\%), and mortality from respiratory disorders shows a consistently declining trend.

The high level and increase of perinatal affliction (every second child) is mainly due to the unfavorable state of the health of pregnant women and poor prenatal fetus protection, which includes low-quality monitoring of pregnancies with an increased risk for the fetus, untimely diagnostics of extragenital hypoxia of the fetus, and lack of prevention of the latter.

A $12.3 \%$ increase in infant mortality in the neonatal period $(11.1 \%$ in the Russian Federation) indicates poor therapeutic and preventive care in maternity institutions, and absence of second-stage care for premature infants. Every year, more than 1,000 infants are born prematurely, and no specialized help is given to them.

In the hierarchy of causes of infant mortality during the neonatal period, congenital anomalies and deformities are in first place (29.6\%), atelectases in second (28.9\%), and birth injuries in third (17.3\%).

The poor protection of children's health in the republic is related mainly to the low level of development of health care institutions in rural areas. The central, rayon, and local hospitals in rural areas are very poorly equipped. Out of 862 health care facilities, $77.3 \%$ (662 facilities) are buildings adapted for medical use. The average area 
per bed in obstetric and children's departments is from 2.5 to 4 square meters, while the standard requirement is $7-10$ meters. Of the total number of medical facilities, $24.5 \%$ have furnace heating, $66 \%$ of medical facilities have no hot water and depend on trucked water. Over $70 \%$ of hospitals have no indoor plumbing. Running water exists in $53.8 \%$ of central and rayon hospitals, and $18 \%$ of central and rayon hospitals depend on trucked water.

In recent years the birth rate in the republic has decreased significantly (Figure 2). As for the life expectancy of the northerners, it is connected directly not only with the medico-biological problem, but also with many social and hygienic problems of health protection of the northern peoples.

Life expectancy figures for northerners are given in Figure 3. During the last 30 years, the life expectancy of northerners has been significantly below that of the Russian Federation. This is particularly true for small sthnic groups living in Yakutia.

In our opinion the concept of the demographic development of the northern peoples should contain the requirements needed to implement a transition to an intensive type of reproduction of the population:

1. Increasing the average life expectancy of northern peoples.

2. Stabilizing a high birth rate.

3. Reducing infant mortality.

4. Reducing mortality in the working-age population, particularly from exogenous causes, and also in the elderly population.

The demographic policy of the government and the regional demographic policy in areas populated by northern peoples must help to solve these problems.

Medical care is provided by 8 central hospitals ( 411 beds), 29 rayon hospitals ( 450 beds), 5 outpatient clinics, 28 paramedical midwife stations, and paramedical stations.

Of the rayon hospitals, approximately $60 \%$ were built during $1930-1950$ and their degree of dilapidation is from $40 \%$ to $100 \%$. All these medical institutions are located in converted buildings.

In 1991, the general morbidity of the adult population was 714.7 per 100,000 . In the hierarchy of morbidity, the dominant components are common colds and diseases of the female organs, $29.0 \%$; complications in pregnancy and delivery, $18.9 \%$;

gastrointestinal diseases, kidney diseases, and dental caries. The infant mortality index in 1990 was $45.0 \%$. 
Protection and improvement of the health status of peoples of the Republic of Sakha (Yakutia) depend on solving many fundamental problems:

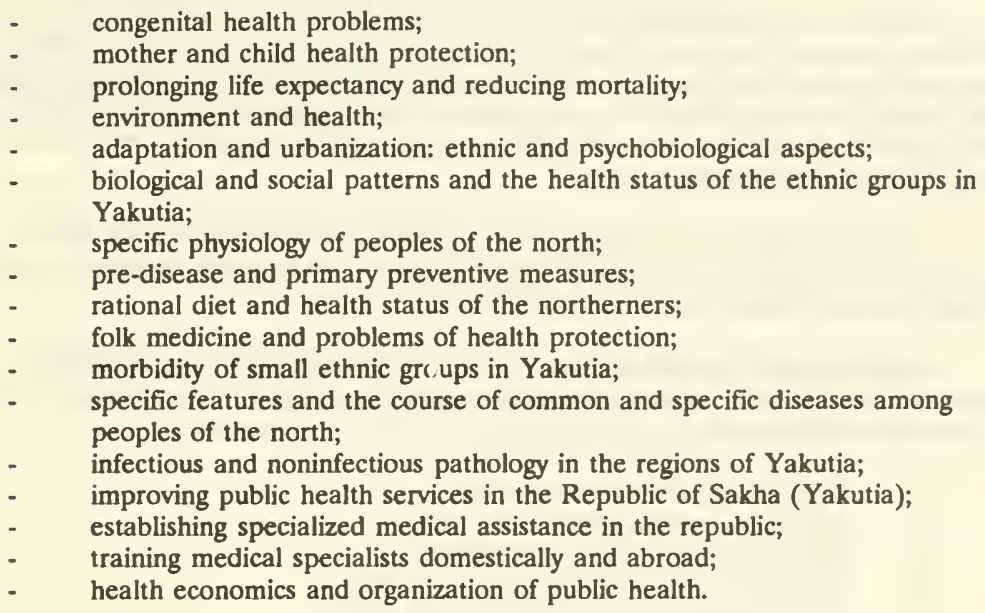

Solving these problems requires further development of medical science in the Republic of Sakha (Yakutia).

Medical science in the republic is represented by minor scientific subdivisions of federal and departmental organizations:

The Yakut Branch of the Scientific Industrial Association and Phthisiopulmonology of the Moscow Institute of Tuberculosis of the Ministry of Public Health of the Russian Federation;

Laboratory of Morphofunctional Research of the Institute of Medical Problems of the North of the Siberian Branch of the Academy of Medical Sciences of the Russian Federation;

- Sector of Medical Ecology of the Yakut Scientific Center of the Siberian Branch of the Russian Academy of Sciences;

Medical sector of the Institute of Problems of Small Ethnic Groups of the North of the Yakut Scientific Center of the Siberian Branch of the Russian Academy of Sciences. 
In addition, there is the Medical Therapeutic Department of the Yakut State University which is involved mainly in applied scientific problems.

Because these subdivisions are poorly equipped and hence have low scientific potential, however, they are not capable of maintaining long-term scientific relations with major science centers in Russia and abroad on an equal basis. This was the reason that this republic has been utilized for a long time as a data-gathering scientific base for other scientific medical institutions of this country, while the Republic's public health system has received nothing in return.

This compelled the leadership of the Republic to accept the decision by the President of the Republic of Sakha (Yakutia) to create the National Institute of Health of the Peoples of Yakutia on the basis of these subdivisions.

The Working Commission on setting up such an Institute has suggested the following basic scientific sectors, taking into account priorities in the public health needs of the republic (Figure 3):

1. Ecological problems of medicine.

2. Ecological pathology of tuberculosis.

3. Biology of Vilyuy encephalomyelitis.

4. Health and regional public health economics.

5. Folk medicine of the peoples of Yakutia. 
USSR MINISTRY OF GEOLOGY

YAKUT PRODUCTION GEOLOGICAL ASSOCIATION

"RADON" RADIATION ECOLOGY CO-OPERATIVE

\section{REPCRT}

ON THE RESULTS OF STUDYING THE EFFECT OF UNDERGROUND NUCLEAR EXPLOSIONS ON THE RADIATION SITUATION IN THE MIRNY RAYON OF THE YAKUT-SAKHA SSR

City of Yakutsk

1990 


\section{RESULTS OF WORK}

The form of the presentation of this section was motivated by the authors' intention to preserve the authenticity of the following materials and methods.

The procedure and the results of the airborne gamma-spectrometric survey that are needed for understanding the text are given here in a very condensed form, because they are set forth in detail in the airborne geophysical team's reports.

\subsection{Airborne Geophysical Work}

In June and August of 1990 , the airborne geophysical team of the Central prospecting survey expedition of the Production Geological Association Yakutskgeologiya conducted an airborne gamma-spectrometric survey on the sites "Taas-Yuryakh", "Aykhal". and "Udachny". The sul vey was performed with an airborne geophysical station SKAT77 mounted on an AN-2 aircraft. The courses, plotted in accordance with a survey scale of 1:25,000 over $250 \mathrm{~m}$ and $1: 10,000$ over $100 \mathrm{~m}$, were tied in by aerial photographic referencing using an AFA-17 aerial camera. Flight altitude was maintained within the range of 50-75 meters above the surface. From the results of these aerial operations gamma field maps were made of the "Taas-Yuryakh" and "Aykhal" sites with a scale of $1: 25,000$ and of the "Udachny" site on a scale of 1:10,000, which characterize the general radiation background above said sites and the distribution of radioactivity over them.

The "Taas-Yuryakh" site, The survey was performed on three separate sectors No. 1, 2, and 3 (Figure 2).

On the map of the gamma field of sector No. 1, the isolines are drawn every 2 $\mu \mathrm{r} / \mathrm{hr}$. The maximum activity of the gamma field, which does not exceed $18 \mu \mathrm{r} / \mathrm{hr}$, is observed only at the southernmost boundary of the sector, and the main portion of the sector, including the town Taas-Yuryakh itself, is characterized by gamma activity levels no greater than $12 \mu \mathrm{r} / \mathrm{hr}$. To understand the nature of the high (up to $18 \mu \mathrm{r} / \mathrm{hr}$ ) gamma activity, detailed surface operations are required involving soil, vegetation and water sampling. The nature of the gamma field in the area of well No. 47, the site of an underground nuclear explosion, is shown in Figure 3. A radioactive contamination spot revealed by surface operations was not recorded by airborne gammaspectrometry, which can be explained by low radioactivity.

On the map of the gamma field of sector No. 2, the isolines are drawn every 5 $\mu \mathrm{r} / \mathrm{hr}$. In general, sector No. 2 is characterized by the background value of the gamma field, and only in certain areas of the Telgespit River valley and in the central part of the area are values up to $20 \mu \mathrm{r} / \mathrm{hr}$ reached. In order to understand the nature of these "spots", a complex of surface operations has to be conducted. In this sector four underground nuclear explosions were conducted. The nature of the gamma field above the wells is normal (Figures 4, 5). 
On the map of the gamma field of sector No. 3, the isolines were also drawn every $5 \mu \mathrm{r} / \mathrm{hr}$. The sector is characterized by a background gamma activity of no higher than $15 \mu \mathrm{r} / \mathrm{hr}$. In this sector two underground nuclear explosions were conducted. The nature of the gamma field above the wells is normal (Figures 6, 7).

The "Avkhal" site. The survey of this sector entailed a series of surface operations (Figure 8).

An airborne geophysical survey confirmed the presence of radioactive contamination $3,250 \mathrm{~m}$ south-southwest from the mouth of the River Chukuka, the left tributary of the River Markha. The sector with radioactivity of higher than $10 \mu \mathrm{r} / \mathrm{hr}$ is 1 $\times 3.75 \mathrm{~km}$ in size and extends in a northeasterly direction (Figure 9). The highest radioactivity of up to $70 \mu \mathrm{r} / \mathrm{hr}$ was registered in the southwestern part of the contaminated sector. Since the nature of radioactivity of this sector was established unambiguously by the surface operations, including that in the mouth of the River Chukuka where gamma field radioactivity is slightly higher than $5 \mu \mathrm{r} / \mathrm{hr}$, surface operations should be conducted in this area for determining the nature of other "spots" with radioactivity over $5 \mu \mathrm{r} / \mathrm{hr}$, and also aerial operations should be expanded for detecting similar "spots" in adjacent areas.

The "Udachno" site. In August of 1990 an airborne gamma-spectrometric survey on the scale of 1:10,000 was conducted on the left bank of the Daldyn (Figure 10). On the gamma field map, the site of the explosion and traces of the discharge are fixed by the $10 \mu \mathrm{r} / \mathrm{hr}$ isogamma; the maximum values in the epicenter reach $25 \mu \mathrm{r} / \mathrm{hr}$ (Figure 11). In addition to the map of the gamma field, we present a copy from the map of uranium concentrations (Figure 12) which indicates that the site of the nuclear explosion was also recorded in the uranium channel.

\subsection{Surthce Dosimetric and Radiometric Operntions}

Surface operations were planned, taking into account the data obtained from an advance airborne gamma-spectrometric survey, in sectors with increased levels of radioactivity that were not clearly related to the sites of underground nuclear explosions by the method of landing an "assault team", conducting measurements and sampling soil and water, in sectors where radioactive contamination was detected, detailed operations were carried out on a scale determined by the dimensions of the object detected.

For performing these tasks the team was equipped with a sufficient number of radiometers and dosimeters: 6 SRP-68-01, 1 DRG-01T, 1 DKS-04, 1 DP-5, 1 IMD-12, 2 RSP-10IM Poisk-Pripyat with gamma and beta detectors, 1 RKB4-IeM. All of these instruments were tested metrologically in 1989-1990.

In the course of carrying out the planned program of operations, the inadequacy of the "assault team" technique immediately became obvious: the time limitation when 
the helicopter waits with its engines running prevents investigating an adequately representative area around the shaft in which the first nuclear explosion was conducted (shaft No. 61), not to mention the increased levels of gamma radiation recorded by airborne gamma-spectrometric survey in marshy river floodplanes, where only a few measurements and random sampling could be made (sector No. 2 of the airborne gamma-spectrometric survey, the Telgespit River valley).

As a result, in the sector "Neva-3" one profile was made through shaft No. 61,400 $\mathrm{m}$ long with azimuth $20^{\circ}$ (fixed measurements at $20 \mathrm{~m}$ intervals, gamma radiation values from 8 to $12 \mu \mathrm{r} / \mathrm{hr}$ and beta radiation values of 1 to 4 particles $/ \mathrm{min} . \mathrm{cm}^{2}$ ). During three landings in the Telgespit River valley, 7-11 $\mu \mathrm{r} / \mathrm{hr}$ and $2-4$ beta-particles/min.cm ${ }^{2}$ were recorded within the boundaries of the gamma fields from the data of the airborne gamma-spectrometric survey with an intensity of up to $20 \mu \mathrm{r} / \mathrm{hr}$ (in each case, one 100120 meter long profile was passed).

The "Taas-Yuryakh" site, (town of Taas-Yuryakh, shaft No. 47).

The shaft is located $7 \mathrm{~km}$ from the town Taas-Yuryakh up the Taas-Yuryakh River on its right bank. According to the information provided by the Production Geological Association Lenaneftegazgeologiya, an underground nuclear explosion was conducted in shaft No. 47 in 1979. There is a sign at the shaft mouth saying "Shaft No. 47, started July 1981, completed February 1986." There is no clear reason for this discrepancy.

The sector was not investigated in detail, the trunk line $(800 \mathrm{~m})$ ran through shafts No. 47 and No. 55 (located $100 \mathrm{~m}$ at azimuth $50^{\circ}$, started October 1981, completed January 1986), three profiles at 100 meter intervals, $280 \mathrm{~m}$ long, and a route along the river bank. The natural rock gamma background was 9-11 $\mu \mathrm{r} / \mathrm{hr}$.

A spot of radioactive contamination was found $100 \mathrm{~m}$ from shaft No. 47 at azimuth $315^{\circ}$ with an intensity of gamma radiation on the surface of $113 \mu \mathrm{r} / \mathrm{hr}$ against the background of $11 \mu \mathrm{r} / \mathrm{hr}$ and a beta radiation flux of 22 particles $/ \mathrm{cm}^{2} \mathrm{~min}$ against the background of 2-4 particles $/ \mathrm{cm}^{2}$ min. During detailed study of a $50 \times 50 \mathrm{~m}$ square area at a scale of 1:500, a maximum radioactivity of $230 \mu \mathrm{r} / \mathrm{hr}$ was recorded (on the surface) [illegible] $\mu \mathrm{r} / \mathrm{hr}$ as well as the 33 particles $/ \mathrm{cm}^{2}$ min flux of beta radiation against the background of 6 particles/ $\mathrm{cm}^{2} \min$ (Figure 13).

Gamma radiation was caused by cesium-137, the spectrum of which was read out by RSI-101M (Figure 11).

Soil sample No. $47 / 1$ was taken from a point with maximum activity. On the outline of the spot $(98 \mu \mathrm{r} / \mathrm{hr})$, in a $0.5-\mathrm{m}$ deep bore hole, two samples were taken from the surface of No. $47 / 2$ and at a depth of $0.5 \mathrm{~m}$ in No. 47/3. The total beta activity of the samples was $148.3,32.4$ and $16.4 \times 10^{-12} \mathrm{Ci} / \mathrm{g}$, respectively, which permits the conclusion that the contamination did not go far below the surface. 
Along with the investigation of the explosion sites, radiometric investigations were conducted on food products and drinking water (the total beta activity was measured with RKB4-IeM by V.I. Cherepanov, the senior engineer of the Department of Radiation Hygiene of the Republic [illegible]. During these investigations concern was aroused by analyses of drinking water from water intakes in the Taas-Yuryakh and UlakhanBotuobuy Rivers, which indicated 2.3 and $3.3 \cdot 10^{-10} \mathrm{Ci} /$ (as a rule, the total beta activity of drinking water in Yakutia is below the sensitivity level of the RKB4-IeM).

The results of the analyses were repeated again on June 27, 1990 in the town of Mirny, which was the reason why part of the group (A.G. Tsyganov, V.I. Cherepanov, V.A. Danilov) returned after completing the planned operations in the town of TaasYuryakh to meticulously test the water in the Taas-Yuryakh and Ulakhan-Botuobuy Rivers. Sampling was conducted on July 7, 1990, i.e. two weeks later. Four samples were taken from the Taas-Yuryakh River, from the site of explosion to the town at 1.5 $\mathrm{km}$ intervals, and five samples at the same intcrvals from the Ulakhan-Botuobuy River. The results of the analysis indicated total beta activity below the sensitivity of the RKB4 IeM. As we have mentioned above, some of the operations, i.e. testing, were duplicated by utilizing several methods of testing and analysis. In this case, on July 26,1990 Yakutgidromet representative $\mathrm{Zh}$.L. Dokhturov took a large sample of 20 liters from the Ulakhan-Botuobuy River, and used the method of concentration of radioactive strontium by sorption on ion-exchange resins. The analysis of this sample performed at the PUGMS of the city of Vladivostok showed $13.2 \mathrm{~Bq} / \mathrm{m}^{3}$. For comparison, a similar sample from the Markha River $1 \mathrm{~km}$ upstream from the site of discharge of a nuclear explosion (Kraton-3), showed $3.2 \mathrm{~Bq} / \mathrm{m}^{3}$.

There are six underground nuclear explosion sites in the Ulakhan-Botuobuy River valley, situated above the site of sampling and in close proximity to shaft No. 47 . Hence the need for systematic monitoring of the water, a very detailed investigation of all explosion sites and possibly a more in-depth examination of the entire problem than the present concept, including: explosions, tectonics, permafrost, etc.

The natural gamma background around the site of underground explosions (19761987) was investigated during a radiometric survey in 1972-1976 carried out by the Botuobury expedition (Report on a geological survey on a scale of $1: 200,000$ in the territory in sheets R-49-XXI, XXII, XXIII, XXIV, XXVIII, and XXIX, from work performed by the Taas-Yuryakh team, I.N. Antipin et al., Mirny, 1977, YATGF, inventory No. 13134). These operations included a radiometric survey on a scale of $1: 200,000$ over $22,885 \mathrm{~km}^{2}$; additional investigation, $979 \mathrm{~km}^{2}$; gamma profiling of the bore holes, 4,475.6 linear meters; trenches, $636.8 \mathrm{~m}^{3}$; gamma logging, 661.1 linear meters; core listening with UPB-25, 1010.6 linear meters. Rock radioactivity: quaternary deposits (loams, sand, clay, pebbles) $-4-10 \mu \mathrm{r} / \mathrm{hr}$, dolerites $-46 \mu \mathrm{r} / \mathrm{hr}$, marine deposits of the Toar and Pliensbachian stages - 4-8 $\mu \mathrm{r} / \mathrm{hr}$, tuffs - $8-10 \mu \mathrm{r} / \mathrm{hr}$. The series of Ukugut, Irelyakh, Ilga and Upper Lena, as well Middle Paleozoic and Ordovician deposits 
displayed a relatively high radioactivity of $10-15 \mu \mathrm{r} / \mathrm{hr}$. Around the site of explosions the natural gamma background of rocks does not exceed $14 \mu \mathrm{r} / \mathrm{hr}$.

We present these data as a basis for further investigation of the radiation situation at sites of underground nuclear explosions, so as to identify radioactive contamination spots against this background.

The Udachny site. It was not included in the plan of operations due to lack of information available to the Coordinating Council on the nuclear explosion conducted there. According to the information obtained from the executive committee of the city council and the sanitation and epidemiology station of the city of Udachny, an underground (near-surface) nuclear explosion was conducted $2.5 \mathrm{~km}$ northeast of the town of Udachny in 1974 for the construction of a water reservoir dam. A powerful outburst was observed by witnesses.

The radioactivity at the site of the explosion was 50-65 $\mu \mathrm{r} / \mathrm{hr}$ on the surface, and up to $200 \mu \mathrm{r} / \mathrm{hr}$ at a depth of $0.4 \mathrm{~m}$ in the excavation.

The results of our investigation are set forth in a document attached to this report (see Appendix No. 5).

According to data from the airborne gamma-spectrometric survey conducted last August, radioactive contamination was recorded both above the explosion crater and in the cloud traces (Figure 11).

In the future, the area of airborne gamma-spectrometric survey must be extended for monitoring the cloud traces, and detailed surface operations must be conducted at the site of the explosion and contamination spots. The fact that radioactive contamination was recorded in the uranium channel during the airborne gammaspectrometric survey (Figure 12) also requires explanation.

\section{The Aykhal site (Kraton-3).}

The natural gamma background of the territory was studied during large-scale prospecting for uranium by the geologists of the Amakinsk expedition in 1971-1973 (M.V. Gavrilyuk et al. Report on the Work of the Khalamanit Team for 1971-1973. Materials for the state geological map, 1:50,000 scale, sheets 0-49-81-Б, $\Gamma$ and 0-49-82A,Б,B. Nyurba, 1973). The radiometric survey on a scale of $1: 50,000$ was made over an area of $1,061.7 \mathrm{~km}^{2}$ with SIT-2 radiometers; gamma profiling of a bore hole 1,323 linear meters deep and $801.8 \mathrm{~m}^{3}$ of trenches was performed.

Procedure: Large-scale uranium prospecting was conducted simultaneously with geological mapping. It involved continuous listening through a telephone with measurements made after each $50 \mathrm{~m}$ and regardless of the interval when the rock 
changed. Bedrocks were studied from profiles with measurements after each $1 \mathrm{~m}$, the profiles were not less than every $10 \mathrm{~m}$.

Prior to the beginning of operations, all instruments were adjusted using an aqueous-radium mode!. Field calibration and adjustment by the aqueous-radium model were conducted at least once a month.

Conclusion: the rock making up this territory has a radioactivity of $4-7 \mu \mathrm{r} / \mathrm{hr}$, seldom up to $14 \mu \mathrm{r} / \mathrm{hr}$ (zones of fractures), and in just one case, the radioactivity of Permian sandstone was determined to be $25 \mu \mathrm{r} / \mathrm{hr}$ (the so-called 946).

Upper Cambrian rock is found only in the valleys of the Rivers Markha and Kuchuguy-Taanaakh. Limestone, dolomites with layers and lenses of calcareous aleurolites, marls, calcareous small pebbled conglomerate, and algal limestone were found.

Lower Ordovician deposits were the most common and found throughout the entire area studied. They are represented by dolomites, limestone, oolitic sandstone and limestone, algal dolomites, and plane pebble conglomerates.

Carbonate deposits are characterized by a quiet gamma field with fluctuations of gamma activity from 4 to $7 \mu \mathrm{r} / \mathrm{hr}$, in some cases, over fracture sections, up to $9-12 \mu \mathrm{r} / \mathrm{hr}$.

Permian deposits are characterized by a wide variety of lithologic variations: sandstone, aleurolites, gravelites, arlillites, carbonaceous shales, sand, tuff sandstone; radioactivity $8-14 \mu \mathrm{r} / \mathrm{hr}$. In a single case, on the northern slope of the brooks Baziony and Trekhglavy, up to $25 \mu \mathrm{r} / \mathrm{hr}$ was detected in sandstone.

The pearl-luminescent analysis of 4 X samples yielded $0.00042,0.00025,0.0001$, and $0.00005 \%$ for uranium. $\boldsymbol{\mu r} / \mathrm{hr}$.

Dolerites covering significant areas of the territory studied registered from 4 to 5

Rock radioactivity over exposed sectors:

1. Limestone and dolomites

$\mu \mathrm{r} / \mathrm{hr}$

Number of

2. Dolerites

3. Permian deposits

4. Quaternary deposits

5. Zones of fractures in carbonate mass

4-7 198

4-5 $\quad 512$

8-14 75

6-8 94

$9-12 \quad 70$

This area was rated as unpromising for finding radioactive raw materials. 
The shaft, where an underground nuclear explosion was conducted in 1978 accompanied by an accidental discharge of radioactive substances, is located on the right bank of the Markha River (120 m from the water's edge), 3,250 m upstream from the mouth of the River Chukuka.

There are no remnants of machinery and equipment in the drilling area, production facilities and living quarters were demolished, and the soil layer was plowed up by a bulldozer within the radius of the first one hundred meters. A tomb was constructed next to the shaft. An earth embankment protects the shaft mouth and the tomb on the side of the slope.

The shaft mouth is a $3 \mathrm{~m}$ high pile of earth with broken boards, pieces of cables, pipes, and pieces of concrete, topped with a cast iron sign "DANGER ZONE," which forbids earth moving and is securely fastened to a drill pipe. Radioactivity at certain points reaches $740 \mu \mathrm{r} / \mathrm{hr}$.

The tomb is a rectangular flat hill, $2 \mathrm{~m}$ high measuring $10 \times 30$ and located parallel to the river bank $100 \mathrm{~m}$ from the water's edge. It is fenced by several rows of barbed wire welded to pipes which are welded into half-barrels filled with cement. The fence was destroyed by frost because the wire was too taut. Radioactivity on the surface of the tomb is $120-280$, and at some points up to $700 \mu \mathrm{r} / \mathrm{hr}$.

The embankment protecting the tomb and the shaft mouth from flood and rain water from the side of the slope is made of earth with broken boards and bushes up to 1 $\mathrm{m}$ high, and adjoins the edge of the flood plain terrace as a semi-ring $75 \mathrm{~m}$ in radius.

Up the slope from the drilling area, toward the geodetic sign "Mouth of the Chukuk", there is a strip up to several hundred meters wide and $2.5 \mathrm{~km}$ long of "dead" forest which consists of standing dead trees, bushes, grass, moss, and reindeer moss, all dead. The only green plants are single, sparse, young willow sprouts spaced 20 to 30 meters apart, $1.0-1.2 \mathrm{~m}$ high with 2-3 leaves. Radioactive background in the axial portion of the trace: $50-80 \mu \mathrm{r} / \mathrm{hr}$, on the ground surface: $100-120$, up to $150 \mu \mathrm{r} / \mathrm{hr}$.

\section{Dosimetric Measurements}

Because of the substantial length of the contamination spot within the sector investigated by airborne gamma-spectrometric survey $(5 \mathrm{~km})$, the scale of 1:25,000 of surface dosimetric operations was used. Measurements were conducted with a pitch of $20 \mathrm{~m}$ over profiles every $250 \mathrm{~m}$. The trunk line was cut along the compass traverse, profiles were passed using inclinatoriums. The minimum limitation was determined by triple repetition of the measured level of $9-10 \mu \mathrm{r} / \mathrm{hr}$. The natural background of the rock making up the area studied was $8 \mu \mathrm{r} / \mathrm{hr}$. 
A total of 12 profiles, 500 to $1,700 \mathrm{~m}$ long, were passed, and radioactive contamination was monitored for $3.0 \mathrm{~km}$ (Figure 16). The results of surface observations were practically comparable with the data from the airborne gamma-spectrometric survey.

The nature of gamma radiation from field observations was determined by the presence of cesium-137 (Figure 17,a-n).

We used the value of the background, $10 \mu \mathrm{r} / \mathrm{hr}$, as the boundary of the contamination spot, when the presence of cesium-137 against a background of $8 \mu \mathrm{r} / \mathrm{hr}$ is recorded reliably by the instrument RSP-101M "Poisk-Pripyat" (Figure 17, ג).

The density of the flux of beta particles within the contamination spot reaches 98 particles/min. $\mathrm{cm}^{2}$ at the shaft mouth and $60-90$ particles/min.cm ${ }^{2}$ along the line in the area of profiles 5 and 6 against the backgrour d of $2-4$ particles $/ \mathrm{min} . \mathrm{cm}^{2}$ beyond the boundaries of the spot (measurements were made at a distance of $10 \mathrm{~cm}$ from the surface).

The results of the measurements suggested the presence of strontium- 90 .

On the isogam of $5 \mu \mathrm{r} / \mathrm{hr}$ (Figure 8), the airborne gamma-spectrometric survey around the main trace revealed and delimited contamination spots that spanned the first few hundred meters to the first few kilometers. The nature of their distribution makes it possible to talk about a possible spread of spots over tens of kilometers. During the test, two spots were visited: the spot on the right bank of the Markha River downstream from the mouth of the Chukoka River: $12 \mu \mathrm{r} / \mathrm{hr}$ (water sampling sites S10 and S11), and the spot that is the closest to the main trace to the east: $15-17 \mu \mathrm{r} / \mathrm{hr}$ (water sampling sites $\mathrm{y}-8 \Pi$ and $\mathrm{Y}-6 \mathrm{P})$.

According to calculations performed by Lt.Col. A.I. Chomchoyev, chief of staff of the Civil Defense of the city of Yakutsk, the levels of radioactivity in the nearest trace at the time of discharge could exceed $200 \mu \mathrm{r} / \mathrm{hr}$, and the total contamination of this area at the present time is up to $3,000,000 \mathrm{~Bq} / \mathrm{kg}$ (calculations were made before the results of the analysis were received).

\section{Results of Sampling}

During field operation on the "Aykhal" site, soil, vegetation and water were tested. Testing as well as analytical operations were performed in accordance with the appropriate departmental procedures. A total of 44 soil samples, 14 vegetation samples, and 20 water samples were taken. The distribution of soil and vegetation sampling sites is given in Figure 18, and water samples are presented in Figure 19. 
The results of laboratory investigations demonstrate a direct relationship between the concentrations of cesium-137 and strontium- 90 and the strength of the exposure dose of gamma radiation (Figure 20 ).

The nature of propagation of radioactivity into depth was investigated in three bore holes 0.50-0.55 m deep; bore hole 3 - PR6.5 PK200, bore hole 4 - PR6.5 PK100, and bore hole 5 - PR6.5 PK0. The breakdown: 0.00-0.05 $\mathrm{m}$ - soil and vegetation layer, 0.05-0.16 - gray sand (only bore hole No. 3 ), $0.05-0.55(0.15-0.50 \mathrm{~m}$ in bore hole No. 3 ) yellow clay. Analyses of 6 samples from each bore hole indicate insignificant permeability of the clay; nevertheless the process of radioactivity redistribution from the surface to the interface of thawing and frozen rock was observed (Figure 21).

Analysis of the surface waters in the trace outline for total beta activity performed with the instrument RKB4-leM at a differentiated counting rate, which makes it possible to show cualitarive wal :r contamination (sarr.ple S112 - $24.6 \mathrm{~s}^{-1}, \mathrm{~S} 113-26.4 \mathrm{~s}^{-1}, \mathrm{~S} 114$ $29.9 \mathrm{~s}^{-1}, \mathrm{~S} 115-29.1 \mathrm{~s}^{-1}$, drinking water $\left.-18-20 \mathrm{~s}^{-1}\right)$, indicates values below $1 \times 10^{-10} \mathrm{Ci} /$.

The results of the analyses make it possible to conclude that radioactive contamination in the trace is of a surface nature; most radionuclides were recorded in the soil vegetation layer, except for the area near the mouth of the explosion shaft and the tomb, where radioactivity increases with depth. In the tomb zone on the surface at $140 \mu \mathrm{r} / \mathrm{hr}$, the total beta activity is $633.1 \times 10^{-12} . \mathrm{Ci} / \mathrm{g}$, at a depth of $0.5 \mathrm{~m}$, it increases to $540 \mu \mathrm{r} / \mathrm{hr}$ and $1,193.6 \times 10^{-12} \mathrm{Ci} / \mathrm{g}$.

Surface water flows do not carry any significant concentrations of radionuclides. Radionuclides enter the Markha River mainly due to mechanical runoff. 
Results of Radiometric Investigations

\begin{tabular}{|c|c|c|c|c|c|}
\hline Nos. & Designation of sample & Quan-tity & $\begin{array}{l}\text { Radioactivity } \\
\text { Ci/kg(liter) }\end{array}$ & $\begin{array}{l}\text { VDU-88 } \\
\text { Ci/kg(l) }\end{array}$ & Comment \\
\hline 1 & 2 & 3 & 4 & 5 & 6 \\
\hline
\end{tabular}

Town of Taas-Ywojalth Miny Rayon

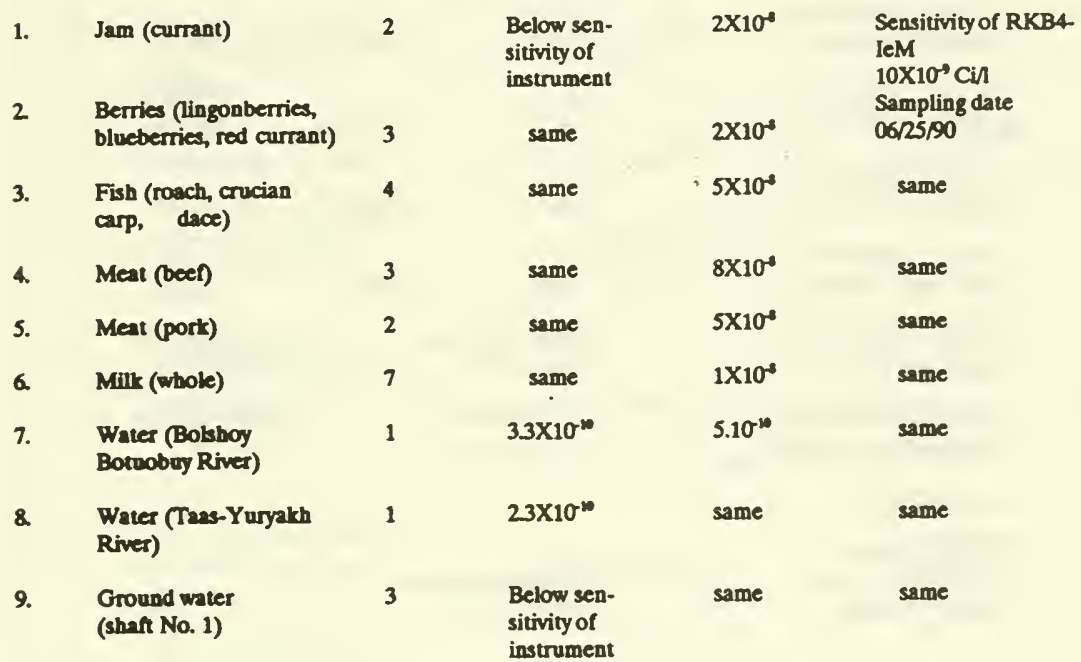

10. Drinting water (Bolshoy Botuo-buy Rtver, samples 1-5, background S $13 \mu \mathrm{r} / \mathrm{hr}$ )

same

Drinking water (Tass-

Yuryath River, samples $1-4,12 \mu \mathrm{r} / \mathrm{hr}$ )

same

same

same 


\begin{tabular}{|c|c|c|c|c|c|}
\hline 1 & 2 & 3 & 4 & 5 & 6 \\
\hline 12. & $\begin{array}{l}\text { Water (Lake Bolshoye, } \\
\text { background } 10 \mu \mathrm{r} / \mathrm{hr} \text { ) }\end{array}$ & 1 & same & same & same \\
\hline 13. & $\begin{array}{l}\text { Water (Lake Khoru-Kel, } \\
\text { background } 8 \mu \mathrm{r} / \mathrm{hr} \text { ) }\end{array}$ & 1 & same & same & same \\
\hline 14. & $\begin{array}{l}\text { Soil No. } 1 \text { (shaft No. 61, } \\
\text { background } 12 \mu \mathrm{r} / \mathrm{hr} \text { ) }\end{array}$ & 1 & same & same & same \\
\hline 15. & $\begin{array}{l}\text { Soil No. } 1 \text { (shaft No. } 47 \text {, } \\
\text { background } 25 \mu \mathrm{r} / \mathrm{hr} \text { ) }\end{array}$ & 1 & same & same & $\begin{array}{l}\text { Sampling date } \\
06 / 25 / 90\end{array}$ \\
\hline 16. & $\begin{array}{l}\text { So:I No. } 2 \text { (shaft No. } 47 \text {, } \\
\text { background } 30 \mu \mathrm{r} / \mathrm{hr} \text { ) }\end{array}$ & 1 & same & same & same \\
\hline 17. & $\begin{array}{l}\text { Soil No. } 3 \text { (shaft No. } 47 \text {, } \\
\text { background } 100 \mu r / h r \text { ) }\end{array}$ & 1 & same & same & same \\
\hline 18. & $\begin{array}{l}\text { Soil No. } 1 \text { (shaft No. } 47 \text {, } \\
\text { background } 98 \mu \mathrm{r} / \mathrm{hr} \text { ) }\end{array}$ & 1 & \multicolumn{2}{|c|}{$\begin{array}{l}4 \text { times higher than } \\
\text { background }\end{array}$} & $\begin{array}{l}\text { Sampling date } \\
07 / 07 / 90\end{array}$ \\
\hline 19. & $\begin{array}{l}\text { Soil No. } 2 \text { (shaft No. } 47 \text {, } \\
\text { background at a depth of }\end{array}$ & & \multicolumn{2}{|c|}{ Below sensitivity } & $\begin{array}{l}\text { Sampling date } \\
07 / 07 / 90\end{array}$ \\
\hline & $0.5 \mathrm{~m}-67 \mu \mathrm{r} / \mathrm{hr})$ & - & & & \\
\hline 20. & $\begin{array}{l}\text { Soil No. } 3 \text { (shaft No. } 47 \\
\text { on the surface, back- } \\
\text { ground } 239 \mu \mathrm{r} / \mathrm{hr} \text { ) }\end{array}$ & 1 & \multicolumn{2}{|c|}{$\begin{array}{l}30 \text { times higher than } \\
\text { background }\end{array}$} & same \\
\hline \multicolumn{6}{|c|}{ Town of Udachny } \\
\hline 1. & $\begin{array}{l}\text { Ground water (explosion } \\
\text { crater near Udachny) }\end{array}$ & 1 & Below se & & $\begin{array}{l}\text { Sampling date } \\
06 / 30 / 90\end{array}$ \\
\hline
\end{tabular}




\begin{tabular}{|l|l|l|l|l|l|}
\hline 1 & 2 & 3 & 4 & 5 & 6 \\
\hline
\end{tabular}

2 Drinking water (River

Ulakhan-Bysyttakh, $1 \mathrm{~km}$ from the explosion site)

same

same

3. Soil No. 1 (southern slope of the crater)

1

same

2 times higher than

background

slope, background 12 $\mu \mathrm{r} / \mathrm{hr}$ )

5. Soil No. 3 (to southeast, background $60 \mu \mathrm{r} / \mathrm{hr}$ ) background
3 times higher than the

3 times higher than the background slope $20 \mathrm{~m}$ from the ridge, background 110 $\boldsymbol{\mu r} / \mathrm{hr}$ )

7. Soil No. 5 (to northeast, $70 \mathrm{~m}$ from the ridge, background $11 \mu \mathrm{r} / \mathrm{hr}$ )

1

Below sensitivity

\section{Martha River, $60 \mathrm{~km}$ from Udachny}

1. Soil No. 1 (river sand, 1 $\mathrm{km}$ downstream from the dry brook, background $10 \mu \mathrm{r} / \mathrm{hr}$ )

Below sensitivity

2.5 times higher than background

same shaft mouth to the wesh, background $20 \mu \mathrm{r} / \mathrm{hr}$ ) same

Sampling date 07/07/90

Sampling date $06 / 30 / 90$

same 


\begin{tabular}{|l|l|l|l|l|l|}
\hline 1 & 2 & 3 & 4 & 5 & 6 \\
\hline
\end{tabular}

3. Soil No. 3 (northern sidé =of the crater, background 50 times higher than $175-220 \mu \mathrm{r} / \mathrm{hr}$ )

background same

4. Soil No. 4 (southeastern side of the crater, background $130-150$ $\mu \mathrm{r} / \mathrm{hr}$ )

1

40 times higher than background

same

5. Drinking water Markha River, samples 1-12 from the mouth of the "dry" brook at $300 \mathrm{~m}$ intervals for $3.3 \mathrm{~km}$ downstream, background $8-13 \mu \mathrm{r} / \mathrm{hr}$ )

Below sensitivity of instrument

Sampling date 07/01/90

6. Reindeer moss (site of contamination, profile 6 , background $60 \mu \mathrm{r} / \mathrm{hr}$ )

20 times higher than background

7. Reindeer moss (site of base 1 of the expedition camp, $1 \mathrm{~km}$ upstream, background $10 \mu \mathrm{r} / \mathrm{hr}$ ) same

same

\section{CONCLUSION}

1. At the sites of nuclear explosions in the Mirny district (town of Taas-Yuryakh, city of Udachny, area of the Markha River) radioactive contamination of the soil and vegetation was found ( 2.50 times higher than the radiation background).

2. The gamma background exceeds the natural values by 25 times and more.

3. The total beta activity of drinking water sources (Botuobuy River, Taas-Yuryakh River, Sytykan water reservoir, and Markha River) is lower than VDU-88 $\left(5 \times 10^{10} \mathrm{Ci} /\right)$.

\section{RECOMENDATIONS}

To improve the performance of specialists who go to areas with an unfavorable radiation situation the following is necessary:

1. Available equipment:

- surveying radiometer SRP-68-01

- RSP-101M unit

- DRG-01T dosimeter

- DKS-04 dosimeter (each specialist should have one) 
- RKB4-1eM radiometer

- RUB-01P radiometer

- RGA-01P or RAS-04P aerosol radiometer

- DK-02, IFKU, and TLD individual dosimeters

2. The optimum composition of a team is $\mathbf{4 - 6}$ specialists.

3. The table of equipment, in addition to protective clothes, sleeping items, and food, must include: bags for soil, vegetation, and other samples

- $\quad 1,10$, and 20 liter water sampling tanks. 
Institute of Biology of the Yakut Scientific Center of the Siberian Branch of the USSR Academy of Sciences

\section{Investigation of Samples of Soil and Vegetation at the Sites of Underground Nuclear Explosions in the Mirny Rayon}

From June 24 to July 7, 1990, on the instructions of the Council of Ministers of the Republic, a group of radiologists worked in the Mirny, conducting a radiation study of the towns of Taas-Yuryakh and Udachny and the surrounding areas. The Institute of Biology of the Yakut Scientific Center of the Siberian Branch of the USSR Academy of Sciences participated in this work.

Field operations employed the SRP-68-01 (No. 2141, metrology of June 1990), and RSP-101M units. Six soil samples and two vegetation samples were taken.

Sample IB-1. $200 \mathrm{~m}$ to the north-northeast from the mouth of shaft No. 47 , soil, background $110 \mu \mathrm{r} / \mathrm{hr}$. $\mu \mathrm{r} / \mathrm{hr}$.

Sample IB-2. $10 \mathrm{~m}$ north of the point of first sampling, soil, background $25-30$

Sample IB-3. Site of the nuclear explosion $2.5 \mathrm{~km}$ from the town of Udachny, soil, background $120 \mu \mathrm{r} / \mathrm{hr}$.

Sample IB-4. Site of the nuclear explosion $60 \mathrm{~km}$ from the town of Udachny "Kraton-3", shaft mouth, soil, background $750-800 \mu \mathrm{r} / \mathrm{hr}$.

Sample IB-5. "Kraton-3", $1150 \mathrm{~m}$ from the shaft mouth along the main line, soil, background $100-120 \mu \mathrm{r} / \mathrm{hr}$.

Sample IB-6. "Kraton-3", $1200 \mathrm{~m}$ from the shaft mouth along the main line, soil, background $90-100 \mu \mathrm{r} / \mathrm{hr}$.

Sample IB-7. Sampling site IB-5, moss, reindeer moss, $600-700$ beta particles $/ \mathrm{cm}^{2} \min$.

Sample IB-8. The sampling site IB-6, moss, reindeer moss, $300-350$ beta particles/cm $\mathrm{cmin}^{2}$.

Samples were taken at the sites of high background, depth $5 \mathrm{~cm}$, area $0.01 \mathrm{~m}^{2}$; beta radiation was measured on the surface. 
The samples were analyzed at the Institute of Plant and Animal Ecology of the Ural Regional Division of the USSR Academy of Sciences at the Department of Continental Radioecology in the town of Zarechny in Sverdlovsk Oblast. The level of cesium isotopes was measured on the AM-A-02F1 multichannel analyzer with a semiconductor detector, model DGDK 50-B. The photopeak areas were calculated on a computer; the error was no greater than $3 \%$. In the prepared soil samples, the content of strontium- 90 was determined from the daughter yttrium- 90 where the radiometry of its precipitates was conducted on the low background UMF-1500 unit with the end-window counter SBT-16, where the reading error was no greater than $15 \%$.

The results of the analyses are presented in the form of a table.

\begin{tabular}{|c|c|c|c|c|}
\hline \multirow{2}{*}{ Sample No. } & \multicolumn{2}{|c|}{ Strontium-90 } & \multicolumn{2}{c|}{ Cesium-137 } \\
\cline { 2 - 5 } & $\mathrm{kBq} / \mathrm{kg}$ & $\mathrm{kBq} / \mathrm{m}^{2}$ & $\mathrm{kBq} / \mathrm{kg}$ & $\mathrm{kBq} / \mathrm{m}^{2}$ \\
\hline IB-1 & $0.210 \pm 0.045$ & $5.25 \pm 1.13$ & $0.7 \pm 0.1$ & $17.5 \pm 10.0$ \\
IB-2 & $0.020 \pm 0.003$ & $0.50 \pm 0.07$ & $1.8 \pm 0.5$ & $45.0 \pm 12.5$ \\
IB-3 & $0.010 \pm 0.001$ & $0.25 \pm 0.03$ & $0.5 \pm 0.1$ & $12.5 \pm 2.5$ \\
IB-4 & $30.72 \pm 2.83$ & $768 \pm 70.8$ & $22.3 \pm 0.1$ & $558 \pm 3.0$ \\
IB-5 & $8.58 \pm 1.25$ & $214.5 \pm 31.2$ & $6.1 \pm 0.5$ & $152.5 \pm 12.5$ \\
IB-6 & $8.99 \pm 0.66$ & $224.8 \pm 16.9$ & $3.4 \pm 0.7$ & $85.0 \pm 17.5$ \\
IB-7 & $152.9 \pm 12.1$ & - & $115.8 \pm 0.3$ & - \\
IB-8 & $160.2 \pm 11.8$ & - & $97.3 \pm 0.3$ & -
\end{tabular}


Strontium-90 and cesium-137 levels in average global fallout (background values) and in some areas of the Chernobyl zone:

\begin{tabular}{|l|l|c|c|c|c|}
\hline No. & \multirow{2}{*}{$\begin{array}{l}\text { Geographical } \\
\text { location }\end{array}$} & \multicolumn{2}{|c|}{ Strontium-90 } & \multicolumn{2}{|c|}{ Cesium-137 } \\
\cline { 3 - 6 } & & $\mathrm{kBq} / \mathrm{kg}$ & $\mathrm{kBq} / \mathrm{m}^{2}$ & $\mathrm{kBq} / \mathrm{kg}$ & $\mathrm{kBq} / \mathrm{m}^{2}$ \\
\hline
\end{tabular}

1. Average global up to 0.2 up to $4-5$ up to 0.2 up to 4-5 fallout

2. Six km south-

$50-200$

up to $500-800 \quad 550-1100$

up to 4000 east of the Chernobyl nuclear power plant (near Lake Kopachi)

3. $18 \mathrm{~km}$ south of $8-20$ up to $100-600 \quad 10-30$ up to $150-300$ the nuclear plant (near Lake Cherevach)

\section{B.N. Fedorov}

Junior research associate, Institute of Biology of the Yakut Scientific Center of the USSR Academy of Sciences 
Laboratory of the Department of Radiation Hygiene, Yakut Republic Sanitation and Epidemiology Station

\section{RESULTS \\ of Radiometric Analysis of Soil Samples from the Mirny Rayon in July 1990}

The total beta activity of the soil samples was determined on the UMF-1500 unit in accordance with procedural instructions approved by deputy chief sanitary physician of the Russian Federation N.S. Titkov on November 14, 1975. Total beta activity of the soil was measured with the aid of a kit including the STS- 5 counter and a loose sample container. Since the beta activity of soil is determined approximately $70 \%$ by potassium40 and $30 \%$ by the isotopes of the uranium and thorium series, UMF-1500 was calibrated against potassium chloride, because the average energy of the beta particles of the uranium and thorium series measured by the counter STS- 5 is practically equal to that of potassium -40 . The specific activity of potassium chloride is $3.87 \times 10^{-10} \mathrm{Ci} / \mathrm{g}$.

The total alpha activity was measured on the BDA unit using the procedure "Determination of Total Alpha Activity of Soil" approved by the deputy chief of the Main Administration of Research Institutions and Scientific Research Coordination, N.A. Demidov on August 25, 1976, and developed.by the Leningrad Research Institute of Radiation Hygiene of the Ministry of Public Health of the Russian Federation. BDA was calibrated.against a soil "reference" .containing $6.3 \times 10^{-10}$ curie of thorium per gram of soil.

The total alpha and beta activity comes from 14 alpha emitters and 6 beta emitters of the uranium and thorium series and potassium-40. With their average concentrations in soil of $U=2.4 \times 10^{-6} \mathrm{Ci} / \mathrm{g}$, Th $-8 \times 10^{-6} \mathrm{Ci} / \mathrm{g}$, and $\mathrm{K}-40=2 \times 10^{-2} \mathrm{Ci} / \mathrm{g}$, the total alpha and beta activities are almost equal:

$$
\begin{aligned}
& \Sigma \alpha=8 \mathrm{p} \alpha(U)+6 \mathrm{p} \alpha(\mathrm{Ih})=6.4 \times 10^{-12}+5.3 \times 10^{-12} \mathrm{Ci} / 1=11.7 \times 10^{-12} \mathrm{Ci} / 1 \\
& \Sigma \beta=3 \mathrm{p} \beta(\mathrm{U})+3 \mathrm{p} \beta(\mathrm{Th})+\mathrm{p} \beta\left(\mathrm{K}^{40}\right)=\left(2.4 \times 10^{-12}+2.6 \times 10^{-12}+16.2 \times 10^{-12} \mathrm{Ci} / \mathrm{g}\right. \\
& =21.2 \times 10^{-12} \mathrm{Ci} / \mathrm{g}
\end{aligned}
$$

hence $\Sigma \alpha=0.55$.

$$
\mathbf{\Sigma} \boldsymbol{\beta}
$$

When there is little uranium and thorium in soil, this ratio is significantly lower.

At present, there are no maximum permissible levels for soil. 
Total Beta and Alpha Activity of Soils

\begin{tabular}{|c|c|c|c|c|c|}
\hline \multirow[t]{2}{*}{ No. } & \multirow{2}{*}{$\begin{array}{l}\text { Place sample } \\
\text { was collected }\end{array}$} & \multirow{2}{*}{$\begin{array}{l}\text { Sample } \\
\text { number }\end{array}$} & \multicolumn{2}{|c|}{ Total activity } & \\
\hline & & & $\begin{array}{l}\text { Beta } x \\
10^{-12} \\
\mathrm{Ci} / \mathrm{g}\end{array}$ & $\begin{array}{r}\text { Alpha } x \\
10^{-12} \\
\mathrm{Ci} / \mathrm{g}\end{array}$ & \\
\hline $\begin{array}{l}1 . \\
2 . \\
3 .\end{array}$ & $\begin{array}{l}\text { Mirny Rayon, } \\
\text { Markha River } \\
\text { same } \\
\text { same }\end{array}$ & $\begin{array}{l}3 / 6 \\
4 / 6 \\
5 / 6\end{array}$ & $\begin{array}{l}31.1 \\
22.9 \\
21.3 \\
\end{array}$ & $\begin{array}{l}3.0 \\
4.2 \\
3.4 \\
\end{array}$ & $\begin{array}{l}0.1 \\
0.2 \\
0.2\end{array}$ \\
\hline $\begin{array}{l}4 . \\
5 . \\
6 .\end{array}$ & $\begin{array}{l}\text { same } \\
\text { same } \\
\text { same }\end{array}$ & $\begin{array}{l}3 / 5 \\
4 / 5 \\
5 / 5\end{array}$ & $\begin{array}{l}59.2 \\
26.6 \\
28.8 \\
\end{array}$ & $\begin{array}{l}2.3 \\
4.0 \\
3.8\end{array}$ & $\begin{array}{l}0.04 \\
0.15 \\
0.13\end{array}$ \\
\hline $\begin{array}{l}7 . \\
8 . \\
9 .\end{array}$ & $\begin{array}{l}\text { same } \\
\text { same } \\
\text { same }\end{array}$ & $\begin{array}{l}3 / 4 \\
4 / 4 \\
5 / 4\end{array}$ & $\begin{array}{r}143.7 \\
24.6 \\
18.4\end{array}$ & $\begin{array}{l}4.7 \\
3.6 \\
6.8\end{array}$ & $\begin{array}{l}0.03 \\
0.15 \\
0.37\end{array}$ \\
\hline $\begin{array}{l}10 . \\
11 . \\
12 .\end{array}$ & $\begin{array}{l}\text { same } \\
\text { same } \\
\text { same }\end{array}$ & $\begin{array}{l}3 / 3 \\
4 / 3 \\
5 / 3\end{array}$ & $\begin{array}{r}252.6 \\
37.6 \\
26.6\end{array}$ & $\begin{array}{l}4.7 \\
2.2 \\
4.2\end{array}$ & $\begin{array}{l}0.02 \\
0.06 \\
0.15\end{array}$ \\
\hline $\begin{array}{l}13 . \\
14 . \\
15 .\end{array}$ & $\begin{array}{l}\text { same } \\
\text { same } \\
\text { same }\end{array}$ & $\begin{array}{l}3 / 2 \\
4 / 2 \\
5 / 2\end{array}$ & $\begin{array}{r}672.5 \\
70.1 \\
75.6 \\
\end{array}$ & $\begin{array}{l}3.1 \\
3.8 \\
4.6 \\
\end{array}$ & $\begin{array}{l}0.004 \\
0.05 \\
0.06 \\
\end{array}$ \\
\hline $\begin{array}{l}16 . \\
17 . \\
18 .\end{array}$ & $\begin{array}{l}\text { same } \\
\text { same } \\
\text { same }\end{array}$ & $\begin{array}{l}3 / 1 \\
4 / 1 \\
5 / 1\end{array}$ & $\begin{array}{r}2,665.2 \\
1,573.2 \\
909.6 \\
\end{array}$ & $\begin{array}{l}2.9 \\
2.7 \\
2.8 \\
\end{array}$ & $\begin{array}{l}0.001 \\
0.002 \\
0.003\end{array}$ \\
\hline $\begin{array}{l}19 . \\
20 .\end{array}$ & $\begin{array}{l}\text { same } \\
\text { same }\end{array}$ & $\begin{array}{l}1 \\
2\end{array}$ & $\begin{array}{r}633.1 \\
1,193.6\end{array}$ & $\begin{array}{l}4.9 \\
4.2\end{array}$ & $\begin{array}{l}0.008 \\
0.003\end{array}$ \\
\hline $\begin{array}{l}21 . \\
22 . \\
23 .\end{array}$ & $\begin{array}{l}\text { Mirny Rayon, } \\
\text { Taas-Yuryakh, } \\
7 \mathrm{~km} \text {, shaft } \\
47 \\
\text { same } \\
\text { same }\end{array}$ & $\begin{array}{l}47 / 3 \\
47 / 2 \\
47 / 1\end{array}$ & $\begin{array}{r}16.4 \\
32.4 \\
148.3\end{array}$ & $\begin{array}{l}2.2 \\
2.5 \\
2.1\end{array}$ & $\begin{array}{l}0.13 \\
0.08 \\
0.01\end{array}$ \\
\hline
\end{tabular}

The measuring time for each sample was 30 minutes. 
The total beta and alpha activity of arable soil of the Yakut SSR is 20-25X10-12 $\mathrm{Ci} / \mathrm{g}$ and $7-10 \times 10^{12} \mathrm{Ci} / \mathrm{g}$, respectively, and to a great extent depends on the quantity and kind of mineral fertilizer applied.

Analysis indicates that the total alpha activity of soil is approximately equal to the mean values of alpha activity of arable soils throughout the Yakut SSR, and its increase was not found in any samples, while the total beta activity increases upwardly and reaches its maximum level on the surface of the soil.

This indicates soil contamination with sources of beta radiation.

Taking into account the fact that more than 10 years have passed since the explosion, these can be strontium- 90 and cesium-137, whose half-life is about 30 years.

\section{T. Lopukhova}

Laboratory Physician of the Radiological

Laboratory of the Republic Sanitation

and Epidemiology Station 
Yakut Republic Sanitation and Epidemiology Station

\section{CONCLUSION \\ on the of Radiochemical Analyses of \\ Water Samples Collected by a Group of Specialists from \\ the Coordination Council in the Mirny Rayon \\ in July, 1990}

Water samples were collected in rivers used as sources of drinking water by settlements located in the area and at the sites of underground atomic explosions in the Mirny Rayon.

The purpose of the laboratory investigation was to try to establish the possibility of artificial (strontium-90 and cesium-137) and natural (uranium-238 and radium-226) radionuclides entering natural waters as a result of explosions. The radiochemical analysis was conducted in August of 1990 at the radiological laboratory of the Yakut Republic Sanitation and Epidemiology Station using procedures approved by Chief State Sanitary Physician P.N. Burgasov on December 3, 1979.

Radiometric apparatus of the UMF-1500 type and a scintillation alpha unit with a BDA unit and photoelectric colorimeter, which passed state testing at the Far East Center of Standardization and Metrology in July 1990, (as evidenced by the appropriate documents) were used. 
Results of Radiochemical Analysis of Water Samples ( $\mathrm{p} \times 10^{-12}$ Curies $/$ or $\mathrm{p} X$ picocuries $/ 1 \mathrm{pCi} / 1$ )

\begin{tabular}{|c|l|c|c|c|c|c|}
\hline & $\begin{array}{l}\text { Sample } \\
\text { collection site }\end{array}$ & $\begin{array}{l}\text { Num- } \\
\text { ber of } \\
\text { sam- } \\
\text { ples }\end{array}$ & $\begin{array}{l}\text { Strontium } \\
-90\end{array}$ & Cesium-137 & $\begin{array}{l}\text { Uranium- } \\
238\end{array}$ & \\
\hline 1 & 2 & 3 & 4 & 5 & 6 & 7 \\
\hline
\end{tabular}

Town of Taas-Yuryalch

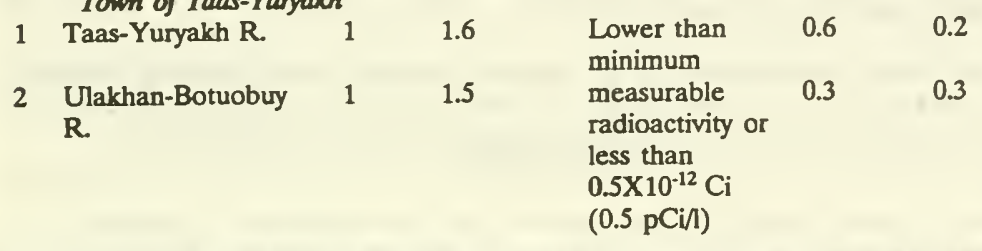

\begin{tabular}{|l|l|l|l|l|l|l|}
\hline 1 & 2 & 3 & 4 & 5 & 6 & 7 \\
\hline
\end{tabular}

\section{Town of Udachny}

3 Markha $\mathbf{R}$. (mouth of brook at explosion site)

4 Markha R. (50 m below mouth of brook at explosion site)

\section{Town of Syuldyrukar}

5 Vilyuy $R$.

\section{Town of Suethy}

6 Vilyuy R.

Permissible concentration for water under Radiation Safety Standards NRB 76/87

11.5

3.0
0.3

0.2

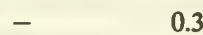


The concentrations of natural radionuclides (uranium-238 and radium-226) in the investigated samples of water from the rivers of the Mirny Rayon are within the mean values of long-term laboratory observations (since 1983) (for the Vilyuy River, the concentration of uranium fluctuated within the range of 0 ...[illegible] $0.5 \mathrm{pCi} /$, for radium-226 it was $0.2-0.3 \mathrm{pCi} / 1$ ), which is slightly below the average values for the Republic, which are $0.4 \mathrm{pCi} /$ for radium-226, and $0.5 \mathrm{pCi} /$ for uranium-238.

Artificial radionuclides enter open bodies of water mostly by being washed out of the soil by rain and thawing waters.

The concentration of cesium- 137 in all water samples was below the minimum measurable activity or lower than $0.5 \mathrm{pCi} /$.

The content of strontium- 90 in the individual samples of water collected from the rivers of the Mirny Rayon is more compa:able with the results of long-term observations of water in the lakes of the Vilyuysk group of rayons, where the concentration of strontium-90 fluctuated within the range of $1.5-3.5 \mathrm{pCi} /$, while in the rivers it was $0.5-1.5$ pCil.

It would be premature to declare the estimate final because of an insufficient number of samples, and work on investigating the level of strontium-90 in these specific sectors must be continued.

In general, the concentration of natural (uranium-238, radium-226) and artificial (strontium-90, cesium-137) radionuclides in the investigated samples of water from the rivers of the Mirny Rayon is at least 100 times lower than permissible concentrations for category B under the Standards of Radiation Safety (NRB-76/87).

G.Ye. Semonov

Head of the Department of Radiation Hygiene

of the Yakut Republic Sanitation

and Epidemiology Station 


\section{Individual Dosimetry}

In order to ensure the safety of personnel during surface operations in the course of radiometric investigations and while sampling plants, soil and water at many sites of radioactive contamination, "Regulations on Radiation Safety During Investigations" of June 22, 1990 (Appendix 6) were developed and approved. The Radiation Safety Service of TsPSO ordered 25 individual photodosimeters (IFKU-1) from the Experimental Procedural Unit of Nuclear Geophysics, which has the right to test dosimeters granted by the Far East Center of Standardization and Metrology (678500, town of Batagay, Verkhoyansk Rayon, Yakut SSR, ul. Oktyabrskaya, 6 .., illegible...). These dosimeters were distributed in the following manner: 11 instruments for operations in the area of the town of Taas-Yuryakh, 12 for operations in the area of the town of Udachny, and two reserve dosimeters (No. 4005 and No. 4016) for determining background values were not used (Appendix 7).

\section{CONCLUSION}

According to information we have gathered, nine underground nuclear explosions were conducted in the Mirny Rayon of the Yakut-Sakha SSR for research and economic purposes in the vicinity of the following population centers: town of Udachny, one explosion, (a site called "Kristall", 1974), town of Aykhal (one, "Kraton-3", 1978), town of Taas-Yuryakh (seven, "Oka", shaft No. 42, 1976, "Vyatka", shaft No. 43, 1978, "Sheksna", shaft No. 47, 1979), "Neva-1", shaft No. 66, 1983, "Neva-2,3", shafts Nos. 61, 68, and 101, 1987).

All nine explosion shafts and adjacent areas were studied, although over limited areas, in 1990 by airborne gamma-spectrometric survey. In two cases, at the sites "Kristall" and "Kraton-3", area radioactive contamination was found. Surface operations were carried out at 4 sites: detailed operations at the site "Kraton- $3^{\text {" }}$ and prospecting at the sites "Kristall," "Sheksna," and "Neva-3". Radioactive contamination was recorded at three sites, "Neva-3" being the exception. The operations employed data from an advance airborne gamma-spectrometric survey, and only at the site "Kristall" were airborne geophysical operations performed later.

Parameters of sectors of radioactive contamination that were found and investigated:

"Sheksna" - $50 \times 50 \mathrm{~m}$, the exposure dose up to $60 \mu \mathrm{r} / \mathrm{hr}$, the minimum dose on the surface $239 \mu \mathrm{r} / \mathrm{hr}$; the total beta activity in soil 640 (460) Bq/kg (here and below the results of radiochemical analysis in parentheses indicate the minimum values for the site); strontium-90, 160 (88) Bq/kg; cesium-137, 350 (70) Bq/kg. In vegetation (reindeer moss), the total beta activity was $979 \mathrm{~Bq} / \mathrm{kg}$; strontium-90, $220 \mathrm{~Bq} / \mathrm{kg}$; cesium-137, 166 
Bq/kg. The contamination is of a surface nature, and radioactivity decreases with depth; its origin is not clear, but may be "technological."

"Kristall": $0.4 \times 0.9 \mathrm{~km}$, the exposure dose up to $65 \mu \mathrm{r} / \mathrm{hr}$, the maximum radioactivity on the surface, $120 \mu \mathrm{r} / \mathrm{hr}$; the total beta activity in soil, 1860 (950) Bg/kg; strontium-90, $483(130) \mathrm{Bq} / \mathrm{kg}$; in vegetation (reindeer moss) the total beta activity is $26,290(10,760) \mathrm{Bq} / \mathrm{kg}$; strontium-90, 788 (220) Bq/kg; cesium-137, 386 (166) Bq/kg. Radioactive contamination was caused by a near-surface underground nuclear explosion. The nature of the explosive operations (stripping) makes it possible to indicate a predesigned discharge of radioactivity.

"Kraton-3": spots of radioactive contamination were revealed by airborne gammaspectrometric survey throughout the entire area investigated $(7 \times 12 \mathrm{~km})$; the main trace was followed for $5 \mathrm{~km}, 0.5$ to $2.5 \mathrm{~km}$ wide; the exposure dose in the axial portion of the trace is up to $210 \mu \mathrm{r} / \mathrm{hr}$, the maximum values near the shaft mouth on the surface are $730 \mu \mathrm{r} / \mathrm{hr}$, the total beta activity in soil is $28,340(670) \mathrm{Bg} / \mathrm{kg}$; strontium- 90,9990 (47) $\mathrm{Bq} / \mathrm{kg}$; cesium-137, 5120 (87) Bq/kg; in vegetation (reindeer moss) the total beta activity is 3,378,000 (19,760) Bq/kg; strontium-90, 55,460 (197) Bq/kg; cesium-137, 19,150 (310) Bq/kg. Radioactive contamination of the area was caused by an accidental discharge during an underground nuclear explosion; the scale of the event is not clear; the location of contamination spots and parameters of the main trace of the radioactive cloud indicate that the close trace extends for tens of kilometers.

During the operations, 148 samples were taken, including 70 of soil, 14 of vegetation, 43 of water, and 21 of food. In all 253 analyses were performed, including 104 for the total beta activity, 23 for the total alpha activity, 111 radiochemical analyses, 12 gamma-spectral analyses, and 3 analyses using a procedure with ion-exchange resins.

Analysis of the total alpha activity of 20 samples from the site "Kraton-3" and 3 samples from the site "Sheksna" produced results within average values of alpha activity of the arable soil of Yakutia, i.e. no alpha-emitting radionuclides at the sites of radioactive contaminations examined.

Special attention was given to testing water; 43 samples were taken, including 34 for the total beta activity, 6 for radiochemical analysis, and 3 samples using the procedure of concentration of strontium- 90 on ion-exchange resins.

"Shelksna": 16 analyses of the total beta activity were carried out, one involving application of ion-exchange resins for strontium- 90 , and radiochemical analysis of two samples for strontium-90, cesium-137, uranium-238, and radium-226. In two samples, taken on June 25, 1990 from the Ulakhan-Botuobuy and Taas-Yuryakh rivers, the total radioactivity of $3.3 \times 10^{-10}$ and $2.3 \times 10^{-10} \mathrm{c} /$ was found, in others it was less than $1 \mathrm{X} 10^{-10} \mathrm{Ci}$. A sample for strontium- 90 with the use of ion-exchange resins taken simultaneously from the Ulakhan-Botuobuy River showed $13.2 \mathrm{~Bq} / \mathrm{m}^{3}\left(3.2 \mathrm{~Bq} / \mathrm{m}^{3}\right)$ in the 
Markha River, (1 km upstream from the "Kraton-3" site of discharge). The radiochemical analysis showed the following: a sample from the Ulakhan-Botuobuy River: strontium-90, $1.5 \times 10^{-12} \mathrm{Ci} /$; cesium-137, less than $0.5 \times 10^{-12} \mathrm{Ci} /$; uranium-238, $0.3 \times 10^{-12} \mathrm{Ci} /$; radium-226, $0.3 \times 10^{-12} \mathrm{Ci} /$; a sample from the Taas-Yuryakh River: strontium-90, $1.6 \times 10^{-12} \mathrm{Ci} /$; cesium- 137 , less than $0.5 \times 10^{-12} \mathrm{Ci} /$; uranium- $238,0.6 \times 10^{-12}$ $\mathrm{Ci} /$; radium-226, $0.2 \times 10^{-12} \mathrm{Ci} / \mathrm{H}$.

"Kristall": two water samples were taken for the total beta activity, one from the crater left by the explosion, the other from the Ulakhan-Bysyttakh River. Analysis showed less than $1 \times 10^{-10} \mathrm{Ci} /$.

"Kraton-3": 16 samples were taken for total beta activity, 2 for radiochemical analysis, and 2 for analysis using the procedure of ion-exchange resins for strontium-90. The total beta-activity of all samples was below $1 \times 10^{-10} \mathrm{Ci} /$. Radiochemical analysis of two samples from the Markha River collected at the mouth of the brook at the site of the explosion and $50 \mathrm{~m}$ downstream showed strontium-90, $2.5 \times 10^{-12}$ and $0.5 \times 10^{-12} \mathrm{Ci} /$; cesium, less than $0.5 \times 10^{-12} \mathrm{Ci} /$; uranium-238, $0.3 \times 10^{-12}$ and $0.4 \times 10^{-12} \mathrm{C} /$; radium-226, $0.2 \times 10^{-12} \mathrm{Ci} /$, in both samples. According to the analysis results of two samples taken from the Markha River $1 \mathrm{~km}$ upstream and $20 \mathrm{~m}$ downstream from the mouth of the same brook, the content of strontium-90 was 3.2 and $8.5 \mathrm{~Bq} / \mathrm{m}^{3}$.

The results obtained from field studies and laboratory investigations make it possible to give recommendations for the future orientation of studies of the radiation situation in the territory of the republic, and for the design and conduct of similar operations in new areas.

1. A more detailed dosimetric study should be made of areas containing radioactive contamination spots in order to develop specific recommendations and proposals on carrying out decontamination, recultivation, or the recording of radioactivity.

2. The areas of airborne gamma-spectrometric survey should be expanded for the purpose of following the trace of the radioactive cloud (sites "Kristall" and "Kraton-3") from the site of discharge to the administrative boundaries of the Republic, on the basis of data provided by the Yakut Hydrometeorological Service.

3. All underground nuclear explosions should be investigated using the technique that has been developed. The investigations should include: an advance airborne gamma-spectrometric survey on the scale of 1:25,000 in a 10-km radius, regardless of the results of aerial operations, a radiometric survey of the site of the explosion shaft opening over an area of $1.0 \times 1.0 \mathrm{~km}$ with dosimetric measurements over a grid of $20 \times 20 \mathrm{~m}$ with topographic layout and pegs set out, spectrometric measurements, testing soil and vegetation on technogenically disturbed and undisturbed land. These operations will make it possible in the future to ensure time control of the radiation situation. 
4. An ecological survey of the town of Taas-Yuryakh should be conducted. The survey should include an airborne gamma-spectrometric survey on a scale of $1: 10,000$, a gamma survey and gamma spectrometry on a scale of 1:2,000 carried out on foot, metallometric and radiohydrogeological testing and sampling of the bottom sediments. Monitoring of the content of radionuclides in the water of the Taas-Yuryakh and Ulakha-Botuobuy rivers (near the town of Taas-Yuryakh) should be organized.

5. The radiological laboratories of the Republic should be equipped with the necessary advanced instruments, first of all a gamma-ray spectrometer, which will improve substantially the quality and speed of analytical research. 
Senator MURKowskI. Our next panelist is Dr. John Middaugh, Alaska State Epidemiologist. We welcome you to the panel and look forward to your testimony, sir.

[The prepared statement of Dr. Middaugh follows:] 
TESTIMONY TO THE

SENATE SELECT COMMITTEE ON INTELLIGENCE

FAIRBANKS, ALASKA

AUGUST 15, 1992

"RADIOACTIVE THREATS TO THE UNITED STATES

AND THE ARCTIC RESULTING FROM PAST SOVIET ACTIVITIES."

JOHN P. MIDDAUGH, MD

STATE EPIDEMIOLOGIST

ALASKA DIVISION OF PUBLIC HEALTH

DEPARTMENT OF HEALTH AND SOCIAL SERVICES

STATE OF ALASKA 
Senator Murkowski, thank you for inviting me to testify before the senate select committee on Intelligence at this hearing on "Radioactive and other Environmental Threats to the United states and the Arctic resulting from past soviet activities." Before I begin my remarks on this important topic, I would like to thank you for your effective leadership in introducing and gaining passage of the Arctic Research and Policy Act, and for your comitment to arctic residents by including health as an integral part of this important legislation.

During the past six months, increasing attention has focused on unverified reports that the former soviet Union dumped vast quantities of contaminants into the Arctic ocean. Most feared are reports of disposal of radioactive wastes and nuclear reactors of scuttled submarines and ice breakers. Great concern also exists that large quantities of potentially toxic heavy metals and organic hydrocarbons have contaminated the Russian arctic and subarctic.

Although these reports have not yet been verified, they are of great concern. Many of us have seen reports and photos of the tragic and catastrophic industrial contamination in Romania documented by National Geographic.

In order to respond to these disturbing reports, the United States must take aggressive action and assume leadership. We need to:

1) Compile existing data that are available to help us understand the potential threat. 
2) Assure adequate baseline data exist to enable us to monitor and detect future potential changes.

3) Establish a monitoring program to provide constant and complete data.

We will need to know:

- What is there?

- How much of which type of contaminant?

- Where are they?

With this information, we will be able to predict how the materials must cause problems. We will be able to identify potentials for contaminants to mobilize and potential pathways by which they might disperse.

The effort will not be easy. The science is complex and challenging. An effective effort will require multidisciplinary and inter-disciplinary communication, collaboration, coordination, and commitment.

Fortunately, existing agencies and organizations exist to implement reeded planning and action. I speak, for example, of the Arctic Monitoring and Assessment Program (AMAP). Called the "Finnish Initiative," it has as its primary purpose the evaluation of arctic environmental contaminants. Four of six priority areas identified by AMAP are those of greatest concern regarding potential contamination from the former soviet Union: radioactivity, heavy metals, organochlorines, and oil pollution.

AMAP has the potential to be the international vehicle by which arctic nations can coordinate and collaborate. But while AMAP has the potential, the United states must assure the job gets done. We must make available adequate resources so that implementation of monitoring, assessment, and evaluation receives appropriate priority. 
The United States is well represented at this time to AMAP by the Envirommental Protection Agency (EPA) and the National Oceanographic and Atmospheric Administration (NOAA). But we must assure adequate support for involvement of the National Marine Fisheries (NMF), the United States Fish and Wildlife (USFW), the United States Geologic Survey (USGS), and the United States Department of Energy (DOE). We must also assure appropriate support for key agencies and activities in Alaska.

During this conference, lots of attention was given to the concept of "management for sustainability." While most focus was given to subsistence resources, I believe we should expand this concept to "management for sustainability of arctic people."

At this time, we have great concerns about the impact of environmental contaminants on human health. Contamination of the food chain is a major potential threat to subsistence and the sustainability of arctic people.

We must respond with adequate resources, good science, and involvement of local arctic people who are impacted. We must empower individuals so they can make informed decisions about their lives and lifestyles.

At this time, although our data are incomplete, we, know that there are not likely to be any serious adverse health impacts in the short term. Available data do not show any recent increase in levels of contaminants in subsistence foods-fish and marine mammals. Available data do not show recent increases in levels of contaminants in arctic people. 
But serious gaps in our knowledge of critical areas exist. We can obtain data in key areas quickly through initial assessments and monitoring. We then can develop more detailed research proposals to close critical gaps.

Because effects of exposure to toxic materials on people are often not seen until many years after exposure, we could obtain important information on the extent of environmental contamination by improving surveillance of health status of people in the former Soviet Union. The national Centers for Disease Control (CDC) has proposed providing technical assistance for public health surveillance by placing medical epidemiologists in key health districts in the former soviet Union, including five medical epidemiologists in siberia.

Using Alaska as a logistics base and support facility, CDC could provide rapid identification of key health status parameters that might identify major contaminants or areas of concern. Surveillance would enable focused evaluation of environmental data to assist in determining potential impacts on arctic people.

In sumnary, I believe it essential that the United States commit adequate resources to assure protection of the arctic and its people. The United States can assure development of a coordinated program that will:

1) Pull together available data,

2) Establish what contaminants have been released,

3) Establish a monitoring program to provide constant and current data, and

4) Interpret data and provide information to those who need it. 
I believe the United States should support strongly the International Arctic Science Council (IASC) and AMAP, fund fully and urgently the proposal by $C D C$ to establish surveillance of health status in the former soviet Union, and provide enhanced resources to fully assess the potential threat from arctic environmental contamination.

Finally, I believe it essential to communicate quickly and responsibly the results of scientific studies to arctic people: We must use the data to empower arctic residents to make informed decisions for themselves. We must quard against the possibility of causing groundless fears that result in scientists taking away from the community an ability to control their decisions while waiting for my study results.

How will it all come about? In the movie, Field of Dreams, we heard whispers in the cornfield, "If you build it, they will come." During the conference of the three days, I heard, "If you fund it, the science will be done." 


\section{STATEMENT OF DR. JOHN MIDDAUGH, STATE OF ALASKA EPIDEMIOLOGIST}

Dr. MidDAUGH. Senator Murkowski, thank you for inviting me to testify before the Senate Select Committee on Intelligence today. Before I begin my remarks on the important topic of this hearing, I would like to thank you for your effective leadership in introducing and gaining passage of the Arctic Research and Policy Act and for your commitment to Arctic residents by including health as an integral part of this important legislation.

During the past six months increasing attention has focused on unverified reports that the former Soviet Union dumped vast quantities of contaminants into the Arctic Ocean. Most feared are reports of disposal of radioactive wastes and nuclear reactors of scuttled submarines and icebreakers. Great concern also exists that large quantities of potentially toxic heavy metals and persistent organic hydrocarbons have contaminated the Russian Arctic and subArctic. Although these reports have not yet been verified, they have great concern. Many of us have seen the reports and photographs of the tragic and catastrophic industrial contamination in Rumania documented by the National Geographic. We have heard earlier today from Mr. Gates of extensive environmental contamination in the former Soviet Union.

In order to respond to these reports, the United States must take aggressive action and assume leadership. We need to compile existing data that are available to help us understand the potential threat. We need to assure adequate baseline data exists to enable us to monitor and to detect future potential changes and establish a monitoring program to provide constant and complete data. We will need to know what is there, how much of which type of contaminant, and where are they. With this information, we will be able to predict how the materials might cause problems. We will be able to identify potentials for contaminants to mobilize and potential pathways by which they might disperse. The effort will not be easy. The science is complex and challenging. An effective effort will require multidisciplinary and interdisciplinary communication, collaboration, coordination and commitment. Fortunately, existing agencies and organizations exist to implement needed planning and action. I speak, for example, of the Arctic Monitoring and Assessment Program, AMAP. Called the Finnish Initiative, it has as its primary purpose the evaluation of Arctic environmental contaminants. Four of six priority areas identified by AMAP are those of greatest concern regarding potential contamination from the former Soviet Union; radioactivity, heavy metals, organochlorines and oil pollution. AMAP has the potential to be the international vehicle by which Arctic nations can coordinate and collaborate. But while AMAP has the potential, the United States must assure the job gets done. We must make available adequate resources so that implementation of monitoring, assessment and evaluation receives appropriate priority. The United States is well represented at this time to AMAP by the Environmental Protection Agency and the National Oceanographic and Atmospheric Administration, but we must assure adequate support for involvement of the National Marine Fisheries, United States Fish and Wildlife Service, United States Geological Survey, and the United States Department of En- 
ergy. We must also assure appropriate support for key agencies and activities in Alaska.

During the Arctic Perspectives Conference, lots of attention was given to the concept of management for sustainability. While most focus was given to subsistence and natural resources, I believe we should expand this concept to management for sustainability of Arctic people. At this time, we have great concerns about the impact of environmental contaminants on human health. Contamination of the food chain is a major potential threat to subsistence and sustainability of Arctic people. We must respond with adequate resources, good science and involvement of local Arctic people who are impacted. We must empower individuals so they can make informed decisions about their lives and lifestyles.

At this time, although our data are incomplete, we know that there are not likely to be any serious adverse health impacts in the short term. Available data do not show any recent increase in levels of contaminants in subsistence foods, fish and marine mammals. Available data do not show recent increases in levels of contaminants in Arctic people. But serious gaps in our knowledge of critical areas exist. We can obtain data in key areas quickly through initial assessments and monitoring. We then can develop more detailed research proposals to close critical gaps. Because effects of exposure to toxic materials on people are often not seen until many years after exposure, we could obtain important information on the extent of environmental contamination by improving surveillance of health status of people in the former Soviet Union. The National Centers for Disease Control has proposed providing technical assistance for public health surveillance by placing medical epidemiologists in key health districts in the former Soviet Union, including five medical epidemiologists in Siberia. Using Alaska as a logistics base and support facility, CDC could provide rapid identification of key health status parameters that might identify major contaminants or areas of concern. Surveillance would enable focused evaluation of environmental data to assist in determining potential impacts on Arctic people.

In summary, I believe it essential that the United States commit adequate resources to assure protection of the Arctic and its people. The United States can assure development of a coordinated program that will one, pull together available data; two, establish what contaminants have been released; three, establish an appropriate program to provide constant and current data; and four, interpret data and provide information to those who need it.

I believe the United States should support strongly the International Arctic Science Committee and AMAP, fund fully and urgently the proposal by the Centers for Disease Control to establish surveillance of health status in the former Soviet Union, and provide enhanced resources to fully assess the potential threat from Arctic environmental contamination.

Finally, I believe it essential to communicate quickly and responsibly the results of scientific studies to Arctic people. We must use the data to empower Arctic residents to make informed decisions for themselves. We must guard against the possibility of causing groundless fears that result in scientists taking away from the 
community an ability to control their decisions while waiting for more study results.

How will it all come about? In the movie, Field of Dreams, we heard whispers in the corn field, if you build it, they will come. During the conference of the last three days I heard whispers, if you fund it, the science will be done. Thank you.

Senator MURKOWSKI. Our next panelist is Charles Tedford, Radiation Health Specialist with the State Department of Health and Human Services. We welcome you to the committee, representing the State of Alaska. Thank you, Charles.

[The prepared statement of Mr. Tedford follows:] 
State of Alaska

Radiation Monitoring, Testing, and Response in Alaska

August 15,1992

Testimony by

Charles Tedford

Bio-Physicist

state of Alaska

Representing the Department of Environmental Conservation and the Department of Health and Social Services

Vice Chairman senator Murkowski, members of the subcommittee, and members of the public, thank you for the opportunity to appear before the senate select committee on Intelligence. Felcome to Alaska. Please accept our appreciation for the time and attention you have given to the threat radiation presents to Alaska.

I am here today representing the Alaska Departments of Environmental Conservation and Health and Social Services. The Department of Health and Social Services (DHSS) has the lead agency responsibility in responding and coordinating response to peacetime radiation incidents and accidents. The Department of Environmental Conservation (DEC) has responsibility for radiation matters relating to the contamination of air, water, and soil. My prepared statement describes Alaska's proposed capability to monitor and respond to radiation pollution and contamination.

A nuclear radiation detection system essentially has two elements: timely notification of an event, and baseline or ambient environmental monitoring. This discussion will be primarily directed toward requirements for environmental radiation monitoring in Alaska; however, the discussion would not be complete without a few brief thoughts on notification. 
Governor Walter J. Hickel recenti." requested the U.S. Ambassador to Russia, Robert Strauss, to provide better notification procedures on Russian nuclear power incidents. The request followed unofficial reports of a radiation release from a nuclear power plant on the Chukotka Peninsula, jusi across the Bering Strait from Alaska.

The release into the atmosphere, which reportedly occurred at the Bilibino power plant on July 10, 1991, was 1isted by The Economist, a British newsmagazine, in the March 28 issue as one of five nuclear power accidents in the former Soviet linion since January 1 . 1991. The magazine also reported that there have been 270 unscheduled stoppages of nuclear reactors in that time, including 10 unscheduled stoppages at the Bilibino facility.

While this particular incident may not have involved crossboundary releases, Governor Hickel told Ambassador Strauss he wants procedures in place to ensure that the state of Alaska receives prompt notification of all future incidents.

Governor Hickel stated, "The state must have immediate and direct information if we are to establish a meaningful monitoring system to evaluate possible impacts." . . .

The Governor also expressed concern about separate news reports that the Russians are considering expansion of the power plant even while 170 specialists are planning to leave the area. 
"This facility is closer to most communities in western Alaska than the State Capitol," Governor Hickel told Ambassador Strauss. "The State of Alaska must be able to provice prompt information to protect our citizens from potential hazard."

The second element of a nuclear radiation emergency detection sýstem is environmental monitoring. The routes of exposure for the people of Alaska to radionuclides would be water and biota, or atmospheric plumes of material. The L.S. Enviconmental Protection Agency (EPA) has considerable experience in analysis of environmental samples, and has indicated they will work with the state to develop agreements to analyze water, biota, and other media samples. The rest of this discussion is limited to the atmospheric pathway proposal. However, it should be noted that atmospheric pathway particulate materials basically become ingestion pathway scenarios involving food, water and soil.

This plan is predicated upon a request by DEC Commissioner John Sandor, and accepted by Mr. Jerry Leitch, EPA, Region 10, Radiation Program Manager. The plan is based on six weeks of discussion with several groups which are experts in facets of the problem. Included were atmospheric scientists from the University of Alaska involving arctic conditions, nuclear emergency prer $\exists r e d-$ ness advisors, and people within the EPA who have operated similar equipment and gained decades of experience and data. The proposal consists of two elements; particulate samplers near population centers, and real time detectors at the perimeter of the state. 
The environmental surveillance sustem consists of a continually operating Environmental Radiation Ambient :onitoring System (ERAMS) with particulate samplers located in the large population centers of Anchorage, Fairbanks and Juneau. The filters would be removed, scanned, and forwarded twice a week to the EPA Iab in Montgomery, Alabama for laboratory aral:sis. Also, four to five Portable Ionization Chambers (PICs) would be located throughout the state. These monitors could be located in Barzow or wainwright, to cover the northern-most region; Nome, Unalakleet, st. Lawrence Island, Little Diomede, or kotzebue to cover the central region; and Bethel to cover the southern region.

EPA has agreed to supply the ERAYS sampling equipment, consumables, analytical services, and data management without cost to the state. The state of Alaska would be responsible for personnel to collect the ERAMS filters, monitor the PICs, and for funds to purchase the PICs and satellite communication services.

The state requested $\$ 70,000$ for alpha beta-, and $\$ 80,000$ for gamma-radiation counting laboratory equipment to provide a radiochemical analytical capability. This equipment would provide Alaska with an on site counting capability for the ERAMS filters. The state also requested $\$ 135,000$ for PICs, $\$ 10 \dot{5}, 000$ for four field monitors, $\$ 25,000$ for computer data collection, and $\$ 5,000$ for installation and training.

Hopefully, through an appropriate congressional bill or funding mechanism, the EPA or military could serve as a vehicle for the funds. 
DEC plans to implement the environment3? surveillance program in three phases. In phase one, the ERAY monitors would be activated: phase two would involve the purchase and activation of the PIC system; and during phase three, procure the latoratory equipment to undertake more regular sampling of water and biota to establish background levels and detect change.

The framework for emergency response to a nuclear radiation incident or accident is contained in the Alaska Emergency Operations Plan. Depending upon the severity of the incident, as many as seven state agencies and four federal agencies would be involved in a coordinated response. The Departments of Health and Social Services, Military Affairs, Environmental Conservation, and Labor signed a Memorandum of Understanding (MOT) in 1982 which describes each of these agencies' responsibilities and roles in a radiation incident or accident scenario. The Conference of Radiation Control Program Directors, a national organization comprised of the Directors of all fifty states' Radiation Programs, will review the Alaska Radiation Program, including our emergency response capability this fall. This review will include recommendations about statutory changes, personnel and equipment, methods to establish a response capability, and funding necessary to accomplisin these tasks.

The Department of Health and Social Services headed by Dr. Theodore Mala, has the responsibility for emergency response action for radiation incidents or accidents. Dr. Mala supports the concept of the environmental monitoring system and efforts should focus on air and water surveillance. He believes that local 
community native involvement should occur and that a portion of the raciation detection responsibility should be placed accordingly. The system should provide accurate, non-panic type information back to the native communities in an understandable manner. The Foderal government should develop preventive strategies to intervene before potential accidents. Dr. Mala stated that representatives should be sent to siberia to work with the peopie, particularly at the reactor at Bilibino. Dr. Mala is pleased that Congressional representatives are working with Alaska representatives to reduce a potential threat to Alaskans.

The state of Alaska and the Chukotka local governments should be included in negotiations and implementation of bilateral emergency response plans, as well as multilateral efforts to improve emergency response in the arctic under study by the eight nations represented in the Arctic Environmental Protection strategy. We should have international response drills at least yearly. Governor Hickel, as Chairman of the Northern Forum, has commissioned an effort to improve environmental health and emergency response in the North in conjunction with thirteen other northern Governors, and that group is prepared to work with their respective nations.

Mr. Chairman, as Congress wraps up the Russian Aid Package, we want to make clear the state of Alaska supports transmitting an appropriate amount of that aid through Alaska. directly to local governments which neighbor our state, to assess, together, with us, all environmental threats of transboundary, potential contamination, and to undertake mitigation. We further believe aid should 
be used to establish improved basic comunication links betrieen Alaska and its neighbors for normal inceracioun and emergenc: response. Einally, we urge the Eederal government to support Russian participation in the Northern Ecrum and citer internationa: agreements established to protect our arctic environment, and the health and well-being of the circumpolar residents. Too often. international meetings are held, and Russians lack the means to attend. If the aid package is to have meaning to this part of the world, we must use it to encourage communication and ensure basic, necessary improvements to the environment and the public health through local exchanges. We support the efforts Senator Murkowski has made already to include an environmental component and a role for the state in the aid package. Regional and local governments are where the people are, not deep in a Koscow bureaucracy.

In summary, prompt notification is required for future nuclear incidents. A basic environmental radiation monitoring system, estimated to cost approximately $\$ 285,000$ in capital funds, is necessary for Alaske to establish a background level of radiation and to subsequently monitor elevated risks. We will do our best to cover increased operations through existing resources and cooperative agreements, although it would be appropriate to allocate permanent operating funds. Appropridte monitoring of 'water. animals, plants, fish, walrus and people for radioactive material should be initiated, and preventive and response strategies developed through working directly with the facilities in Russia which pose potential threats. 
STATEMENT OF CHARLES TEDFORD, RADIATION HEALTH SPECIALIST, DEPARTMENT OF HEALTH AND HUMAN SERVICES, STATE OF ALASKA

Mr. TEDFORD. Chairman Murkowski, thank you very much for the opportunity to come today and testify before the Senate Committee on Intelligence. Also I'd like to add to Dr. Middaugh's thought and thank you for the time and the attention you have given to the threat radiation presents to Alaska.

I represented today two agencies, or two departments, if you will, the Department of Economic Conservation and the Department of Health and Social Services. The Department of Health and Social Services has a lead responsibility in responding and coordinating response to peace-time radiation incidents and accidents. The Department of Environmental Conservation has responsibility for radiation matters relating to contamination of air, water and soil.

A nuclear radiation detection system essentially has two elements: timely notification of an event and a baseline or ambient environmental monitoring capability. This discussion will be primarily directed toward requirements for environmental radiation monitoring in Alaska, and will add to Admiral Guimond's comments this morning, and I think we're on the same frequency on that particular matter.

However, a few brief thoughts or comments are in line on notification. Recently Governor Hickel requested Ambassador Robert Strauss to provide better notification procedures on Russian nuclear power incidents. And the request followed unofficial reports of a radiation release from the Bilibino nuclear power plant on the Chukotka peninsula just across the Bering Strait from Alaska. This notification was based on reports in The Economist, which is a British news magazine, the March 28th issue to be precise, which The Economist listed five nuclear power accidents in the former Soviet Union since January 1, 1991, and the magazine also reported that there have been 270 unscheduled stoppages of nuclear reactors in that time, including 10 unscheduled stoppages at the Bilibino facility.

Governor Hickel stated, "The State must have immediate and direct information if we are to establish a meaningful monitoring system to evaluate possible impacts." He also indicated that this facility is closer to Bilibino with four reactors to most communities in Western Alaska than the state capitol. And Governor Hickel indicated this to Ambassador Strauss in a message he also forwarded. He said that the State of Alaska must be able to provide prompt information to protect our citizens from potential hazards.

Now the second element of a nuclear radiation emergency detection system is environmental monitoring. And the recent exposure for the people of Alaska to radionuclides will be water, biota, or atmospheric plumes of material. The rest of this discussion is limited to the atmospheric pathway proposal. However, it should be noted that atmospheric pathway particulate materials basically become ingestion pathway scenarios involving food, water and soil, once they've played out on the water or the soil. This plan for Alaska is predicated on a request by the DEC Commissioner John Sander and accepted by Mr. Jerry Leach, EPA in Region 10, the Radiation Program Manager. The proposal basically consists of two elements: 
particulate samplers and their population centers, and real time detectors at the perimeter of the state.

The environmental surveillance system consists of a continually operating environmental radiation ambient monitoring system for which the acronym is ERAMS, and they have particulate samplers and they will be located in large population centers of Anchorage, Fairbanks and Juneau. And as the paper noted, one of these have been activated at this time in Fairbanks. The filters would be removed, scanned and forwarded twice a week to the EPA lab in Montgomery, Alabama for laboratory analysis. Obviously this is an after-the-fact evaluation. Also, four or five portable ionization chambers, pics, will be located throughout the State. These monitors could be located in Barrow or Wainwright to cover the northern-most region and appropriately located in the central regions and one located in the southern region.

The Environmental Protection Agency has agreed to supply the ERAMS sampling equipment, consumables, analytical services and data management without cost to the State. The State of Alaska would be responsible for personnel to collect the ERAMS filters, monitor the pics, and for funds to purchase the pics and satellite communication systems and computer services.

The State has requested $\$ 150,000$ for radiation counting laboratory equipment. The State has also requested $\$ 135,000$ for pics, for a total I believe of $\$ 285,000$. Hopefully, through an appropriate Congressional bill or funding mechanism, the EPA or military could serve as a vehicle for the funds. The framework for emergency response to a nuclear radiation incident or accident is contained in the Alaska Emergency Operations Plan. The Conference of Radiation Control Program Directors, a national organization comprised of the directors of all 50 state radiation programs, will review the Alaska Radiation Program, including our emergency response capability, this fall. This review will include recommendations about statutory changes, personnel and equipment, methods to establish the response capability, and funding necessary to accomplish these tasks.

The Department of Health and Social Services is headed by Dr. Theodore Mala. Dr. Mala supports the concept of the environmental monitoring systems, and he indicated efforts should focus on air and water surveillance. He also indicated the federal government should develop preventative strategies to intervene before potential accidents. Dr. Mala stated that representatives should be sent to Siberia to work with the people, particularly at the reactor at Bilibino. And we should have international response drills at least yearly.

Mr. Chairman, as Congress wraps up the Russian aid package, we want to make clear the State of Alaska supports transmitting an appropriate amount of that aid through Alaska, hopefully, and directly to local governments, which will enable our state to assess all environmental threats of transboundary potential contamination and to undertake mitigation.

Finally, we urge the federal government to support Russian participation in a northern forum. Too often international meetings are held and Russians lack the means to attend. If the aid package is to have meaning in this part of the world, we must use it to en- 
courage communication and assure basic necessary improvements to the environment and to the public health through local exchanges. We support your efforts, Senator Murkowski, to include in the environmental component the role for the state and the aid package.

In summary, prompt notification is required for future nuclear incidents and the basic environmental radiation monitoring system, estimated to cost about $\$ 285,000$ in capital funds in necessary. And lastly, appropriate monitoring of water, animals, plants, fish, walrus and people for radioactive material should be initiated, and preventative and responsive strategies developed through working directly with facilities in Russia which pose potential threats. Those conclude my remarks, Mr. Chairman, and I will submit it in the complete text to you.

Senator MURKOwSKI. Thank you very much, Charles Tedford. I want to thank the panelists. We've heard from the health panel. I think clearly the highlights have been self-evident and are certainly food for thought. And we appreciate the extent of your documentation and your recommendations. Obviously we see this process not as a single hearing to reach a final resolution, but a hearing in an evolutionary process of the problems and then proceeding on an orderly course of corrective action. But first of all, we have to highlight the extent of the problems and I think we've seen that communicated by the members of the previous panel and certainly substantiated by those of the health panel. I want to thank you for participating, and we certainly appreciate our Russian academician and his translator and we wish you a good day.

We're going to continue on with our next panels. I think the significance of the next panel, which is noted as the non-governmental organizations, is representative of a significant group that has been, you might say, maintaining a level of awareness for some time in their concern over what's happening in the Arctic. Mr. Charlie Johnson will represent the Inuit Circumpolar Conference. He's also a member of the Arctic Research Commission, from Nome, Alaska. He is followed by Dr. Stephanie Pfirman and Scott Hajost of the Environmental Defense Fund, followed by Joshua Handler of the Nuclear Free Seas Program, Greenpeace. I would ask that that panel come before us and we will proceed. And Again I would encourage you to keep your remarks down to six to $10 \mathrm{~min}$ utes, and we will, of course, take any additional remarks for the record and you may feel free to summarize your remarks. I'll call on Mr. Charlie Johnson first. Please proceed.

\section{STATEMENT OF CHARLIE JOHNSON, INPUT CIRCUMPOLAR CONFERENCE}

Mr. JoHnson. Thank you, Mr. Chairman. I'm here representing the Inuit Circumpolar Conference which is comprised of the Inupiat, Yupik and Kalalit people of Alaska, Canada, Greenland, and now Chukotka in Russia, which at our general assembly last month in Inuvik, Canada became our full-fledged members. I am pleased to be here to represent the collective views of the indigenous people of the north and to state our concerns about the possible contamination of our homeland. Our people have been the 
first line of defense for North America against the former Soviet Union.

First, it was the Eskimo scout battalion of the Alaska National Guard. And now ironically it is our people again as the first line of defense against the results of the military and industrial buildup of the former Soviet Union and the contamination that has resulted from their single-minded domination of the Russian north. I was startled to learn today from Director Gates about the dumping of radioactive waste off the Kamchatka Peninsula. This has immediate implications for the people of Western Alaska. But there also should be concerns from the vast fishing fleets on the Bering Sea. The report on the increase of cancer among the people in Chukotka, which is only a few miles from my home, has scared the hell out of me. I wondered why from the last panel EPA has not put one of their monitors in Western Alaska, the place that is closest to the nuclear plant at Bilibino.

The Inuit Circumpolar Conference has dedicated numerous years in establishing cooperation between the indigenous people of the Arctic, especially in the protection of the environment and its habitants. Since 1983 extensive research and in-depth work has taken route in implementing the guiding principles of an Arctic policy. This policy has recently been ratified by the General Assembly of the Inuit Circumpolar Conference delegate members in Inuvik. The reasoning for a comprehensive Arctic policy to be implemented was to protect the environmental integrity of the northern regions to ensure the survival of Inuit identity and the cultures, and as stated in the introduction to the Comprehensive Arctic Policy, from an Inuit viewpoint, Arctic policies must provide more than a prescribed course of action. They must reflect a vision of the Arctic that promotes fairness and social justice for northern peoples. Arctic policies must support the aspirations of indigenous peoples and nurture their cultural development.

Equally important, Arctic policy must fully recognize and respect fundamental indigenous rights. With a concern for our environment, we have created a comprehensive project called the Inuit Regional Conservation Strategy, which is ongoing, and where government agencies can work cooperatively with the Inuit Circumpolar Conference. This project has gained international recognition and has earned the United Nations Environmental Protection Global 500 Award in 1988. To date, we have established regional projects in Greenland, Canada, Alaska, and the thrust has been to collect data on the use of our animals, plants and other resources from the traditional knowledge of the elders. We are also collecting data on our environment.

One of the main obstacles facing the Inuit Regional Conservation Project is the fiscal constraints of inadequate funding. An ambitious project without adequate funding hampers the coordination on research on species and resources. But underlying the need for protecting our environment is to realize that people by nature need a wholesome environment to live from. Therefore the need to gather scientific data on possible health pollutants being transferred to our animals and in the end transferring as polluted harvested food to the industrial people becomes paramount. 
The ICC has also been heavily involved in the drafting of the Arctic Environmental Protection Strategy that has been referred to in the past during this meeting.

I will submit to this body three resolutions adopted by the ICC Sixth General Assembly addressing pollution of the Arctic and subArctic waters by the former Soviet Union, resolutions concerning seaborne nuclear reactors, and a resolution on health and social values. In the interest of brevity, I will only read the critical sentences.

On the pollution of thee Arctic and sub-Arctic waters by the former Soviet Union, be it resolved that the Inuit Circumpolar Conference supports and encourages all international efforts to identify and map all actual and potential sources of marine contamination in the waters in and near the former Soviet Union. Be it resolved that the Inuit Circumpolar Conference supports and encourages all international efforts to determine the extent to the present and future threats posed by such contamination to the Arctic and subArctic marine ecosystems and to the human residents of these regions. And be it resolved that the Inuit Circumpolar Conference supports and encourages all international efforts to identify and implement actions to alleviate the threats posed by such contaminations. And be it further resolved that the ICC be directly involved in these efforts.

Concerning nuclear reactors on sea-borne vessels, be it resolved that the Inuit Circumpolar Conference reaffirms its opposition to the use of nuclear reactors anywhere in the Arctic because of their unacceptable environmental health, safety and security risks. Concerning health, that the ICC promote the development of appropriate health and social indicators so that Inuit can better determine whether social, mental and physical conditions are improving, and should carry out baseline data studies against which future change can be measured and should encourage the statistical and other relevant health and social indicators.

Finally, Mr. Chairman, let me state that we are greatly encouraged by the conclusion of the conference which just concluded on U.S. Arctic Policy, where there was general agreement that state, federal, and industry and environmental officials that research remedies and other factors affecting the north is incomplete without the equal and full participation of indigenous people. And I would like to state that we cannot sit back and wait for Russia to clean up its act. The U.S. must immediately begin identifying the causes and immediately start applying the solutions.

Thank you.

Senator MURKOwSKI. Thank you very much, Mr. Johnson. We appreciate your testimony.

Our next witnesses will be representing the Environmental Defense Fund, Dr. Stephanie Pfirman and Scott Hajost. I had the opportunity to welcome them both in my office last week, and I was particularly moved by their presentation and identification of the exposures as a consequence of Russian development in the Arctic, which as you pointed out to me, leaves an awful lot to be desired. Please proceed with your testimony and I appreciate you being here. 
Dr. PFIRMAN. Thank you. I'm a senior scientist at the Environmental Defense Fund. My background is in oceanography and I've been concerned about the changing environment in the Arctic for quite some time. With your permission, I'd like to summarize my remarks here and add my written testimony later.

Senator MURKOWSKI. Please, your entire testimony will be entered into the record as if read.

[The prepared statement of Dr. Pfirman and Mr. Hajost follows:] 
Capral Office

1875 Connecticut Ave., N.W

Washington. DC 20009

(202) $387-3500$

Far: 202.234-6049

\section{TESTIMONY BY}

STEPHANIE L. PFIRMAN, PH.D. SENIOR SCIENTIST

and

SCOTT A. HAJOST, ESQ. INTERNATIONAL COUNSEL

before the

\section{SELECT COMMITTEE ON INTELLIGENCE UNITED STATES SENATE}

on

'Radioactive and other Environmental Threats to the United States and the Arctic Resulting from Past Soviet Activities"

University of Alaska Fairbanks

Fairbanks, Alaska

August 15, 1992 
The Environmental Defense Fund (EDF) is a leading national environmental organization with over 200,000 members which links science, economics and law to create economically viable solutions to today's environmental problems. EDF has launched a major initiative to address Arctic environmental issues, including an assessment of the multi-media pollution threats to the Arctic and an evaluation of the effectiveness of the existing legal regime to provide sufficient protection for the Arctic.

We are concerned that the Arctic environment is faced with significant threats from a wide variety of anthropogenic sources of contamination. In order to assess how much the Arctic is now at risk, we need to get a better understanding of the sources, pathways, accumulation zones, and effects of pollutants entering the Arctic. We are beginning to define some of the sources of pollution, in particular the nuclear reactors and wastes dumped in the shallow waters near Novaya Zemlya. But we have other concerns as well: oil spills and leaks, acid rain, heavy metals, PCB's, dioxin, DDT, global warming, ozone depletion and Arctic haze are all stresses on the Arctic environment and are placing the Arctic and its people at risk. Pollutants are transported throughout the Arctic by wind, water and sea ice, as well as with migrating species. Here we describe the possible fate of pollutants entering the Arctic atmosphere and oceans.

The Arctic Ocean receives a large volume of freshwater input from the surrounding Arctic rim States. The majority of it originates from Russian rivers of which a large percentage are severely polluted. Figure 1 depicts the distribution of these rivers around the Arctic Ocean. Former Soviet scientists have measured high concentrations of PCB's, heavy metals, radioactive contaminants, and raw sewage in many Siberian rivers. Effluents from these rivers reach out into the surface waters of the Arctic Ocean and may be transported eastwards with the near shore currents towards Alaska. Figure 2 depicts the surface salinity of Arctic Ocean water during the summer time. These data were compiled by Gorshkov, a Soviet scientist, in 1980 and probably represent extensive sampling of the nearshore waters. Freshwater llowing out from the rivers into the seas can be seen as regions of low salinity (marked in black) near the Siberian margin. These pulses of low salinity extend far out onto the continental shelves and may indicate that pollutants are carried far offshore into the Kara, Laptev and East Siberian Seas.

Figure 3 is a detailed compilation of surface currents within the Arctic Ocean presented by Gorshkov, 1980. Of major interest is the eastward llowing Siberian Coastal current, which may transport polluted coastal waters towards the Bering Strait. 
Soviet scientists have indicated that about $70 \%$ of their Arctic coastline has been severely damaged by acid precipitation (figure 4) placing both the native populations and inhabitants of the numerous Russian towns and cities under severe health risks. The source of the acid precipitation is the intense industrialization of eastern Europe and Asia as well as from the Russian Arctic itself. Figure 4 also depicts the path of one pulse of air pollution stemming from eastern Europe and moving $10,000 \mathrm{~km}$ northwards across Scandinavia, across the North Pole to Alaska where it swung around and headed eastwards towards Canada. It is thought that the elevated Brooks Range in Alaska serves as a barrier to the long range transport of this Arctic air pollution. However, because of the pathways of the winds, which tend to spiral into the north polar region in winter, a thick lens of haze builds up within the Arctic air mass. Because of meteorological conditions, the haze does not fall out until the spring when the Arctic region warms. However, the exact location of the fallout is not known. It is possible that the bulk of the air pollution falls into the oceans on the periphery of the Arctic air mass where warmer air allows for large scale precipitation (figure 5) (G. Shaw, pers. comm. 1992). If this is the case, then a large portion of the fallout may occur exactly within the prime Arctic fishing grounds (figure 6) where more than $10 \%$ of the world's fish are caught annually.

Figure 7 shows the probability of sea ice moving into and melting in the shaded regions. The sea ice that melts in the Beaufort Sea comes mainly from the east and north. Pollutants carried by winds across the Arctic basin may be dropped on the sea ice, and then transported with the ice when it drifts toward the coast. Particles on and within the ice will be released to the surrounding water when the ice floes break up and melt, potentially adding more pollutants to the nearshore areas.

A future problem developing in the Arctic region is the rising concentration of chlorine monoxide at high levels in the atmosphere (figure 8). Elevated chlorine monoxide level are considered to be a precursor to stratospheric ozone depletion. Should this occur, then a very large population within Europe, native populations and delicate ecosystems in the Arctic would be in danger.

Figure 9 depicts the serious pollution threat to the Arctic in the form of radioactive fallout, and potential leakage from shallow water dumping of nuclear waste including nuclear reactors and an unknown quantity of containers. To date most of the information suggests that major dumping has taken place during the last forty years in both the Kara and Barents Seas. A close up of the Barents Sea (figure 10) 
indicates the magnitude of the problem. This map is a composite of a map published in 1991 by the Norwegian Mapping Authority and a Greenpeace document which shows the position of dumped nuclear reactors off the coast of Novaya Zemlya.

In addition to the radioactive waste sites, other dumping grounds are indicated. It is forbidden to anchor in these sites because they have been the repository of military dumping since World War II. The hatchured regions are locations on the seafloor that Russian fisheries biologists consider to be devastated habitats. If one compares this with the high concentrations of benthic biomass (biological material on the sea floor)in the Barents Sea from Zenkovitch, 1963, one observes the overlap of the dumping sites and the highly productive regions (figure 11). If the data that were used to compile this map could be located in Russia, one could begin to ascertain the degree of impact of dumping activities in this region. If these areas are resurveyed and are found to have changes in the character or number of its biota, then a quantitative assessment of the damage can be carried out.

Figures 12 and 13 show the oceanography of the Barents Sea as compiled by Tansiura, 1973. The arrows indicate the directions of currents both in the surface and deep waters. Using information on current flow, we can estimate the transport pathways of pollutants, including radioactivity, in this region. Therefore, this kind of data is crucial to assess the regions that may be affected by materials dumped in the Barents Sea. If we do not act now to locate these data and support the former Soviet Union scientists who have access the information, then most of it will probably be lost and we will have to spend substantial resources redoing the earlier studies

In addition to the threat of leaking radiation from the nuclear reactors dumped on the sea floor, there are numerous threats facing the Arctic environment today. The combined effects of these stresses may range from immediate harm to humans (as indicated by the Russian health statistics that we have heard today) and destruction of plant and animal habitats, to long-term damage to entire ecosystems and potential disruption of the global climate system.

It is imperative for the U.S. to take a lead role not only in the assessment of the dangers facing the Arctic environment, but in cleanup and preventive measures that must be initiated to protect the Arctic. The Arctic has not been adequately protected by the existing international legal regime. The recently adopted Arctic Environmental Protection Strategy may make a contribution if effectively implemented, but this requires a much higher priority be accorded to it by U.S. agencies, along with correspondingly higher level of resources to support their involvement in the Arctic Monitoring and 
Assessment Program. For example: although the Environmental Protection Agency (EPA) was designated the lead agency for development of the U.S. component of the Arctic Monitoring and Assessment Program with the assistance of the National Oceanic and Atmospheric Administration, these agencies do not have resources available to effectively develop and implement such a plan.

The Arctic Research Commission and the Interagency Arctic Research Policy Commission should develop a coordinated monitoring and response program for nuclear contamination issues. The program should include strategies for national activities as well as actions to provide U.S. leadership in the Arctic Environmental Protection Strategy and the International Arctic Science Committee.

Strengthening U.S. monitoring and assessment programs will provide more information on some of the less well-defined threats to the Arctic environment. At the same time, we must also start to reduce the risk from known threats, such as nuclear reactors that have been dumped near Novaya Zemlya. Right now there are two possibilities:

1) if the reactors are found to be leaking, then we must assist the Russians with technology to raise the reactors or cap them in place; and

2) if they are not leaking, then we must also decide whether to deal with them on the sea floor or remove them and dispose of them elsewhere.

Therefore, at this point we feel that it is crucial to involve our nuclear and environmental engineers, as well as those of Russia to assess the risk posed by the reactors and to design plans to desl with the risks. An action plan should be developed immediately with highlevel State Department coordination.

The Senate-passed Russian Aid Bill contains important provisions concerning support of Russian scientists, improving energy efficiency and environmental protection in general which have vital bearing for the Arctic. Such assistance is required if we are to protect the Arctic. This legislation deserves priority attention by congress when it returns in September. EDF strongly believes that environmental protection should be at the forefront of bilateral and multilateral assistance to Russia.

We are pleased to hear that the State Department intends to place higher priority on the Arctic, including Assistant Secretary Bohlen's statement at the recent Arctic Policy Conference to establish an Arctic Advisory Committee at the State Department. An immediate priority for this committee should be an evaluation of the effectiveness 
of existing treaties and international agreements relating to the Arctic environment, including their application to the nuclear contamination in the Arctic. We have spoken with the International Maritime Organization (IMO) and have been told that the Secretary General of IMO is currently seeking information from the Russian Federation with regard to its Arctic Ocean dumping activities. We have also been in contact with the Secretariat for the Long-Range Transboundary Air Pollution Convention (LRTAP) and it appears that little or no attention has been directed toward the problem of Arctic Haze. It is also important that there be a complete evaluation of the Arctic relevant chapters of Agenda 21 adopted at the recent United Nations Conference on Environment and Development. We also strongly support a re-evaluation of United States Arctic Policy as articulated in the 1983 National Security Decision Directive Number 90 in light of these environmental threats and the changes which have occurred in the former Soviet Union as a result of the end of the Cold War.

The U.S should consider the establishment of an Arctic Convention which could incorporate protective measures to address all forms of anthropogenic contaminants entering the Arctic. This comprehensive approach is necessary to ensure that all assessment, monitoring, preventive, mitigation, and enforcement efforts are working efficiently to achieve the same goal: the protection of the Arctic environment from further decline.

We urge that this hearing be the first in a series to uncover the extent of the risks to the Arctic environment that will lead to the development of a coordinated plan for addressing them.

Thank you for the opportunity to present testimony to the Committee. 


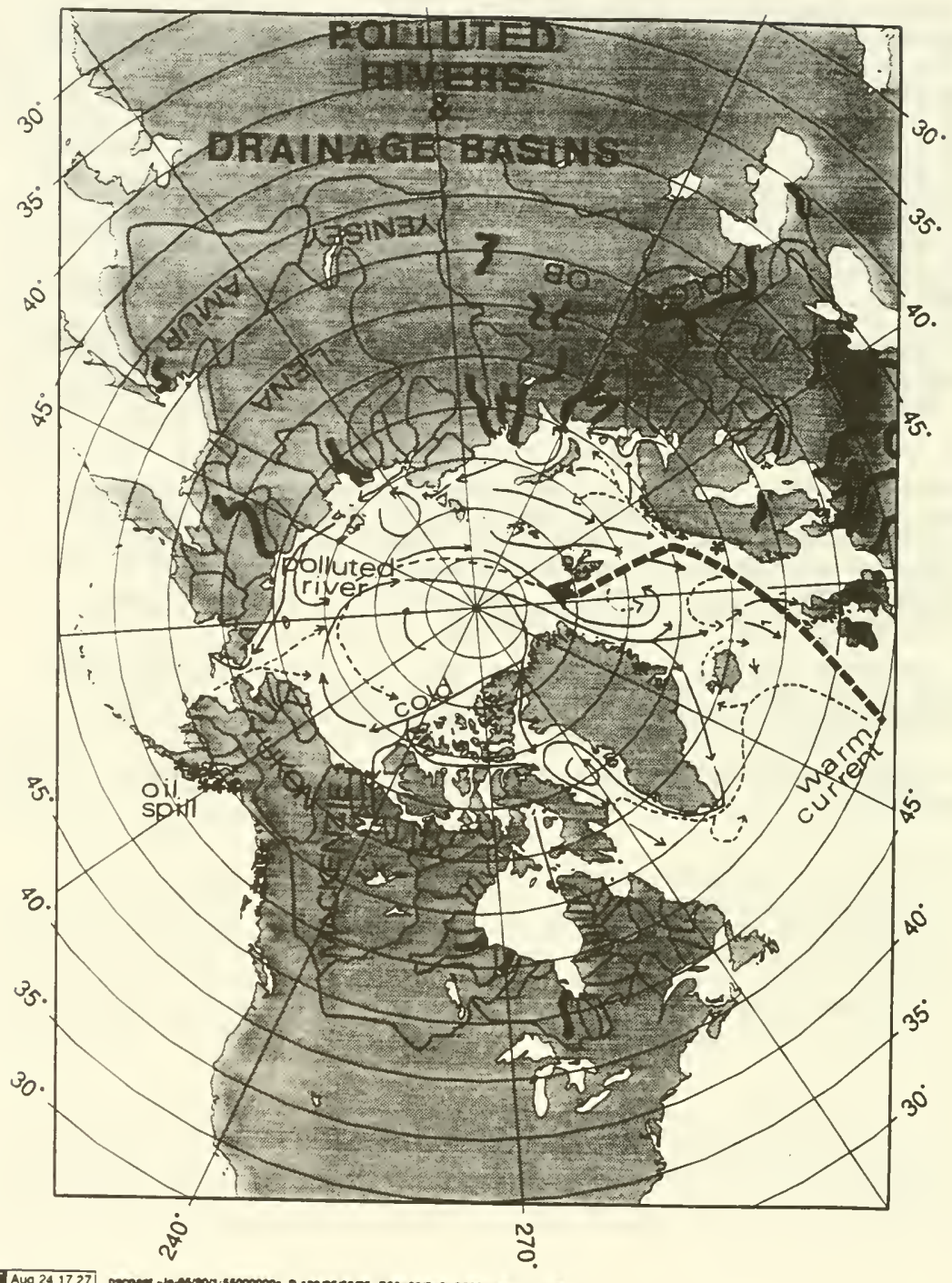

GMT Aug 241727 . 


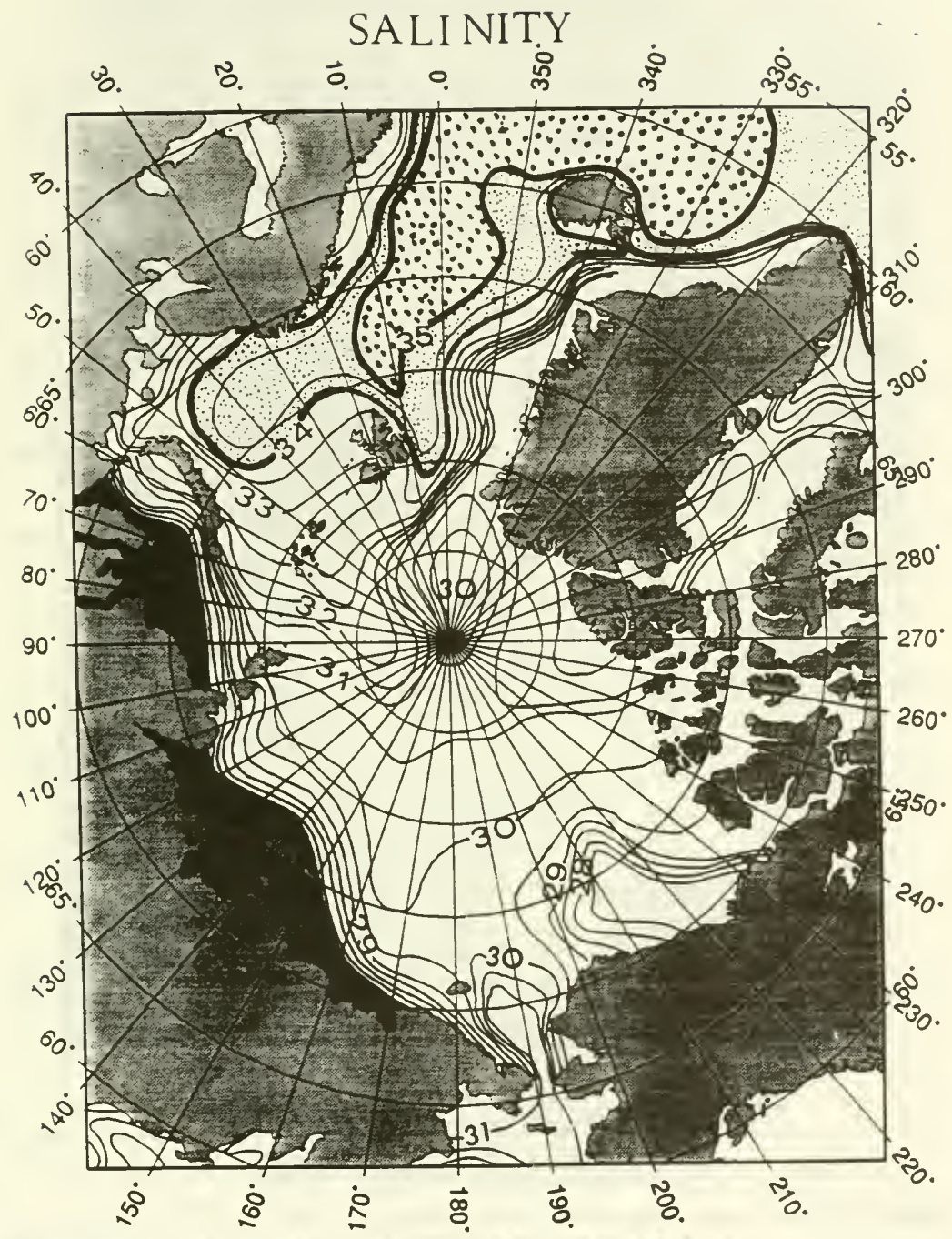

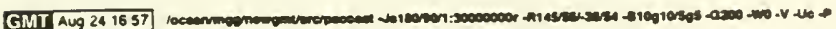


Environmental Defense Fund

SURFACE CURRENTS

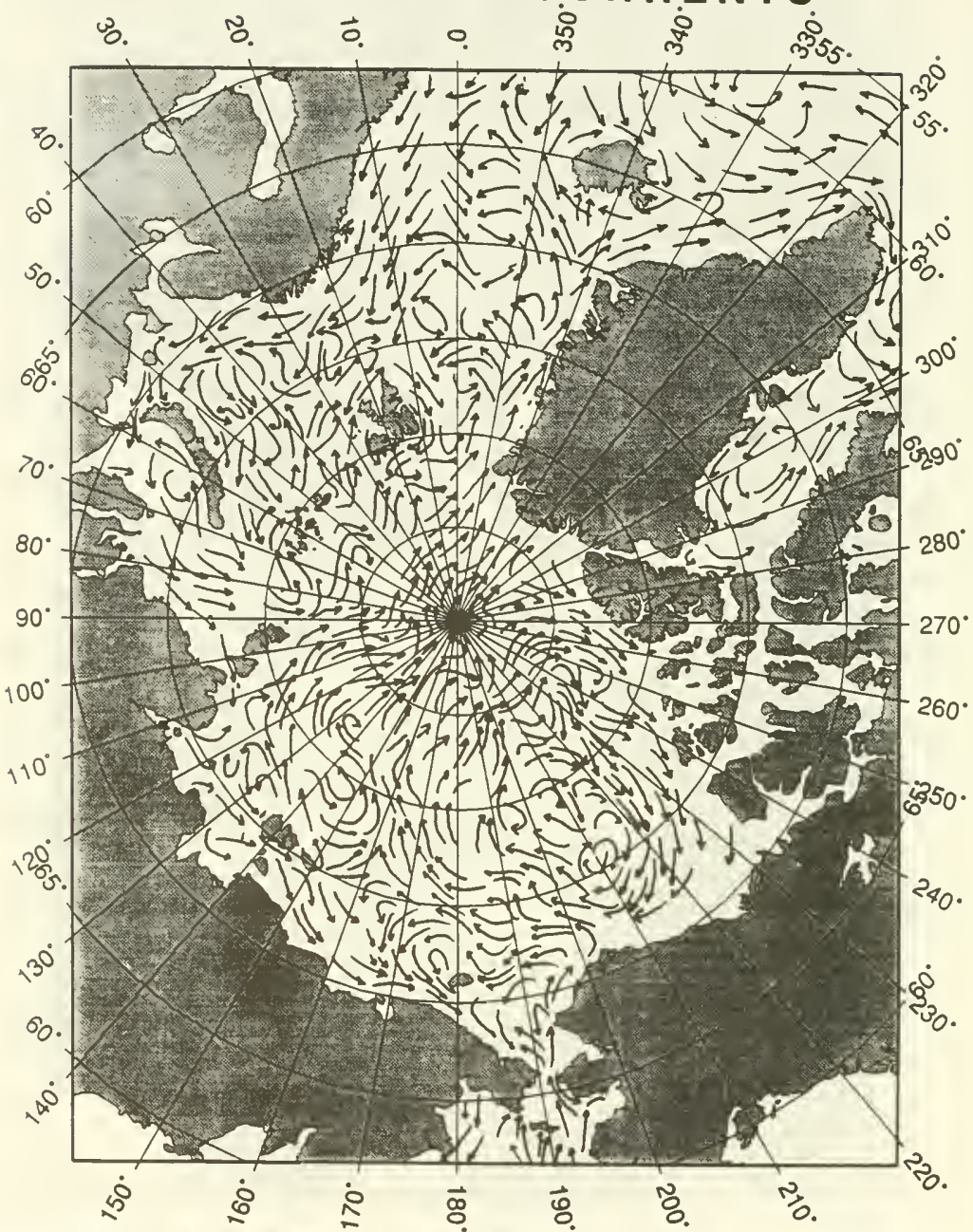

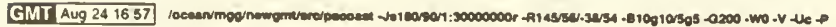




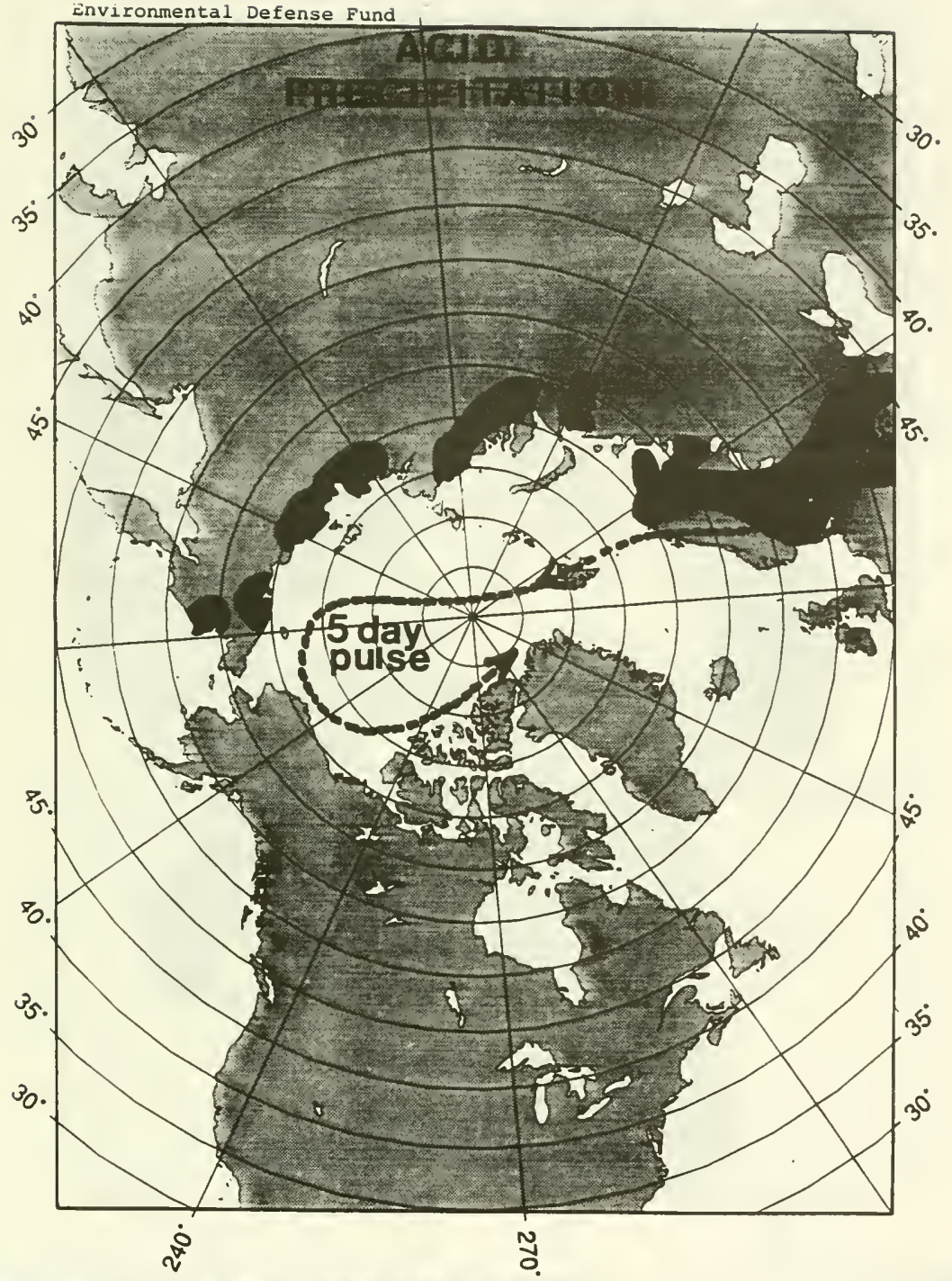




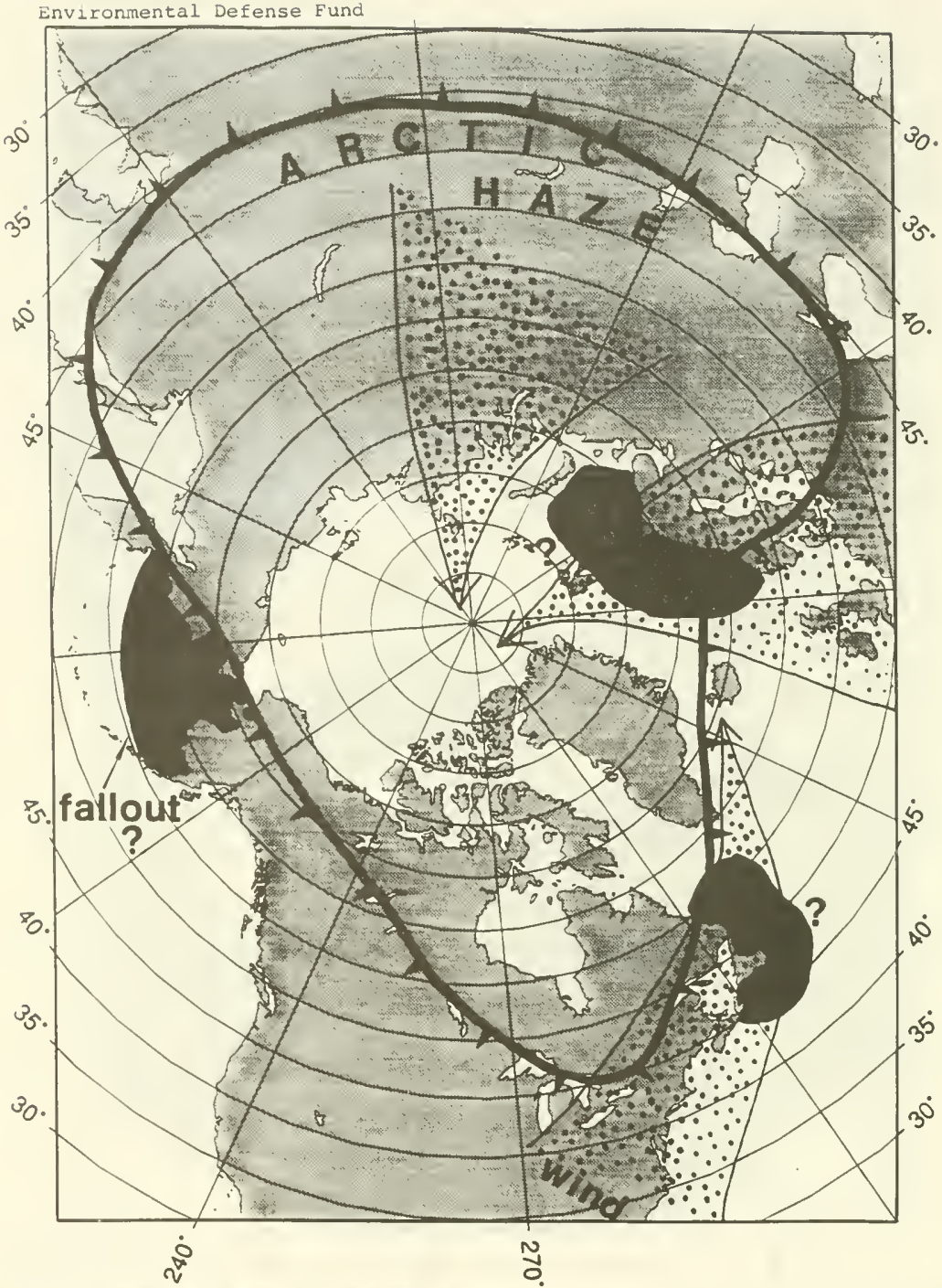

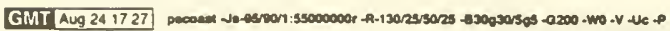




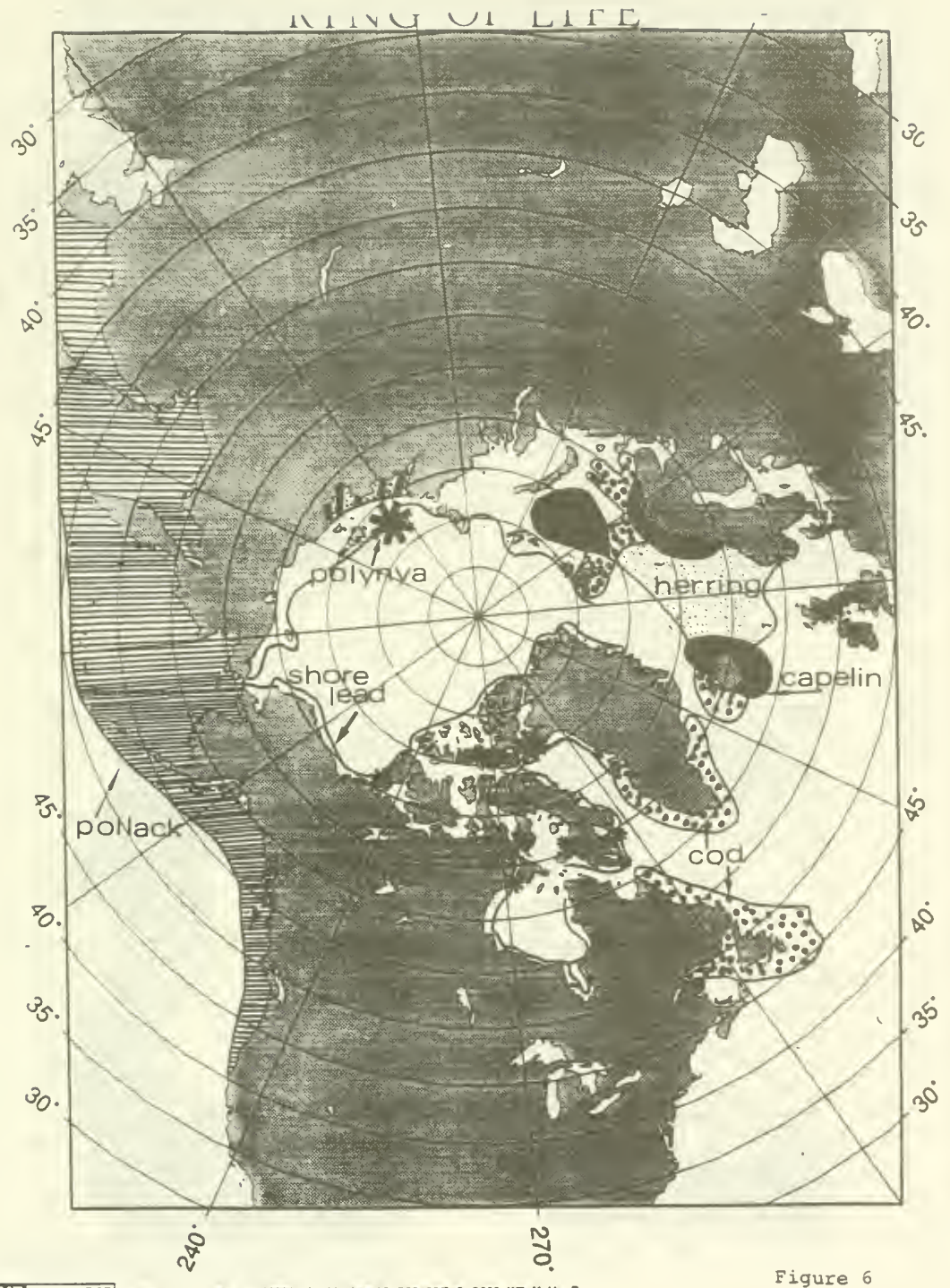

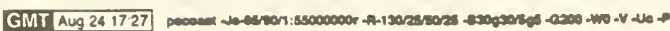

Figure 6

knvironmental Defense Fund 

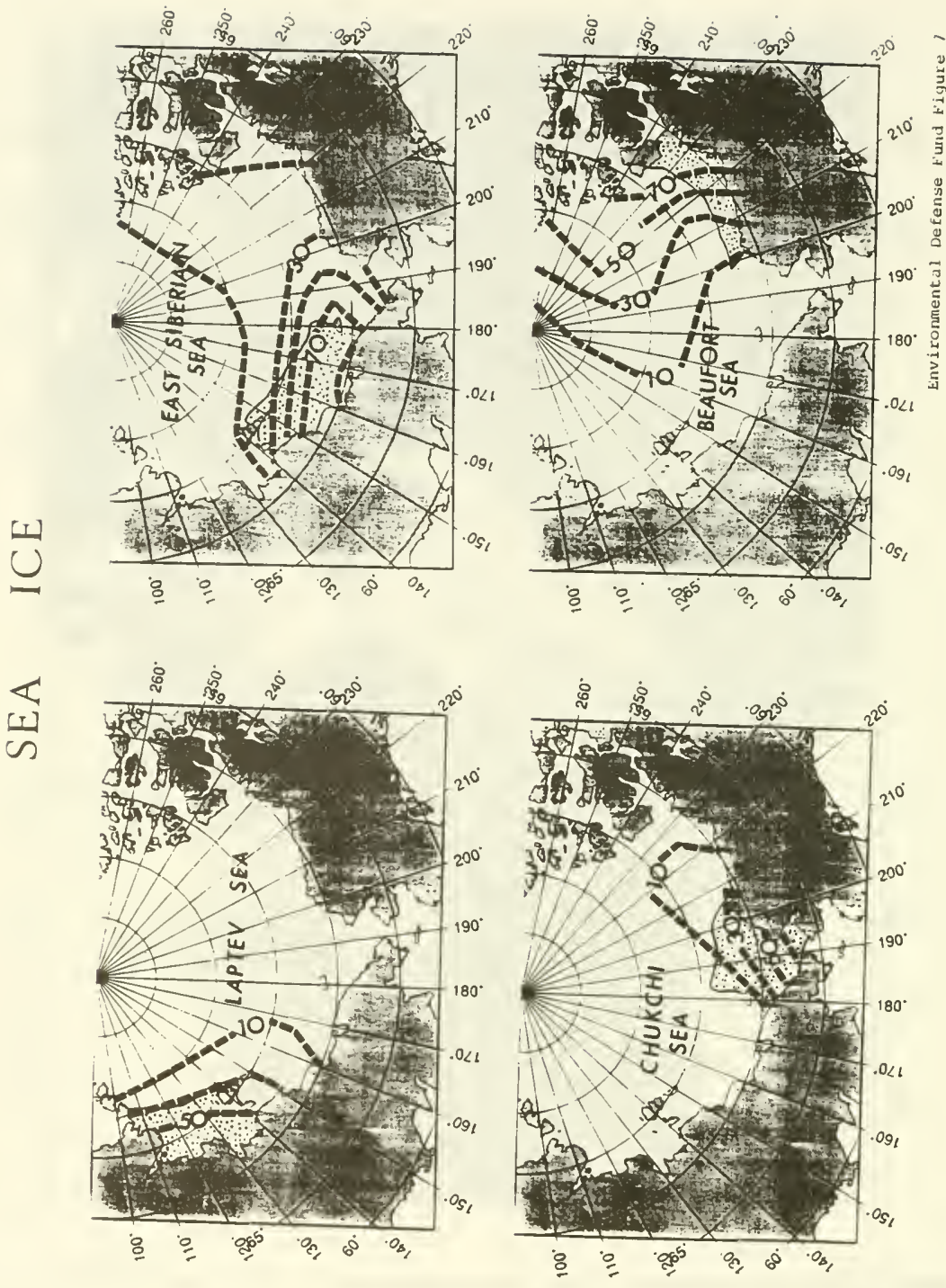


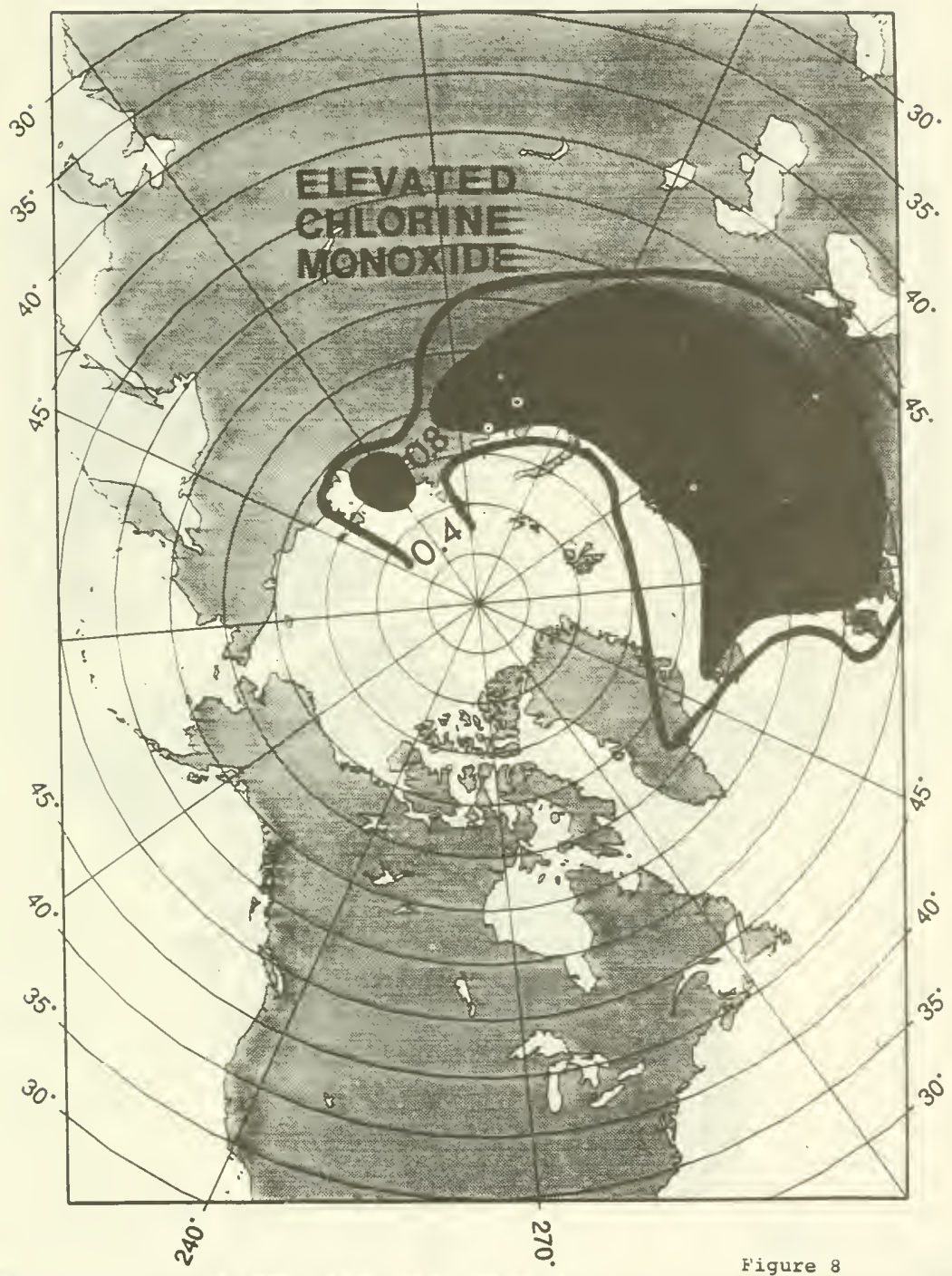

GIII $\overline{N_{0} 241727}$.

Environmental Defense Fund 


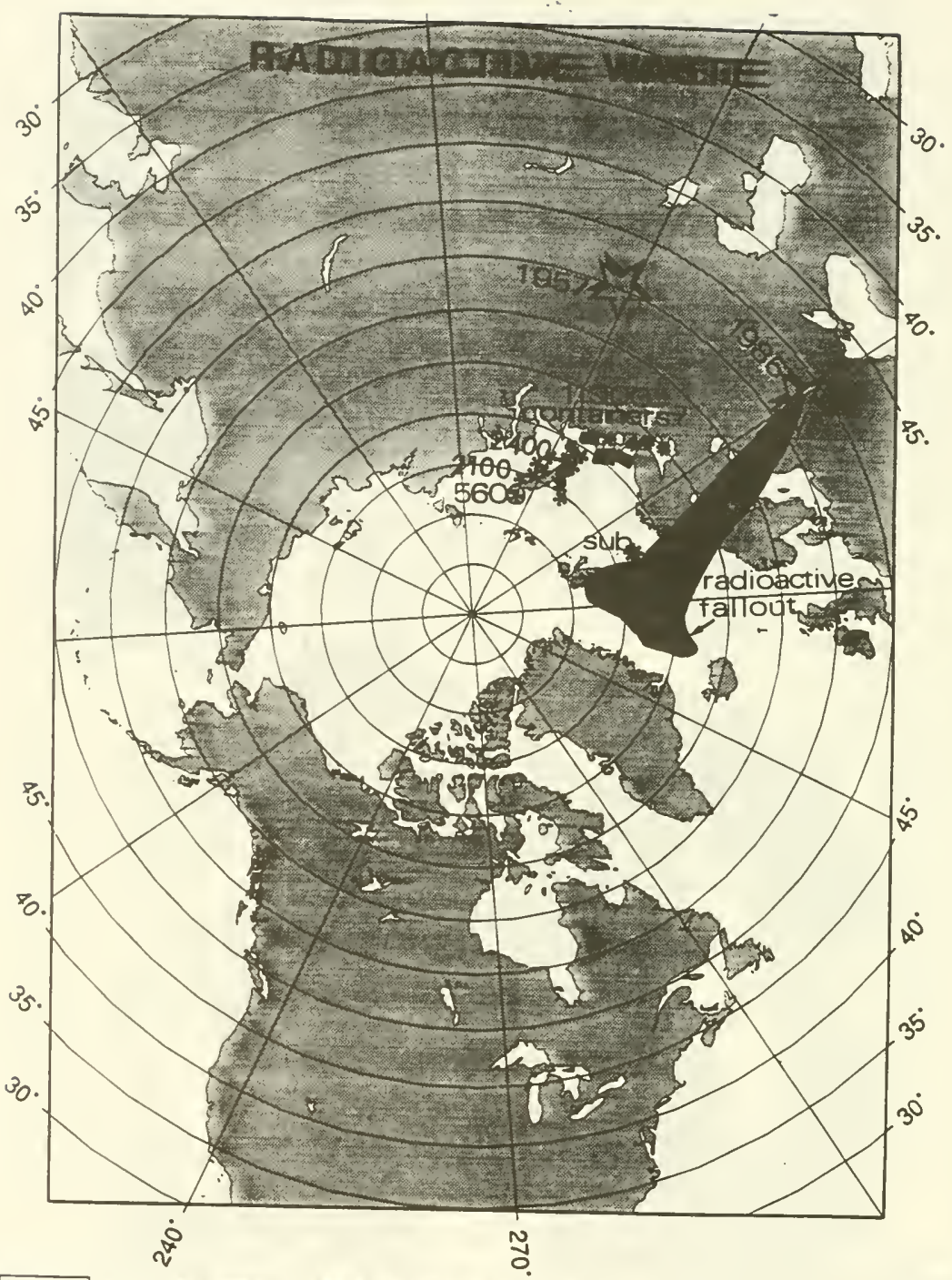

GMT Aug 24 1727 ] Énvironmental Defense Fund

Figure 9 


\section{Polar Subregion \\ BARENTS SEA}

POLLUTION

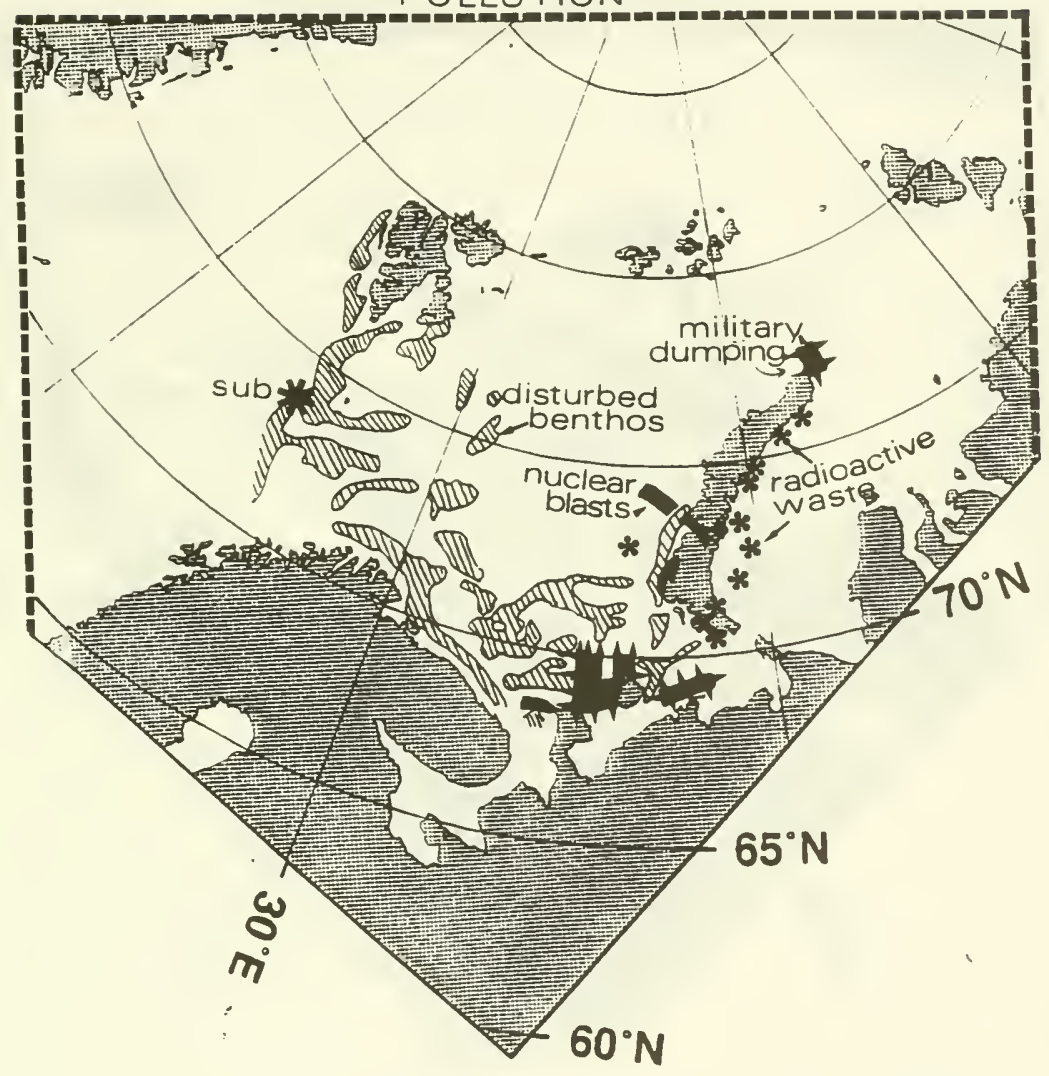




\section{Polar Subregion BARENTS SEA}

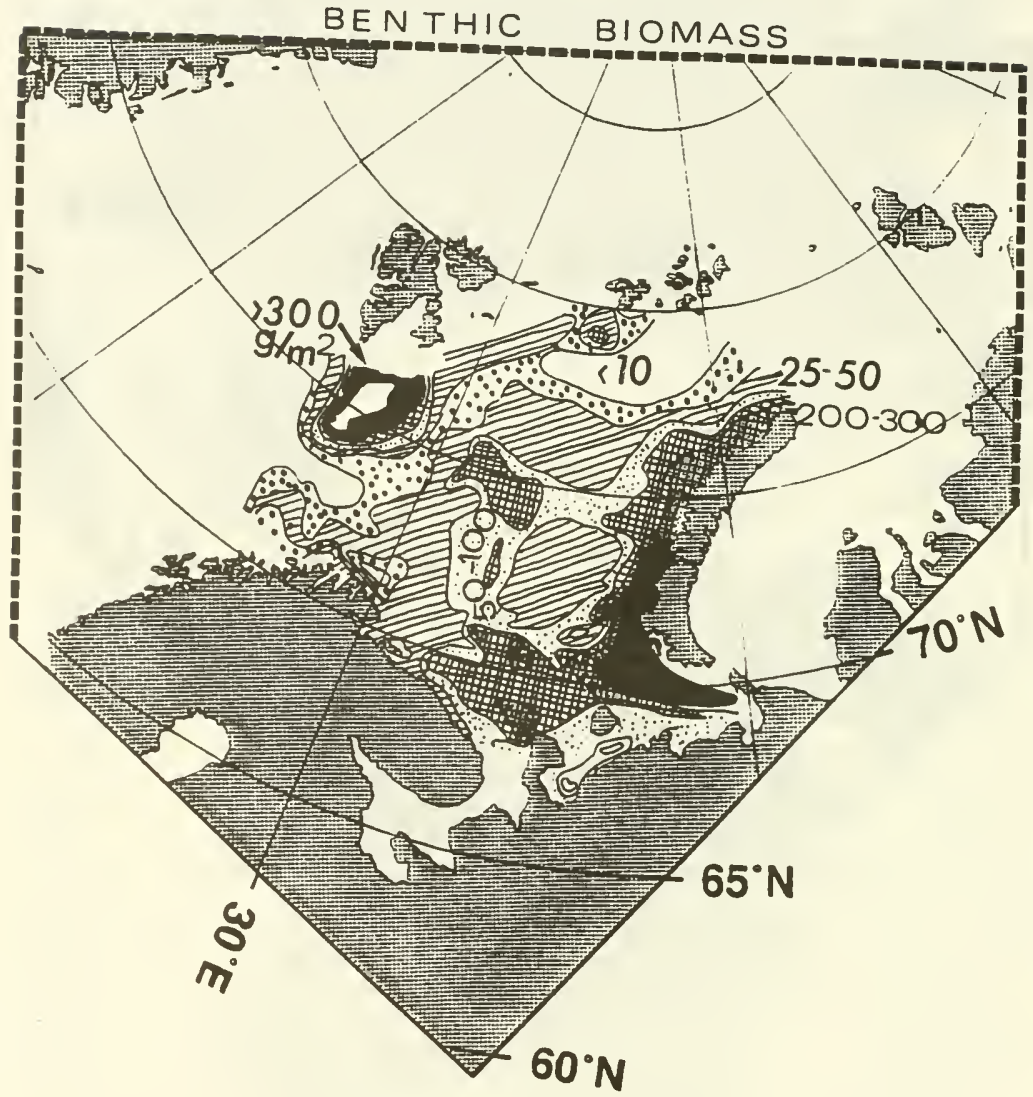

Environmental Defense Fund 


\section{Polar Subregion BARENTS SEA}

SURFACE

CURRENTS

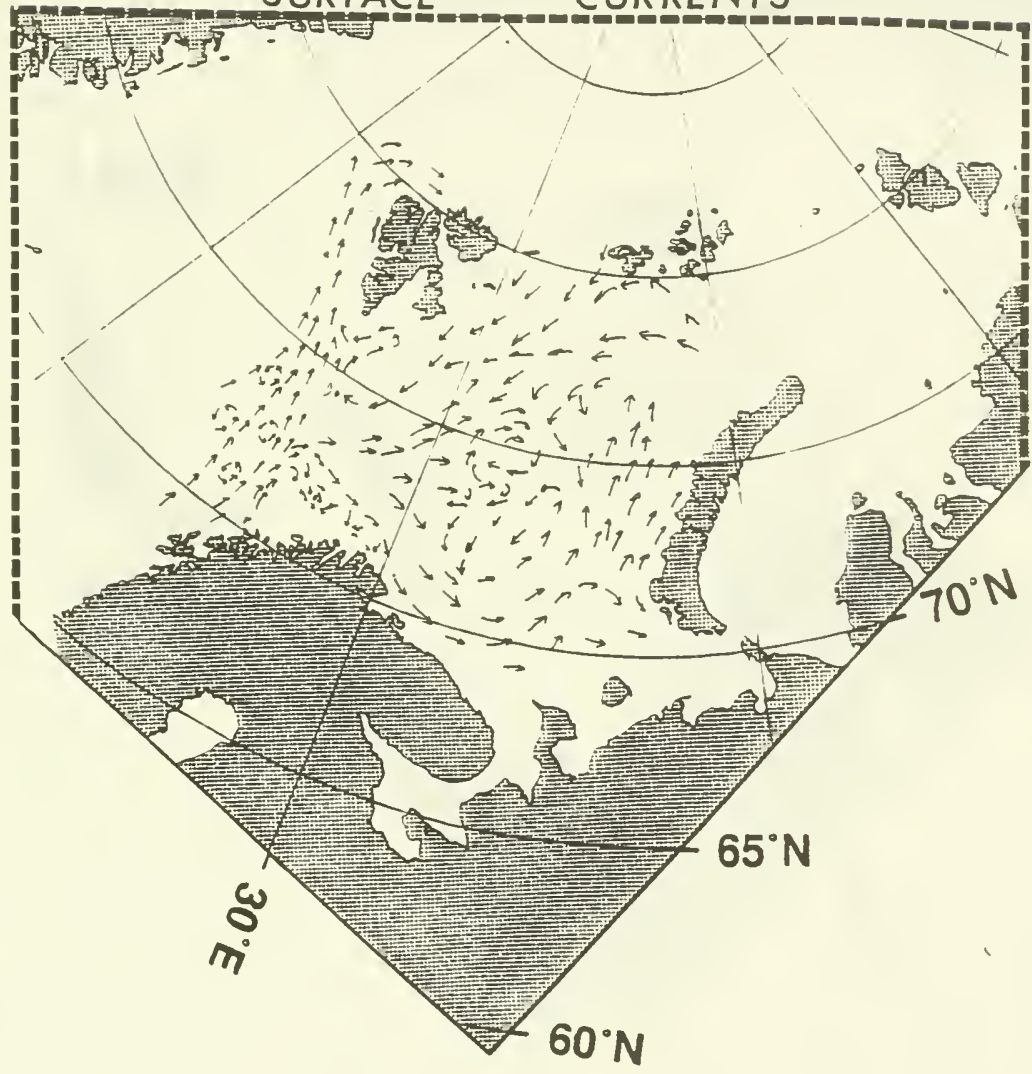




\section{Polar Subregion} BARENTS SEA

\section{BOTTOM CURRENTS}

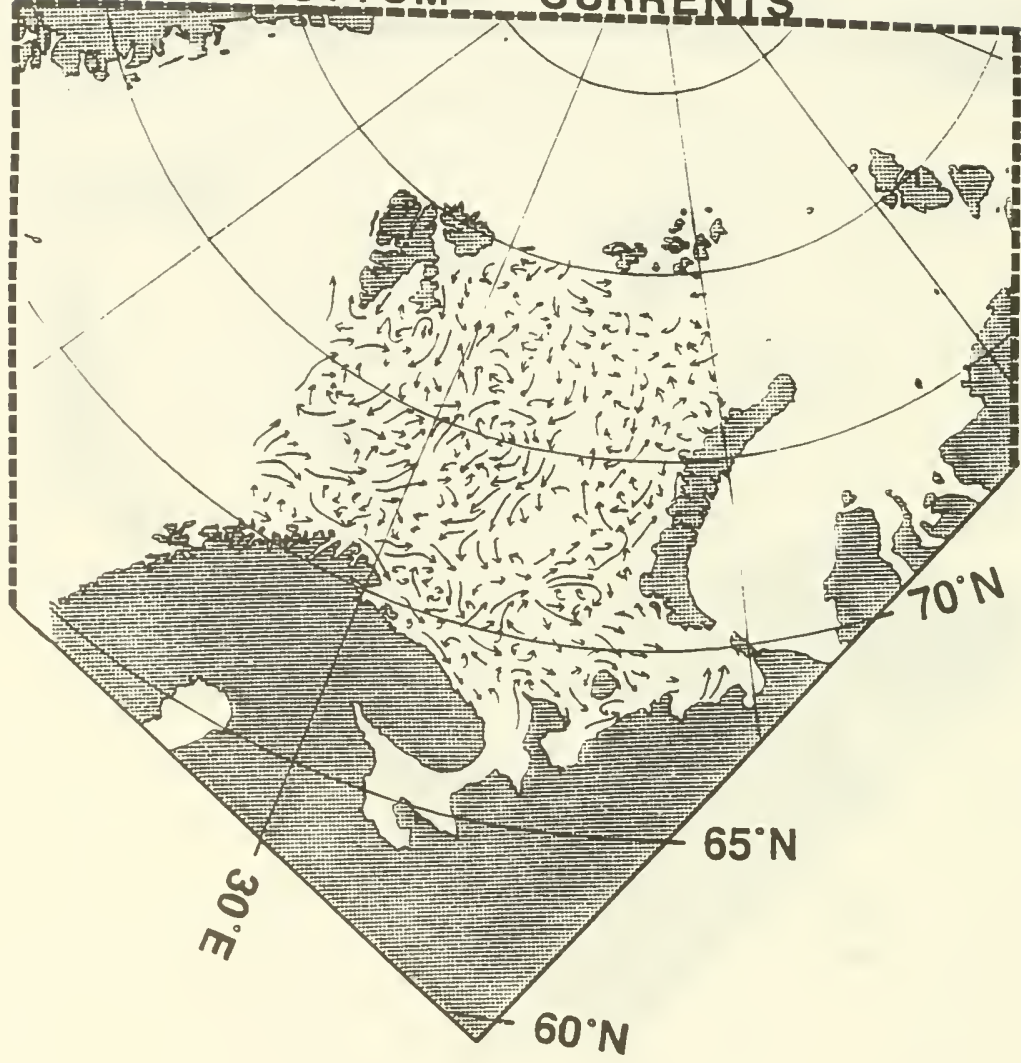

Environmental Defense Fund 


\section{STATEMENT OF DR. STEPHANIE PFIRMAN, ENVIRONMENTAL DEFENSE FUND}

Dr. PfIRman. Thank you. The Environmental Defense Fund has recently launched a major initiative to address Arctic environmental issues, including an assessment of the multimedia threats to the Arctic environment and an evaluation of the effectiveness of the existing legal regime to provide sufficient protection for the Arctic. The Arctic environment is presently faced with significant threats from a wide variety of anthropogenic sources of contamination. In addition to the nuclear reactors and wastes dumped in shallow waters near Novaya Zemlya, that we've been focusing on mostly today, there are also significant threats to the Arctic through oil spills, acid rain, heavy metals, PCB's, dioxin, DDT, and superimposed on all of these threats are the additional concerns of global warming, ozone depletion and Arctic haze. These environmental threats are putting the Arctic and its people at risk. The effects of these stresses range from immediate harm to humans, as we've heard, from Russian health statistics in the previous panel, as well as to Arctic flora and fauna, to potential long-term damage to entire ecosystems, and potential disruption of the entire global climate system.

What I'd like to do now is show some overheads that detail some of the possible sources of pollution in the Arctic and some of the transport pathways that you've been hearing about on previous panels. This map here was put together by the Norwegian Polar Research Institute together with the Academy of Sciences of the USSR, and also the Polish Academy of Sciences. What it shows are some of the biological resources of the Barents Sea. Norway is down here. Spitsbergen is here. And Novaya Zemlya, the area we've been talking about, is over here. In addition to the areas of concern that the map originally identified, I also included the sites of reactor dumping and the areas where low level nuclear wastes may have been disposed of. This data is from Greenpeace. 'Highlighted in red are some of the areas that we're especially concerned about. In this box down here and along these areas we have reports of unspecified dumping. The dump sites may contain some radioactive waste. The mushroom-shaped sites here are where explosive nuclear tests occurred.

Now we've been talking a lot about what data exists, and what we still need to find out. What I'd like to show here is that there is actually an extensive data base already available. It's located within the former Soviet Union and we just have to do some work in ferreting it out.

In 1973 a Russian scientist, Tansiura, published this map showing bottom current transport in the Barents Sea, exactly in the area where these dumping activities have occurred. Taking this data together with similar data from other sources, we can put together a projection of where radioactive contaminants, as well as other pollutants could be transported in the Barents Sea and potentially enter the Arctic Ocean. We, of course, cannot rely on these maps that just show circles and arrows. We must get back to the original data. And for this reason, it's very important that we make contact with the scientists who have put together these maps, find 
out where the original data is, and then see how we can apply it to trying to understand the extent of the problems.

The next map that I'll show gives an indication of what the productivity is like on the sea floor on the Barents Sea. You can see here on this lower corner the area where the most extensive dumping has occurred, located on the west side of Novaya Zemlya. It's the most highly productive area in the Barents Sea. This map shows the distribution of benthic biomass. It was put together in 1963 , and this is interesting because it probably was put together based on data that was collected before much of the dumping occurred. This means that perhaps we have baseline information here that we can use to see the effects of dumping activities, if we can get back to the original data.

Now as I mentioned in my opening statement, what the EDF is doing right now is putting together a multimedia approach to try to understand the Arctic environment and the threats to it. What you can see here in this oval-shaped delineation is the area of the Arctic that's affected by Arctic haze during the wintertime. This is the Arctic air mass that Glenn Shaw had talked about before. Any pollutants that are put into this air mass during the wintertime have the possibility of being transported throughout the entire Arctic, so we're linked whether we like it or not. What you see here in this hook shape is a pulse of highly polluted air that was released from Europe and was transported across the Arctic within five days. This gives you an indication of just how closely we're linked to Siberia and Eastern Europe. What you see in green is an area that may be influenced by ozone depletion in the future. It's an area that's particularly susceptible to ozone depletion. The areas in pink show where acid rain has already substantially affected the ground, acidifying the lakes and the lands. And in the areas that I have marked in yellow, you can see places where the fallout from acid rain, a wide variety of contaminants and also of Arctic haze, could be affecting the marine ecosystems.

Superimposed on all this, of course, we have the potential threat of stresses to the Arctic environment from global warming. In addition, I've marked in black here some Russian rivers that we've heard are incredibly contaminated with a wide variety of materials, including PCB's, bacteria, dioxin and DDT. Now what will happen to these pollutants when they enter the Arctic ecosystem? The surface water salinity that I show here is once again from a Russian atlas, this was published in 1980. And here along the boundary of Siberia you can see the extent of influence of the Russian rivers in the coastal areas marked in yellow. What you see is that the Russian rivers contribute to changing the salinity of the coastal seas. This means that any pollution that's transported with the rivers has the potential to affect these wide shelf seas that are adjacent to some of the most productive seas in the world.

Now could this pollution eventually be transported towards Alaska? Again, the same Russian source, you can see this very busy map. Now one reason I chose the Russian data is to give you an indication of the wealth of information that is potentially stored in the former Soviet Union that we have to work hard to ferret out. But you can see here, in the same area marked in yellow before, a coastal current that's transporting water along the northern mar- 
gin of Siberia, and it's heading towards the Bering Strait. This is an area that, of course, we need to investigate further in the future, but it shows the potential for some transport of pollution along the Siberian margin. There are also other pathways through the Arctic Ocean system.

There's another potential transport pathway which is through sea ice. Sea ice is transported basically in the same directions as the surface water is transported. There is an important circulation pattern here, this gyre that you see. Any particulates that are transported off the Siberian margin and land onto the sea ice could move into the area along the northern coast of Alaska and melt. Most of the sea ice that melts along the coast of Alaska actually is formed in place. But there is a possibility that some of the sea ice from the central Arctic will be transported into this coastal regior. as well.

I'd just like to close with a few further remarks. There are numerous threats facing the Arctic environment today. And I would hope that this hearing will be the first in a series to try to uncover the exact extent of the risks and to develop a coordinated plan for addressing them, in addition to the threat of nuclear waste.

As far as dealing with the nuclear reactors that have already been identified in the vicinity of Novaya Zemlya, at this point I believe that there are two possibilities. First of all, we'll find out that the reactors are found to be leaking. In that case, we must assist the Russians with appropriate technology to either raise the reactors or to cap them in place. We would also have to support the Russians in their efforts to try to contain the leaks. If they are not leaking, then we must also decide whether to deal with them on the sea floor or to remove them. Therefore, at this point, we feel that it is crucial to involve our nuclear and environmental engineers as well as those of Russian to assess the risks posed by the reactors and to design plans to deal with the risks. And we hope to hear in the final panel today that such an action plan has already been put in place.

The Arctic Research Commission and the Interagency Arctic Research Policy Commission should develop a coordinated national monitoring and response program. We were pleased to hear that the State Department is interested in placing more emphasis on the Arctic and we hope that they would play a central role at a high level in directing the overall intergovernmental effort.

And finally, we agree that IASC, the International Arctic Science Committee, has an important role to play, and the governments of the Arctic rim countries should rely on its expertise. Thank you.

Senator MURKOwSKI. Thank you, Dr. Pfirman.

Scott Hajost.

\section{STATEMENT OF SCOTT HAJOST, ENVIRONMENTAL DEFENSE FUND}

Mr. HAJOST. Thank you Senator, It's a pleasure to be here today. I am the International Counsel for the Environmental Defense Fund. I just have a few brief policy points to make in addition to what Stephanie has had to say.

The first point has to do with communications we've had with the International Maritime Organization recently, with respect to 
nuclear dumping in the Arctic. It's been confirmed to us that the Secretary General of the International Maritime Organization is currently requesting information from the Russian Federation as to the nature and extent of that dumping. I should give credit to my colleagues from Greenpeace for originally bringing this issue to the attention of the IMO last year. We strongly believe that the U.S. government should be supporting this effort and that there should be a full and timely response from the Russian government. At the same time the U.S. government should be evaluating the application of all relevant international agreements that might address this issue and publicly report their conclusions on an urgent basis.

The second point, there's a fair amount of discussion about the Russian Aid Bill. An effective assistance to Russia is vitally important and hopefully a good bill can be passed before this Congress adjourns this fall. It's important to keep the Russian scientists who have been involved in putting baseline information together in the process of supporting this environmental effort. I'd note that the Russian Aid Bill not only contains some very important provisions on the Arctic to this end, but also some critical provisions on improving energy efficiency in Russia and on broader environmental protection. In this regard, I would note that at the July Group of Seven Economic Summit in Munich, the Group of Seven leaders committed, as part of their assistance to Russia in the nuclear area, to promote and assist efforts to improve energy efficiency and alternative energy as an alternative to some of their nuclear reactors. This is critical. Improvements in energy efficiency is not only the most effective means to shut down Chernobyl type reactors but also to address a host of environmental problems including pollution in the Arctic. A Russian aid bill promoting conservation and efficiency would help give some meaning to that if passed. It's vital that assistance be provided to Russia if we are going to actually protect the Arctic environment.

The other point I'd like to note, that it's important to the U.S. not only to take a lead in the assessment process but also in the mitigation and prevention side of protection of the Arctic. The Arctic has not been adequately protected by the existing international environmental legal regime. The Arctic Environmental Protection Strategy adopted in 1991 could make a contribution to this end if effectively implemented. This will take a much higher level of policy and attention to it by the Federal government, including the State Department, as Assistant Secretary Bohlen has mentioned and Stephanie noted, but also by agencies such as EPA and NOAA, who need substantially new resources in order to effectively implement the Arctic Monitoring and Assessment Program. Moreover in this process there needs to be a much greater effort to try and ensure that the existing international environmental agreements, such as those are we might address Arctic haze: the convention on Long-Range Transboundary Air Pollution are fully brought to bear.

Fourthly, I'd also like to welcome the statement at the recently concluded Arctic Conference by Assistant Secretary Bohlen of his intention to create a State Department advisory committee on the Arctic. I believe this could be a very important vehicle in getting nongovernmental input of all types into Arctic environmental pro- 
tection issues and indeed contribute to giving it a higher priority. It could also affect in reevaluating the 1983 NSC statement of U.S. Arctic policy in the post-Cold War era, which was an important part of the discussion at the Fairbanks Conference.

Finally, in light of some of the gaps and questions of applications that I and others noted in the Arctic legal regime, is the view of the EDF that it is time for there to be a serious consideration by the U.S. government and Arctic countries on the development of an Arctic convention. Such a convention would incorporate protective measures to address all forms of anthropogenic contaminants entering the Arctic as well as a comprehensive approach for addressing and development activities.

Thank you.

Senator MURKowSKI. Thank you very much, Scott. Moving to our last participant, Joshua Handler, Nuclear Free Zone Program with Greenpeace. Please proceed.

\section{STATEMENT OF JOSHUA HANDLER, NUCLEAR FREE SEAS PROGRAM, GREENPEACE}

Mr. HANDLER. I'd too like to thank you, Senator Murkowski, for holding this hearing. And it's a very important and timely one. Greenpeace is a large, international environmental and peace organization, some four million members worldwide in over 100 countries. We've been opposing-we've been actually promoting nuclear disarmament for over 20 years. One of our first activities was opposing nuclear testing plants for Amchitka here in the Aleutian Islands 20 years ago. Over the last two years we've been particularly concerned about the situation in Russia and we've been intensively investigating problems in their naval nuclear program, particularly aboard their submarines and nuclear icebreakers. I personally have visited Russia six times, visiting previously-closed areas, and still closed areas, in the Far East and Far North. During these trips we've gathered documentary evidence. We've taken geiger counters to verify reports of radiation, and we've spoken with admirals all the way down to local ecologists about the situation.

I don't want to dwell on the dumping question off Novaya Zemlya. I think that's been extensively discussed earlier. Colleagues at EDF did a very good job of explaining the situation. Others discussed it earlier. Suffice to say, our reports continue to indicate there are 15 nuclear reactors that were dumped off Novaya Zemlya, three from the icebreaker Lenin, 12 from submarines, half of the submarine reactors reportedly still have their fuel in them, and the Lenin reactors also contain their fuel. In addition to this, there's over 10,000 barrels of low level nuclear wastes that have been dumped around the area.

The situation in the Pacific, as far as we know-well, my point is we don't know what the situation is specifically, I'm somewhat reassured in my conversations with naval officers but we still want to investigate this further.

What I will though submit for the record is a number of our reports and articles dealing with our trips to the region as well as conferences we've held in Moscow, and I think they will serve as a useful record of our activities. 
Senator MURKowskI. They will be entered into the record as if read.

[The documents referred to follow:] 
Testiony for the

U.8. Senate Select Coenittee on Intelligence Hearing Held 15 August 1992 at the University of Fairbanks, Alaska on

Radioactive and Other Environaental Threats to the United states and the : Arctic Resulting fros Past soviet Activities

by

Joshus Handler

Research Coordinator

Orempeace Huclear Frae seas Caupaign

Uashington, D.C.

ph. 202/319-2516

FAX 202/462-4507

[Revised for the Record 18 Auguet 1992] 
1. Introduction Gremence and the Huclene free sens Ganden

First, I would like to thank the Conelttee for this opportunity to teetify on the ieportant eatter of radioactive thrifts to the Arctic. Brempeace, as you any know, is a large international environeental and peace organization with soee four allilon eebers in over 100 countries around the world. We have been active for twenty years on environeental and nuclear disaraaent lasues, and have offices throughout North and Bouth Aeerica, Europe Including Rusels and Ukraine, and the Paciflc.

(It eay be of interest to the 8enator and residents of Alask to know that Breenpese's origins IIe in atteapts by Vancouver activiste to stop U.8. plans to teat nuclear weapons on Aachitke in the Aleutian Ielande in the early 1970s.)

One of our eajor concerns is nuclear weapons and ailitary and civil nuclear-power plants. Wo oppose this technology and seak its eventual elieination for a variety of ieportant reasones the environaental dangers posed by nuclear accidents, the vexing nuclear waste probles, the econoelc costis, the possibility of nuclear war, and the antidesocratic secrecy that surrounds nuclear technology. Just as slgnificant to our perspective is that core resconable and sefer alternatives to solving disputes between nations and addressing the world's energy needs exist or could be readily developed.

8ince July 1987, the Oreenpeace Huclear Free seas Caepaign has been actively secking the elieination of nuclear wapons and reactors at sea. The nuclear ares race at see we large, dynaelc and dingerous. Nuclear weapons first went to sea aboard U.8. aircraft carriers in the early 1950s. 8y the late 1980s, soes one fourth to one third of the world's aleost 50,000 nuclear weapons were avallable to the naval forces in the U.8., soviet, 8ritish, French and Chinese navies. The first nuclear-powered vessel, the subearine U88 Nautlius, was coeviseioned in 1954. Dy the late 1980s, Just over half of the aleost 1,000 nuclenr renctore in the world were naval nuclear reactors prisarily on the cubearines of the soviet, U.S., British, French and Chinese 1leet. New nuclear wapons and nuclear-powered veseels were entering the llets or were planned.

At the tie our casplign started there was considerable concern anong andyets thit the U.8. Mavy's agressive harlties strategy would have agoravated an U.8.-8ovitet crisis into war. And, If it had done so, aclear war could have sterted at we rather than on land. We were also worried that peacetiee navel cperations posed a serious environeental threat. In one our Meptune Paper reporta, Hunl Aceldente 1945-1988 CBrempeace/Institute for Policy studien, June 1989), w found that some (1fty nuclear warheads and elght subarine nuclear reactors, the eajority soviet and the rest froe the United states, had been lost or dueped at sea due to alitary accidents.

We have had some successes in achieving our goals. We found it significant that President Bush in his 8epteeber 1991 post-coup atteept speech involving nuclear weapone reductions proposed to reaove all tactical naval nuclear weapons froe U.8. surface chlps and subearines, and elieinate part of thee. This was a esjor reveral in policy, as previousiy the United states 
and particularly the U.8. Navy had adaeantly refused any soviet offer to reduce or even discuss the probles of tactical naval nuclear weapons.

Fortunately, President Borbachev responded $1 \mathrm{in}^{-} k$ ind, and went further by proposing a autual total elidination of tactical nuclear weapons at sea. President Bush did not take President Corbachev up on his offer. iut in early July 1992, President sush announced his 8epteeber proposals had been fully iepleaented, i. .. that no core ships or subarines carried tactical weapons during peacetiee, and that 857 nuclear depth boabs deployed overseas in the $U, K$. and Italy had been brought back to the United states. We are awaiting a parallel announceent fros the Russian Mavy. We also hope that desplte President Bush's position, we ay see the total elieination of tactical naval nuclear weapons soon.

\section{Brenpence Nuciear Free sene Activities in the soviet, union and Russia}

Two years ago, spurred by our investigation of naval nuclear accidents, we begsn to focus on naval nuclear problees in the soviet Union. 8ince February 1990, I personally have visited Russia six ties for extended periods. I just returned from a three-week trip, Including two weeks in the Vladivostok and Khabarovsk ragions on 9 August. Other Oreenpeacers have spent sieilar aeounts of tiee there, and we also have orenpeace Russia office in Hoscow.

He have ande a special effort to go where the probleas are. I have been to the Vladivostok area three tiees, Petropavlovik-Kaechatskil once, severodvinsk on the White sea twice, once to mureansk, and have eade several visits to hoscow. Other Greenpeacers have visited these areas and Krasnoyarsk. Also we have brought a Greenpeace boat to fureansk on the Kola peninsula and Nakhodka in the Far East, and landed a teas on Movaya Zeelya, the Russian nuclear-test site, in October 1990.

In each of these trips we have distributed translated copies of our inforation dealing with Rassian naval accidenta. We have also sought further Inforation bout nuclear concerns in the regions and about probleas with the soviet nuclear subearine force in general.

To verify and expand our datebase of inforeation, we have obtained official docuaents relating to these problems, visited sites of nuclear contaeination and storage areas with radiation ceasuring instruents, and held eetings with supree soviet eabers, people's deputies, local ecologists and environeental authorities, halth officials, radiation conitoring specialists, subearine plant officers, and senior Navy captains and adeirals with responsibilities relating to nuclear subearines.

We also held a unique conference in noscow in septeaber 1991 in conjunction with the Russian Inforation Agency to exaline the deadly nuclear legacy of the soviet Navy. At this conference we asseabled citizens, officials, and apecialists for the first tiat froe Petropavlovsk, Vladivostok, severodvinsk, and Muraansk with western specielists and hoscow offlelals to share inforation about the problese in their regions. We also brought 
inforation available in the West about western navies and nuclear probles to assist the Russians in their understanding of the relative aagnitude of the challenge they face.

It was at this conference that Andrel Zolotkov, an engineer with ATONFLOT (the Muraanak based organization that operates the Russian nuclearpowered lcebreaker fleet) and anion people's deputy froe Mureansk, provided the first concrete detalis about the dueping of the nuclear reactors froe the Ice-breaker Lenin off Hovaya Zeelya and thousands of barrels of nuclear-waste in the Barents 8ex.

Shortly after this conference further reports about the duaping of nuclear waste at sea cae to the fore. In October 1991, a supreas soviet eesber in hoscow told e that an experieental liquid-eetal cooled nuclear subearine had experienced a severe eccident in May 1968 and that its reactors were not repairable. He said it was subsequently disposed of off Movaya Zealya.

In early February 1992, Alexander Eeelyanenkov, a People's Deputy Proe Arkhingel'sk and aceber of the supreae soviet of the foreer Union, published in sobesednik further inforeation about the dueping of naval nuclear reactors and barrels of radioactive waste off Movaya Zeelya. His data caes froe official inforantion provided to hic because of his inquiries as People's Deputy who sat on the defense and environeental coendttees of the supreeo soviet. According to hiv, twelve reactors Pron nuclear subearines that had serjous accidents were dueped off Novay Zeelya. 81x of these still had soee or all of their fuel in thee, two of which wore Iroe the liquid-aetal subearine described above. Others were froe soviot cubearines we know had experienced serious radiation accidents in the early 1960s. Thus besides the previously discused eight subearine reactors lost or discarded due to accidents -- three fron the U.8. and live frow the soviet Lnion -- there are now twenty-three reactors fros ships and cubearines on the ocean 1 loor.

I provide a tranelation of Andral Zolothov's presentation, Alexander Eoelyanenkov's article plus a Orempeace press relense with con additional detalis, and several trip reports and articles dending with our experiences in Russia for record.

\section{Our concerne bout Rudionctive Pollution in the Arctic}

A. Past luepling of radiactive enterials by the soviet Havy and ATONFLOT.

I do not want to dwell here on our concerns about the past ducping of radioactive and nucles eaterials. The stuation is alaraing. It has been well described by several other of today's presenters and previously published in the wet in our reports. How to proceed is relatively stralghtforwards The Russian goveraeent should coepletely disclose what has happened in the past) data about what has been dueped needs to be provided down to the cheeical coeposition of reactor veseds and fuel eleeents so soes estiente of corrosion and leakage rates can be eadel a substantial international 
scientific and engineering investigation of the situation should occur and, if the containeent of the dueped aterials is robust, they should be raised, or If It is not, they need to be entoabed and conitored.

However, because of the chaos and political Jockeying in Russia, it is foolish to rely totally on inforantion provided by the Russian governeent. Western governeents and particularly intelligence agencles need to provide all the inforation they have about these events, so a solution can be devised as quickly as possible.

\section{B. Future redistion poliution probless.}

A enjor worry is what is going to happen in the future. There are several areas of concern!

1. Deconalssioned Russian nuclear-powered subarinfe and associated icproperly stored naval nuclear waste leaking radioactive eaterials into the currounding environeent.

2. Accidents on nuclear-powered wbearines endangering the Arctic, North Atlantic, or, Pacific.
3. Huclear weapone tests resueding at Novaya Zeelya.
4. Construction of new nuclear-power stations in the Rusesian Far East.

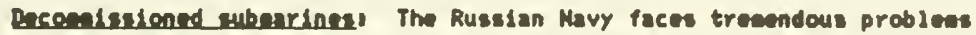
In disposing of its decosalseioned subearines and their sescolinted nuclear waste. Currently soee 60-80 Russian nuclear-powered subarines are awalting disposal. Senior Russian Adeirals estieate 150 nuclear-subearince should be disposed of by the year 2000. U.8. Rear Adeiral Edward shaefor, Director of Hevel Intelligence, told Congress on 5 February 1992 in his ennual testieny, these cubearines will pose ma growing environeental problee for the Russians, In whose harbors they are lying."

Regarding the Pacific, sentor Paclife Fleot captains have sadd there ore thirty-fiv decoedseloned nuclear-powered subearines in the Puciflc flet. All told, sixty nuelear-powered subearines w11l be taken cut of cervice by the your 2000. Due to lack of planning, funds, yard epace, and the non-cospletion of a service ship at the Mikoled yards in Ukraine, the Pacific Fleet has a shortage of capability for defuelling and decomalesioning ubearines. Only elghteen have had their fuel resoved as of 1992. Only 1.5 cubearines a year can be processed. Without on increase in resources, it will take forty years to defuel and scrap the decoedseloned wbearines in the paciflc fleet.

Ther are only general plans for IInal dispowal of these subarines. According to the Russian naval officers, soeties after the year 2000, a landbesed storage site soewhere in the north any be coepleted. So far nelther the site, heavy lift cranes, nor transport barges for the reactor sections have been constructed. Weanwile, the pacific fleet is resoving the reactor 
and two nelghboring hull sections, and storing these sealed sections afloat at the Pavlovik subearine base near Vladivostok. Two subasines have been coepletely diseantled, and three oore -- all Yonke ballistic aisedle subarines -- are being worked on. The reanining iêctions of the subarines have been sold for scrap.

The slow processing of the subwarines weans that vessuls in poor eaterial shmpe and with uneotivated crews are tied-up in harbors with the possibility they will atart laking radiosctive aterials and/or sink. An outstanding concern, until we are fully reassured by the highest levels of the Rusaian governeent and elistary, it that soes future at sea duaping any occur.

Beyond disposal of deconelesioned subearines, particularly their irradiated reactor veseels, there is the problen of the sssociated high and low-level nuclear waste produced fros servicing and decomissioning the cubarines. Waste facilities, soese of which ore located on or near the coast -- . g., east of Vladivostok on the Shikotovo penineula, near the Bornyak subearine ropair yards across Avachinakaya Bay frou Petropavlovak-Kanchatak11, and on the Kola peninsula -- are variously reported to be full or in poor eaterial shape. Residents in the Petropavlovik-Kanchatakil area have expressed concern that the ceeent "graves" containing radiosctive waste way bo leaking in to the bay.

Accldente on nuclear-oowered subenrines Thare are soes forty operating civil nuclear plants in the foreer Sovint Union. By coeparison, excluding land-based trainers and prototypes, Russis operates sone 270-280 naval nuclear reactors on it pleat of ellitary ubasines, warahips and civilisn veseelsi 130-140 nuclear powered subearinas are powered by 250-260 nuclear reactor in total and another twenty naval nuclaar reactors are on the doen nuclase-power ed cruleors, lcebrakers, barge-carriers and auxiliary ships operated by the Navy and ATONFLOT.

These nuclear-powered veseels have been plagued by serlous accidents since the beginning of the soviet naval nuclear reactor propras. On July 4, 1961, on of the first 8oviet nuclear accidents happened not in the U88R, but In the Norwegian Sea. One hundred dies off the Jan Mayen islands, the K-19 nuclear-powered Hotel clase ballistic eisalle subarine cuffered a prieary coolant leak. The ractor autoatically scraesed, but then the enin and auxiliary coolant pueps falled and the temprature began to rise. The paint on the coeparteent walls started to burn, threstening to start a esjor fire.

In the face of this desperate eeverency, the captain of the subarine ordered aystee be leprovised to get cooling water to the reactor. 8everal een froe the ractor division volunteared to enter the reactor coeparteent. It took the two hours to install the cooling systes, but they were successful. Thank to their fforts the cubarine was saved, and returned to port. The en, however, were not so lucky. All received lothal doses of 5,000-6,000 rea, and died painfully several days ofterwards. The subarine was subsequently nicknased HIroshima.

Reports 11ke this are becoeding regular fare in the Russian press. Site 
visits to subearine operating areas are turning up sore previously unknown disaster. During ay last trip, I learned new inforation about two altdowns -- one In 1979 and one in 1985 -- on cubearines in the pacifle fleet. In October 1991, we Investigated a reactor explosion that occurred on a Russian subarine on the shkotovo near viadivostok in Auguat 1985. Ton en were k111ed, and 100,000 of curles of radiation were released. There 15 stilla containated fallout trace in the area today.

Whatever the coapetence of Individual Rusalan subarine officers, they do not work in a vacuue. The huan and industrial infrastructure in the country 1s in bad shape. Even in "good" tiese the soviet Mavy suffered terrible disasters on nuclear suberines. Blven the bad tides the Russian Navy now faces, there is considerable reason to bi alaraed about the possibility of a serlous accident involving a Russian nuclear-powered subearine in the next fow years.

A second subarine-sceldent problen is subarine collisions. During a recent visit to Noscow, the Chief Mavigator of the Rusuian Mavy, ContraAdairal Valery Aleksin comlained to es quite strenuously about the February $1992^{\circ}$ collision between the U.S. and CI8 subearines. He notad that 100 of ean and three nuclear resctors could have ended up on the ocean floor.

There have been several draetic collisions between U.8. and Russian nuclear ubeariner since the 1960s. In one case, In June 1970 in the Pacific Involving the U.8. suberine U88 Trutog and the Russian Echo-class subearine K-877, cubeariners in both crew thought the other subearine had ank after the collision. So long as Russien, U.8. and U.K. euberines continue to play cat and couse gases under the wister, there will the possibility of a fatal disaster taking nuclear reactors to the ocean floor.

Wuclenr weneons teste! The resueption of testing at Hovaya Zealya will present an ecological hazerd to the region. According to Vietor Nikhallov, hesd of the Russian Ainistry of Atonic Energy, 30 percent of soviet nuclear tests have vented radiation to the ateosphere. Continued testing w111 also legitialze non-nuclear states' sepirations for acquiring nuclear weapons.

Hucler eower There ore plans to construct several nuclear power plants In the Ruseian Fir East. In the Khabarovak reglon, two 650 aegawatt reactor are scheduled for construction. 8everal seslier reactors -- actually subarina reactors burled underground and optialzed for alectrical production -- ear be constructed in the Prieorik11 Kray in closed eilitary areas. Also, the Kechatka regional adainistration roportedly wishes to build nuclear plante in their region. The dangers posed by the Rusisian civil nuclear progres do not need to be described here.

\section{What an the United stater do?}

On 7 Aprll 1992, we wrote Prestdent Bush and several senators and congresseen to express our concerns about the dangers posed by Russian nuclear 
suberines. I ubeit a copy for the record since what we suggested is still pertinent. In the letter, we strongly recoesended that eeetings and alte visits should be arranged between U.S. and Russian naval officers, civilian experts, and interested busineseaen to see what courd be done to assist the Russians solve their deconaissioning and waste problee.

To avoid eore Russian subearine accidents at sea, we urged that the United States stop its nuclear subearine operations. This would be the best wy to insure the Russians kept their subarines from saling. Due to the current lack of a substantive ailitary eission, halting attack subearine operations thould be feasible. As for ballistic alssile subarines, in President Yeltsin's January response to President Bush's state of the Union address, he noted Russia had already reduced its ballistic aisile subarine patrols, and he proposed halting the entirely on a wtual basis. Reduction in the alert status of nuclear forces and general lessened tensions should also allow the cessation of ballietic eisile subearine patrols.

We received a quick positive response from Rep. Charles Bennett, Chairean of the House Seapower subcoesittee, regarding or uggestions for asiditing Russia with its decoevissioning problee. He has taken a leadership position on this issue in the House, realizing thare are ecological and diltary benefits in having a sealler Russian nuclear-powered subearine force. Also he has noted that this prograe would not cost the American taxpayer a penny, as profits from selling scrap froe subearines would cover any woney Ient for this purpose.

Only in July did we receive s short non-comilttal response froe the President's office. Unfortunately, this Adeinistration is not ready to face this problee. Apparently, the U.8. Mavy, and priearily its nuclear propulsion prograe, has blocked any atteepts to cooperate with or help their foreer foes to decoedseson their nuclear-powered subearines. This offort extends beyond Just frustrating congressional initlatives. Reportediy, the Navy even has obstructed efforts by private U.8. busineseeen to work with the Ruseians to scrap nuclear-powered subearines.

The reasons for the U.8. Mavy's opposition ere apparently several-fold. First, there is a concern that if the Russian Navy followed U.8. suggestions and an accident occurred the lnited states in soes way would be held responsible: Yet, reportedly, this should not be an iscue, since the Russian Havy has indicated its willingness to assume full liability.

8econd, the U.8. Navy's subearine force levels hive traditionally been predicated on the size of the Soviet Union's naval forces. As such, helping the Russian Navy to reduce its ubearine force weakens the argueents for a sizable U.8. subearine force.

Finally, the U.S. Navy fears that helping the Ruseian Navy with their decoesissioning problea will inadvertently raise questions about the costs and problese with the U.S. deconed seioning prograe.

Currently the U.8. has soee fifty deactivated or decoeeissioned nuclearpowered subarines. Several nuclaar-powered surface thips and probably 
another flfty cubarines will be taken out of service in the next elght years. Reactor compartaents are currently being resoved fros the subeerines at the Pugat Sound Naval Shipyard, and then being barged to the Hanford Nuclear Reservation for shallow burial. 8oe twenty reactor coepartents have already been soved to Hanford.

This prograe is expensive. A July 1992 GAO report "Nuclear Subaarinest Navy Efforts to Reduce Inactivation Costs," estieated the total cost for Inactivating 100 wbearines and coepletely disposing of es would be soes $\$ 2.7$ b1121 on through the year 2000. This flgure does not reflect the full cost of decoesessioning nuclear subearines. It excludes the costs of transporting and storing the epent fuel of the reactors at the Departeent of Energy's expended fuel facillty in Idaho.

Discuseing Russian cubearine problees will ralse the questions in the United states ibout the cost of the U.8. decomissioning progran. Due to the flscal crisls, the problematic future of the U.8. nuclear-power suberine prograe, and the debate over ordering the next nuclear-powered alreraft carrler, the U.8. Navy apparently wants to avold having nuclear decoinissioning costs and waste disposel problees factored in to the "true" cost of purchasing and operating nuclear-powered subearines and surface chips. Although the decoasissioning cost per sub ay appear seall, it eust be renecbered in this perdod of declining defense budgets that the total cost of the prograe approxleately equals the purchase price of one new seawolf cubearlne.

As for the other iswes raised above, clearly the best way to stop Russian nuclear testing, is to stop U.8. testing. We are heartened that the recent votes in the House and senate show that the Congress is berianing to take a leadership position on this 1seue. He are working to incure that the House-Senate conference will strengthen rather than weaken the existing bilis" provisions, so that a peranent coseation of nuclear testing can occur within the year. Certainly in teres of the U.S. national interest in curtalling nuclear proliferation, winding dow the superpower nuclear ara race, and buttrassing the core ilberal forces in Russia, the ties wore than ever has cone to stop nuclear testing.

As for the civil muclear prograe in Russia, ald coney provided by the U.8. and the west has to go to alternative energy sources and energy efficiency prograes. The Uest is going to be throwing good eoney after bad if the Hest continues to support an ongoing Russian nuclear prograe. Alto, than we and the citizens of the forear soviet Union will continue to live with the threat of another Charnobyl.

Lastly, I want to say an overarching problee hers is not the environeent, but secrecy. The activities that we have discused today occurred in conditions of uteost secrecy in the soviet Union. Conversely, cost events were only learned about in the West through secret eathods, and were not ade known to the public. As a result of this secrecy, dangerous practices were adopted in the past, and now we are suddenly confronted by their deadly legacy. secrecy has been part of the problee. The sooner it is dispelled on all sides, the sooner we 111 will be better off. 
Insuring Russia provides a full disclosure of the Soviet Union's nuclear dueping activities, however, ay be hard. Desplte glasnost and the changes in the foreer soviet Union, obtaining authoritative inforation about past elpractices is still very difficult. This is soecthat understandable, as nations are generally reluctant to expose their darker secrets, particularly at the urging of outsiders.

In order to facilitate the provision of inforeation, the United states should to do Itself, wat It is asking the Russians to do. The U.S. eilitary and the Departent of Energy should provide coeplete inforeation about their nuclear problees, and nuclear weapons and reactor accidents.

such disclosures are necessary to show the Russians that this is not a eatter of aseigning blaee, but of trying to reach the best poseible coneon solutions. They are also leportant for reassuring the citizens of both countries that' their governeents can be open and so accountable. Finally, this is the way two equal netions who wish to enjoy good relations between their governients and cdtizens in the future should behme. 


\section{NUCLEAR FREE SEAS $\begin{array}{lllllllllllllllllllll}\text { G } & \text { R } & \text { E } & \text { E } & \text { N } & \text { P } & \text { E } & \text { A } & \text { C } & \text { E }\end{array}$}

Transiation cf the Presentation by:

Andrei Zolotkov

Feople's Deput $;$ : Suprer = Sovzet! for Mumarsl: reglon.

Cn the Dumping of Radioactive waste at Sea Near Novaya Zenl ya

at the

Greenpeace Nuclear Free Seas Campaign/Russian Intormat:on Agenzy Sor:inaz:

"Violent Peace -- Deadly Legacy"

Moscow. September $=3$ and 24 
The word "aste" has never aroused pleasant teelings. being associated sth odorous dimps. chaotically heaped rusting constructions or simply ath matter presenting no interest for men. Though the word may be used with dufferent adjectives. ie shall foc'ss our interest on RADIOACTIVE wastes.

They do not smell and for the most do not call up any negative feelungs with their view: human organs do not sense them. Is all wastes they accumulate. create the problem of disposal. but recently this problem has acquired special significance. It would be unjust to say the acuteness of it is solely the result the Chernobyl catastrophe, however it was specufically the year 1986 which marked the end of the uncontrolled reign of secrecy in the USSR atomic authority. Almost regularly. the new facts of the barbaric attitude to the environment are being revealed by the workers of the atomic industry. The population of the territories surrounding atomic installations has been yreatly damaged. However. the mark of secrecy has stood in the way of anybody trying to establish the truth. The truth was feared by the upper echelons. Who therefore thoroughly concealed the bad side of the "peaceful" and multary atom industr.

The information gulf. especially in regard to radioactive waste (RAW) has been so deep that it now wll require great effort to overcome the mistrust of the population to everything connected with the word radioactuvity. That is why we cannot do without a brief historic introduction to the problem of R.AW disposal. particularly concerning their dumping at sea.

From the very start of the development of the atomic industry. oceans and seas were viewed as the eternal burial sites for RAW. In 1946. the first dumping was made by the USA. in 1949 by the LK. in 1955 by Japan. in 1965 by the Netherlands. It is difficult for me to say when the USSR did this for the first time. but it as no later than 1964. Both in the USSR and abroad. sea dumping has been accompanied by special permissions but with llo control from international bodies.

In the 1360s. IAEA and the fyency for Atomic Energy of the Organization for Economic Cooperation and Development started research to determine the hazard of RAW sea dumping and to work out international standards and regulations.

In the period 1971 to 1983 annual dumping was made by Belguum. LKK. and periodically by the Netherlands and Switzerland. The qualitatıe and quantitative evaluation of these operations was controlled by the Agency, the characteristics of the main areas of RAW dumping sites in the Atlantic Ocean present no secret: the review of low-level RAW sea dumping was published in the "Information Bulletin" No. 5 in 1991 by the Center on Public Information on Atomic Energy.

What are the criteria for choosing dumping sites? They are: the depth 
Dumplr.g of Railoactive Waste at Sea Greenpeace/RIA Moscow Deadly Legacy Serriar

which should be no less than $4.000 \mathrm{~m}$. remoteness from man ocean routes. minimal jea prodictivity in the vicinity of dumping which manly regards fishin:- zones, and remoteness from the continents and islands.

The 1372 Lundon Convention. which was joined in 1376 by the Soviet Union. defined the categorv of high-level radioactive material forbidden for sea dumping (based on the total radioactivity: spent irradiated fuel. highly active liquid wastes of approximately 0.5 curie/l with beta and gamma radiators with half-lives of more than one year) and the category of radioactive materials permitted to be dumped (comprising low- and intermediate level active wastes). The convention has worked out relevant recommendations which nere to be followed by the national organizations of the member states.

In 1983. the 7 th Onsultative leeting of the London Convention adopted a resolution for a moratorium of RAW sea dumping for 2 years (USA. LK. the Vetherlands. Switzerland. Suuth tfrica. and Japan voted aganst. and the (SSR. France. Greece. Brazl. and FRG abstained). This was caused by serious oppusition both within the dumping nations and in the countries located near the selected site of dumping in the Atlantıc Ocean. Groups of independent experts were set up to carry out additional research.

Although the results of determining the environmental consequences of long-term RAW dumping in the Atlantic were quite optimistic, and the preliminary calculations have shown that even at the existing level of dumping on a particular site during the next 500 years individual radiation doses would not reach significant magnitudes (no more than 0.001 "PDD" [maxumal allowable dosage]). the discussion of these conclusions at the 9 th Consultative Heeting in 1985 did not lead to the solution of this problem.

The controversy shifted from the fields of science and technology to the political sphere: again there "as adopted a resolution on further research thich pre-supposed. in reality, the moratorium extension for the indefinite perıod of time. Twenty-five countries voted in favor (UK, Canada. LSA. France. Switzerland and South Africa were against, and Argentina. Belgium. Italy, Portugal. Greece, USSR, and Japan abstaned.)

It may be noted that the review of the foreign press presents detauled information on the activity of different countries in the field of RAW sea dumping. The location of sites, depth, number and mass of containers, and the total activity of the waste could be found in the materials accessible not only to specialists. What about the Soviet Union?

The USSR joined the Convention 15 years ago: the USSR Council of Ministers adopted a special decree Yo. 222 of March 6, 1979 in this respect. In accordance with this document the LSSR Goscombydromet was held responsible for issuing special licenses and general permissions for RAW sea dumping (in coordination with the Ministry of Fisheries). I would like to quote 
Dumping of Radioactive Waste at Sea Greenpeace/RIA Moscow Deadly Legacy Semınaz

an official response to $m y$ deputy inquiry:

"In accordance "ith I.AE.A docunents. the L'SSR Goscombydromet from the mument of joining the convention has issued no permission for R.th d d mping to their unners. The regulation of the Convention do not apply to the vessels enjoving sovereign immunity in accordance with international law. As it was explained by the Foreign tffairs Ministry these are the vessels of the lavy."

Thus. It appears to be like this: the civilian vessels have been given no permission. : ihile for the Yavy the regulations of the convention do not constitute a law: they dump as they wish. Is this indeed so? The cited part of the answer above is yet another lie. which is refuted by the attached map.

The map shows harbors and marine regions where RAW was dumped for more than 20 years. from 1964 to 1986, by vessels of the Uurmansk shipping Company. the status of which has got nothing to do with the liavy. though the freight in the majority of these trips was the property of both the ihipping company and of the liavy.

RAW (mostly solid), dumped in the vicinity of the Yovaya Zemlya archipelago, is composed of containers. metal structures, and additional equipment of nuclear energy installations. The documents of these operations, which I have read. are quite interesting from the point of view of the technique of dumping.

The very notion of a container presupposes a hermetically sealed construction. preventing even a brief contact of the contents with the environment. However the containers' content allowed them to remain buoyant (they simply didn't sink). What was to be done in such cases? The problem ' $\mathrm{x}$ as solved in the simplest possible way: in the hermetically sealed (:) contaner two holes were cut. it was filled with water. and thus sinking was guaranteed. It is hardly worth analyzing different methods of RAW cementing, bitumenising, or vitrifying, when the documents report on the search for floating containers and their content.

The reports testify to the sea water and ground samples being taken in the area of the dumping, but the research results do not exist. I would like to refer to an official document. given upon request and signed by the LSSR Goscomhydromet chief Mr. Israel:

"As for the radioactive contamination of the Barents and Kara Seas, the research conducted by the scientific research establishments allowed the determination of the fact that the main source of these seas contamination comes from global fallout from previously conducted atmospheric nuclear explosions and from contaminated water masses coming from the Sellafield Plant in Great Britain." 
A. Zolotkov

Durping of Radioactive Waste 3 : Sea Greenpeace/RIA Moscow Deadl $Z$ Lagacy Semnar

i am not going to refute this statement. havinir no data on the radiation in the ; ilfs of lovaya Zemlya archipelago. However knowing the habits of our olficials (n) make false statements. : think the best as to calm down the public joubts ill be to follow ip the tppeal of the jth Extraordinary jession of the Murmansk Soviet of Peoples Deputies Prom Aigust 31. 1391. which sais. "We demand to solve the question of opening the archipelago and the adjacent *aters. primarly for scientufic research. taking into account that it has been a fishing zone for the local population for hundreds of years."

I am not sure the RAW dumped completely followed the requirements of the I.IEA. Thus in one of the gilfs there vas drowned a contanner wh the screen assembly of the icebreaker Lenin's nuclear installation unit: the witnesses state that the container could have no less than 100 spent fuel assemblies. Another fact: in 1384 in the Abrosimov Gulf there $w$ as found a ontaner with the radiation level of $160 \mathrm{r}$ /hour. which was resunk in the same drea after additional processing had been made.

It would hardly be serious to try to compare the dumping depth with IAEA recommendations, as these values for the liovaya Zemlya gulfs are limited to a few dozen meters. The remoteness from land is also hardly worth discussing. The seas routes in this region are blocked by the proxamity of the nuclear test site. Until recently the whole vast region of the northern seas *as somehow viewed as Soviet property -- as a kind of an inner sea which could be worked in as is thought best.

But the time has changed. Without concealing past mistakes and takıng responsibility of the past actions, we should open all data regarding the activity of the nuclear authority at sea. We need normal civilian research. not the secret expeditions.

The experience of the Chernobyl catastrophe shows that the attempts to conceal the truth end without results. Similarly, we will eventually get a full picture of the Novaya Zemlya testing ground and RAW sea dumping although it may take years and some facts may be lost.

I would not like to see the atmosphere of hot publications and sensational articles round the Yovaya Zemlya affair -- it will only hamper' serious research, and today the specialist's work has lost part of its respect as it is. At the same time it is high time to understand that without the qualified personnel and modern technology the development of nuclear science is impossible.

Even if we shut all nuclear objects today, their safe decommissioning wll take dozens of years and more than one square kilometer of the countrys territory. This is axomatic. And we have no possibility to launch RA to the sun. as of yet. 
Having on the territory of Murmansk and 1 rkhangelsk regions bases of coastal service lor nuclear ice-breakers and nuclear submarınes. and large plants for overhaulins. : e shall also need big loneterm facilities for storing jolnd and solidified R.AW -- the so-called regional burial sites for several hundred sears.

I do not agree with the preluminary conclusion of one the linistry of ftomic Energy Production of the USSR which states that "the preferable point for dumping RAl of the Northern Region Vavy will be near the settlement of Dalnye Zelentsy."

Why Dalnse Zelentsy? Is it only because that the capital investment for the analogous construction will be 2.5 tumes more in Novaya Zemlya? Have the social and political aspects been taken into account? Or is it more profitable for someone to make burial sites in non-contaminated areas? I lot of questions and fe $\%$ answers.

There is correspondence in this respect but it is not open.

I would also like to say a few words about the pouring off of liquid RAW. They were dumped in certan localities of the Barents Sea from 1963 to 1984 by the vessels of the Murmansk Shipping Company. The official information: "the investigation has shown that for $j$ days after dumping the concentration of Caesium 137 surpassed the background reading and a number of other radioactive components have been found. Upon the further dilution of waste. after the 5 day period of time their influence on the radiation situation was not registered." These are facts:

In the conciusion. I would like to note that the data quoted refer only to the activity of the vessels of the iurmansk Shipping Company. I have no information regarding similar activities by the vavy.

City of Murmansk

Andrei Zolotkov 
2DE AIVE - AMSTERZAM . ANCHORAGE - AUCKLAND - BRUSSEIS - BLENOS AIRES - CHICAGO - COPEVHAGEV. ZL $3 L V$

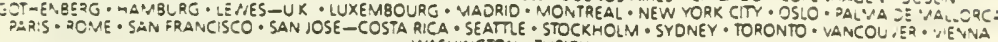

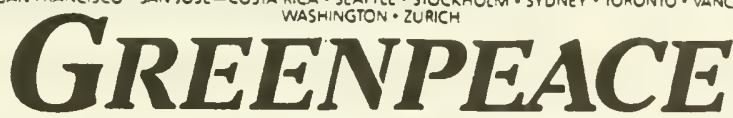

Greerpeace - 1436 U Street NW - Washington DC 20009 - Tel (202) 462.1177 Tix 89.2359 - Fax (202) 462.4507

\section{FOR IMMEDLATE RELEASE}

Contact: John Sprange or Jacquelyn Walsh in London, $071833-0600$

Joshua Handler in Washington, DC, 202/319-2516

\section{RUSSLAN NUCLEAR REACTORS DUMPED AT SEA}

London -- Greenpeace today released information confirming that 12 submarine nuclear reactors and three icebreaker reactors have been dumped in the waters off the coast of Novaya Zemlya. This is the first public disclosure that Russian submarines and their nuclear reactcrs were dumped in the Kara Sea.

One whole submarine, the K-27 powered by a liquid-metal cooled reactor, was dumped in the Stepovov Guif after an accident in May 1968. Its two fueled nuclear reactors were dumped in the same location off the southern island in 1982.

Eight reactors, three of which still contain their nuclear fuel, were dumped with sections of four accident-damaged nuclear submarines in waters just south of the K-27. The submarine sections - from the K-11, K-3 Leninski Komsomol, K-19 Hiroshima, and one unknown - were reportedly dumped during the years 1964-65.

Five more reactors litter the seabed, including the three damaged reactors from the icebreaker "Lenin." Over 17,000 containers of liquid and solid radioactive waste were also dumped; the location of some 10,000 of these containers has now been made public.

Novaya Zemiya, an island archipelago in the Arctic Circle used as a nuclear test site, is proving to be one of the CIS's largest nuclear dumping grounds. The information comes from sources inside the CIS, researched by Alexander Yemelanenkov, Russian chairman of the anti-testing association "Towards Novaya Zemlya," and Andrei Zolotkov, a nuclear engineer aboard the "Imandra," a nuclear refueling ship for icebreakers in Murmansk.

The waste from the nuclear icebreakers is a molehill compared to the mountain of waste created by the Russian nuclear navy," said John Sprange, Greenpeace disarmament campaigner. "This is the beginning of an uncontrolled landslide."

Greenpeace is working towards a worldwide ban on nuclear-powered and nuclear-armed ships and submarines. In October 1990, the Greenpeace flagship "MV Greenpeace" sailed to Novaya Zemlya to protest continued nuclear testing. 
Submarine, Reactor, and Waste Dump Sites:

Novaya Zemlya Trench: 1450 containers. Barge with a damaged nuclear reactor (Activity $170,000 \mathrm{Ci})$. Barge with liquid radioactive wastes.

Neypokoyev Gulf: Solid radioactive wastes (Activity 3,400 Ci).

Sivolky Gulf: 4750 containers. The barge "Bauman." The central section of the icebreaker Lenin and screen assembly and three damaged reactors.

Oga Gulf: 850 containers.

Stepovov Gulf: 1850 containers and a damaged nuclear submarine with two fueled nuclear reactors. The submarine is reportedly the $\mathrm{K}-27$ which had a liquid metal accident on 24 May 1968; the reactors were dumped in 1982.

Abrosimov Gulf: 550 containers. Sections of four accident-damaged nuclear submarines with a total of eight reactors, three of which still contain their nuclear fuel. Sections of submarines K-11, K-19 Hiroshima, K-3 Leninski Komsomol, and another unknown, that were dumped in 1964-65. The K-19 had a severe accident in the North Atlantic in 1961.

Blagopoluchiye Gulf: 650 containers.

Techenniya Gulf: Accident-damaged nuclear reactor without the nuclear fuel (Activity 1,850 Ci). Open Sea: (two different sites) 400 containers. 250 containers.

Unnamed location on southern end of south island: Presumed location of regional radioactive waste storage.

Sites of Nuclear Explosions:

Sykhoy Nos Cape: The area where the biggest atmospheric nuclear explosion took place.

Matochin Char: This is where the last test on Novaya Zemlya too place.

Black Inler: Area of the first underwater, above water, and under-seabed nuclear tests on Novaya Zemlya. Area where the vessel "Kit" was located and presumed location of the disposal of the sunken submarine "Komsomolets" (assuming it will be salvaged).

South-west sector of southern island: The presumed area for the development of a long-range program of nuclear testing. 


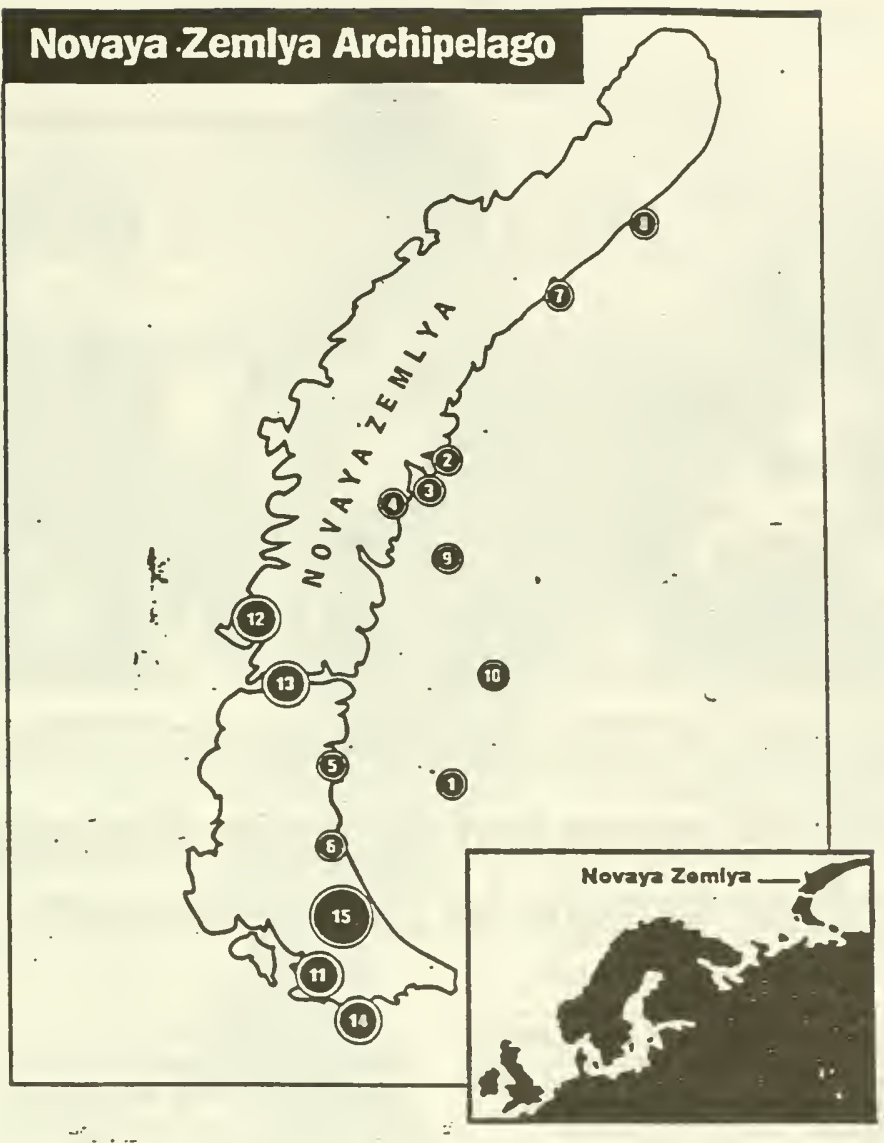

1 Nevare Zemb/n Troneh 1450 contuinars E-ro wat a dineged nedes mecor (Aeriving

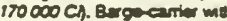
iquid redonctio wark

2 Henokeres cull Sofdradoscin ates (Netiving 34000 )

3 streby aut

750 centinure the berge

Bumen: The conerd encion of

no icebrester Lerin and screen

axumby and tif. demeged

recert.

\section{- Oen cul}

co container.

\section{5 stepovor Cut}

1850 contin end a damaged

mudae abonerine with mo tueled

nuclae resecr.

- Abresiner cur.

sso coneniner. Scetene of bu eccident demagod nucher

romarines wh a toval of cion

recers, three of which and

conten their necter tuet.
7 Elegeoncture ar 650 contarers

\section{- Tectennhr cult} Acoidunt daneged nucles reacto withar the nucher ful. (Acivin) 1 osoc)

\section{- Open see}

400 contaners.

10 omen 50

20 containas.

14 froumed berion a major radocion wess earg.
Stes of Nuclear Explasion:

12 sylhey Nes rape

The area where the bugest

atmosphenc nuciex explosion

bot dace.

Controliod area

13 Matechin Char

This as where the last is on

Novera Zemtya nok olece.

Contolied eree

14 Diset inlet

Area of the first underwate. abow water and under-sabod rucie

test on Novaya Zerrye Nea

where the vessed $\mathrm{KC}$ " was beated

and the presumed location tor the

cinos of the senken subreme

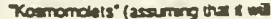

be navoed) Controlind are.

is sartwe mear of the

canem riand of tre Norere

Zertir arencolago. The prearmed area lace me ceveconert of a bong rangs programm of nudase is ang on Noraya Zemite 


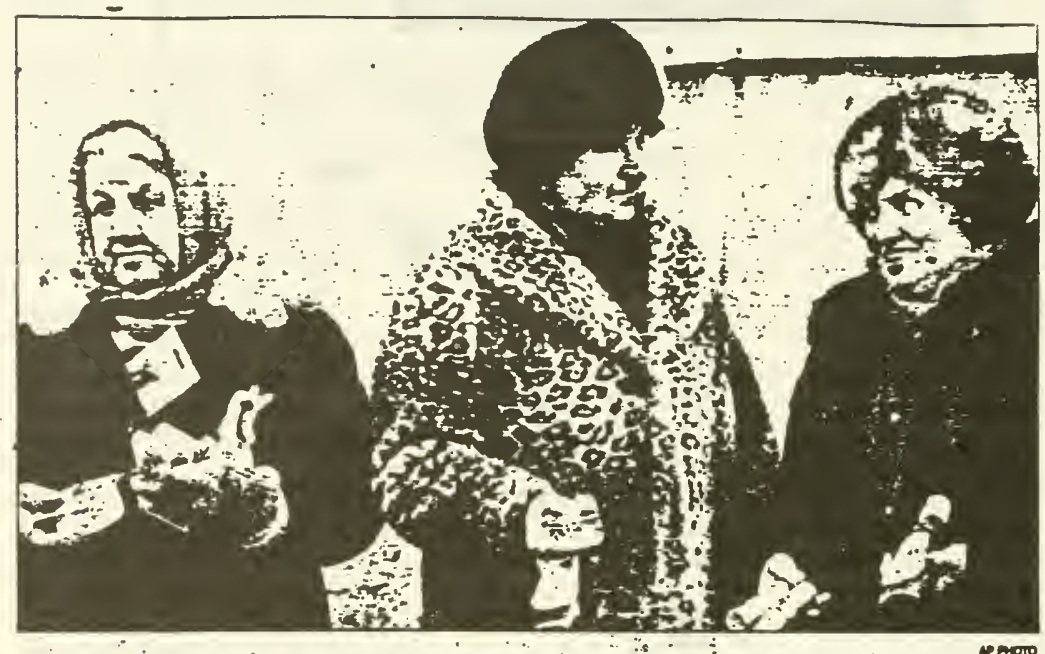

Three women bearing shampoo and other household Items wait for eustomers yesterday in Moseow, where shortages at state-owned stores are prodding resldents to do thelr shopplog with sidewalk entrepreneurs.

\section{Soviets reported to have dumped nuclear waste in aretic waters}

\section{netres}

LONDON - British television reported yesterdsy that thousands of tons of nuclear waste hrve been cecres ly duroped in Rascin artic waters for more than 20 years, creating a "ticlang time bomb" threatening the whole of Europe.

Independent Televtsón News quoted a Rucirin muclear expert, Andrel Zolotkov, as aying the sea of the northern coat of Rursin had been used as a major dumping ground for radiosctive wite for yeri.

Zolotkor end the RGB lllowed hin to see papen showing that 17,000 container of auclear wute vere dumped over 22 Jeas in the Rare Sea in the Runing Aretie.

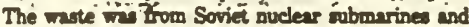
lcebreakers and inctided spent reactor fuel and weapons-grade plutonime.

"All the documients I read are kept on one of the chips," Zolotkor told IIN. Chnenel 4 News trom Murmanak.

Accorting to the documents 17,000 contriners were dumped" be added.

$$
\therefore:
$$

There were 10 mijor duraping grounds in the Kir Sen most to the east of the island of Novay Zemlyr the progern said. 3

It said submarine with nuclear fuel aboard were se

\section{Joshua Handler of}

Greenpeace called it a classic

case of a ticling time bomb'

that poses a serious threat to

$$
\text { all Europe. }
$$

cretly munk ofibore Sailors were told to ahoot drum costuining wustef with rides until the contsiness sank to the seabed.

The metal forer protecting the tuel ... क will deterioirite in the marife environment. The water will reach the ivel... It is quife o dangerous siturtion," Zolotkow axid. Johnu Hangler of the environmental group Greenpeade told IT: it was "a clascic case of a tieking time bomb" that pos? a serious threat to all Europe. Without setion, radioact ity could enter the food chain and for all we know it atready cocured, "he anid.

The Rusesian ravy has to start decommistioning 30 nuclear abma ines coon, work which in the past led to in explosion atd 10 deathe, the program suid.

ITN amed bn arctic nuclear waste dump containing cobalt and cesict guarded by just one man and a dog. 


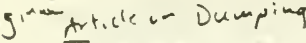

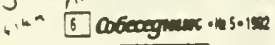

Ядерная смерть

Ічитаилась в заливе Благополучия.

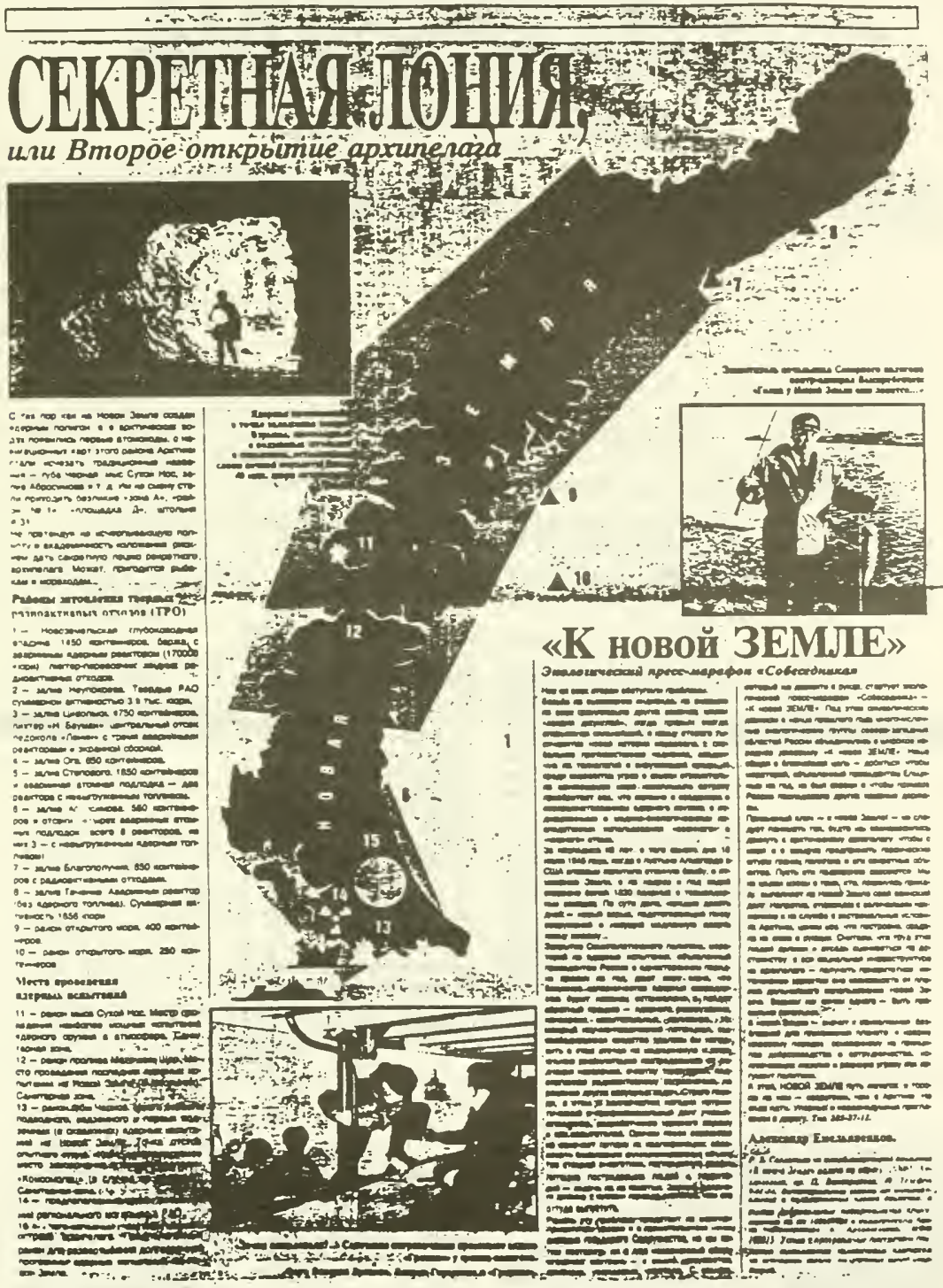


ADELAIDE - AMSTERDAM - ANCHORAGE - AUCKLAND - 8OSTON \& BRUSSELS - BUENOS AIRES - CHICAGO - COPENHAGEN . DUBLIN FORT LAUDERDALE. GOTHENBERG . MAMBURG . LEWES - UK . LONDON . LUXEMBOURG * MADRID. MONTREAL OSLO . PALMA DE MALLORCA

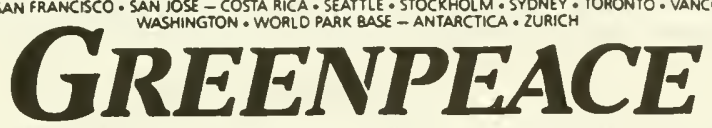

Greenpeace USA • 1436 U Street NW. Washington DC 20009 • Tel (202) $462-1177$ Tlx 89.2359 • Fax (202) 462.4507

7 April 1992

Honorable George Bush

President of the Lnited States

The White House

1600 Pennsylvania Avenue, I.W.

Washington. DC 20500

Dear : $1 r$. President:

You are well aware the break-Up of the USSR has engendered numerous political. economic and environmental problems. I wish to draw your attention to one question that has not received adequate attention: the safe decommissioning and disposal of ex-Soviet Navy nuclear-powered submarines.

I was impressed your recent aid proposal specifically mentioned a desire to improve nuclear plant safety, and assist in demilitarization and defense conversion in Russia. I would urge you to include a program of assistance for the safe decommissioning and disposal of CIS Navy nuclear submarines in your initiative.

Earlier models of the CIS Navy's nuclear-powered submarine force are being retired en masse. Some 80 submarines are probably awaiting disposal. and another 80 submarines are likely to be retired in the next few years, meaning some 300 submarine nuclear reactors will have to be disposed of in total.

I recently visited submarine facilities in both the North and Far East of Russia. and it is evident from my observations and conversations with naval officers and plant managers that the Russian government and the CIS Vavy lack the ability to deal with this growing environmental menace.

These submarines are a major environmental hazard. The fuel from the submarines and their irradiated reactors and reactor compartments can cause serious radioactive contamination if not adequately handled and stored. A even greater catastrophe could occur if the waste or decommissioned submarines were dumped at sea. This is not idle speculation. Recent news has come from Russia that the Soviet Navy dumped up to 12 damaged submarine reactors, five of them still containing their fuel, of the Arctic islands of Novaya Zemlya.

The CIS Vavy knows it has a problem. At the end of March a high-level delegation of CIS naval officers was actually brought to Washington by a private firm to seek help in safely scrapping their nuclear-powered submarines (see the attached Wall Street Journal article). Unfortunately. the l's government agency that is best equipped to assist the Russians -- the L'S Vavy -- did not meet with the CIS officers. 


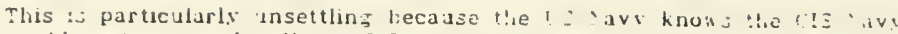
has a prohlein t sannot handle. IS Ear idmiral cliard Shaefer. Eirector aval Intelligence. ulightlx underestmatins the situation. told Congrosis this "ebruar: that:

The ::s lues nut ret have i julution : ibmarine ractors. is a result. the number ot retured nuclear ¿abmarıncs zecrapped per" "car "ill probably remain low. ind :tare are already over fol discarded niclear submarines requirin. [roper torage and itsposal. posing a zrowing znvironmental problem for the Russians. In whose harbors they are ling.

t first simple and inexpensive step towards assistinz Russia -- since the l'S Yavy faces parallel problems in decommissioning its own nuclearpowered tbmarmes -- :oulal be to arrange a veries wi aretings between the responsible CIS naval officials and $U \Xi$ Navy officers to share technical "xpertise and develop a program of how to proceed. Interested t's naval experts and businessmen could also be included in thesc discussions.

ilutual visits to each countries iubmarine shipjards could also be part of the aid program. In partıcılar. Russian officials could be brought to puget sound Maval shipyard and Haniord. Nashington. to observe the lis Vavy's decommissioning procedures. lisits to the Severodvinsk submarine billding facility on the White Sea, and the Bolshol Kamen submarine facility near lladivostok in the Pacific would be particularly iseful.

A short list of $s$ hat $w 1 l$ be needed to help Russia could be rleveloped relatively quickly. There is clearly a need for advanced metal cutting :echnolog $y$, heavy-lift cranes. and construction of land-storage areas for submarine reactors and their compartments. L's public expenditures for these items could be minimized by providing credit aganst revenue raised from tho scrapping of the non-radioactive parts of submarines.

is a next ztagc, a compichensive reciprocal sichange of information and inspections could be arranged. Jo that we can fully understand the extent of the decommissioning problem. This should include:

- mutual inspection of shipsards. and exchange of environmental data on the state of the shipyards. and the health records of their orkers.

- exchange of information on the state. size and operation of the nuclear-powered naval forces. submarine operating bases. land-based prototype and training reactors. naval reactor fuel fabrication facilities, and nuclear and radioactive $x$ aste processing and storage sites. Iutual and reciprocal visits to facilities should be planned. Information on past submarine radiological accidents should be exchanged.

- development of bilateral or multilateral programs for environmental monitoring of nuval nuclear submarine laculities and past areas of ocean dumping of naval nuclear aste. Specific attention should be paid to the area off :iovayd Zcmlya where the Euviet Viavy dumped submarine nuclear reactors. 
in terms of the final lisposal of the ant t: fl from the 1 bmarines.

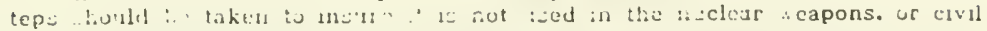
or mitary reactor fiel cyeles.

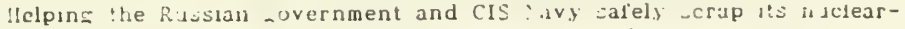
ponered jubmarincs. .uuld have ceveral additional binetist:

- Increased . lits and ajistance to jtull iused areas thesc more conservative and skeptical parts of Rusita about the linited states intentions and open these areas to uitside knowledge;

- increased milatary-to-nulitary ties would be very reassuring to CIS naval officers in this period of turmol:

- the ard sill allo: Russian submarine yards to earn hard currency from .crapping zubmarines. easing theis ability to cunvert to civitian production (something Severodvinsk plant officials thave told me they are eager to dol:

- additional employment to nuclear specialists in the t's or Russia could result. particularls at the hard hit Elcctric Buat plant in Croton. Cunnccticit. or to Russian nuclear tcchnicians. ince their expertise could be used to assist the with breaking up of the submarines and environmental monitoring and clean-up.

- such assistance has elements of reciprocity, since CIS naval officers could visit shipjards in the LS and observe US decommissionin: procedures (as you know. reciprocity is polutically very important to the Russians):

Some analists have questioned $w h y$ the Russians should be helped to solve their problem. Ince the CIS $\therefore a v y$ continues to build nuclear-powered abmarines. This is a myopic perspective.

Unfortunately. because the haphazard nature of ex-soviet technology and the current conomic conlusion in Russia. Russian problems are ilso the Nest : problems. Cliernobyl stands as the glaring reminder that the llest irnorcs Russia's predicaments at its own peril.

Concern about the CIS Vavy submarıne building program would best be addressed throigh halting orders for new nuclear-powered submarincs. With the termination of the US SS.T-21 Seawolf program and the signuficant dounturn in Russian nuclear-powered submarine construction. it would be relativels simple to insure no new nuclear submarine orders were placed -- or even cease production of currently ordered submarines.

It might interest you to kno: there if international interest in some of these questions. The Yorwegian jovernment is pursuins with the Russian bovernment ways to monitor and. If necessary. retrieve the nuclear waste dumped off Yovaya Zcrlya. The Yorwegian Defense Minister Johan Joergen Holst brought this to the attention of $11 \mathrm{r}$. Peginald Bartholomew at the Department of State in imd-!larch. 
If course there are other steps that could be taken to reduce the hazarils presented by nıclcar-powered submarine operations. juch is ristititin; a moratorium on their operations. "e fuund it very interesting hat. is bou mas recall. President Boris leltsin proposed a mutual halt to SSB. verations in his response to your January 1992 State of linion address.

1 : ould be very happy to meet wath jou or members the whte llouse stalf to discuss these proposals further. or provide a briefing on our tio $\therefore$ ral's of $\because$ ork in Rissia un these issues.

l look forward to your response.

Sincerels.

Joshua Handler

Researc! Coordinator

viuclear Free Seas Campaign

P.S. 1 also include for your information a photograph of the shoreline of Iurmansk harbor. It clearly illustrates the problems the Soviet vavy has had in disposing of retured vessels.

cc: Senator llbert Gore

Senator Sam lunn

Representative Les Aspin

Representative Charles Bennett 


\section{suviel suns - a Neglected Nuclear Time Bomb}

\section{BY Joshar Handler}

TIIE Soviet I/ninn's cullapse has privoked III. 1 tense concern about the safecy of Siviet nuclear weapons. Aruther Chernobyl accident aınidst econnnuc clinos aud tech. nological breakclown is also a worry.

No attenuon, Inwever. has been paid to a third nuclear dan. ger: the accident-pronic Sovet nuclear-powered submarute furce. To avoud a nuclear calamity at sea, stopping Suvict nuclear submanne uperautions stould be a major goal of Western assistance

Soviet nuclear subnimines are known to liave a poror salety rec. ord. In 1990, Admiral Bruce DeMars, head of the United States Navy's nuclear propulsion pro gram, mold Congress that the Soviets "have a history of major reac. cor plant casualies over the years. They have had real reactor accidents, things that we have nightmares aboul."

Some Sovet nightmares are well-known Three Sonet nuclear submannes lave sunk, one each in 1970, 1986, and 1989. These accidents carned five nuclear re actors and some 38 nuclear war. heads to the ocean finor. But this is only half the story. Invesuga tions in the Soviet Union over the past year have uncovered new nightmares prevously undis. closed:

Early Soviet nuclear subma rines suffered from almost con tinuous accidents. A retired So viet submarinet sad that one of the first four nuclear submannes was nicknamed "Automat." If the submanne left the base, on average It took only one day to come back because of an accident, i.e. it automatically returned. Another mas dubbed "Half-Automat" be cause it spent two days at sea be fore being forced to return because of malfunctions.

- In 1968, the liquid-metal reactor coolant on an early model Northern Fieet submanne froze, causing significant damage to the nuclear reactor. A senior naval of. ficer said that many crewmen were severcly irmitiated and inany were reured. It is believed that aff or parts of the rcactor were dumped of the Arctic isearly 1970s.

On Al1g. 10, 1985, dunng refuelling. the reactor on a Victorclass submanne exploded and

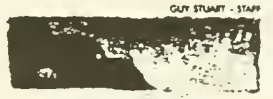

Technical help should be',

provided to

sofely defuel

and dispose

of these

submarines.
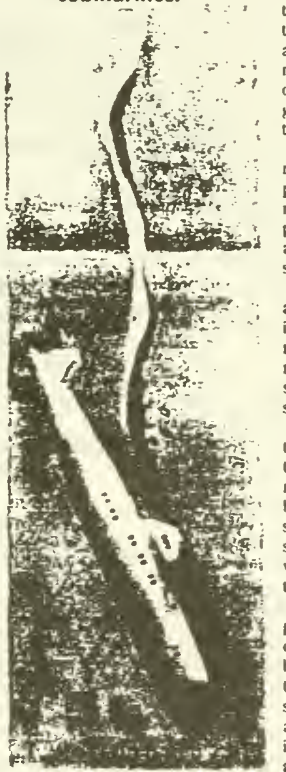

burned in Chame Bax some 35 miles from Vadvostok in the Pa. cific. Ten men in the reactor room were killed. Soviet news accounts claim that radiatlan meters in the area went of the scale at fatally Jugh levels of 600 roentgens an hour. The Sovec Navy estimaces it will take 50 years for the area to return to normal.

Accirlents cothinue (1) beset he Suviet submanne force. Last September, a missile misfired aboard a Typlioon ballistic missile submanne in the White Sea during a training exercise. Fortu- along whth its two nuclear reacurs and nuclear-armed nussules With econonuc decline. fewe rcources, material, and trammig. the chances of accidents is likely to uicrease. One Vhadivostiok based naval officer sard. "in princuple and in practsce an nowien like the 1985 calastrophe cuuld occur again.

The Sonet Navy iperates sume 150 submannes carcying approximately 300 nuclear reac tors. Sovnet subinannes stull patol the lugh seas. parucularly in the Arctic and Nortl Pacific. An accident aboard any of these submannes could release deadly ra diuartivinty into nch fishuing sroumis and affect ncarby nacuens.

This is not a far-fetched sio nario. The suking of the nuclear powered and armed Mike subma rine oft Norway in Apnl 1989 lins provoked undespread concern about radiation posoning the seas in the area.

As the West considers how in assist the ex-Soviet Union, dealing whth Soviet nuclear subma rines should be a pnonty. Tech nical help should be provided to rafely defuel and dispose of these submarnes.

US Navy sources report that the US also is facing difficultues as to how to dispose of its own aging nuclear submanne force. Since both Navies face the problem of sajely decommissionung nuclear submannes and stonng their waste, a natural area of coopera tion exists.

If the Sovet Navy balles at proposals to reduce or reture its nuclear-powered submanne fleet. because the West would contunue to keep its own nuclear-powered submarnes, senous consideration should be given to abanduning nuclear-powered submarnes altogether.

To some, abandoning nuclear. - Turered submannes is adica proposal. But with the end of the cold war, there ts less need for nu. clear submannes. More important, first-hand observation of the deadly legacy left by the Sonet uubmanne feet suggests such a solution is necessary to aven a Soviet nuclear disaster of potential global effect.

Jashua Handler is resenrch comrinator for Greenpeuce's Nuclear.Free Seas Campaign. He recently returned from 57 . ueeks in Russta ussling sub. marine facilities in prezumuly closed oreas in Severrituinsk and near Vindivastok. 


\section{NUCLEAR FREE SEAS

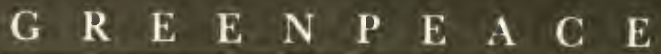

Preliminary Report on:

Greenpeace Visit to

Vladivostok and Areas Around

the Chazma Bay and Bolshoi Kamen Submarine Repair and Refuelling Facilities

9-19 October 1991

Joshua Handler

Research Coordinator

Nuclear Free Seas Campaign

Washington, DC

ph. 202/319-2516

FAX: 202/462-4507

6 November 1991

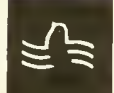




\section{Introduction}

The effects of glasnost and the end of the Cold War have opened previously secret areas and topics in the Soviet Union. In the case of the Soviet Far East, residents around nuclearpowered submarine facilities in the Vladivostok area are asking questions about past submarine accidents, and current and planned nuclear waste disposal procedures. The military in the region, somewbat uncomfortably and reluctantly, has been forced for the first time to respond to what they term popular "radiophobia." In doing so, the military bas provided new and unprecedented information about a reactor explosion aboard a nuclear-powered submarine in August 1985, and nuclear waste bandling in the region.

More openness by the military may ameliorate civil-military tensions in the region. However, they may also exacerbate them. The military in the region has not held the environment in high regard. As more information about past abuses becomes available, residents may redouble their criticisms of the local commanders. Also, the size of the clean-up cost from past mispractices, as well the cost to decommission old auclear-powered submarines, may engender more reproaches.

The information about the accidents, as well as additional information about submarine reactor design, is providing a different perspective on Soviet submarine operations. A high accident rate, plus low fuel enrichment levels, provides technical reasons why Soviet submarines have lower operating tempos than their western counterparts. Also, the size of the Soviet submarine force may have been partially derived from a need to keep an adequately repaired and fuelled force at sea. Although the Soviet Union may have technically advanced submarines, the information coming to the fore raises questions about its overall operationally capability, hindered as it may be by accidents and limited reactor core lives.

Ultimately, additional information about past Soviet submarine accidents and reactor operations, may show the Soviet submarine force was less a threat to the U.S. and its allies, and more of a threat to its own sailors and the environment.

\section{Nuclear-Powered Submarine Facilities in the Vladivostok Region}

The centers of nuclear-powered submarine operations in the Vladivostok area are to the east of Vladivostok, some 35 miles across Ussuryiskyi Bay, in the Shkotovo region and on Strelok Bay. The region includes at least four facilities, all or some of which have been operational since the early to mid-1960s:

A A major nuclear submarine overhaul and refuelling yard at Bolshoi Kamen (Shkotovo17), on the west side of the Shkotovo peninsula on Ussuryiskyi Bay facing towards Vladivostok. There at least two plants here concerned with overbauling and refuelling submarines (one or collectively known as the ZVEZDA plant), as well as disposing of their nuclear waste. In addition, the first decommissioned submarine to be dismantled in 
the Pacific Fleet, was broken up at Bolshoi Kamen. Its reactor compartment is still stored at the plant(s). Two other submarines may be undergoing scrapping there as well.

B. A smaller refit and refuelling yard near the settlements of Dunay (Shbotovo-22) and Temp located on Chazma Bay on the east side of the Shbotovo peninsula facing Strelok Bay. It was here that the submarine reactor cuploded on 10 August 1985, contaminating the surrounding land and water. Reportedly, plans ecist to turn the Charma plant into a major dismantling facility for decommissioned submarines.

C. A permanent nuclear waste disposal site, Installation 927-III, is located at the tip of the Shkotovo region peninsula. High-level waste is stored here. There are plans to expand the facility by 1995 , in order to be able to store more waste.

D. A major submarine base at Pavlovsk on the eastern edge of Strelok Bay, which at least houses ballistic missile submarines (U.S. inspectors visited this base in 1990 as part of the verification inspections for START).

\section{Greenpeace's October 1991 Visit}

While in Vladivostok in September 1990, Greenpeace heard reports from residents about a devastating reactor coplosion at Dunay on board a Soviet nuclear powered submarine in the Spring of 1985. Greenpeace also observed a meeting of the Primorikii Kray Soviet's Environmental Committee where this accident was discussed. Sketchy reports about this accident continued to surface in the Soviet press after September 1990.

Greenpeace returned to the region in October 1991 to investigate this accident, as well as other accidents, radioactive waste disposal procedures, radiosctive contamination in the area, and the procedures being developed for the decommissioning of auclear-powered submarines in the Pacific Fleet.

While in Vladivostok, Greenpeace held meetings with senior officen from the Pacific Fleet including: Chief of the Chemical Service and his assistant, Chief Radiologist, Assistant Chief of the Nuclear Reactor Refuelling Section, Chief of the Technological Service, Assistant Chief of staff/Chief of the Command Section of the Fleet. Meetings included members of the Primorskii Kray Nature Protection and Ecological Committec, the Sanitary-Epidemiological Service, and the Hydromet Service. Field trips to the ares of the Chazma facility accident, and Bolshoi Kamen also were conducted, and several official documents discussing the accident and its aftermath were provided.

IV. 1985 "Primorskii Chernobyl" Accident.

On 10 August 1985 the reactor of a Victor-class submarine suffered an explosion while 
undergoing refuelling at the submarine repair and refuelling facility on Chazma Bay. The Navy officers Greenpeace spoke with said the explosion resulted after the reactivity control elements of a new reactor core were inadvertently removed as the reactor lid was being re-lifted, after being improperly placed the first time.

The explosion ejected highly radioactive materials onto the surrounding land and into the water. According to the Navy officers, several 100,000 curies of radioactivity were released (including the short-lived isotopes). Ten men in the reactor compartment were billed instantly. The submarine has not been repaired and is still visible at dockside at the Chazma facility.

The "fallout" from the accident spread across the peninsula (some $6 \mathrm{kms}$ long) towards Vladivostok in a band several bundreds meters wide, but according to the Navy officers, didn't reach the city. A secret Nayy map prepared four days after the accident (14 August 1985, 1600 hours) outlined an area $3,800 \mathrm{~m}$ long and $530 \mathrm{~m}$ wide where at the outer edges the level of activity was 600 decays/minute $/ \mathrm{cm} 2$. On a local road going through the trace, levels of 4,500 decays/minute/ $\mathrm{cm} 2$ beta radiation were measured (after decontamination in the first four days, this dropped to 20 decays/minute/ $\mathrm{cm} 2$ ). Lab analysis showed rates of $1-80$ decays/minute/cm2 for alpha radiation.

The Navy officers said near the explosion, rates of 260 roentgens/hour were recorded from some smaller pieces of the reactor core. Also some of the radioactive cloud went over Ussuryiskyi Bay to the west, although it did not go as far as Vladivostok.

Due to the new core there was a relative minimum of accumulated fission products. Thus the Navy officers claim there was little or no plutonium contamination. Also, the officers said the core was only enriched to 20 percent HEU, and so this minimized uranium-235 contamination. Finally, the officers said it was the third time for the reactor to be refuelled. They said this accounts for the pervasiveness of cobalt -60 as the remaining source of radiation today.

\section{A. Clean-up}

In terms of clean-up, for the highly radioactive materials, the Navy officers said a special military service with special equipment for clean-up was used. All the fuel elements which were thrown out, and other highly radioactive materials, were gathered by this special military service and put into specialized containers. The screen assembly which holds the fuel was taken out and a specialized container was created for it. These bighly radioactive materials were transported by sea to a permanent burial site at Installation 927 -III.

The screen assembly and the clean-up of the radioactive materials was effected within 10 days of the accident, according to the Navy officers. The total volume of the screen assembly and the fuel which was disposed of was approximately $4 \mathrm{m3}$. The Navy officers said they are not sure about the total volumes of the high and medium level wastes since measurements were not taken in the first few days due to the hurry to eliminate the worst of the problem. 
In terms of contamination of the trace and the low-level waste, the Navy officers said the area of the trace where the roads pass through was ferced off, the access of the population was stopped for gathering berries and mushrooms, and radiation warning signs were posted.

In order not to spread radiation by transporting contaminated materials over long distances, the officers said a temporary burial site in the trace was created in the first days after the accident. A spot was selocted with the most clay, lack of ground water and water sources, most removed from mushroom gathering, yet cloce to the sccident site. Five trenches were dug to the clay level, sand and mud, and cement and or asphalt were poured over the buried materiak. A drainage system was dug around it.

The officers said, some $2,000 \mathrm{~m} 3$ of material was gathered in the first 7-10 days, and in total $5,500 \mathrm{~m} 3$ of low-level waste was put into this area in the days and months following the accident. This material included contaminated clothes from the clean-up workers, sea weed from the territory of the Charma facility, asphalt and sand, metal construction, ete. The site was surrounded by a triple fence of barbed wire, and clearly marked with radioactive warning signs.

There is a second area in the trace zone which is used as a temporary dump site. The officers said it contains the roofs of buildings taken down after the accident.

\section{B. The situation today}

In terms of today, the officers admit the first burial site is no longer adequately cordoned off. The officers say this is because people keep stealing the fencing and marking signs. The military has "recreated" the site several times, sometimes using bulldozers to assist in clearing areas to re-setup barriers, but to no avail. As of October 1991, there were large holes in the barbed wire fencing, and warning signs are missing.

The Navy plans to move the materials from the region of the temporary burial site to a permanent facility at Installation 927-III at the tip of the peninsula, according to the Navy officers. The clean-up of the burial area will commence towards the end of the year, in December-January, as soon as the construction for the permanent repository at the burial site at the tip of the peninsula is finished. The officers feel there is no sense in fixing up the temporary burial site again, as it soon will be moved.

But although there are higher than background levels of radioactivity in the area, according to the officers, the situation in the trace zone is under control. In Augist 1991, the military did an extensive survey of the $602 \mathrm{~km}$ area which contains the radioactive trace (the area that has levels of activity higher than 60 micro-roentgens/bour is approximately $4.5 \mathrm{~km} \times 200-300$ m). Readings varied from a high of 800-1200 micro-roentgems/hour at the center of the trace, to $60-80$ micro-roentgens/bour at the edges for gamma radiation (alpha and beta mearurements were not available). Ninety-nine percent of the radiosctivity is from cobalt-60. Seventy to eighty percent of the cobalt was in the top 10-15 cm of the ground though it was found as doep as 60 $\mathrm{cm}$. The navy officers calculate that there is five curies/ $\mathrm{km} 2$ now in the trace zone. 
In public access areas, the officers said, the levels of radiation are below what is permitied, and no radiation is leaching from the temporary dump site. In spring 1991, as the thaw was starting, the regional Hydromet office took samples around the burial site, and found no radioactivity in the water.

The rest of the trace zone will be left to be decontaminated by natural decay of the radiation. The Navy officers estimate that it will take 50 years for the situation to return to normal (ten 5.26 year half-lives of cobalt-60). As for the disposal of the submarine and its reactor, the Navy officers vaguely said it would be disposed of along with the other decommissioned submarines awaiting disposal.

As for the waters surrounding the accident, according to the Navy officers, there is no radiation in them. However, there are still contaminated sediments. In the sediments underneath the submarine at dockside, the August 1991 survey found levels as high as 117 milliroentgens/hour gamma radiation. The officers admitted radioactivity is spreading outwards into the sediments of Strelok Bay.

As for long term bealth effects, the officers said a medical survey of children was done in the settlements of Dunay and Temp. They said it found their health was unaffected by the accident. No information was available on the health of military or civilian workers used in the clean-up.

\section{Doubts about the Navy's reassurances}

A number of factors raise questions about the Navy officers optimistic attitude about the effects of the accident. Reports about high levels of radiation in the area after the accident, and the extent of the clean-up efforts suggest there is reason to be concerned about the health of military and civilian workers involved in the clean-up.

A 25 October 1991 TASS account (see attached article), based on a report in Trud, describes extremely high levels of radiation in the area near the submarine. After the accident it was found that "radiation levels during the accident reached 90,000 roentgens per hour," and those who fought the fire resulting from the explosion or "bappened to be nearby received at least 30 to 40 rems each.".

An 11 October 1991 report titled "Evaluation of Radiational Control and Radiological Situation for Shkotovo-22" prepared by Vladivostok region military officers and civilian agencies also describes high levels of radiation in the area in the aftermath of the accident.

The report says that thirty percent of the territory of Military Division 63971 (which contains the Chazma and the Bolshoi Kamen facilities) was contaminated by the accident. The average dosage in August 1985 was 200 milli-roentgens/hour gamma, and beta radiation was 200,000 decays/minute/cm2. Shards of the reactor and fuel in the area had levels of radiation of $30-40$ roentgens/hour. 
According to the report, the clean-up eventually involved the removal of $5,000 \mathrm{~m} 3$ of contaminated materials and 760 tons of metal construction, deactivation of $2,100 \mathrm{~m} 2$ of metal construction and $34,000 \mathrm{~m} 2$ of roads with cement and asphalt tops. $400 \mathrm{~m} 2$ of docls were also decontaminated.

According to residents of the area, civilian workers did participate in the clean-up, and received radiation doses. Some local people claimed clean-up workers were running in and out of the accident site picking up radioactive debris with their hands. (The Navy officers denied this. They said quick runs were only used to practice the attaching of lifting cables to the damaged reactor, and then to attach the cables.)

One detailed eyewitness account was provided by the chief mechanic from the floating crane Vityaz (a civilian rescue vessel commandeered from the Far East Shipping Company) He recounted that at the time his vessel was given an emergency assignment in Chazma Bay, witbout being told the nature of this assignment.

Their job was quite simple, he said. They were to approach the sub from the back and keep it afloat from the rear. The nose section was being supported by a Nakhodka ship, Bogatyr. The Vityaz crew was told there was a crack in the sub. The crack needed to be cloeed, and at the same time water in the sub needed to be pumped out.

The mechanic said when they arrived the water was being pumped out of the sixth section containing the reactor, out of the top of the submarine, and directly into the waters of Chazma Bay. Because it was a hot August day, the Vityaz crewmen were walking around shirtless. He said the Navy sailors on the submarine also were also shirtless. Some of the sailors were sitting on the edge of the hole made by the reactor explosion and dangling their feet into the reactor space.

On the second day the Vityaz was there, he said the second mechanic accidentally turned on the KP-5 dosemeter aboard the ship. The measuring equipment immediately went off scale, and because it is connected to the emergency mobilization equipment aboard the ship, a siren began to sound. At that point the captain of the ship, Kuznetzov, went to clarify with the Navy what they were dealing with

On the third day, he said the Vityaz received 14 sets of protective equipment and dosemeters, and explanations of how to avoid radioactive contamination. The Vityaz crew worked for a week, after which they had a dose measuring of the personnel. All of the spaces in the ship, such as the bridge and living spaces, were so contaminated it was impossible to take measurements there. The only part of the ship that was not contaminated was the machine compartment; nobody had entered this space because the ship was not underway.

The crew was not told the amount of exposure they had received, he said, but they were told all the clotbes they were wearing during the week had to be burned. Nothing about their work was recorded the ship's official medical log. In addition, the Vityaz crew had to sign a 
document swearing they would not say anything about the incident.

The chief mechanic said that a friend of his who worked on the Vityaz as well, said the burial site contains nothing but the bits of fuel. The other pieces of metal and highly contaminated materials were dumped into a little lake next to the bay where the submarine exploded.

Locals also complain that today it is not clear what is buried in the temporary waste site in the trace, the more contaminated spots in the trace are not adequately marked and/or sealed off, and that despite warnings people do wander through the burial site, gathering mushrooms and berries in the area.

A 15 January 1991 letter by the Chief Radiologist of the Pacific Fleet, discussing the plans to move the temporary waste site suggest local residents have reason to be concerned. He notes that there is "no official data on the activity of materials" in the waste site, but that it may contain radioactive waste of "group III," i.e. more than 1000 milli-roentgens per hour. He said that when the site's fence was reconstructed in 1989, and the area was levelled with bulldozers, the burial site was opened and wastes of "group II," i.e. more than 30 milli-roentgens per hour, were extracted. He wrote, that until this "interference, the exposure dose on the surface of the burial site did not exceed 3.6 milli-roentgens per hour."

In a visit to the burial site in mid-October, Greenpesce found that it is poorly fenced off, and there are trails through it. Levels of activity are in some places higher outside the burial site than at its edge. Some hot spots 30 meters from the temporary waste site registered almost 1700 counts per minute on a geiger counter (approximately 1 milli-rem/hour), while at boundary of the site it was only as high as $900-1000$ counts per minute. This compares to a background of 13 counts per minute in the city of Vladivostok. A small lake off Chazma Bay next to the refit facility (mentioned above as having had contaminated materials dumped in it) bad counts as high as $\mathbf{3 0 9}$ per minute on some parts of its shore. Local residents said children swim there in the summer, although it is forbidden to do so. There are no signs marking off the lake area as contaminated.

- The Navy officers downplayed the contamination to the sea-bed during the meetings. But, the 15 January 1991 letter says that a commission that worked during 3-10 December 1990 reported to the Commander-in-Chief of the Navy that radioactive materials on the sea floor near dock \#2, where the submarine exploded, pose the greatest "radiological danger to the environment." A survey in August 1989 found the situation at 125 meters from dock \#2 to be "unsatisfactory." At 125 meters from the dock the level was 750 micro-roentgens an hour, and the letter says, "the total activity of the bottom silt is $8.6 * 10-7$ curie/kg, is 40 times higher than the background (2-3 * $10-8$ curie/kg)." The letter notes, "with the approach to the dock the radiational situation deteriorates rapidly, which indicates the presence of highly radioactive materials on the bottom."

According to the 11 October 1991 report by regional military and civilian officials, 
radioactivity bas been migrating outwards into Razboynik Bay and the western passage of Strelok Bay. Cobalt-60 has been detected as far away as Abrek Bay to the north and Konyushkova Bay in the south. The report says, the use of two floating drydocts and other vessel traffic is continuing to spread the radioactivity in the bottom sediments.

The size of the accident and the magnitude of the clean-up would suggest some official monitoring of the bealth of the workers and residents of the area would have occurred. But during Greenpeace's visit no such information was forthooming. In fact, residents complain the health effects of the accident are being dismissed or covered-up.

One worker at the plant at the time of the explosion recently complained to Soviet TV that doctors in the area do not attribute blood diseases to radiation exposure. Residents of the region say the examination of the children in the Dunay and Temp settlements was superficial and cannot be trusted. They also say that military personnel used in the clean-up were conscripts. Residents thought no effort had been made to track the bealth of these people after they were released from service.

\section{Secrecy and Suspicions}

As late as 1989 the military continued to deny a nuclear accident had occurred. In 1989, General Yazov, the then Chief of the armed forces, told a Chazma plant worker who had witnessed the accident that it had not happened.

In the summer of 1990 news about the accident finally began to appear in the Soviet press. On 17 July 1990 Lzvestiya published an open letter to Fleet Admiral Chernavin by V. Perovskiy, former commander of the survivability division of the Leninskiy Komsomol, the first Soviet nuclear-powered submarine [translated in FBIS-SOV, 18 July 1990].

Perovsky, in complaining about the safety of nuclear-powered submarines, noted their reactors are most dangerous during the refuelling process, and that the smallest mistakes can lead to serious consequences. He concluded, "How this alt ends is well known from the tragic example of the refuelling of a Pacific Fleet submarine."

Since then there have been other brief mentions in the Soviet press, most notably by Sobesednik (April 1991), which said it irvotved a thermal explosion of the reactor of submarine project 670 due to accidental removal of control rods from a reactor during refuelling. .

In the aftermath of the October 1991 Greenpeace visit, the Primorskii Chernobyl story bas gained more attention. The Washington Post ran a story based on some of Greenpeace's findings, and the Soviet publication Trud also did, by Soviet standards, an extensive story providing new details about the accident (see attached Washington Post and TASS articles).

Obviously, much more is now known about this accident and its aftermath. Yet, the history of secrecy or lies on the part of the military and the authorities bas left local residents very 
suspicious of the Navy's account of the accident and its reassurances. Local residents were eager to have more and reliable information about the accident, particularly about the bealth effects on people in the area at the time of the accident, the clesn-up workers, and the population living in the area.

\section{Other Submarine Accidents}

No other information about specific Pacific Fleet submarine accidents was forthcoming from the Navy officers. They denied reports about an accident which was rumored to bave happened around 1988, where a submarine scrapped its bottom on rocks in the Peter the Great Bay and leaked radioactivity when it came into Bolshoi Kamen.

However, further details were uncovered about the 1968 accident on board the liquidmetal cooled Northern Fleet submarine.

One of the senior naval officers, who had worked in the Northern Fleet from the early 1970 s to the mid-1980s and had dealt directly with questions of radiation safety, confirmed that the accident had happened. He added, that many men were severely ir sdiated, and many of the crew were retired after the accident. The captain of the submarine was quite "illiterate." After the accident, the crew had dinner as usual and proceeded back to base seemingly at a normal rate, and pulled up to the dock without any special precautions. Thus people at the dockside were also irradiated.

He refused to explicitly confirm the reactor was subsequently dumped off Novaya Zemlya. But he said Greenpeace's description of its disposal was not entirely incorrect.

He also noted, the frozen lead-bismuth coolant is a major alpha emitter. He said it can only be removed with a "hammer and chisel" type operation, hazarding workers with high levels of radiation.

VI. Submarine refuelling, decommissioning and radioactive waste disposal and contamination

\section{A. Refuelling}

The information provided about refuelling paralleled what Greenpeace learned in visits to Murmansk and Severodvinsk about the Northern Fleet. A refuelling ship comes along submarine and removes the spent fuel with a special crane apparatus. Fuel is temporarily stored in the refuelling ship. As soon as the storage area aboard the support ship is full, the spent fuel is offloaded to a coastal storage site. The length of time it is stored there, before it is shipped to Chelyabinsk for disposal, depends on when the reactor was stopped before refuelling. If it had been stopped a long time, then its activity is lower and so the fuel can be stored a shorter time, and if it was stopped just before refuelling then the fuel needs to be stored longer before 
shipment.

To eliminate the release of aerosols when the top of the reactor is lifted, there is an apparatus which vacuums in the air around the top of the reactor. This air is filtered several times and then released into the atmosphere.

The officers claimed that newer submarines have fuel that lasts the life of the submarine Older submarines are refuelled every 5-10 years. Newer submarine fuel is in the form of crossshaped rods. Odder fuel is in the shape of round rods.

Discussions with Moscow and Northern Fleet specialists in September 1991, indicated the fuel is enriched to the $40-60$ percent range. The assistant chief of refuelling, however, insisted the reactors in the exploded Victor submarine were only 20 percent enriched. An officer from the chemical service said each reactor contained $47 \mathrm{~kg}$ of uranium-235, but he did not know what percentage of enrichment this represented.

In terms of other refuelling techniques: Perovstiy in his Lrvestiya letter claimed the refuelling methods used by the Soviet Navy were archaic and basically unchanged from thirty years ago. He wrote, "the chief protagonist when cores are being removed from reactors remains the sailor with a sledgehammer.".

The Navy officers said Perovskiy's letter was essentially correct, except sledgehammers only need to be used to knock lose stuck fuel rods or other material approximately one every ten times. They also noted this procedure is made more difficult when there have been accidents.

They said approximately five submarines a year were refuelled a year between the Bolshoi Kamen and Chazma Bay facilities.

\section{B. Waste}

The assistant chief of the nuclear reactor refuelling section of the Pacific Fleet provided some information on the amount of waste generated by a single submarine during refuelling or decommissioning. He said the weight of liquid waste (coolant, washing waters, etc) from refuelling a twin-reactor submarine is $50-80$ tons. Solid waste from refuelling a submarine has a volume of 15-20 cubic meters (this number includes resins from ion-exchangers, but not the fuel). The volume of the spent fuel is $2-3$ cubic meters. Filtered washing waters are loaded aboard a support ship and are dumped at sea.

One regional storage point for nuclear waste is at the tip of the Shkotovo peninsula, identified in military documents as Installation 927-III. According to the Navy officers, some storage areas are full at the facility, but others are still mostly empty. There are plans to expand the storage facilities to handle more waste. The new areas should be ready by 1995 . 
It is unclear what other waste facilities exist in the region. The Navy officers confirmed that the Khabarovsk region has waste sites, and one added There is a big area there which is a mess." They said, however, they were not concerned with it. Thus it is unclear whether these are wastes sites associated with the Sovetskaya Gavan or other Navy facilities, with other military facilities, or just "general" sites.

\section{Decommissioning}

The Navy officers said there are approximately $\mathbf{4 0}$ nuelear-poivered submarines in the Pacific Fleet which are awaiting decommissioning. They are stored in coves and bays in the area. At least some ate at Bolshoi Kamen and Pavlovsk. Minimum crews are kept aboard them to assure they are kept afloat, and prevent radiation leakage.

When asked about the 8 September 1990 Krasnaya Zvezda article discussing the decommissioning of submarines in the Pacific Fleet [translated in JPRS-UMA, 3 October 1990], the officers said this referred to activities at the Bolsboi Kamen facility.

They said one submarine has already been broken up there. Its reactor compartments are stored at the plant awaiting a final plan to dispose of them.

Details about future plans for dealing with decommissioned submarines were hard to come by. Partly this was due to the lack of plans. The Navy officers said the situation was being studied but no final plan had been decided. They said they had heard that President Gorbachev had proposed that 150-250 billion roubles would be needed to decommission the submarines, dispose of their waste, and clean-up the nuclear naval facilities. They did not think this money would be made available. They were very interested in U.S. decommissioning plans, and meeting their U.S. military counter-parts and experts to discuss the problem.

Local residents, bowever, expressed concerns about what was going to be done with the decommissioned submarines. One plant worker at the Chazma Bay facility, told state TV that the military planned to turn their plant into the decommissioning center for Pacific Fleet submarines by 1993 . She was concerned that another accident, like the 1985 explosion, might occur again.

\section{Radioactive safety and contamination}

This was a very difficult and confusing topic to pursue. The Navy officers claimed that no civilian workers at the Chazma or Bolshoi Kamen plants have exceeded the 5 rem limit per year. Seemingly this is because the submarine crew is responsible for normalizing the situation after an accident and also works on the overbaul and refuelling of a submarine. Questions about the exposure of military personnel and subsequent medical follow-up went unanswered.

Questions about contamination or problems at Bolshoi Kamen, Chazma Bay, Installation 
927-III, or Pavlovsk went unanswered. One naval officer, bowever, said the Paviovsk submarine base was constructed in the 1960 s without a thought to the future, and today it is an "ugly child."

The Navy said prior to the 1985 the waters around Peter the Great Bay were free of any radioactivity beyond what occurred naturally, and today the situation is normal as well. Until 1989 , the military took their own sediment samples and anatyzed them. Now the Navy takes the samples and hands them over to the regional Hydromet office for analysis. The Hydromet also claim the situation is normal.

VII. Conclusions

\section{A. Radiophobia}

In the past five years, there has been a history of strong anti-nuiclearism in the Primorskii and Khaborvosk regions. Local residents bave:

- stopped plans for a civil nuclear-power station in the Primorstii Territory,

- opposed Navy plans to dismantle decommissioned submarines in the Sovetskaya Gavan area (which lead to cancellation of these plans);

- criticized plans to offload seactor cores from decommissioned submarines in Vladimir

Bay, a relatively unknown submarine facility, located between Vladivostok and Sovetskaya Gavan;

- prevented the docking of the nuclear-powered merchant ship Sevmorput at several ports in the area;

- protested the military's handling of the clean-up of the 1985 accident.

There are no signs that this opposition is slacking off. One Bolshoi Kamen city people's deputy is planning to take the military to the State Arbitrator's office in the coming months to seek 23 million roubles for more clean-up of the 1985 accident, paving roads in the irradiated region, and social compensation for the people who live in the Shlotovo region.

The military is very concerned about this "radiophobia." In general, the Soviet military is caught in a serious dilemma as it tries to reshape its role. To begin to regain the public trust, it needs to provide more information to the public about its past and present activities. But its past history of environmental degradation is so bad, the more information the military provides, the more angry the public may become.

It is not clear how this dilemma will be resolved. Public concerns were one of the reasons Greenpeace was given unprecedented access and information about the 1985 accident. Local environmental officials expressed surprise about how much information was provided. But the Navy officers also feared this information would be further used to agitate the population. They were very reluctant to discuss any procedures or problems at other nuclear facilities in the region. 
Greenpeace's observations made over the past year in the Vladivostok region, Petropavlovsk-Kamchatskii, Murmansk and Severodvinsk suggest that anti-nuclearism is alive and well in Russia. In so far as popular wishes play a role in post-Soviet politios, pronouncements by high elected leaders, well-known scientists, or other senior officials that a sizable, or even any, military nuclear infrastructure will be maintained either in Russia or other republics, must be treated with caution.

There is another interesting development which may lead to more political pressure on the military. At least people in the Vladivostok region are beginning to understand the adverse impact of continued military spending on their well-being, and that resources from the military could be used to help the economy. As one local environmental committee member angrily noted, "Before they said there is no money, because we need to build submarines. Now they say there is no money, and they still continue to build submarines."

\section{B. The Soviet Submarine Fleet: Sinister or Struggling?}

A quite different view of the Soviet submarine threat is beginning to emerge. Rather than a sinisterly large submarine force, if the reports about accidents and enrichment levels of fuel are true, the Soviet Navy may'have been struggling for many years just to keep an adequate number of submarines operational.

\section{Accidents}

One of the first group of 30 students graduated from military schools in 1958 to operate nuclear-powered submarines recently provided some interesting insights about the first Soviet nuclear-powered submarines to a Soviet reporter.

The first four submarines - K-3 Leninstriy Komsomol, K-8, K-5 and K-14 -- were constructed at the Severodvinsik yard. Only two were completed, and even then only poorly, when they were sent in 1958 from Severodvinsk to the partially completed base at "Zapadnaya Litsa" or Severomorsk-7. They had to leave without being properly completed in order to fulfil the plan.

One of the submarines, the K-5 was given the nickname "Automat." If the submarine left the base, on average it took only one day to come back because of an accident, i.e. it . automatically returned. The K-8 was dubbed "Half-Automat," because it spent on average two days at sea before it was forced to return due to malfunctions. Serious restrictions were put on their area of operations. The submarines were not supposed to operate more than 200 kilometers from the base.

The 1985 accident was one of the worst of many accidents which bave undermined the potency of the Soviet submarine ticet. Serious accidents haye removed five submarines from the leet. Three have sunk: a November in 1970, a Yankee in 1986, and the Mike in 1989. Two 
more are no longer operational: a raised Charlie-submarine which sank in 1983 and the exploded Victor submarine.

Serious accidents continue to occur. A Typhoon ballistic missile submarine suffered a missile launch failure in the White Sea in late September 1991. With such a safety record, the Soviet Union's large nuclear-powered submarine fleet, either may have been constrained by its reliability, or, with its frequent accidents, may have been partially necessitated to keep an adequate number of reliable submarines at sea.

The prospects for improvements in the future are not good. The naval officers in the Vladivostok region expressed special concern about more refuelling accidents. One Vladivostok region naval officer said, "in principle, and in practice," the possibility of accident like the 1985 disaster could not be excluded. With decreasing resources negatively affecting training and the availability of materials, the chances of accidents occurring may even increase.

2. Fuel enrichment levels and refuellings

Older submarines seemingly have much lower fuel enrichment levels than U.S. submarines. Experts in Moscow and the Northern Fleet indicated the fuel in older submarines is enriched to 40-60 percent uranium-235 (the newest subs reportedly have levels comparable to the U.S., i.e. greater than 90 percent). The 1985 accident Victor submarine's fuel reportedly was only enriched to 20 percent.

Refuellings of submarines may occur much more frequently than in the west. The naval officers in Vladivostok said older submarines are refuelled every 5-10 years. But experts in Moscow and the Northern Flẹt, said four years, and sometimes less, between refuellings is not atypical.

The low level of enrichment of Soviet fuel casts a different light on the size and pattern of operations of the Soviet nuclear-powered submarine force, and its availability for operations. Other things being equal, such low levels of enrichment means a larger force of two reactor submarines with an average low operating tempo would be needed to keep a required number of adequately fuelled submarines at the ready. Conversely, subs that were operating at high levels, would be undergoing frequent refuellings, limiting their availability and increasing the chances they suffered a refuelling incident. 


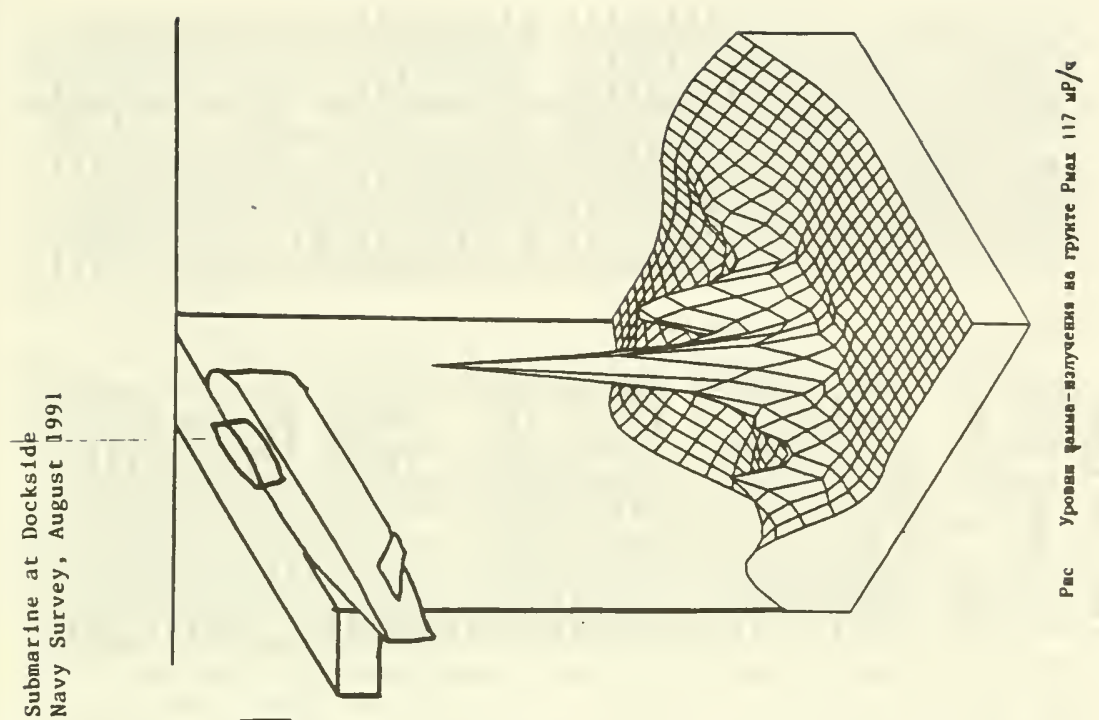

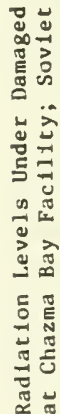
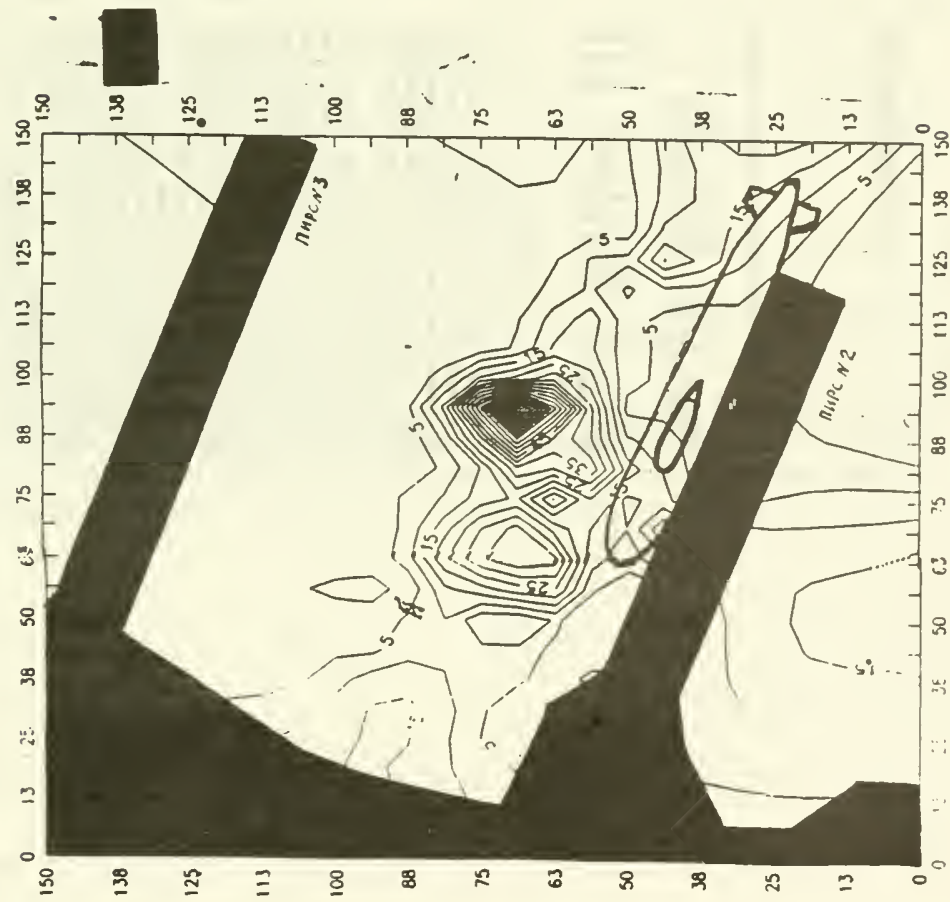


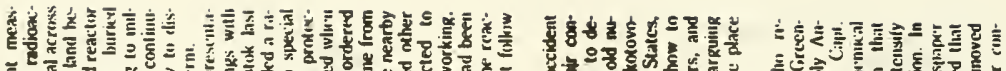

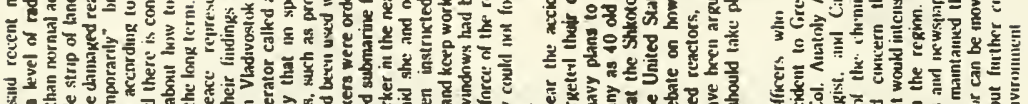

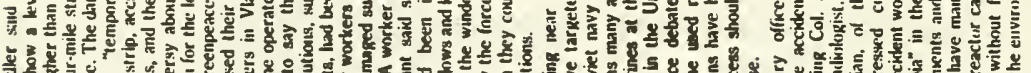

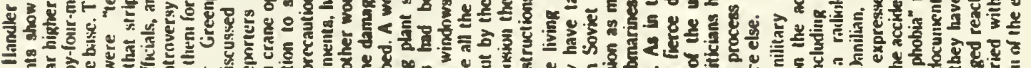

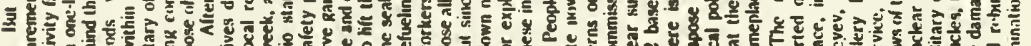

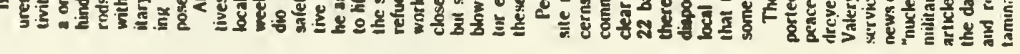

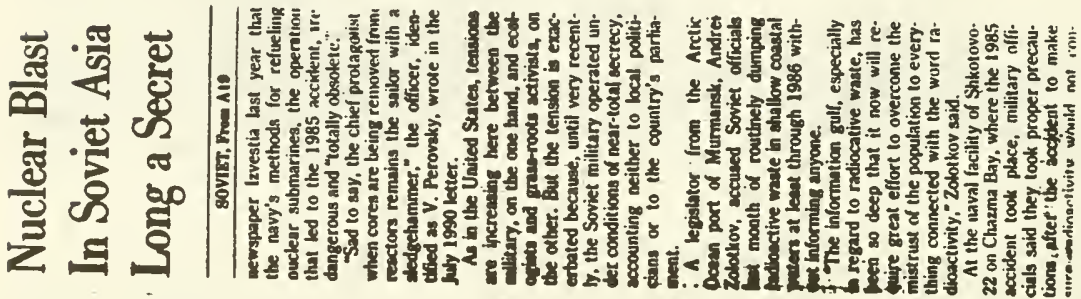

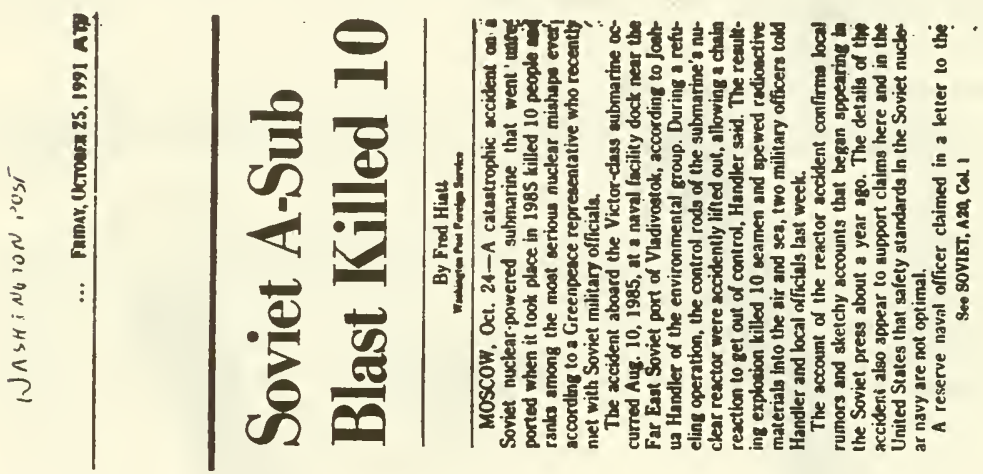


10/25 UNION NEWSPAPER REVEALS LARGEST SOVIET NUCLEAR ...

MOSCOW (OCT. 25) TASS - Ten people were killed and many exposed to dangerous radiation levels in 1985 in the largest nuclear accident in the soviet navy over the past 30 years, according to a newspaper report revealing the disaster for the first time.

The trade union daily Trud said today the catastrophe took place at the Defence Ministry's Shkotovo-22 ship-repair facility in the maritime territory on the pacific coast on August 10, 1985.

The accident occurred at noon during the replacement of a reactor core on a nuclear submarine.

A routine operation required every five years, it also needs extreme caution not to disturb the protective lattice almost right under the reactor cover. Should the lattice, containing radioactive fuel and high-temperature water under high pressure, be shifted, a nuclear reaction gets under way.

Describing what happened after the reactor cover began to be lifted, trud said:

The reactor cover was slowly creeping upwards when it suddenly went askew, knocking against the lattice. The reaction started. High-pressure, super-heated steam broke loose from the reactor depths, hitting the cover with great-force.

"The ship-repair yards shuddered from a powerful explosion. Everyone rushed to see what bad bappened. What they saw were flames and brown fumes bursting from gaping boles in the crippled sub."

Three hours later radiation meters, designed to register emissions of up to 600 roentgens, read off scale, Trud said.

It added that later studies found that radiation levels during the accident reached 90,000 roentgens per hour and those who fought the blaze or happened to be nearby received at least 30 to 40 rems each.

"The fire was put out in one and a half to two hours and a the one-tonne reactor cover was thrown about 100 meters by the explosion almost to the other side of the bay ten people, who were on board the sub, were torn into little pieces."

Military commanders arriving on the scene of the tragedy, Trud continued, ordered the place to be tidied up and the facility to be back in operation by the beginning of the following week.

They also ordered the nuclear accident to be officially described as a thermal explosion, and all military service personnel and civilian employees at the facility had to sign a pledge not to reveal the disaster.

Trud said that a proper burial ground for the contaminated submarine was not even constructed in view of the rush to resume work as soon as possible. Instead, three deep pits were dug in the hills near the settlement housing the facility's staff and their families, and the radioactive wreckage was dumped there. 
military reform is not taken into consideration. The impression is that some people are obviously carried away with the very process of putting forward differen proposals on military reform. We. on the other hand. believe that a more fruitful course is to adopt. in parylel with the theoretical elaboration of all aspects of milifary buijding. measures to implement these proposals.

In this sense military reform is already a reality. fundamentally new defensive grouping of our troops within Soviet borders is being consistently created. Twenty-one combined arms divisions as well as a aumber of formations and units of other branches of the Armed Forces and categories of troops have been disbended. As for the military budget and the preparation and discussion in organs of state power of the progerm for conversion and the renewal of the composition of the Ministry of Defense leadership, these problems are also loday at the stage of practical solution. The number of control organs has decreased by 20 to 60 percent. More than 400 defense complex enterprises and 100 civilian installations producing military output have undergone conversion. The total savings in expenditure on defense in the current five-year period with regard to the ratified plan amounts to almost $R 30$ billion. A system of contract manpower acquisition for the Army and Navy is being investigated. Surely all this cannot be classed as "cosanetic changes"'?

We believe that the letterwriters have not managed to protect the Army. The contran is the case: By specu. bting on real army pains and problems. they are willyailly whipping up anti-Army hysteria in society.

So who will actually protect the Army?

[Signed] USSR People's Deputies: E. Vorobyev, N. Kaliain. A. Kolinichenko. A. Kostenko. A. Makashov. N. Moiseyev. N. Morozov. V. Osipov, S. Postnikov. B. Pyankov. V. Semenov, M. Surkov

RSFSR People's Deputies: V. Achalov, A. Voronin, A. Koviunov, I. Rymorov. V. Tarasov.

\section{Belorussian People's Deputy V. Dubynin}

281h CPSU Coneress Delerates: A. Adivenov, V. Arkhipov, B. Baranov, M. Belov, M. Burlanov, N. Bykov, Ye. Vysotskiy. S. Grechin. A. Demin. P. Deyaneain, G. Donskoy. V. Yefanov, Ye, Zanudnev, V. Zimin. O. Zinchenko, G. Kanunin. A. Kamenetskiy, V. Karpov. V. Kirilin. P. Kozlovskiy, P. Krasnov, V. Kremlev, V. Kuznetsov, A. Lebed. N. Makarov, A. Makunin. N. Maryashin, A. Maslov, Ye. Mikulchik. A. Novikov, V. Novikov, V. Novozhilov, V. Oenev, I. Oleynik. F. Orlov, V. Plekhanov, V. Rodin. V. Ryzhov, A. Saushin, V. Safronov. A. Sibilev, V. Snetkov, G. Stogradskiy, A. Stolyarov, I. Uelin. V. Filatov, S. Cheryukanov, A. Chumakov. Ye. Shaposhnikov, B. Sharikov, V. Sharysin.
Acadcmics V. Davydov. A. Kuznetsov, A. Kuntscyich, -A Mesheheryakov, V. Puzik. Yc. Rybkin. A. Sivachev. L. Ushakov, A. Shurygin.

Assurances on Safety of Nudjear Subs Doubted P.UI707130390. Koscon 1ZIESSTIY.t in Russian $17 \mathrm{Jul}$ 90 Morning Edition $p 6$

[Open letter to Fleet Admial V.N. Chemavin, commander in chief of the Nary. from V. Perovskiy. former commonder of thesufrivability division of the Lenin. skiy Komsomol. the first Soviet nuclear submarine. under the rubric "Follow. U $p ":$ " DangerReactor!"- - first paragraph is editorial introduction]

[TexI] IZVESTIYA (No. 166) published a piece about the protests of residents of the city of Sovetskaya Gavan at the Pacific Feet command's plans 10 unload spent nuclear fuel from obsolete submarines in Postovaya Bay. The commentary by Fleet Adm. V.N. Chernavin was patently reassuring but. as subsequent events have shown. did not eliminate the tension in Sovetskaya Gavan. Moreover. there is also a different view regarding the safety of the nuclear submarine fleet. The letter that we are publishing is about this.

Esteemed Vladimip Nikolayevich! I understand the sheer delicacy of a situation in which a civilian ventures to give advice to the top man in the country's Navy. Nevertheless. exceptional circumstances prompt me, a reserve officer. to address you in precisely that way because the matters discussed in the IZVESTIYA piece-it talked about safety in exchanging the charge of reactors in our nuclear submarines-were for a long time part of my official duties in more than 25 years service in the Northem Fleet. So I have a few remarks about your commentary.

Though you rightly speak of many years of experience of operating nuclear submarine reactors. you fail to mention that this experience has been paid for with people's lives and losses of ships and. sad to say, is still being paid for to this day.

It is very difficult to agree that techniques for recharging reactors are well organized and backed up with the necessary resources. If they are organized. it is only in the worst possible way and they are based solely on the selflessness of officers and the patience of sailors. The iechnological modus operandi laid down in 1959-1960 is totally obsolete. It is absurd, wasteful, and scarcely capable of ensuring an appropriate standard of work in the future.

As for the technical equipment. there is always a disastrous shortage of it. Recharging equipment has remained fundamentally unchanged for decades and. sad 10 say. the chief protagonist when cores are being removed from reactors remains the sailor with a sledgchammer.

Greal hopes were pinned on the new lechnical suppon and depot ships. However, the unpreparedness of the 
centers at which they are based. design miscalculations. and organizational disarray sharply reduce the potenizal of these expensive technical resources. Years are passing. but there are no signs of any hopes of an improvement. Rather the reverse: The prestige of the trade of recharger is declining and the level of specialized training is falling with the change of generations. Conflicts are brewing between the officers of technical suppor ships. rear services. and control organs and may have an unpredict. able effect on the safety of work whose nature is unique.

The pressure-vessel reactors used in ship power plants are reliable at all stages of operation except one-ihe unsealing of the reactor prior to unloading the spent nuclear fuel. Durng this operation there is only passive monitoring of the state of the reactor and the slightest blunder by personnel may displace the reactivity com pensation devices. entailing a reiease of reactivity. How all this ends is well known from the tragic example of the refueling of a Pacific Fleet submarine.

Even after the spent nuclear fuel has been unloaded. the unsealed reactor is itself an exiremely powerful radiation source for a while and requires special measures to matniain the safely of the environment.

The commentary mentions an expert commission that found no violations at the naval bases on the Kola Peninsula and in Arkhangelsk Oblast. With all due respect for the prestige of the panicipanis in the survey. I don't think that its resulis should be interpreted with such latitude. The commission's task did not include a detaled survey of installations and technology intended for handling radioactive waste and spent nuciear materials-ihe end products of the activity of nuclearpowered Northem Fleet ships and nuclear-powered. ships betonging to the Murmansk Steamship Company.

We who are professionally involved in this problem feel simply ashamed to speak of the extent of the technical neglect in this sphere. The unpreparedness of the fleets for the decommissioning of nuclear submarines-and nuclear icebreakers too-which have reached the end of their If fettme has exacerbated this problem to an exireme extent.

There is not enough space in a letter. Comrade Fleet Admiral. 10 cite all the proof confirming the depressing situation in such a delicate sphere of the fleet machinery The author hopes for direct dialogue and is prepared for it at any level. especially as the urgency of taking measures is self-evident. It is even more self-evident that science should rectify the situation in a timely way. Alas. at present official science with its departmental character and hierarchical structure is scarcely capable of this. Technological breakthroughs are possible only via unorthodox approaches.

One last point. Everyone must know that the dismanlling of nuclear submarines that have reached the end of their lifettme and the creation of a modern infrestructure for handling radioactive waste will entail expenditure comparable with the construction of new nuclear. powered ships.

[Signed] V. Pcrovskiy. former commander of the survivability division of the Leninskiy Komsomol. the first Soviet nuclear submanne. Leningrad.

60 Motor Vehicle Battalions Detailed to Harvest 9OL:WOTJIB Moscow IZVESTIY.t in Russian $9 \mathrm{Ju} 90$ Morning Edilion p ?

[Report on interview with Lieutenant General A. Nadolskiy. deputy chief of the Main Staff of the Ground Forces. by N. Medvedev; place and date not given: "Army Harvests Crops"]

[Text] By a decision of the Government of the USSR. 30.000 military trucks. or 60 motor vehicle battalions. are being assigned to take part in the current harvest. campaign. They are scheduled to star work on 10 July. but have actually started already. A temporary staff has been set up in the Ministry of Defense. headed by Lieutenant General A. Nadolskiy.

[Medvedev] Anton Kononovich, your organizational position is deputy chief of the Main Staff of the Ground Forces. What did you think about when you found out that there would be "grain battalions" this year?

[Nadolskiy] About the fact that the hot months are starting again. We assign dozens of motor vehicle batta! ions to take pan in the harvest every year. frequently in the hottest sectors. The officers and soldiers give all they have in the work - from the start of the harvest campaign until snowfall. as the saying goes. until the last pood of grain is transported out of the fields.

I also thought about the difficulties that we inevitably will encounter. We have the equipment. but what will it be like with the driver complement? There is a big shorage. The Army is being cut and probiems are accumulating that are related to the virtual breakdown in the current spring call-up in the Baltics and some Transcaucasus republics.

[Medvedev] But, nonetheless. baltalions are being formed?

[Nadolskiy] This year we must send 50 motor vehicle battalions to the autonomous republics. krays. and oblasts of the Russian Federation as well as 10 to Kazakhstan. Each battalion has about 500 vehicles. I should note that this is a temporary formation. They have been set up in almost all military districts and in the neets and in the services of the Armed Forces. Approximately one-third of them have been manned with personnel. We will call up military reservists-this is what was decided by the USSR Council of Ministers and the Governments of the RSFSR [Russian Soviel Federated Socialist Republic] and Kazakhstan in coordination with soviet organs in the oblasts where the battalions will be working. Only military reservists who are not directly 


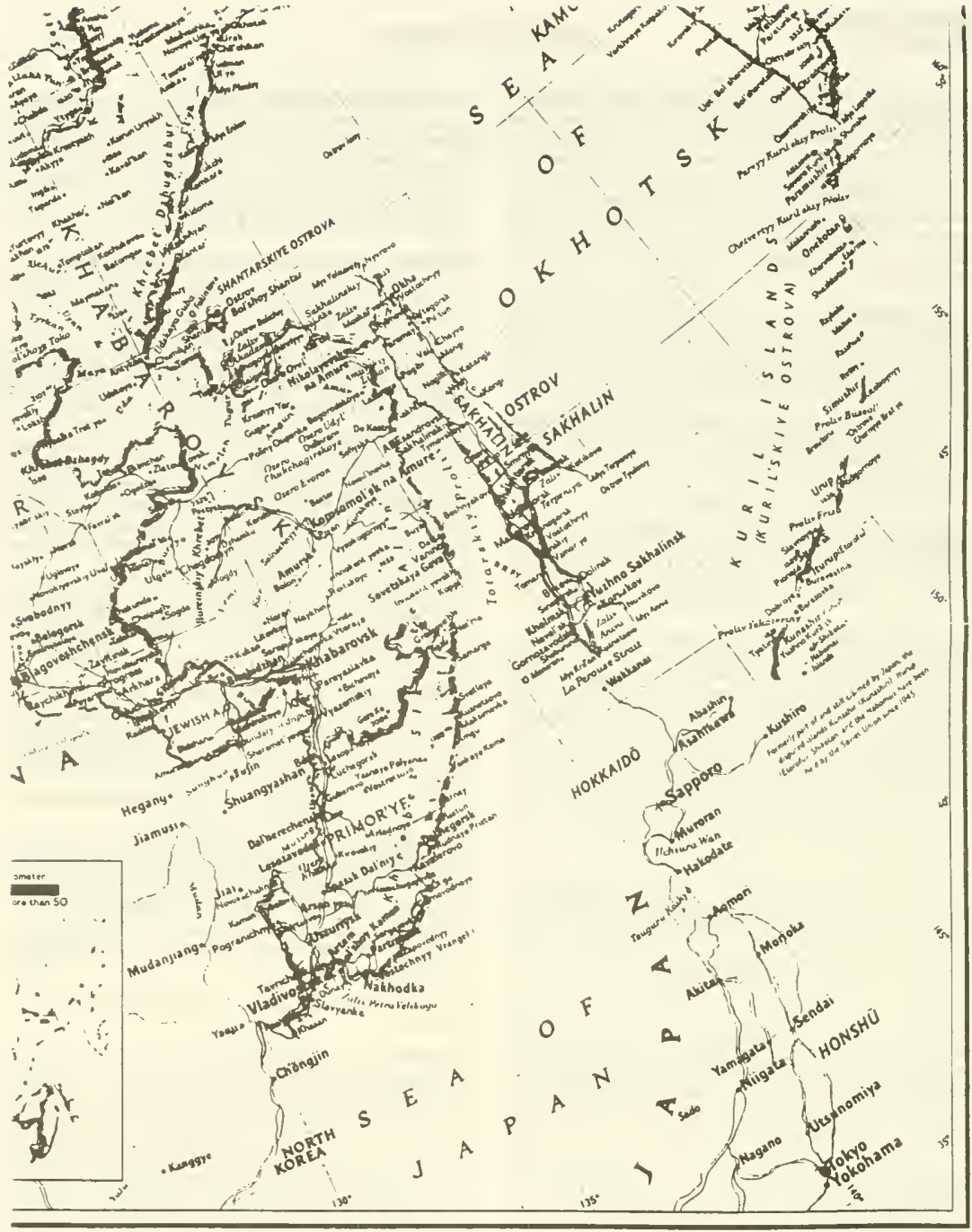

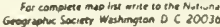


THE ANSWERS OF THE QUESTIONS SHA ASKED BY

WITH NAV! REPRESENTAT:VES.

1. It is plarred up to 2000 year to write off battlo order o: Mavy of C.'T.F. and screp toraly 150 nuclear silbmarires.

2. The list or the nuciger submarines are intended to te writicen off battle order includes as milidjurposes nuclear submarines as woll i: th bailistec missiles.

3. All the nuciear submarines intenced to be wr:iten of: in accordarce with the treaty are considered in prelimiriary evaluation of capital lavestment for $1 t^{\prime}$ 's scrapping.

4. The exchange or demolition, iecnnology of riuciseas submarines, stcrage nuclear blocks and ruclear waste.

5. The jemolition of nucleer submarines is plannod to realize on the existerit shipyard taking lnto account tie suppiing of the edditional special gquipment.

6 . The sele of nuclear submarines is pianned to extiute as a scrap.

it is expeiling the technology crantmisision.

Deputy of Commander in Chief of Navy C. I.S. for operat.ioni and overhaule

Admiral 
476

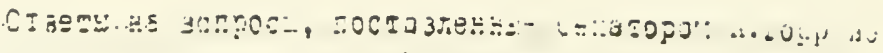

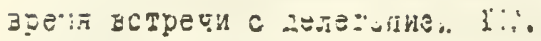

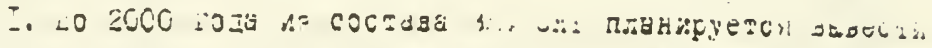

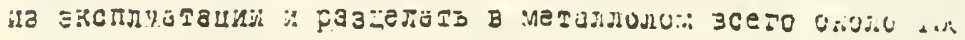

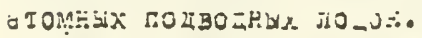

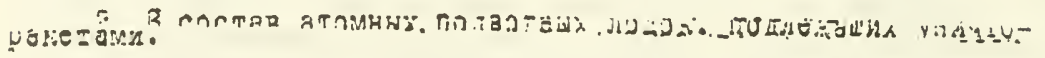

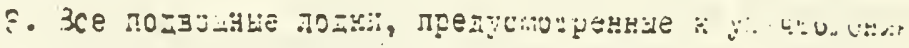

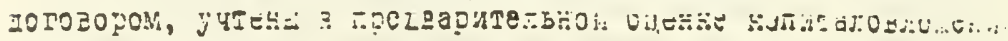

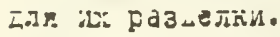

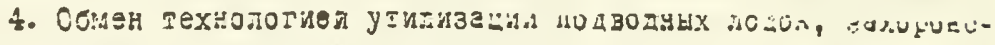

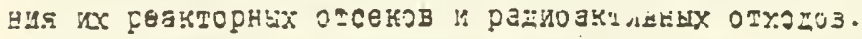

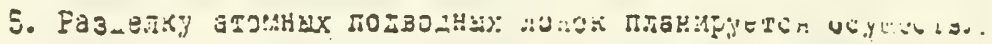

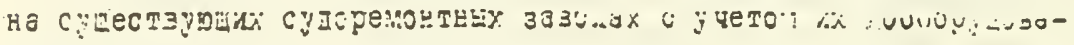

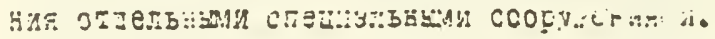

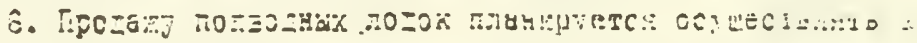
виде vieталтоло: 15.

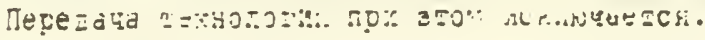

$$
\text { T EA }
$$

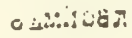

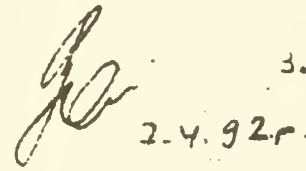




\section{Submarine Safety The Soviet/Russian Record}

\section{Joshua Handler}

Since the 1950 s the debate over the threat posed by the former Soviet submarine fleet has been one of quantity versus quality Did the force s large size. coupled with its unusual technologies such as titanium hulls liquid-metal reactors elc. compensate for its geographical disadvantages and overall inlerior quality? Because of the lack of reliable open information. this question was never salısfactorily answered Western analysis. however. generally erred on the side of caution and concluded that the strengths of the Soviel submarine fleet oulweighed its weaknesses

Glasnost and the controversy over the sinking of the Mike submarine in April 1989 have provided new information that allows a prelımınary reassessment of the quality versus quantity debate to take place New. and at tumes dramatic.

intormation about submarine accidents has recently appeared in the Soviet press In addition visits to submarine bases and facilities have been able to corroborate many of these reports and provide lurther insights

It is well known that accidents have frequentily afflicled the Soviel submarine force Fires collisions, radiation exposure and sinkıngs are the regula lare of Soviet submariners Western surveys of Soviet naval accidents from 1945 to 1989 catalogued some 60 incidents involving Soviel submarınes
The testimonies of officials before the US Congress indicate this is the tip of the iceberg in 1975-85 the then Chief of Naval Operatıons Admıral James Watkıns. told Congress that the Soviets had over 200 submarine accidenis scme of which he noted were very Se:ious

Soviet reports logether with on-site visils have added another 30 accidents 10 the 60 reported up 101989 The Soviel reports have also extensively discussed submarine salely and problems with construction it is sill impossible. however. to evaluate statistically the sately of the Soviet submarine fleet compared to its Western counterparts Clearly. its nuclear force has had more major disasters Moreover the economic chaos in the former USSR is increasing the possibility of accidents

\section{Radiation Safety Problems}

Most intriguing of all the Soviet submarıne problems has been the safety of Soviet naval nuclear-powered submarines it was known quite early-on that the Soviet Navy was having troubles with its nuclear reactors In 1961 . Only three years alter the first Soviet nuclearpowered submarines went to sea. the New York Times reported that there is no evidence that any of them have cruised the hign seas. and there is some beliet that the Russians nave encountered difficulties with their nuclear reactors Since then. Western reports have repeatedly underscored the weakness of the Soviet naval nuclear propulsion programme Most recently on 7 Apri! 1992. Admiral Bruce DeMars. Head ol the US Navy s Propulsion Programme revealed 10 Congress that Soviet naval reactor accidents are to blame lor approximately 80 deaths since the early 1960 s. and the loss or retirement of a number of ships 'A number of cases of radiation accidenis were also recorded in CIA reports, and a list of Soviet nuclear submarine accidents was provided by the US Navy to Congress in 1982 ' But new detalls about reacior accidents and nuclear satety problems are now coming 10 light providing additional basis for Admiral DeMars sobservations

The most serious accident yet uncovered occurred on 10 Augusi 1985 when the reactor of a 'Victor' class submarine exploded while undergoing refuelling at the Chazma Bay facility near Vladivosiok Soviet naval olficers based there said the explosion resulted from the reactor going critical because the contro rods were inadvertently removed from a new fuel core as the reactor lid was being lifted alter being improperly placed the first time The explosion killed 10 men in the reactor compartment instantly and ejected highly radioactive materials onto the surrounding land and into the water

The submarine repair yard at Severodvinsk. Russian press reports clarm that a tire in a submarine $(\mathrm{K}-11)$ reactor caused a realease of radiation back in February 1965. (Pholograph: Bjorn Jorgensen)

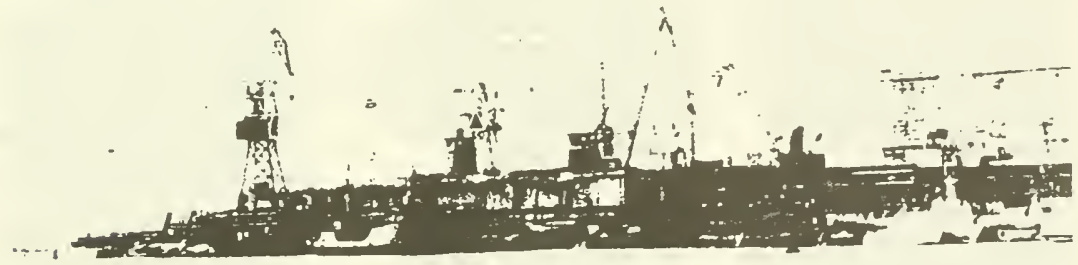




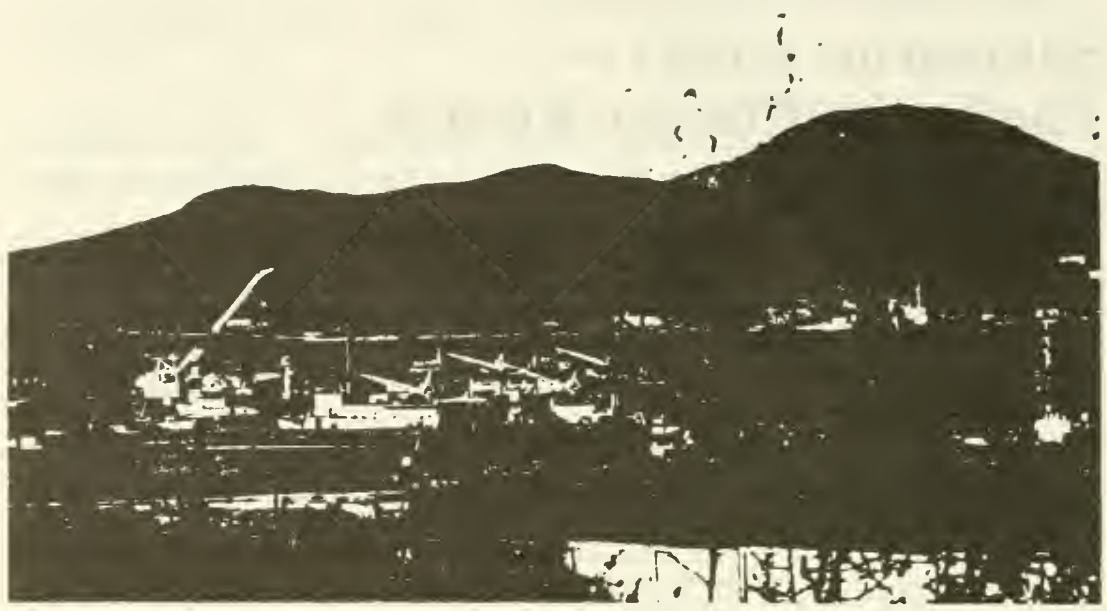

A view of the Chazma Bay facility reveals the damaged 'Victor' submarine which exploded on 10 August 1985 while reluelling. It is hidden behind the diesel boat at the dockside with its tall tin just showing on the right. (Photograph: J Mandlen)

According to the same officers, several hundred of thousands of curies were released including short-lived isotopes A TASS report on 25 October 1991 said that radiation meters in the area went off the scale at fatally high levels of

600 roentgens $/ \mathrm{h}$. The fallout from the accident spread for some $6 \mathrm{~km}$ across the Shkotovo peninsula towards

Vladivostok in a band several hundreds metres wide However according to the naval ofticers the cloud did not reach the fily The submarine has not been eparred and was still visible at the dockside of the Chazma facility in midOctober 1991

Additional and recent accidents or past problems involving reactors include the $K-19$ Holel class SSBN which sutiered a prımary coolant leak on 4 July 1991 ( 10 men were killed). the K-8 November class SSN's generator which exploded on 9 September 1961 causing a release of radiation (the crew was hospitalized) the prototype submarıne. $K-27$. which suffered a coolant failure in the lıquid-metal cooled reactor causing a major radiatıon accident (nıne sailors killed) The last submarine could not be repaired and it was scultled with its fuelled reactors in Stepovov Bay ofi Novaya Zemlya

in addition to the Chazma Bay accident, other radiation incidents at submarine shipyards are now being reported ${ }^{6} \mathrm{~A} K-11$ 's reactor was

accidently started on 12 February 1965 while at the Severodvinsk submarıne repair facility Severodvinsk plant olficials deny this but Russian press reports claim there was a fire and release of radiation in 1970 the K-320 submarıne suffered an uncontrolled start up during construction at the submarıne building lactory 'Krasnoye Sormovo' in Gorkı This resulted in a fire and radioactive release There are also contemporary incidents One 1990 report recounted that when scientists cut open a Pacific Fleet nuclear submarine to study the reactor pipelines they accidentally disturbed a section where radioactive dirt' had settled 'As a result. personnel of the radiation safely service spent a month decontaminating the boat" - Another radiation incident occurred at Severodvinsk on 1 November 1991 durıng an attempl to return radioacive materiais 10 a protective container Eight hours transpired before the incident was contained and the radiation levels returned to normal' A person handling the materıals was hospitalızed ${ }^{\circ}$

Recent Russian accounts report that 12 damaged reaciors from nuclear submarınes were dumped in gulfs around Novaya Zemlya Two were from the $K-27$ submarine and reactors from the K-19. K-11 and the K-3 Leninsk" Komsomol were also reportedly dumped between $1964-65^{\circ}$ Even Inis tally leaves several serious submarıne reactor accidents unaccounted for

\section{Current Safety Problems}

More information is now becoming avarlable about recent safety problems on submarınes Contınuing criticism over the Soviet Navy's safety record after the 'Mike' accident prompted Admiral
Konstatın Makarov to detend the Navy's recent safety record Without providing specifics, he offered some general statisitics on how the rate of most accidents has dropped in the late 1980s compared to the beginning of the decade He did note however, there were a greater number of technical incidents involving ships - explosions fires, and flooding comprised almost nal of accidents The Admiral also said that in 1985-90. 85 per cent of the accidents involving submarines were the result of technical causes He stated that

technical causes were responsible for the sinking of the Mike submarine in 1989 and the 'Yankee' submarıne in 1986 He concluded that the major cause of technical accidents is the extreme complexity and unsatisfactory reliability of some items of equipment and armament. spot cases of poor quality of new ship construction, and. in a number of cases. shoncomings in training of service personnel'

Although. Admiral Makarov sought 10 be reassuring about the safety of Soviet naval vessels, other reports belie his confidence. According to other naval officers. 1989 saw one the highest accident rates in the last 20 years for the Soviet Navy', with $\mathbf{4 5}$ people killed including those who died in the Mike sınkıng "Another account. based on reports from the Chief of Military Procurement during 1986-90, says that 1283 people died because of accidents in the Navy ${ }^{12}$

Many complaints about the lack of firefighting, rescue equipment, and crew emergency training were made in the 


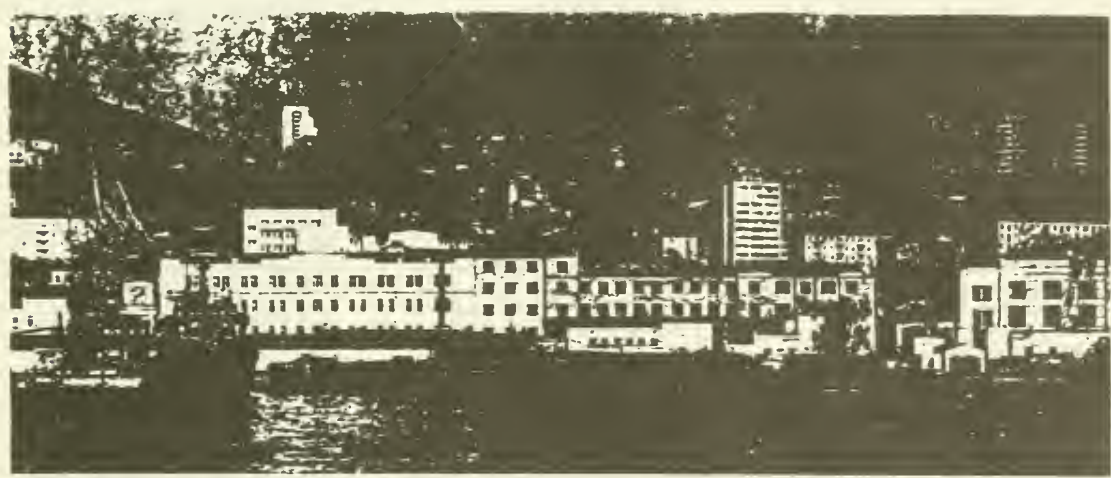

An 'India' class submarine is in the process of being scrapped al Golden Horn Bay, Vladivoslok. (Photograph: J Handlen

aftermath of the Mike' sinking Other reports about substandard construction. poor maintenance inadequate trainıng. careless seamanship shore-based logistical support. anid insulficient preparations before departures have also come to the fore "In one case in the Far East. offıcers on a nuclear-powered Soviet submarıne based near

Pelropavlovsk-Kamchatskit were so perturbed that they spoke to a local TV station in early ig90s about a variety of protlems These included lack of spare parts to repair submarınes properly submarines which were old and often kept in use even when they are unsate. equipment which was often old and of an inlerior design submarınes which were understalled and personnel who were overworked. language problems which existed because many new draftees did not speak Russian the six months of schooling given prior to service was inadequate and irrelevant 10 service needs. and olficers who were uncertain as to inert leveis of radiation exposure since checks were only perlormed upon embarkation but nol upon

disembarkation

Other reports have made sımilar charges One account discussing how unreliable equipment led to accidents and limited operational capability noied that one nuclear submarine spent the majority of its trial period undergoing repair and modilication. and that this was a trequent problem In 1989 two submarınes were prohibiled from operating to avoid the failure of their electrical equipment During the same period the Ministry of Shipbuilding recerved 529 complaints about the delivery of suostandard equipment for nuclear submarines This resulted in tines of more than three million roubles Moreover, through the failure of the main reduction gear, the Kurov nuclearpowered cruiser. had to undergo unscheduled repars in 1989-90, and because of the dock's unplanned use. a whole combined unit of submarınes could not undergo a planned overhaul"

In anolher report a submarine commander complaıned that 11 of the 28 new recruils who arrived at his

submarine did nol know Russian, and he asked How can I explain the siructure of the nuclear reactor to them?

A third article expressed concern about the level of lechnical support at naval bases. noting that shore power supply networks are in such poor condition that frequently there are voltage surges and power fallures And yet the electronic complexes of the latest submarines will not tolerate any bursis or fluctuations in voltage in excess of state standards.

Several reports discuss the poor qualıty in submarıne construction One report claımed that in 1988, eight nuclea submarınes $x$ sre not accepted for service because they did not fulfit requirements, and because of othe deviations that substantially reduce a ship's combat capabilities "Anothe lists several other construction problems

- A new submarine in 1990-91 had to be sent back 10 the shipyard to eliminate serious faults in the main shalt lines

- One new nuclear submarine left the shipyard with unpainted bulkheads. unlabelled equipment, no electrica switches in ine cabins and battle stalions, a malfunctioning high pressure valve at the chemical fire extinguisher station. leaks in the piping. e?c The builders promised the light switches would be insialled before the submarıne was delivered but they were not

- Another submarine lost a month and a half of traıning and insiruction time because it could not put to sea through serious malfunctions in the support system of the main power plant The construction yard was found to be at fault for this

\section{Known Soviet Accidents}

The known data on Soviet submarine accidents is 100 incomplete to draw specific slalistical conclusions But some observalıons about the existıng data are in order

Collisions are the most prevalent type of accident involving Soviet submarines with some 31 known instances At leas: one led to the sinking of a submarine in Peter the Greal Bay oulside Vladivostok in October 1981 Some 13 of these involved Western submarınes Hovever the blame cannot be fully placed on the Soviel crews since they may have been unaware of the Western submarines Another 11 collisions involved the snagging of lishing vessels nels with seven happening in the 1980s

Fires are also quite frequent on Sovie submarines Twenty of the incidents involved fires in the case of the November class Submarıne in 1970 and the Mike in 1989 the fires contribuled io the sinking of both vessels

intriguingly the data reveals recurring problems with missiles and missile lubes

There are six accidents recorded

involving fires or explosions in missile tubes one of which led to the ejection of a nuclear warhead in the late 1970s or early 1980s, and another caused the sinking of the 'Yankee class submarine in 1986

The number of sinkıngs indicaies a major problem but an accurate count is impossible because of incomplete data Up to 15 submarınes have been reported as sinking but only half of these can be reliably confirmed The confirmed tally includes four nucleat-powered boats. 
three of which have not been raised namely the November submarine in 1970 the Yankee in 1986, and the Mike in 1989

\section{Conclusions}

The large Soviel nuclear submarine force was thought to be a major threat to NATO navies However a diflerenl view of the Soviet submarine threat is beginning to emerge The reports about accidents and material problems indicate the Soviet Navy may have had problems keeping an adequale number of submarınes sale and operational As more intormation emerges. on balance $\|$ may shown to have threatened its own sailors as much as II did Western navies

What is interesting is the persistence of salely problems Clearly. early Soviel nuclear submarınes regularly suttered trom accidenis One of the tirst was reporledly nicknamed 'Automal' because It look the submarıne only one day to return after an accident. Another was dubbed Half-Automa: because it spen wo days al sea betore maltunctions orced it back to porl' Sadly improvements over time were not forlhcorning Four major disasters occurred in the 1980s the modern 'Mike' submarine sank in 1989. the second generalıon 'Yankee' submarıne sank in 1986. the second-generation Victor submarine exploded in 1985, and the second-generation 'Charlie submarıne sank in 1983

Several Russıan reports survey safety probiems that have existed for some 30 years The learning/teedback loop belween design, production and mantenance does nol seem to have been adequafe. Although lechnically advanced submarınes were produced. design llaws. consiruction defecis, poor crews and inadequate mainienance. taken individually or collectively. seriqusly affecled the sately of ine force.

The prospects for improvernents in the luture are not good with decreasing resources impairing trainıng, added to the unavailability of materials. then the chances of accidenis occurring may even increase In Oclober 1991, on Vladivostok naval olficer went so far as 10 say. "in principle. and in praclice. the possibility of accidents like the 1985 disaster could nol be excluded

\section{References}

1 Arkm W and Handler J. Naval ACcidents 1945-88: Neplune Papers No 3 Greenpeace institute lor Policy Studres. June 1989. Bussert J.' The Salety of Sovel Nuclear Submarines:. Jane's Delence Weekly. 18 Apri 1987. pp 715-719: Breemer J S. Soviet Submarine

Accidents: Background and Chronotogy', Navy International. May 1986: Kaplan D E and Dinkelspiel F The Soviel Navy's Long History of Nuclear Accidents Center for Investigative Reporting 12 March 1985

2 House Appropriations Committee (HAC) FY 1986 DOD Appropriations Hearings. Parl 2. p 928 See also Senate Armed Services Commiltee (SASC), FY 1986 DOD Authorization Hearings. Part 8 D 4359

3 Baldwin $\mathrm{H}$ Navy Sours Study of Underse Warlare Soviet Submarine Progress is Key in Plan for Ocean Survelllance System. New York Iimes 5 November 1961

4 Admiral DeMars B. Prepared Stalement belore the Seapower and Strategic and Critical Materiats Subcommitlee of the House Armed Services Committee (HASC). 7 Apfll 1992. 08

5 CIA Orrectorate ol Operations Domestic Collection Division Foreign Intelligence Intormation Reports on Soviet Submarine Accidents. partially released under the Freedom of iniormation ACt in December 1984 to the Center for investigative Peporting San Francisco. CA, HASC Hearıngs on Naval Nuclear Propulsion Program - 1982: 29 April 1982. op 18 19

6 See in particular Emelyanenkov A F 'From the Sobesednik Files - Split Alom. The Firsi 50 Years'. Sobesednik No 12. March 1992

7 Captain 3rd Rank Gladkevich Yu Nuclear-Powered Ships in the Bay is this Dangerous tor People and the Envionment?' Krasnaya Zvezda 20 December 1990 (Translated in JPRS.UMA i February 1991 pp 49.50) the incident took place at the Gornyak nuclear submarıne shıpyard on Krashenınınkova Bay near Petropavlovsk-Kamchatskı

8 Emergency at a Military Submarine Facility in Severodvinsk', Intertax News Agency reporting from the Arkhangel sk based newrsoaper Pravoda Severa (FBIS SOV. 4 November 1991. p 41 Transmitted via Kyodo News Service)

9 Emelyanenkov A F. From the Sobesednik Files - Split Alom The First 50 Years Sobesednik. No 12 March 1992

10 Interview with Admiral of the Fleet. Makarov K. by Caotain Ist Rank Pilpchuk. 'Is the Navy Accident Rate High? Krasnaya Zvezda. 2 February 1991 (Translated in JPRS-UMA-91-010, 12 April 1991. 0 39)

11 Intervew with Rear Admural Zatula V. Chie of the Ship Combat Training Department of the Navy. and his depuly. Candidate of the Military Sciences. Captain ist Rank Dobrovolkıy V. 'Miltary Retorm Problems and Opinions', Kommunis! Vooruzhennykh SUI. No 1. January 1991. (Translated in JPRS. UMA-91.013.20 May 1991, p 47).

12. Colonel of Juslice (Reserve) Romanor $N$. Captain ist Rank Khraptovich. and Emelyanenkov Af. Without Hcoe for Escape? Reesons lor High Accident Rate in the Navy'. Izvestiya. 12 July 1991. (Translated in JPRS-UMA-91-021,7 August 1991, p 53 )
13 Captain 2nd Rank Stelanovskıy V Chiel Engineer of the Sevastopol Ship Repair Yard in Writings Damage.Control Ouarlers Znamya No 9 September 1990 (Translated in JPRS-UMA. 91.002 14 January 1991 po 18.25)

14 Captain ist Class Bystrov S. Loss ol Nuclear.Powered Vessels The Undercurrents It Revealed: Mrasnaya Zvezda 15 March 1990 (Translated in FBIS-SOV-90.054 20 March 1990 pp 90 92)

15 Androsenko V. Restricled Cily Will Those People Who are Obligated To Do So Turn and Face the People With a Dillicult Fate? Rabochaya Tribuna 23 June 1990 op 2.3 (Translated in JPAS-UMA-90.023 15 October 1990 o 57

16 Captain 3rd Rank Gladkevich Yu How Nuctear Submarınes Orıgınate Krasnaya Zvezda 29 June 1991. (Translaled in JPAS. UMA-91-020. 25 July 1991 p 67)

17 Colonel of Justice (Reserve) Rornanov N Captain ist Rank Khraplovich A. and Yemelyanenkov A Without Hope lor Escape? Reasons lor High Accident Rate in the Navy Izves/lya. 12 July 1991 (Transiated in JPAS-UMA-91-021. 7 August 1991. op 53.55)

18 Captain-Lieutenant Puteyev K Readers Ask Nonstandard Nuclear Submarines Krasnaya Zvezda 7 May 1991. (Translated in JPAS-UMA-91.015 21 June 1991 PD 51-52) For a discussion how the design and crowded nature of Sov'et submarines contribules to problems in preventing and controlling tires see Rear Admural (Reserve) Protessor Kostev G and Caplan isı Rank Kostev Depuly Commander of a Submarine Unil. The Fleet Today and Tomorrow Why Do Compartments Burn?' Krasnaya Zvezda 15 February 1991 itranslated in JPRS-UMA-91-012 3 May 1991 pp 55-56)

19 These collisions are worth noting since the incidents may have sparked malfunctions in equipment Alter a Goll submarine snagged a Japanese lishing boat's net in September 1984 a fire may have resulled in the submarine due to stressed equipment

20 The K-219 could have had continua problems as it also suffered a missive lube accident in Augusi 1973

21 One nuclear submarine. a Charlie ciass which sank of Pelropavlovsk in 1983. was raised. Two more sinkings of unknown nuclear subrnarines. one in Decernber 1979 in the Allantic. and one in September 1983 in the Pacilic were reported by Bussert J in 'The Salety of Soviet Nuclear Submarines', Jane s Defence Weekly 18 April 1987. p 7 is it has not been otherwnse corroborated Admiral Aleksin V Chief Navigator of the CIS Navy told the author in Fobruary 1992 in Moscow that only three nuclear submarines have sunk which have nol been raised

Joshua Handier is a research co ordinalor with an international environmental organization 


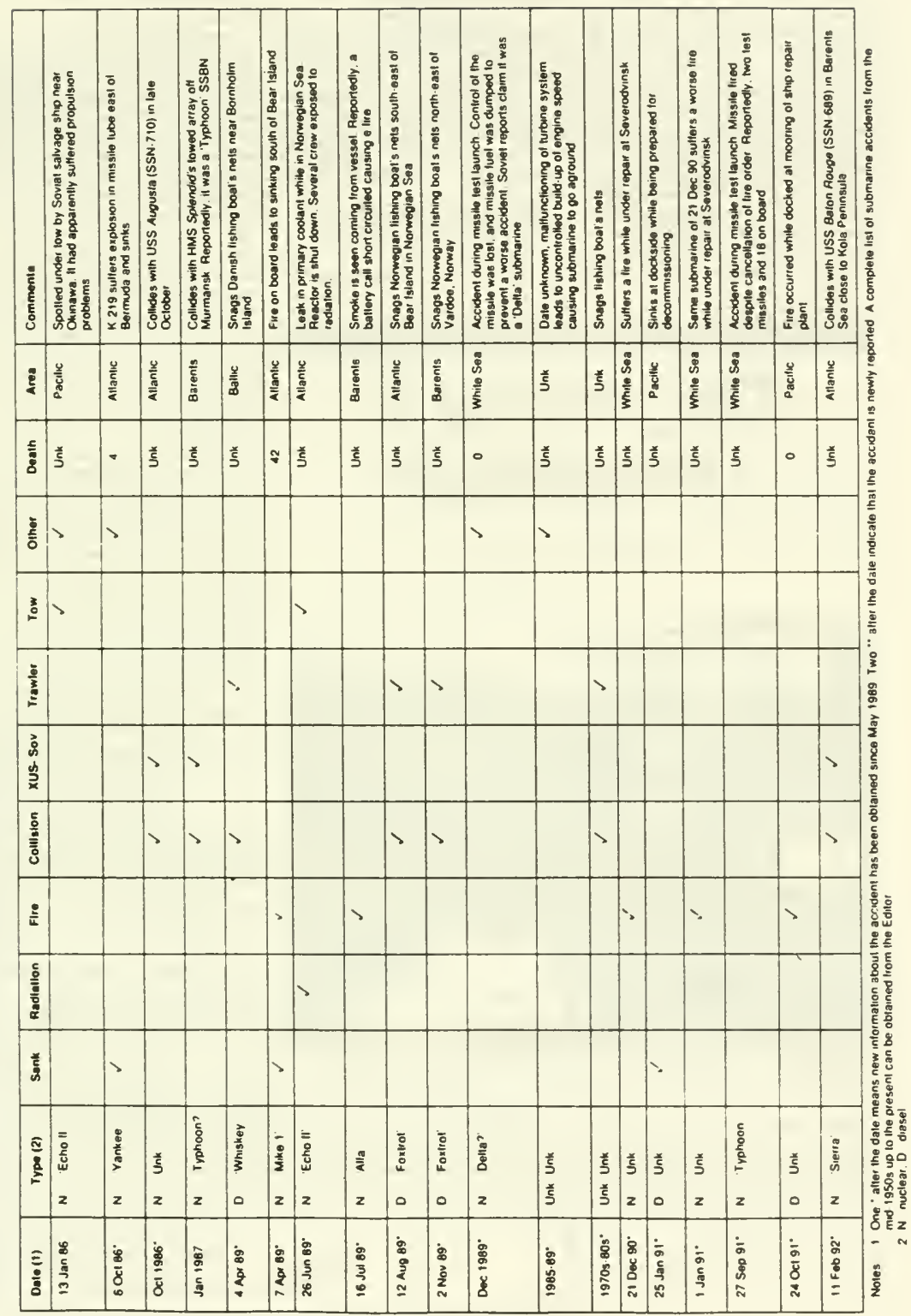


ities put feelers out about building additional nuclear power stations in Guangdong. In March the Chinese apparently decided that a second nuclear plant in Guangdong, China's fastest-groping province, was a necessity. The province conducts an annual $\$ 50$ billion trade with Hong Kong, and new industrial projects include three polyethylene plants. a 3200-million oll refinery near Guangzhou. and an \$80-million upgrade of a steel mill. To porer these and other projects, provincial officials plan to increase Guangdong's generating capacity from 8.500 megawats to 15,000 megawatts over the next five years.

With the missing steel rods at Daya Bay and the delsy in the startup of the Qinshan plant, the Chinese have halted nuclear projects while seeking solu. tions to problems that have emerged. In the Qinshan case, a major redesign to strengthen the plant's earthquake resistance is under way and the plant is expected to begin startup tests later this year.

Although politics can determine decisions about major projects in China, even during the cultural revolution in (continued ox page 46 )

\section{SOLIET LNION}

\section{The greening of Petropavlovsk}

\author{
By JOSHL'A HANDLER
}

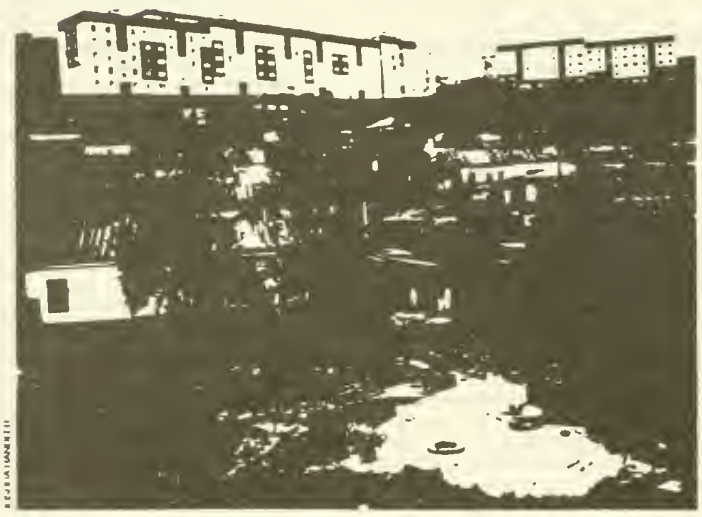

The majo Soviet nuclear submanne base at Avachinskaya Bay has done irttle to stimulate the local economy in nearby Petropaviovsk.

No thaw in the Cold War ever reached Avachinskaya Bay. Located in the chilly northerm Pacific on the hamchatka Penınsula. the bay houses a major Soriet nuclear submarıne base and naval shipyard. It faces $L^{\prime} . S$. naval nuclear forces based in Alaska and the West Coast. Soviet ballistic missile submarines still leave regulariy on strategic patrols, and the United
States still tries as hard as ever to track their movements.

Some 10 miles across the bay from the submarine base is the bustling por of Petropavlovsk, a city with a population of over 200,000 people. It too contains military facilities, but nothing as sensitive as the submanne base. Yet. as a result of military secretiveness. the whole bay area has been closed to foreigners and to most Soviets. Re. cently, a few outsiders have been allowed into the city, but the bay itself and the surrounding towns remain tightly closed. Foreign ships cannor enter the bay. In the most restricted areas near the submarine base, even residents who have nothing to do uzth the military and who work in Petropavlovsk still have to carry special papers that allow them to re-enter their villages and towns at the work day's end.

Local military commanders are not eager to open the region. Greenpeace was invited by the $F$ ar Eastern Soviet Academy of Sciences to a mid-June conference in Petropavlovsk, to present a paper on the ecological consequences of nuclear-pouered ship operations in the northern Pacific. Four of us obtained special permission (with some difficulty) to journey to Petropavlovsk, and traveled overiand. Meanwhile. the Greenpeace flagsinip Rainbow Warror attempted to enter Avachinskaya Bay in mid-June. wzth out obtaining advance permiszion Adm. I. Shumanin, a regional military. leader, threatened to fire on the ship. Locals said this uas no idle threat, as he had fired at ships before. Last year. when reporters went to investigate a fire aboard a military ship burning in the bay, guards fired warning shots.

The old guard, as represented by Shumanin, however, has not been unopposed. When Greenpeace insited local Greens were actively promoting an environmental agenda in the Kam. chatka regional parliament and were beginning to challenge the military The first independent television station in the Soriet Union. TV'K or T $T^{\circ}$ Kamchatka. was stared in Petropavlorsk. It has taken an independent line, uzth innovative programming and interestIng political commentary: Jt also took up the cause of the Rainbou Wamor. On the morning of June 17 , in an emer. gency show of support for the ship: เisit. 1.000 signatures were gathered in (contiliued all pagt -

$$
\begin{aligned}
& \text { Bulletin o The october } 190111 \\
& \text { ATomid scientists }
\end{aligned}
$$


PETROPALLOVSK (cont. from p. 11) front of the local parliament building. This persuaded the parliament to at least discuss the entry of the Rainbou' Warmor into the harbor. But nothing came of it. The Rainbou Warrior stayed beyond the Soviet L'nion's declared 12 -mile coastal limit, and left after 10 days.

The contradictions between the Soviet Lrion's domestic and military development are readily apparent in Petropavlovsk. It may be bustling, but it is like a poor city in the developing world. Half the population is housed in dreary prefabricated concrete highnses. The other half lives in houses that appear to be not much better than shacks, and are ranged along the mud tracks and roads that meander around the hillsides of the city. Meanwhile, biltion-ruble nuclear-powered submarines can be seen sailing in and out of the bay.

The Cold War will leave another legacy for the inhabitants of the region. The nuclear submarine base, which has no known name, was built in the 1960 s. Nuclear-powered submarines were sailing from the base by the late 1960 s, and today some dozen ballistic missile submarines. carryng strategic missiles with hundreds of nuclear warheads, are based there. Other attack and cruise missile-qupped nuclear-powered submarines also operate out of the base.

The submannes' reactors have generated an undisclosed amount of nuclear waste over the past 20 years. A number of cement "graves" - we could not determine how many - filled with high-level wastes are spread around the area. Several of these graves were reportedly built in the late 1960 s near the bay. Residents fear that they may be leaking their contents into the water, or that an earthquake in this active volcanic area may crack the graves and release a catastrophic amount of radiation.

For the first time, some outside monitoring of the naval facilities had recently begun. The Kamchatka State Environmental Committee began sur reving the larger area in the fall of 1990. In January 1991, a team began to work near the submanne shipyard. So far they have not detected waste leak ing into the water. However, after receiving a tip, they examined the town dump, where they found a few

\section{A Bold New Study for a Changing World Order BEYOND
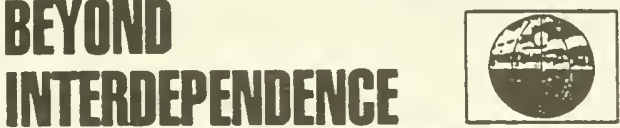

The Meshing of the World's Econorny and the Earth's Ecology

JIM MACNEILL PIETER WINSEMIUS, and TAIZO YAKUSHLI

Remartable: - Dand Rocketeller, North Amencan Chaman, Tnlateral Commissuon

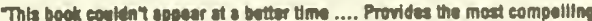
economle as wall ss endronmental case for such rotorm that I have read."

- Maunce Strong. Secretary General. United Nations Conterence on the Emvironment and Development, Jume, 1992

Beyond interdependences shows that the interlocking of the world's econormy and the earti's ecology is the now reality of the century. Within the context of environmental and political change the world over, it shows how industnalized nations can take unilateral and regional action to address envionmental threats while improving microeconomic efficiency and international competitiveness. As the 1992 Earth Summit in Rio aporoaches, this book offers the kind of incisive analysis and tar-reaching recommendations for policy reform needed to advance our common future.

192 op.; 20 illus. paper $\$ 7.95$

At better bookstores or directry from

OXFORD PAPEREACKS

Oxtord Unversity Press - 200 Madison Avenua - How Yonk - HY 10018 areas that emitted $t, 000$ micro-roentgens an hour. (The background radiation in the area is 7 micro-roentgens.) In one place pollution had spread some 200 meters. The commuttee is workng with the nuclear shipyard to "remedy" loose disposal practices.

Remedying lax radiation safety procedures, as well as instituting a general clean-up of the military sites. promises to be a big job. As one local leader of the Kamchatka Green Association noted. -The region has a lot of secrets. and the military worked a long tume without regard to the local people."

The attitudes of the local military commanders will also make dealing with radiation problems an uphill batthe. Dismissing concerns about radiation exposure. Admiral Shumanin sadd. "Look. I've been on submannes for 21 years and it hasn't affected me." $\mathrm{He}$ added. "A little bit of radiation is good for you-it makes things grow nice and big." -

Joshua Handler. co-author of $\mathrm{En}$ cyclopedia of the U.S. Military (1990). is research coordinator for Greenpeace International . Vuclear Free Seas Campaign.

HONG KONG (cont. from p. 11)

the 1960 s Premier Zhou Enlaj made certain that scientists and engineers working in China's nuclear weapons and long-range missile programs were insulated from the chaos that overtook the rest of Chinese society. Chinese leaders may put an "out of bounds" sign on political behavior as far as Daya Bay is concerned.

Daya $B a y$ is a high-prestige, highprofile project. Guangdong needs power from Daya Bay, along with the additional reactors that may be built in the future. China is caught in the classic dilemma facing less-developed countries-the need to balance economic growth aganst environmenta protection. China continues to invest a great deal of money, skill, and materaa in its nuclear power program. That alone insures that Daya Bay will soon be generating power.

Hichael C. Gallagher is a research associate at the Centre for Asian Pacific Studies, Lingnan College. Hong Kong. 


\title{
NUCLEAR FREE SEAS

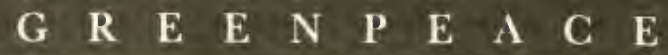

\author{
Preliminary Report on: \\ Greenpeace Visit to \\ Closed City of Severodvinsk \\ 1.2 October 1991 \\ Joshua Handler \\ Research Coordinator Nuclear Free Seas Campaign \\ Washington, DC \\ ph. 202/319-2516 \\ FAX 202/462-4507 \\ John Sprange \\ Coordinator Nuclear Free Seas Campaign USSR \\ London, UK \\ ph. $071-833-0600$ \\ FAX 071-837.6606 \\ 9 October 1991
}




\section{Introduction}

On October the 1st and 2nd. Greenpeace campaigners visited the city of Severodvinsk .. the first time that an outside environmental group was allowed into this naval city which houses the Sovie! Union's major nuclear submarine building and repair plants.

Severodvinsk is a closed city of 250,000 people, located in the north of the Soviet Union near Arkhangelsk. Since 1938, it has been a center of naval construction. The city contains the world's largest nuclear powered submarine shipyard and a major submarine overhaul, repair and nuclear reactor refuelling facility. The Soviet Union's first nuclear-powered submarines were built in Severodvinsk in the late 1950s, and the world's largest submarines, the 18,500 ton Typhoon class ballistic missile submarines, were constructed there.

The visit to Severodvinsk was part of an investigation into the environmental impact of the Soviet nuclear navy carried out by Greenpeace campaigners over the past year, in the north (Murmansk and Severodvinsk) and in the Far East (Vladivostok and Petropavlovsk) of the Soviet Union. On September the 23 and 24, Greenpeace hosted a conference in Moscow which brought people from naval nuclear ports around the Soviet Union together with western representatives. The seminar disclosed new information about the dumping of Soviet naval nuclear radioactive waste at sea.

In Severodvinsk, Greenpeace campaigners met City Council members, the Chief of Staff of the White Sea naval base, Vice-Admiral N. P. Pakhomov, the vice-director of the Severodvinsk industrial complex and head of the repair and refuelling facility, N. Y. Kalistratov, and radiological safety and environmental specialists from the Navy, industrial plants and city. The trip was arranged with the help of city council members and Alexander F. Emelyanenkov, Peoples's Deputy for the Arkhangelsk region, and with the permission of the USSR Ministry of Defense.

The meetings covered radiation safety, radioactive waste bandling procedures, accident plans, decommissioning programs, bealth effects, and defense conversion plans.

\section{A number of problems emerged:}

- monitoring carried out by the City Environmental Committee shows that radioactive material has migrated outside the nuclear submarine plant. But monitoring within the plant itself is not allowed by the military;

- Civilian authorities are not notified of accidents at the plant or aboard submarines, and contingency plans for an accident on a vuclear submarine are kept secret from them.

- Health data from the city region is unreliable. Better data is needed to understand the health impact of the plant on the local population.

- Submarine production is falling at the plant, but there are no coherent plans for defense 
conversion, or for an environmental clean-up of the area.

\section{Greenpeace is concerned that:}

- The Soviet Navy's secrecy will prevent a full environmental and health impact assessment from being completed.

- There is an enormous nuclear waste disposal problem on the Kola peninsula. The military needs to make clear as soon as possible how much waste is located there, and what are the plans for it. Otherwise the world community will remain suspect that the waste is being dumped at sea, as has happened in the past.

- The lack of planning will make the difficult process of converting the plant to civilian production harder; and in fact military production may be unnecessarily drawn out if a plan for conversion is not forthcoming.

IV. In particular Greenpeace found that:

\section{A. Radioactive safety and contamination:}

According to a map prepared by the City Environmental Committee, large parts of Severodvinsk have radiation levels which are twice the background level of 7 microroentgens an hour.

Of special concern was an area on the north side of the refuelling facility where inadequately or unfiltered water used for washing submarine and repair equipment spreads outside the plant. Radioactive particles in this water bave raised radiation levels to above 35 micro-roentgens an bour outside the plant. It is assumed that the levels are higher actually inside the facility's grounds; however, this information is still secret as local authorities are not allowed to enter the plant to examine the source of this radioactive pollution. Refuelling facility authorities admitted the designers of the facility bad not taken into account adequate filtering or disposal of this water when the facility was constructed. The plant is conducting research to assess the situation, but according to Kalistratov, it is "not so dangerous as to shut down the entity." No plans for a clean-up seemingly exist.

Vice-Admiral N. P. Pakhomov, admitted that workers bad suffered from spills of radioactive liquids. He refused to elaborated on the frequency or extent of these spills. He did indicate, however, the refuelling facility had luckily avoided any serious accidents, like the reactor explosion that befell a Pacific Feet submarine during refuelling in 1985 near Vladivostok. 
B. Plans for responding to a nuclear reactor accident aboard a submarine:

These plans exist but are kept secret from local authorities, according to Severodvinsk city officials. Local authorities wish to know about these plans and coordinate with the Navy to develop a joint response. No coordination, however, has been forthcoming. If an accident were to occur, an already chaotic situation would be made more disastrous by the lack of such planning.

\section{Radicactive waste and submarine decommissioning:}

Nucjear submarines are almost constantly in the refit facility undergoing refuelling, generating a constant stream of spent reactor fuel and other radioactive wastes. According to Admiral Pakhomov, spent reactor fuel is loaded on specialized submarine service ships and directly taken to the Murmansk area. Otber radioactive wastes are beld temporarily at the facility but then are also shipped to the Murmansk area.

Submarines are also being decommissioned. according to the Admiral, at a rate of about one a year. At the refit facility, the fuel is taken off and other equipment is removed. The reactor comparment the submarine is sealed up and then the whole submarine is towed to a facility in the Murmansk area, and held in a storage afloat condition pending plans of how to dispose of the reactor compartments, and the hull itself. Local residents complain that there is a backlog of submarines in the area awaiting the decommissioning process. They wish these submarines would be removed as soon as possible.

These details, combined with information Greenpeace gathered in Murmansk about radioactive waste disposal from naval sbips and nuclear-powered icebreakers, indicates there are sizable radioactive waste depositories on the Kola peninsula in the Murmansk region. Admiral Pahkomov and plant officials denied any waste was dumped in the White Sea, but given what is being discovered about past ocean dumping of radioactive waste by the USSR, Greenpeace is concerned that some of the waste in the Murmansk regions is or will be dumped at sea.

\section{Submarine accidents:}

While Greenpeace was in Severodvinsk, the news about a submarine accident in the White Sea broke. A modern Typhoon ballistic missile submarine, reportedly carrying 18 nuclear armed submarine-launched ballistic missiles, as well as two testing missiles, suffered an accident when one of the training missiles misfired.

Plant workers reportedly complained they had little advance notice before the submarine was brought into Severodvinsk. As a result they had to burriedly shift some of the nuclear refuelling barges to make room for the damaged submarine. Accidents like this are reported to happen at least once a year. 
Greenpeace also received confirmation from Admiral Pakhomov that a early model liquidmetal cooled reactor submarine suffered a severe accident in 1968 when its coolant "froze." There are conflicting reports, however, what was done with the reactor. The Admiral claimed it was removed from the submarine, and has been in a land based storage site near Murmansk for the past twenty years. Analysts in Moscow, however, said that the damaged reactor was only kept on land for several years after the accident, after which it was encased in concrete and dumped on or just off Nova Zemlya.

\section{E. Health effects:}

As an measure of the safety of the plant operations, local health officials claimed that local infant mortality rates had declined from 30.3 per thousand in 1961 to 8.8 per 1000 in 1985 ( 8.8 per thousand is lower than that of Russia's as a whole and the whole Arkhangelsk region as well). However, they also noted there is an increase in the proportion of tumors in the 8.8 number. There was a general agreement, however, that the data needed to make an accurate assessment of the effects of the plant on the health of the residents was not available.

\section{F. Defense Conversion:}

Indications are that submarine production will be falling at Severodvinsk. Navy officials in Murmansk told Greenpeace during a visit to that city in early September, that production has almost halted in Severodvinsk. Admiral Pakhomov noted that economic troubles, and the break up of the Soviet Union had already interrupted supplies to the plant. Local residents said two of the building ways were full of a equipment, but that nothing was being built on them, while others related that unemployment was on the rise at Severodvinsk as work was cut back at the plant. City officials thought that production would drop, perhaps as much as by a half next year.

Due to declining military production, Severodvinsk city officials are interested in defense conversion plans. The large scale effort of coordination between the plant, the city and higher level authorities that will be needed to achieve conversion of this specialized facility has not yet occurred. Nor are city officials sure where the capital for such conversion will be found. They expressed interest in receiving technical help from the west on how to achieve defense conversion. 
Report on Missile Fining Accident in the White Sea which occurred on 27 September 1991. B. LINSHITS, -Accident in the White Sea: A Hair Away from Disaster." Pravda Severa (Severodvinsk), Wednesday, 2 October 1991

This information came suddenly and gave us a start. Our city of 250.000 people once again became a bostage. Something irreparable could bave bappened. the only thing that saved us from the irreparable was eitber chance or ...

The voice that called the journalist center, that in the evening last friday one of the northern leet submarines that was conducting regular operations an accident took place. The crew was about to fire a missile with a "blank" from an underwater position, but they could not do it. During the surfacing a fire started inside a missile tube, and a situation was created that threatened both the crew and the nearby city with great disaster.

The boat was located in the White Sea near Nenoksa, it carried missiles with nuclear warheads. The submarines had to pour out to sea a large quantity of missile fuel...

All this was presented as a supposition. What must a journalist do receiving such information? Obviously he must check the trutbfulness of the facts. I called the staff of the White Sea naval base, and knowing that the commander L. M. Salnikov was on vacation asked to meet his replacement, N. P.

Pakhomov.

But the meeting did not take place. I must say already then, when I spoke with the duty officer who connected me with one of the staff officers, I realized that no conversation would bappen. An annoyed voice asked who was calling on what issue, and what exactly was I interested in.

Yes an accident took place, be said, a competent commission is working on ih, but how does it concern you? I insisted on a meeting and was told to come at 13:00 hours. At the agreed time I arrived at the checkpoint. but was forced to wait a balf an hour until finally an officer calling himself V.V. Volnov appeared. Having inquired of the saibr on duty where the "some sort of correspondent" is around bere, be lead me to understand that my furber standing at the checkpoint would be hopeless.
Having worked in Severodvinsk for many years, I bave long lost any illusions I have had that the Deet commanders bave any gentility. This time as well they spoke of me at the doorstep, they dida't ask me to come in, didn't listen me, they simply poured out their annoyance, even though they understood I was simply carrying out my work duty.

"Comrade Pakbomov is eating lunch at this moment and cannot meet you.."

"When can we meet tben?"

7 don't know, call after dinner."

I called after dinner. I was informed that $V$. V. Volnow himself is in a meeting...

Witbout denying the occupance in principle the staff refused to provide any official information for the newspaper.

Why would they not want to meet with the journalists, to jump abead of the developments to prevent the rumors and conjectures : bat usually grow around any sort of accident? When will our military learn to work with the press in a civilized fashion, displaying respect towards not only the law of the press, but to the journalists and to themselves [i.e. the military]. In the final analysis because of their behavior the authority of the army and fleet suffer.

However, the awl could not be concealed in the naval bag. The municipal council of the city soviet already knows about the accideat. They are worried that yet again the waters of the White Sea may become poisoned. There is a concern caused by the past practice of the military authority of not informing the organs of the local autbority about the occurrences, and so feel itself unpunishable in the process.

So what did take place aboard the boat? And when will we know the truth? In the spring when the sboreline will be covered by starfish? Or when the storm waves throw out dead sea animals? Apparently the previous accident which about so much was written, did not teach us anything. 

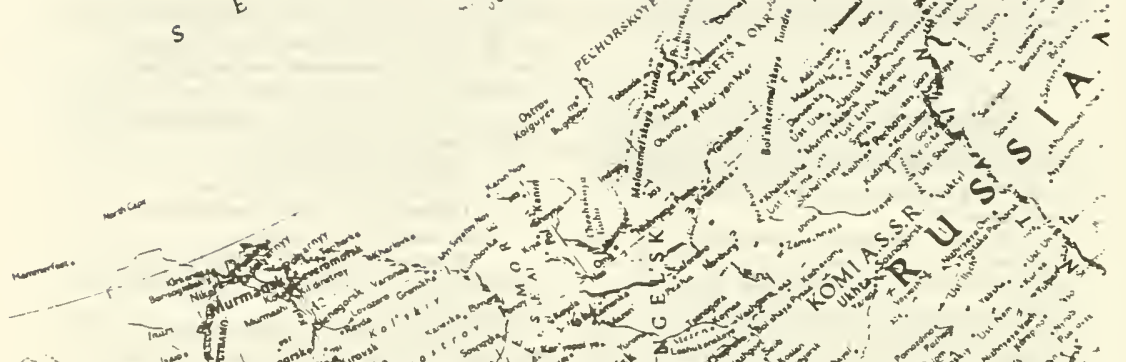
Ton

0

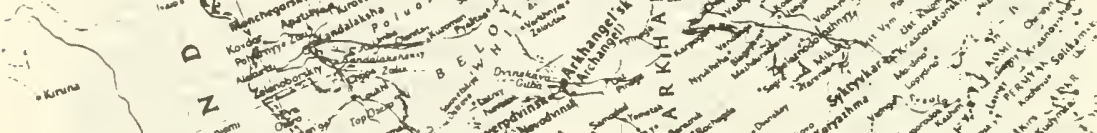

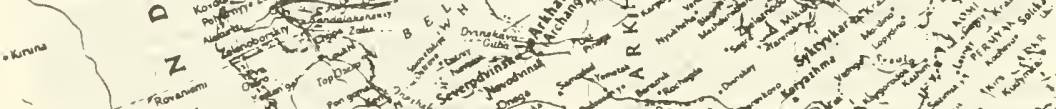

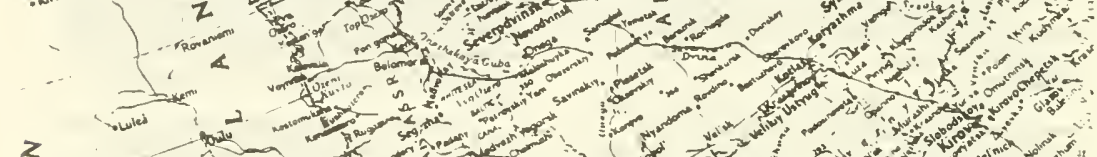

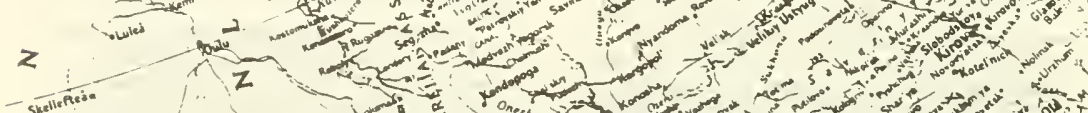
$\omega$ unt - 12 rampere . Iuth - Lene Aind sumu

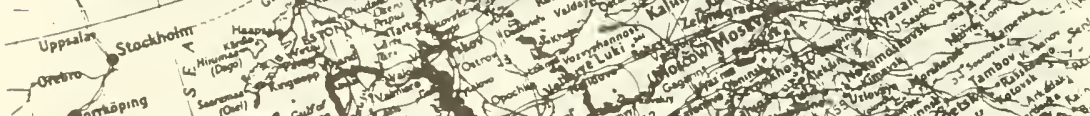

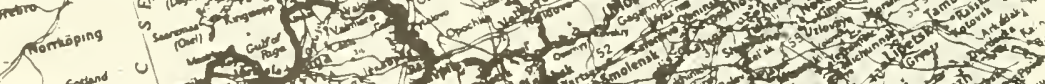

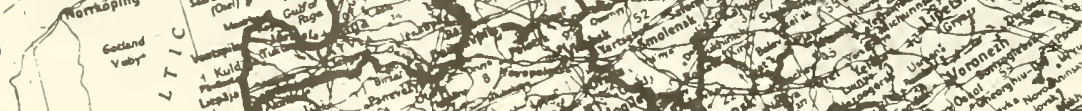

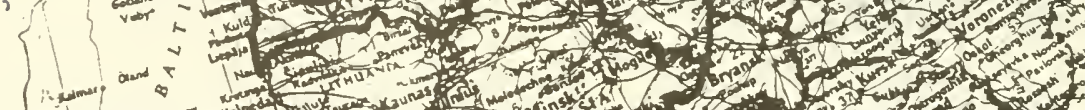
Twa 4 2

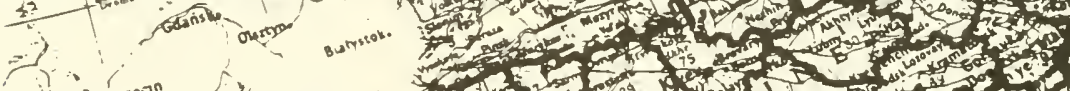
(19) 


\section{THE BULLETIN}

\section{Send help, not charity}

In the once closed city of Se verodvinsk. Russia, change has at least reached the outskirts. No longer do guards examine papers at the checkpoint at the edge of town: the checkpoint guardpost has been converted into a small commercial store. But within the city a debate is raging over how much more change should be allowed. Home to the "Northern Machine Building Plant," the largest nuclear submarine-building construction yard in the world, Severodrinsk lies on the White Sea coast near Arkhangelsk. The town's 250,000 inhabitants are divided about what should happen next, with conservative plant directors, military men, and security forces pitted against more liberal community members.

Conservative leaders want to keep the torrn closed.

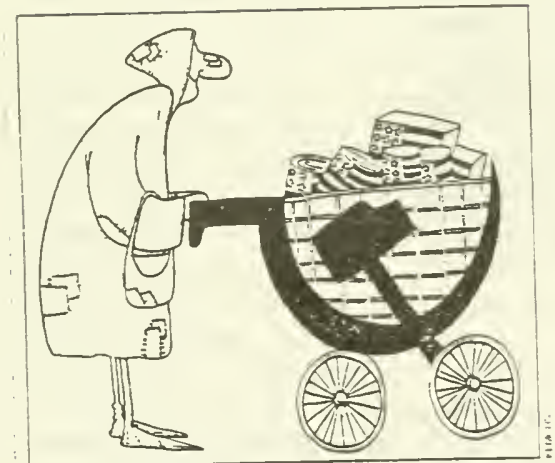

Since the 1950 s, 115 nuclearpowered submarines have been built at the yards, but now Russian military production is on the decine, and submanne construction is no exception. At one time Russian shipyards launched six new nuclear subs a year, now the head of the Russian navy says they will be lucky to produce an average of three every two years. Liberal residents know that some sort of manufacturing conversion is needed to save the city, and they say the city should be more open to external investment or aid.

But what kind of assistance, particularly from the West, would be useful? City and plant officials are critical of current Western aid programs. In contrast to reports from Moscow and St. Petersburg, which have re realed a wide variety of re sponses from aid recipients. officials in Severodvinsk de scribe food aid as insulting. We can take care of our old people, they say. According to the submarine plant's chief engineer, N. Kalistratov, the number one priority in aid is not food, but the technology and technical know-how to convert to a civilian economy. The chairman of the city's Soviet says that Russians need the kind of assistance that allows them to help themselves. not handouts.

Arkhangelsk is a 40-minute drive from Severodvinsk It has also been receiving Western aid, particulariy from Seandinavian countries. Some local residents described the food aid as counterproductive, noting that if one person receives a food package and dozens do not, friction results. They were particularly uncomplimentary about American aid. Aging military rations originally intended for $\mathrm{De}$ sert Storm-packaged with plastic utensils and sunglasses-compared poorly to 90-kilogram Norwegian aid packages. Here people also asked for "real" aidtechnical help that will be useful in the long run. If the West wants to send humanitarian aid, they said, it shouid send children's vitamins and other medical supplies, which will really save lives.

Time recently wrote that Western aid was supposed to "take the edge off hunger and provide a simbol of international solidarity" (March 16. 1992). But without a clear aid strategs; there may be a wide gap between Wester intentions and Russian perceptions. Mlany regard food aid as either insulting or inadequate. Long-term assistance that will help to create an open society and allow the military-industrial complex to reorient toward civilian needs would do more to reduce Russian worries about the future.

- Joshua Haudles

Joshua Handler is re. search coordinator tor the Greenpeace Vurlear Fiee Sers Camprign. 


\section{The tonshington post}

\section{A.V INDEPENDENT NEWSPAPER}

\section{Our Turn to Talk. About WIAs}

Piesıient Bons Yeitsu's dramatic revelacons about tmencan :MLts still alive in Russia were 3 great post-Cold War gesture of zoodwill [news story. June 13|. It is a shame the Bush administration did not see lit to respond with iniormation adout Russian illis.

Lronically, the U.S. government possesses such uniormacion. In 1974. with the he!p of the Howard Hugines constructed salvage siuo. the friomar Expiorer, the Cit recovered parts of a Suviet diesel-powered Gulf bailistic missle submarne that sank in the Pacific in 1968. Accounts of this operation say that bodies of jajors raised with the sub were given a proper bunal at ses, and the cre's members of the Glomar Explore: ndeouped the ceremones.

Recent Russian press reports have carried appeais to the U.S. govermment to provide iniormation about these burials in order to comiort the families of the salors. We should also put more of the Cold War behind us and tell our newly found friends what happened to their missing sons.

JOSHUA HANDLER

Revearch Coordinator Nuclear Free Seas Camparga
Greenperce

Washington 
Mr. HANDLER. What I want to underscore is our concern for the future in regards to the naval nuclear propulsion program in Russia and other nuclear activities. They are four-fold. One, as Mr. Rogne mentioned earlier, is the decommissioning of Russian nuclear submarines and the disposal of their nuclear waste. Currently the Russian navy has some 60 to 80 nuclear-powered submarines that are taken out of service. They basically don't know what to do with them. Thirty-five of these are in the Pacific. There will be 150 that are up for disposal by the end of the century. They have no final disposal plans and these must be considered a lingering regional environmental threat until a final solution is found for these submarines.

Second, our concern is accidents on nuclear submarines. The situation is quite serious. I was particularly interested that Director Gates said earlier that large numbers and the advancing age of these reactors on the submarines will increase safety risks. I find the situation, as I said, quite serious. I have visited personally the spot near Vladivostok where the submarine exploded in 1985 that Director Gates referred to. And just in my last trip, which I returned from last Sunday, I found out about two more nuclear meltdowns in Russian submarines, one that occurred in 1979 and one in 1985. Clearly, in the good times when Communism was working, things were quite bad in the Russian navy. Now that the bad times are upon the Russian navy, this does not auger well for the future.

Second, in terms of accidents, we are concerned about collisions of nuclear-powered submarines at sea. In February 1992 a U.S. submarine collided with a CIS submarine off the Kola Peninsula. As a senior admiral explained to me in Moscow, this could have taken hundreds of men and three nuclear reactors to the ocean floor. I think we must do everything in the next five years in this period of chaos to reduce or stop nuclear-powered submarine operations, particularly in the Arctic region and Pacific region, to ensure we don't have another Chernobyl at sea.

Third, we have a concern about nuclear testing in Novaya Zemlya. And fourth, we have concerns about the construction of new civil nuclear power plants in the Far East. Rather than addressing these other questions specifically, I'd like to return to the decommissioning problem. I think this country needs to do something to help out the Russians in this score. And in fact, steps have been taken in Congress to address this question. Unfortunately, the administration of the U.S. Navy has refused to be helpful. Representative Charles Bennett, Chairman of the House Sea Power Subcommittee, has been very active in trying to put language into the Russian Aid Bill and raise a separate bill, as I understand, in Congress and the House side, to get money funneled to helping the Russians decommission their submarines and safely store the reactor compartments on land. The administration has not been helpful and particularly the U.S. Navy, the Naval Nuclear Propulsion people, have been adamant in opposing any information or assistance be given to the Russians in this regard. I think we need to change our perspective in this situation. I've sent a letter to President Bush about this in early April. I again submit that for the record.

Senator MURKOWSKI. It will be entered into the record as if read. 
Mr. HANDLER. The recommendations I made at that point are still relevant.

Finally, I'd like to echo some of the comments earlier that we need another hearing soon and action soon, if you will. Missing from the lineup today, despite the excellent forum we have here, is unfortunately the U.S. Navy and the Department of Energy, two of the people that are most cognizant about problems on Russian or Soviet nuclear-powered submarines. In addition, it would be very handy to have a panel of nuclear engineers. I know some personally in Washington, D.C. that are basically frothing at the mouth to try to do something to help out with the Russian problem, and they've been very frustrated how slowly the administration is moving to spend some of the money that's been allocated for this.

And finally, I say I must disagree with some of the comments that Director Gates made at lunch. And to follow up actually on your question earlier today to Director Gates, Senator Murkowski, about the need for quid pro quos, in terms of you need to give a little to get a little from the Russians when it comes to information about past nuclear activities. My experience, talking with these senior admirals, senior captains in the Pacific fleet, the Northern fleet and Moscow, is that there comes a point where they just get very upset, but you just keep asking all these questions and they're asking, what is this for, what are we going to get in return. We're not guaranteed help; we're not guaranteed assistance; we're not guaranteed further information. And basically their question is to me, when are you going to tell us about what you've been doing or when are you going to even tell us about what you know about what we're doing. So I would actually put that as a very high priority, that we have to tell we know about our past activities, whether this is in a technical conference, whatever the case may be, and it'd be also if people such as the Director of the CIA was a little bit more open about what we know about past Russian activities.

So finally, I'd like to conclude that I'm looking forward to some movement taking place in this issue after having these reports basically in the public domain over the last few years about the dumping of radioactive materials at sea, and I'm looking forward to further hearings on this matter as well.

Senator MURKOwSKI. Thank you. I might add for the record, the Department of Energy has submitted written testimony. I want to thank the panel. I think that you've heard an alarm raised, justifiably, relative to information that's been documented and the need for action to be initiated. And thanks very much for your input and your patience. And I know you've sat through a good portion of the day. The only people who have sat a little longer are the next panel. Thank you.

I'd call the next panel and the last panel prior to our wind-up. And I believe we have two or three pending. Mr. Tom Albert, North Slope Borough, he's with the Wildlife Management. Frank Charles, Natural Resource Director for the Association of Village Council Presidents. And I'm not sure whether the person from the Northwest Arctic Borough is with us, but if not, we'll proceed and just keep plugging along here.

Gentleman, it's 4:00 o'clock and we're moving right along here. So we will continue with that note of optimism and proceed to look 
forward to your testimony and look over your shoulder. Mr. Tom Albert with the North Slope Borough, please proceed with your testimony and thank you for being with us.

[The prepared statement of Dr. Albert follows:] 


\section{FORTH SLOPE BOROUGH}

\section{OFFICE OF THE MAYOR}

\section{P.O. Box 69}

Barrow, Alaske 00723

Phone: 9078522011

Jeelie Kaleak, Sr., Mayor
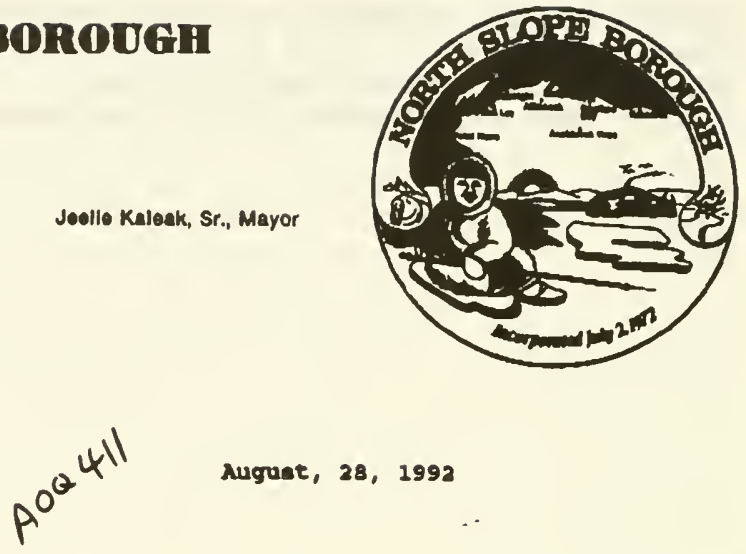

Auguet, 28, 1992

Honorable Erank H. Murkowak1

onlted state Benate

709 Hart Bullding

Washington, D.C. 20510-0202

Dear sanator surkowakl:

This letter concerns the Auguet 15 hearing madlonctive and Othar Bnviromantel Ihreate to the Onited state and the Arctic Reoulting Fro. part soviot sctivitien" held at the Univereity of Alacka Falrbanke by your senate sel cot comittee on Intelligence. lat ne thank you for holding the hearing in Nlagka and for allowing us to present formal ooriente to the coriltea.

As you remeiber oomente on behnle of the North slope Borough

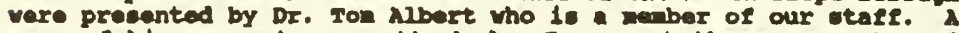
copy of his ocmante are ettached. I aupport these comente and adk that this letter and the attached coments be ade a part of the Hearing record. As you on lnagine, wo wo live in the nrotio are very concerned about potential impact fron emviromentel pollutante that way reach the Arotio ooen froi the former sovlet Union. Wo are crpeoleliy conoarned with heavy sutal and radioactive pollutente and the effect they ay have upon people and the antrals upon vitah we depend. 
Honorable Frank $\mathrm{B}$. Murkowek1

Aucuet 28,1992

Page Tro

Iet as wish you and the select comittse success in youx review of this poliution threat. I look forward to the roport from the Hearing and ack that you keop my offlee Inforned a addtional Information bocone evaliable regerding the extant and nature of the pollution you are oonsldering.

$8 \operatorname{lnoeraly.}$<smiles>C1CC1</smiles>

tow hel

Mayor

attachment (1)

ce: Banjanin Nageak, D1reotor, N8B N11d11fe Manageeent

Ide Olumaun, Dlrector, MBB Health Departaent

Dx. Thoma Albert, N8B Hilallee knnegomant

o: Igen.cor Ired_hear. Ing 
Comments Presented on behalf of the Nask's North Slope Borough during the U.S. Senav Select Committec on Intalligence Hearing "Redionctive and other Environmental Threats to the United Sutes and the Aretic resulting from pase Sovitat activities." Hearing held Auguat 15, 1992 on the campus of the University of Alasto Paibanks in Fairbanks, Alasion.

\section{Comments presented by:}

Thomas F. Albert V.M.D., Ph.D. Senior Scientit

Department of Wildile Management

North Slope Borough

Box 69

Barrow, AK 99723

The comments noted below were presented at the August 15 hearing. The comments are arganized into 4 sections.

1. Introductory ethiement

Thanks are due to Senetor Fronk Murkownid for bolding the hearing in Alatb and for his longtime support of arctic research. Thanks are sles due to Assistant Secretary of State Curtis Bohlen and Director of the Central Intellipenece Agency Robert M. Cates for coming to Alvibe to present their comments.

It is a pleasuro for me to present these comments to the Committee on behalf of Alsika's North Slope Borough. Mayor Jealie Kaleak is not able to be here but has anked me to present comments. Mayor Kaleak will provide a letter to the Committee.

By way of background let me remind you that the North Slope Borough is a Connty-like municipality, cocuspying approximately the northern 1/6 of the State of Alaka. Moet of the people of the Borough are Bsidmo who depend upon land and sea crentures for mout of their food. As might be expected these people are very concemed about the generil topic of environmeatal pollution and have special tnterest in pollution from ectivities of the former Sovile Union.

2. Mnior concerse reandine environmentil pollntants.

The two mnjor concerns that people of the North Slope Borough have regending environmental pollutants are:

(1) impects thet the pollutents may hive on people, and

(2) Impacts that the pollutants may have on the wildilife upon which the people dopend. 
3. Rorms of envtronmental pollution abour which poople ane mort concemed.

Since the restdents of the North Slope Borough live in the Aretic and ance most are Enkimo people who depend hervily upoe wildifie resources of the land and $2 e n$, it is reasonable to expect that there is a high bevel of concem reganting pollution of the aretic eavironmeat. Prom baving lived in the Alasom Arctic for many years, from having traveled extensively throughout coastal and inland areas, and from long aseociation with users of wildife resources it is clear to me that meny people often group enviroameatul pollutant into 5 categaries briefly noted below.

3.1 and 3.2: Probably the most warrisone pollutanes to many pecple aro soilled oil and the poise succiated with ofishore activides of the oil and gas industry. Since at this hearing wo are considering pollution from activities of the former Soviet Union, these two forms of pollution (all spill and noise) are probably not appropriate for further mentioa.

3.3: - In the context of pollutants from the former Soviet Union people are concerned about Aretic Hiva and all forme of atmonoheric mollution. Atmoepharle pollutanth, come of which came from (and still come from) the former Sovitet Union, not only direetly sfioet appects of the eoviroament (meh as the tundm) but these pollutants of the air cm also indirectly affect the aretic enviroment through their contribrtion to the clobal werming problem. Since efiects of globul warming will be both enty and siguiflent in the Aretic, it is easy to se that atmoepheric pollution is a real coscern to aretic residents.

3.4: As can be imagined, people of the North Slope Borough are also concerned about rotionethe pollument, no matter what their source my be. The information in popular medile and information presented at this bearing show that there has been mastive pollution of the northern areas of the former Sovite Union by ndionetive material.

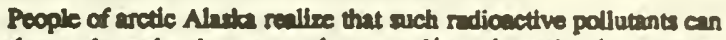
reach them throogh the itmosphere and/or through the marine enviroameat. No matter bow the redionctive compounds arive they will arrely reach people through the food chnir.

3.5: In addition to the chove soted polthtents, people of the North Slope

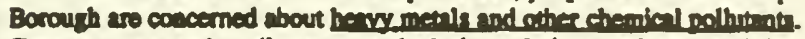
Concers ove auch pollotents (particularly cedmitum and mexcary) hes been belighened oven before we learned about relenes from the former Sorlet Union. Unfortunitily, there axe elovated lovels of certin heavy metals in ecome of the martine mammin (particularly winv) usto the Bering Seen Since these enimnils are important sources of food to Nitive 
people, particularly in constal areas, there is concern as to human health. Unfortunatuly, the sctual extent of the threat to humen bealth by existing pollutant levels is not all that clevr.

With the potential of additional heavy metal and other chemical pollutant reaching the marine ecosyatem from the former Soviet Union, one can understand how the indigenous people of the U.S. Anctic are worried that marine food resources can become even more contaminated.

4. Recommendations

In view of the concerns noted above and in view of the appareat magnitude of the eavironmental pollution, in and discharging from northern areas of the former Soviet Union, it seems reneonable to put forth the 4 recommendations noted below. These recommendations seem especintly appropriate since the people of the U.S. Aretic are likely to be among the very fint that will be affected by the above discussed covtronmental pollutant.

4.1: The fint recommendation is that there be a review of, and the wide distribution to aretic reaidents of, the health implications of the heavy metul contamination already documentaled in Bering See marine mammals that people use as food.

This is necesary ince there is the perception by some of an existing bealth threat due to existing levels of heavy metsl contaminants in some Bering Sea marine mammals. The precise nature of this situation should be defined before there is further complication by din likely to arise from studies that will document the nature of the threat posed by pollutints from aress of the former Soviet Union.

4.2: The recond recommendation is that there be the preparation and wide distribution of a brial (5-10 pages) illustrated overview of what is bnown or reliably ruspected reganding pollution $\alpha$ the Aretic Ocean by the former Sovid Unioa. Of particular importances would be radionctive and heavy metal pollutunts.

This is necousary since there have already been alarming data presented in sewspapers which have the potential to perhaps overstate or underatute the sibuation and thereby lead people to onco apain face a pereelved environmental threal with lltule but news medis reports. Since we have been laformed that the proceatings of this hearing will be released in 8 weckes, will probably be voluminous, and probably have a limited distribution, it seems reasonable to ask that the hearing sponsors prepare and widely distribute the brief illustrated overview mentioned 
above.

4.3: The third recommendation ts that the U.S., with participation by Arctlc residents, take a major rolo is the intemationsl research prognam that la needed: $a$ to define the mature of the pollutant problem, and b) to determine how to deal with the pollution problem.

Thi is necerming since avalbable information is aketchy, bowever, it socms that the extent of pollution is masstve. The nature of the pollution problem must be defined (rather then epeculated upon) and solutions must be found. To do thls will obviously require a massive and an international reacarch effort. The U.S. should take a leaderchip role and should involve its aretic realdents aloce they are the mont likely U.S. revidents to be impacted by the pollutants.

4.4: The fourth resommendution is that a particular effort should be expended to koep arctic realdents informed as to the progress of the studies, especially any findinge Indicating a possible health threat to the people or to the wildife upon which they depend.

This is necessary since aretic residents are the most likely U.S. citizens to be impacted if the extent of the pollution is as great at it seems to be.

In conclusion let me thank you for the opportunity to present these comments and I hope they are helpful to you. 


\section{STATEMENT OF TOM ALBERT, DEPARTMENT OF WILDLIFE MANAGEMENT, NORTH SLOPE BOROUGH}

Mr. AlBERT. Thank you, Senator. My name's Tom Albert. I work with the Department of Wildlife Management, North Slope Borough. And before I say anything, I wanted to thank you, Senator Murkowski, for bringing this group to Alaska and for having the interest that you do in Arctic peoples and in Arctic research. Also I want to thank Secretary Bohlen and Director Gates for taking the time to come here. They're very busy, just as you are, and it was nice of them to come here and do this.

Mayor Jeslie Kaleak, Mayor of the North Slope Borough, asked that I put together a few comments concerning pollution and some views. As most of you know, the North Slope Borough is a countylike municipality in northern Alaska and occupies about the northern sixth of the state. Most of the people who live there are Eskimo people and they depend upon the animals and birds and so on of the land and of the sea. So obviously, they're very concerned about pollution. And when it comes to environmental pollutants, from having lived there many years and talked to people up and down the coast and inland and so on, there seems to be two major concerns that people have regarding environmental pollutants, and I don't think these are very surprisingly.

The first is they're worried about the effects of pollutants, environmental pollutants, on the people themselves, and secondly, the impacts to the wildlife, the whales, seals and so on, that these people depend upon. And if one were to go around and talk to most of these folks, you would find out that there are five forms of pollution that folks seem to talk about over and over again. The first two maybe are not appropriate here but I should mention them anyway, and that is spilled oil, and noise in the marine environment from offshore industrial activity. The third, which is relevant for this group, is atmospheric pollution of one kind or another, particularly Arctic haze and other forms of atmospheric pollutants that may affect global warming, and Dr. Shaw already mentioned some of that. But the average person up there is interested in atmospheric pollution, and we all know that when global warming rears its head even higher, the people that live in the north will be recipients of the problems. The fourth pollution type that people are very concerned about, and once again it's probably not a surprise, is radioactive pollutants, and people are well aware that these can arrive through the air or through the water and reach the people obviously through the food chain. The fifth type of pollutant concerns heavy metals and various other chemicals. And without much doubt, people particularly are concerned about cadmium and mercury. And folks are already aware of the levels of some of these heavy metals in the marine mammals of the Bering Sea upon which many of these people depend for food.

In light of all this, I think it's fair to ask you folks to consider the following four requests, or maybe these could be four recommendations to your group, and once again, I don't think there are too great of surprises. The first is could possibly be a little bit of a surprise, and that is to review and to provide for the wide distribution to Arctic residents of health implications of heavy metal contamination already known to exist in Bering Sea marine mam- 
mals that people depend upon as food. People are aware that this is happening. There needs to be a better release or let's say consideration and then distribution very widely of the perceived health effects. There's just a little too much confusion on that.

The second request or recommendation might be that there be the preparation and wide distribution of a brief, that is, five to 10 pages or so, illustrated overview of what is known or what is reliably suspected regarding pollution of the Arctic Ocean by the former Soviet Union. Of particular importance would be radiation and heavy metal type pollutants. And this is a point we try to keep making over and over again is this plain language summary of research or of significant findings in that it find its way to the people of the Arctic. As an example, I would ask you, Senator or staff or someone anyway, to maybe make a five or 10-page plain language summary of what the Secretary Bohlen and Director Gates said and to add to that some of your thoughts maybe and to distribute it widely, maybe to your constituents. And not necessarily wait the eight weeks or whatever it is that we're going to wait for the final document which, you know, it'd probably be more than eight weeks and, once again, it'll be heavy and not widely distributed. What we need is something fairly brief, plain language, and get it out to a lot of people because folks are worried.

The third little request or recommendation would be the U.S., with participation by Arctic residents, take a major role in the international research program that is needed to define the nature of the pollutant problem and how this problem can be dealt with. Once again, this has been mentioned by other people too and it's perfectly obvious.

The fourth thing would be a particular effort should be made by all parties involved here to keep Arctic residents informed as to the progress of the studies that are going to be done hopefully, especially any findings indicating a possible health threat to the people or to the wildlife that they depend upon. And in this regard, just from having attended here, I want to echo or support the comments that Charlie Johnson just made and that Dr. Middaugh made. These are very reasonable things.

So, I think it's fair to say that in conclusion the people that live in the Arctic, and you know many of them, they want to be kept informed, and if they have to wait endlessly for large reports which come out and are distributed in two or three copies to each Borough mayor or whatever it is, it just never gets down to people. And as we mentioned at the arctic Research Commission and in dozens of other forums, please begin to distribute some of this information in brief, readable format in a wide manner. Thank you. And the Mayor of the North Slope Borough will submit some written comments.

Senator MURKowski. Thank you very much, Tom. Give our regards to the Mayor, and I think it's the consensus of the three of us here that we are going to initiate a synopsis. However, we want to be very careful because we don't want to alarm anyone or mislead anyone, because a lot of this information that's been given here could be taken out of context. This is clearly a necessity to address concerns, but we also want to be sure that we don't generate any needless heartburn out there. 
Nevertheless, moving right along, we have $\mathrm{Mr}$. Calvin Simeon who is appearing on behalf of Frank Charles, I believe, Association of Village Council Presidents. Please proceed.

[The prepared statement of Mr. Simeon follows:] 


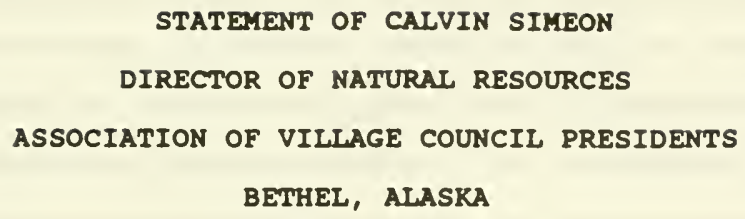

HEARINGS ON RELEASES OF RADIATION ON THE ARCTIC ENVIRONMENT

AUGUST 15, 1992

FAIRBANKS, ALASKA 
Thank you. Good morning Mr Chairman. Members of the committee. My name is Calvin simeon. I represent the Association of Village Council Presidents, a regional nonprofit consortium of 56 Native villages in southwest Alaska. We rely on our marine resources for sustenance and we are very concerned about the presence of heavy metals and radionuclides in our waters. These elements represent the greatest threat to us since the epidemics that decimated entire villages in Alaska at the turn of the century.

our needs, with respect to this forum, are basic: What is the extent of contamination, how might it affect us and when will it get here? This is an entirely achievable goal in the near future. This country has a significant amount of data within the Dept. of Defense. However, it's classified status prevents a wholly-coordinated effort at deciphering the total exient of damage. We urge, in the strongest terms possible, that the office of Naval Research de-classify this data. I request this committee to urge the former Soviet Union to release their data for our acquisition.

Other nations also hold a certain amount of responsibility for the deterioration in the Arctic and we are glad to see them assume their full share. Sadly, this nation also has a considerable level of involvement in polluting the arctic. I can think of no task more difficult than an internal accounting but it must be done. We may not 
be able to stop cesium from entering the eastern siberian current but this nation can certainly contain it's own activities. My immediate concerns, with respect to this accounting, are the extraordinarily high levels of mercury and cadmium in the Bering, Chukchi and Beaufort seas.

My people need to be assured that this nation will help Russia in a full monitoring effort of the flow of radionuclides and heavy metals. My questions can be summarized as follows: What timeline can we expect for a significant amount of radionuclides to enter the East siberian current. How does the icepack affect the flow of pollutants? Is there any likelihood that these contaminants will become airborne? What can the people can do to protect themselves? What are the responsibilities of this nation \& the former Soviet Union in this respect?

In summary, I would like to stress to both countries to hold nothing back, neither money nor data, in this monumental task. The health of this nation depends on this effort and I can think of nothing else more important to my people. 


\section{STATEMENT OF CALVIN SIMEON, ASSOCIATION OF VILLAGE COUNCIL PRESIDENTS}

Mr. Simeon. Thank you, Mr. Chairman, members of the Committee. It's been a long day so I'll try to be short. I represent the Association of Village Council Presidents, a regional non-profit consortium of 56 Native villages in Southwest Alaska. We rely on our marine resource for sustenance and we are very concerned about the presence of heavy metals and radionuclides in our waters. If the reports that we are getting are true, then these elements represent the greatest threat to us since the epidemics that decimated entire villages in Alaska at the turn of the century.

Our needs with respect to this forum are basic: What is the extent of the contamination? How might it affect us and when will it get here? This country has a significant amount of data within the Department of Defense. However, its classified status prevents a wholly-coordinated effort to ciphering the total extent of the damage. We urge in the strongest terms possible that the Office of Naval Research declassify this data. I request this Committee to urge the former Soviet Union to release all their data for our acquisition.

Other nations also hold a certain amount of responsibility for the deterioration in the arctic. And we are glad to see them assume their full share. Sadly, this nation also has a considerable level of involvement, including the Arctic. I can think of no task more difficult than an internal accounting, but it must be done. We may not be able to stop the cesium from entering the east Siberian current, but this nation can certainly contain its own activities.

My people need to be assured that this nation will help the former Soviet Union in a full monitoring effort of the flow of radionuclides and heavy metals. My questions can be summarized as follows: What time line can we expect for a significant amount of radionuclides to enter the east Siberian current? How does the ice pack affect the flow of pollutants? Is there any likelihood that these contaminants will become airborne? What can the people do to protect themselves? And what are the responsibilities of this nation and the former Soviet Union in this respect?

In summary, I would just like to stress to both countries to hold nothing back, either money nor data, in this monumental task. The health of this nation depends on this effort and I can think of nothing else more important to my people.

I would like to close by saying that the people are ready and willing to help the affected nations to both ascertain the extent of the damage and to help them clean it up.

Thank you.

Senator MURKowski. Thank you very much, Mr. Simeon. We appreciate your standing in for Mr. Charles. And I think your statement summarized the concern of many of the people that live in the rural regions of our state and the bush. And we will attempt to initiate a synopsis that is general enough in capturing the spirit of this hearing with appropriate caveats on this initiation of action. I would suggest that most scientists would probably acknowledge to many of the questions the answers, we don't know enough yet. And that's something that we simply have to address. And in order to address it, we'll have to prioritize it and it has to be brought to 
a level where there is enough public awareness that the public simply demands that action be taken. And I think we're off to that first or second step now. But we can't wait too long and I certainly agree with your recommendations. I want to thank you. And we're going to call the last panel now.

This panel is unique. I would call them up: Dr. Luis Proenza, Vice President for Academic Affairs and Research, the University of Alaska; Dr. William Shipp, the Reactor Technology Center, Batelle Memorial Institute; Academician Leonid Bolshov, Director of the Institute of Nuclear Safety and the Russian Academy of Science; Dr. Vera Alexander, Director of the Institute of Marine Science, University of Alaska Fairbanks; Dr. Lee Gorsuch, Director of the Institute for Economic and Social Research of the University of Alaska Campus in Anchorage. And this group has volunteered to come together to conclude the hearing with an identification of a concept for action, which oftentimes, as I indicated in my opening remarks, does not occur in a hearing of this nature. We usually generate facts and evidence and testimony but seldom are a group of this capability and caliber willing to voluntarily present a concept for action. A concept for action speaks for itself. Obviously, those of you who have been monitoring this process all day are going to evaluate and see whether you agree or disagree. We won't have a showing of hands but I'm sure you will, in the course of an opportunity, develop a dialogue, give the group some idea of whether you agree with their recommendations or not.

One other significant notion is that they have agreed to limit their comments to five minutes, and this is a unanimous agreement, I'm told, by David Garman and John Moseman, and we're going to hold you to that. So, we're going to let you determine who will start out first. So with that, anyone who wants to jump the microphone first could proceed.

[The prepared statement of Dr. Proenza follows:] 


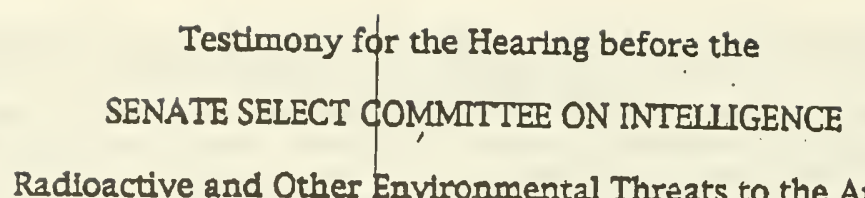

Radioactive and Other Environmental Threats to the Arctlc

Resulting from Past Soviet Activities

15 August 1992

Dr. Luis M. Proenza

Acting Vlce President for Academic Affairs and Research

Uniyersity of Alaska

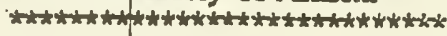

A FRAMEWORK FOR ACTION

Mr. Chairman, we thank you for this opportunity to outline a framework for action in regard to the issue before you today. I am joined by four colleagues which represent the Institute of Nuclear Safety of the Russlan Academy of Sclences, the Paclfic Northwest Laboratories - Battelle, and the University of Alaska in a jolnt approach to the problem. My remarks are intended simply as an lotroductory background to those of my colleagues.

Alaska, the last frontier of the U.S., has suffered and gained experlence from natural disasters in modern times: the 1964 Anchorage earthquake, the 1967 Fairbanks flood, and, more recently, the massive oil spill of the Exxon Valdez and the Mt. Redoubt eruption. It now has the potentlal for another assauit along its northern coast in the form of pollution migrating from the former Soviet Union and from othef countries.

In 1989, the University of Alaska was able to respond within hours to the Exoxon. Valdez oil spill, and we are prepared to respond in a siodilar and timely fashion now. We have many of the experts and much of the expertence necessary to accomplish this mission, and haye established, working relationships with colleagues throughout the clrcumpolar north, as well as collaborative agreements and facilities in conjunction with virtually every federal and state agency. As such, our university seryes both as a natlonal resource for Arctlc research and as a global observatory. The University of Alaska has 
both a scientific and a personal interest in this problem, since the Arctic is our own backyard.

In the matter we are addressing today, a framework for action requires multinational and interdisciplinary linkages, and there is no arena more conducive to such collaboration than the circumpolar north and our own U.S. Arct c in Alaska. Here, by historical fact and of necessity, multinational and interdisciplinary linkages are commonplace and extensive.

Let me give you just a glimpse of what is already in place, because it is through Alaska, and through the University of Alaska, that the United States has a front door to the Russlan Far East. Our scientific contacts go back to the 1950 's and 60's. Scientffic cooperation began in the 1970's, expanded In the 1980's, and during the past two to three years has turned into true collaboration and scientific partnerships.

Indeed, the university's work with Russian colleagues bas long gone past paper agreements (which we have with the Russian Academy of Sclences and Its branches and institutes), to joint fleld operations, jolnt research, data gathering and analysis, and the common use of facliltes including laboratories, computing and telecommunications resources, and ships, alrcraft, and other logistical resources. A particularly salient example is our University of Alaska - Russian Academy of Sclences Joint International Scientific Center ARKTIKA in Magadan. The center, ARKTIKA, represent a bllateral research support consortlum for full sclentific collaboration, including personnel, space, scientific equipment, informational and logistical resources, and telecommunications which even include a telephone line that is part of our university's telephone exchange. In other words, a local call in Ealrbanks rings in Magadan and vice versa. The center Is not only supporting our own sclentlsts, but also supports collaborations with other universities and the efforts of federal agencies such as NOAA, EPA, the National Park Service, among others.

Our linkages into Russia extend well beyond Magadan, into Chukotka, Yakutia, Kamchatka, Vladivostok, Khabarovsk, Novosybirsk, and Proyidenya in the Russian Far East, and into Moscow, St.Petersburg, Murmansk, and; Indeed, the entire Arctic between Murmansk and Proyldenya. These contacts extend across the basic and applied sclences and also include informatlonal, telecommunications, and logistical resources. Suffice it to say that our working linkages are 
extensive and that through them, we have come to understand that direct scientist to scientist, institute to institute collaboration must serve as the basis for the funding support decisions that are made in Moscow and Washington. We applaud you efforts in Congress, Mr. Chalrman, to move this matter expedittously in the appropriations process.

In closing, I submit that the success of any framework for action rests on organizational relations that have the following characteristics: First, a vested and direct interest; second, an institutional commitment; and, third, linkages that can transcend national and international boundaries. The principal organizatlons represented by my colleagues, from which you will now hear, manifest all of these characteristics as well as a large base of technical and scientific expertise. I represent the commitment of these organdzatlons to the success of pursulng these questlons, and we are prepared to seek and accept additional collaborative expertise as appropriate.

Mr. Chairman, The Institute of Nuclear Safety of the Russian Academy of Sclence, represented by Professor Leonid Bolshov, the Pacfic Northwest Laboratorles - Battelle, represented by Mr. William Shipp, and the University of Alaska, represented by Professors Vera Aleseander and lee Gorsuch stand ready, willing, and able to direct their energles and expertise to this important problem.

Thank you. 


\section{STATEMENT OF DR. LUIS PROENZA, VICE PRESIDENT, ACADEMIC AFFAIRS AND RESEARCH, UNIVERSITY OF ALASKA}

Dr. ProenzA. Senator Murkowski, thank you very much. We thank you for the opportunity to outline a framework for action. My remarks are intended simply as an introductory background to those of my colleagues. Alaska, this last frontier of the United States, has suffered and has gained experience from natural disasters in modern times: The 1964 Anchorage earthquake, the 1967 Fairbanks flood, and more recently, the massive oil spill of the Exxon Valdez and the Mount Redoubt eruption. It now has the potential for another assault along its northern coast in the form of pollution migrating from the former Soviet Union, and from other countries. In 1989 the University of Alaska was able to respond within hours to the Exxon Valdez oil spill and we are prepared to respond in a similar timely fashion now.

We have many of the experts and much of the experience necessary to accomplish this mission and have established working relationships with colleagues throughout the circumpolar north and collaborative agreements and facilities with virtually every federal agency. As such, our University serves both as a national resource for Arctic research in the United States and as a global observatory.

We are, of course, interested, scientifically and personally, in these problems since the Arctic is our own background. In the matters we are addressing today, a framework for action requires multinational and interdisciplinary linkages, and there is no arena more conducive to such collaboration than the circumpolar north and our own U.S. Arctic in Alaska. Here, by historical fact and of necessity, multinational and interdisciplinary linkages have been commonplace and extensive.

Let me give you just a glimpse of what is already in place, because it is through Alaska and through the University of Alaska that the United States has a front door to the Russian Far East. Our scientific contacts go back to the 1950's and '60's, scientific cooperation began in the '70's, expanded into ' 80 's, and during the past two or three years has turned into true collaboration and scientific partnerships. Indeed, the University's work with Russian colleagues has long gone past paper agreements to joint field operations, joint research, data gathering and analyses, and the common use of facilities, including laboratories, computing and telecommunication resources, ships, et cetera.

A particular salient example is our University of Alaska-Russian Academy of Sciences joint international scientific center, "Arktika," in Magadan. The center represents a bilateral research support consortium for full scientific collaboration, including personnel, space, scientific equipment, informational and logistical resources, and telecommunications, which even include a telephone line that is part of our University telephone exchange; in other words, a local call in Fairbanks rings in Magadian and vice versa.

The center is not only supporting our own scientists, but also supports collaboration with other universities and the efforts of federal agencies such as NOAA, EPA, the National Park Service, et cetera. Our linkages extend well beyond Magadan and go as far as Murmansk and the entire Artic in between. These contacts shall be 
detailed in my written testimony, Mr. Chairman, with your permission. But suffice it to say, that our working linkages are extensive and that through them we have come to understand that direct scientist to scientist, institute to institute collaboration must serve as the basis for the funding support decisions that are made in Moscow and Washington.

We applaud your efforts in Congress, Mr. Chairman, to move this matter expeditiously in the appropriations process.

In closing, I submit that the success of any framework for action rests on organizational relations that share the following characteristics: One, a vested and direct interest. Two, an institutional commitment. Three, linkages that can transcend national and international boundaries. The principal organizations represented by my colleagues, from which you will now hear, manifest all of these characteristics as well as a large base of technical and scientific expertise. I represent the commitment of these organizations to the success of pursuing these questions, and we are prepared, of course, to seek and accept additional collaborative expertise as appropriate.

Mr. Chairman, the Institute of Nuclear Safety of the Russian Academy of Sciences, represented by Professor Bolshov; the Pacific Northwest Laboratories Batelle, represented by Mr. Shipp; and the University of Alaska, represented by Professor Alexander and Dr. Lee Gorsuch, stand ready, willing and able to direct their energies and expertise to this important problem. Thank you.

Senator MuRKowski. Thank you, Dr. Proenza.

Dr. William Shipp.

\section{STATEMENT OF DR. WILLIAM SHIPP, REACTOR TECHNOLOGY CENTER, BATELLE MEMORIAL INSTITUTE}

Dr. SHIPP. Thank you very much, Mr. Chairman. This is indeed a unique opportunity in order to present not only framing a problem but a potential solution to that problem, and I commend you for allowing us to do that.

The Pacific Northwest Laboratory is a multi-program national laboratory operated for the Department of Energy by the Batelle Memorial Institute. Most of the facilities at PNL, if you'll allow me to use the acronym, are located in Richland, Washington. However, we have a marine sciences laboratory at Sequim, Washington on the Puget Sound. PNL represents a multidisciplinary organization with over 4,000 scientists and engineers and support staff that are dedicated to a variety of activities primarily with the Department of Energy, but we are involved with most federal agencies and several hundred industrial clients as well.

Over the course of the 25 years that Batelle Memorial Institute has operated the Pacific Northwest Laboratory, we have conducted environmental research in a variety of areas, both nuclear and nonnuclear, that have direct applications to the Arctic environment. Of particular significance to the Arctic situation is our very real unique capability of radiochemistry, where we can take very large samples of both air and water and condense them down and do state-of-the-art, at the lowest level, radionuclide determinations. We have participated in many programs of this type over the years. We own a G-3 aircraft that is completely equipped with environ- 
mental monitoring capability. It was most recently deployed at the Kuwait fires to try to understand and characterize the worldwide significance of that event. We have very well equipped chemical laboratories at the marine sciences laboratory at Sequim as well. PNL has a large cadre of health physicists and nuclear engineering capabilities that we have brought to bear on a wide range of nuclear and reactor-related situations for both the Department of Energy, the Utilities, and the Nuclear Regulatory Commission.

We have the responsibility for the monitoring and oversight of the Hanford Reservation in Hanford, Washington. We have also the responsibility for the development of the technology associated with the decontamination and decommissioning of the excess nuclear facilities that are also related at Hanford. All of this capability has direct application to this effort.

I have eliminated most all of the prepared presentation, Mr. Chairman, that I have. So I would like to get to the very bottom line of the issue.

Senator MURKowski. We'll take your testimony for the record. [The prepared statement of Dr. Shipp follows:] 
Senator Murkowski, thank you for the opportunity to appear before you today. I am Bill Shipp, Manager of the Reactor Technology Center at the Pacific Northwest Laboratory.

The Pacific Northwest Laboratory (PNL) is a multi-program national laboratory operated for the Department of Energy by Battelle Memorial institute. Most of the facilities are located in Richland, Washington, but a smaller Marine Sciences Laboratory is situated at Sequim, Washington on the Puget Sound. PNL represents an inter-disciplinary resource that consists of 4,000 scientists, engineers and support staff serving principally the Department of Energy, but also a myriad of other Federal agencies and several hundred clients in the industrial sector. Over the course of the 25 years, PNL has conducted research that has a whole array of environmental applications. Of significance to the Arctic contamination problem is PNL's unique radio-chemistry capability to analyze air and water samples for quantities of radionuclides. PNL has participated in many programs of this type in the past for a variety of clients and owns a G3 aircraft as well as chemical laboratories at the Marine Sciences Laboratory in Sequim.

PNL also has a large capability in health physics and nuclear engineering that has been brought to bear on several reactor safety-related questions for the Department of Energy, the utilities, and the Nuclear Regulatory Commission. The responsibility for oversight and monitoring of the Hanford site belongs to PNL as well as the technology development program for decontamination and decommissioning of excess nuclear facilities at the Hanford site. The combination of PNL's research capabilities and experience in a variety of projects, combined with the University of Alaska's interdisciplinary capabilities and the Institute of Nuclear Safety of the Russian Academy of Sciences makes for a successful combination of resources. In addition, the opportunity for a national laboratory, university and our international counterparts to 
work together responds to a variety of recommendations made by the Congress and the White House over the last several years. In fact, there is legislation currently pending in Congress, S. 2566, which encourages laboratory/university/industry partnerships for addressing technological challenges such as Arctic contamination.

In summary the existing teaming arrangement between the University of Alaska, the Russian Institute of Nuclear Safety and Battelle and our commitment to utilize the best of national and international capabilities will result in the successful execution of this program. 
Dr. SHIPP Thank you very much. Because I would like to spend the rest of my time talking about the direct application of the approach that we are talking to. And the issue before us is not the accumulation of more data. The task before us is the shortest route to the solution of the problem, and the problem is the mitigation and remediation of the environmental insult that is in the Arctic region. We have heard numerous testimonies today about the extent of that contamination. I could substantiate a number of those values but I won't, for the sake of brevity.

Let's assume, for the most part, that the information is correct and the extent of the contamination is in the order that we have stated. The long-term approach to this set of problems obviously involves source term characterization, assessment, definition assessment of remedial measures, of a very large scale. But, sir, any scientist can write that statement. That's the what of the problem.

The issue before us is the how of the problem. And this organization before you today is bringing you a solution to that. And it is represented a great deal by Professor Bolshov to my left, who represents an independent scientific organization, a very well worldrenowned reputation in Russia.

The commitment of my colleague to my left, and he will talk about this in a moment himself, but the commitment of my colleague is to get the information that we have been talking about. And I would like to draw a distinction between information and data, sir. Everything that we have heard today has been data. Data is not-we cannot draw conclusions or make recommendations or form remedial actions based on data. We must have information.

So, I would also like to draw a distinction between inventory and source term. We have heard today a lot of requests for information on inventories. Again, my colleague to my left has made the commitment to make the appropriate connections within Russia, and he has made many of them already, to develop the inventory that we need in order to gather the-I mean, yes, to gather the data on which we can determine the inventory. And the inventory then with the application of good science. And again, I'd like to acknowledge your statement early on, Mr. Chairman, is that science is the root of the solution to this problem. And we must do directly to the root of the problem, and that is the application of the knowledge base within Russian, with the science applied to that. And that science is very, very difficult. I'd like to acknowledge what Dr. Pfirman said a moment ago here. It's not just oceanographic information. It's nuclear engineering information. It is the high whole of scientific and engineering disciplines that must be brought to bear to solve this problem.

As an example, if we have a reactor core sitting on the ocean floor, simply sitting there tells us nothing. We must know the inventory of that and we must know the burn-up. We must be able to calculate the fission product inventory of it. And that in itself is not enough. We must then understand the mechanism by which that can be released to the environment. We are dealing with a risk-based approach. We must make a risk-based approach in which to prioritize the limited resources that are going to be available to us. 
We simply must deal with the issue of what is imminent hazard versus what is long-term contaminant problems. And those are two very different issues. And it's going to take a multidisciplinary approach that's represented by this organizational approach here to arrive at the set of information that will allow us to draw that set of conclusions, sir.

And speaking for the organization and myself, certainly, we're prepared to put our scientific reputations on the line.

Senator MURKOWSKI. Good.

Dr. SHIPP. And frankly, sir, we will require no less from any other organizations that support us in the solution of the problem should we proceed in that regard. With that, you have the commitment of my organization, our staff and my corporation to assist you in the solution of this problem and in concert with this organizational team that we've developed. Thank you, sir.

Senator MURKOWSKI. Thank you very much for that offer. Needless to say, we accept.

Let me move on to the next panelist, Dr. Leonid Bolshov, Director of the Institute of Nuclear Safety, Russian Academy of Science. Please proceed.

[The prepared statement of Dr. Bolshov follows:] 
Russian Academy of Sciences

Institute of Nuclear Safety

\section{Senator Murkowski,}

I am pleased to appear before you today representing the Institute of Nuclear Safety of the Russian Academy of Sciences. I am Professor Leonid A. Bolshov, Director of the Institute of Nuclear Safety.

The Institute of Nuclear Safety of the Russian Academy of Sciences was founded in late 1988 by an act of government. It was a response to the severe accident which occurred at the Chernobyl Nuclear Power Plant in April, 1986 and in conjunction with special governmental programs was designed to guarantee future safe development of nuclear power. This was the reason why the Institute was established outside our nuclear industry totally controlled by the Ministry of Nuclear Energy. The primary goals of the Institute are:

- to conduct fundamental research in the field of nuclear energy;

- to formulate independent evaluations of the safety of existing and projected nuclear power plants, waste management, and other problems associated with the use of nuclear energy for the Academy of Sciences, government organizations, and the parliament;

- to provide information and analytical support to government programs regarding the mitigation of the consequences of the Chernobyl and other radioactive accidents.

We are an independent scientific organization dedicated to understanding and mitigating a broad range of nuclear activities. We are doing different projects for Russian Chernobyl Consequences State Committee, Ministry of Ecology, Russian, Ukranian and American NRCs.

In regard to the Arctic disposal of nuclear materials, my organization has no prior involvement in the disposal. Therefore, we can, and will, provide the necessary independence to ensure that scientifically accurate and defensible inventories and analyses are provided. The Arctic Seas Contamination Project requires multi-disciplinary and multi-national efforts. Completeness of the inventory list is of crucial importance. Russia, as well as the UK, USA, Canada, and others, must incorporate ali past activities that have contributed to the inventory. That is why a multinational participation in the Project is so important to assure that all inventories are included.

Source term and inventory are definitely not the same. A lot of physics, chemistry, material science and engineering are necessary to determine an environmental source. term after an accurate inventory has been established. The philosophy of approach is very similar to a probabilistic risk assessment (PRA) or a risk assessment for severe nuclear accidents. That is why the great experience of Battelle, the University of Alaska, and the Russian Academy of Science is so valuable for finding the right guideline in the studies. 
My organization, the Institute of Nuclear Safety of the Russian Academy of Sciences, will commit the necessary personnel in association with other Russian organizations (and I have agreed scope of work to be done together with very well informed organizations) to ensure success of this project should you proceed with project authorization and funding. 


\section{Contamination of the Arctic \\ Key Radiological Aspects in Defining an Approach}

\section{Introduction}

Although the extent and intensity of radioactive and hazardous contamination of the Arctic are just beginning to be defined, several key aspects of this problem are now apparent. These aspects and some of their implications for formulating an approach to this problem are highlighted here.

\section{Key Aspects}

Among the most important aspects of the arctic contamination problem are the multiple-source, multiple contaminant nature of the source term, and the location of sources in riverine and marine ecosystems. The straightforward implications of these features hold several important implications for a the design of an approach.

Over the last 50 years, a multiplicity of sources have contributed radioactive and hazardous wastes to the Arctic environment and adjoining oceans. While it now appears that much of this waste arose in connection with defense related activities in the former Soviet Union, other sources, including ocean dumping of radioactive wastes by the British and U.S. weapons testing, may also be important.

Four major classes of source account for much of the suspected source term to the arctic - [1] Wastes from the weapons production complex, [2] Ocean Dumping and disposal, [3] Waste Disposal at Novaya Zemlya, and [4] Atmospheric testing of nuclear weapons. These four categories of source term are all potentially serious contributors from a long-term human health and ecological risk perspective. Each needs to be better defined and all need to be assessed in terms of contribution to relative risk levels.

The discharge of high-level radioactive and hazardous wastes from the production complex at Chelyabinsk-65 continued for many years, including direct discharge of reprocessing wastes (fission products and transuranics) to the Techa River, which enters the Kara Sea east of Novaya Zemlya. This source term is on the order of millions of curies, and has caused extensive and at least partially documented human health and ecological effects within the riverine system. The extent of transport to and within the arctic ocean environment is not well known.

Ocean dumping of hazardous and radioactive wastes in the Barents and Kara Seas continued over at least a 20 year period. These wastes included a variety of solid and liquid wastes at locations that are only generally documented in many cases.

At Novaya Zemlya, both the island and surrounding bays have been used extensively for waste disposal, including disposal of thousands of containers of radioactive wastes, and several damaged propulsion reactors, some containing fuel. Nuclear weapons testing, much of which was atmospheric, was 
conducted in the vicinity of Novaya Zemlya for 35 years, resulting in the deposition of fission products "on-site" and throughout the northern hemisphere generally, including land and water areas.

The release of these source terms in a riverine/marine system over long periods of time implies a high degree of complexity in defining the scope of characterization, assessment, and remedial measures planning. Given the number and diversity of sources, the transport aspects alone will make the linkage of environmental observations and source terms difficult.

\section{Principal Implications for Approach}

The long-term approach to this set of problems obviously involves source-term characterization, assessment, and definition/assessment of remedial measures of a large scale. The Pacific Northwest Laboratory, in addition to a decadeslong background of achievement in the radiological sciences, has directly relevant experience in each of these areas from its work for the USDOE, USEPA, and the international community. Perhaps as important, this experience suggests that a problem of this complexity and scope cannot be addressed in a simple progression through the above steps. Getting a first-order handle on the relative contributions of sources and pathways will save many years of effort, and considerable resources through early identification of the important pathways and remedial possibilities. A complete program will include field studies at release locations and in the environment and biota, historical research on releases, and both large-scale modeling and local transport modeling. Given the time required for historical research on the source term, even the very first field characterization efforts should be prioritized using available risk information. Thus a responsive program will provide for an intensive and early assessment phase in parallel with program formulation and planning.

Both the time factor and the geographic extent of the problem argue for the application of advanced remote sensing technology, the efficient fusion of information across technologies, and the development of additional sensing technology and measurement systems. PNL is familiar with this technology in its current state, its hands-on application to national security and environmental problems, and the prospects for technological evolution in the near term.

Finally, no large scale mitigation of this contamination will be accomplished without the cost-effective application of current and new remediation technologies. This require real world-experience in both the development and application of technologies for confinement, retrieval, immobilization or insitu treatment of a wide range of wastes, often in combination. While no organization has all of the required experience in this area for marine environment, PNL, the University of Alaska and the Institute of Nuclear Safety of the Russian Academy of Sciences have extensive recent involvement in both oceanographic and environmental remediation/decontamination areas. 


\section{STATEMENT OF DR. LEONID BOLSHOV, DIRECTOR, INSTITUTE OF NUCLEAR SAFETY, RUSSIAN ACADEMY OF SCIENCE}

Dr. Bolshov. Thank you, Mr. Chairman. I am pleased to appear before you today representing the Institute of Nuclear Safety of the Russian Academy of Science. The Institute was established in late ' 88 by an act of government and it was in response to the severe accident which occurred at Chernobyl in '86. In conjunction with a special governmental program, it was suggested to facilitate future safe development of nuclear power in my country. And this was the reason why this Institute was established outside our nuclear industry, which is totally governed by Ministry of Nuclear Energy. And the primary goals of the Institute was to conduct fundamental research in the field of utilization of nuclear energy, to formulate independent evaluation of the safety of existing and projected nuclear power plants, waste management and other problems associated with the use of nuclear energy for the Academy of Science, government organization and the Parliament.

I am very happy that during the three years of our existence we have done a lot of work and while this summer in Munich where the Group of Seven Economic leaders of countries were discussing the problem of safe usage of Soviet plants and what to do with our present plants was expressed, opinions that was prepared inside academy and we were doing these, and I cannot say that it was a word to word of what ministry of Atomic Energy prepared for our authorities. And another task of our institute to provide informational and medical support to government problems regarding mitigation by the government's agencies of the Chernobyl and other radioactive accident as well as Chelyabinsk and Novaya Zemlya, et cetera.

And we are an independent scientific organization delegated to understanding and mitigating in a broad range of nuclear activity. We are doing now different projects for research for Russian Chernobyl conferences, state committee for Ministry of Ecology, for Russian, Ukrainian, American and French Nuclear Regulatory Commissions. And we are working also with our military scientists in some areas.

And as for organizational part of what we are discussing here, I was very pleased to hear from Mr. O'Dowd, his remarks and consideration. He was precisely in the target that we have large numbers of scientists in country, and there are very different groups inside, and it's very good to use experience and expertise of good group and you must be very precise in selection of right group that's going to represent them.

And as regard to Arctic disposal of nuclear materials, my organization has no prior involvement in the disposal. They probably can and will provide the necessary independence to ensure that scientifically accurate and defensible inventories and analysis are provided.

I totally agreed with what was said here that it should be multidisciplinary and multinational efforts; completeness of the inventories is of crucial importance. Russia as well as UK and other countries must incorporate all past activities that have contributed to the inventory. That's why a multinational participation in the project is so important to assure that all essential inventories are 
included. I totally agree that source term and inventory are definitely not the same and a lot of physic chemistry material science and engineering are between these two words. And I'm very happy that together with my colleagues from Pacific Batelle Northwest Laboratories and University of Alaska we feel that we have enough expertise and desire to develop this project to mutual benefit of all mankind.

And from what I heard here, I would like to make one short comment that I am very pleased to hear from public movements such as Greenpeace who have done a good job directing attention to very sensitive issues all over the world and in my country also. While solving the problem, I would like to say once more that solution of the problem is not so simple if the problem is complex enough. We all should be very careful to find the right approach and right solution for complex problem, and we are ready to do it altogether. Thank you.

Senator MURKowski. Thank you very much, Dr. Bolshov.

Dr. Vera Alexander, Director of the Institute of Marine Sciences for the University of Alaska.

[The statement of Dr. Alexander follows:] 
Testimony delivered at the hearing of the Senate Select Committee on Intelligence on Radioactive and other Environmental Threats to the Arctic resulting from past Soviet activities, Saturday, August 15, 1992, Fairbanks, Alaska. Vera Alexander.

I am here speaking in my capacity as an arctic scientist. I hold the positions of Professor, and Director of the Institute of Marine Science and Dean of the School of Fisheries and Ocean Sciences at the University of Alaska Fairbanks. The School has 56 faculty with expertise in areas ranging from marine microbiology, toxicology, seafood safety, marine mammals, and oceanography, to name just a few, and has 30 years of experience addressing arctic and Alaskan problems relating to the marine environment and its resources. This testimony in large part reflects the thoughts and knowledge of many of these colleagues.

The pollution in the Arctic can be contrasted with the Exxon Valdez oil spill. It is similar in that we sense that there is a major problem, but lack information and understanding of all details. It is much less spectacular, since it is the result of many individual pollution events over a period of decades, rather than a single catastrophic accident. On the other hand, because of the number and geographic distribution of the potential pollutant releases, its effects are likely to be much more widespread and it will also be much more long lasting because of the nature of the pollutants. The problem could persist through decades, centuries and even longer.

I am very pleased to have this opportunity to address the question of research needs in addressing potential hazards from radionuclide waste entering the arctic seas. Although at first it may seem reasonable to believe that the enormous dilution which occurs when substances are mixed into sea water could alleviate any impacts, it is by no means safe to assume that this is the case. A contraindication is the ability of biological systems to accumulate substances, and the ability of oceanographic processes to channel and transport them. Therefore, it is very important that we develop an understanding of what processes are active, and to understand the sources and distribution of the materials. For example, sedimentation processes can result in the transport of contaminants into the sediments, impacting the biota within them. Water flow over the bottom can further move the toxic materials into the deeper ocean basins. Biological accumulation can concentrate the pollutants. For example, phytoplankton have a huge capacity for accumulating large quantities of elements from sea water in a relatively short time, and this largely accounts for the effective passage of radionuclides and other toxins to higher 
trophic levels, including fishes, mammals and birds. Although our ultimate concem relates to the public health effects, understanding the oceanographic and ecological processes is a key to evaluating the hazard.

From the oceanographic perspective, the first priority must be the understanding of the sources of and distribution of the radionuclides and other pollutants. At this time, the scientists who are considering these questions do not have "hard" information on the present distribution of the radioactive materials in the ocean. A practical approach to satisfying this need is the procurement of existing Russian data, followed by the acquisition of new data through collaborative work with Russian scientists.

The circulation of the Arctic Ocean is such that materials accumulating on the Barents Sea shelf are likely to be transported northward into the Arctic Basin, "but it is unlikely that this transport will immediately impact Alaskan shores. There is a much greater potential for danger to Alaska from materials entering via the vast northward-flowing rivers of Russia. The East Siberian Current, which flows eastward along the North Siberian arctic coast transports materials and organisms originating in coastal fresh and marine waters of the Kara, Laptev and East Siberian Seas eastward. We do not know whether they are likely to reach the Chukchi Sea off Alaska. It is possible that pollution from the easternmost rivers, such as the Lena, could. This needs to be evaluated.

The Bering Sea also might be subject to some hazards, and, as the most productive fishing ground in the world, needs special consideration. The food production from the walleye pollock captured in the Bering Sea provides a mechanism for transferring pollutants released into the Siberian and Kamchatka Peninsula waters to people worldwide via the commercial fishery and to Alaskan Natives via subsistence harvest. Pollock are also very important in the diets of sea birds and marine mammals, which provide a second pathway for radionuclides and toxic materials to enter Native peoples who rely heavily on marine birds and mammals for subsistence. The Anadyr River enters the western Bering Sea, an immensely productive area, and moves northward, primarily to the west of St. Lawrence Island onto the western portion of the northem Bering Sea shelf and through the Bering Strait into the Chukchi Sea. These areas are the most productive within the Bering Sea, and in fact within the entire western Arctic. They are the principal feeding grounds for the majority of Alaska's walrus population. Walrus feed on bottom-living organisms, which accumulate materials from the sediments, providing a direct link to human food. Furthermore, walrus feeding in the Chukchi Sea in areas under 
the influence of pollution from the west could transport pollutants southwards through the Bering Strait into the Bering Sea. This biological flow moves in anopposite direction to the dominant ocean currents, which transport materials northward through the Bering Strait.

We can't be sure that the pollutants and their effects will be confined to the Arctic. Seasonal presence of migratory birds and marine mammals in the Arctic provides a mechanism for possible rapid transport to north temperate latitudes. The issue of marine pollution is clearly an international problem because the oceans unite all lands. As soon as you introduce anything into the sea, you are influencing an environment which embraces the entire planet. International cooperation is the key to addressing the problems.

The University of Alaska has developed close relationships with Russian institutions in a number of areas. We in the marine areas at the University of Alaska have forged strong cooperative agreements with two institutes of the Far East Branch of the Russian Academy of Sciences - the Marine Biological Institute and the Pacific Oceanological Institute. We also work with TINRO, the Far East fishery agency in Russia. For the Barents Sea, we have an agreement with the Marine Biological Institute of the Kola Science Center of the Russian Academy of Sciences, based at Murmansk. This Institute operates research vessels capable of sampling some of the critical areas in the Barents Sea. In the Bering and Chukchi Seas, we work through the Environmental Bilateral on joint cruises on board the R/V Akademic Korolev. Planning is underway between the United States Fish and Wildlife Service and the State Committee for Hydrometeorology of Russia for their fourth such expedition scheduled for 1993, and our scientists are involved in the scientific planning and will participate in the cruise. The Institute of Marine Science and colleagues from other institutions and nations regularly conduct research in the Bering and Chukchi Seas using the research vessel Alpha Helix, which is operated by the University of Alaska for the National Science Foundation.

Immediate action is imperative. Even without the current questions about nuclear waste disposal, there would be a need for long-term monitoring of the Alaskan arctic coast. Now, the urgency is increased. Carefully planned research is the only sound approach to evaluating the impact of pollutants which have been discharged into the Arctic Ocean. The marine portion of the work must include evaluation of distribution, food chain processes and transportation mechanisms. 
I will end with a cautionary comment, that the issue is not just a need to demonstrate and document contamination. It is equally important to identify the absence of a problem, so that economic and social disruption due to a perception of contamination can be minimized. 
STATEMENT OF DR. VERA ALEXANDER, DIRECTOR, INSTITUTE OF MARINE SCIENCES, UNIVERSITY OF ALASKA

Dr. Alexander. Thank you Senator. And thank you very much for inviting me to take part in the scientific panel originally By moving me to the end of the day, I guess I moved myself in a sense, it made it very easy for me, because everything that's worth saying has probably already been said today. And so, I have to-it makes my job much easier.

However, we haven't really addressed in depth the problems that Alaska faces or that the Alaska marine environment faces, and I think that's the other side of the equation to what we have just heard, and I think we need to look at that. And our team proposes also to address that problem.

Let me first say a few words about my organization since this has been the mode. I'm Director of the Institute of Marine Science but the Institute is now within the School of Fisheries and Ocean Sciences, of which I'm also Dean. And that school has some 56 faculty in tremendous range of expertise. We've got all the way from marine microbiology, toxicology, seafood safety, marine mammals, oceanography, et cetera. We have more than 30 years experience in doing research in Alaskan waters, addressing Arctic and Alaskan problems relating to the marine environment and its resources.

I have used these colleagues in preparing this testimony. It's not all my own thoughts, on the contrary, it reflects the thoughts and knowledge of many colleagues. One of them provided to me by Dr. David Shore was illuminating. And he contrasted the pollution in the Arctic, which we're looking at now, with the Exxon Valdez oil spill. Similar in that we know that there's a problem, at least we sense that there's a major problem, but we really don't know the details at this point. But it's much less spectacular. Our oil spill was very spectacular. It was an individual catastrophic event.

But on the other hand, in this case, we have a much different situation. We have a large number in a broad geographic distribution of the potential pollutant releases, and the effects are likely to be very much more widespread, and it will last much longer because of the nature of the pollutants. We could be affected through decades, centuries or even longer.

Now as far as the question of research needs in connection with the potential hazards from radionuclide waste entering Arctic seas, at first it may seem reasonable that the tremendous dilution that sea water offers to any substances entering it would preclude any serious problems. But in a fact, it's really the very same properties of sea water that make it possibly a dangerous situation, because within the sea biological systems have tremendous ability to accumulate subsistencies. And there's a great ability for oceanographic processes to channel and transport substances.

And so, we really have to develop an understanding of what processes are active and to understand the sources and the distribution of the materials. That's the first step and that's what we have been talking about.

Mitigation is another part of that part of the equation. But take one example. Sedimentation can result in the accumulation of wastes in the sediments which immediately impact the biota within them, which accumulate these toxic materials and radioactive ma- 
terials. But then water flow over the bottom and even sediment transport itself can transport these materials into the deep Arctic Ocean basin. Then in the water column itself, phytoplankton have a tremendous ability to concentrate materials from the water, and this accounts for the very effective passage of radionuclides and other toxins into higher trophic levels, including fishes, mammals and birds.

Although our ultimate concern relates to the public health effects, understanding the oceanographic processes and the ecological processes are both keys to evaluating the hazards.

Now from the oceanographic perspective, the first priority must be understanding the exact nature of the sources of the radionuclides and, at this time, the scientists who are considering these questions simply don't have hard information on the present distribution. One step, of course, is the procurement of the existing Russian information and the other is the conduct of new collaborative measurements, which we hope will be underway with our colleagues before long.

Now the circulation of the Arctic Ocean is such that materials accumulating on the Barents Sea shall be likely to move out into the Arctic Ocean, and it's unlikely that they will immediately travel towards Alaska. There's a much greater potential danger for Alaska from materials entering by the vast northward flowing rivers of Russia. The East Siberian current which flows eastward along the north Siberian Arctic coast transports materials and organisms originating in the coastal fresh and marine waters of the Kara, Laptev, and East Siberian Seas eastward. But we don't know whether they are likely to reach the Chukchi Sea; maybe not. That's a long distance to expect these waters to transport materials. But it's possible that pollution from the easternmost rivers such as the Lena could make it to the Chukchi Sea. This needs to be evaluated.

We are also concerned about the hazards in the Bering Sea, because the Bering Sea is the most productive fishing ground in the world. I don't think anybody's going to argue about that. This needs special consideration. The food production from walleye pollock captured in the Bering Sea could provide a mechanism for transferring pollutants released into the Siberian and Kamchatka Peninsula waters to people worldwide by the commercial fishery, and especially to Alaskan Natives via subsistence harvest. Pollock are also very important food for sea birds and mammals. And of course, sea birds and mammals are also very important foods for coastal resident populations. And therefore this is another mechanism for transferring radionuclides to the coastal people.

Now the Anadyr River, which enters western Bering Sea, enters into an immensely productive area. This is possibly the most productive region in the whole of the Arctic. This water that goes through the Anadyr Gulf moves northward, mostly to the west of St. Laurence Island, into the northern Bering Sea shelf, through the Bering Strait on the west side, and into the Chukchi Sea and onto the shelf.

Now look at it this way. Almost the entire Alaskan population of walrus feeds in that area. Enormously productive. Very big populations of organisms live in the bottom. These walrus are feeding 
on these bottom organisms. The bottom organisms accumulate anything that's coming into that water, and therefore it's getting into the walrus. This could be a key to why we're having a problem with our walrus contamination right now. Obviously a very, very important problem.

We can't be sure that the pollutants and their effects will be confined to the Arctic even, because so many of the animals and birds in the Arctic are migratory, especially the birds. They migrate long distances into the northern temperate latitudes. So we clearly have a global problem here in this whole pollution. Anything you put in the sea, of course, is automatically a global problem because the sea is one thing that touches all our lands, all our continents at least. So, you're influencing an environment which embraces the entire planet. And international cooperation is really the key to addressing the problems.

Now as several people on this panel have already mentioned, the University has established very close relationships with a number of circumpolar entities and has a tradition of working together with these to address problems. For example, our major Bering Sea research which was primarily two major products, Probes and Ishtar, both of which really helped us understand the Bering Sea ecosystem more thoroughly than ever before, involved Russian people, it involved Japanese, Danish, plus universities from all over the United States. So we're used to operating in that mode very effectively.

We've forged strong cooperative agreements with institutes of the Russian Academy of Sciences in the Far East, particularly the Pacific Oceanological Institute and the Marine Biological Institutes in Vladivostok. We're already working together with them. We also have a similar arrangement with the Marine Biological Institute of the Kola Science Center in Murmansk. And so, we have forged some relationships. We also, for several years, have been working on another avenue to get some Bering Sea information, and that's through the Environmental Bilateral, in which we've taken part in cruises of the academic core lift periodically. Planning is now underway through the U.S. Fish and Wildlife Service for the next such cruise, also on the Russian side, of the State Committee for Hydrometeorology, for the fourth such expedition scheduled for 1993, and our scientists are involved in the planning and will participate in the cruise. So that could be part of the equation here also.

Immediate action is imperative therefore to also look at our systems here, our marine ecosystems here. We have heard so much about the concern already in the testimony. And so I don't think we can ignore that while we're addressing the problem of the sources and the distribution.

Carefully planned research is really the only sound approach to evaluating the impact of pollutants which have been discharged into the Arctic Ocean. But I want to make one final suggestion, and that is let's not look at this as a way of showing that there's a serious problem. Let's use this-let's go on the assumption that our fish are safe, but we've got to demonstrate this. Let's show that the marine mammals don't have radioactive pollution so that people can enjoy their traditional ways of using them. I don't think we 
have to look at this as a doomsday but I think we just have to have the facts and not have any hysteria over the matter. Thank you. Senator MURKOWSKI. I very much appreciate those remarks, Vera. I think to highlight the positive aspects is much more practical than the negative aspects.

I don't know how it feels, Lee, to be the cleanup hitter, but Dr. Lee Gorsuch, Director of the Institute for Economic and Social Research, University of Alaska Anchorage, you've got it.

[The statement of Dr. Gorsuch follows:] 


\title{
534
}

\author{
A STATEMENT ON \\ THE HUMAN CONCERNS RELATED TO THE \\ IDENTIFICATION, EVALUATION, AND REMEDIATION \\ OF RADIOACTIVE AND HEAVY METAL CONTAMINATION \\ IN THE RUSSIAN ARCTIC \\ Presented to \\ The U.S. Senate Select Committee on Intelligence \\ by \\ Edward Lee Gorsuch, Dean \\ School of Public Affairs \\ University of Alaska Anchorage
}

Mr. Chairman and members of the U.S. Senate Select Committee on Intelligence, my name is Edward Lee Gorsuch. I serve as the Dean of the University of Alaska Anchorage's School of Public Affairs. In this capacity I oversee the University's Environment and Natural Resources Institute, and for the past sixteen years I have also directed the Institute of Social and Economic Research. I appreciate the opportunity to express my views on the importance of investigating the locations and extent of potential radioactive contamination in the Russian Arctic. My colleagues have spoken to the immediate task of preparing an inventory and assessment of radioactive materials and of projecting how these materials have been or may be transported far beyond the initial sources of dispersal.

My comments relate to four human concerns, all of which should be addressed in the scope of the study:

- First, how has or may the health of Arctic people be harmed by exposure to or consumption of contaminated materials, food, and water?

- Second, how may their socio-cultural and economic well-being be affected?

- Third, following risk assessments, what are the relative costs and 


\section{benefits of alternative mitigation strategies?}

- And, fourth, how will the study, its Identified potential risks and mitigation alternatives, be communicated to Arctic residents, and how will their concerns and views be solicited and considered?

While radiochemists and marine scientists are investigating, tracing, and projecting how radioactive materials may be transported and enter the food web, bio-medical researchers, epidemiologists, economists and social scientists should be conducting complementary investigations, locating human populations living in proximity to these pathways, and documenting where Arctic people gather, harvest, process, and share or distribute food and water. These important social, economic, and cultural patterns will vary significantly by size and cultural composition of each community.

Enormous economic, as well as ecological and cultural values, would be at risk should radioactive materials be transported into the Bering Sea. The study called for and the monitoring and mitigation which will follow will help protect this invaluable ecosystem where literally billions of dollars of fish product are harvested annually, representing almost ten percent of the entire world's fish supply. Economic models of the Bering Sea fisheries would need to be built to estimate and distribute these potentially catastrophic losses among the tens of thousands of fishermen, processors, boat owners, wholesalers, retailers, and the hundreds of thousands of consumers, all of whom directly benefit from the Bering Sea's bounty. 
UAA researchers have over 30 years of experience in social, economic and environmental assessment work in the Circumpolar North, concucting large random surveys, geographically mapping realdent fishing, hunting, and food gathering activities of culturally diverse groups; projecting population, employment, and income changes assoclated with natural disasters or potential large scale resource development projects; asaessing the relative benefits and costs of alternative mitigation strategies; and organizing effective public participation in the conduct of sensitive research.

The University hosts the headquarters of the International Union of Circumpolar Health which networks bio-medical and epidemiological researchers throughout the circumpolar region. The Institute of Social and Economic Research has active cooperative research agreements with its counterpart institutes throughout the Russian North. Academician Alexander Granberg, the Chairman of the RAS's Arctic Research Commiasion has, for the past two years, held a distinguished visiting professorship with the University. Similar cooperative agreements with bio-medical and health professional organizations of Russia's Far North and the University of Alaska have been active for many years.

I would like to make two concluding remarks regarding the proposed study. First, Speaking from a public policy perspective, the study should be designed within the context of what can and should be done. Simply assessing the problem is not adequate. Remediation, decontamination, and other mitigation alternatives should be integral components of the atudy, and each alternative associated with the varying degrees of risk should be assessed for its relative costs and 
benefits.

Second, in my view we should not limit the scope of concern to threats to ourselves. Russians are Alaska's close neighbors and increasingly our friends. They need our help and we should extend it not only in our self interest but in the interests of humanity. Both the problems (and potential) of dispersed radioactive materials and premanageme (or prevention) of them are the responsibilities of the Russian Federation and its relevant institutions. The proposed study should be conceived of as an opportunity to strengthen the capabilities of the Russian host institutions and organized accordingly.

Mr. Chairman, I commend you and the Select Committee for your farsighted leadership in calling for immediate investigations into the potential radioactive risks to the Arctic and to its people. Thank you again for the opportunity to briefly share my views.

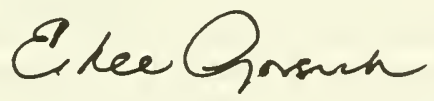


STATEMENT OF DR. LEE GORSUCH, DIRECTOR, INSTITUTE FOR ECONOMIC AND SOCIAL RESEARCH, UNIVERSITY OF ALASKA ANCHORAGE

Dr. GoRsuCH. Thank you, Mr. Chairman. Like my colleague Vera during the University's retrenchment in the spirit of economy, I serve as both the Dean of the School of Public Affairs of the University of Alaska Anchorage as well as the Director of the Institute of Social and Economic Research. And in that capacity, I also oversee the Environment and Natural Resources Institute of the University. And I've been directing the institute for the past 17 years.

I'm going to focus my views really in adjunct to those of my colleagues who are investigating the locations and extent of potential radioactive contamination in the Russian Arctic. They've already spoken to the immediate tasks at hand, which really are a priority, and that is preparing this inventory and assessing radioactive materials and projecting how these materials may or may not have been transported far beyond their initial sources of dispersal. My task is really to try to wrap up some of the concerns that were expressed in the earlier panels, and these really address the human concerns. And I've listed essentially four of them. I think each of these can, in fact, be incorporated within a reasonable scope of study, consistent with the priorities that have been suggested.

The first is this issue of the health of Arctic people and how they may be harmed by the exposure to or consumption of contaminated materials, be it in food, water or air. Secondly, it's easy to incorporate within the design the sociocultural and economic well-being that may be affected. As you well know, Senator, there are over 150 nationalities in the Soviet north, some of which are quite small and precarious, and just as we're concerned about biological diversity, we're also very much concerned about the cultural diversity. Documenting their proximities to any potential sources of contamination is a very straightforward but an important task. Similarly, the economic tolls that might be associated with contamination are enormous. Simply looking at the news accounts recently on the projected costs for the Hanford cleanup estimated in excess of $\$ 60$ billion, simply begins to suggest the enormous amount of diversion of the funds from sources of support for education, food, clothing, employment illustrates this in our own country.

And third, following the assessments of risk and the identification of alternative mitigations, which I think is our principal focus and our ultimate objectives, we really need to assess the relative costs and benefits of each of these alternative mitigations to ensure that we're doing the most that we can with the resources that are available.

And finally, as the earlier panel just emphasized, I think quite personally, the study should in the process of identifying its potential risk and mitigation strategies communicate these to the residents of the Arctic and ensure that the process of the study itself addresses not only the findings but the concerns of the citizens of the Arctic as well. While radiochemists and marine scientists are investigating, tracing and projecting how radioactive materials may be transported and enter the food web, biomedical researchers, epidemiologists, economics and social scientists should be conducting complimentary investigations, locating human populations living in 
proximity to those pathways, documenting where Arctic people gather, harvest, process and share or distribute food and water. These important social, economic and cultural patterns will vary significantly by size and cultural composition of each community.

As Dr. Alexander indicated, the U.S. interest in part lies in some of the enormous economic as well as ecological and cultural values which would be at risk should radioactive materials be transported into the Bering Sea. The study called for and the monitoring and mitigation which will likely follow will help protect this invaluable ecosystem. There, in the Bering Sea, literally billions of dollars of fish product are harvest annually, representing a significant portion of the entire world's fresh fish supply. Economic models of the Bering Sea fisheries would need to be built to estimate and distribute these potentially catastrophic losses should in the conclusions of the study this be suggested as warranted. Literally tens of thousands of fishermen, processors, boat owners, wholesalers and retailers, and hundreds of thousands of consumers throughout the world, all of whom would be impacted potentially should the Bering Sea's bounty be adversely affected.

As my colleagues indicated, University of Alaska Anchorage researchers have over 30 years of experience in social, economic and environmental assessment work in the circumpolar north, conducting large random surveys, geographically mapping resident fishing, hunting and food gathering activities of culturally diverse groups, projecting population employment and income changes associated with natural disasters or potential large scale development projects, and assessing the relative benefits and costs of alternative mitigation strategies, not to mention organizing an effective public participation in the conduct of sensitive research.

As was noted by the health panel, the University hosts the headquarters of the International Union for Circumpolar Health which networks biomedical and epidemiological researchers throughout the circumpolar region. The Institute of Social and Economic Research has active, cooperative research agreements, as many of my other colleagues do, with its counterpart institutes in the Russian North. Academician Alexander Gramberg serves as the chairman of the Russian Academy of Science's Arctic Research Commission focused on the Arctic. Dr. Gramberg has been serving as a distinguished visiting professor with the University for the past two years and will be coming to Alaska this September.

Similarly cooperative agreements with biomedical and health professional organizations of Russia's Far North and the University of Alaska have been active for several years, as Professor Ebbeson had indicated in his testimony.

In my closing remarks I'd like to offer two comments on the conduct of the study. First, speaking from a public perspective, the study should be designed within the context of what can and should be done. As Bill Shipp said, simply assessing the problem is not adequate. A focus should be on the remediation, decontamination and other mitigation alternatives as well as the overall goal of prevention of any large-scale future releases.

Similarly in the approach towards the finalization of recommendation, these alternatives for remediation all warrant careful scrutiny of their relative costs and benefits. 
And finally, in my view, Mr. Chairman, I don't think we should limit our scope to the threats to ourselves. Russians are Alaska's close neighbors and increasingly are our personal friends. They need our help and we should extend it, not only in our self interest but in the interest of humanity. Thank you for the opportunity to share by views, Mr. Chairman.

Senator MURKOWSKI. Thank you very much, Dr. Lee Gorsuch.

I think you've heard it all, ladies and gentlemen. I think we'd agree that we've learned an awful lot today. I think we also agree that our own government is going to have to make Arctic pollution a priority, and I'll certainly make every effort to share with my friends in the Senate the necessity of this. I intend to use this testimony over an extended period of time for floor speeches on the floor of the United States Senate to highlight the testimony given today by the witnesses in order again to bring more public awareness to the realities that have been discussed here.

We've talked about a good deal of specific information but I think we all are aware that we need to know much, much more. That's been brought out time and time again. I think particularly about the health impacts of disposal of radioactive material and the implications on the plant life and the fauna and so forth. I think we'd agree that in the general area of information, that is probably one of the areas where we are clearly deficient. It's probably the most difficult to get the documentation on as well. I think we're all in agreement that we must work with the international community and finally take action to marry science, and we're talking about good science, with international organizations that can propose specific programs. I'm certainly very proud of the talent that has been evident here in the testimony given by the experts. I think we've also had an opportunity to show the world, as well as the national scientific community, the capability of our own Alaska scientists who are in residence here. We're very proud of them. And our public officials and our Native leaders as well. I think it's fair to say that we can all make a difference.

And with regard to that, I would like to reiterate a remark that was referred to by Secretary Bohlen in his statement relative to the letter that was delivered to me last night from the Russian Ambassador Lukin. And I'll just read the last paragraph because I think it reflects the true extension of friendship and willingness for cooperation. And it reads in this regard,

Russia would be extremely interested in cooperation with the United States in the field of monitoring of environmental items in the Arctic on a bilateral basis as well as in the framework of multi-international cooperation of Arctic states and particular to the program of Arctic monitoring and assessment. In our view, these hearings will be a first step in putting on track a large practical bilateral cooperation in this important field. I take this opportunity to wish you a successful and fruitful work. With my respects, Vladimir Lukin, Ambassador of Russia in the United States.

So there we have, I think, the official position of the government of Russia. I think that there was one mention of a reference with 
the United States Navy. And while they are lacking in presence here, I can assure you that we have had numerous discussions in the Intelligence Community with regard to the appropriate role of the Navy. And they, as usual, are more than up to the task.

I think it's appropriate to thank a number of people who have worked very, very hard on this, certainly the cooperation of the President of the University of Alaska, Dr. Komisar; Vice President Proenza; Chancellor Wadlow; and the University group that worked in putting this on. You know, it hasn't been easy. This isn't the first conference. This was just an extension of another three day conference. And they did a great job with the hearing. We want to thank our reporter as well. And there are many unnamed people who played a role in this, including those of you who sat through it, and we're most appreciative. I think we would all agree that it's been mutually beneficial. A great deal of thanks goes to the staff, on my left John Moseman, who is Staff Director for the Minority, and a long-time associate of mine, my former Chief of Staff. And David Garman on my right who has worked so diligently, he couldn't even go on a picnic down the Tanana River last night, he stayed and worked. So, I want to thank you both and the others that are responsible.

And again, I would remind you that we will have, if you'll give us your names, a copy of the record mailed to you, I'm told, within eight weeks but we'll try and do better with a summary. And I think that we can all agree that the process that was unveiled here in generating this concern to the appropriate levels of the scientific community as well as the citizens of our state who are most affected. I'm often reminded of the reality that if we had four or five other states that had Arctic in them, why we would be much further along. But unfortunately, Alaska is the only one. But I think as we look at the statements and testimony given today, we find that our Intelligence Community is now working in the area of environmental intelligence. Our State Department has indicated that they are going to initiate an Arctic advisory committee. Those are significant advancements and I think they were made possible primarily by the awareness and participation of all of you here today, both you in the audience and you who were part of the group testifying. I want to thank you because I think we've all made a meaningful contribution to a process where there's still a lot of hard work but I think we're up to the tasks ahead. So with that, and on behalf of the Chairman, Senator Boren, thank you for being here. And we would conclude this field hearing of the Senate Select Intelligence Committee and advise you that the record will remain open for testimony for the next two weeks. Thank you very much. The Committee is adjourned.

[Thereupon, at 5:03 o'clock p.m., the hearing was adjourned.] 

A P P E N D I X

Facts and Problems Related to Radioactive Waste Disposal in Seas Adjacent to the Territory of the Russian Federation

(Materials for a Report by the Government Commission on Matters Related to Radioactive Waste Disposal at Sea,

Created by Decree No. 613 of the Russian Federation President, October 24, 1992)

Office of the President of the Russian Federation Moscow, 1993

(543) 


\section{4}

\section{Authors:}

A. V. Yablokov

V. K. Karasev

V. M. Rumyantsev

M. Ye. Kokeyev

O. I. Petrov

V. N. Lystsov

A. F. Yemelyanenkov

P. M. Rubtsov

A complete list of the Government Commission and Working Group can be found on p. $\mathbf{8 2}$.

Office of the President of the Russian Federation

All publication and translation rights belong to the Office of the President of the Russian Federation 


\section{From the Authors}

Recently, the world public has been vigorously discussing the problem of the former USSR's disposal of radioactive waste ( $R W$ ) in the seas adjacent to the territory of the Russian Federation. This debate has drawn upon reports based on rumors and unverified information, which substantially distorts the actual picture and creates a pretext for various forms of speculation.

In October 1992, in order to obtain objective information and subsequently ensure Russia's compliance with obligations under international treaties which it signed as successor to the Soviet Union, the President of the Russian Federation formed a Governmental Commission on Matters Related to Radioactive Waste Disposal at Sea (hereafter the Commission). The Commission included representatives of the Russian Ministry of Nature, the Russian Ministry of Defense, the Russian Ministry of Foreign Affairs, the Russian Ministry of Public Health, the Russian Ministry of Atomic Energy, the Russian State Committee for the Supervision of Nuclear and Radiation Safety, the Russian State Committee for Sanitary and Epidemiological Supervision, other ministries and agencies, and representatives of administrations of northern and far eastern areas of Russia (cf. p. 55). The Commission formed a working group and an expert group (cf. p. 56). The working group was subdivided into subgroups: data collection, radiology, international law, and archives. Members of the working group made trips to deployment locations of ships and vessels of the Russian Navy and Russian Ministry of Transportation. In response to Commission inquiries, central agencies of federal executive power and the administrations of Primorsky Territory, Arkhangelsk, Kamchatka and Murmansk Provinces furnished a large volume of factual material.

All these data formed the basis for the Commission's report, submitted to the President of the Russian Federation in February 1993, on the results of the work performed.

When the text of the Commission's report was processed into a White Paper, it was edited for publication; moreover, minor cuts of a non-substantive nature were made, the Commission's suggestions to the President and the Government of the Russian Federation concerning plans for specific measures to establish monitoring and processing of liquid and solid RW were deleted, and some comments separate from the text were also added.

In the future, some data presented below on calculations of the amount of radioactive contamination of seas must be organized, since the level of radioactivity of submerged reactors was not determined precisely at the time and the Commission was forced to rely on expert estimates.

In our opinion, the data provided fully and objectively reflect the situation with RW disposal in the seas adjacent to the territory of the Russian Federation. 
Table of Contents

PREFACE

SECTION 1. INTERNATIONAL ASPECTS OF THE PROBLEM OF RADIOACTIVE WASTE

DisPOSAL AT SEA

1.1. International Law Governing Procedures for Handling Radioactive Waste

1.2. Current Practice in Radioactive Waste Disposal at Sea by Countries Using Nuclear Power Technologies

1.2.1. Data on Radioactive Waste Disposal at Sea by Selected Countries

1.3. Positions of Various Nations on Matters of Radioactive Waste Disposal at Sea.......14 (18)

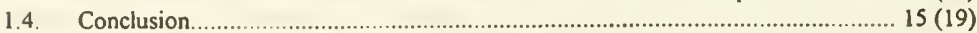

SECTION 2. RADIOACTIVE WASTE DISPOSAL IN SEAS ADJACENT TO THE TERRITORY OF THE RUSSIAN FEDERATION

2.1. Normative Documents That Regulated Radioactive Waste Disposal at Sea in the

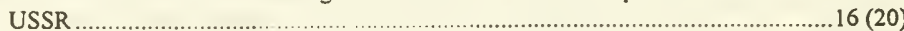

2.2. Russian Federation Law on Radioactive Waste Disposal at Sea ..........................20 (26)

2.3. Total Volume and Characteristics of Radioactive Waste Dumped at Sea by the USSR between 1959 and 1991

2.3.1. Disposal Sites, Volumes, and Total Activity of Radioactive Waste Dumped by the USSR in Northern Seas

2.3.2. Disposal Sites, Volumes, and Total Activity of Radioactive Waste Dumped by the USSR in Far Eastem Seas ...........................................................29 (38) 2.3.3. Total Amount of Radioactive Waste Dumped by the USSR at Sea ..............32 (44)

2.4. Radioactive Waste Disposal in the Seas of the Russian Federation ........................33 (46)

SEction 3. Radiological Conditions IN MARINE Radioactive Waste Disposal AREAS IN THE NORTH AND FAR EAST

3.1. Organization of Radiation and Sanitary-Hygienic Monitoring in Marine Radioactive Waste Disposal Areas ............................................................35 (48)

3.2. Radiation Conditions in Seas Used for Radioactive Waste Disposal.........................37 (50)

3.3. Anticipated Changes in Radioecological Conditions at Sites of Radioactive Waste Disposal at Sea

3.4. Accident on a Nuclear Submarine in Chazhma Bay (Primorsky Territory), 1985.....41 (59)

3.5. Accident on the Nuclear Submarine Komsomolets in the North Atlantic, $1989 \ldots \ldots .43$ (62)

3.6. Conclusion.......................................................................................... $45(65)$

Section 4. Ways of Solving the PRoblem of Handling Radioactive Waste PRODUCED IN THE SySTEM OF THE NAVY AND MURMANSK MARINE SHIPPING LINE.

4.1. Problems in Recycling Decommissioned Nuclear Submarines and Handling Spent Nuclear Fuel in the Northern Fleet and Murmansk Marine Shipping Line .

4.2. Problems in Recycling Decommissioned Nuclear Submarines and Handling Spent Nuclear Fuel and Other Radioactive Waste in the Far Eastern Area

\footnotetext{
'-Page numbers in this section have been adjusted to correspond to those in the translation, with parenthesized figures corresponding to those in the original.-Trans.
} 
4.3. Analysis of the Proposed Russian Government Program for Handling, Recycling and Dispasal of Radioactive Wastes and Spent Nuclear Materials for the 1993-1995

Period and Through 2005, and of the Russian Federation Government Resolution of

August 31, 1992 on the Recycling of Nuclear Submarines............................50 (72)

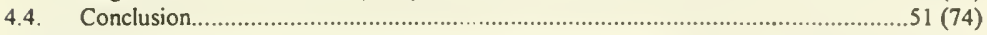

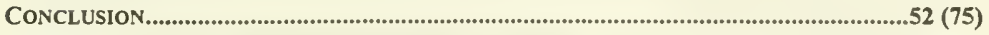

FINDINGS......................................................................................................5 53 (76)

MAKEUP OF THE GOVERNMENT COMMISSION ON MLATTERS RELATED TO RADIOACTIVE

WASTE DISPOSAL AT SEA.............................................................................54 (78)

MAKEUP OF THE COMMISSION'S WORKING GROUP AND EXPERT GROUP .....................55 (79)

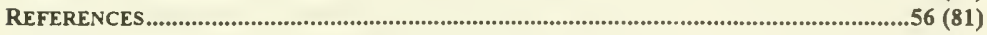

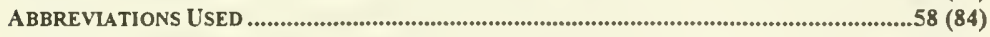

APPENDICES ...................................................................................................59 (85)

Table A1. Characteristics of Liquid Radioactive Waste Discharge Areas in Northern Seas ..59 (86)

Table A2. Characteristics of Liquid Radioactive Waste Discharge in Northern Seas..........60 (87)

Table A3. Characteristics of Solid Radioactive Waste Disposal Areas in the Kara Sea .......62 (92)

Table A4. Characteristics of Solid Radioactive Waste Dumping in Northern Seas .............63 (93)

Table A5. Characteristics of Liquid Radioactive Waste Discharge and Solid Radioactive

Waste Dumping Areas in Far Eastern Seas..................................................67 (97)

Table A6. Characteristics of Liquid Radioactive Waste Discharge in Far Eastern Seas .......68 (98)

Table A7. Characteristics of Solid Radioactive Waste Dumping in Far Eastern Seas .........69 (102) 


\section{PREFACE}

The main aim of RW disposal ${ }^{2}$ at sea has been to isolate these hazardous wastes from man's habitat for a sufficient period for physical decay of radionuclides.

The disposal of liquid and solid RW has been performed by many countries with nuclear fleets and nuclear industries.

The accumulation of RW dumped at sea and accidents on nuclear-powered ships and nuclear submarines (NS's) is causing growing concern in the world community, and serious claims are being addressed to the former USSR, and now to Russia.

It should be noted that the first press reports on the former Soviet Union's practice of dumping RW in northern seas appeared in publications by activists in the ecological movement Toward a New Earth. A. A. Zolotkov, an engineer in the radiation safety service of the Murmansk Maritime Shipping Line, played a leading role here. Because no official confirmations or denials were made, the international organization Greenpeace held a briefing on the subject in Moscow in September 1991 and prepared material, for presentation to the 15th Consultative Meeting of members of the London Convention (November 1992), on the need to correct the IAEA list on RW dumped at sea to account for available unofficial reports. The material included maps of disposal sites and fragmentary, sometimes erroneous data on cases of RW disposal in northern seas by the former USSR.

This White Paper consists of four sections that examine international aspects of the problem of RW disposal at sea, present and analyze factual data, examine radioecological conditions and formulate conclusions.

The Appendix presents all data obtained by the Commission on RW disposal in northern and far eastern seas.

The White Paper does not contain data on the characteristics, time or sites of underwater, surface, or above-water nuclear explosions in the waters of the Kara and Barents Seas. It is known, for example, that explosions were produced in Chernaya Bay in connection with a study of the possible destruction of enemy warships in closed harbors. A small number of nuclear explosions was evidently produced slightly above the surface of the Barents Sea northwest of Matochkin Shar Strait. There is eyewitness testimony to the production of underground nuclear explosions. In all these cases, some fraction of radioactive materials must have entered the sea. Knowing the characteristics of the nuclear explosions, we can calculate the amount of activity and the spectrum of radionuclides that entered the sea.

Another possible source of radioactive contamination not considered by the Commission is radionuclides formed from nuclear explosions on Novaya Zemlya archipelago. Recent data (J. Scorve, J. K. Slogan, 1992) show that at a test site near the town of Severny, 5 of 28 detonations produced cra-

${ }^{2}$ - In accordance with established practice in the White Paper, radioactive waste is understood to mean both liquid radioactive waste (circulating kater from ship nuclear reactors, flushing and deactivation water, and domestic sewage from special lines), and solid waste (reactors with reactor fuel in place and reactor components with induced radioactivity, wastes produced when ships and vessels were repaired or damaged, nuclear warheads that have been lost or have accidentally fallen inıo the sea, and other radioactive objects).

According to the customary classification, radioactive wastes are divided into:

\begin{tabular}{|c|c|}
\hline $\begin{array}{l}\text { low-level } \\
\text { intermediate-level } \\
\text { high-level }\end{array}$ & $\begin{array}{l}\text { less than } 100 \mathrm{kBq} / \mathrm{l}(26 \mu \mathrm{Ci} / 1) \text {; } \\
\text { more than } 100 \mathrm{kBq} /(26 \mu \mathrm{Ci}) \\
\text { more than } 15 \mathrm{GBq} /(0.4 \mathrm{Ci} /) \text {. }\end{array}$ \\
\hline
\end{tabular}


ters in the Earth's surface. The formation of such craters indicates the destruclion of the entire permafrost layer under the explosion site and the formation of a so-called chimney over the explosion cavity. Leakage of a significant amount of radionuclides through such structures is inevitable, and some portion (possibly a substantial one) of the released radioactivity could have entered the sea. In principle, the entry of radioactivity from underground explosions into the sea through soil and ground water cannot be ruled out. As yet, even an approximate estimate of the amount of radioactive contamination that could have entered the ecosystems of the Barents and Kara Seas has not been made. - A. Yablokov. 


\section{Section 1. International Aspects of the Problem of Radioactive Waste Disposal at SEa}

An objective assessment of the status of the problem of RW disposal in the seas adjacent to the coast of the Russian Federation requires an examination of its international legal aspects, an analysis of the factual data on practices followed by other nations in disposing of RW at sea, and consideration of the position of various nations with respect to the problem.

\subsection{International Law Governing Procedures for Handling Radioactive Waste}

In international law, matters of $R W$ disposal at sea are governed primarily by the Convention on Prevention of Pollution of the Sea by Discharges of Wastes and Other Materials, which was signed in London in 1972 and took effect August 30, 1975 (January 1976 for the former USSR). The Convention's applicability extends to all marine spaces except internal salt waters [2].

According to the London Convention, signatories assumed the obligations of taking all possible steps to prevent pollution of the sea by discharges of wastes and other materials that could present a danger to human health or damage living resources and life in the sea (Art. 1). The dumping of high-level RW is prohibited (Art. IV). The disposal of low- and intermediate-level RW is allowed by special permission with notice to the Secretariat of the International Primorsky Organization, provided an observer from a competent international organization is present aboard the ship performing the disposal operations and three main IAEA requirements [3] are observed:

- the location of the disposal sites is beyond the limits of the continental shelf, internal and marginal seas;

- depths in the disposal area are at least 4,000 meters;

- the latitude is between $50^{\circ} \mathrm{N}$ and $50^{\circ} \mathrm{S}$.

As Fig. 1 shows, the Russian Federation has water areas that meet these requirements only in its far eastern seas.

The provisions of the London Convention (Art. 7) do not apply to ships and planes enjoying sovereign immunity (that is, belonging to a state), but reports required by the IAEA on dumpings must cover all RW discharges regardless of the departmental subordination of the originating source.

Since the London Convention took effect, 15 consultative conferences of representatives of the signatories have been held.

In 1983, the 7th Consultative Conference of Representatives adopted resolution LDC.14[7] [4], urging parties to refrain from disposal of all forms of RW at sea. Two years later, Resolution LDC.21[9] was adopted in a roll-call vote [4], favoring a voluntary moratorium on the disposal of all forms of RW at sea until the completion of an assessment of all aspects of their impact on human health, the marine environment and life in the sea. The USSR abstained in the voting on this resolution. ${ }^{3}$

3-The USSR's official position, as announced by the Soviet delegation to the 9th Consultative Conference of Signatories to the London Convention in 1985 [5] in a discussion of the moratorium question, was essentially that the USSR had not dumped, was not dumping, and did not plan to dump ndioactive waste in the sea for purposes of disposal, and therefore a 'zero report' was sent to the DMO Secretariat. This position was confirmed in 1989 when the IAEA's circular questionnaire was completed [6]. 
Figure 1. Map of the Location of Water Areas of the World's Oceans Complying with LAEA Requirements for Disposal of Low- and Intermediate-Level Radioactive Wastes (between $50^{\circ} \mathrm{N}$ and $50^{\circ} \mathrm{S}$, outside the continental shelf, at

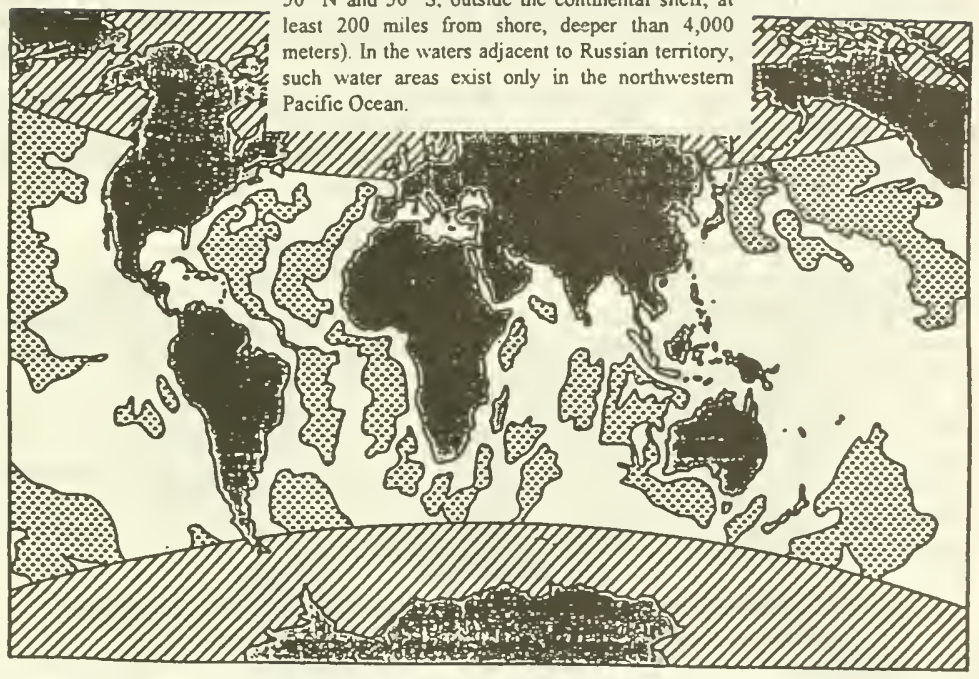

The 14th Consultative Conference (1991) demanded that the USSR furnish information on past dumpings.

In the course of the 15th Consultative Conference (1992), this demand was made in a stronger form, and augmented with a recommendation that Russia furnish information on RW disposal to the IAEA and the IMO Secretariat for inclusion in official international documents and use to complete the work of IGPRAD.

The UN Conference on Environment and Development in Rio de Janeiro (June 1992), with Russia participating, unanimously adopted the main program document, Agenda for the 21st Century, which proposed a transition from the "voluntary moratorium on the disposal of low-level radioactive waste at sea currently in effect" to a ban on the practice, taking account of the "preliminary approach for purposes of adopting a valid and timely solution to this problem" (Para. $22.5 \mathrm{c}$ ). It also proposed not to encourage or permit storage or disposal of RW "near the marine environment" without a preliminary assessment of the acceptability of the risk arising from the practice (Para. 22.5c).

Among regional multilateral agreements related to the problems of RW disposal at sea, we must note the Convention on the Protection of the Marine Environment of the Baltic Sea Region (Helsinki, 1992) [7], which requires parties to prevent and reduce pollution of this maritime re- 
gion by hazardous substances, including RW.

The Convention on the Protection of the Marine Environment of the Northeastern Allantic (Paris, 1992) [8], signed by Belgium, Great Britain, Germany, Denmark, Iceland, Ireland, Spain, the Netherlands, Norway, Portugal, and Sweden, imposes a ban on the dumping of RW in the sea (Art. 3, Para. 3a, Appendix II). However, Para. 3b of the same Appendix contains a stipulation granting Great Britain and France the opportunity to reduce $R W$ dumping in the sea through 2018.4

The Convention on the Protection of the Black Sea from Pollution (Bucharest, 1992) [9], signed by all Black Sea nations, including the Russian Federation, unconditionally bans the disposal of RW in the basin (Art. X and the special Protocol on the Protection of the Black Sea from Pollution Caused by the Disposal of Radioactive Waste in the Sea).

\subsection{Current Practice in Radioactive Waste Disposal at Sea by Countries Using Nuclear Power Technologies}

The major areas of disposal of solid radioactive waste (SRW) in the world's oceans are shown in Fig. 2. The first disposal of RW at sea was carried out in 1946 by the U.S. in the northeastern Pacific Ocean at a distance of about $80 \mathrm{~km}$ from the California coast.

The dumping of low-level SRW at sea began practically simultaneously with the wide development of nuclear power and industry. Dumpings were initiated by Great Britain in 1949, Japan in 1955, the Netherlands in 1965, and so on. By 1983, 1 countries (Table 1) were practicing the dumping of SRW in the open sea. The last officially recorded disposal of RW at sea (not counting dumpings by the USSR and Russia-see Section 3) was in 1982, in an area of the Atlantic $550 \mathrm{~km}$ from the boundary of the European continental shelf.

Table 1. Characteristics of Radioactive Wastes Dumped in the World's Oceans by Various Countries (omitting data for the USSR and Russia) [10]*

\begin{tabular}{|c|c|c|c|}
\hline Country & Amt. Dumped (TBq) & Percentage [of Total] & Years \\
\hline \multicolumn{4}{|c|}{ Allantic Ocean } \\
\hline Belgium & 2120 & 4.63 & $1960-1982$ \\
\hline Great Britain & 35077 & 76.55 & $1949-1982$ \\
\hline Germany & 0.20 & 0.0004 & $1967 ?$ \\
\hline Italy & 0.19 & 0.0004 & $?$ \\
\hline Netherlands & 336.1 & 0.73 & $1967-1982$ \\
\hline United States & 2942 & 6.42 & $1949-1967$ \\
\hline France & 353.4 & 0.77 & $1967-1969$ \\
\hline Switzerland & 4419 & 9.64 & $1969-1982$ \\
\hline Sweden & 3.23 & 0.01 & 1963 \\
\hline Total & 45252.5 & 98.76 & \\
\hline
\end{tabular}

- -Neglecting waste water from nuciear fuel processing plants, lost nuclear warheads, and other sources of ionizing radiation, sunken nuclear submarines, and radionuclides that have entered the ocean as a result of underwater nuclear explosions.

4-If the Russian Federation signs this Convention, our obligations would concern part of the Barents Sea and all of the White Sea. 
Table 1 (continued)

\begin{tabular}{|c|c|c|c|}
\hline Country & Amt. Dumped (TBq) & Percentage [of Total] & Years \\
\hline \multicolumn{4}{|c|}{ Pacific Ocean } \\
\hline Korea & not determined & & $?$ \\
\hline New Zealand & 1.04 & 0.02 & $?$ \\
\hline United States & 5542 & 1.21 & $1946-1970$ \\
\hline Japan & 15.44 & 0.03 & $1955-1969$ \\
\hline Total & 570.7 & 1.24 & \\
\hline
\end{tabular}

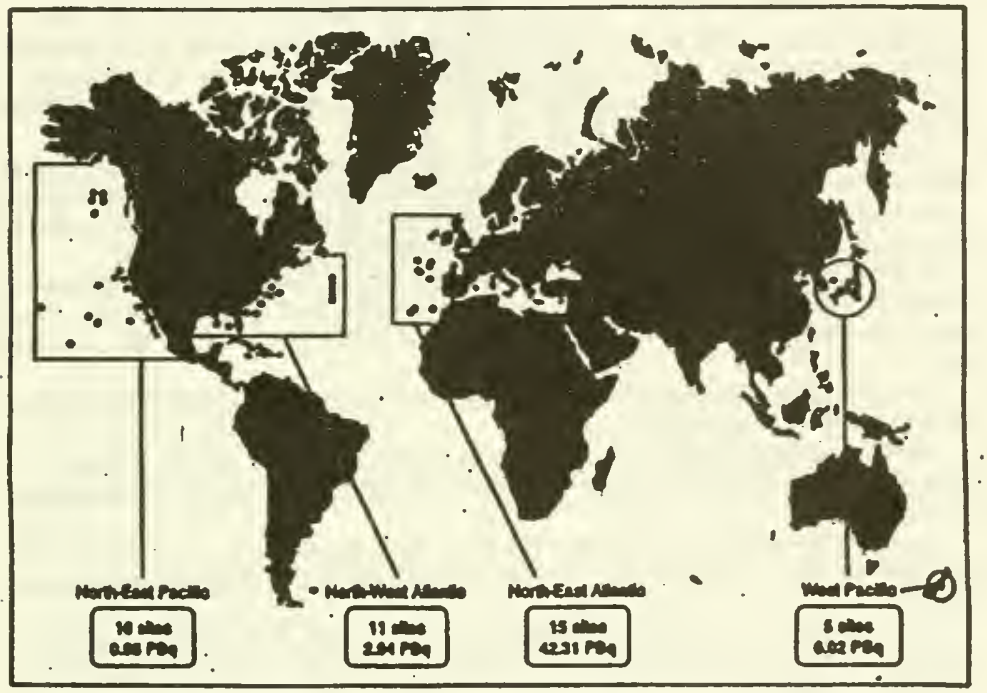

Figure 2. Location of Areas Used by Foreign Countries for Radioactive Waste Disposal at Sea [11]

According to IAEA data [10], dumpings of SRW in the world's oceans (neglecting the USSR and Russia) are characterized by the following data: ${ }^{5}$
Pacific Ocean
northeastern part
$0.55 \mathrm{PBq}(14.9 \mathrm{kCi})$
western part
$0.02 \mathrm{PBq} \quad(0.5 \mathrm{kCi})$

\footnotetext{
3-Neglecting lost nuclear warheads and other sources of ionizing radiation, sunken nuclear submarines and radionuclides that have entered the ocean as a result of underwater nuclear explosions.
} 


\title{
554
}

\author{
Atlanic Ocean \\ northwestern part $\quad 2.94 \mathrm{PBq}(79.4 \mathrm{kCi})$ \\ northeastern part $\quad 42.3 \mathrm{PBq}(1143.0 \mathrm{kCi})$
}

Thus, for the period from 1946 to 1982, according to IAEA data, RW with a total activity of about $46 \mathrm{PBq}$ (1.24 MCi) has been dumped the world's oceans (not counting dumpings by the USSR and Russia, which have not been reported either to the IAEA or to other international organizations to this day, and neglecting the sea dumping of liquid radioactive waste [LRW] from nuclear fuel processing plants; cf. Fig. 2).

\subsubsection{Data on Radioactive Waste Disposal at Sea by Selected Countries}

Belgium. Between 1960 and 1982, Belgium (along with Great Britain) dumped low-level RW in the North Atlantic, Bay of Biscay and English Channel. There were a total of 15 dumpings at six sites. The 55,324 containers (weighing a total of 23,100 tonnes) contained a total of $2.12 \mathrm{PBq}$ $(57.24 \mathrm{kCi})$

Great Britain, which has dumped three-quarters of all RW at sea, conducted 34 dumpings of SRW between 1949 and 1982 at 15 sites in the North Atlantic, English Channel, and Bay of Biscay and off the Canary Islands. The weight of the containers (their number has not been officially reported) was 75,052 tonnes, and they contained a total activity of $35.1 \mathrm{PBq}(949 \mathrm{kCi})$.

It should be added that Great Britain has widely practiced the disposal of LRW from enterprises in the nuclear industry by discharge through pipelines into the Irish Sea. Fig. 3 shows total annual discharges for ${ }^{137} \mathrm{Cs}$ and tritium between 1970 and 1988 from one nuclear fuel processing plant.

The scale of the dumpings was so great (on the order of $1 \mathrm{MCi}$ ) that their effect could be traced to the Barents and Kara Seas.

Germany conducted one RW disposal operation in 1967 in the North Atlantic. It dumped 480 containers weighing 185 tonnes with a total activity of $203 \mathrm{GBq}(0.0055 \mathrm{kCi})$ at a minimum depth of 2,500 meters.

Korea performed dumpings between 1968 and 1972 at one site in the Sea of Japan. In all, 115 containers with a combined weight of 45 tonnes were dumped. No official data on activity are available.

Italy performed one RW dumping operation at one site in the North Atlantic at a depth of about 4,000 meters in 1969. It dumped 100 containers weighing 44.7 tonnes with a total activity of $185 \mathrm{GBq}(0.005 \mathrm{kCi})$.

The Netherlands carried out 14 dumpings between 1967 and 1982 at four sites in the North Atlantic at a depth of $3,200-5,200$ meters. The dumpings were made in 28,428 containers (weighing 19,162 tonnes) with a total activity of $336,000 \mathrm{GBq}(9.08 \mathrm{kCi})$.

New Zealand performed 11 dumpings between 1954 and 1976 at four sites in southern Cook Inlet. Thirty-nine $\mathrm{RW}$ containers with a total activity of $1,040 \mathrm{GBq}(0.028 \mathrm{kCi})$ were dumped.

France has performed two RW dumpings at sea (in 1967 and 1969) at two disposal sites in the Atlantic Ocean at depths of 4,000-5,300 ineters. It sank 46,396 containers of RW (total weight 14,299 tonnes) with a total activity of $353,000 \mathrm{GBq}(9.54 \mathrm{kCi})$. In 1979, discharges from French nuclear enterprises into the English Channel amounted to $920 \mathrm{GBq}$ of plutonium [11].

Switzerland performed 12 RW dumpings between 1969 and 1982 at three sites in the North Atlantic at depths of 3,600 to 4,700 meters. It dumped 7,420 containers weighing 5,321 tonnes with a total activity of $4.42 \mathrm{PBq}(119 \mathrm{kCi})$. 


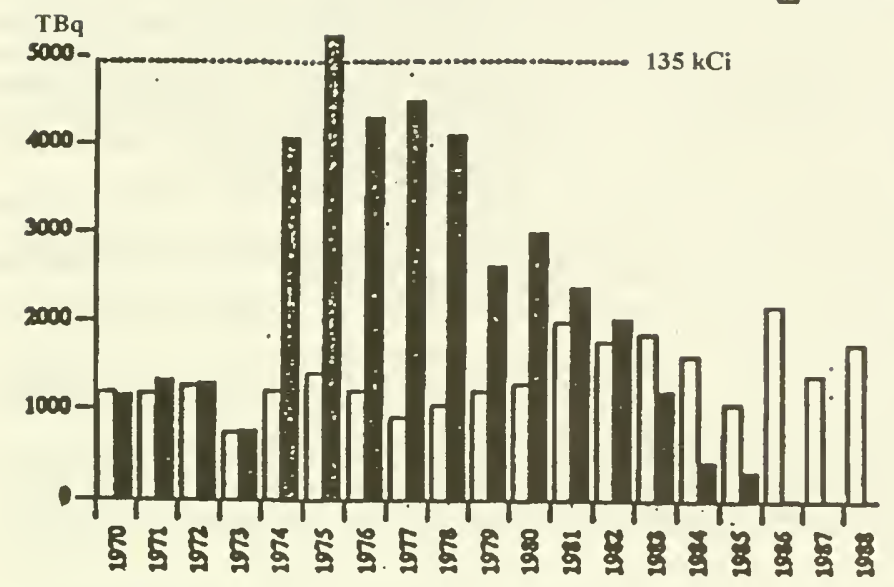

Figure 3. Total Activity of Liquid Radioaclive Waste ( ${ }^{137} \mathrm{Cs}$ and tritium) Dumped in the Irish Sea from the Sellafield plant (Great Brilain), by Year [11].

Sweden performed one RW dumping in 1969 at a single site in the North Atlantic at a depth of 4,000 meters. It dumped 2,895 containers weighing 1,080 tonnes with a total activity of 3,240 $\mathrm{GBq}(0.09 \mathrm{kCi})$.

The U.S. dumped 34,282 containers (weight not specified) with a total activity of $2.94 \mathrm{PBq}$ (79.4 kCi) (some of them at a minimum depth as low as 11 meters!) between 1949 and 1967 at 11 sites in the Atlantic (the number of operations has not been reported).

Between 1946 and 1970, the U.S. performed dumpings (number of operations not specified) of 560,261 containers (weight not specified) with a total activity of $554,000 \mathrm{GBq}(15.0 \mathrm{pCi})$ at 18 sites in the Pacific Ocean at a minimum depth of 896 meters.

According to some data [12], RW dumpings by the U.S. in the northeastern Atlantic exceed the amounts specified in official reports. In at least one case in 1957, the U.S. Navy sank radioactive materials in the open sea.

In 1960 alone, the total activity of wastes dumped by the U.S. along the California coașt was about $1 \mathrm{PBq}(27 \mathrm{kCi})$. Almost as much was dumped in the waters of the Atlantic Ocean [15].

During the era of the nuclear submarine fleet (i.e., since the mid-50s), the U.S. Navy has lost two NS's: the Thresher in April 1969, and the Scorpion in May 1968. Both submarines sank after accidents in areas of heavy maritime shipping and active fishing. Besides its reactor, the Scorpion carried two Astor nuclear torpedoes, according to expert opinions [14]. About $270 \mathrm{kCi}$ (10 PBq) of fission products was deposited at the site of the Thresher's sinking on the bottom of the Atlan- 
tic Ocean [12].

Earlier, in 1959, the U.S. Navy sank the compartment of the nuclear submarine Sea Wolf's reactor, which had performed unsatisfactorily, 120 miles from the U.S. Atlantic coast.

The foreign press has reported that nuclear warheads (NWH's) have been lost at sea aboard an A-4 Skyhawk attack plane that fell off an aircraft carrier into the Pacific Ocean in December 1965, as well as those installed on two Thor missiles during unsuccessful launches from Johnston Atoll in 1962. In March 1956, the U.S. Air Force lost a bomber over the Mediterranean Sea carrying radioactive components for nuclear weapons, and in January 1966, a U.S. plane lost 4 hydrogen bombs, which fell into the Mediterranean near Palomares, Spain [14].

An incident with a U.S. NS in February 1980 off the coast of Scotland resulted in a discharge of radioactive materials from a reactor cooling system [14]

Since 1977, the U.S. Environmental Protection Agency has performed radiological studies at RW disposal sites in the northwestern Atlantic and in the Pacific [15].

In a number of cases, high levels of cesium and plutonium have been found in the immediate neighborhood of dumped containers [13].

Japan dumped RW in the Pacific near its coast between 1956 and 1969 . It performed 12 dumping operations at six sites. It dumped 3,031 containers (weight not specified), with a volume of $606,200 \mathrm{~m}^{3}$, containing a total of $15,400 \mathrm{GBq}(0.416 \mathrm{kCi})$ of activity.

Analysis of all available information shows that official data furnished by 12 countries to the IAEA [10] do not give a complete picture of RW dumpings at sea, especially after 1989. There is little information on radionuclides that have entered the marine environment due to accidents and disasters.

\subsection{Positions of Various Nations on Matters of Radioactive Waste Disposal at Sea}

The problem of RW disposal in the world's ocears is being actively debated in the U.S. In 1992, the U.S. Senate Intelligence Committee conducted public hearings on the matter, during which the possibility of activating international cooperation in the interests of reducing possible dangerous consequences of such dumpings was discussed [16].

Most nations favor a ban on the disposal of all forms of RW at sea, considering the growing concern in the world and in certain countries over contamination of the marine environment by RW. This was the aim of a Danish initiative calling for a total ban on RW disposal at sea, and of the idea, first advanced in 1983 within the framework of the London Convention, of a moratorium on RW dumping at sea [4]. A resolution adopted at the time urged a refrain from disposal of all forms and types of RW at sea until IGPRAD completes its work. As a result, the moratorium was extended until the 16th Consultative Conference of signatories of the London Convention, which is to be held in November 1993, with the understanding that by then IGPRAD will have completed its assessment and offered recommendations for disposal of intermediate- and low-level RW at sea (the USSR abstained from the vote on the moratorium resolution in 1985, and Russia has not expressed a position on the matter).

The U.S., France, Great Britain, and Japan take a special position on matters of RW disposal at sea: they do not reject the idea of a moratorium per se, but insist on a transition period, during which all questions of the handling, recycling, storage and land disposal of RW could be resolved.

In answwering the IAEA 1989 questionnaire, Belgium, Great Britain and Nauru have not given a clear response on whether they plan to dispose of RW at sea in the future. Germany, Greece, Italy, Canada, China, Mexico, Nauru, the Netherlands, the USSR, the U.S., and Finland stated at 
the time that they considered RW disposal at sea still an open question. Canada reserved the right to sea disposal of RW produced in the decontamination of contaminated soils, as did France for tritium [10].

China has taken a more and more active position on these matters recently.

The UN Conference on Environment and Development endorsed an initiative by Denmark, Iceland and Norway in favor of adopting a recommendation prohibiting RW disposal at sea. The recommendation [17], adopted by a consensus of some 150 nations (including Russia), will be reflected more and more strongly in the positions of many nations.

\subsection{Conclusion}

RW dumping at sea is strictly regulated by international law, primarily the 1972 Convention on Prevention of Pollution of the Sea by Discharges of Wastes and Other Materials (the London Convention), as well as special IAEA regulations and standards.

According to official IAEA data, the current practice of RW disposal and location in countries that use nuclear technologies meets international legal requirements in most cases (although, according to unofficial data, some countries are violating them).

In 1992, the UN Conference on Environment and Development in Rio de Janeiro favored ending the practice of RW disposal at sea. The same year, the Conventions on the Protection of the Marine Environment of the Baltic Sea Region and on the Protection of the Black Sea from Pollution were signed (with Russia signing), as was the Convention on the Protection of the Marine Environment of the Northeastern Atlantic (which the Russian Federation has not yet signed). The latter (Paris) Convention grants Great Britain and France the opportunity for staged reduction of RW discharges into the sea through 2018 , that is, it offers a solution that meets Russia's interests and capabilities. 


\section{Section 2. Radioactive IVASTe Disposal in Seas Adjacent to THE TERRITORY OF THE RUSSIAN FEDERATION}

The nuclear arms race and the development of nuclear power have raised the problem of handling large quantities of RW, whose solution has never received special attention. This has caused significant contamination of the territories of nuclear power enterprises and the environment.

The USSR's creation of a nuclear-powered icebreaker fleet and deployment of a fleet of NS's have forced it to find disposal sites for the RW produced.

In the atmosphere of the cold war, this problem was not given priority, and the simplest solution was to dispose of RW directly in the sea, which was practiced widely by most countries with developed nuclear industries.

After the London Convention took effect, the USSR took a series of steps aimed at complying with international standards and the obligations it had assumed in this area. In 1979, the Council of Ministers adopted Resolution 222, Measures to Ensure Performance of the Soviet Side's Obligations Following from the 1972 Convention on the Prevention of Pollution of the Sea by Discharges of Wastes and Other Materials.

RW discharges from facilities of the Murmansk Marine Shipping Line were gradually reduced and then completely halted. However, steps to halt RW discharges from Naval facilities were not taken. The reasons were the inefficient system of handling RW in the country as a whole, the Navy's lack of RW processing equipment, the insufficient capacity of shore storage facilities, and the USSR Ministry of Foreign Affairs' mishandling of the concept "immunity of warships," which allowed it to regard RW discharges from Naval vessels as not violations of the requirements of the London Convention.

\subsection{Normative Documents That Regulated Radioactive Waste Disposal at Sea in the USSR}

The first normative document in this area was the 1960 Temporary Sanitary Requirements for Discharge of Liquid Wastes Containing Long-Lived Radioactive Substances into the Sea from Naval.Facilities. It was prepared by the Navy in concert with the USSR Ministry of Medium Machine-Building and the Third Main Administration of the USSR Ministry of Public Health, and was predicated on ensuring that discharges of RW into the sea complied with sanitary and hygienic standards existing at the time.

In 1962, a new version of the Requirements appeared. It regulated the amount of LRW that could be discharged in terms of volume (not over $1,000 \mathrm{~m}^{3}$ ), volumetric activity (not over 50 $\mu \mathrm{Ci} /(1850 \mathrm{kBq} /)$, for shor-lived isotopes and not over $10 \mu \mathrm{Ci} /(370 \mathrm{kBq} /)$, for short-lived isotopes), and total activity (not over $10 \mathrm{Ci}$ ). It stipulated that ships be outfitted with equipment to dilute RW by at least $250 \%$ during dumping. Direct discharges of RW from NS's were permitted only in case of emergency.

In 1965, the Navy implemented new regulatory measures permitting the dumping of LRW from NS's outside the 10-mile limit, discharge of secondary-loop water and waste water with an activity of less than $10 \mathrm{nCil}(370 \mathrm{~Bq} / \mathrm{l})$. These measures also provided for the possibility of disposing of SRW in metal containers without special shielding, and large pieces of waste without containers. The Northern and Pacific Fleet Commands were charged with selecting areas for dis- 
posal of SRW. Thus, the Navy attempted to solve problems falling beyond the scope of its departmental authority, by making decisions with long-term consequences that threatened the ecological state of large areas of the country and areas under international jurisdiction without coordination with state governing bodies.

A more detailed regulation on the disposal of RW at sea was adopted in 1966 with the implementation of the Temporary Sanitary Requirements for Disposal of Radioactive Wastes at Sea (VSTZ-66), approved by the Navy and the USSR Ministry of Public Health.

VSTZ-66 applied to all facilities where NS's were based, refueled or repaired, as well as ship repair and shipbuilding yards. VSTZ-66 contained requirements for RW discharge and disposal areas, standards for the discharge of LRW and disposal of SRW, procedures for preparation and transportation of $\mathrm{RW}$, and instructions on the conduct of radiation hygiene monitoring at disposal sites. VSTZ-66 largely conformed to generally accepted standards, but again, since it applied to the open sea, it should have been approved by the Government instead of an individual department.

The selection of areas of the sea for discharge of LRW and disposal of SRW was made by the headquarters of the Northern and Pacific Fleets and approved by the Navy General Staff in 19661967. Until 1986, areas allocated to the Northem Fleet also received RW dumped by the USSK Ministry of the Merchant Marine's Murmansk Maritime Shipping Line. The areas selected are shown in Fig. 4.

The procedures defined by VSTZ-66 for RW disposal at sea remained in effect until 1983. When the USSR signed the 1972 London Convention and became subject to it on January 29 , 1976 , it was forced to review standards and fulfill the obligations it had assumed.

On March 6, 1979, the USSR Council of Ministers adopted a resolution [18] prohibiting the intentional discharge for purposes of disposal at sea of RW and other radioactive substances with high levels of radiation whose discharge at sea was deemed unacceptable for biological and other reasons from Soviet ships and other surface vessels, aircraft, platforms, and other structures artificially constructed at sea. As for RW and other radioactive materials that do not fall into the above classifications, their discharge was permitted by special approval of the USSR State Committee for Hydrometeorology (Goskomgidromet), in coordination with the USSR Ministry of Fisheries.

Under the resolution, Goskomgidromet was charged with the following tasks:

- recording the characteristics and quantity of RW and other materials approved for dumping;

- recording the site, time, and method of dumping;

- observing the condition of the sea in conformity with the aims of the London Convention;

- transmitting information on dumpings performed to the International Maritime Organization in its role as Convention Secretariat (and to other Convention signatories).

The Navy developed, coordinated with Goskomgidromet, and approved Regulations for Discharge of Radioactive Waste at Sea (PS-82), and implemented it starting in 1983.

The USSR performed the majority of its RW dumpings at sea between 1959 and 1976, i.e., before the London Convention applied to the USSR. After signing the Convention, it violated the requirements, including its own $P S-82$, consciously and frequently.

These Regulations did not require selection of disposal sites beyond the continental shelf, in- 
ternal and marginal seas, contained no prohibition on disposal at high latitudes (above $50^{\circ} \mathrm{N}$ ), and did not stipulate regular notification of the disposal of RW at sea using the form prescribed by the IMO and IAEA, as required by the London Convention.

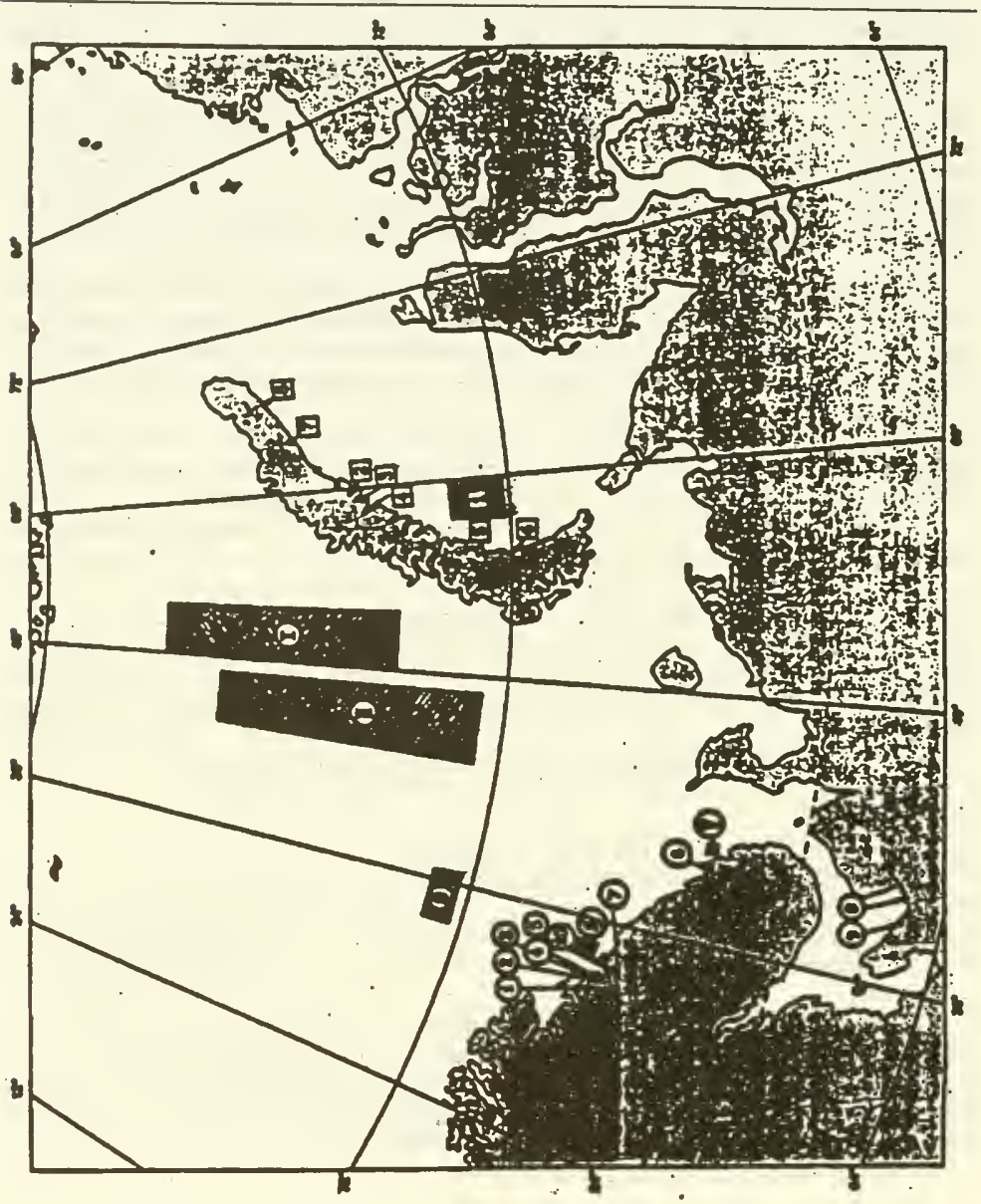


In agreeing to PS-82, Goskomgidromet assumed that the Navy was planning to commission RW handling facilities by 1986 , and it scheduled a review of the Regulations for 1986-1987 in accordance with the recommendations of the IAEA and London Convention $[2,3,4]$. However, no RW handling facilities had been built, and the Navy was forced to continue dumping RW at sea. In 1985, Goskomgidromet refused to agree to the Navy's proposed disposal areas in the northern seas, some of which were on the eastern coast of the Novaya Zemlya archipelago. In view of the continued dumping of RW at sea, Goskomgidromet withdrew its consent to PS-82 effective December 1, 1987. From then on, approvals to dump RW at sea were issued by Navy Headquarters.

In February 1992, the Commander-in-Chief of the Navy submitted a request to the Government of the Russian Federation for a temporary extension of the Navy's existing procedures for dumping RW at sea. In accordance with Instruction No. A-2-611 of the Government of the Russian Federation, the Russian State Nuclear Power Supervisory Administration (Gosatomnadzor) reviewed the request and recommended that the Navy obtain an opinion from scientific institutions and interested ministries. According to the opinions of the Russian Ministry of Nature, Ministry of Foreign Affairs, and the Scientific Commission for Radiation Protection, decisions on matters of RW disposal at sea should be guided by international standards, which effectively meant prohibiting dumping at sea.

In violation of the requirements of the London Convention and the USSR Council of Ministers resolution [18], Goskomgidromet did not furnish information on RW disposal at sea to the IMO and IAEA. Moreover, in its answers to the London Convention's questionnaire in 1989, it declared that "the USSR has not dumped, is not dumping, and does not plan to dump radioactive waste at sea" [6].

It is especially important to dwell on the normative documents relating to the disposal of high-level RW. Such dumpings are completely prohibited by the London Convention and existing national regulations, but the USSR made them from 1965 onward under ad hoc decisions of the USSR State Committee for Shipbuilding, the USSR State Committee for the Use of Atomic Energy, and the Navy on individual projects developed earlier by scientific research institutes (in particular, the Russian Ministry of Atomic Energy's Scientific Research and Engineering Institute of Power Technology).

Beginning in 1987, the dumping of RW at sea by the USSR was doubly unlawful:

- first, normative documents approved by the USSR contained requirements for disposal of RW at sea that did not conform to the requirements of international standards recognized by the USSR;

- second, even these normative documents approved by the USSR were violated (RW was dumped without coordination with environmental bodies and without appro-

\&Figure 4. Location of Major Radioactive Waste Sources and Disposal Areas in Northern Seas [14]. Northern Fleet Bases: 1-Nerpichya Bay; 2-Andreyev, Bolshaya Lopatka and Malaya Lopatka Bays; 3-Olenya and Sayda Bays; +-Ara Bay; 5-Pala Bay; 6-Yokanga. Holding and Recycling Sites for Decommissioned Nuclear-Powered Naval Vessels and Ships: 4-Polyarny; 6-Yokanga; 7-Murmansk (Nuclear Fleet Radio Regiment); 8-Severodvinsk (water area of Zvẽzdochka Shipyard, North Production Association). Temporary Storage Sites for Spent Nuclear Fuel: 1-Andreyev Bay; 6-Yokanga; 7-Mother ships Imandra, Lepse, and Lotta; 2-Navy tender for refueling reactors of NS's. Shipyards: 8-Severodvinsk (Northern Machinery Enterprise Production Association, North Production Association); 4-Polyarmy (Naval shipyard); 4-Vyuzhny (Nerpa Shipyard). Not shown on map: Saint Petersburg (Baltic Yard Production Association, Admiralty Production Association), Nizhniy Novgorod (Krasnoye Sormovo Production Association). I, V: LRW dumping sites. I, VIII (boxed): SRW disposal areas. 
priate extradepartmental government monitoring and supervision of nuclear safety in the handling of $\mathrm{RW}$ ).

Thus, the information presented in this section of the report on normative acts regulating RW disposal procedures in northern and far eastern seas shows that the USSR violated international agreements in this area either completely or partially. The discrepancy between the USSR's actions and obligations under the London Convention, as stated more than once at closed interdepartmental conferences held between 1983 and 1990 by Goskomgidromet and the USSR State Committee for Nature, was not corrected at the level of the USSR Government.

The legal side of all the departmental standards, regulations, and methodological instructions permitting RW disposal at sea (in nonobservance of provisions of the London Convention binding upon the USSR) requires special assessment from the legal standpoint.

\subsection{Russian Federation Law on Radioactive Waste Disposal at Sea}

With the Russian Federation's assumption of the obligations of the USSR in the area of observance of international accords and agreements, the London Convention came to apply to Russia in full measure, and therefore, the disposal of RW at sea must be governed by generally accepted international standards.

The regulations for disposal of RW at sea that the Navy follows, and the areas where such dumping has been conducted in the north and (partly) the far east are in sharp contradiction with the London Convention, which invalidates all departmental instructions and regulations for Russia.

This opinion is completely confirmed by the Russian Federation Law, Protection of the Natural Environment (December 1991), Art. 50 of which, Ecological Requirements in the Use of Radioactive Materials, provides:

"50.3. The import of radioactive waste and materials from other nations for storage or disposal purposes, and the sinking or sending into space of radioactive waste and materials for disposal purposes, is prohibited" [20].

Thus, this Law not only prohibits the disposal of RW in the territorial waters of the Russian Federation, it prohibits any disposal of RW produced on Russian territory in any sea.

\subsection{Total Volume and Characteristics of Radioactive Waste Dumped at Sea by the USSR between 1959 and 1991}

The first dumpings of RW in the USSR were connected with the run testing of NS's and the nuclear icebreaker Lenin. In $1959,600 \mathrm{~m}^{3}$ of low-level waste $(20 \mathrm{mCi})$ was discharged in the White Sea, and in 1960, the Lemin discharged $100 \mathrm{~m}^{3}$ of LRW (total activity $200 \mathrm{mCi}$ ) near Gogland Island in the Gulf of Finland.

The practice of regularly dumping LRW began in 1960, and the disposal of SRW in northern and far eastern seas began in 1964.

\subsubsection{Disposal Sites, Volumes, and Total Activity of Radioactive Waste Dumped by the USSR in Northern Seas}

This section reviews the situation with LRW discharges and the disposal of low-, intermediate-, and high-level SRW at sea.

The data presented on the activity of sea-dumped SRW (excluding reactor components and 
actual reactors with spent nuclear fuel [SNF]) require the following clarification:

Information in original sources used by the Commission on the aclivity of SRW is presented as "activity ( ${ }^{\circ 0} \mathrm{Sr}$ equivalent), curies." This artificial characteristic was recommended for practical use in the departmental methodology Regulations for Discharge of Radioactive Wastes at Sea (PS-82) and is designed for generalized description of various amounts of SRW (for example, a container) as a source of radiation at the time of disposal. Numerical values of "activity ( ${ }^{90} \mathrm{Sr}$ equivalent)" were establisbed on the basis of measurements of the dose power near the SRW mass using a simple empirical dependence, accounting for a priori knowledge of the radionuclide content of the SRW mass.

Information on the activity of LRW is presented in the customary form "activity, euries," which simplifies quantitative comparison with discharges made by other countries, which cannot be said of SRW when the form "activity ("0) Sr equivalent), curies" is used.

An assessment of the radioecological consequences of dumping of both solid and liquid RW on the basis of the data presented in the Appendix is rather problematic due to the lack in various cases of detailed information on the radionuclide composition of wastes and the shielding properties of the containers or tanks. In this sense, work on a more detailed description of SRW dumpings and LRW discharges must be continued.

It must be noted that the summary results (for years, districts, etc.) presented in the tables in the Appendix have no physical meaning, and therefore cannot be used in scientific research, although they do have a certain illustrative meaning. Moreover, the lack of information on radionuelide content prevents calculation of the activity at a given moment in time after disposal.

Nevertheless, on the basis of the information presented in the Appendix, a relative comparison can be made both for solid and for liquid RW of the amount of RW dumped in various areas of the northern and far eastern seas, and a comparison can also be made with analogous data for other countries. -P. M. Rubtsov

The geographic location of the five officially designated areas for dumping of LRW in northem seas was shown in Fig. 4. Characteristics of these areas are presented in Table Al of the Appendix. As noted in the previous section, these areas were selected in 1960-1966 by the Northern Fleet Headquarters and approved by the Navy General Command.

Detailed information on LRW dumping in northern seas is given in Table A2 of the Appendix. A small portion of the dumping was conducted outside the designated areas. Information on the rate of dumping of LRW in northern seas is illustrated in Fig. 5.

The data show that according to available data, ${ }^{\prime}$ the total activity of $\mathrm{LRW}$ is $24 \mathrm{kCi}$ (903 TBq), distributed as follows across various seas:
Baltic Sea
$0.2 \mathrm{Ci}$
White Sea
$100 \mathrm{Ci}$
$(0.0007 \mathrm{TBq})$
Barents Sea
$12153 \mathrm{Ci} \quad(450 \mathrm{TBq})$
Kara Sea
$8500 \mathrm{Ci} \quad(315 \mathrm{TBq})$

Liquid RW discharges at sea were extremely irregular (Fig. 5), with the maximum activities of dumped RW occurring:

- in 1965: northeastern Barents Sea, Area 2, about 1,000 Ci (37 TBq);

- in 1975: central Barents Sea, Area 3, over $800 \mathrm{Ci}(29.6 \mathrm{TBq})$, and Kara Sea, 8,500

$\mathrm{Ci}$ (315 TBq) (dumped from the Lenin);

- in 1988: northeastem Barents Sea, Area 1, about 5,300 Ci (196 TBq);

- in 1989: Ara Bay, 2,000 Ci (74 TBq) (result of an accident on an NS).

1-The activity of liquid radiosctive waste that entered [the sea] through leaks from shore stonge facilities and due to accidents on nuclear submarines was not included. 


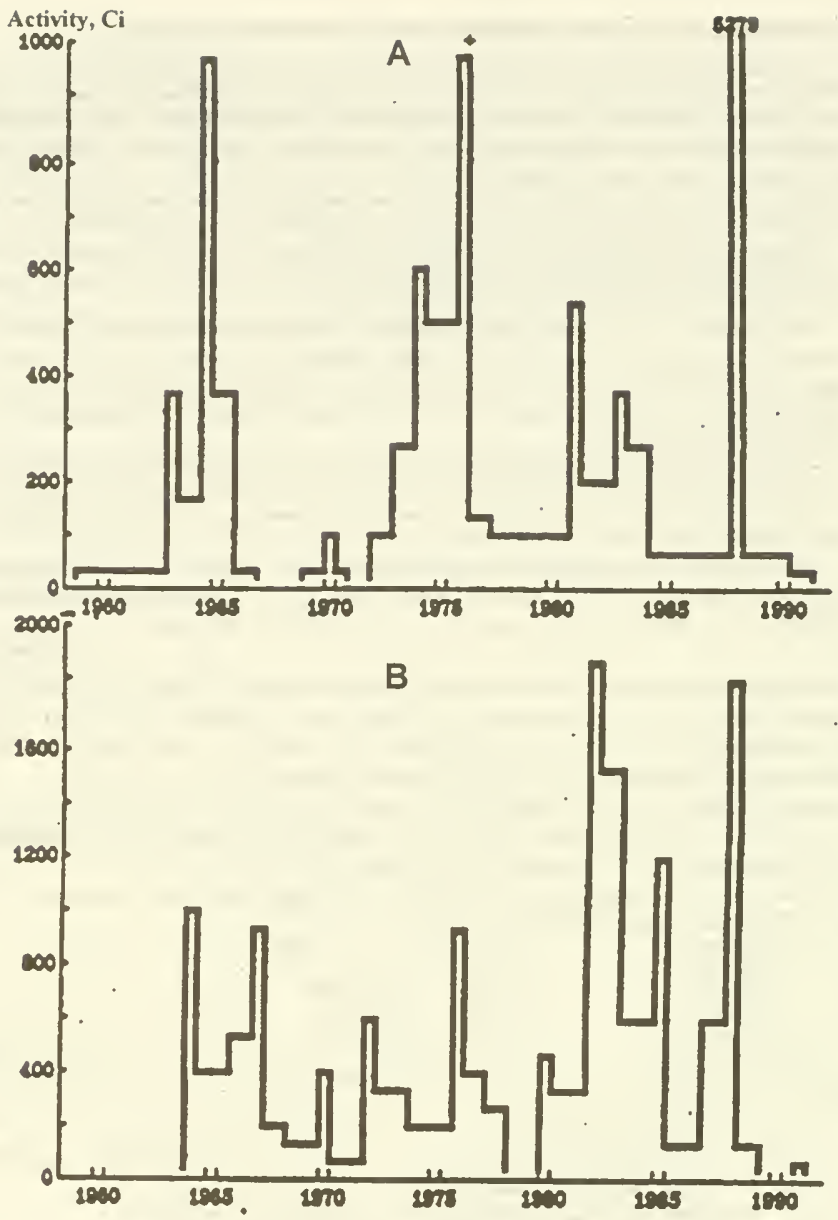

Figure 5. Rate of Radioactive Waste Disposal in Northern Seas by Year.

$A$ : dumping of liquid RW; $B$ : disposal of low- and intermediate-level solid RW. Bar height is proportional to annual dumping activity. 
The Murmansk Maritime Shipping Line halted LRW dumping at sea in 1984, but the Navy continues to this day, although in lesser amounts.

The location of officially designated areas for disposal of SRW in northern seas has been shown in Fig. 4. Characteristics of the main disposal areas are presented in Table A3 of the Appendix. None of these SRW disposal areas complies with a single international requirement for this kind of activity (either in depth, or in distance from shore, or in location on the globe)

In terms of volume, the majority of the SRW dumped in northern seas is low- and intermediate-level RW produced during the operation of Naval nuclear-powered surface vessels and NS's and the nuclear icebreaker fleet, and at the corresponding shipyards. Fig. 4 showed the location of the main sources of SRW in northem Russia.

As a rule, low- and intermediate-level SRW sunk in northern seas was enclosed in metal containers. Large pieces of RW were sunk separately or within specially designated ships-barges, lighters, or tankers (Table A4 in Appendix). This SRW comprised mainly:

- contaminated film coverings, tools, personal protective devices, uniforms, fittings, pipelines, activity filter boxes, pumps, steam generators, and various contaminated objects produced during ship repair work. The total activity of sunken intermediateand low-level SRW, according to available data, was over $15.5 \mathrm{kCi}(574 \mathrm{TBq})$ in the Kara Sea and $40 \mathrm{Ci}(1.5 \mathrm{TBq})$ in the Barents Sea. The most SRW in terms of volume was dumped in the Kara Sea, in Area 1 (Novaya Zemlya Depression), and in terms of total activity, in Area 2 (Sedov Inlet, Novaya Zemlya) (Table A4 of Appendix, Fig. 6, and Table 2).

The largest number of dumpings of low- and intermediate-level SRW was in the years 1967 and 1982, and the greatest activities of SRW dumped was in 1983 and 1988 (see Fig. 5).

Since 1986, the Murmansk Maritime Shipping Line has halted disposal of SRW at sea.

Table 2. Summary Data on Low- and Intermediate-Level Solid Radioactive Waste Dumped in the Kara and Barents Seas

\begin{tabular}{|c|c|c|c|c|c|}
\hline \multirow{2}{*}{$\begin{array}{c}\text { Area } \\
\text { See Fig. 4) }\end{array}$} & \multicolumn{2}{|c|}{ Activity } & $\begin{array}{c}\text { Number of } \\
\text { Dumpings }\end{array}$ & Years & \multicolumn{1}{|c|}{ Remarks } \\
\cline { 2 - 6 } & 3320 & 123 & 22 & $1967-1991$ & $\begin{array}{l}3174+? \mathrm{C}, \\
9 \mathrm{LO}, 8 \mathrm{~V}\end{array}$ \\
\hline 1 & 3410 & 126 & 8 & $1982-1984$ & $1108 \mathrm{C}, 104 \mathrm{LO}$ \\
\hline 2 & 2027 & 75 & 8 & $1968-1983$ & $\begin{array}{l}472+? \mathrm{C}, \\
4 \mathrm{LO}, 1 \mathrm{~V}\end{array}$ \\
\hline 3 & 2684 & 99 & 8 & $1964-1978$ & $\begin{array}{l}1600+? \mathrm{C}, \\
6 \mathrm{LO}, 1 \mathrm{~V}\end{array}$ \\
\hline 4 & 1280 & 47 & 5 & $1968-1975$ & $5 \mathrm{LO}$ \\
\hline 5 & 661 & 25 & 7 & $1966-1981$ & $8+? \mathrm{C}, 7 \mathrm{LO}, 4 \mathrm{~V}$ \\
\hline 6 & 235 & 8 & 1 & 1972 & $1 \mathrm{LO}$ \\
\hline 7 & 1845 & 68 & 3 & $1982-1988$ & $\begin{array}{l}146+? \mathrm{C}, \\
18 \mathrm{LO}, 1 \mathrm{~V}\end{array}$ \\
\hline 8 & 40 & 1.5 & 1 & 1978 & $1 \mathrm{~V}$ \\
\hline $\begin{array}{c}\text { Off Kolguyev } \\
\text { Island }\end{array}$ & & & & & \\
\hline
\end{tabular}

Key to Remarks: $C$-containers; $L O$-large objects; $V$-vessels. 
Table 2 (continued)

\begin{tabular}{|c|c|c|c|c|c|}
\hline \multirow{2}{*}{$\begin{array}{c}\text { Area } \\
\text { (See Fig. 4) }\end{array}$} & \multicolumn{2}{|c|}{ Activity } & \multirow{2}{*}{$\begin{array}{l}\text { Number of } \\
\text { Dumpings }\end{array}$} & \multirow{2}{*}{ Years } & \multirow{2}{*}{ Remarks } \\
\hline & $\mathrm{Ci}$ & $\mathrm{TBq}$ & & & \\
\hline $\begin{array}{c}\text { Chernaya Bay } \\
\text { Novaya Zemlya) }\end{array}$ & 300 & 11 & 1 & 1991 & $1 \mathrm{LO}$ \\
\hline Barents Sea & $>100$ & $>4$ & 1 & $?$ & $\begin{array}{l}\text { Barge with solid } \\
\text { RW in welded hold }\end{array}$ \\
\hline Total & -6000 & $\sim 590$ & 65 & & $\begin{array}{l}6508+? \mathrm{C} \\
155 \mathrm{LO}, 17 \mathrm{~V}\end{array}$ \\
\hline
\end{tabular}

Key to Remarks: $C$-containers; $L O$-large objects; $V$-vessels.

Among all RW dumpings in northern seas, the greatest ecological hazard is presented by sunken objects with SNF, which are a mixture of fission products and actinides. Summary information on these objects is presented in Table 3.

Table 3. Objects with Spent Nuclear Fuel Dumped in Northern Seas

\begin{tabular}{|c|c|c|c|c|c|}
\hline Object & $\begin{array}{l}\text { Coordinates, } \\
\text { Year }\end{array}$ & $\begin{array}{l}\text { Depth, } \\
\text { meters }\end{array}$ & $\begin{array}{c}\text { Total } \\
\text { Activity } \\
\text { (max.). } \mathrm{kCi}\end{array}$ & $\begin{array}{l}\text { Radionuclide } \\
\text { Content }\end{array}$ & $\begin{array}{l}\text { Description of } \\
\text { Protective Barriers }\end{array}$ \\
\hline $\begin{array}{l}\text { Compartment of NS No. } \\
285 \text { with two reactors, } \\
\text { one containing SNF in } \\
\text { place (see also Table } 4 \text { ) }\end{array}$ & $\begin{array}{l}71^{\circ} 56^{\prime \prime} 2^{\prime \prime} \mathrm{N}, \\
55^{\circ} 18^{\prime} 5^{\prime \prime} \mathrm{E} \text {, } \\
\text { Abrosimov } \\
\text { Inlet, } 1965\end{array}$ & 20 & 800 & $\begin{array}{l}\text { Fission } \\
\text { products }\end{array}$ & $\begin{array}{l}\text { Stock reaclor com- } \\
\text { partment and interior } \\
\text { structures filled with } \\
\text { furfurol mixture }\end{array}$ \\
\hline $\begin{array}{l}\text { Comparment with two } \\
\text { reactors containing SNF } \\
\text { from NS No. } 901\end{array}$ & $\begin{array}{l}71^{\circ} 56^{\prime \prime} 2^{\prime \prime} \mathrm{N}, \\
55^{\circ} 18^{\prime} 9^{\prime \prime} \mathrm{E} \text {, } \\
\text { Abrosimov } \\
\text { Inlet. } 1965\end{array}$ & 20 & 400 & $\begin{array}{l}\text { Fission } \\
\text { products }\end{array}$ & Same \\
\hline $\begin{array}{l}\text { Shielding assembly of } \\
\text { reactor from OK-150 } \\
\text { unit of nuclear icebreak- } \\
\text { ef Lenin with residual } \\
\text { SNF ( } 60 \% \text { of fuel } \\
\text { complement based on } \\
\mathrm{UO}_{2} \text { ) }\end{array}$ & $\begin{array}{l}74^{\circ} 22^{\prime} 1^{\prime \prime} \mathrm{N}, \\
58^{\circ} 42^{\prime} 2^{\prime \prime} \mathrm{E}, \\
\text { Tsivolka } \\
\text { Inlet, } 1967\end{array}$ & 49 & 100 & $\begin{array}{l}{ }^{137} \mathrm{Cs}(\sim 50 \\
\mathrm{kCi}),{ }^{90} \mathrm{Sr} \\
(\sim 50 \mathrm{kCi}), \\
{ }^{238} \mathrm{Pu},{ }^{241} \mathrm{Am}, \\
{ }^{244} \mathrm{Cm}(\sim 2 \\
\mathrm{kCi})\end{array}$ & $\begin{array}{l}\text { SNF residue bound } \\
\text { by furfurol-based } \\
\text { mixture, shielding } \\
\text { placed in reinforced } \\
\text { concrete container } \\
\text { and metal shell }\end{array}$ \\
\hline $\begin{array}{l}\text { Reactor from NS No. } \\
421 \text { with SNF }\end{array}$ & $\begin{array}{l}72^{\circ} 40^{\prime} \mathrm{N}, \\
58^{\circ} 10^{\prime} \mathrm{E}, \\
\text { Novaya } \\
\text { Zemlya De- } \\
\text { pression, } \\
1972 \\
\end{array}$ & 300 & 800 & $\begin{array}{l}\text { Fission } \\
\text { products }\end{array}$ & $\begin{array}{l}\text { Metal container with } \\
\text { lead shell dumped } \\
\text { along with barge }\end{array}$ \\
\hline $\begin{array}{l}\text { NS No. } 601 \text { with two re- } \\
\text { actors containing SNF }\end{array}$ & $\begin{array}{l}72^{\circ} 31^{\prime} 15^{\prime \prime} \mathrm{N}, \\
55^{\circ} 30^{\prime} 15^{\prime \prime} \mathrm{E}, \\
\text { Stepovoy } \\
\text { lnlet. } 1981\end{array}$ & 50 & 200 & $\begin{array}{l}\text { Fission prod- } \\
\text { ucts }\end{array}$ & $\begin{array}{l}\text { Stock reactor com- } \\
\text { partment and interior } \\
\text { structures filled with } \\
\text { furfurol mixture }\end{array}$ \\
\hline $\begin{array}{l}\text { Total: } 5 \text { objects with } 7 \\
\text { reactors containing SNF }\end{array}$ & $1965-1981$ & & 2300 & & \\
\hline
\end{tabular}

- Expert estimates were made at the time of sinking, based on power generated by NS reactors (12.5 GW/day), 


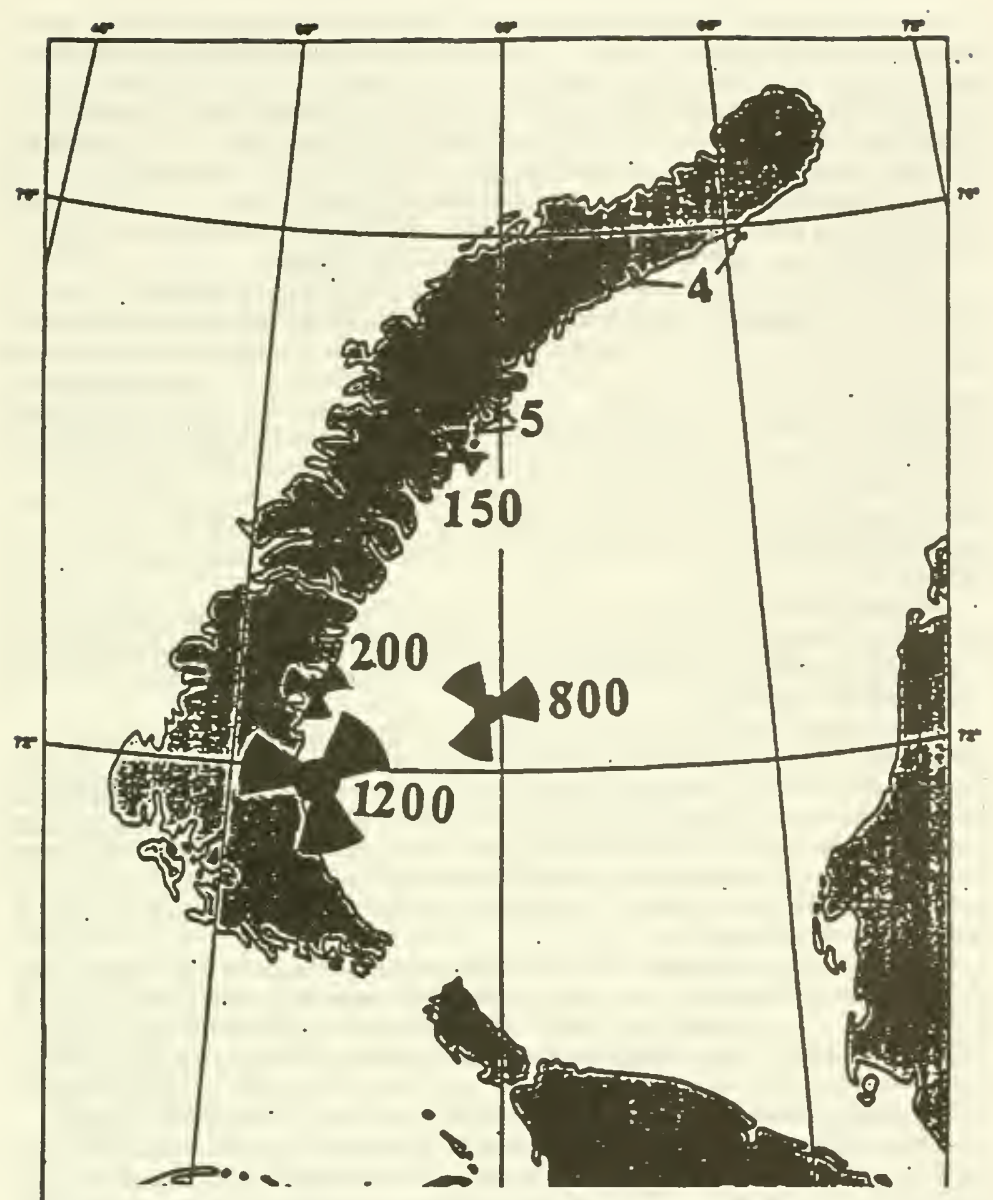

Figure 6. Expert Estimates of Maximum Possible Total Activity (at time of disposal) of All Forms of Solid Radioactive Waste in the Kara Sea.

Size of symbol is proportional to activity; figures are in $\mathrm{kCi}$. Exact coordinates of areas are given in Tables $\mathrm{A} 3$ and $\mathrm{A} 4$. 
As the table indicates, the inlets along the coast of Novaya Zemlya hold one NS with two reactors containing fuel in place, a reactor compartment with two reactors containing SNF, a reactor comparment with one reactor containing SNF in place and one reactor with SNF removed, and an NS reactor with SNF in place. Removing the SNF from all six sunken NS reactors was impossible due to the damaged condition of their cores. For the same reason, 125 irradiated fuel assemblies (FA's) could not be removed from the core plate of the OK-150 reactor unit on the nuclear icebreaker Lenin. Thus, according to available official data, six reactors with SNF in place and one shielding assembly from the Lenin with partially removed SNF were dumped in the inlets of Novaya Zemlya and the Novaya Zemlya Depression of the Kara Sea.

An exact estimate of the radionuclide content of these cores (without knowledge of which the environmental consequences of each dumping cannot be assessed) and determination of their total activity requires laborious scientific research. Such estimates can be made only after analysis of data on the operating conditions of each nuclear reactor throughout its life. Such an analysis has been performed only for the Lenin. This permitted the activity of the SNF at the time the reactor was dumped in 1967 to be estimated at $100 \mathrm{kCi}$. This work has not been done for NS reactors sunk off Novaya Zemlya, and the minimum estimate of their total activity furnished by the Navy, $120 \mathrm{kCi}$, is not well enough grounded and requires further calculations that account for the reactors' operating conditions. The maximum estimate of the overall total activity at the time of dumping, in the opinion of one Commission expert, could be at least $2.3 \mathrm{MCi}$ (see Table 3 and Fig. 6)

We should note the activity of the reactor sunk as a result of the accident aboard the NS Komsomolets, which is lying at the boundary between the Norwegian and Barents Seas at a depth of 1,700 meters $300 \mathrm{~km}$ from shore. According to expert estimates, the total activity of this NS's reactor core is at least $150 \mathrm{kCi}$.

Before sinking, reactor compartments with SNF in place were filled with a hardening furfurol-based mixture (except one NS reactor). According to estimates by the power plant's designer, this filling will prevent the SNF from contacting seawater for a period of several hundred (up to 500 ) years. As noted in Table 3, the shield assembly with SNF from the Lenin was additionally placed in a reinforced concrete container and a metal shell. Table 4 presents available data on the disposal of reactor compartments and reactors with SNF in place in northern seas. These data show that a grand total of 10 reactors with SNF in place have been dumped in the inlets of Novaya Zemlya and the Kara Sea.

It is difficult to determine their total radioactivity accurately enough. In these reactors, most of the radionuclides were produced through the action of neutron fluxes in the working reactor, so their activity is also crucially determined by the reactor's operating history. Moreover, the activity of these objects depends on their elemental makeup. Thus, in the structural members of the Lenin, cobalt was used, which resulted in a very high level of induced ${ }^{60} \mathrm{Co}$ activity (about 50 $\mathrm{kCi}$ ). An expert estimate of the total induced activity is at least $1000 \mathrm{kCi}$ at the time of sinking.

Thus, available data show that RW was discharged and dumped in the Barents and Kara Seas beginning in 1960. This was were mainly liquid and solid RW (the latter low-, intermediate-, and high-level, including reactor compartments from NS's with fuel in place) produced during operation of nuclear icebreakers and Naval vessels.

Analysis of the situation with radioactive contamination of the northern seas will not be sufficiently complete without an account of the possible entry into the marine environment of manmade radioactive substances from the atmosphere, from river runoff, possible drift from the Gulf 
Stream, one branch of which passes through the Barents Sea, and products of underground and surface nuclear tests on Novaya Zemlya.

Table 4. Objects without Spent Nuclear Fuel Dumped in Northern Seas, 1965-1968

\begin{tabular}{|c|c|c|c|c|c|}
\hline Object & $\begin{array}{l}\text { Coordinales. } \\
\text { Year }\end{array}$ & $\begin{array}{l}\text { Depth, } \\
\text { meters }\end{array}$ & Total Activity & $\begin{array}{l}\text { Radio- } \\
\text { nuclide } \\
\text { Content }\end{array}$ & $\begin{array}{c}\text { Description } \\
\text { of Protective } \\
\text { Barriers }\end{array}$ \\
\hline $\begin{array}{l}\text { Reactor of NS No. } 285 \text { (see } \\
\text { Table 3) }\end{array}$ & $\begin{array}{l}71^{\circ} 56^{\prime \prime} 2^{\prime \prime} \mathrm{N}, \\
55^{\circ} 18^{\prime \prime} 5^{\prime \prime} \mathrm{E} \text {, } \\
\text { Abrosimov } \\
\text { Inlet. } 1965\end{array}$ & 20 & $\begin{array}{l}\text { Requires special } \\
\text { analysis }\end{array}$ & Unclear & $\begin{array}{l}\text { Stock reactor } \\
\text { compartment } \\
\text { structures }\end{array}$ \\
\hline $\begin{array}{l}\text { Reactor comparment (two re- } \\
\text { actors) from NS No. } 254\end{array}$ & $\begin{array}{l}71^{\circ} 55^{\prime} 13^{\prime \prime} \mathrm{N}, \\
55^{\circ} 32^{\prime} 32^{\prime \prime} \mathrm{E} \text {, } \\
\text { Abrosimov } \\
\text { Inlet. } 1965\end{array}$ & 20 & $\begin{array}{l}\text { Requires special } \\
\text { analysis }\end{array}$ & Unclear & $\begin{array}{l}\text { Stock reactor } \\
\text { compartment } \\
\text { structures }\end{array}$ \\
\hline $\begin{array}{l}\text { Reactor compartment (two re- } \\
\text { actors) from NS No. } 260\end{array}$ & $\begin{array}{l}71^{\circ} 56^{\prime} 2^{\prime \prime} \mathrm{N} . \\
55^{\circ} 18^{\prime} 5^{\prime \prime} \mathrm{E} . \\
\text { Abrosimov } \\
\text { lnlet. } 1966\end{array}$ & 20 & $\begin{array}{l}\text { Requires special } \\
\text { analysis }\end{array}$ & Unclear & $\begin{array}{l}\text { Stock reactor } \\
\text { compartment } \\
\text { structures }\end{array}$ \\
\hline $\begin{array}{l}\text { OK-150 nuclear power plant } \\
\text { from icebreaker Lenin, compri- } \\
\text { sing three reactors with prima- } \\
\text { ry loop pipelines and water- } \\
\text { tight stock equipment }\end{array}$ & $\begin{array}{l}74^{\circ} 26^{\circ} 4^{\circ} \mathrm{N}, \\
58^{\circ} 37^{\prime} 3^{\circ} \mathrm{E}, \\
\text { Tsivolka } \\
\text { Inlet. } 1967\end{array}$ & 50 & $\sim 50 \mathrm{kCi}$ & $\begin{array}{l}\text { Mainly } \\
{ }^{60} \mathrm{Co}\end{array}$ & $\begin{array}{l}\text { Biological } \\
\text { shielding unit } \\
\text { (B-300 steel, } \\
\text { concrete) }\end{array}$ \\
\hline Two reactors from NS No. 538 & $\begin{array}{l}73^{\circ} 59^{\prime} \mathrm{N}, \\
66^{\circ} 18^{\prime} \mathrm{E}, \\
\text { Techeniye } \\
\text { Inlet. } 1988\end{array}$ & $35-40$ & $\begin{array}{l}\text { Requires special } \\
\text { analysis }\end{array}$ & Unclear & $\begin{array}{l}\text { Metal con- } \\
\text { tainer with } \\
\text { lead shell }\end{array}$ \\
\hline $\begin{array}{l}\text { Total: } 5 \text { objects with } 10 \text { reac- } \\
\text { tors withoul SNF }\end{array}$ & $1965-1988$ & $20-40$ & $\begin{array}{l}\text { Requires special } \\
\text { analysis (possibly } \\
\text { up to } 100 \mathrm{kCi} \text { at } \\
\text { time of dumping) }\end{array}$ & & \\
\hline
\end{tabular}

As a result of radioactive fallout, the soils of the Far North contain ${ }^{137} \mathrm{Cs}$ at a level of about $40 \mathrm{mCi} / \mathrm{km}^{2}$, and ${ }^{90} \mathrm{Sr}$ at about $30 \mathrm{mCi} / \mathrm{km}^{2}$. According to data from the Russian Committee for Hydrometeorology (Roskomgidromet), entries of ${ }^{90} \mathrm{Sr}$ and ${ }^{137} \mathrm{Cs}$ to the Barents Sea with river runoff between 1961 and 1989 were about $6 \mathrm{kCi}(200 \mathrm{TBq})$. The total entry of ${ }^{137} \mathrm{Cs}$ and ${ }^{90} \mathrm{Sr}$ to the Barents Sea from the atmosphere with global fallout of the products of nuclear explosions over the same period is estimated at approximately $100 \mathrm{kCi}(3700 \mathrm{TBq})$.

Similar calculations for the Kara Sea give corresponding values of $33 \mathrm{kCi}(1200 \mathrm{TBq})$ and 70 $\mathrm{kCi}(2600 \mathrm{TBq})$.

Calculations have also been made which indicate that the transport of LRW dumped by nuclear fuel processing plants at Sellafield, Great Britain and La Hague, France could have contributed about $200 \mathrm{kCi}(7400 \mathrm{TBq})$ to the Arctic Sea and the ecosystem of the Barents Sea. Without denying the very principle of transport of some portion of LRW from the Arctic Sea, we should note that this matter requires considerable further research (see Fig. 7).

Table 5 presents a summary radionuclide budget of the Barents and Kara Seas ecosystem. Despite the indeterminacy in its precise assessment, noted more than once above, we believe that the order of values objectively reflects the situation existing at the time of RW disposal. 


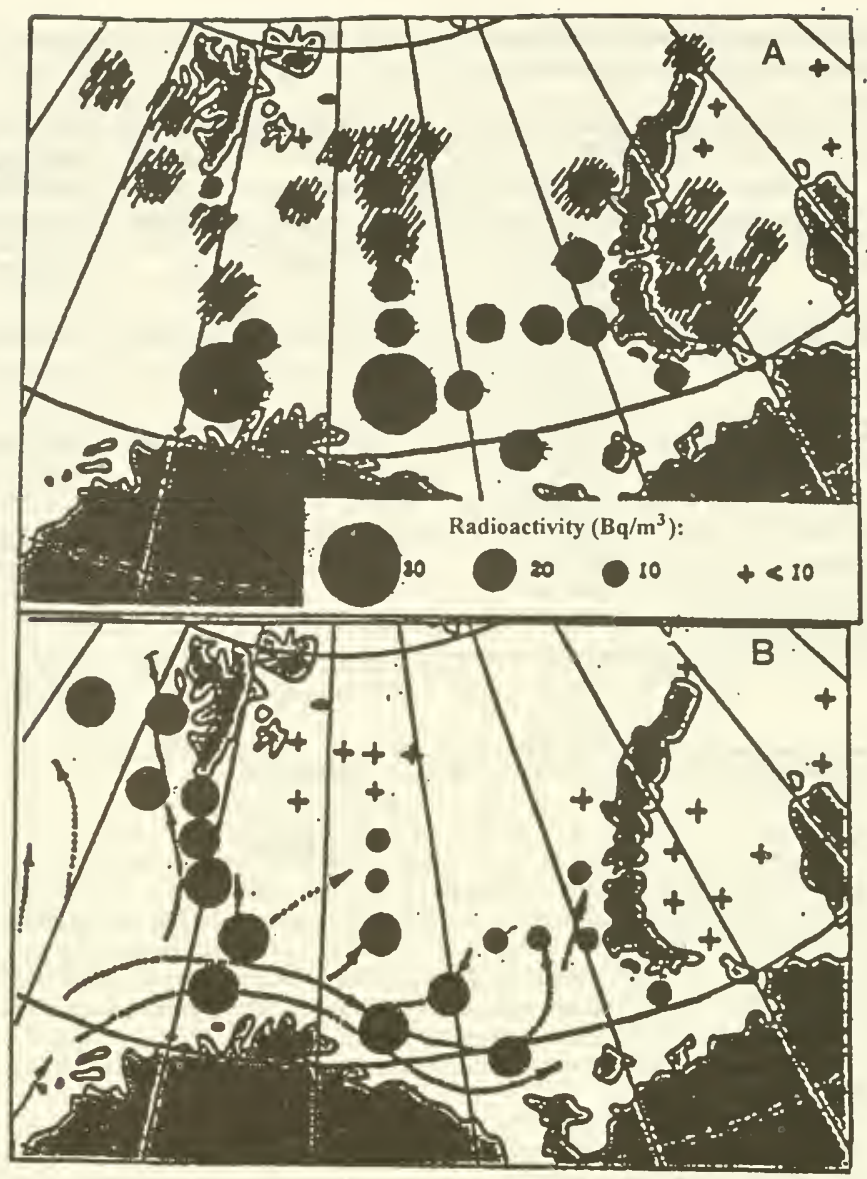

Figure 7. Distribution of Radioactivity in Surface Waters of the Barents, Kara and Greenland Seas.

$A$ : Distribution of radioactivity $\left({ }^{137} \mathrm{Cs}\right)$, based on 1982 data; $B$ : Hypothetical distribution of radioactivity of surface waters of Barents and Kara Seas if the source of the radioactivity had been transport by currents from northern seas. Hatching indicates areas of high and low concentrations (near Spitzbergen Island) that cannot be explained by transport from the Arctic Sea alone. Arrows: directions of major currents. 
Table 5. Anthropogenic Radionuclide Budget of the Barents and Kara Seas Ecosystem, 1961-1990

\begin{tabular}{|c|c|c|c|c|c|c|c|}
\hline \multirow{3}{*}{$\begin{array}{l}\text { Source of Long- } \\
\text { Lived Radionuclides }\end{array}$} & \multirow{2}{*}{\multicolumn{2}{|c|}{$\frac{\text { Barents Sea }}{\text { Activity }}$}} & \multirow{2}{*}{\multicolumn{2}{|c|}{$\frac{\text { Kara Sea }}{\text { Activity }}$}} & \multicolumn{3}{|c|}{ Ecosystem as a Whole } \\
\hline & & & & & \multicolumn{2}{|c|}{ Activity } & \multirow{2}{*}{$\begin{array}{c}\begin{array}{c}\text { Contri- } \\
\text { bution }\end{array} \\
\% \\
\end{array}$} \\
\hline & $\mathrm{kCi}$ & $\mathrm{TBq}$ & $\mathrm{kCi}$ & $\mathrm{TBg}$ & $\mathrm{kCi}$ & $\mathrm{TBq}$ & \\
\hline 1. Atmospheric fallout & 100 & 3700 & 70 & 2600 & 170 & 6300 & 6.2 \\
\hline 2. River runoff & 6.0 & 200 & 33.0 & 1200 & 39 & 1400 & 1.4 \\
\hline $\begin{array}{l}\text { 3. Contributions from } \\
\text { Gulf Stream system }\end{array}$ & 200 & 7400 & - & - & 200 & 7400 & 7.3 \\
\hline $\begin{array}{l}\text { 4. Dumping of solid and } \\
\text { liquid RW }\end{array}$ & 13 & 480 & 16 & 600 & 30 & 1100 & 0.7 \\
\hline $\begin{array}{l}\text { 5. Sinking of SRW with } \\
\text { SNF }\end{array}$ & - & - & $2300^{*}$ & $85300^{*}$ & $2300^{*}$ & 85100 & 84.4 \\
\hline $\begin{array}{l}\text { 6. Underwater and sur- } \\
\text { face nuclear explosions }\end{array}$ & \multicolumn{7}{|c|}{$\ldots(N \circ d a t a) \ldots$} \\
\hline Total (upper limit) & 319 & 11780 & 2419 & 89700 & 2739 & 101300 & 100 \\
\hline
\end{tabular}

- Expert estimate of the upper limit of activity at the time of disposal.

2.3.2. Disposal Sites, Volumes, and Total Activity of Radioactive Waste Dumped by the USSR in Far Eastern Seas

In this section, as in the previous one, we review data on the discharge and dumping of lowand intermediate-level liquid and solid RW at sea.

The geographical locations of officially designated areas for disposal of liquid and solid RW are shown in Fig. 8, and descriptions of the areas are given in Table A4 of the Appendix. Of the ten areas used for disposal, only Area 4 satisfied IAEA requirements for disposal of RW in terms of depth and location.

LRW was dumped in far eastem seas by the USSR from 1966 through 1991 in five of the designated areas (Table A6 of Appendix). In volume, the most LRW was dumped in Area 7 (near the southeastern coast of Kamchatka Peninsula), and in activity, in Area 9 (Sea of Japan). The annual variation in LRW dumping in far eastem seas is shown in Fig. 9. In terms of activity, the most LRW was clearly dumped in 1986-1987.

Available data demonstrate that a total of at least $12,335 \mathrm{Ci}(456 \mathrm{TBq})$ of $\mathrm{LRW}$ was dumped in far eastern seas.

Data on the disposal of low- and intermediate-level SRW in far eastern seas are presented in Table A7 of the Appendix. Such dumpings were conducted regularly in four of the 10 designated areas beginning in 1986. In volume of SRW dumped, Area 9 (Sea of Japan) stands out, and in total activity of low- and intermediate-level SRW dumped, Area 8 off the southeastem coast of Kanchatka stands out. According to available data, the total activity of intermediate- and lowlevel SRW dumped by the USSR in specially designated areas in far eastern seas is $6,851 \mathrm{Ci}$ ( 254 TBq). This activity is contained in 6,868 sunken containers, 38 sunken ships, and over 100 other individual sunken large objects.

The variation in dumping of low- and intermediate-level SRW in far eastern seas is shown in Fig. 9. These data indicate that the maximum amount of such SRW (in terms of activity) was 
dumped in far eastern seas in 1975 and 1985.

Table 6 presents all available data on the disposal of NS reactors in far eastern seas.

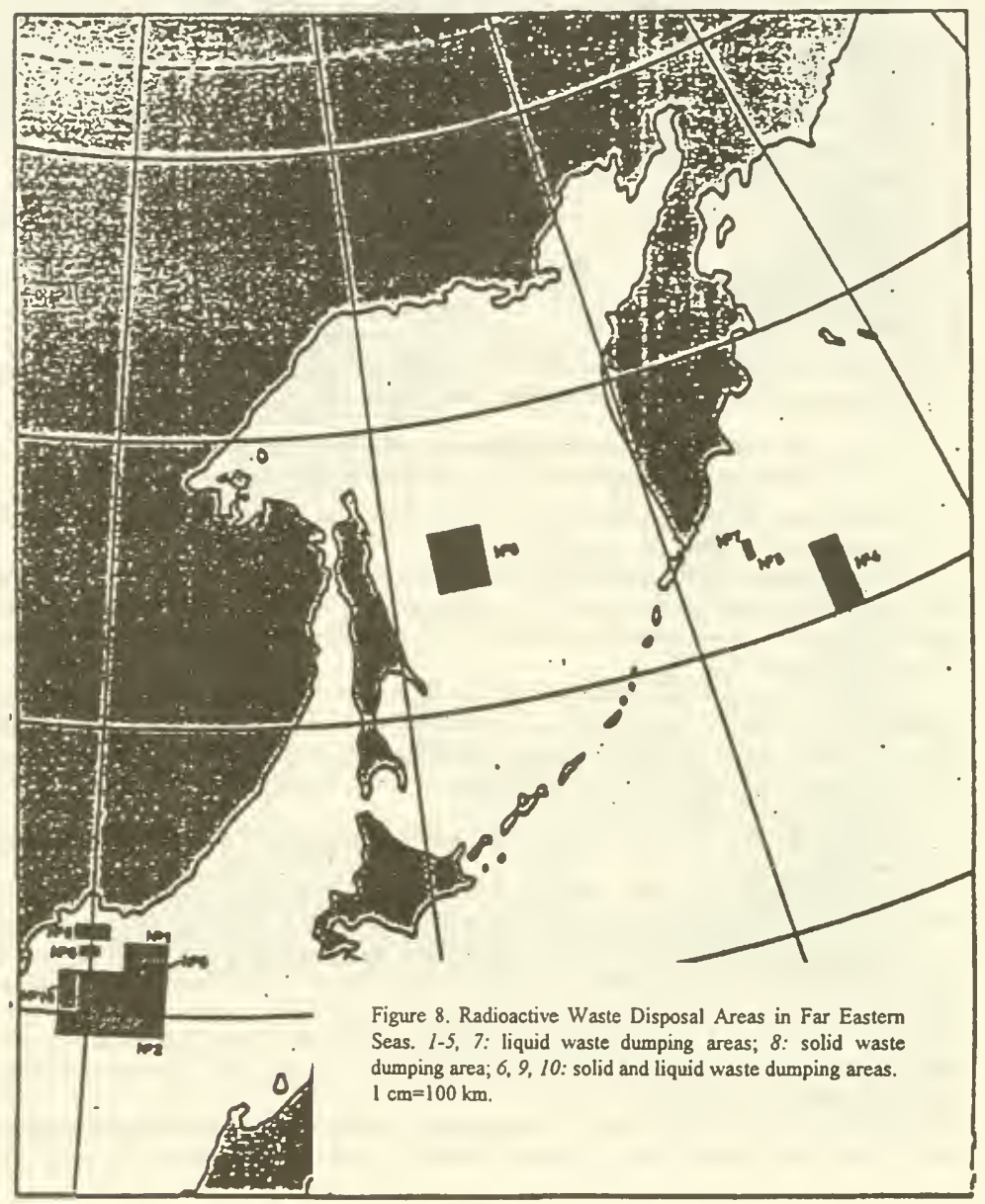



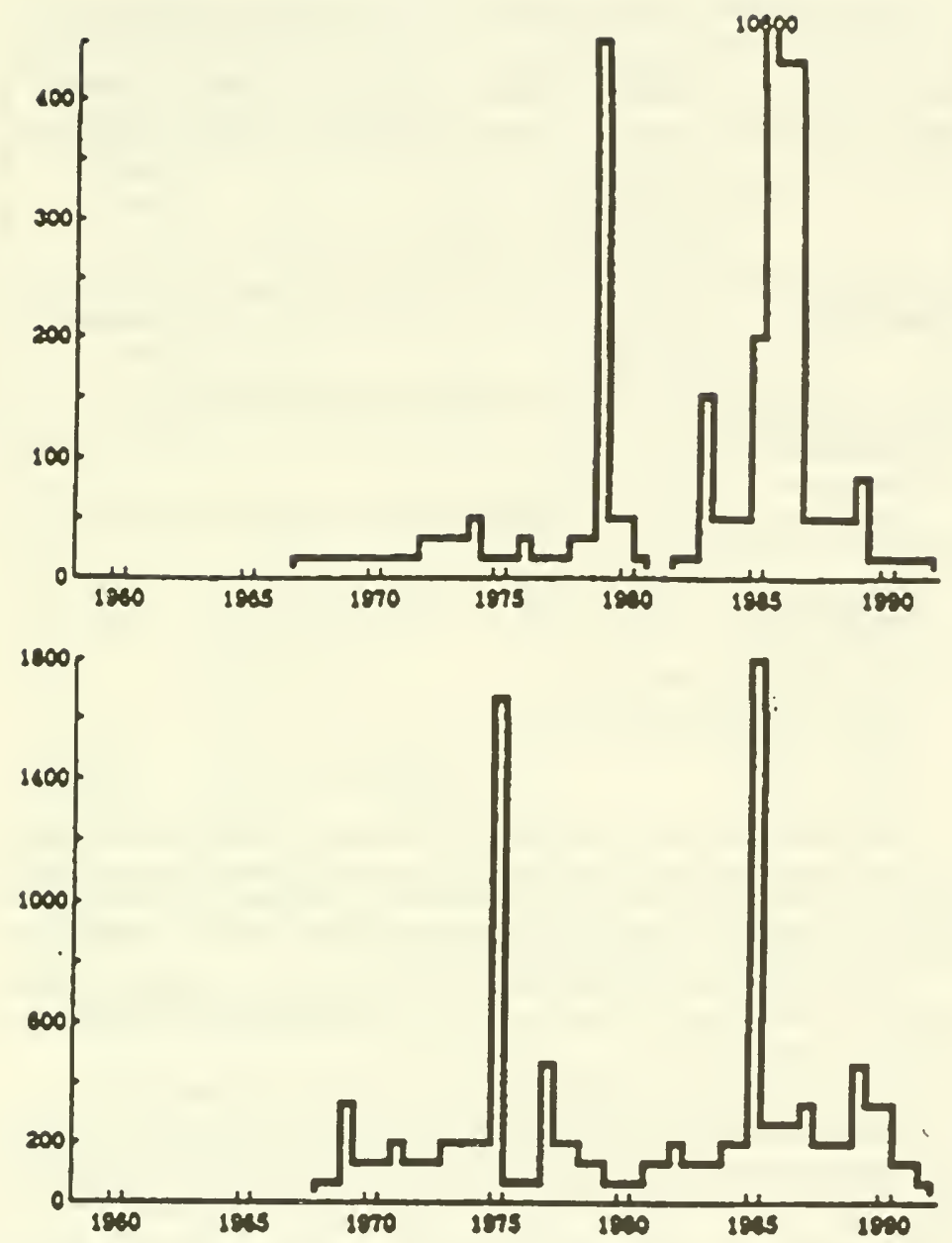

Figure 9. Rate of Disposal of Radioactive Waste in Far Eastern Seas by Year.

$A$ : dumping of liquid RW; $B$ : disposal of low- and intermediate-level solid RW. Bar height is proportional to annual dumping activity. 
Table 6. Disposal of Reactors with Spent Nuclear Fuel in Place in Far Eastern Seas

\begin{tabular}{|l|l|c|c|c|c|}
\hline \multicolumn{1}{|c|}{ Object } & $\begin{array}{c}\text { Coordinates, } \\
\text { Year }\end{array}$ & $\begin{array}{c}\text { Depth, } \\
\text { meters }\end{array}$ & $\begin{array}{c}\text { Total } \\
\text { Activity, } \\
\mathrm{Ci}(\mathrm{TBq})\end{array}$ & $\begin{array}{l}\text { Radio- } \\
\text { nuclide } \\
\text { Content }\end{array}$ & $\begin{array}{l}\text { Description of } \\
\text { Protective } \\
\text { Barriers }\end{array}$ \\
\hline Two NS reactors & $\begin{array}{l}40^{\circ} 10^{\prime} \mathrm{N}, \\
131^{\circ} 15^{\prime} \mathrm{E}, \\
\text { Sea of Japan } \\
\text { (Area 10), } \\
1978\end{array}$ & 3000 & $46.2(1.7)$ & Unclear & $\begin{array}{l}\text { Lead-lined } \\
\text { metal con- } \\
\text { tainer }\end{array}$ \\
\hline $\begin{array}{l}\text { Core plate from the } \\
\text { reactor of NS No. }\end{array}$ & $\begin{array}{l}52^{\circ} 30^{\prime} \mathrm{N}, \\
159^{\circ} 9^{\prime} \mathrm{E}, \\
\text { east of Kam- } \\
\text { chatka, 1989 }\end{array}$ & 2500 & $70(2.6)$ & Unclear & $\begin{array}{l}\text { Lead-lined } \\
\text { metal con- } \\
\text { tainer }\end{array}$ \\
\hline $\begin{array}{l}\text { Total: } 2 \text { reactors and } \\
\text { one shield assembly }\end{array}$ & & & $116(4.3)$ & & \\
\hline
\end{tabular}

- Al time of disposal.

Thus, according to available data, the activity of RW dumped by the USSR in far eastern seas is distributed as follows:
Liquid RW
$12,337 \mathrm{Ci}(456 \mathrm{TBq})$
Intermediate- and Low-Level Solid RW
$6112 \mathrm{Ci}(225 \mathrm{TBq})$
Solid RW (induced activity in two reac-
tors and one shield assembly without
SNF)
Total

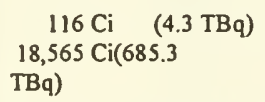

No dumpings of reactors with SNF in place were conducted in far eastern seas. In addition to the above data, we must include information on RW that entered the waters of the Sea of Japan as a result of a radiation accident aboard an NS in Chazhma Bay (see Section 3), the loss of a 350 kCi RTG radionuclide power supply during transport near Sakhalin Island, and radioactive contaminations resulting from atmospheric fallout and river nunoff.

Considering the areally enormous waters of the far eastern region, the liquid and solid RW dumped by the Pacific Fleet do not appear to be more than several percent in the budget of manmade radioactive contamination.

\subsubsection{Total Amount of Radioactive Waste Dumped by the USSR at Sea}

On the basis of accumulated documentary data and expert findings, the total activity of all RW discharged and dumped by the USSR in seas adjacent to Russian territory may be estimated at $325 \mathrm{kCi}(12 \mathrm{PBq})$. Experts estimate the upper limit of the activity of RW dumped at up to 2.5 $\mathrm{MCi}(92 \mathrm{PBq})$.

In addition to data on RW dumped in northern and far eastern seas (see Tables 2-6), we must include information on radioactive materials that entered the marine environment by accident. Among these are: 
- radioactive materials aboard NS's that sank as a result of accidents (including nuclear reactors and NWH's);

- radioactive materials aboard other objects that suffered accidents and fell into the world's oceans (nuclear reactors on satellites, NWH's that fell into the sea from aircraft accidents or failed launches);

- radiation sources that accidentally fell into the ocean;

- LRW that accidentally entered the sea from shore storage facilities as a result of leaks;

- products of underwater and surface nuclear explosions.

Sufficient information is not available on a single one of the items listed above, so its collection is an urgent objective. Available data on all these sources of radioactive contamination of the world's oceans are presented in Table 7.

Table 7. Information on Radioactive Objects that Have Fallen into the World's Oceans Through Accidents with Soviet Submarines

\begin{tabular}{|l|l|c|c|c|c|}
\hline \multicolumn{1}{|c|}{ Object } & \multicolumn{1}{|c|}{$\begin{array}{c}\text { Location, } \\
\text { Date }\end{array}$} & $\begin{array}{l}\text { Depth, } \\
\text { meters }\end{array}$ & $\begin{array}{c}\text { Maximum } \\
\text { Reactor } \\
\text { Activity, } \\
\mathrm{kCi}\end{array}$ & $\begin{array}{c}\text { NWH } \\
\text { Activity } \\
\text { at Time of } \\
\text { Accident, } \\
\mathrm{Ci}\end{array}$ & \multicolumn{1}{|c|}{ Remarks** } \\
\hline $\begin{array}{l}\text { Diesel } \\
\text { submarine }\end{array}$ & $\begin{array}{l}\text { Pacific Ocean, } \\
\text { Hawaiian } \\
\text { Islands, April } \\
1968\end{array}$ & 6,000 & None & 1.0 & $\begin{array}{l}\text { Bow section with } \\
\text { NWH's raised in } \\
\text { August 1974 by Glo- } \\
\text { mar Explorer (activity } \\
0.4 \text { kCi) }\end{array}$ \\
\hline $\begin{array}{l}\text { Nuclear } \\
\text { submarine }\end{array}$ & $\begin{array}{l}\text { Bay of Biscay, } \\
4 / 8 / 1970\end{array}$ & 4,000 & $250^{*}$ & 0.8 & $\begin{array}{l}2 \text { nuclear power } \\
\text { plants }\end{array}$ \\
\hline $\begin{array}{l}\text { Nuclear } \\
\text { submarine }\end{array}$ & $\begin{array}{l}\text { Bermuda } \\
\text { Islands, } \\
10 / 6 / 1986\end{array}$ & 5,500 & $250^{*}$ & 3.8 & $\begin{array}{l}2 \text { nuclear power } \\
\text { plants }\end{array}$ \\
\hline $\begin{array}{l}\text { NS Komso- } \\
\text { molets }\end{array}$ & $\begin{array}{l}\text { Norwegian } \\
\text { Sea, } 4 / 7 / 1989\end{array}$ & 1,685 & $150^{*}$ & 0.43 & 1 nuclear power plant \\
\hline Total & & 650 & 6.03 & \\
\hline
\end{tabular}

- Exper estimate (at time of sinking)

**-The world's oceans contain a total of 50 NWH's from various countries [22].

The total activity of all RW sources that have entered the world's oceans from USSR territory cannot be determined with sufficient accuracy at present due to the lack of confidence in the inventory of each and every source of radioactive contamination of the ocean. Tentative data, largely of an expert nature, are presented in Table 8.

\subsection{Radioactive Waste Disposal in the Seas of the Russian Federation}

The disposal of RW at sea, long practiced in the USSR, was continued in 1992 by the Navy in far eastern and northern seas. Factual data obtained by the Commission on the matter are presented in Table 9. 
Despite the comparatively low values of activity for dumped $\mathrm{RW}$, it should be reemphasized that this has placed the Russian Federation in the position of having violated the provisions of the London Convention, which it has obligated itself to observe, and has also led to violation of the Russian Federation Law, Protection of the Natural Environment.

Table 8. Summary Data on the Scale of Contamination of the World's Oceans by Radioactive Wastes from USSR Territory, 1961-1990

\begin{tabular}{|l|l|c|}
\hline \multicolumn{1}{|c|}{ Source of Contamination } & \multicolumn{1}{|c|}{ Location and Date } & \multicolumn{1}{c|}{$\begin{array}{c}\text { Suspected Total } \\
\text { Activity, kCi* }\end{array}$} \\
\hline $\begin{array}{l}\text { LRW from Navy and Murmansk } \\
\text { Maritime Shipping Line }\end{array}$ & $\begin{array}{l}\text { North Atlantic Ocean. } \\
\text { Northwest Pacific Ocean. } \\
1959-1991\end{array}$ & $\begin{array}{c}\text { About } 25 \\
\text { Over 12 }\end{array}$ \\
\hline $\begin{array}{l}\text { SRW from Navy and Murmansk } \\
\text { Maritime Shipping Line, including } \\
\text { sunken reactors }\end{array}$ & Same & $\begin{array}{c}\text { About 300 } \\
\text { (experts estimate } \\
\text { not over 2,500) }\end{array}$ \\
\hline $\begin{array}{l}\text { Sunken NS's } \\
\text { Lost NWH's, RTG's, satellites, etc. }\end{array}$ & $\begin{array}{l}\text { Atlantic and Pacific } \\
\text { Oceans }\end{array}$ & $\begin{array}{l}\text { Under } 650 \\
\text { Oceans }\end{array}$ \\
\hline $\begin{array}{l}\text { Discharge of RW from Yenisey and Ob } \\
\text { Rivers }\end{array}$ & Arctic Seas & Several thousand \\
\hline Total & All the world's oceans & Several thousand \\
\hline
\end{tabular}

*-At time of disposal.

Table 9. Disposal of Radioactive Waste at Sea by the Russian Navy in 1992

\begin{tabular}{|c|c|c|c|}
\hline \multirow{2}{*}{$\begin{array}{l}\text { Disposal Area } \\
\text { (Coordinates) }\end{array}$} & \multirow[t]{2}{*}{ Type of Dumping } & \multicolumn{2}{|c|}{ Activity } \\
\hline & & $\mathrm{Ci}$ & $\mathrm{GBg}$ \\
\hline \multicolumn{4}{|c|}{ Barents Sea } \\
\hline Area 5 (coastal) & $3,066 \mathrm{~m}^{3} \mathrm{LRW}$ & 18 & 666 \\
\hline \multicolumn{4}{|c|}{ Far Eastern Seas } \\
\hline Area 5 , Sea of Japan & $906 \mathrm{~m}^{3} \mathrm{LRW}$ & 1.3 & 48 \\
\hline Area 7, east coast of Kamchatka & $906 \mathrm{~m}^{3} \mathrm{LRW}$ & 1.3 & 48 \\
\hline Area 9, Sea of Japan & $1774 \mathrm{~m}^{3} \mathrm{LRW}$ & 7.6 & 281 \\
\hline $\begin{array}{l}\text { Area } 8,52^{\circ} 30^{\prime} \mathrm{N}, 159^{\circ} 9^{\prime} \mathrm{E} \text {, east } \\
\text { coast of Kamchatka }\end{array}$ & $46 \mathrm{~m}^{3} \mathrm{SRW}, 41$ containers & 12 & 444 \\
\hline $\begin{array}{l}\text { Area } 9,41^{\circ} 40^{\prime} N, 133^{\circ} 30^{\prime} \text { E, Sea } \\
\text { of Japan }\end{array}$ & $2640 \mathrm{~m}^{3} \mathrm{SRW}$, tanker TNT-II & 14.5 & 534 \\
\hline $\begin{array}{l}\text { Area } 9,41^{\circ} 40^{\prime} \mathrm{N}, 133^{\circ} 30^{\prime} \mathrm{E} \text {, Sea } \\
\text { of Japan }\end{array}$ & $55 \mathrm{~m}^{3} \mathrm{SRW}, 41$ containers & 0.5 & 19 \\
\hline Total by type & $\begin{array}{l}6,652 \mathrm{~m}^{3} \text { LRW } \\
2,741 \mathrm{~m}^{3} \text { SRW }\end{array}$ & $\begin{array}{l}28.2 \\
27.0\end{array}$ & $\begin{array}{l}1050 \\
1000\end{array}$ \\
\hline Total Activity & & 55.2 & 2050 \\
\hline
\end{tabular}




\section{SECTION 3. Radiological CONDITIONS IN MARINE Radioactive WaSte Disposal aREas in the NORTH and Far EaST}

Before reviewing the specifics of the radioecological situation in the seas adjacent to the northern and far eastern coasts of the Russian Federation, we should address the organization of radiation and sanitary-epidemiological monitoring in marine RW disposal areas.

\subsection{Organization of Radiation and Sanitary-Hygienic Monitoring in Marine Radioactive Waste Disposal Areas}

Until 1983, monitoring of radiation conditions in marine RW disposal areas was performed by the forces and assets of the Northern and Pacific Fleets. The scope and frequency of monitoring was regulated by sanitary requirements for disposal of $R W$ at sea, with the most attention devoted to investigating levels of biologically hazardous radionuclides in seawater, bottom sediments, and commercial and marker species of water life in RW disposal areas.

Radiation hygiene studies of RW disposal areas were performed using radiation monitoring ships, which were part of the Navy's support fleet and represented modified MRT class fishing trawlers. In technical condition and navigational properties, the radiation monitoring ships did not fully meet the requirements placed on ships for navigation in open seas with difficult ice and weather conditions. For this reason, monitoring could not always be complete.

More detailed radiological studies of marine areas were carried out during the performance of a series of scientific research studies on the problems of RW disposal at sea in 1960, 1966, 1967, 1972, 1980, and 1984-1990 by the Maritime Branch of the USSR Ministry of Defense's Twelfth Central Scientific Research Institute, the USSR Ministry of Defense's 126th State Scientific Research Test Area, Roskomgidromet's Typhoon Scientific Research Institute, and the Navy's Central Medical Laboratory. These studies were aimed at assessing possible radioecological consequences and developing optimal conditions for discharge of liquid and dumping of solid RW by nuclear vessels and ships at sea at high latitudes with severe ice conditions, in coastal and noncoastal waters, and at Naval bases.

Before areas designated for discharge and dumping of waste began to be used, preoperational radiation inspections were conducted according to special programs including determination of radionuclide activity in seawater, commercial water life, and bottom sediments.

With the implementation of the PS-82 regulations specifying procedures for issuing approvals to dump RW at sea, monitoring of radiation conditions in RW discharge and dumping areas began to be performed by the forces and assets of Goskomgidromet, and in water areas of basing, refueling and repair areas for nuclear-powered ships, by radiation safety services of ship formations or units.

Radiation inspection of seas used for RW disposal was performed by Goskomgidromet in a series of expeditions by research vessels. In 1975, the Navy hydrographic ship Abkhaziya performed a radiation inspection of the Sea of Japan. In 1982, the research icebreaker Otto Shmidt performed a radiation inspection of the Kara Sea. In 1992, a joint Russian-Norwegian expedition on Roskomgidromet's RVV Viktor Buynitskiy performed a radioecological inspection of the Barents and Kara Seas (Fig. 10).

An expedition planned for 1992 by Roskomgidromet and the Navy to inspect SRW disposal areas in the bays and inlets of the eastern coast of the islands of Novaya Zemlya did not occur through the Navy's fault. 


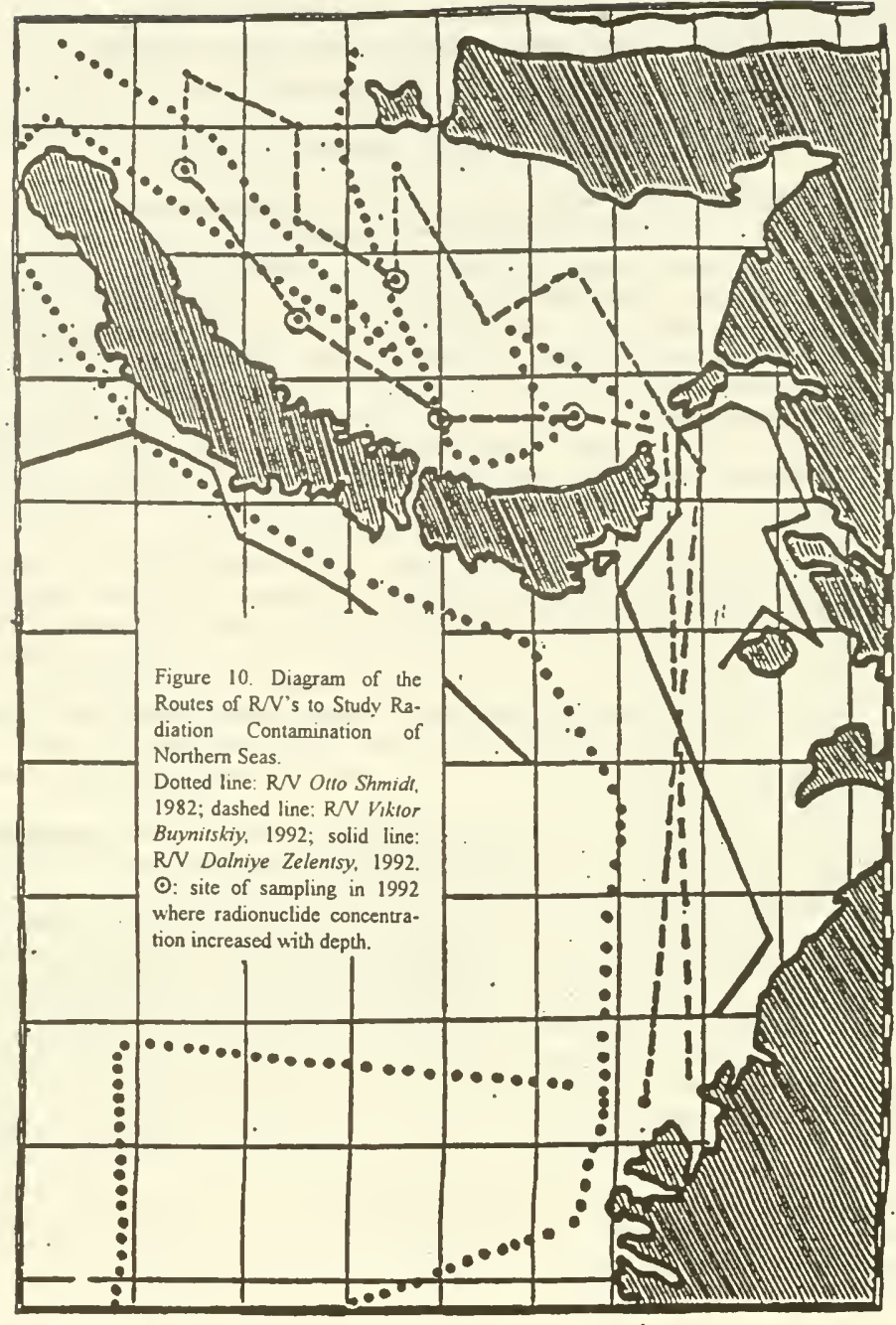

All studies of radiation conditions since 1967 have been performed in water areas loca- 
ted $50-100 \mathrm{~km}$ from SRW disposal areas. Direct monitoring of radiation conditions in such waste disposal areas themselves has not been performed for 25 years.

It should be noted that the dumping of RW in containers does not guarantee absolute safety from the standpoint of possible seawater contamination, since the container material is subject to corrosion. Metal containers fail in seawater after 10 years, and concrete ones in 30 years. The possible pollution of the marine environment by furfurol, which was used to seal many reactor compartments when they were sunk, has been insufficiently studied.

On the whole, the state of radiation and sanitary-hygienic monitoring at RW disposal sites in both northern and far eastern seas in recent years should be recognized as unsatisfactory. Despite the fleets' annual generation of a large quantity of RW requiring disposal and dumping at sea over the course of decades (including high-level and potentially hazardous RW), a system for observing and monitoring the condition of radioactive objects dumped at sea is practically nonexistent, although the systems of the Russian Ministry of Defense, Ministry of Industry, and Ministry of Atomic Energy have numerous scientific research institutes involved with the development and operation of nuclear-powered vessels.

Work to develop a system of marine radioecological monitoring in disposal areas was not begun by the Navy until 1992

\subsection{Radiation Conditions in Seas Used for Radioactive Waste Disposal}

In the course of radiation hygiene inspections conducted at SRW disposal sites before 1967 and areas of LRW discharge before 1990, no cases of dangerous radioactive contamination of the marine environment were discovered, either in the disposal areas themselves or in adjacent water areas, with the exception of brief (up to several days) local increases in radionuclide activity in seawater during discharge of LRW.

Information is lacking on the status of radiation conditions at SRW disposal sites themselves in northern and far eastern seas. This has evoked not only concern by specially authorized government agencies of the Russian Federation for monitoring of the status of the environment in the Russian Federation, but also sharp criticism directed at Russia on the part of other countries and international public organizations.

An assessment of the total radioactive contamination of sea surface waters where RW disposal took place requires more detailed data. Levels of radioactive contamination of northem and far eastern seas discovered so far show no dangerous rise in levels of radionuclides in the marine environment (Table 10).

\subsection{Anticipated Changes in Radioecological Conditions at Sites of Radioactive Waste Disposal at Sea}

An estimation and prediction of possible radiation hygienic and radioecological consequences of sea disposal of RW produced during the operation, refueling and repair of nuclear-powered vessels and ships were performed on the basis of a study of documentary data on the quantitative and qualitative composition of RW, analysis of technology and radiation protection measures used in preparing RW for disposal and disposing of it, and a comparison of various sources of radioactive contamination of Russia's Arctic and Pacific coastal seas.

The analysis shows that there are important differences in the estimated impact of liquid and solid RW dumped at sea. 
Table 10. Average ${ }^{90} \mathrm{Sr}$ Concentration in Sea Surface Waters, 1990-1991, pCi/ [23]

\begin{tabular}{|l|l|l|c|}
\hline \multicolumn{1}{|c|}{ Area } & 1990 & 1991 & $\begin{array}{c}\text { Number of } \\
\text { Samples in 1991 }\end{array}$ \\
\hline Baltic Sea & $0.53-0.57$ & $0.44-0.46$ & 15 \\
\hline Sea of Azov & 0.85 & 0.83 & 5 \\
\hline White Sea & 0.25 & 0.25 & 4 \\
\hline Barents Sea & 0.21 & 0.16 & 6 \\
\hline Caspian Sea (northern part) & 0.40 & $0.33-2.35$ & 13 \\
\hline Sea of Okhotsk & 0.09 & 0.10 & 4 \\
\hline Sea of Japan & 0.17 & 0.10 & 4 \\
\hline Black Sea (Dnepr-Bug estuary) & - & 2.1 & 14 \\
\hline $\begin{array}{c}\text { Pacific Ocean (coastal waters of } \\
\text { East Kamchatka) }\end{array}$ & 0.08 & 0.09 & 12 \\
\hline
\end{tabular}

Calculations performed using models of radionuclide migrations in marine systems demonstrate low levels of possible entry of radionuclides from LRW into the human body through food chains. Even with a conservative approach, exposure doses for possible critical population groups do not reach significant values and are not reliably different from doses caused by the natural and technogenically altered radiation background.

In the course of research on the subject, Summary Documents on the Disposal of Radioactive Waste from Naval Facilities in Special Areas of the Sea between 1960 and 1966, performed in 1967, no increase in radionuclide activity in seawater, plankton, or commercial water life was detected in areas of LRW discharges. Computational studies on the subject, Documents on the Validation of the Draft "Sanitary Requirements for Disposal of Radioactive Waste at Sea" also showed that discharges of regulated amounts of LRW would not lead to a hygienically significant increase in the concentration of artificial radionuclides in seawater and commercial water life. Actual values of LRW discharges were, as a rule, significantly lower than regulatory standards.

Consequently, data from previous research permit us to draw the preliminary conclusion that the LRW discharged from facilities of the Northern and Pacific Fleets and the Murmansk Maritime Shipping Line presents no significant radiation hygiene danger, either to the population as a whole or to critical population groups (fishermen, residents of coastal areas). Further studies could refine the above preliminary assessment of the effect of LRW, but are unlikely to substantially alter it.

It is more complicated to assess the effect of LRW disposal on the marine ecosystem and marine biocenoses. Our knowledge of the circulations of substances in northern and polar ecosystems is too fragmentary for final definite conclusions. For example, our knowledge is totally inadequate even in the area of hydrography. Recent discoveries of powerful bottom currents that vary with the seasons and deep storms in which the rate of movement of water masses exceeds several knots show the depth of our ignorance, even of apparently well-studied parameters of the sea.

A conclusion on the effect of LRW disposal on shaping radioecological conditions at sea requires comprehensive comparative studies of marine water life over large areas [24-27]. A comparison of various local populations of vertebrates, invertebrates, microorganisms and algae is needed.

Such studies, even if they are energetically begun in the near future, will take several years. 
Serious concerns are provoked by ever more frequent cases of diseases and pathological changes (including those to the cardiovascular system) noted in pinnipeds inhabiting the Barents-White Sea ecosystem [27]. These changes cannot be unambiguously linked to LRW dumping, but the theoretical possibility of such a link exists.

At the same time, budget calculations of the share of total anthropogenic radiation contamination of marine ecosystems due to LRW (2.5-5.0\%) indicates with a fair degree of certainty that the effect of discharged LRW on marine ecosystems cannot be a determining negative factor on the scale of the northern and far eastern seas adjacent to Russian territory.

The radiation hygienic and radioecological danger of SRW dumped at sea is determined by their radionuclide content and activity, the condition of their protective barriers (degree of water tightness of their packing containers, rate of the latter's corrosion, etc.).

A comparative analysis of the potential danger of SRW dumped at sea from vessel and ship nuclear power plants suggests the conclusion that the greatest threat in radiation hygienic and radioecological terms is presented by reactors with SNF in place in the Kara Sea. In cases when reactor compartments and reactors with damaged cores in place dumped at sea were specially prepared with reinforced protective barriers (filling internal cavities with furfurol or cement, additional sealing, etc.), a substantial release of radionuclides in the near future seems unikely.

However, this theoretical conclusion may be incorrect, since the actual course of corrosion processes and transformation of protective barriers erected is unknown. No full-scale experiments of sufficient duration and similarity to actual conditions were performed during the development of protective barriers and estimation of computed time to seal failure. And until each and every dumped SRW with high activity levels is inspected, no final conclusions concerning them can be drawn.

The computed design time to possible seal failure for the block of the first nuclear power plant of the icebreaker Lenin, which contains three reactors without nuclear fuel, is up to 500 years. No similar data for other sunken reactors were furnished to the Commission, and reevaluating all these calculations, if they exist, is an important objective for the immediate future. Moreover, it must be kept in mind that a number of reactors with SNF removed were dumped at sea without the creation of any additional protective barriers to the release of radionuclides into the marine environment.

The aforesaid also applies to containerized SRW, and to RW dumped in the holds of sunken vessels. According to calculations, the container walls (3-4 mm of steel 3 ) could be subject to significant corrosion within 20-30 years after dumping at seal. Since the corrosion of steel 3 would proceed uneveniy over the surface of the container, the flushing of its contents will not be uniform. In that period, all radionuclides with half-lives shorter than 3 years will decay, and ${ }^{90} \mathrm{Sr}$ and ${ }^{137} \mathrm{Cs}$ activity in the waste will decline by half.

The rate of release of the remaining long-lived radionuclides seems impossible to estimate with certainty, although there is no doubt that the process will inevitably take a long time.

Unfortunately, even these theoretical calculations could be far from reality. We know from eyewitness testimony that during the disposal of low-level SRW, cases were noted when metal containers were shot to accelerate their sinking. This means that without the slightest doubt, the release of radionuclides began immediately after disposal of the containers. The radioecological consequences of the release of large amounts of radionuclides in the shallow areas of the Kara Sea must have affected the ecosystems, but this effect can be assessed only after observations are made in the disposal areas.

For now, we have only some alarming data indicating that in a number of water areas in the 
western Kara Sea, the concentration of radionuclides $\left({ }^{137} \mathrm{Cs}\right)$ rises at depth (Table 11 ; see also Fig. 10).

Table 11. ${ }^{137} \mathrm{Cs}$ Concentration $\left(\mathrm{Bq} / \mathrm{m}^{3}\right)$ at Various Depths

in the Southwestern Kara Sea at Five Sampling Points

\begin{tabular}{|l|c|c|c|c|c|}
\hline \multirow{2}{*}{ Depth } & \multicolumn{5}{c|}{ Number of Sampling Point } \\
\cline { 2 - 6 } & 1 & 2 & 3 & 4 & 5 \\
\hline Surface & 6.9 & 2.9 & 3.2 & 3.5 & 3.4 \\
\hline $7-80$ meters & 5.0 & 6.9 & 6.2 & 10.3 & 4.4 \\
\hline $85-230$ meters & 10.9 & 11.1 & 19.5 & 11.6 & 9.8 \\
\hline
\end{tabular}

Future analyses must be done with the awareness that in a number of cases, sunken vessels were loaded with highly toxic substances such as heptyl.

The majority of noncontainerized SRW dumped at sea is equipment manufactured of high alloy steels. Such steel is subject to corrosion at a rate of about $1 \mathrm{~mm}$ per 100 years. The thickness of the radioactive layer on articles made of this steel removed from a reactor is $0.1-0.5 \mathrm{~mm}$. Consequently, all the activity from noncontainerized SRW of this type must have passed into the marine environment within 10-12 years after disposal. The release (flushing) of radionuclides from other noncontainerized wastes proceeds even more rapidly. Consequently, a large portion of the radionuclides from noncontainerized $\mathrm{RW}$ must have entered the environment. However, since the total activity of this RW is low, it must not have had a noticeable effect on shaping overall radioecological conditions in the sea.

However, we should keep in mind that accidental contact with individual radiologically rather hazardous objects is possible, for example due to removal during diving work, or when storms cast them ashore from the shallow bays and inlets of the islands of Novaya Zemlya, where a large portion of RW has been dumped (Fig. 11).

To prevent people from accidentally contacting radiologically hazardous objects thrown ashore, the Novaya Zemlya Northern Test Site performs an annual visual inspection of the eastern coastline of the archipelago. In Maritime Territory, aerial gamma-ray photography was performed in 1991 in the area of the NS accident at Chazhma and along the coast of the Sea of Japan. No radiologically hazardous objects or articles have been found, with the exception of an unidentified metal object with high levels of radiation (over $100 \mathrm{r} / \mathrm{hr}$ : fragments of fuel rods) in 1984 on the coast of Abrosimov Inlet, Novaya Zemlya.

We must note two other circumstances that increase the potential radioecological hazard of dumped SRW. The first concerns the possibility of a significant acceleration of corrosion processes affecting RW composed of different metals (for example, steel with copper, zinc, titanium, etc.) in seawater. In such cases, electrolytic reactions can occur, in which the corrosion rate of metals can be increased manyfold. Just such a process characterizes the rapid destruction of elements of the NS Komsomolets (the steel-titanium combination).

The second circumstance is the possibility of unauthorized disposal of RW at sea, or its disposal in violation of approved standards.

Everything that has been said with respect to SRW forces the Commission to refrain from any final conclusions on the degree of their radioecological hazard until each and every disposal site has been inspected. 


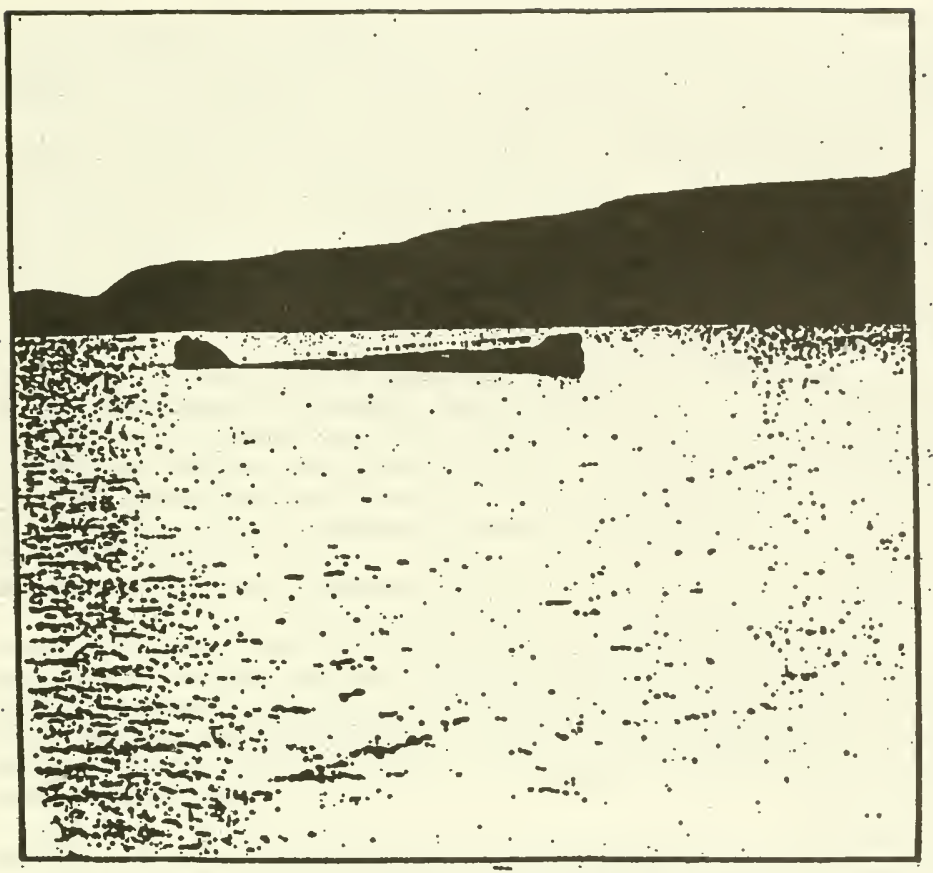

Figure 11. September 1, 1981, Stepovoy Inlet (Novaya Zemlya): Sinking of a damaged NS with two liquid metal reactors. Depth about 20 meters.

An urgent task is the organization of reliable monitoring (observation, tracking and analysis) of the release of radionuclides from dumped SRW.

Since all dumpings of SRW in northern seas (and most dumpirigs in far eastern seas) were made in gross violation of international standards, and considering their potential radioecological hazard, the only reliable solution to the problem can be to raise large high-level SRW from shallow disposal sites and reinter it in specially equipped repositories on land. However, this solution must be adopted after comprehensive studies to assess the radiation risk of such SRW dumpings.

\subsection{Accident on a Nuclear Submarine in Chazhma Bay (Maritime Territory), 1985}

On August 10,1985, during completion of reactor refueling work on an NS at a pier in a Naval shipyard in Maritime Territory (Chazhma Bay, town of Shkotovo-22), due to violation of nuclear safety requirements and reactor lid raising technology, an uncontrolled spontaneous uranium fission chain reaction occurred in the port reactor.

The resulting thermal explosion of the reactor destroyed the forward and aft machine rooms 
and the forward compartment of the control system. One assembly with a freshly loaded core was blown out of the reactor. The fueling shack was also partially destroyed, and its roof was blown off to a distance of $70-80$ meters, landing in the water 30 meters from shore. The NS sustained damage to its pressure hull in the aft portion of the reactor compartment.

Immediately after the explosion in the reactor compartment, a fire broke out, which was brought under control after four hours. The combustion products, along with fission and activation products and particles of unreacted fuel compound in the form of fine particles and slurry, fell out within a radius of 50-100 meters around the damaged NS.

A radioactive plume was deposited with an axis intersecting Dunay peninsula in a northwesterly direction and extending seaward toward the coast of Ussuri Inlet. The plume was $5.5 \mathrm{~km}$ across on the peninsula (later fallout of aerosol particles occurred on the water surface up to 30 $\mathrm{km}$ from the release site).

The release of radioactive substances into the atmosphere was calculated (neglecting radioactive noble gases) at about $185,000 \mathrm{TBq}(5 \mathrm{MCi})$. The release of radioactive noble gases was estimated at approximately $81,000 \mathrm{TBq}(2 \mathrm{MCi})$. The heaviest contamination was noted at the epicenter of the release and along the axis of the radioactive plume. Seven and one-half hours after the accident the exposure dose rate (EDR) of radiation in the area of the accident reached $250-500 \mathrm{mr} / \mathrm{hr}$, and contamination of surfaces by beta-emitting nuclides was $0.5-4.0 \times 10^{6}$ decays $/ \mathrm{cm}^{2}-\mathrm{min}$.

Significant radioactive contamination affected submarines and special vessels near the accident site, piers, and the shipyard's land and manufacturing structures.

Also radioactively contaminated was a large part of the water area of Chazhma Bay, especially near the damaged NS. Contamination of the bay occurred at the time of the explosion and formation of the plume, and also when radioactive water from the damaged compartment entered the water through the hole formed in the pressure hull. One hour after the explosion, the activity of short-lived radionuclides in the seawater reached $74 \mathrm{kBq} /(2 \mu \mathrm{Ci})$. Two months after the accident, radionuclide levels in the seawater had declined to original background values, where they remain today.

The accident created a focus of radioactive contamination on the bottom of the water area of Chazhma Bay. The area of intense radioactive contamination is concentrated at the accident site and within the limits of EDR $>240 \mu \mathrm{r} / \mathrm{hr}$ occupies an area of about $100,000 \mathrm{~m}^{2}$. In the central part of the focus, the EDR is $20-40 \mathrm{mr} / \mathrm{hr}$, with a maximum of $117 \mathrm{mr} / \mathrm{hr}$ as of 1992 . Currents are gradually moving the radioactive contamination toward the entrance to Chazhma Bay. The radioactivity of bottom sediments is due mainly to ${ }^{60} \mathrm{Co}(96-99 \%)$ and partly to ${ }^{137} \mathrm{Cs}$.

The maximum ${ }^{60} \mathrm{Co}$ unit activity in bottom sediments at the accident site is $78 \mathrm{kBg} / \mathrm{kg}(2.1$ $\mu \mathrm{Ci} / \mathrm{kg})$, and in marine water life $670 \mathrm{~Bq} / \mathrm{kg}(18 \mu \mathrm{Ci} / \mathrm{kg})$. The total ${ }^{60} \mathrm{Co}$ activity in the bottom sediments of Chazhma Bay as of 1992 was approximately $185 \mathrm{GBq}(5 \mathrm{Ci})$.

Contamination of bottom sediments by ${ }^{137} \mathrm{Cs}$ is seen in local areas and in concentrations comparable to or slightly above background values.

Radioactive contamination of the water area affects the southeastern part of Chazhma Bay. The area of maximum contamination of the bay bottom is $0.08-0.1 \mathrm{~km}^{2}$ (within limits of gamma ray $\mathrm{EDR}>240 \mu \mathrm{r} / \mathrm{hr}$ ). Contamination of bottom sediments can be observed moving from the accident area toward the western entrance to Strelki Inlet. Contamination of the water area of eastern Ussuri Inlet within a radius of $3-5 \mathrm{~km}$ from the explosion site of the shore radioactive plume creates an elevated gamma ray EDR over background of between 1 and $8 \mu \mathrm{r} / \mathrm{hr}$.

Radioactive contamination in the water area of Chazhma Bay, the western passage of Strelki 
Inlet, and the eastern part of Ussuri Inlet is caused by concentration of radionuclides, mainly ${ }^{60} \mathrm{Co}$, by bottom sediments. The activity of radionuclides in the seawater in these areas is at the level of background values typical of other parts of the Pacific coast. All activity is concentrated in the bottom sludge and can be removed only along with it or from the surface mud layer.

The observed tendency for radioactive contamination in the bottom layer to move and disperse along the bottom of Chazhma Bay will entail no serious ecological consequences, since the total radionuclide activity in the bottom sediments is relatively low (about $5 \mathrm{Ci}$ ), and the leading radionuclide is ${ }^{60} \mathrm{Co}$, with a half-life of 5.26 years.

During the accident and cleanup, 290 persons were exposed to elevated radiation. At the time of the accident, 10 persons died of their injuries (eight officers and two enlisted men). Ten persons developed acute radiation sickness, and 39 displayed radiation reactions

Continuous monitoring of radiation conditions in the accident area and in the radioactive plume has been performed by the yard's radiation safety service. Periodic monitoring of radioactive contamination of natural environmental systems is being performed by units of the Pacific Fleet's Chemical and Medical Services, the Maritime Flotilla, the Maritime Territory Sanitary and Epidemiological Service, and the Maritime Hydrometeorological Administration.

In the future, radioecological studies of the consequences of the NS accident in Chazhma Bay (including to refine the boundaries of the radioactive plume in the marine environment and its rate of dispersion along the bottom of the bay and inlet) must be continued.

\subsection{Accident on the Nuclear Submarine Komsomolets in the North Atlantic, 1989}

On April 7, 1989, a fire broke out in the stern section of the Komsomolets, a nuclear submarine. The vessel surfaced, but after several hours' struggle for survival, it sank, killing 42 crew members. The NS reached bottom at a depth of $1680 \mathrm{~m}$ at a point with coordinates $73^{\circ} 43^{\prime} 16^{\prime \prime} \mathrm{N}$ by $13^{\circ} 15^{\prime} 52^{\prime \prime} \mathrm{E}$, near the island of Medvezhiy. The site is about 300 nautical miles from the Norwegian coast.

One difference between this accident and others, including those involving American NS's, is the threat of accelerated release of radionuclides into the marine environment. The reason is that the Komsomolets has a titanium pressure hull. The rate of corrosion is increased manyfold when a titanium hull reacts in seawater with the steel reactor parts and other ship components made of various metallic materials.

The reactor was switched to stable cooldown mode, ensuring nuclear safety, both at the time of sinking and when the vessel remained sunken.

From the time of sinking, engineering design features of its NWH's made a nuclear explosion absolutely impossible, so the problem of nuclear safety for the ship in its sunken position can be regarded as solved. However, the problem of ensuring radioecological safety remains.

From information on the power generated by the power plant of the Komsomolets, experts estimate that the reactor core contains approximately $42 \mathrm{kCi}$ of ${ }^{90} \mathrm{Sr}$ and $55 \mathrm{kCi}$ of ${ }^{137} \mathrm{Cs}$. The radioactivity of its NWH's, resulting from their ${ }^{239} \mathrm{Pu}$ content, is about $430 \mathrm{Ci}$.

The area where the accident took place is among the most biologically productive in the world's oceans, and is of special economic importance. It falls within the spheres of interest of Russia, Norway, Sweden, Great Britain, and Iceland. Even minimal transport of radionuclides (fission products and transuranian elements) up the food chain from seawater to plankton to fish could have grave political and economic consequences.

The first expedition in the area of the NS's sinking was undertaken in May 1989 by the RN Akademik Mstislav Keldysh. The results of the study were of a reconnaissance nature. 
A full-scale research program was carried out on a second expedition on several ships from April to September 1991. Two Mir deep-water manned submersibles were outfitted with standard dosimetric instruments and specially developed radiometric apparatus. The submersibles delivered special cartridges with selective sorbents to capture certain radionuclides to the NS and recovered them. Between August 23 and 31, 1991, both submersibles dived to the Komsomolets simultaneously for a total time of 66 hours 31 minutes. Thirty-two water and soil samples were taken immediately alongside the NS's hull. The results of analyses obtained by January 1992 showed that although the primary loop of the reactor was not watertight, the release of radionuclides was extremely low $\left({ }^{137} \mathrm{Cs}\right.$ concentrations not over $\left.10 \mathrm{pCi} /\right)$.

It was learned that the upper part of the pressure hull in the area of the forward compartments is damaged. It was also found that the doors of the torpedo tubes are open and seawater is in contact with the bodies of the missile torpedoes. The casings of the NWH's have lost their seals, and active warhead materials are in contact with seawater.

A third expedition to the Komsomolets was conducted from May 7 to 18, 1992 aboard the RV Akademik Mstislav Keldysh and the RV Ivan Kruzenshtern. Submersibles performed six dives to the Komsomolets and to a rescue chamber discovered to have surfaced 300 meters away.

Even the second expedition noted that the NS's hull had sunk into the mud relative to its base plane at least 2.5 meters at the bow and up to 4.5 meters at the stern. In 1992, noticeable changes were found compared to 1991 . Hull encrustation by living organisms was less noticeable than in August 1991, evidently due to seasonal variation.

The pressure hull had significantly more damage in the bow than had been recorded in 1991 videotapes. Along the port side, in the area of the bulkhead between Compartments I and II, a transverse crack about 2 meters long and up to $50 \mathrm{~mm}$ wide was discovered. Along the same port side of the pressure hull, a long longitudinal crack had appeared, approximately $30 \mathrm{~mm}$ wide along nearly its entire length, and in some areas the crack's opening had reached $400 \mathrm{~mm}$. In the upper part of the pressure hull of Compartment II, along the port side near the attachment of an emergency flotation buoy, the damage comprises a crack at least three meters long and up to 300 $\mathrm{m}$ wide. A noticeable increase in the amount of corrosion products (ferric oxide) within torpedo tube 2 has been recorded.

The predicted entry of small quantities of ${ }^{137} \mathrm{Cs}$ into the seawater, first recorded in 1991, was confirmed. The maximum cesium concentration near the NS was $180 \mathrm{~Bq} / \mathrm{m}^{3}$, and it averaged - on the deck above the reactor compartment-29.6 Bq/ $\mathrm{m}^{3}$ (the allowable concentration of ${ }^{137} \mathrm{Cs}$ in drinking water is $550,000 \mathrm{~Bq} / \mathrm{m}^{3}$ ). Although the official report states that analyses of water samples, bottom sediments and selective sorbents did not detect ${ }^{239} \mathrm{Pu}$ release from the NWH's into the environment in 1992, other data indicate that such releases have already been observed, albeit so far not in dangerous amounts [32].

Inspection of the area around the Komsomolets disclosed local irregularities in the distribution of natural and artificial (technogenic) radionuclides in bottom sediments. Areas with somewhat elevated but not ecologically hazardous radionuclide concentrations have an area on the order of tens of $\mathrm{m}^{2}$, located at distances of tens of kilometers from the NS. At present, the area's complex hydrology (currents up to $1.5 \mathrm{~m} / \mathrm{s}$ ) and geomorphology do not permit an unambiguous link to be drawn between the presence of irregularities in technogenic radionuclides and their release from the Komsomolets.

Turning to predictions, we can note that it is rather favorable for reactor radionuclides and no significant change in the marine environment should be expected in the immediate future.

The radioecological situation regarding the plutonium component of the NWH's is more 
alarming. The beginnings of ${ }^{239} \mathrm{Pu}$ escape can be expected in 1995-1996. The uncontrollable process of plutonium escape could occur in pulses and last several years. This could create a zone of stable contamination by ${ }^{239} \mathrm{Pu}$ corrosion products, which will be both highly active and chemically toxic, on the bottom near the NS

The Polar Institute of Marine Fishery and Oceanography (PINRO) has made assessments of the potential economic damage due to ${ }^{239} \mathrm{Pu}$ contamination of sea products. Commercial fish can be expected to be contaminated to levels double the allowable limit for ${ }^{239} \mathrm{Pu}$. Moreover, in addition to the heavy economic damage (up to 2.5 billion rubles in 1991 prices), negative political reaction by the Scandinavian countries will inevitably follow.

The most radical preventive measure would be to raise the NS. The costs of such an operation would exceed 250 million U.S. dollars. Existing damage to the pressure hull and continuing corrosion could make salvage impossible.

Local sealing could impede the rapid release of radionuclides. One proposed method of sealing the NS is to pump in a gel consisting of $1-2 \%$ chitosan (an active absorber of heavy metal salts). The gel would undergo polymerization in the presence of calcium contained in seawater, forming a glassy substance (which would not erode quickly even in strong currents), and practically completely prevent radionuclides from entering the external environment for decades.

Yet another alternative solution to the problem is to detach and raise only the NS's bow section containing the torpedo tubes (or only the torpedo tubes) and the NWH's they contain (with subsequent destruction or disposal of the warheads).

If any of these alternatives were selected, systematic radioecological monitoring at the resting place of the Komsomolets would remain mandatory. International participation in such monitoring must be expanded.

\subsection{Conclusion}

Direct measurements of the radioactivity of surface seawater in areas used for LRW disposal have shown no dangerous rise in levels of radioactive contamination over backgrounds.

At sites of direct disposal of the most hazardous SRW (reactors with SNF in place), no observations have been made since 1967. Now, a quarter of a century later, such observations must be made immediately. With this aim, a full-scale expedition must be organized this very season (summer 1993) to inspect the condition of sunken objects in inlets of the eastern coast of Novaya Zemlya and the Novaya Zemlya Depression. The expedition plans must include all SRW disposal areas, in both northern and far eastern seas.

The organization of radioecological monitoring at RW disposal sites must be done jointly by the Navy, the Russian Ministry of Nature and Roskomgidromet. For objects proven to be a radioecological hazard, the Russian Navy, Committee for Special-Purpose Underwater Work (KOPRON), Ministry of Atomic Energy and Ministry of Nature must develop a plan of measures to raise them to the surface and subsequently dispose of them on shore.

Fleet hydrographic services must establish the precise coordinates of sunken large objects and show their position on maps and in piloting books.

To assess the radiological consequences of RW disposal at sea, scientific research should be initiated immediately concerning a) the radionuclide composition of sunken objects and the condition of their protective barriers, and b) the uptake of radionuclides by food chains and dose burdens in water life.

A thorough study of the radionuclide budget of ecosystems in northern and far eastern seas should also be assigned. 


\section{Section 4. Ways of Solving the Problem of Handling Radioactive Waste Produced in The SySTEM OF THE Navy AND MURMANSK MARINe ShIPPING LINE}

The widespread practice of RW disposal at sea, followed in the former USSR from 1959 to 1991, arose as a result of unpreparedness for the deployment of an industry specializing in the handling of RW.

The design and construction of complexes for treating liquid $\mathrm{RW}$ and compacting solid $\mathrm{RW}$, begun in the $60 \mathrm{~s}$, was terminated for reasons of false economy and due to the lack of immediate danger from RW dumping at sea. As a result, Russia now faces a whole series of acute problems with the operation of its nuclear fleet, which require immediate solution.

The USSR (and now Russia) possesses 235 nuclear-powered vessels and ships, including 228 in the Russian Ministry of Defense's Navy and seven in the Russian Ministry of Transportation ( 394 nuclear reactors in the Navy and 13 on icebreakers $-60 \%$ of the world total). Each year, the operation of NS's and nuclear-powered ships produces up to $20,000 \mathrm{~m}^{3}$ of liquid RW and up to 6,000 tonnes of solid RW.

Clarification of ways of solving the problem requires a clear idea of the features of the RW produced.

Most of the LRW (up to 70\%) is low-salinity discharges of circulating waters and water loop flushes with activities on the order of $1 \mu \mathrm{Ci}$. Higher levels of activity are typical of wastes from loop decontamination, water from spent fuel assembly (SFA) holding ponds, and a number of other liquid wastes. This LRW has high salinity and comprises up to $15 \%$ of all LRW. Most of the total activity comes from this group of LRW. A third group includes waters from special sewage systems of shore sanitation stations, laundries, decontamination stations, and radiation safety laboratories. Their activity is low (up to $10 \mathrm{nCi}$ ), and they differ little in salinity from the second group, but contain surfactants. In volume, the third group also comprises about $15 \%$.

The highest levels of contamination in SRW are found in equipment used in reactor compartments.

Significant levels of activity accumulated on filters during treatment of LRW. The majority (by volume) is contaminated film coatings, uniforms, and other objects. SRW with high levels of activity was produced in operations with SNF. Handling of SNF should be singled out as an especially important problem, along with the problem of decommissioning and recycling NS's.

\subsection{Problems in Recycling Decommissioned Nuclear Submarines and Handling} Spent Nuclear Fuel in the Northern Fleet and Murmansk Marine Shipping Line

As a result of arms reductions and for technological reasons, the Russian Ministry of Defense's Navy is decommissioning NS's.

On an NS being decommissioned, SNF must be removed from reactors, decontamination must be performed, reusable equipment must be removed, and the reactor compartment must be cut out and placed in a properly equipped, ecologically safe storage or disposal site. However, due to technical unpreparedness, this cycle cannot presently be fully implemented.

The most urgent problem is removing SNF from reactors. As of January 1, 1993, SNF had been removed from only $15 \%$ of NS's decommissioned by the Navy. Only six reactor compartments had been prepared for long-term storage. A special problem is the removal of SNF from 
NS's with damaged cores, which is impossible with current technology. Abroad, such damaged NS's are placed whole in underground repositories for long-term storage.

The removal of SNF from other NS's requires properly equipped transfer points and sufficient capacity for its storage.

As of January 1, 1993, the Northern Fleet was storing 3,000 bundles with SFA's. Since each bundle contains seven FA's, the total number of SFA's is 21,000 .

The Murmansk Maritime Shipping Line is storing SFA's on the tenders Lepse, Imandra, and Lotta. They hold a total of about 4,500 SFA's, and their reserve storage capacity is practically exhausted. Conditions of removal of SFA's are just as unfavorable for the Murmansk Maritime Shipping Line as for the Navy. The repository aboard the Lepse is damaged, with a current activity of $750,000 \mathrm{Ci}$ (and $17,000 \mathrm{Ci}$ of that is due to long-lived and toxic transuranian elements).

However, the Navy and the Murmansk Maritime Shipping Line have not decided to send SFA's which are damaged, come from reactor cores with liquid metal coolant, or are being stored in containers at outdoor sites for reprocessing.

As a result of the unsatisfactory organization of work to provide timely removal of SNF from units of the Russian Navy to reprocessing plants of the Russian Ministry of Atomic Energy, existing SRW storage facilities are overflowing, both in the Navy and, to a lesser extent, in the Murmansk Maritime Shipping Line and at enterprises of the former USSR Ministry of the Shipbuilding Industry. Sufficient capacity for compacting solid (flammable) RW exists only at the Murmansk Maritime Shipping Line's Nuclear Fleet Radio Regiment, but it has not set up a special system for treatment of LRW. The Navy lacks such systems.

At present, on orders from the Russian Ministry of Defense's Navy, industry has manufactured 50 TK-VG-18 containers, whose use will support the disposal of SNF, but their use is being held up by the fleets' lack of SNF transshipment terminals (their creation is planned for 1998). According to schedules, the Navy is prepared to dispose of SNF beginning in mid-1993 using the TK-VG-18 containers.

\subsection{Problems in Recycling Decommissioned Nuclear Submarines and Handling Spent Nuclear Fuel and Other Radioactive Waste in the Far Eastern Area}

The shore bases and ships of the Pacific Fleet store 1,200 packing bundles ( 8,400 SFA's).

Only four reactor compartments have been prepared for long-term storage. As in the Northem Fleet, the problem of SNF storage facilities is extremely critical: they are overflowing and do not comply with international requirements. The condition of low- and intermediate-level SRW storage facilities aiso does not comply with these requirements.

Storage facilities for SFA's at floating maintenance centers for reactor refueling are in a dangerous condition, and the SFA's cannot be removed. Moreover, damaged reactors from three NS's are being stored with nuclear fuel, and the SFA's cannot be removed from them. This is creating a problem with future disposal of these reactor units.

Thus, the Pacific Fleet, like the Northem Fleet, lacks regional strategies for handling RW and SNF that specify and develop all technological operations involving RW from the time of production until disposal. A consistent technical policy in this vital area of fleet activity can be termed lacking. Developers and manufacturers of nuclear-powered ships and vessels are not properly coordinating their actions with local governing bodies. Their disregard for the interests of these bodies is absolutely intolerable at present. 


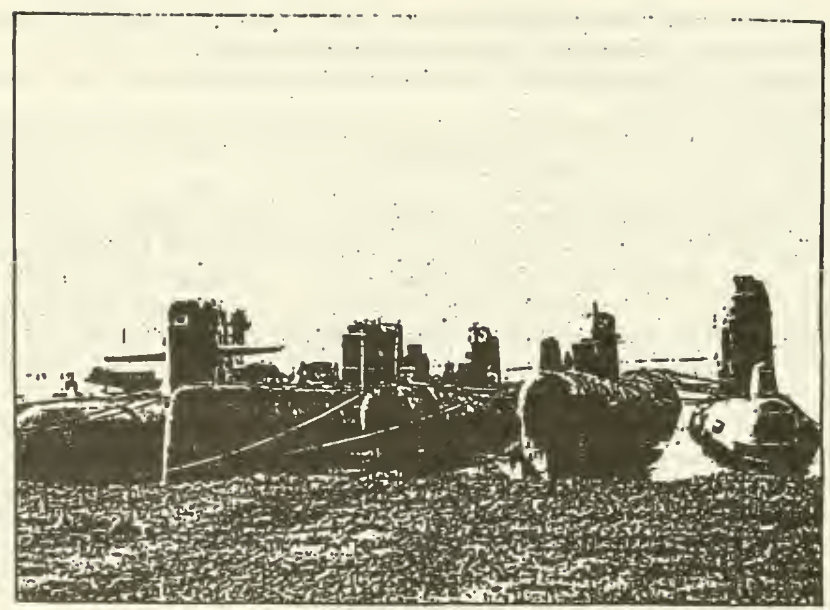

Figure 12. Decommissioned Nuclear Submarines Awaiting Reactor Core Removal and Further Recycling. Pacific Fleet, Pavlovskiy Bay.

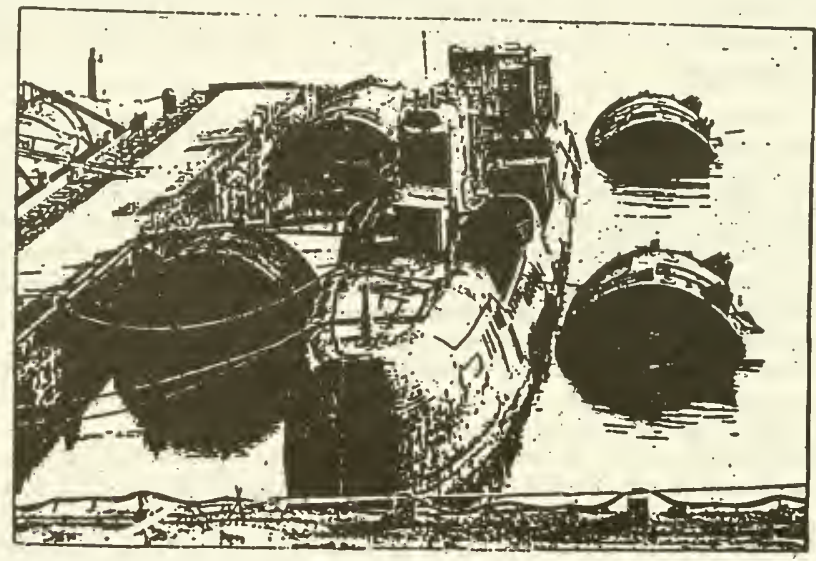

Figure 13. Pacific Fleet. Nuclear Submarine on Which Unauthorized Reactor Startup Was Performed in August 1985, Accompanied by Thermal Explosion and Fire. Nuclear fuel from re- 


\subsection{Analysis of the Proposed Russian Government Program for Handling,} Recycling and Disposal of Radioactive Wastes and Spent Nuclear Materials for the 1993-1995 Period and Through 2005, and of the Russian Federation Government Resolution of August 31, 1992 on the Recycling of Nuclear Submarines

The termination of discharges of LRW produced on Naval ships and at shipyards requires development and implementation of a special program. Expert assessments show that the realization of such a program will require at least five years and expenditures on the order of a billion rubles. A program of compaction, reprocessing, storage and disposal of SRW will require significantly greater outlays. The implementation of both these programs can be realized in the framework of the special-purpose Russian Government Program for Handling, Recycling and Disposal of Radioactive Wastes and Spent Nuclear Materials for the 1993-1995 Period and Through 2005. The program is presently under review by the Government of the Russian Federation.

Section 9 of the Program, titled Handling Wastes Produced in the Operation and Decommissioning of Nuclear Propulsion Units, stipulates the allocation of over six billion rubles (in 1992 prices) for the creation of shore and ship systems and units for reprocessing liquid and solid RW produced during the operation and repair of nuclear power plants.

The Program for Handling Radioactive Waste schedules for 1993 the conduct of a general analysis of the formation and accumulation of RW in northern and far eastern areas of Russia and the workup of a feasibility study for the development of specialized industrial capacity that will meet the needs for temporary storage, processing and disposal of RW. Under the 1993-1995 Program, pilot repositories are to be developed for disposal of solid and solidified low- and intermediate-level RW.

If work on the Program is begun immediately, capacity for disposal of high-level SRW could be brought on line in 1996. The plan calls for developing designs and by 2000 completing work on the decommissioning or modernization of radioactively contaminated engineering structures of shore maintenance centers and other Naval facilities.

Measures to normalize the radiation conditions in Chazhma Bay and the town of Shkotovo22, Maritime Territory, are to be developed in 1993 and implemented by 1995.

One item in Section 9 of the Program provides for assessment of the radioecological consequences of RW disposal at sea and the sinking of NS's.

A study of sinking sites of reactors with SNF in place is an urgent priority and must be performed by the forces of a Russian expedition with international involvement no later than summer 1993.

The other urgent measures included in the Program for Handling Radioactive Waste must include immediate organization of the removal of SNF from storage facilities (primarily floating ones) of the Navy and Murmansk Maritime Shipping Line. Construction of new SNF storage facilities at Naval bases must also be arranged immediately and included in the program, and the commissioning of the proposed SNF storage facilities of the Murmansk Maritime Shipping Line must be advanced from 1995 to 1994.

Thus, the current draft Program does not take sufficient account of the RW handling problems that have arisen in the operation of nuclear-powered ships and vessels.

A source of concern is the slow progress of the Program. Financing of work for the Program appears clearly low and does not correspond to its stated objectives.

A Resolution adopted by the Govemment of the Russian Federation in August 1992 specified 
practically the entire range of priority steps to recycle NS's and nuclear-powered ships decommissioned through 2000. These steps include the construction of temporary storage sites for floating NS's; the retrofitting of shelters for temporary storage of NS reactor compartments; and the construction of shore bases for vessels, compartments and equipment for removing reactor cores and receiving and reprocessing $\mathrm{RW}$, decontamination shops, sections for preparing SRW for disposal with incinerators, special water treatment and laundries with tanks for temporary storage of liquid RW and space for temporary storage of solid RW.

On the other hand, the resolution does not resolve questions of the disposal of NS reactor compartments from which removal of SNF is technically impossible, and does not resolve questions of the selection of optimal methods and techniques for disposing of reactor compartments and their equipment and technologies for dismantling and recycling nuclear-powered ships and NS's and their weapons and armaments in order to prevent radioactive contamination of the environment.

\subsection{Conclusion}

Thus, the Northern and Pacific Fleets have accumulated an aggregate total of about 30,000 SFA's, which corresponds to the contents of about 140 NS reactor cores. Storage facilities have free space to accept only three more cores.

Given that the normal operation of NS's requires the transfer of about ten reactor cores in each fleet annually, it is obvious that a critical situation now exists that rules out the further safe operation of the NS fleet.

At present, the Navy is not prepared to completely halt the discharge of LRW at sea before commissioning of shore processing centers, planned for 1997.

The current draft of the Government Program for Handling Radioactive Wastes does not sufficiently account for problems connected with the comprehensive solution of the RW handling problems created by the operation of nuclear-powered ships and vessels.

The Government resolution adopted in August 1992 provides for the solution of most of the urgent problems relating to the recycling of NS's and nuclear-powered ships. However, even if the measures called for in the resolution are fully realized, the necessary capacity to recycle RW produced thereunder will not be commissioned until 1996-1997. The resolution also does not address the problem of recycling liquid and solid RW produced during the operation of nuclearpowered Naval vessels, and does not resolve problems of the disposal of damaged reactor compartments. 


\section{CONCLUSION}

In accordance with the objectives stated by the President of the Russian Federation, we have examined two basic aspects of the problem, international and domestic Russian.

The problems of RW disposal at sea have acquired special importance from the standpoints both of Russia's compliance with international obligations and of ensuring Russia's ecological safety.

The unacceptability of RW disposal at sea for Russia follows from the Russian Federation Law, Protection of the Natural Environment, Article 50, Paragraph 3 of which prohibits the sinking of RW, and from the repeated official position of the Russian Federation, which signed a corresponding declaration in Rio de Janeiro and two conventions on the protection of the marine environment (the Baltic and Black Seas) that prohibit the disposal of RW at sea.

The performance of Russia's international obligations under the London Convention require:

1) presentation of data collected by the Commission on RW dumpings conducted at sea and official statistical manuals to the Secretariat of the International Maritime Organization and the IAEA;

2) inspection of RW disposal sites at sea with the support and participation of representatives of interested nations and competent international organizations;

3) organization of effective monitoring of sites where dumpings of high-level RW have been conducted in the past;

4) development of plans for purifying seas of high-level RW that presents an environmental hazard;

5) immediate resolution of problems of processing and safe storage of RW produced by the operation of nuclear-powered vessels and ships (primarily regarding the construction of storage facilities and commissioning of capacity to process RW). 


\section{FindingS}

1. We have established and documented that beginning in 1959, the former USSR disposed of various levels of RW. This refers to RW produced during the operation and repair of nuclearpowered Naval vessels and ships of the Murmansk Maritime Shipping Line. There were cases of unauthorized and accidental sinking of vessels containing RW. Some RW (including NS reactor compartments and damaged reactors with nuclear fuel residues) was transferred for sinking from ship repair enterprises of the USSR Ministry of the Shipbuilding Industry.

In 1991-1992, the Navy continued dumping liquid RW in the Barents Sea, as well as liquid and solid RW in Far Eastem seas.

2. The Soviet Union did not furnish any information to the International Maritime Organization of the International Atomic Energy Agency on RW dumping at sea performed by the USSR.

Normative legal acts and departmental instructions regarding the disposal of RW at sea that have been retained from the time of the USSR and are applicable on Russian territory either do not comply with or directly contradict the London Convention accepted by the Russian Federation, other international agreements in this area, and the 1991 Russian Federation Law Protection of the Natural Environment.

3. Due to the fleets' unpreparedness for a transition to new means of transporting SNF, existing temporary storage facilities for SFA's are overflowing. SRW from vessels, ships and yards is accumulating in containers in outdoor areas.

This is why it is practically impossible to halt RW dumping at sea without simultaneously solving problems of handling it on shore. It would lead to a further accumulation of RW at its points of production and temporary storage, degrade radiation and overall ecological conditions, and cause a rise in social tensions and a real threat to personnel and the public.

4. Because the leaders of the former USSR adopted the concept of disposing of intermediate- and low-level RW at sea, construction of capacity for processing solid RW and purifying liquid RW, begun by the Navy in the 60s, was halted in 1972 .

The 1985 USSR Government decision to build special storage facilities in the northern and Pacific Fleets for disposal of reactor compartments from NS's, with commissioning of their first stages scheduled for 1993, has not been implemented.

5. It appears impossible to establish the amount of radionuclides that entered the marine environment in RW discharges from the territory of the USSR with the desired accuracy. According to documentary data at the Commission's disposal, the activity of dumped RW was $325 \mathrm{kCi}$. According to expert estimates, the maximum activity of RW that entered seas adjacent to Russian territory could have been as much as $2,500 \mathrm{kCi}$ (at the time of disposal).

6. The greatest potential radioecological hazard is presented by reactors from NS's and the core plate of the nuclear icebreaker Lenin, with nuclear fuel in place, which were dumped in shallow inlets of Novaya Zemlya archipelago in the Kara Sea.

7. Monitoring of radiation conditions in marine disposal areas for SRW has not been performed for over 25 years. 


\section{MAKEUP OF THE GovernMENT COMMISSION ON MATTERS \\ Related to Radioactive Waste Disposal at Sea}
A. V. Yablokov
G. V. Berdennikov
N. N. Yegorov
O. P. Yefimov

Yu. N. Zubkov

V. D. Reva

V. A. Kimstach

V. F. Menshchikov

\section{A. A. Monisov}

A. M. Moskvichev

S. V. Palekhov

A. F. Poryadin

V. Ye. Selivanov

V. A. Timofeyev

V. K. Karasev

\section{Commission Chairman:}

Adviser to the President of the Russian Federation for Matters of Ecology and Public Health

Commission Members:

Russian Federation Deputy Minister of Foreign Affairs

Russian Federation Deputy Minister for Atomic Energy

Director, Main Administration of the Shipbuilding Industry of the Russian Federation Committee for Defense Industries

Deputy Chairman, Gosatomnadzor

Director, Federal Administration of Medical, Biological and Emergency Problems, Russian Ministry of Public Health

Deputy Chairman, Roskomgidromet

Deputy Chairman, Russian Federation Supreme Soviet Committee for Matters of Ecology and Efficient Use of Natural Resources

Deputy Chairman, Russian State Sanitary and Epidemiological Supervisory Committee

Russian Federation Deputy Minister of Public Health

Deputy Director, Department of Maritime Transportation, Russian Ministry of Transportation

Russian Federation First Deputy Minister of Environmental Protection and Natural Resources

Director, Navy General Command, Russian Ministry of Defense

Russian Federation Deputy Minister of Security

Executive Secretary of the Commission:

Consultant to the Office of the Adviser to the President of the Russian Federation for Matters of Ecology and Public Health 


\section{MAKEUP OF THE COMMISSION'S WORKING GROUP AND EXPERT GROUP}

\section{N. Lystsov}

A. I. Tsubannikov

Yu. D. Kovalenko

A. Ye. Berkov

N. A. Tsybikov

S. I. Bashevoy

V. N. Androsyuk

A. A. Solovyanov

N. Z. Bisovka

A. V. Kulik

P. M. Rubtsov

O. I. Petrov

A. D. Spiridonov

S. A. Bubliy

V. I. Demin

G. P. Kolyadko

M. Ye. Kokeyev

V. A. Makarenkov

V. M. Rumyantsev

I. N. Torgun

Ye. V. Borisov
A. M. Petrov
G. A. Vorobyëv
V. M. Chistokhin
A. P. Lvov

T. N. Borisov

A. F. Yemelyanenkov

Yu. V. Sivintsev

V. N. Yakimets

I. V. Lisovskiy

P. A. Ruzhanskiy
Members of the Working Group:

Russian Ministry of Nature (Head of Data Collection Subgroup)

Navy, Russian Ministry of Defense

Main Administration of the Shipbuilding Industry, Russian Federation

Committee for Defense Industries

Department of Maritime Transportation, Russian Ministry of Transportation

Roskomgidromet

Computer Center, NLK of Russian State Committee for $\underline{\mathrm{ChS}}$

Special Shipments Office, Russian Ministry of Railroads

Russian Ministry of Fuel and Energy

Russian State Nuclear Power Supervisory Administration

Russian Ministry of Defense

State Institute of Applied Ecology, Russian Ministry of Nature

Navy, Russian Ministry of Defense (Head of Radiology Subgroup)

Federal Administration of Medical, Biological and Emergency

Problems, Russian Ministry of Public Health

Russian State Sanitary and Epidemiological Supervisory Committee

Russian Committee for Land

Russian Ministry of Nature

Administration of International Trade Relations, Russian Ministry of Foreign Affairs (Head of International Law Subgroup)

Russian Ministry of Security

Russian Ministry of Nature

Russian Ministry of Defense

State Oceanographic Institute, Russian Committee for

Hydrometeorology

Center for Storage of Modern Documentation, Russian Federation State Archival Service (Head of Archive and Document Subgroup)

Navy, Russian Ministry of Defense

Russian Ministry of Atomic Energy

Russian Ministry of Nature (Executive in charge of drafting this report)

Chairman, KOPRON

Experts:

Chairman, Toward a New Earth popular movement

Kurchatov Institute Russian Science Center

Institute of Management Problems, Russian Academy of Sciences

First Central Scientific Research Institute, Russian Ministry of Defense

State Institute of Applied Ecology, Russian Ministry of Nature 


\section{REFERENCES}

1. Decree No. 613-rp of the Russian Federation President, October 24, 1992, Formation of a Governmental Commission on Matters Related to the Disposal of Radioactive Waste at Sea. Collected Decrees of the Russian Federation President, April-November 1992, p. 135.

2. 1972 London Convention on Prevention of Pollution of the Sea by Discharges of Wastes and Other Materials. Leningrad: GGUNiO, Book 9055, 1986.

3. IAEA Requirements for Disposal of Radioactive Waste at Sea. IAEA Safety Series, 78. Vienna, 1978.

4. Resolutions of Consultative Conferences of Representatives of the Contracting Parties to the 1972 London Convention. LDC.13/Inf. Doc. 14, Annexes 19, 20, 21, 22. London: IMO, 1990.

5. Report 10 of the Consultative Conferences of Representatives of the Contracting Parties to the 1972 Convention on Prevention of Pollution of the Sea by Discharges of Wastes and Other Materials. LDC.9/W. P. 14. London: IMO, 1985.

6. Summary of Nations' Reports on the IAEA Circular Questionnaire. IAEA TECDOC 588. Vienna, March, 1990.

7. Diplomatic Conference on the Protection of the Marine Environment of the Baltic Sea Area. Conf. Doc. No. 4, Helsinki, 1992.

8. Oslo and Paris Convention for the Prevention of Marine Pollution. Doc. Ministerial Meeting, Annex 2, 1992.

9. 1992 Convention on the Protection of the Black Sea from Pollution (manuscript at Russian Ministry of Foreign Affairs).

10. Inventory of Radioactive Material Entering the Marine Environment: Sea Disposal of Radioactive Waste. IAEA TECDOC 588, March 1991.

11. Gromov, V. V., Moskvin, A. I., Sapozhnikov, Yu. A. Technogenic Radioactivity of the World's Oceans. Moscow: Energoatomizdat, 1985.

12. Documents of Greenpeace International. Manuscript at Russian Ministry of Natuse.

13. Shvedov, V. P., Patin, S. A. Radioactivity of Oceans and Seas. Moscow: Atomizdat, 1975.

14. The Atom Declassified: Viewpoints. Compiled by A. Yemelyanenkov and V. Popov. Moscow, Berlin: H\&P Druck, 1992, 144 pp.

15. Poluektova, G. B. Disposal of Low- and Intermediate-Level Wastes Abroad. Review of Foreign Sources for the Years 1981-1989. Informational Bulletin No. 5, TsNILAtominform, pp. 28-61.

16. J. Handler. "Testimony for the U.S. Senate Select Committee on Intelligence Hearing, held August 15, 1992, on Radioactive and Other Environmental Threats to the U.S. and the Arctic Resulting from Past Soviet Activities." Ms., pp. 1-9.

17. Agenda for the 2/st Century. Report of the UN Conference on Environment and Development. A/Conf. 151/26 Vol. II, Chap. 22. Safe and Ecologically Grounded Disposal of Radioactive Waste, pp. 284-286.

18. USSR Council of Ministers Resolution No. 222, March 6, 1979, Measures to Fulfill the Obligations of the Soviet Side Following from the 1972 Comvention on Prevention of Pollution of the Sea by Discharges of Wastes and Other Materials. Leningrad: GUNiO, Book 9055, 1986. 
19. Legin, A. V., Gusev, B. I. Upper Limits of the Concentration of Radionuclides in Seawater during Prolonged Contamination of Areas with Various Commercial Uses. Report of the USSR Chief State Physician, 1982.

20. "Russian Federation Law, Protection of the Natural Environment." Ekologicheskiy vestnik Rossii, No. 5, 1992.

21. Vakulovskiy, S. M., Nikitin, A. 1., Chumichev, V. B. "Contamination of Arctic Seas by Radioactive Wastes from Western European Radio Factories." Atomnaya energiya, Vol. 58 (1985) No. 6, pp. 445-449.

22. The Russian Submarine. Information and Commentary by the Russian State Nuclear Power Supervisory Administration, 11/24/92.

23. Radiation Conditions on the Territory of Russia and Adjacent Nations in 1991. A Yearbook. Ed. by K. P. Makhonko. Obninsk: Rosgidromet, 1992, 362 pp.

24. Matishov, G. G. Anthropogenic Destruction of Barents and Nonwegian Sea Ecosystems. Apatity, 1992, p. 113

25. Comprehensive International Expedition of the Murmansk Biological Institute to Areas of High-Latitude Archipelagos of the Barents Sea (Franz Josef Land, Novaya Zemlya). AugustSeptember 1991 (RV Dalmiye Zelentsy, RV Pomor). Apatity, 1992, 56 pp.

26. Matishov, G. G., et al. "Radionuclides on the Kola Peninsula, Novaya Zemlya, Franz Josef Land, and in the Barents Sea." Kola Science Center Preprint. Apatity, 1992.

27. "International (American-Norwegian-Russian) Ecological Expedition in the Pechora Sea, to Novaya Zemlya, Kolguyev, Vaygach and Dolgiy. July 1992 (R/V Dalniye Zelentsy)." Preprint. Apatity, 1992, 42 pp.

28. "Navy General Staff of Russian Defense Ministry Refutes ABC Television Report..." Information and Commentary by the Russian State Nuclear Power Supervisory Administration, 11/24/92, 3 pp.

29. Burbyga, N. "How We 'Presented' the Americans Two Atom Bombs, and the Japanese Helped." Izvestia, No. 110, May 12, 1992, p. 7.

30. Agafonov, S., Burbyga, N., Illesh, A. "International Scandal over Atom Bombs from the Bottom of the Sea of Okhotsk." Izvestia, No. 112, May 14, 1992, p. 6.

31. Decision No. 160 of the Murmansk Province Council of People's Deputies, December 22, 1992, Measures to Improve the Level of Nuclear and Radiation Safety on the Territory of Murmansk Province.

32. "International Meeting on Assessment of Actual and Potential Consequences of Dumping of Radioactive Waste into Arctic Seas, Oslo, Feb. 1-5, 1993." Ocean Disposal of Radioactive Waste: The IAEA "Definition and Recommendations" and the IAEA Database.

33. "Summary Findings of the Expert Commission of the State Ecological Inspectorate of the Russian Federation Ministry of Ecology, Based on Materials from an Inspection of the Novaya Zemlya Archipelago and Adjacent Territories." Manuscript of the Russian Ministry of Nature. Moscow, 10/13/1992, 40 pp.

34. J. Scorve, J. K. Skogan \& Nyt "NUPI Satellite Study of the Northern Underground Nuclear Test Area on Novaya Zemlya." Norwegian Institute of International Affairs Research Report No. 164, December 1992, Oslo, 52 pp. 1993, p. 8

35. I. Palekhov. "The Motherland Has Forgotten Us." Federatsiya, No. 16, February 11, 


\section{ABBREVIATIONS USED}

\begin{tabular}{ll} 
Used in Translation & Used in Original \\
\cline { 2 - 2 } Gosatomnadzor & Gos \\
Goskomnadzor \\
IAEA & \\
IGPRAD & MAGATE \\
& IGPRAD \\
IMO & \\
KOPRON & IMO \\
LRW & KOPRON \\
NS & ZhRO \\
NWH & APL \\
PINRO & YaBP \\
PS-82 & PINRO \\
Roskomgidromet & PS-82 \\
RTG & Roskomgidromet \\
RW & RITEG \\
SFA & RAO \\
SNF & OTVS \\
SRW & OYaT \\
VSTZ-66 & TRO \\
& VSTZ-66
\end{tabular}

\section{Expansion}

fuel assembly

Russian State Committee for the Supervision of

Nuclear and Radiation Safety

USSR State Committee for Hydrometeorology

International Atomic Energy Agency

Intergovernmental Working Group on Radioactive

Waste Disposal

International Maritime Organization

Committee for Special-Purpose Underwater Work

liquid radioactive waste

nuclear submarine

nuclear warhead

Polar Institute of Marine Fishery and Oceanography

Regulations for Discharge of Radioactive Waste at Sea

Russian Committee for Hydrometeorology

radioisotope thermoelectric generator

radioactive waste

spent fuel assembly

spent nuclear fuel

solid radioactive waste

Temporary Sanitary Requirements for Disposal of Radioactive Wastes at Sea 
APPENDICES

Table A1. Characteristics of Liquid Radioactive Waste Discharge Areas in Northern Seas

\begin{tabular}{|c|c|c|c|c|c|}
\hline \multirow{2}{*}{ Area } & \multicolumn{2}{|c|}{ Coordinates } & \multirow{2}{*}{$\begin{array}{c}\text { Geographic } \\
\text { Name }\end{array}$} & \multirow{2}{*}{$\begin{array}{l}\text { Depth, } \\
\text { meters }\end{array}$} & \multirow{2}{*}{ Remarks } \\
\hline & N. Lat. & E. Long. & & & \\
\hline 1 & $\begin{array}{l}78^{\circ} 0^{\prime} \\
78^{\circ} 0^{\prime} \\
74^{\circ} 0^{\prime} \\
74^{\circ} 0^{\prime}\end{array}$ & $\begin{array}{l}48^{\circ} 0^{\prime} \\
52^{\circ} 0^{\prime} \\
48^{\circ} 0^{\prime} \\
52^{\circ} 0^{\prime}\end{array}$ & Barents Sea & $180-300$ & Open sea \\
\hline 2 & $\begin{array}{l}77^{\circ} 0^{\prime} \\
77^{\circ} 0^{\prime} \\
72^{\circ} 30^{\prime} \\
72^{\circ} 30^{\prime}\end{array}$ & $\begin{array}{l}43^{\circ} 0^{\prime} \\
47^{\circ} 0^{\prime} \\
43^{\circ} 0^{\prime} \\
47^{\circ} 0^{\prime}\end{array}$ & Barents Sea & $200-300$ & Open sea \\
\hline 3 & $\begin{array}{l}72^{\circ} 45^{\prime} \\
72^{\circ} 45^{\prime} \\
72^{\circ} 15^{\prime} \\
72^{\circ} 15^{\prime}\end{array}$ & $\begin{array}{l}33^{\circ} 30^{\prime} \\
36^{\circ} 30^{\prime} \\
33^{\circ} 30^{\prime} \\
36^{\circ} 30^{\prime}\end{array}$ & Barents Sea & $200-300$ & Open sea \\
\hline 4 & $\begin{array}{l}69^{\circ} 51^{\prime} \\
69^{\circ} 51^{\prime} \\
69^{\circ} 34^{\prime} \\
69^{\circ} 34^{\prime}\end{array}$ & $\begin{array}{l}34^{\circ} 15^{\prime} \\
34^{\circ} 51^{\prime} \\
34^{\circ} 15^{\prime} \\
34^{\circ} 51^{\prime}\end{array}$ & Barents Sea & $100-200$ & Coastal \\
\hline 5 & $\begin{array}{l}68^{\circ} 18^{\prime} \\
68^{\circ} 18^{\prime} \\
68^{\circ} 10^{\prime} \\
68^{\circ} 10^{\prime}\end{array}$ & $\begin{array}{l}40^{\circ} 13^{\prime} \\
40^{\circ} 36^{\prime} \\
40^{\circ} 13^{\prime} \\
40^{\circ} 36^{\prime}\end{array}$ & Barents Sea & $50-100$ & Coastal \\
\hline
\end{tabular}


Table A2. Characteristics of Liquid Radioactive Waste Discharge in Northern Seas

\begin{tabular}{|c|c|c|c|c|c|c|c|c|c|c|c|}
\hline \multirow[b]{2}{*}{ Year } & \multicolumn{2}{|c|}{ Area 1} & \multicolumn{2}{|c|}{ Area 2} & \multicolumn{2}{|c|}{ Area 3} & \multicolumn{2}{|c|}{ Area 4} & \multicolumn{2}{|c|}{ Area 5} & \\
\hline & \begin{tabular}{|c|}
$\begin{array}{c}\text { Volume, } \\
\mathrm{m}^{3}\end{array}$ \\
\end{tabular} & $\begin{array}{l}\text { Activity, } \\
\mathrm{Ci} \text { (TBq) }\end{array}$ & \begin{tabular}{|c|}
$\begin{array}{c}\text { Volume. } \\
\mathrm{m}^{3}\end{array}$ \\
\end{tabular} & $\begin{array}{l}\text { Activity, } \\
\mathrm{Ci} \text { (TBq) }\end{array}$ & \begin{tabular}{|c|}
$\begin{array}{c}\text { Volume, } \\
\mathrm{m}^{3}\end{array}$ \\
\end{tabular} & $\begin{array}{l}\text { Activity. } \\
\mathrm{Ci} \text { (TBg) }\end{array}$ & \begin{tabular}{|c|}
$\begin{array}{c}\text { Volume, } \\
\mathrm{m}^{3}\end{array}$ \\
\end{tabular} & \begin{tabular}{|l|} 
Aclivity, \\
Ci (TBq) \\
\end{tabular} & \begin{tabular}{|c|}
$\begin{array}{c}\text { Volume, } \\
\mathrm{m}^{3}\end{array}$ \\
\end{tabular} & $\begin{array}{l}\text { Accivity, } \\
\mathrm{Ci} \text { (TBq) }\end{array}$ & \\
\hline 1960 & & & 760 & 0.21 & & & & & & & \\
\hline 1961 & & & 930 & 16.5 & & & & & & & \\
\hline 1962 & & & 850 & +61 & & & & & & & \\
\hline 1963 & & & 1054 & 358.15 & & & & & & & \\
\hline 1964 & & & 910 & 153.11 & & & & & & & \\
\hline 1965 & & & 6520 & 963.62 & & & & & & & \\
\hline 1966 & & & 3540 & 366.84 & 1220 & 5.97 & & & 449 & 1.01 & \\
\hline 1967 & & & 144 & $\$ 017$ & 530 & 2.2 & & & 2000 & 2.69 & \\
\hline 1968 & 353 & 2.81 & & & 1357 & 0.50 & & & 1400 & 1.52 & \\
\hline 1969 & 316 & 109.51 & $3+16$ & 51.87 & 1290 & 0.29 & & & 750 & 0.41 & \\
\hline 1970 & 2703 & 65.42 & & & 4370 & 96.13 & & & 2257 & 0.56 & \\
\hline 1971 & & & 2371 & 20.65 & 1096 & 3.62 & & & 1549 & 1.41 & \\
\hline 1972 & 850 & 5.9 & 930 & 195 & 4101 & 101.33 & & & 2560 & 8.40 & \\
\hline 1973 & 882 & 22.0 & 405.7 & 76.6 & 3872 & 129.36 & & & 885 & 4.00 & \\
\hline 1974 & & & 8645 & 265.7 & 3155 & 321.3 & & & 838 & 0.80 & \\
\hline 1975 & 1947 & 430.0 & 4720 & 55.27 & 851 & 15.3 & 835 & 6.35 & 1610 & 8.16 & \\
\hline 1976 & 1800 & 630 & 6229 & 759 & 2788 & 811.9 & & & 830 & 11.20 & \\
\hline 1977 & 1500 & 68.32 & 4150 & +735 & 860 & 1.5 & & & 870 & 8.70 & \\
\hline 1978 & 340 & 30.19 & & & 5170 & 90.25 & & & & & \\
\hline 1979 & 604 & 12.01 & & & 7286 & $78+2$ & & & & & \\
\hline 1980 & 650 & 27.06 & $3+05$ & 22.32 & 3957 & 37.67 & & & 800 & 8.00 & \\
\hline 1981 & & & 2146 & 26827 & 2130 & 201.06 & 906 & 3.99 & 2755 & 21.13 & \\
\hline 1982 & 1250 & 169.0 & 1745.4 & 1107 & $1+76.6$ & 18.52 & & & 1855 & 9.70 & \\
\hline 1983 & 685 & 72.41 & 17721 & 265.34 & +72 & 11.06 & & & 3247 & 22.34 & \\
\hline 1984 & & & 5125.4 & 222.13 & 820 & 5.99 & 740 & 2.78 & 1614.8 & 51.38 & \\
\hline 1985 & & & & & 2376.6 & 65.85 & & & 3980.5 & 21.9 & \\
\hline 1986 & & & 900 & 10.59 & 870 & 29.49 & 1410 & 5.74 & 3410 & 23.73 & \\
\hline 1987 & & & 1740 & 34.8 & 780 & 14.7 & 2211 & 22.38 & 2063 & 20.61 & \\
\hline 1988 & $36+5$ & 5278.51 & & & & & & & & & \\
\hline 1989 & & & & & 2472 & 39.76 & 875 & 1.41 & 2752 & 11.10 & Total, Areas 1-5 \\
\hline 1990 & & & 751 & 0.84 & & & 1267 & 7.12 & 5913.6 & 59.03 & Volume, Activity, \\
\hline 1991 & & & & & & & 263.2 & 3.99 & 2382.8 & 19.61 & \begin{tabular}{|l|l}
$\mathrm{m}^{3}$ & $\mathrm{Ci}(\mathrm{TBg})$ \\
\end{tabular} \\
\hline Total & 14244 & $\begin{array}{l}6356 \\
(235) \\
\end{array}$ & 66811 & $\begin{array}{l}3341 \\
(123)\end{array}$ & 53300 & $\begin{array}{c}2082 \\
(77)\end{array}$ & 8507 & $\begin{array}{l}54 \\
(2) \\
\end{array}$ & 46772 & $\begin{array}{l}17 \\
(12) \\
\end{array}$ & \begin{tabular}{|l|l|}
189634 & $\begin{array}{l}12153 \\
(450)\end{array}$ \\
\end{tabular} \\
\hline
\end{tabular}


Table A2 (Continued)

\begin{tabular}{|c|c|c|c|}
\hline \multirow[b]{2}{*}{ Year } & \multicolumn{3}{|r|}{ Discharge Outside Areas 1-5 } \\
\hline & $\begin{array}{c}\begin{array}{c}\text { Volume, } \\
\mathrm{m}^{3}\end{array} \\
\end{array}$ & $\mid \begin{array}{l}\text { Activity, } \\
\mathrm{Ci} \text { (TBq) }\end{array}$ & Remarks \\
\hline 1959 & 600 & 0.00 & $65^{\circ} 44^{\prime}$ N. $35^{\circ} 54^{\prime}$ E, White Sea \\
\hline 1960 & 100 & 0.2 & Near Gogland island. Baltic Sea \\
\hline 1965 & 100 & 100 & Severodvinsk, explosion at plant \\
\hline 1976 & $?$ & 8500 & $\begin{array}{l}\text { Kara Sea, LRW from nuclear icebreaker } \\
\text { Lenin }\end{array}$ \\
\hline 1982 & $?$ & 1000 & Andreyev Bay, resen oir leak \\
\hline 1989 & $?$ & 2000 & Ara Bay, accident aboard an NS \\
\hline Total & $\begin{array}{r}800 \\
+? \\
\end{array}$ & $\begin{array}{l}11600 \\
(429)\end{array}$ & \\
\hline $\begin{array}{c}\text { Areas } \\
1-5\end{array}$ & 189634 & $\begin{array}{r}12153 \\
(450) \\
\end{array}$ & \\
\hline $\begin{array}{l}\text { Grand } \\
\text { Total }\end{array}$ & $\begin{array}{r}190434 \\
+? \\
\end{array}$ & $\begin{array}{r}23753 \\
(879) \\
\end{array}$ & \\
\hline
\end{tabular}




\section{3}

Table A3. Characteristics of Solid Radioactive Waste

Disposal Areas in the Kara Sea

\begin{tabular}{|c|c|c|c|c|}
\hline \multirow{2}{*}{ Area } & \multicolumn{2}{|c|}{ Coordinates } & \multirow{2}{*}{ Geographic Location } & \multirow{2}{*}{$\begin{array}{l}\text { Depth, } \\
\text { meters }\end{array}$} \\
\hline & N. Lat. & E. Long. & & \\
\hline 1 & $\begin{array}{c}72^{\circ} 5^{\prime} \\
73^{\circ} 17^{\prime}\end{array}$ & $\begin{array}{l}57^{\circ} 30^{\prime} \\
60^{\circ} 0^{\prime} \\
\end{array}$ & $\begin{array}{c}\text { Kara Sea, } \\
\text { Novaya Zemlya Depression }\end{array}$ & 380 \\
\hline 2 & $\begin{array}{l}74^{\circ} 40^{\prime} \\
74^{\circ} 42^{\prime} \\
\end{array}$ & $\begin{array}{l}59^{\circ} 53^{\prime} \\
60^{\circ} 17^{\prime} \\
\end{array}$ & $\begin{array}{c}\text { Sedov Inlet, } \\
\text { east coast of Novaya Zemlya }\end{array}$ & $13-33$ \\
\hline 3 & $\begin{array}{c}74^{\circ} 35^{\prime} 1^{\prime \prime} \\
74^{\circ} 7^{\prime} \\
\end{array}$ & $\begin{array}{l}59^{\circ} 18^{\prime} \\
59^{\circ} 12^{\prime} \\
\end{array}$ & $\begin{array}{l}\text { Oga Inlet, } \\
\text { east coast of Novaya Zemlya }\end{array}$ & 24 \\
\hline 4 & $\begin{array}{l}74^{\circ} 22^{\prime} 3^{\prime \prime} \\
74^{\circ} 22^{\prime} 0^{\prime \prime}\end{array}$ & $\begin{array}{l}58^{\circ} 42^{\prime} 1^{\prime \prime} \\
58^{\circ} 41^{\prime} 0^{\prime \prime} \\
\end{array}$ & $\begin{array}{c}\text { Tsivolka Inlet, } \\
\text { east coast of Novaya Zemlya }\end{array}$ & $56-135$ \\
\hline 5 & $\begin{array}{l}72^{\circ} 33^{\prime} 4^{\prime \prime} \\
72^{\circ} 32^{\prime \prime} 4^{\prime \prime}\end{array}$ & $\begin{array}{c}55^{\circ} 34^{\prime} \\
55^{\circ} 23^{\prime \prime} 3^{\prime \prime} \\
\end{array}$ & $\begin{array}{c}\text { Stepovoy Inlet, } \\
\text { east coast of Novaya Zemlya }\end{array}$ & $25-27$ \\
\hline 6 & $\begin{array}{l}71^{\circ} 56^{\prime} 5^{\prime \prime} \\
71^{\circ} 56^{\prime \prime} 0^{\prime \prime} \\
\end{array}$ & $\begin{array}{l}55^{\circ} 22^{\prime} 1^{\prime \prime} \\
55^{\circ} 19^{\prime} 11^{\prime \prime}\end{array}$ & $\begin{array}{c}\text { Abrosimov Inlet, } \\
\text { east coast of Novaya Zemlya }\end{array}$ & $12-20$ \\
\hline 7 & $75^{\circ} 40^{\prime} 9^{\prime \prime}$ & $63^{\circ} 59^{\prime}$ & $\begin{array}{c}\text { Blagopoluchiye Inlet, } \\
\text { east coast of Novaya Zemlya }\end{array}$ & $13-16$ \\
\hline 8 & $\begin{array}{l}75^{\circ} 58^{\prime} \\
75^{\circ} 59^{\prime}\end{array}$ & $\begin{array}{l}66^{\circ} 20^{\prime} \\
66^{\circ} 18^{\prime} \\
\end{array}$ & $\begin{array}{c}\text { Techeniye Inlet, } \\
\text { east coast of Novaya Zemlya }\end{array}$ & up to 50 \\
\hline
\end{tabular}




\section{4}

Table A4. Characteristics of Solid Radioactive Waste Dumping in Northern Seas

\begin{tabular}{|c|c|c|c|c|c|c|c|}
\hline \multirow{2}{*}{ Year } & \multicolumn{2}{|c|}{ Coordinates } & \multirow{2}{*}{$\begin{array}{c}\text { Volume, } \\
\mathrm{m}^{3}\end{array}$} & \multirow{2}{*}{$\begin{array}{l}\text { Activity }\left({ }^{90} \mathrm{Sr}\right. \\
\text { equivalent. } \mathrm{Ci})\end{array}$} & \multicolumn{3}{|c|}{ Form of Disposal } \\
\hline & N. Lat. & E. Long. & & & Containers & Ships & Unenclosed \\
\hline \multicolumn{8}{|c|}{ Area 1. Kara Sea } \\
\hline 1967 & $73^{\circ} 173$ & $59^{\circ} 54^{\prime}$ & 212 & 35.3 & 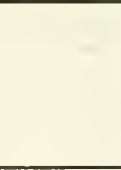 & & $\begin{array}{l}\text { Main circu- } \\
\text { lating pump } \\
\text { from nuclear } \\
\text { icebreaker } \\
\text { Lenin (3 } \\
\text { pcs.) }\end{array}$ \\
\hline 1967 & $72^{\circ} 21^{\prime}$ & $57^{\circ} 50^{\prime} 18^{\prime \prime}$ & 910 & 359 & & $\begin{array}{l}\text { Steamer } \\
\text { José Diaz }\end{array}$ & \\
\hline 1968 & $73^{\circ} 06^{\prime}$ & $59^{\circ} 10^{\prime}$ & 150 & 5.6 & & Barge No. 3 & \\
\hline 1969 & \multicolumn{2}{|c|}{ Area 1} & 144.8 & 159.2 & $?$ & $?$ & $?$ \\
\hline 1970 & $73^{\circ} 11^{\prime}$ & $59^{\circ} 54^{\prime}$ & 144 & 5.6 & $?$ & $?$ & $?$ \\
\hline 1972 & $72^{\circ} 24^{\prime}$ & $57^{\circ} 55^{\prime}$ & $?$ & 160 & & $\begin{array}{l}\text { Lighter } \\
\text { Savany }\end{array}$ & \\
\hline 1973 & $72^{\circ} 23^{\prime}$ & $58^{\circ} 0^{\prime}$ & $?$ & $?$ & & $\begin{array}{l}\text { Tanker } \\
\text { TNTIS }\end{array}$ & \\
\hline 1974 & $72^{\circ} 11^{\prime}$ & $57^{\circ} 40^{\prime}$ & $?$ & $?$ & & $\begin{array}{l}\text { Lighter } \\
\text { Oma }\end{array}$ & \\
\hline 1975 & $72^{\circ} 38^{\prime}$ & $58^{\circ} 20^{\prime}$ & 5000 & 30 & & Lighter $L-3$ & \\
\hline 1977 & $72^{\circ} 19^{\prime} 22^{\prime \prime}$ & $57^{\circ} 46^{\prime}$ & 600 & 0.6 & & $\begin{array}{l}\text { MBSN- } \\
801250 \\
\end{array}$ & \\
\hline 1980 & $72^{\circ} 18^{\prime} l^{\prime \prime}$ & $57^{\circ} 36^{\prime} 4^{\prime \prime}$ & 243 & 118.4 & & & \\
\hline 1980 & $72^{\circ} 15^{\prime}$ & $57^{\circ} 35^{\prime}$ & $?$ & $?$ & & & \\
\hline 1984 & $72^{\circ} 15^{\prime}$ & $57^{\circ} 30^{\prime}$ & 295.1 & 248.6 & $\begin{array}{c}\text { Containers } \\
(\mathrm{V}+)\end{array}$ & & \\
\hline 1984 & & & 4.0 & 5.8 & & & $\begin{array}{l}\text { Class III fur- } \\
\text { furol-acetone } \\
\text { resin }(\mathrm{V}+)\end{array}$ \\
\hline 1984 & & & 3.0 & 14.8 & & & $\begin{array}{l}\text { Primary loop } \\
\text { circulating } \\
\text { pump }\end{array}$ \\
\hline 1985 & $72^{\circ} 21^{\prime}$ & $57^{\circ} 50^{\prime} 18^{\prime \prime}$ & 5182.1 & 738.24 & 1027 & & SRW \\
\hline 1985 & $73^{\circ} 06^{\circ}$ & $59^{\circ} 10^{\circ}$ & 693.26 & 506.99 & 535 & & \\
\hline 1986 & $72^{\circ} 21^{\circ}$ & $57^{\circ} 50^{\prime} 18^{\prime \prime}$ & 419.4 & 156.83 & 321 & & \\
\hline 1987 & $73^{\circ} 06^{\circ}$ & $59^{\circ} 10^{\prime}$ & 1302.3 & 628.14 & 847 & & $\begin{array}{l}\text { Steam gene- } \\
\text { rator, prima- } \\
\text { ry loop cir- } \\
\text { culating } \\
\text { pump }\end{array}$ \\
\hline 1989 & $73^{\circ} 06^{\prime}$ & $59^{\circ} 10^{\prime}$ & 370.26 & 87.095 & 256 & & \\
\hline 1989 & $72^{\circ} 21^{\prime}$ & $57^{\circ} 50^{\prime} 18^{\prime \prime}$ & 142 & 24.18 & 57 & & \\
\hline 1991 & $73^{\circ} 173^{n}$ & $59^{\circ} 54^{\prime}$ & $\begin{array}{r}264.4 \\
54.5 \\
\end{array}$ & $\begin{array}{l}20.66 \\
14.92 \\
\end{array}$ & 131 & & SRW \\
\hline Total & & & 16134 & $\begin{array}{l}3320 \\
(123)\end{array}$ & 3174 & 8 & 9 \\
\hline
\end{tabular}


Table A4 (continued)

\begin{tabular}{|c|c|c|c|c|c|c|c|}
\hline \multirow{2}{*}{ Year } & \multicolumn{2}{|c|}{ Coordinates } & \multirow{2}{*}{$\begin{array}{c}\text { Volume, } \\
\mathrm{m}^{3}\end{array}$} & \multirow{2}{*}{$\begin{array}{l}\text { Activity }\left({ }^{90} \mathrm{Sr}\right. \\
\text { equivalent. } \mathrm{Ci})\end{array}$} & \multicolumn{3}{|c|}{ Form of Disposal } \\
\hline & N. Lat. & E. Long. & & & Containers & Ships & Unenclosed \\
\hline \multicolumn{8}{|c|}{ Area 2. Sedov Inlet } \\
\hline 1982 & $74^{\circ} 40^{\prime}$ & $59^{\circ} 55^{\prime}$ & $?$ & 100 & & & \\
\hline 1982 & $74^{\circ} 40^{\prime}$ & $59^{\circ} 55^{\prime}$ & 2357.6 & 1718.2 & 298 & & $\begin{array}{l}914 \mathrm{k}-650 \mathrm{~B} \\
\text { bundles }\end{array}$ \\
\hline 1982 & $74^{\circ} 42^{\prime}$ & $69^{\circ} 56^{\prime}$ & 218.4 & 63.56 & 182 & & \\
\hline 1982 & $74^{\circ} 41^{\prime}$ & $59^{\circ} 53^{\prime}$ & 276 & 118.32 & 230 & & \\
\hline 1983 & $74^{c} 40^{\circ}$ & $59^{\circ} 56^{\prime}$ & 280.5 & 1121.44 & 231 & & \\
\hline 1984 & $74^{\circ} 41^{\prime}$ & $60^{\circ} 17$ & 136.5 & 172.8 & 108 & & \\
\hline 1984 & $74^{\circ} 41^{\prime}$ & $60^{\circ} 17$ & 3.0 & 6.0 & & & $\begin{array}{l}\text { Furfurol- } \\
\text { acetone resin } \\
\text { (6 pcs.) }\end{array}$ \\
\hline 1984 & $74^{\circ} 41^{\prime}$ & $60^{\circ} 17^{\prime}$ & 10.5 & 52.5 & & & $\begin{array}{l}\text { Primary loop } \\
\text { circulating } \\
\text { pump }\end{array}$ \\
\hline 1984 & $74^{\circ} 41^{\prime}$ & $60^{\circ} 17$ & 150.9 & 57.21 & 59 & & $\begin{array}{l}\text { Steam gene- } \\
\text { rator }\end{array}$ \\
\hline Total & & & 3433 & $\begin{array}{l}3140 \\
(126)\end{array}$ & 1108 & & 104 \\
\hline \multicolumn{8}{|c|}{ Area 3. Oga Inlet } \\
\hline 1968 & $74^{\circ} 07$ & $53^{\circ} 12^{\prime}$ & 400 & 4 & & Barge $S B-5$ & SRW \\
\hline 1976 & $74^{\circ} 35^{\prime} 1^{\prime \prime}$ & $59^{\circ} 15^{\prime} 4^{\prime \prime}$ & 560 & 929 & & & \\
\hline 1978 & $74^{\circ} 17^{\prime}$ & $58^{\circ} 18^{\prime}$ & 170 & 15.5 & & & SRW \\
\hline 1980 & $74^{\circ} 35^{\prime}$ & $59^{\circ} 14^{\prime}$ & 278 & 274.35 & & & SRW \\
\hline 1980 & $74^{\circ} 35^{\prime}$ & $59^{\circ} 14^{\prime}$ & 500 & 59.21 & & & \\
\hline 1981 & $?$ & $?$ & $?$ & 349.06 & containers, ? & & SRW \\
\hline 1983 & $74^{\circ} 35^{\prime}$ & $59^{\circ} 13^{\prime} 5$ & 540 & 205.32 & 212 & & \\
\hline 1983 & $74^{\circ} 35^{\prime} 1^{\prime \prime}$ & $59^{\circ} 13^{\prime} 1^{\prime \prime}$ & 580 & 190.6 & 260 & & \\
\hline Total & & . & 3028 & $\begin{array}{r}2027 \\
(75)\end{array}$ & $472+?$ & 1 & 4 \\
\hline \multicolumn{8}{|c|}{ Area 4. Tsivolka Inlet } \\
\hline 1964 & $74^{\circ} 22^{\prime} 3^{\prime \prime}$ & $58^{\circ} 41^{\prime}$ & 640 & 977.37 & 1600 & $\begin{array}{l}\text { Special } \\
\text { lighter } \\
\text { N. Bauman }\end{array}$ & SRW \\
\hline 1965 & $74^{\circ} 22^{\prime} 3^{\prime \prime}$ & $58^{\circ} 41^{\prime}$ & 266 & 448.96 & & & SRW \\
\hline 1966 & $74^{\circ} 22^{\prime} 3^{\prime \prime}$ & $58^{\circ} 41^{\circ}$ & 446 & 534.17 & & & SRW \\
\hline 1967 & $74^{\circ} 22^{\prime} 3^{\prime \prime}$ & $58^{\circ} 42^{\prime}$ & 240 & 374.97 & & & SRW \\
\hline 1967 & $74^{\circ} 22^{\prime \prime} 2^{\prime \prime}$ & $58^{\circ} 41^{\prime} 5^{\prime \prime}$ & 25.2 & 28.64 & & & SRW \\
\hline 1967 & $74^{\circ} 22^{\prime} 3^{\prime \prime}$ & $58^{\circ} 42^{\prime} 1^{\prime \prime}$ & 72.2 & 77.2 & & & SRW \\
\hline 1976 & $74^{\circ} 22^{\prime}$ & $58^{\circ} 42^{\prime}$ & 1233 & 12 & & $\begin{array}{l}\text { Special } \\
\text { lighter } \\
\text { Kolezhma }\end{array}$ & \\
\hline 1978 & $74^{\circ} 22^{\prime}$ & $58^{\circ} 41^{\prime}$ & 438 & 230.5 & $?$ & & \\
\hline Total & & & 3360 & $\begin{array}{r}2684 \\
(99)\end{array}$ & $1600+?$ & 2 & 6 \\
\hline
\end{tabular}


Table A4 (continued)

\begin{tabular}{|c|c|c|c|c|c|c|c|}
\hline \multirow{2}{*}{ Year } & \multicolumn{2}{|c|}{ Coordinates } & \multirow{2}{*}{$\begin{array}{c}\text { Volume, } \\
\mathrm{m}^{3}\end{array}$} & \multirow{2}{*}{$\begin{array}{l}\text { Activity }\left({ }^{90} \mathrm{Sr}\right. \\
\text { equivalent, } \mathrm{Ci})\end{array}$} & \multicolumn{3}{|c|}{ Form of Disposal } \\
\hline & N. Lat. & E. Long. & & & Containers & Ships & Unenclosed \\
\hline \multicolumn{8}{|c|}{ Area 5. Stepovov Inlet } \\
\hline 1968 & $72^{\circ} 32^{\prime} 4^{\prime \prime}$ & $55^{\circ} 33^{\prime} 9^{\prime \prime}$ & 185.2 & 184.78 & ' & & $\begin{array}{l}\text { SRW from } \\
\text { nuclear ice- } \\
\text { breaker } L e- \\
\text { nin }\end{array}$ \\
\hline 1970 & $72^{\circ} 33^{\circ}$ & $55^{\circ} 29^{\prime} 2^{\prime \prime}$ & 243 & 371.12 & & & SRW \\
\hline 1972 & $72^{\circ} 33^{\prime} 2^{\prime \prime}$ & $55^{\circ} 26^{\prime} 2^{\prime \prime}$ & 242 & 212 & & & SRW \\
\hline 1973 & $72^{\circ} 33^{\prime} 2^{\prime \prime}$ & $55^{\circ} 23^{\prime} 3^{\prime \prime}$ & 532 & 325.24 & & & SRW \\
\hline 1975 & $72^{\circ} 33^{\circ} 4^{\prime \prime}$ & $55^{\circ} 24^{\prime}$ & 445 & 187 & & & SRW \\
\hline Total & & & 1647 & $\begin{array}{r}1280 \\
(47)\end{array}$ & & & 5 \\
\hline \multicolumn{8}{|c|}{ Area 6. Abrosimov Inlet } \\
\hline 1966 & $71^{\circ} 56^{\prime} 1^{\prime \prime}$ & $55^{\circ} 19^{\prime} 5^{\prime \prime}$ & $?$ & $?$ & & Barge & \\
\hline 1967 & $71^{\circ} 56^{\prime} 5^{\prime \prime}$ & $55^{\circ} 21^{\prime} 5^{\prime \prime}$ & $?$ & 0.28 & & $\begin{array}{l}\text { Barge } \\
M N N- \\
231500\end{array}$ & \\
\hline 1967 & $71^{\circ} 56^{\circ}$ & $55^{\circ} 21^{\prime}$ & $?$ & 30 & & $\begin{array}{l}\text { Barge } \\
M B S N- \\
378250\end{array}$ & SRW \\
\hline 1974 & $71^{\circ} 56^{\prime} 0^{\prime \prime}$ & $55^{\circ} 21^{\prime} 0^{\prime \prime}$ & 520 & 229 & & & \\
\hline 1977 & $71^{\circ} 55^{\prime} 3^{\prime \prime}$ & $55^{\circ} 22^{\prime} 1^{\prime \prime}$ & 254.8 & 387 & 8 & & \\
\hline 1980 & $71^{\circ} 56^{\prime}$ & $55^{\circ} 21^{\prime}$ & 750 & 10 & & $\begin{array}{l}\text { Lighter } \\
L-871 I\end{array}$ & $\begin{array}{l}\text { Steam gene- } \\
\text { rators ( } 5 \\
\text { pcs.), SRW }\end{array}$ \\
\hline 1981 & $71^{\circ} 56^{\prime}$ & $55^{\circ} 21^{\prime \prime} 2^{\prime \prime}$ & 392 & 5 & $?$ & & \\
\hline Total & & & 1917 & $\begin{array}{l}661 \\
(24.5)\end{array}$ & $8+?$ & 4 & 7 \\
\hline \multicolumn{8}{|c|}{ Area 7. Blagopoluchive Inlet } \\
\hline 1972 & $75^{\circ} 40^{\prime} 9^{\prime \prime}$ & $63^{\circ} 39^{\prime}$ & 331 & 234.84 & & & $\begin{array}{l}\text { SRW from } \\
\text { Lenin }\end{array}$ \\
\hline Total & & & 331 & $\begin{array}{r}235 \\
(8)\end{array}$ & & & 1 \\
\hline \multicolumn{8}{|c|}{ Area 8. Techenive Inlet } \\
\hline 1982 & $\begin{array}{l}76^{\circ} 58^{\prime} \\
"\end{array}$ & $\begin{array}{l}66^{\circ} 20^{\prime} \\
"\end{array}$ & $\begin{array}{l}91.2 \\
84.0 \\
\end{array}$ & $\begin{array}{c}29.34 \\
4.0\end{array}$ & $\begin{array}{l}76 \\
70 \\
\end{array}$ & & \\
\hline 1988 & $73^{\circ} 59^{\prime}$ & $66^{\circ} 18^{\prime}$ & 229 & 1811.21 & & $\begin{array}{l}\text { Lighter No. } \\
4\end{array}$ & \\
\hline Total & & & 404 & $\begin{array}{r}1845 \\
(68)\end{array}$ & 146 & 1 & \\
\hline
\end{tabular}


Table A4 (continued)

\begin{tabular}{|c|c|c|c|c|c|c|c|}
\hline \multirow{2}{*}{ Year } & \multicolumn{2}{|c|}{ Coordinates } & \multirow{2}{*}{$\begin{array}{c}\text { Volume, } \\
\mathrm{m}^{3}\end{array}$} & \multirow{2}{*}{$\begin{array}{l}\text { Activity }\left({ }^{90} \mathrm{Sr}\right. \\
\text { equivalent. } \mathrm{Ci})\end{array}$} & \multicolumn{3}{|c|}{ Form of Disposal } \\
\hline & N. Lat. & E. Long. & & & Containers & Ships & Unenclosed \\
\hline \multicolumn{8}{|c|}{ Outside Areas 1.8} \\
\hline 1978 & $69^{\circ} 34^{\prime} 1^{\prime \prime}$ & $47^{\circ} 56^{\prime} 3^{\prime \prime \prime}$ & 1100 & 40 & & $\begin{array}{l}\text { Lighter } \\
\text { Nikel }\end{array}$ & $\begin{array}{l}\text { Crnise mis- } \\
\text { siles ( } 7 \text { pcs.), } \\
\text { steam gene- } \\
\text { rators (5 } \\
\text { pcs.), PR- } \\
50 \text { 's (2 pcs.), } \\
\text { warheads (4 } \\
\text { pcs.) }\end{array}$ \\
\hline Total & & & 1100 & $\begin{array}{l}40 \\
(1.5)\end{array}$ & & 1 & 18 \\
\hline \multicolumn{3}{|c|}{ Grand Total } & 31534 & $\begin{array}{c}15502 \\
(574)\end{array}$ & 6508 & 17 & 154 \\
\hline
\end{tabular}

- 20 miles northwest of Kolguyev Island, possible coordinates $69^{\circ} 34^{\circ} 0^{\prime \prime} \mathrm{N}, 47^{\circ} 56^{\prime} 2^{\prime \prime} \mathrm{E}$. 
Table A5. Characteristics of Liquid Radioactive Waste Discharge and Solid Radioactive Waste Dumping Areas in Far Eastern Seas

\begin{tabular}{|c|c|c|c|c|c|}
\hline \multirow[t]{2}{*}{ Area } & \multicolumn{2}{|c|}{ Coordinates } & \multirow[t]{2}{*}{ Geographic Location } & \multirow{2}{*}{$\begin{array}{l}\text { Depth, } \\
\text { meters }\end{array}$} & \multirow[t]{2}{*}{ Remarks } \\
\hline & N. Lat. & E. Long. & & & \\
\hline 1 & $\begin{array}{l}42^{\circ} 0^{\prime} \\
42^{\circ} 0^{\prime} \\
41^{\circ} 0^{\prime} \\
41^{\circ} 0^{\prime}\end{array}$ & $\begin{array}{l}133^{\circ} 10^{\prime} \\
134^{\circ} 30^{\prime} \\
133^{\circ} 10^{\prime} \\
134^{\circ} 30^{\prime}\end{array}$ & Sea of Japan & $3250-3700$ & Liquid RW \\
\hline 2 & $\begin{array}{l}41^{\circ} 10^{\prime} \\
41^{\circ} 10^{\prime} \\
39^{\circ} 30^{\prime} \\
39^{\circ} 30^{\prime}\end{array}$ & $\begin{array}{l}131^{\circ} 10^{\prime} \\
134^{\circ} 30^{\prime} \\
131^{\circ} 10^{\prime} \\
134^{\circ} 30^{\prime}\end{array}$ & Sea of Japan & $2900-3300$ & Liquid RW \\
\hline 3 & $\begin{array}{l}53^{\circ} 0^{\prime} \\
53^{\circ} 0^{\prime} \\
51^{\circ} 20^{\prime} \\
51^{\circ} 20^{\prime}\end{array}$ & $\begin{array}{l}148^{\circ} 10^{\prime} \\
146^{\circ} 40^{\prime} \\
148^{\circ} 10^{\prime} \\
146^{\circ} 40^{\prime}\end{array}$ & $\begin{array}{l}\text { Pacific Ocean } \\
\text { (east coast of } \\
\text { Kamchatka) }\end{array}$ & $?$ & Liquid RW \\
\hline 4 & $\begin{array}{l}50^{\circ} 0^{\prime} \\
50^{\circ} 0^{\prime} \\
48^{\circ} 0^{\prime} \\
48^{\circ} 0^{\prime}\end{array}$ & $\begin{array}{l}162^{\circ} 45^{\prime} \\
161^{\circ} 35^{\prime} \\
162^{\circ} 40^{\prime} \\
161^{\circ} 35^{\prime}\end{array}$ & $\begin{array}{c}\text { Pacific Ocean } \\
\text { (east coast of } \\
\text { Kamchatka) }\end{array}$ & $?$ & Liquid RW \\
\hline 5 & $\begin{array}{l}42^{\circ} 26^{\prime} \\
42^{\circ} 26^{\prime} \\
42^{\circ} 17^{\prime} \\
42^{\circ} 17^{\prime}\end{array}$ & $\begin{array}{l}131^{\circ} 37^{\prime} \\
132^{\circ} 20^{\prime} \\
131^{\circ} 37^{\prime} \\
132^{\circ} 20^{\prime}\end{array}$ & Sea of Japan & $1100-1500$ & Liquid RW \\
\hline 6 & $\begin{array}{l}41^{\circ} 55^{\prime} \\
41^{\circ} 55^{\prime} \\
41^{\circ} 45^{\prime} \\
41^{\circ} 45^{\prime}\end{array}$ & $\begin{array}{l}131^{\circ} 47^{\prime} \\
132^{\circ} 13^{\prime} \\
131^{\circ} 47^{\prime} \\
132^{\circ} 13^{\prime}\end{array}$ & Sea of Japan & $1900-3300$ & $\begin{array}{l}\text { Liquid and } \\
\text { solid RW }\end{array}$ \\
\hline 7 & $\begin{array}{l}52^{\circ} 28^{\prime} \\
52^{\circ} 28^{\prime} \\
52^{\circ} 40^{\prime} \\
52^{\circ} 40^{\prime}\end{array}$ & $\begin{array}{l}159^{\circ} 02^{\prime} \\
159^{\circ} 12^{\prime} \\
159^{\circ} 02^{\prime} \\
159^{\circ} 12^{\prime}\end{array}$ & $\begin{array}{l}\text { Pacific Ocean } \\
\text { (east coast of } \\
\text { Kamchatka) }\end{array}$ & $1400-1500$ & Liquid RW \\
\hline 8 & $\begin{array}{l}52^{\circ} 28^{\prime} \\
52^{\circ} 28^{\prime} \\
52^{\circ} 34^{\prime} \\
52^{\circ} 34^{\prime}\end{array}$ & $\begin{array}{l}159^{\circ} 06^{\prime} \\
159^{\circ} 11^{\prime} \\
159^{\circ} 02^{\prime} \\
159^{\circ} 11^{\prime}\end{array}$ & $\begin{array}{l}\text { Pacific Ocean } \\
\text { (east coast of } \\
\text { Kamchatka) }\end{array}$ & $2000-2570$ & Liquid RW \\
\hline 9 & $\begin{array}{l}41^{\circ} 36^{\prime} \\
41^{\circ} 36^{\prime} \\
41^{\circ} 46^{\prime} \\
41^{\circ} 46^{\prime}\end{array}$ & $\begin{array}{l}133^{\circ} 22^{\prime} \\
134^{\circ} 42^{\prime} \\
133^{\circ} 22^{\prime} \\
134^{\circ} 42^{\prime}\end{array}$ & Sea of Japan & $3250-3700$ & $\begin{array}{l}\text { Liquid and } \\
\text { solid RW }\end{array}$ \\
\hline 10 & $\begin{array}{l}40^{\circ} 10^{\prime} \\
41^{\circ} 10^{\prime} \\
40^{\circ} 10^{\prime} \\
41^{\circ} 10^{\prime}\end{array}$ & $\begin{array}{l}131^{\circ} 15^{\prime} \\
131^{\circ} 15^{\prime} \\
131^{\circ} 35^{\prime} \\
131^{\circ} 35^{\prime}\end{array}$ & Sea of Japan & $2900-3300$ & $\begin{array}{l}\text { Liquid and } \\
\text { solid RW }\end{array}$ \\
\hline
\end{tabular}


Table A6. Characteristics of Liquid Radioactive Waste Discharge in Far Eastern Seas

\begin{tabular}{|c|c|c|c|c|c|c|c|c|}
\hline \multirow{3}{*}{ Year } & \multicolumn{2}{|c|}{ Area 1 } & \multicolumn{2}{c|}{ Area 2 } & \multicolumn{2}{c|}{ Area 3 } & \multicolumn{2}{c|}{ Area 4 } \\
\cline { 2 - 8 } & $\begin{array}{c}\text { Volume, } \\
\mathrm{m}^{3}\end{array}$ & $\begin{array}{c}\text { Activity, } \\
\mathrm{Ci}(\mathrm{TBq})\end{array}$ & $\begin{array}{c}\text { Volume, } \\
\mathrm{m}^{3}\end{array}$ & $\begin{array}{c}\text { Activity, } \\
\mathrm{Ci}(\mathrm{TBq})\end{array}$ & $\begin{array}{c}\text { Volume, } \\
\mathrm{m}^{3}\end{array}$ & $\begin{array}{c}\text { Activity, } \\
\mathrm{Ci}(\mathrm{TBq})\end{array}$ & $\begin{array}{c}\text { Volume, } \\
\mathrm{m}^{3}\end{array}$ & $\begin{array}{c}\text { Activity, } \\
\mathrm{Ci}(\mathrm{TBq})\end{array}$ \\
\hline Total $^{*}$ & 16250 & $\begin{array}{c}1.5 \\
(0.1)\end{array}$ & 3156 & $\begin{array}{c}0.9 \\
(0.03)\end{array}$ & 1513 & $\begin{array}{c}0.1 \\
(0.004\end{array}$ & 4803 & $\begin{array}{c}0.2 \\
(0.007\end{array}$ \\
\hline
\end{tabular}

-For Areas 1-4, only summary data are presented, without year-by-year breakdown.

\begin{tabular}{|c|c|c|c|c|c|c|c|c|c|c|c|}
\hline \multirow[b]{2}{*}{ Year } & \multicolumn{2}{|c|}{ Area 5} & \multicolumn{2}{|c|}{ Area 6} & \multicolumn{2}{|c|}{ Area 7} & \multicolumn{2}{|c|}{ Area 9} & \multicolumn{2}{|c|}{ Area 10} & \\
\hline & $\begin{array}{c}\begin{array}{c}\text { Volume, } \\
\mathrm{m}^{3}\end{array} \\
\end{array}$ & \begin{tabular}{|l|} 
Activity. \\
$\mathrm{Ci}$ (TBg)
\end{tabular} & $\begin{array}{c}\text { Volume, } \\
\mathrm{m}^{3}\end{array}$ & \begin{tabular}{|l|} 
Activity, \\
$\mathrm{Ci}$ (TBq) \\
\end{tabular} & \begin{tabular}{|c|}
$\begin{array}{c}\text { Volume. } \\
\mathrm{m}^{3}\end{array}$ \\
\end{tabular} & \begin{tabular}{|l|} 
Activity, \\
Ci (TBq) \\
\end{tabular} & \begin{tabular}{|c|}
$\begin{array}{c}\text { Volume, } \\
\mathrm{m}^{3}\end{array}$ \\
\end{tabular} & \begin{tabular}{|l|} 
Activity, \\
$\mathrm{Ci}$ (TBq) \\
\end{tabular} & \begin{tabular}{|c|}
$\begin{array}{c}\text { Volume, } \\
\mathrm{m}^{3}\end{array}$ \\
\end{tabular} & $\begin{array}{l}\text { Activity, } \\
\mathrm{Ci}(\mathrm{TBq}) \\
\end{array}$ & \\
\hline 1966 & $?$ & 0.12 & & & \begin{tabular}{|l|}
800 \\
\end{tabular} & $\begin{array}{ll}0.09 \\
\end{array}$ & & & & & \\
\hline 1967 & $?$ & 0.16 & & & 900 & 0.02 & & & & & \\
\hline 1968 & $?$ & 3.10 & & & 900 & 0.05 & & & & & \\
\hline 1969 & $?$ & 0.89 & & & 1200 & 0.20 & & & & & \\
\hline 1970 & $?$ & 1.8 & & & $?$ & 0.24 & & & & & \\
\hline 1971 & $?$ & 1.5 & & & $?$ & 1.18 & & & & & \\
\hline 1972 & $?$ & 32.35 & & & 2100 & 0.17 & & & & & \\
\hline 1973 & 2930 & 23.4 & & & 3700 & 5.09 & & & & & \\
\hline 1974 & 900 & 28 & & & $?$ & 0.05 & 2835 & 22.212 & & & \\
\hline 1975 & & & & & 856 & 0.09 & 2028 & 3.45 & & & \\
\hline 1976 & & & & & & & 3630 & 13.057 & & & \\
\hline 1977 & & & & & 1517 & 0.95 & 2210 & 0.376 & & & \\
\hline 1978 & & & & & 2334 & 5.29 & 4124 & 19.966 & & & \\
\hline 1979 & & & & & & & & & 3140 & 411.03 & \\
\hline 1980 & & & & & 2335 & 0.29 & & & 3545 & 52.051 & \\
\hline 1981 & & & & & 3530 & 2.79 & & & 929 & 3.998 & \\
\hline 1982 & & & & & 2960 & 149.88 & & & 2840 & 13.57 & \\
\hline 1983 & & & & & 1730 & 28.54 & & & 3553.6 & 20.387 & \\
\hline 1984 & & & & & 526 & 19.14 & 1500 & 3.27 & 3600 & 34.55 & \\
\hline 1985 & & & & & 305 & 12.81 & 2997.5 & 190.49 & & & \\
\hline 1986 & 259 & 0.15 & 824 & 318.15 & 2550 & 26.44 & 3698.74 & 10250.37 & & & \\
\hline 1987 & & & 4248 & 170.6 & 780 & 31.90 & 2710 & 217.4 & & & \\
\hline 1988 & 1808 & 18.7 & & & 1230 & 42.9 & 720 & 10.45 & & & \\
\hline 1989 & & & & & 1660 & 10.86 & 1807 & 88.9 & & & \\
\hline 1990 & 133 & 0.7 & & & 890 & 1.3 & 902 & 8.44 & & & Total, Areas $1-10$ \\
\hline 1991 & 900 & 5.3 & & & 580 & 9.98 & 2034 & 4.178 & & & Volume, Activity, \\
\hline 1992 & 906 & 1.3 & & & 906 & 1.3 & 1774 & \begin{tabular}{|l|}
7.6 \\
\end{tabular} & & & \begin{tabular}{l|l}
$\mathrm{m}^{3}$ & $\mathrm{Ci}(\mathrm{IBg})$ \\
\end{tabular} \\
\hline Total & $7836+?$ & $\begin{array}{r}117 \\
(4) \\
\end{array}$ & 5072 & $\begin{array}{l}489 \\
(18) \\
\end{array}$ & $34289+?$ & $\begin{array}{l}352 \\
(13) \\
\end{array}$ & 32970 & $\begin{array}{l}10840 \\
(401) \\
\end{array}$ & 17608 & $\begin{array}{l}536 \\
(19) \\
\end{array}$ & \begin{tabular}{|l|l|}
123497 & 12337 \\
& $(456)$ \\
\end{tabular} \\
\hline
\end{tabular}


Table A7. Characteristics of Solid Radioactive Waste Dumping in Far Eastern Seas

\begin{tabular}{|c|c|c|c|c|c|c|c|}
\hline \multirow{2}{*}{ Year } & \multicolumn{2}{|c|}{ Coordinates } & \multirow{2}{*}{$\begin{array}{c}\text { Volume, } \\
\mathrm{m}^{3}\end{array}$} & \multirow{2}{*}{$\begin{array}{c}\text { Activity, } \\
\mathrm{Ci}\end{array}$} & \multicolumn{3}{|c|}{ Form of Disposal } \\
\hline & N. Lat. & E. Long. & & & Containers & Ships & Unenclosed \\
\hline \multicolumn{8}{|c|}{ Area 6} \\
\hline 1968 & \multicolumn{2}{|c|}{ No data } & 136 & 21 & 136 & - & - \\
\hline 1969 & \multicolumn{2}{|c|}{ No data } & 1145 & 209 & 1145 & - & - \\
\hline 1970 & \multicolumn{2}{|c|}{ No data } & 693 & 22 & 693 & - & - \\
\hline 1971 & \multicolumn{2}{|c|}{ No data } & 481 & 111 & 481 & - & - \\
\hline 1973 & \multicolumn{2}{|c|}{ No data } & 241 & 122 & 241 & - & - \\
\hline 1973 & \multicolumn{2}{|c|}{ No data } & 550 & 58 & - & $\begin{array}{l}\text { Fire control } \\
\text { tower Litiy }\end{array}$ & - \\
\hline 1973 & \multicolumn{2}{|c|}{ No data } & 70 & 3 & 一 & $\begin{array}{l}\text { Floating fire } \\
\text { control } \\
\text { tower }\end{array}$ & - \\
\hline 1986 & $41^{\circ} 50^{\prime}$ & $131^{\circ} 30^{\prime}$ & 59 & 72 & 52 & - & - \\
\hline 1986 & $41^{\circ} 50^{\prime}$ & $131^{\circ} 30^{\prime}$ & 40 & 4 & 40 & - & - \\
\hline 1986 & $41^{\circ} 50^{\prime}$ & $132^{\circ} 0^{\prime}$ & 371 & 11 & - & $\begin{array}{l}\text { Medium } \\
\text { fishing traw- } \\
\text { ler/refrigera- } \\
\text { tor ship } \\
\text { Indra }\end{array}$ & - \\
\hline 1986 & $41^{\circ} 51^{\prime}$ & $132^{\circ} 0^{\prime}$ & 180 & 115 & - & $\begin{array}{l}\text { Fishing sei- } \\
\text { ner Kapitan } \\
\text { Aron }\end{array}$ & - \\
\hline 1987 & $41^{\circ} 50^{\prime}$ & $132^{\circ} 0^{\prime}$ & 21 & 43 & - & - & $\begin{array}{l}\text { Part of a } \\
\text { crane }\end{array}$ \\
\hline 1987 & $41^{\circ} 50^{\prime}$ & $132^{\circ} 0^{\prime}$ & 200 & 17 & - & Barge & - \\
\hline 1987 & $41^{\circ} 50^{\prime}$ & $132^{\circ} 0^{\prime}$ & 95 & 14 & 44 & - & - \\
\hline 1987 & $41^{\circ} 50^{\prime}$ & $132^{\circ} 0^{\prime}$ & 16 & 1 & - & - & Metal \\
\hline 1987 & $41^{\circ} 50^{\prime}$ & $132^{\circ} 0^{\prime}$ & 37 & 34 & 37 & - & - \\
\hline 1987 & $41^{\circ} 50^{\prime}$ & $132^{\circ} 0^{\prime}$ & 48 & 5 & 32 & - & - \\
\hline 1988 & $41^{\circ} 50^{\prime}$ & $132^{\circ} 0^{\prime}$ & 26 & 6.9 & 14 & - & - \\
\hline Total & & & 4409 & $\begin{array}{l}869 \\
(32)\end{array}$ & 2915 & 5 & 2 \\
\hline
\end{tabular}

\begin{tabular}{|c|c|c|c|c|c|c|c|}
\hline \multicolumn{8}{|c|}{ Area 8} \\
\hline 1969 & \multicolumn{2}{|c|}{ No data } & 61 & 133 & 61 & - & - \\
\hline 1970 & \multicolumn{2}{|c|}{ No data } & 20 & 14 & 20 & - & - \\
\hline 1970 & $52^{\circ} 28^{\prime}$ & $159^{\circ} 6^{\prime}$ & 16 & 14 & 16 & - & - \\
\hline 1970 & $52^{\circ} 28^{\prime}$ & $159^{\circ} 11^{\prime}$ & 4 & 6 & 4 & - & - \\
\hline 1970 & $52^{\circ} 34^{\prime}$ & $159^{\circ} 2^{\prime}$ & 4 & 5.1 & 4 & - & - \\
\hline 1970 & $52^{\circ} 34^{\prime}$ & $159^{\circ} 11^{\prime}$ & 16 & 16 & 18 & - & - \\
\hline 1970 & \multicolumn{2}{|c|}{ No data } & 16 & 63 & 16 & - & - \\
\hline 1971 & \multicolumn{2}{|c|}{ No data } & 20 & 9 & 20 & - & - \\
\hline 1971 & \multicolumn{2}{|c|}{ No data } & 5 & 70 & 5 & - & - \\
\hline
\end{tabular}




\section{1}

Table A7 (continued)

\begin{tabular}{|c|c|c|c|c|c|c|c|}
\hline \multirow{2}{*}{ Year } & \multicolumn{2}{|c|}{ Coordinates } & \multirow{2}{*}{$\begin{array}{c}\text { Volume, } \\
\mathrm{m}^{3}\end{array}$} & \multirow{2}{*}{$\begin{array}{c}\text { Activity, } \\
\mathrm{Ci}\end{array}$} & \multicolumn{3}{|c|}{ Form of Disposal } \\
\hline & N. Lat. & E. Long. & & & Containers & Ships & Unenclosed \\
\hline \multicolumn{8}{|c|}{ Area 8 (continued) } \\
\hline 1972 & \multicolumn{2}{|c|}{ No data } & 300 & 3.8 & - & $\begin{array}{l}\text { Heavy } \\
\text { trawler } \\
\text { Sungay }\end{array}$ & 一 \\
\hline 1972 & \multicolumn{2}{|c|}{ No data } & 14 & 3.2 & 14 & - & - \\
\hline 1973 & \multicolumn{2}{|c|}{ No data } & 60 & 26 & 60 & - & - \\
\hline 1974 & \multicolumn{2}{|c|}{ No data } & 56 & 4.8 & 56 & - & - \\
\hline 1975 & \multicolumn{2}{|c|}{ No data } & 64 & 47 & 64 & - & - \\
\hline 1976 & \multicolumn{2}{|c|}{ No data } & 27 & 17 & 27 & - & - \\
\hline 1977 & \multicolumn{2}{|c|}{ No data } & 25 & 41 & 25 & - & - \\
\hline 1978 & \multicolumn{2}{|c|}{ No data } & 50 & 36 & 50 & - & - \\
\hline 1980 & $54^{\circ} 34^{\prime}$ & $159^{\circ} 2^{\prime}$ & 94 & 27 & 94 & - & - \\
\hline 1981 & $52^{\circ} 28^{\prime}$ & $159^{\circ} 11^{\prime}$ & 48 & 27 & 48 & - & - \\
\hline 1982 & $54^{\circ} 34^{\prime}$ & $159^{\circ} 11^{\prime}$ & 95 & 242 & 95 & - & - \\
\hline 1983 & $52^{\circ} 28^{\circ}$ & $159^{\circ} 2^{\prime}$ & 60 & 44 & 60 & - & - \\
\hline 1985 & $52^{\circ} 30^{\circ}$ & $159^{\circ} 4^{\prime}$ & 82 & 1537 & 51 & - & - \\
\hline 1986 & $52^{\circ} 31^{\prime}$ & $159^{\circ} 9^{\prime}$ & 47 & 11 & 41 & - & - \\
\hline 1986 & $52^{\circ} 30^{\prime}$ & $159^{\circ} 8^{\prime}$ & 15 & 8 & 15 & $=$ & - \\
\hline 1986 & $52^{\circ} 31^{\prime}$ & $159^{\circ} 8^{\prime}$ & 8 & 39 & - & - & $\begin{array}{l}\text { Primary loop } \\
\text { circulating } \\
\text { pump (50 } \\
\text { pcs.) }\end{array}$ \\
\hline 1986 & $52^{\circ} 31^{\prime}$ & $159^{\circ} 8^{\prime}$ & 105 & 45 & 105 & - & - \\
\hline 1987 & $52^{\circ} 31^{\circ}$ & $159^{\circ} 8^{\prime}$ & 50 & 41 & 50 & - & - \\
\hline 1987 & $52^{\circ} 32^{\prime}$ & $159^{\circ} 8^{\prime}$ & 51 & 40 & 50 & - & - \\
\hline 1988 & $52^{\circ} 30^{\prime}$ & $159^{\circ} 8^{\prime}$ & 2.7 & 8 & - & - & $\begin{array}{l}\text { GTsN-146 } \\
\text { main circula- } \\
\text { ting pump }\end{array}$ \\
\hline 1988 & $52^{\circ} 30^{\prime}$ & $159^{\circ} 9^{\prime}$ & 70 & 59 & - & - & $\begin{array}{l}\text { Steam gene- } \\
\text { rator (10 } \\
\text { pes.) }\end{array}$ \\
\hline 1988 & $52^{\circ} 30^{\circ}$ & $159^{\circ} 9^{\prime}$ & 97 & 37 & 97 & - & - \\
\hline 1989 & $52^{\circ} 30^{\prime}$ & $159^{\circ} 9^{\prime}$ & 46 & 13 & 46 & - & - \\
\hline 1989 & $52^{\circ} 30^{\prime}$ & $159^{\circ} 9^{\prime}$ & 7 & 70 & - & - & $\begin{array}{l}\text { Submarine } \\
\text { core plate }\end{array}$ \\
\hline 1989 & $52^{\circ} 30^{\prime}$ & $159^{\circ} 9^{\prime}$ & 3.7 & 0.85 & - & - & $\begin{array}{l}\text { Primary loop } \\
\text { circulating } \\
\text { pump (1 pc.) }\end{array}$ \\
\hline 1989 & $52^{\circ} 30^{\prime}$ & $159^{\circ} 9^{\prime}$ & 30 & 17 & 30 & - & - \\
\hline 1989 & $52^{\circ} 30^{\prime}$ & $159^{\circ} 9^{\prime}$ & 14 & 3.5 & - & - & $\begin{array}{l}\text { Hydrova- } \\
\text { cuum decon- } \\
\text { tamination } \\
\text { cylinders }\end{array}$ \\
\hline 1989 & $52^{\circ} 30^{\prime}$ & $159^{\circ} 9^{\prime}$ & 56 & 8.4 & 56 & - & - \\
\hline
\end{tabular}


Table A7 (continued)

\begin{tabular}{|c|c|c|c|c|c|c|c|}
\hline \multirow{2}{*}{ Year } & \multicolumn{2}{|c|}{ Coordinates } & \multirow{2}{*}{$\begin{array}{c}\text { Volume, } \\
\mathrm{m}^{3} \\
\end{array}$} & \multirow{2}{*}{$\begin{array}{c}\text { Activity, } \\
\text { Ci }\end{array}$} & \multicolumn{3}{|c|}{ Form of Disposal } \\
\hline & N. Lat. & E. Long. & & & Containers & Ships & Unenclosed \\
\hline \multicolumn{8}{|c|}{ Area 8 (continued) } \\
\hline 1990 & $52^{\circ} 30^{\prime}$ & $159^{\circ} 9^{\prime}$ & 72 & 13 & 72 & - & - \\
\hline 1990 & $52^{\circ} 30^{\prime}$ & $159^{\circ} 9^{\circ}$ & 600 & 138 & - & Barge & - \\
\hline 1990 & $52^{\circ} 30^{\prime}$ & $159^{\circ} 9^{\prime}$ & 55 & 29 & 50 & - & - \\
\hline 1991 & $52^{\circ} 30^{\prime}$ & $159^{\circ} 9^{\prime}$ & 41 & 13 & 41 & - & - \\
\hline 1992 & $52^{\circ} 30^{\prime}$ & $159^{\circ} 9^{\prime}$ & 46 & 12 & 41 & - & - \\
\hline Total & & & 2553 & $\begin{array}{l}2992 \\
(111)\end{array}$ & 1502 & 2 & $62+$ \\
\hline
\end{tabular}

\begin{tabular}{|c|c|c|c|c|c|c|c|}
\hline \multicolumn{8}{|c|}{ Area 9} \\
\hline 1974 & $41^{\circ} 40^{\prime}$ & $133^{\circ} 30^{\prime}$ & 14 & 6 & 14 & - & - \\
\hline 1974 & $41^{\circ} 45^{\prime}$ & $133^{\circ} 41^{\prime}$ & 32 & 17 & 32 & - & - \\
\hline 1974 & $41^{\circ} 44^{\prime}$ & $133^{\circ} 2^{\prime}$ & 28 & 2 & 28 & - & - \\
\hline 1974 & $41^{\circ} 36^{\prime}$ & $133^{\circ} 22^{\prime}$ & 132 & 33 & - & $\begin{array}{l}\text { Seiner No. } \\
100\end{array}$ & - \\
\hline 1975 & $41^{\circ} 4 l^{\prime}$ & $133^{\circ} 40^{\prime}$ & 40 & 36 & 40 & - & - \\
\hline 1975 & $41^{\circ} 40^{\prime}$ & $133^{\circ} \mathrm{I}^{\prime}$ & 4 & 22 & 4 & - & - \\
\hline 1975 & $41^{\circ} 40^{\circ}$ & $133^{\circ} 1^{\prime}$ & 40 & 296 & 40 & - & - \\
\hline 1975 & $41^{\circ} 49^{\prime}$ & $133^{\circ} 10^{\prime}$ & 18 & 28 & 18 & - & - \\
\hline 1975 & $41^{\circ} 40^{\prime}$ & $133^{\circ} 30^{\prime}$ & 22 & 8.4 & 22 & - & - \\
\hline 1975 & $41^{\circ} 40^{\prime}$ & $133^{\circ} 30^{\prime}$ & 20 & 26 & 20 & - & - \\
\hline 1975 & $41^{\circ} 36^{\prime}$ & $132^{\circ} 22^{\prime}$ & 130 & 16 & - & Seiner No. 5 & - \\
\hline 1975 & $41^{\circ} 36^{\prime}$ & $132^{\circ} 22^{\prime}$ & 63 & 4 & 63 & - & - \\
\hline 1975 & $41^{\circ} 36^{\prime}$ & $132^{\circ} 22^{\prime}$ & 230 & 20 & - & Seiner No. 6 & - \\
\hline 1975 & $41^{\circ} 36^{\prime}$ & $132^{\circ} 22^{\prime}$ & 204 & 19 & - & Seiner No. 4 & - \\
\hline 1975 & $41^{\circ} 41^{\prime}$ & $134^{\circ} 41^{\prime}$ & 196 & 26 & - & Seiner No. 2 & - \\
\hline 1975 & $41^{\circ} 41^{\prime}$ & $134^{\circ} 41^{\prime}$ & 154 & 16 & - & Seiner No. 3 & $=$ \\
\hline 1975 & $41^{\circ} 41^{\prime}$ & $134^{\circ} 41^{\prime}$ & 36 & 3.6 & 36 & - & - \\
\hline 1976 & $41^{\circ} 41^{\prime}$ & $133^{\circ} 30^{\prime}$ & 40 & 16 & 40 & - & - \\
\hline 1977 & $41^{\circ} 42^{\prime}$ & $133^{\circ} 30^{\prime}$ & 46 & 164 & 46 & - & - \\
\hline 1977 & $41^{\circ} 41^{\prime}$ & $133^{\circ} 22^{\prime}$ & 62 & 3 & 38 & - & - \\
\hline 1977 & $417^{\circ}$ & $133^{\circ} 42^{\prime}$ & 174 & 6 & - & Fishing ship & - \\
\hline 1977 & $41^{\circ} 37$ & $133^{\circ} 42^{\prime}$ & 160 & 6 & - & Fishing ship & - \\
\hline 1978 & $41^{\circ} 40^{\prime}$ & $133^{\circ} 40^{\prime}$ & 29 & 11 & 29 & - & 二 \\
\hline 1978 & $41^{\circ} 40^{\prime}$ & $133^{\circ} 40^{\prime}$ & 13 & 18 & 13 & - & - \\
\hline 1978 & $41^{\circ} 40^{\circ}$ & $133^{\circ} 40^{\prime}$ & 23 & 3.4 & 23 & - & 二 \\
\hline 1978 & $41^{\circ} 43^{\prime}$ & $133^{\circ} 35^{\circ}$ & 28 & 2.5 & 28 & - & - \\
\hline 1978 & $41^{\circ} 4 I^{\prime}$ & $133^{\circ} 31^{\prime}$ & 39 & 68 & 39 & $=$ & 二 \\
\hline 1978 & $41^{\circ} 40^{\prime}$ & $133^{\circ} 31^{\prime}$ & 36 & 7.5 & 36 & - & - \\
\hline 1978 & $41^{\circ} 38^{\prime}$ & $133^{\circ} 41^{\prime}$ & 33 & 5 & 33 & - & - \\
\hline 1978 & $41^{\circ} 37$ & $133^{\circ} 42^{\prime}$ & 235 & 15 & - & Fishing ship & - \\
\hline 1978 & $41^{\circ} 37$ & $133^{\circ} 42^{\prime}$ & 178 & 11 & - & Fishing ship & - \\
\hline 1978 & $41^{\circ} 44^{\prime}$ & $133^{\circ} 26^{\circ}$ & 29 & 2 & 27 & - & $=$ \\
\hline
\end{tabular}


Table A7 (continued)

\begin{tabular}{|c|c|c|c|c|c|c|c|}
\hline \multirow{2}{*}{ Year } & \multicolumn{2}{|c|}{ Coordinates } & \multirow{2}{*}{$\begin{array}{c}\text { Volume, } \\
\text { m }^{3}\end{array}$} & \multirow{2}{*}{$\begin{array}{c}\text { Activity, } \\
\mathrm{Ci}\end{array}$} & \multicolumn{3}{|c|}{ Form of Disposal } \\
\hline & N. Lat. & E. Long. & & & Containers & Ships & Unenclosed \\
\hline \multicolumn{8}{|c|}{ Area 9 (continued) } \\
\hline 1978 & $41^{\circ} 44^{\prime}$ & $133^{\circ} 26^{\circ}$ & 321 & 5 & 321 & - & - \\
\hline 1984 & $41^{\circ} 41^{\prime}$ & $134^{\circ} 2^{\prime}$ & 34 & 236 & 34 & $=$ & - \\
\hline 1984 & $41^{\circ} 39^{\prime}$ & $133^{\circ} 30^{\prime}$ & 29 & 8.5 & 29 & - & - \\
\hline 1985 & $41^{\circ} 38^{\prime}$ & $133^{\circ} 30^{\prime}$ & 36 & 833 & 31 & $=$ & - \\
\hline 1985 & $41^{\circ} 39^{\prime}$ & $133^{\circ} 30^{\prime}$ & 40 & 9.7 & 60 & - & - \\
\hline 1985 & $41^{\circ} 40^{\prime}$ & $133^{\circ} 23^{\prime}$ & 201 & 14 & - & $\begin{array}{l}\text { Experimen- } \\
\text { tal vessel } \\
\text { Ungur }\end{array}$ & - \\
\hline 1985 & $41^{\circ} 37^{\prime}$ & $134^{\circ} 0^{\circ}$ & 80 & 21.5 & 80 & - & - \\
\hline 1985 & $41^{\circ} 41^{\prime}$ & $134^{\circ} 1^{\circ}$ & 50 & 90 & 50 & - & - \\
\hline 1985 & $41^{\circ} 38^{\circ}$ & $133^{\circ} 25^{\prime}$ & 58 & 3.3 & 58 & - & - \\
\hline 1986 & $41^{\circ} 40^{\prime}$ & $134^{\circ} 10^{\prime}$ & 38 & 70 & 37 & - & - \\
\hline 1986 & $41^{\circ} 40^{\prime}$ & $134^{\circ} 18^{\prime}$ & 31 & 15 & 31 & - & - \\
\hline 1986 & $41^{\circ} 46^{\circ}$ & $134^{\circ} 10^{\prime}$ & 20 & 5 & 18 & - & - \\
\hline 1987 & $41^{\circ} 40^{\prime}$ & $134^{\circ} 20^{\prime}$ & 31 & 26 & 34 & - & - \\
\hline 1987 & $41^{\circ} 46^{\prime}$ & $134^{\circ} 30^{\prime}$ & 41 & 85 & 28 & - & - \\
\hline 1987 & $41^{\circ} 36^{\prime}$ & $133^{\circ} 22^{\prime}$ & 474 & 13.5 & - & $\begin{array}{l}\text { Fishing ship } \\
\text { Never }\end{array}$ & - \\
\hline 1987 & $41^{\circ} 36^{\prime}$ & $134^{\circ} 30^{\prime}$ & 42 & 8 & 28 & - & - \\
\hline 1988 & $41^{\circ} 36^{\prime}$ & $134^{\circ} 30^{\prime}$ & 208 & 8 & - & $\begin{array}{l}\text { Fishing ship } \\
\text { Trebovatel- } \\
\text { nyy }\end{array}$ & - \\
\hline 1988 & $41^{\circ} 46^{\prime}$ & $134^{\circ} 30^{\prime}$ & 50 & 10 & 34 & - & - \\
\hline 1988 & $41^{\circ} 40^{\prime}$ & $134^{\circ} 30^{\prime}$ & 1665 & 17 & - & $T N T-14$ & - \\
\hline 1988 & $41^{\circ} 40^{\prime}$ & $134^{\circ} 18^{\prime}$ & 362 & 36 & - & SRTM-8 & - \\
\hline 1988 & $41^{\circ} 42^{\prime}$ & $134^{\circ} 30^{\circ}$ & 56 & 62 & 56 & - & - \\
\hline 1988 & $41^{\circ} 40^{\prime}$ & $134^{\circ} 18^{\prime}$ & 110 & 8.2 & - & $S R T M-427$ & - \\
\hline 1989 & $41^{\circ} 40^{\circ}$ & $134^{\circ} 0^{\prime}$ & 35 & 14 & 35 & - & - \\
\hline 1989 & $41^{\circ} 40^{\prime}$ & $134^{\circ} 0^{\prime}$ & 360 & 373 & - & Barge & - \\
\hline 1990 & $41^{\circ} 40^{\prime}$ & $134^{\circ} 0^{\prime}$ & 114 & 103 & 14 & $\begin{array}{l}\text { Fishing ship } \\
\text { Tayezhnyy }\end{array}$ & - \\
\hline 1991 & $41^{\circ} 40^{\prime}$ & $134^{\circ} 0^{\prime}$ & 18 & 1.4 & - & - & - \\
\hline 1991 & $41^{\circ} 40^{\prime}$ & $134^{\circ} 0^{\prime}$ & 15 & 6.5 & - & - & $\begin{array}{l}\text { Steam gene- } \\
\text { rator ( } 5 \text { pcs.) }\end{array}$ \\
\hline 1991 & $41^{\circ} 40^{\circ}$ & $134^{\circ} 0^{\prime}$ & - & - & & - & $\begin{array}{l}\text { Primary loop } \\
\text { circulating } \\
\text { pumps (21 } \\
\text { pcs.) }\end{array}$ \\
\hline 1991 & $41^{\circ} 40^{\prime}$ & $133^{\circ} 30^{\prime}$ & 124 & 39.5 & - & $\begin{array}{l}\text { Fishing ship } \\
\text { Ovazhnyy }\end{array}$ & - \\
\hline 1992 & $41^{\circ} 40^{\prime}$ & $133^{\circ} 30^{\prime}$ & 2640 & 14.5 & - & $T N T-11$ & - \\
\hline 1992 & $41^{\circ} 40^{\prime}$ & $133^{\circ} 30^{\prime}$ & 55 & 0.8 & 41 & - & - \\
\hline Total & & & 9846 & $\begin{array}{r}2230 \\
(82) \\
\end{array}$ & 1689 & 18 & 26 \\
\hline
\end{tabular}




\section{4}

Table A7 (continued)

\begin{tabular}{|c|c|c|c|c|c|c|c|}
\hline \multirow{2}{*}{ Year } & \multicolumn{2}{|c|}{ Coordinates } & \multirow{2}{*}{$\begin{array}{c}\text { Volume, } \\
\mathrm{m}^{3} \\
\end{array}$} & \multirow{2}{*}{$\begin{array}{c}\text { Activity, } \\
\mathrm{Ci}^{-}\end{array}$} & \multicolumn{3}{|c|}{ Form of Disposal } \\
\hline & N. Lat. & E. Long. & & & Containers & Ships & Unenclosed \\
\hline \multicolumn{8}{|c|}{ Area 10} \\
\hline 1978 & $40^{\circ} 10^{\prime}$ & $131^{\circ} 15^{\prime}$ & 31 & 46 & 一 & - & $\begin{array}{l}\text { Submarine } \\
\text { reactor tank } \\
\text { (2 pcs.) }\end{array}$ \\
\hline 1979 & $41^{\circ} 30^{\prime}$ & $131^{\circ} 35^{\prime}$ & 60 & 125 & - & 一 & $\begin{array}{l}\text { Tank of re- } \\
\text { servoir for } \\
\text { spent process } \\
\text { channels ( } 2 \\
\text { pcs.) }\end{array}$ \\
\hline 1979 & $40^{\circ} 10^{\prime}$ & $131^{\circ} 15^{\prime}$ & 162 & 9.2 & - & Fishing ship & - \\
\hline 1979 & $41^{\circ} 23^{\prime}$ & $131^{\circ} 25^{\prime}$ & 50 & 4.2 & 42 & - & 二 \\
\hline 1979 & $40^{\circ} 10^{\prime}$ & $131^{\circ} 15^{\prime}$ & 800 & 20.7 & 21 & 一 & - \\
\hline 1980 & $41^{\circ} 05^{\prime}$ & $131^{\circ} 30^{\prime}$ & 68 & 72.7 & 68 & - & - \\
\hline 1980 & $41^{\circ} 25^{\prime}$ & $131^{\circ} 20^{\prime}$ & 65 & 0.95 & 53 & - & - \\
\hline 1980 & $40^{\circ} 10^{\circ}$ & $131^{\circ} 15^{\prime}$ & 200 & 2.2 & - & $\begin{array}{l}\text { Fishing ship } \\
\text { Tedzhem }\end{array}$ & - \\
\hline 1980 & $40^{\circ} 10^{\prime}$ & $131^{\circ} 15^{\prime}$ & 240 & 3 & - & $\begin{array}{l}\text { Fishing ship } \\
\text { Tauz }\end{array}$ & - \\
\hline 1980 & $41^{\circ} 29^{\prime}$ & $131^{\circ} 18^{\prime}$ & 34 & 0.2 & 34 & - & - \\
\hline 1980 & $40^{\circ} 10^{\prime}$ & $131^{\circ} 18^{\prime}$ & 284 & 3.6 & - & $R S-309$ & - \\
\hline 1981 & $40^{\circ} 10^{\prime}$ & $131^{\circ} 18^{\prime}$ & 165 & 2.5 & - & $\begin{array}{l}\text { Fishing ship } \\
\text { Tekeli }\end{array}$ & 一 \\
\hline 1981 & $41^{\circ} 20^{\prime}$ & $131^{\circ} 26^{\prime}$ & 183 & 144.5 & 188 & - & - \\
\hline 1981 & $41^{\circ} 00^{\prime}$ & $131^{\circ} 26^{\prime}$ & 74 & 0.5 & 48 & - & - \\
\hline 1981 & $40^{\circ} 10^{\circ}$ & $131^{\circ} 15^{\prime}$ & 472 & 7.3 & - & $\begin{array}{l}\text { Fishing ship } \\
\text { Tagil }\end{array}$ & - \\
\hline 1981 & $40^{\circ} 10^{\prime}$ & $131^{\circ} 15^{\prime}$ & 217 & 2.8 & - & $R S-300$ & - \\
\hline 1982 & $41^{\circ} 20^{\prime}$ & $131^{\circ} 26^{\prime}$ & 40 & 38.4 & 40 & - & - \\
\hline 1982 & $41^{\circ} 05^{\prime}$ & $131^{\circ} 30^{\prime}$ & 36 & 23.4 & 36 & - & - \\
\hline 1982 & $40^{\circ} 40^{\prime}$ & $131^{\circ} 15^{\prime}$ & 255 & 7.1 & - & $\begin{array}{l}\text { Fishing ship } \\
\text { Troitsk }\end{array}$ & - \\
\hline 1982 & $41^{\circ} 40^{\prime}$ & $131^{\circ} 26^{\prime}$ & 31 & 0.12 & 31 & - & - \\
\hline 1982 & $41^{\circ} 40^{\prime}$ & $131^{\circ} 21^{\prime}$ & 42 & 0.35 & 38 & - & - \\
\hline 1982 & $40^{\circ} 40^{\prime}$ & $131^{\circ} 15^{\prime}$ & 450 & 11 & - & $\begin{array}{l}\text { Fishing ship } \\
\text { Kosmonavt } \\
\text { Yegorov }\end{array}$ & - \\
\hline 1983 & $41^{\circ} 40^{\circ}$ & $131^{\circ} 26^{\prime}$ & 107 & 92.3 & 83 & - & $\begin{array}{l}\text { Reactor lid } \\
(8 \text { pcs.) }\end{array}$ \\
\hline 1983 & $41^{\circ} 40^{\prime}$ & $131^{\circ} 25^{\prime}$ & 47 & 2.35 & 47 & - & - \\
\hline 1983 & $41^{\circ} 40^{\circ}$ & $131^{\circ} 25^{\prime}$ & 405 & 10.6 & - & $\begin{array}{l}\text { Medium } \\
\text { fishing traw- } \\
\text { ler/refrigera- } \\
\text { tor ship }\end{array}$ & - \\
\hline
\end{tabular}

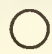



I SBN 0-16-041057-6

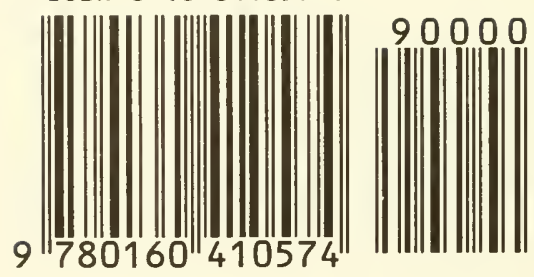



